\title{
Improving Climate Control and Energy Performance in Greenhouses and Livestock Houses: Modeling Advances and Experimental Results
}

\author{
Ph.D. Dissertation \\ Andrea Costantino
}

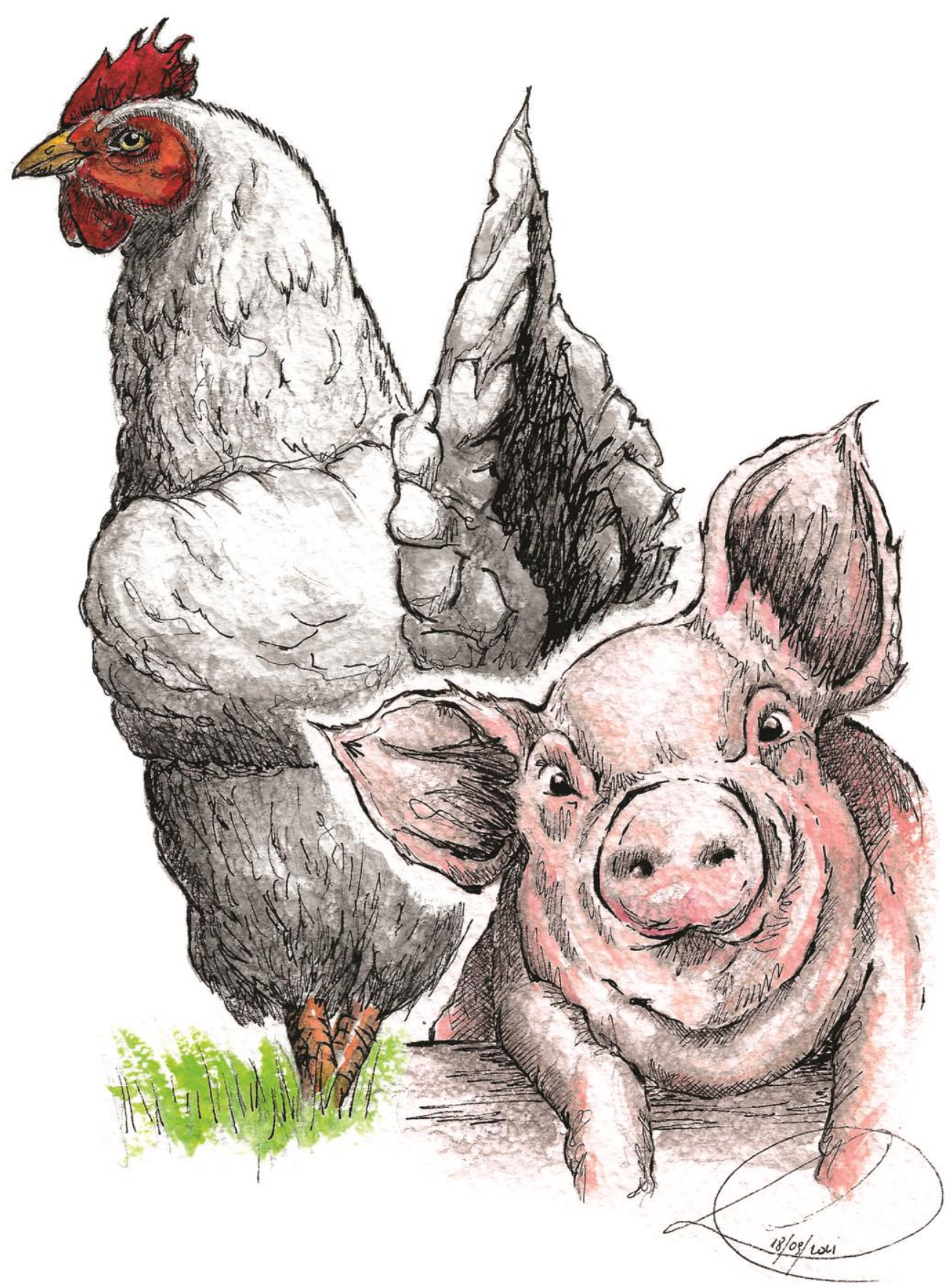




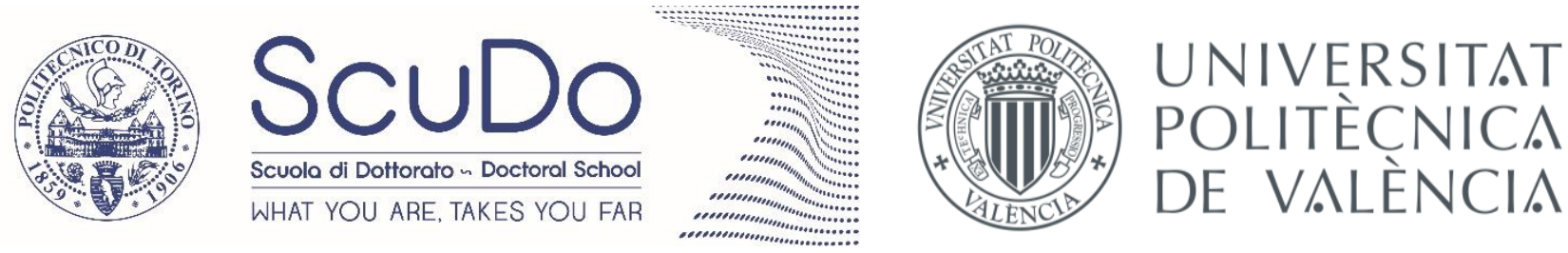
POLITĖCNICA DE VALÈNCIA

Doctoral Dissertation

Doctoral Program in Energetics ( $33^{\text {rd }}$ Cycle)

Doctoral Program in Animal Production Science and Technology

\title{
Improving Climate Control and Energy Performance in Greenhouses and Livestock Houses: Modeling Advances and Experimental Results
}

\section{Andrea Costantino}

\author{
$* * * * * *$
}

\author{
Supervisors \\ Prof. Enrico Fabrizio, Supervisor \\ Prof. Salvador Calvet Sanz, Supervisor
}

\section{Doctoral Examination Committee:}

Prof. V. Lemort, Referee/Examiner, University of Liège

Prof. M.R. Rodríguez Rodríguez, Referee, University of Santiago de Compostela

Prof. P. Tassinari, Referee/Examiner, University of Bologna

Prof. T. Bartzanas, Examiner, Agricultural University of Athens

Prof. R. Choudhary, Examiner, University of Cambridge

Prof. A. Kindinis, Examiner, ESTP Paris

Politecnico di Torino

Universitat Politècnica de València 
This thesis is licensed under a Creative Commons License, Attribution - Noncommercial NoDerivative Works 4.0 International: see www.creativecommons.org. The text may be reproduced for non-commercial purposes, provided that credit is given to the original author.

I hereby declare that the contents and organization of this dissertation constitute my own original work and does not compromise in any way the rights of third parties, including those relating to the security of personal data.

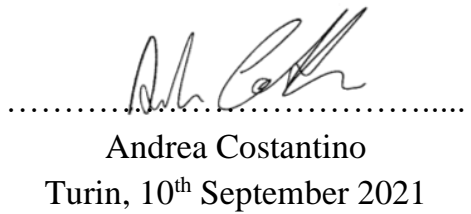

* This dissertation is presented in partial fulfillment of the requirements for Ph.D. degree in the Graduate School of Politecnico di Torino (ScuDo) and in the Doctoral School of Universitat Politècnica de València. 


To my family and to Enzo

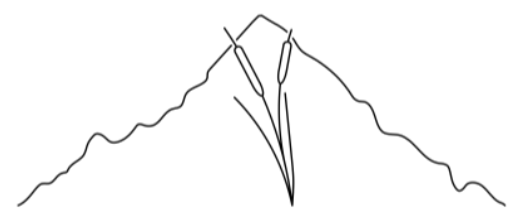





\section{Acknowledgments}

This thesis has been an amazing journey. I performed exciting activities, I lived in two incredible cities, I travelled to several countries, and I met a lot of amazing people. These people gave me part of their time to improve not only my work, but also myself. I am very grateful to each one of them.

I truly acknowledge my tutors, Prof. Enrico Fabrizio and Prof. Salvador Calvet, for leading me through this journey. Without your guidance, all my effort and work would not have provided the results, which I am very proud of. This work is undoubtedly a result of your foresight. Thank you, Enrico, for undertaking such innovative and promising research line and for giving me great opportunities since the EPAnHaus Project. Thank you, Salva, for accepting this challenging and unconventional co-tutelle agreement and for bringing your brilliant point of view and contribution to this research.

I would like to extend my deepest gratitude to Dr. Lorenzo Comba, without whom this work would not have been the same. Thank you, Lorenzo, for your valuable collaborations and for the time you dedicated to explaining me many interesting new things. I will treasure it.

I would like to acknowledge the companies that were involved in this work.

Many thanks to Società Agricola San Bernardo Colombè where we performed a long-term monitoring campaign and to Dr. Benedetto for his expertise that was glad to share.

Many thanks to Munters Italy s.p.a., especially to Mauro Bariani, Andrea Ghiggini, and Giacomo Sicardi, for their appreciate contribution in designing and carrying out some of the experiments. A special mention to Mauro Bariani (*1976 - $\uparrow 2021)$ that will be always remembered by our research group for his experience, practical knowledge, and communication skills.

I am also grateful to the Department of Agricultural, Forest and Food Sciences of University of Torino, especially to the animal scientists Prof. Luca Battaglini and Dr. Paolo Cornale, for their collaboration in this research activity. 
I would like to recognize the coordinators of doctoral programs Prof. Federico Millo at Politecnico di Torino and Prof. Pilar Hernández at Universitat Politècnica de València. Thank you for managing these fruitful $\mathrm{PhD}$ programs and for your availability and support in to the co-tutelle agreement.

Many thanks to all the friends of Politecnico di Torino and of Universitat Politècnica de València. I learnt so much about energy, acoustics, animal production and even genetics from you. Your presence was fundamental during this journey. I really wish you all the best for your personal and professional life. You really deserve it.

I would like to express my sincere gratitude to all my friends spread among Italy and Spain (but also Panama). You are the family I chose, and you make me feel like home in both places. I really appreciate it.

I am deeply grateful to Agos. Thank you for being present during this journey with valuable advice, practical suggestions, and personal support. Your infinite patience cannot be underestimated.

Finally, my greatest acknowledgment is for my family. Thank you for supporting me and for teaching me that any target is achievable with hard work. You gave me the best example. I hope you are proud of what I have learnt from you. 


\section{Summary (English)}

\section{"Improving Climate Control and Energy Performance in Greenhouses and Livestock Houses: Modeling Advances and Experimental Results"}

Socio-demographic trends, such as population growth and urbanization, are leading to a significant increase of the world food demand. At the same time, there is a shift of the human diet toward livestock products, vegetables, and fruit rather than cereals. In this context, greenhouses and livestock houses can play a primary role since they can supply the necessary agricultural products with higher yields than on-field crop production and extensive animal farming. One way in which productivity is enhanced in these agricultural buildings is by a fine-tuned control of the indoor climate conditions. For this purpose, mechanical climate control systems are often adopted, but they entail a considerable energy consumption whose estimated increase may jeopardize the transition toward a sustainable agriculture. The overall objective of this thesis, hence, is to contribute to the transition toward a sustainable agriculture by improving the energy performance for climate control of greenhouses and livestock houses.

To achieve this objective, a three-pronged approach was taken involving a literature review, experimental monitoring campaigns, and energy modelling activities. The literature review was performed to unpick the tangle of mutual relations between climate control and other domains of agricultural production. The nexus between energy performance and climate control was investigated analyzing real datasets acquired through monitoring campaigns performed in a greenhouse and two pig houses. This nexus was further studied adopting a numerical approach which led to the development and validation of three energy simulation models for greenhouses, broiler houses and pig houses. Each simulation model integrates the main features typical of greenhouses and livestock houses to accurately estimate the time profiles of lumped indoor climate conditions and thermal and electrical energy consumption. The opportunities in improving the energy performance and the indoor climate conditions provided by the developed energy models were explored by analyzing specific energy-related problems. The broiler house energy model, in fact, was adopted to evaluate the potentialities of a new primary energy approach for the energy-efficient envelope design of broiler houses. The same model was applied to evaluate the variation of energy consumption achieved by an improved ventilation strategy aimed at enhancing broiler welfare by reducing indoor noxious gas concentrations.

This thesis contributes to the transition toward a more sustainable agriculture providing new knowledge and tools necessary for improving the energy performance for climate control of greenhouses and livestock houses. The performed analyses, in fact, quantify potential decrease of energy consumption achievable through the implementation of energy-efficient measures at both 
envelope -thermal insulation- and climate control system -variable angular speed fans- level. Further energy-efficient measures could be evaluated adopting the developed energy simulation models that are valuable outputs of this investigation. These models, in fact, could have a positive impact at local level since stakeholders -farmers, engineers, and manufacturers- could adopt them as decision support tools for the evaluation of new technologies, strategies and solutions aimed at decreasing the overall energy consumption of greenhouses and livestock houses. These novel models represent also a robust starting point for future research in this field. Future advances may lead to the development of further calculation modules to evaluate other aspects of greenhouses and livestock houses, such as productivity variations, contaminant emissions and animal welfare. The new knowledge generated in this thesis could have positive impacts also at global level since it may represent the technical basis for new normative frameworks and incentive schemes aimed at improving the energy performance of climate-controlled agricultural buildings through a top-down approach. 


\section{Summary (Italian)}

\section{"Il miglioramento del controllo climatico e della prestazione energetica in edifici per la produzione vegetale e animale: progressi nella modellazione e risultati sperimentali"}

Importanti cambiamenti sociodemografici, come la crescita della popolazione mondiale e l'urbanizzazione, stanno incrementando il fabbisogno di alimenti a livello mondiale. In contemporanea si sta assistendo ad una profonda trasformazione della dieta umana che tende sempre più a prediligere prodotti di origine animale, frutta e verdura al posto dei cereali. In quest'ottica, serre e stalle per l'allevamento intensivo possono ricoprire un ruolo di spicco, in quanto in grado di produrre tali alimenti con dei rendimenti decisamente maggiori rispetto a quelli che caratterizzano la produzione di vegetali in campo aperto e l'allevamento estensivo. Tra i vari fattori che contribuiscono ad incrementare la produttività di questi edifici agricoli vi è il controllo delle condizioni climatiche interne. Tale controllo del clima interno avviene, in molti casi, attraverso sistemi meccanici il cui utilizzo causa un considerevole consumo energetico che costituisce una minaccia per la transizione verso un'agricoltura più sostenibile. L'obiettivo generale di questa tesi è, quindi, di contribuire alla transizione verso un'agricoltura più sostenibile attraverso il miglioramento della prestazione energetica per il controllo climatico di serre e stalle per l'allevamento intensivo.

Per raggiungere tale obiettivo, è stato adottato un triplice approccio basato su un'analisi di letteratura, campagne sperimentali di monitoraggio ed attività di modellazione energetica. L'analisi di letteratura è stata svolta con il fine di districare la complessa rete di relazioni esistente tra controllo climatico e altri domini di interesse della produzione agricola. Il nesso tra prestazione energetica e controllo climatico è stato approfondito analizzando dei set di dati reali acquisiti in una serra e due porcilaie attraverso campagne di monitoraggio. Questo nesso è stato ulteriormente approfondito adottando un approccio numerico che ha portato allo sviluppo e validazione di tre modelli di simulazione energetica per serre, per stalle da polli da carne e per stalle da suini da ingrasso. Ciascun modello di simulazione integra le principali caratteristiche tipiche di tali edifici per stimare con accuratezza i profili temporali delle condizioni ambientali interne e del consumo di energia termica ed elettrica. Le potenzialità di questi modelli nel migliorare la prestazione energetica e le condizioni climatiche di serre e stalle sono state esplorate analizzando specifiche problematiche relazionate al consumo energetico. Il modello energetico per le stalle per polli da carne, infatti, è stato adottato per valutare le potenzialità di un nuovo approccio per la progettazione energeticamente efficiente dell'involucro basato sull'energia primaria. Lo stesso modello è stato usato per valutare la variazione del consumo energetico causata dall'adozione di una strategia 
di ventilazione mirata al miglioramento del benessere dei polli allevati attraverso la riduzione della concentrazione interna di gas nocivi.

Questa tesi contribuisce alla transizione verso una agricoltura più sostenibile fornendo nuove conoscenze e strumenti necessari al miglioramento della prestazione energetica per controllo climatico di serre e stalle per l'allevamento intensivo. Le analisi svolte, infatti, quantificano potenziali riduzioni del consumo energetico ottenibili attraverso l'implementazione di misure di efficientamento energetico, sia a livello di involucro (isolamento termico) che a livello di sistema di controllo climatico (ventilatori a portata variabile). Ulteriori misure per l'efficientamento energetico potrebbero essere valutate attraverso tali modelli che rappresentano importanti risultati di questa ricerca. Essi, infatti, potrebbero avere ricadute positive a livello locale in quanto vari portatori d'interesse (agricoltori, ingegneri e fabbricanti) potrebbero adottarli come strumenti di supporto alle decisioni per valutare nuove tecnologie, strategie e soluzioni mirate alla diminuzione del consumo energetico di serre e stalle. Questi nuovi modelli rappresentano anche un solido punto di partenza per future ricerche in questo campo. Futuri sviluppi potrebbero portare alla creazione di ulteriori moduli di calcolo per valutare altri aspetti, come la variazione della produttività, l'emissione di contaminanti e il benessere animale. Le nuove conoscenze generate in questa tesi potrebbero avere ricadute positive anche a livello globale, in quanto potrebbero rappresentare i fondamenti tecnici per nuovi quadri normativi e schemi di incentivi mirati al miglioramento della performance energetica di edifici agricoli controllati climaticamente attraverso una strategia di tipo top-down. 


\section{Summary (spanish)}

“La mejora del control climático y de la prestación energética en invernaderos y granjas: avances en la modelización y resultados experimentales"

Importantes cambios sociodemográficos, como el aumento de la población y la urbanización, están conduciendo hacia un considerable crecimiento de la demanda de alimentos a nivel mundial. Al mismo tiempo se está observando una profunda transformación de la dieta humana, que tiende a incluir más productos de origen animal, fruta y verdura en lugar de cereales. En este contexto, invernaderos y granjas de ganadería intensiva pueden desempeñar un papel principal, debido a que proporcionan los productos agrícolas necesarios con rendimientos notablemente mayores que los de la producción en campo abierto y de la ganadería extensiva. Entre los distintos factores que contribuyen a incrementar la productividad de estos edificios agrícolas se sitúa el control de las condiciones climáticas internas. Dicho control del clima interno se realiza, en muchos casos, a través de sistemas mecánicos cuyo uso causa un considerable consumo energético que representa una amenaza para la transición hacia una agricultura más sostenible. El objetivo general de esta tesis, por lo tanto, es contribuir a la transición hacia una agricultura más sostenible a través de la mejora de la prestación energética por control climático de invernaderos y granjas de ganadería intensiva.

Para alcanzar dicho objetivo, se ha adoptado un enfoque triple basado en un análisis de literatura, campañas experimentales de monitorización y actividades de modelización energética. El análisis de literatura se ha llevado a cabo con el fin de desentrañar la compleja red de relaciones existentes entre el control climático y otros dominios de interés de la producción agrícola. El nexo entre prestación energética y control climático se ha acometido analizando conjuntos de datos reales, adquiridos en un invernadero y dos granjas de cerdos a través de campañas de monitorización. El análisis de dicho nexo se ha profundizado aún más adoptando un enfoque numérico que ha llevado al desarrollo y validación de tres modelos de simulación energética para invernaderos y para granjas de pollos y cerdos de engorde. Cada modelo de simulación integra las principales características típicas de estos edificios para estimar con precisión los perfiles temporales de las condiciones ambientales internas y el consumo de energía térmica y eléctrica. Las potencialidades de estos modelos para la mejora de las prestaciones energéticas y las condiciones climáticas de invernaderos y granjas se han explorado analizando problemáticas específicas relacionadas con el consumo energético. Por lo tanto, el modelo energético para granjas de pollos se ha adoptado para el diseño energéticamente eficiente de la envolvente de este tipo de edificio. Además, el mismo modelo se ha usado para evaluar las variaciones de consumo energético causadas por la adopción de una estrategia de ventilación orientada a la mejora del 
bienestar de los pollos a través de la reducción de la concentración interior de gases nocivos.

Esta tesis contribuye a la transición hacia una agricultura más sostenible proporcionando nuevos conocimientos e instrumentos necesarios para la mejora de la prestación energética para el control climático de invernaderos y granjas. Los análisis realizados cuantifican potenciales disminuciones del consumo energético alcanzables a través de la implementación de medidas para la eficiencia energética tanto a nivel de envolvente (aislamiento térmico) como a nivel de sistema de control climático (ventiladores con caudal variable). Ulteriores medidas para la eficiencia energética podrían evaluarse a través de dichos modelos que representan importantes resultados de esta investigación. Estos modelos, de hecho, podrían tener repercusiones positivas a nivel local, ya que muchas partes interesadas (agricultores, ingenieros y fabricantes) podrían adoptarlos como instrumentos de apoyo a la toma de decisiones para evaluar nuevas tecnologías, estrategias y soluciones orientadas a la disminución del consumo energético de invernaderos y granjas. Estos nuevos modelos representan también un sólido punto de partida para futuras investigaciones en este campo. Futuros desarrollos podrían implementar nuevos módulos de cálculos para evaluar otros aspectos, como la variación de la productividad, la emisión de contaminantes y el bienestar animal. Los nuevos conocimientos generados en esta tesis podrían tener repercusiones positivas incluso a nivel global, puesto que podrían representar los fundamentos técnicos para nuevos marcos normativos y sistemas de incentivos orientados a la mejora de la prestación energética de edificios agrícolas controlados climáticamente a través de una estrategia de tipo top-down. 


\section{Summary (valencian)}

\section{"La millora del control climàtic $i$ de la prestació energètica en hivernacles $i$ granges: avanços en la modelització i resultats experimentals"}

Importants canvis sociodemogràfics, com l'augment de la població i la urbanització, estan conduint cap a un considerable creixement de la demanda d'aliments a nivell mundial. Al mateix temps s'està observant una profunda transformació de la dieta humana, que tendeix a incloure més productes d'origen animal, fruita i verdura en lloc de cereals. En aquest context, hivernacles i granges de ramaderia intensiva poden exercir un paper principal, pel fet que proporcionen els productes agrícoles necessaris amb rendiments notablement majors que els de la producció en camp obert i de la ramaderia extensiva. Entre els diferents factors que contribueixen a incrementar la productivitat d'aquests edificis agrícoles se situa el control de les condicions climàtiques internes. Aquest control del clima intern es realitza, en molts casos, a través de sistemes mecànics, l'ús dels quals causa un considerable consum energètic que representa una amenaça per a la transició cap a una agricultura més sostenible. L'objectiu general d'aquesta tesi, per tant, és contribuir a la transició cap a una agricultura més sostenible a través de la millora de la prestació energètica per al control climàtic d'hivernacles i granges de ramaderia intensiva.

Per a aconseguir aquest objectiu, s'ha adoptat un enfocament triple basat en una anàlisi de literatura, campanyes experimentals de monitoratge $i$ activitats de modelització energètica. L'anàlisi de literatura s'ha dut a terme amb la finalitat de desentranyar la complexa xarxa de relacions existents entre el control climàtic i altres dominis d'interés de la producció agrícola. El nexe entre prestació energètica i control climàtic s'ha analitzat amb conjunts de dades reals, adquirides en un hivernacle i dues granges de porcs, a través de campanyes de monitoratge. L'anàlisi d'aquest nexe s'ha aprofundit encara més adoptant un enfocament numèric que ha portat al desenvolupament i validació de tres models de simulació energètica per a hivernacles i per a granges de pollastres i porcs d'engreixament. Cada model de simulació integra les principals característiques típiques d'aquests edificis per a estimar amb precisió els perfils temporals de les condicions ambientals internes i el consum d'energia tèrmica i elèctrica. Les potencialitats d'aquests models per a la millora de les prestacions energètiques i les condicions climàtiques d'hivernacles i granges s'han explorat analitzant problemàtiques específiques relacionades amb el consum energètic. Per tant, el model energètic per a granges de pollastres s'ha adoptat per al disseny energèticament eficient de l'envolupant d'aquesta mena d'edifici. A més, el mateix model s'ha usat per a avaluar les variacions de consum energètic causades per l'adopció d'una estratègia de ventilació orientada a la millora del benestar dels pollastres a través de la reducció de la concentració interior de gasos nocius. 
Aquesta tesi contribueix a la transició cap a una agricultura més sostenible proporcionant nous coneixements i instruments necessaris per a la millora de la prestació energètica per al control climàtic d'hivernacles i granges. Les anàlisis realitzades quantifiquen potencials disminucions del consum energètic assolibles a través de la implementació de mesures per a l'eficiència energètica tant a nivell d'envolupant (aïllament tèrmic) com a nivell de sistema de control climàtic (ventiladors amb cabal variable). Ulteriors mesures per a l'eficiència energètica podrien avaluar-se a través d'aquests models que representen importants resultats d'aquesta investigació. Aquests models, de fet, podrien tindre repercussions positives a nivell local, ja que moltes parts interessades (agricultors, enginyers i fabricants) podrien adoptar-los com a instruments de suport a la presa de decisions per a avaluar noves tecnologies, estratègies i solucions orientades a la disminució del consum energètic d'hivernacles i granges. Aquests nous models representen també un sòlid punt de partida per a futures investigacions en aquest camp. Futurs desenvolupaments podrien implementar nous mòduls de càlculs per a avaluar altres aspectes, com la variació de la productivitat, l'emissió de contaminants i el benestar animal. Els nous coneixements generats en aquesta tesi podrien tindre repercussions positives fins i tot a nivell global, ja que podrien representar els fonaments tècnics per a nous marcs normatius i sistemes d'incentius orientats a la millora de la prestació energètica d'edificis agrícoles controlats climàticament a través d'una estratègia de tipus top-down. 


\section{Contents}

Summary (English) ................................................................................................... XI

Summary (Italian) ...........................................................................................................XIII

Summary (Spanish) ...................................................................................................XV

Summary (Valencian) ..........................................................................................XVII

Contents ................................................................................................................... XIX

List of Figures..........................................................................................................XXV

List of Tables ............................................................................................................ XXXI

1. Introduction ................................................................................................................ 1

1.1. Meeting the future food demand ........................................................ 3

1.1.1. Crop production in greenhouses …………………………………….... 3

1.1.2. Animal production in livestock houses …………………………………. 5

1.2. Problem statement, aim and approach.................................................. 6

1.2.1. The need of a transition toward sustainability ............................................ 6

1.2.2. Aim of the thesis .............................................................................

1.2.3. Thesis outline and adopted approaches ..................................................... 7

2. Climate control in agricultural buildings: a tangle of relations ................ 9

2.1. Climate control: a tangle of relations .................................................... 11

2.2. Unpicking the tangle of relations: greenhouses..................................... 11

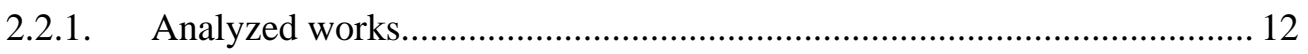

2.2.2. The central role of climate control in greenhouses .................................. 14

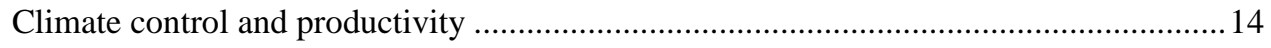

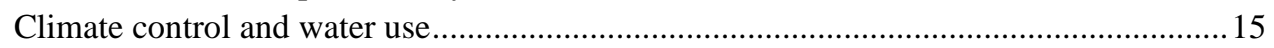

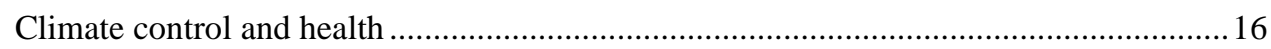

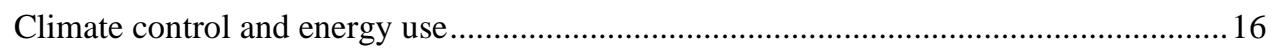

2.3. Unpicking the tangle of relations: livestock houses ............................... 18 


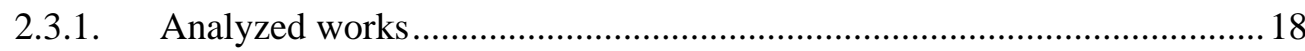

2.3.2. The central role of climate control in livestock houses ..............................21

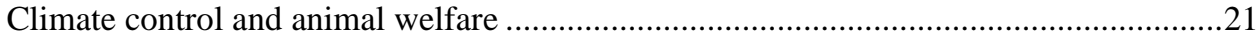

Climate control and air emissions ............................................................................ 23

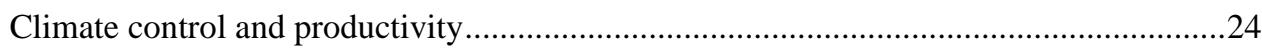

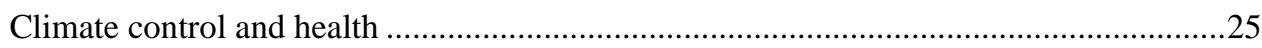

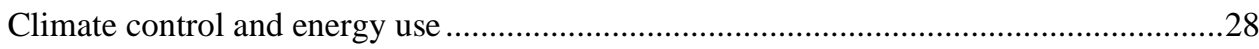

2.3.3. Further considerations about climate control in livestock houses.............29

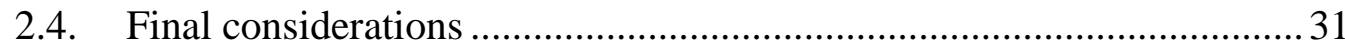

3. The nexus between climate control and energy: results from case studies 33

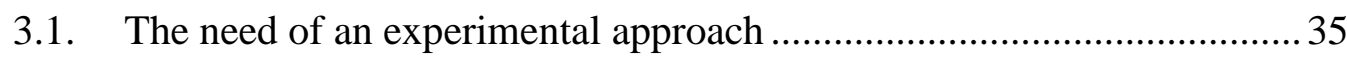

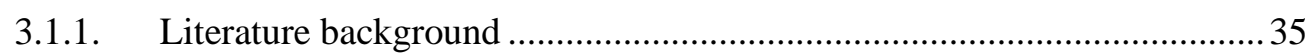

3.1.2. Overview on the performed monitoring campaigns ................................... 37

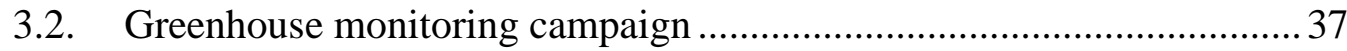

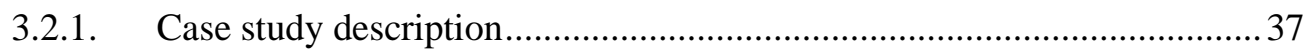

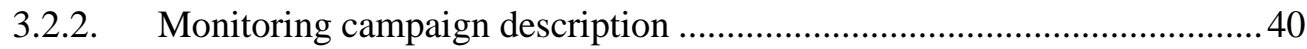

3.2.3. Main results from the monitoring campaign ........................................... 42

Analyses of the monitored indoor climate conditions .....................................................42

Analyses of the monitored electrical power absorbed by fans ......................................46

3.3. Livestock house monitoring campaign ................................................... 49

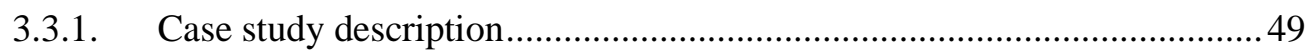

3.3.2. Monitoring campaign description ......................................................... 51

3.3.3. Main results from the monitoring campaign .........................................54

Analyses of the monitored indoor climate conditions ....................................................54

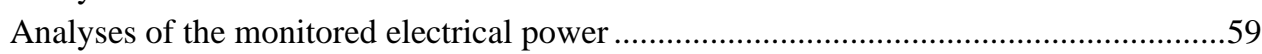

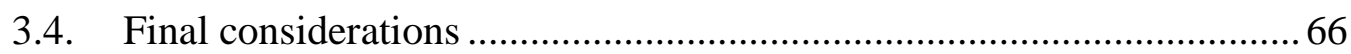

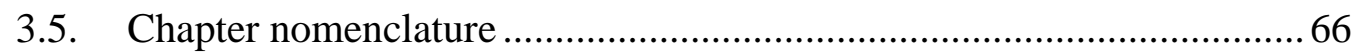

4. A new modelling framework for fully mechanically controlled greenhouses ................................................................................................................6 69

4.1. The need of a numerical approach ..................................................... 71

4.2. Overview on greenhouse modelling issues.......................................... 72

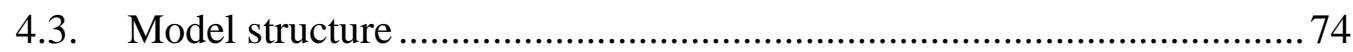

4.3.1. Literature background on existing greenhouse models ............................. 74

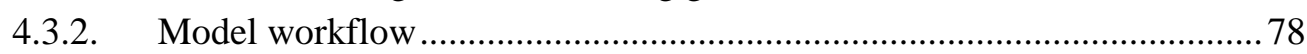

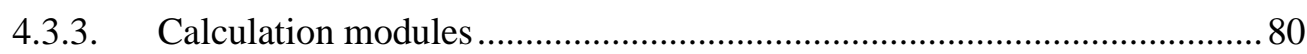

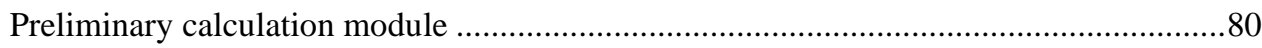

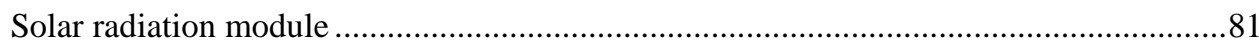

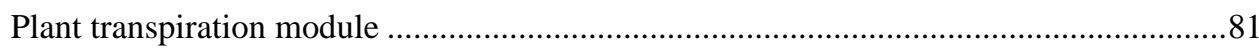

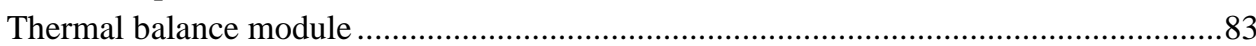




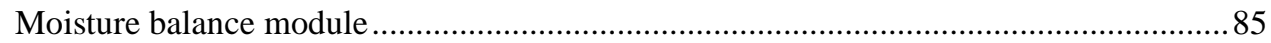

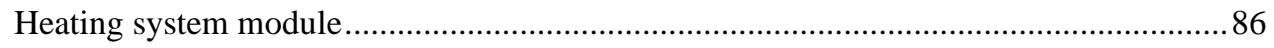

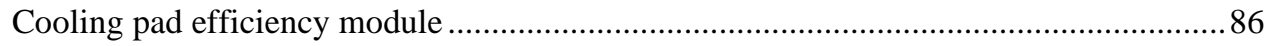

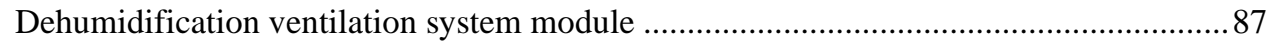

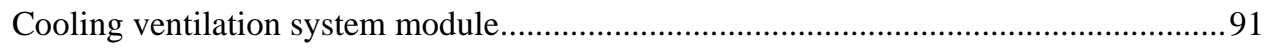

4.4. Model calibration and validation.......................................................... 95

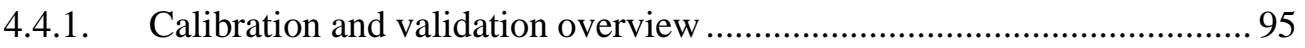

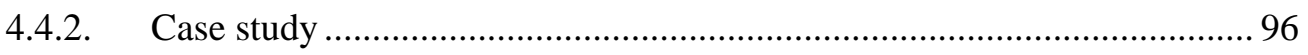

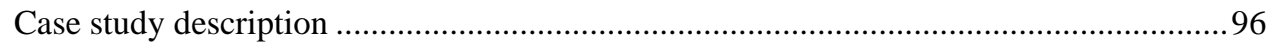

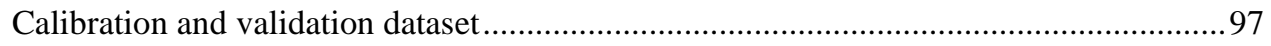

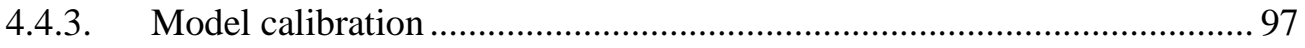

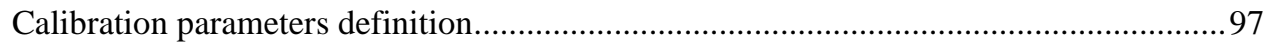

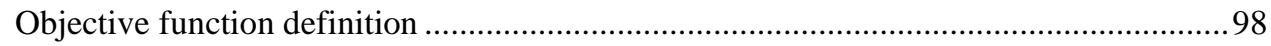

4.4.4. Model validation ................................................................ 100

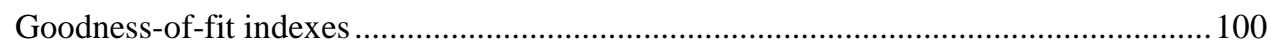

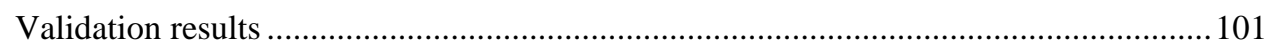

4.5. Model Application............................................................................. 105

4.6. Final considerations....................................................................... 107

4.7. Chapter nomenclature........................................................................... 108

5. A new modelling framework for fully mechanically controlled livestock houses ...................................................................................................................... 111

5.1. A numerical approach for livestock houses ………………………...... 113

5.2. Literature review: energy models for livestock houses ........................... 113

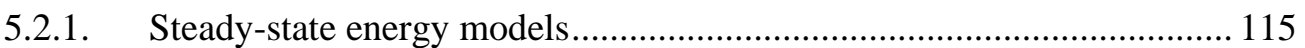

5.2.2. Dynamic energy models......................................................................... 117

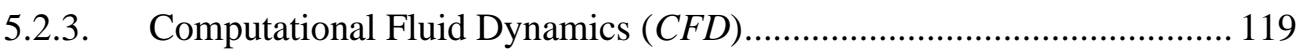

5.3. An energy modelling framework for climate-controlled livestock houses 120

5.4. Model customization for broiler houses: development ........................ 124

5.4.1. The need of a broiler house energy model ............................................ 124

5.4.2. Overview on broiler houses modelling issues........................................ 124

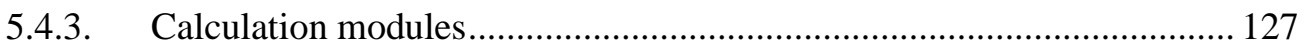

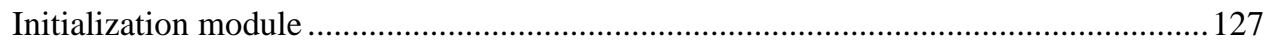

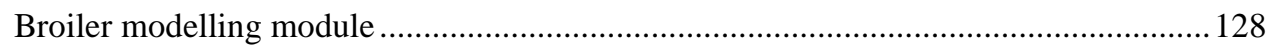

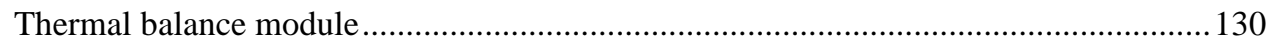

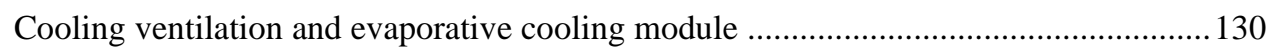

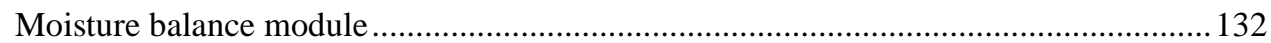

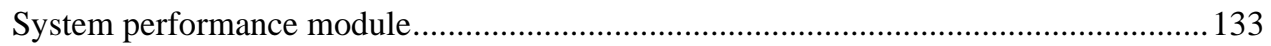

5.5. Model customization for broiler houses: validation .............................. 134

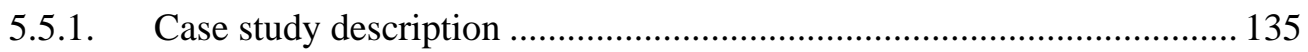

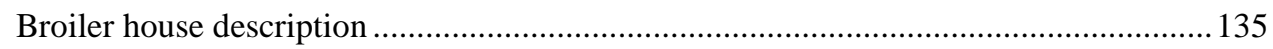




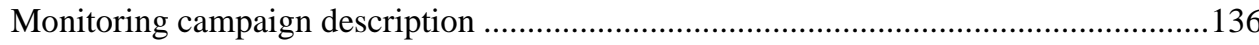

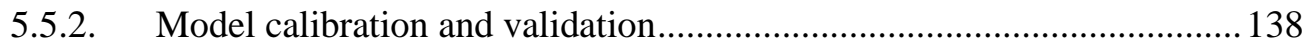

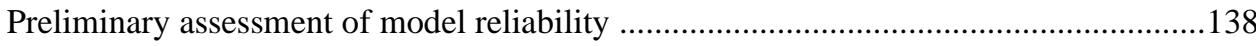

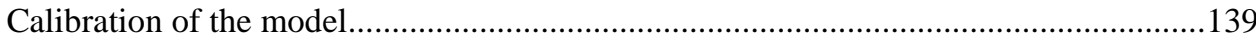

Validation of the model: indoor climate conditions .................................................... 140

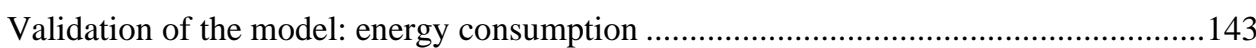

5.6. Model customization for pig houses: development ........................... 144

5.6.1. The importance of a pig house model .................................................... 145

5.6.2. Overview on pig houses modelling issues ............................................. 146

Peculiarities of buildings for growing-finishing pigs ............................................... 146

Peculiarities of climate control in growing-finishing pig houses ................................146

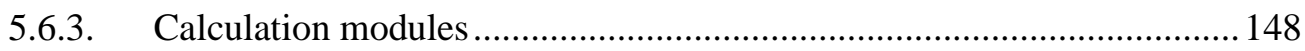

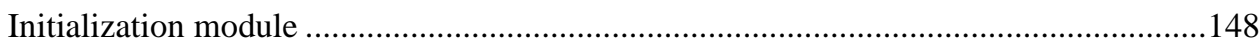

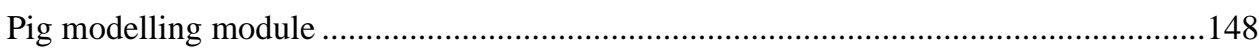

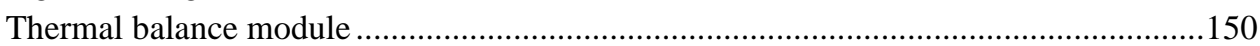

Cooling ventilation calculation module ................................................................... 150

Moisture balance module ....................................................................................... 150

System performance module ............................................................................... 151

5.7. Model customization for pig houses: validation................................ 152

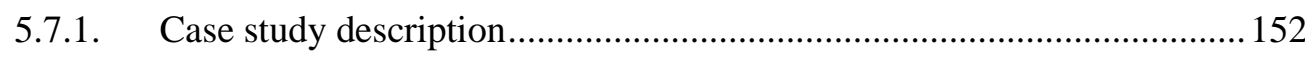

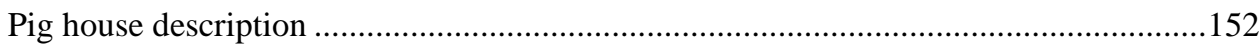

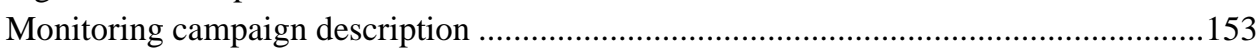

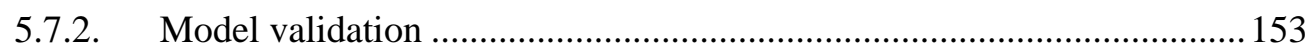

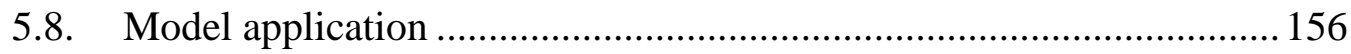

5.9. Alternative energy simulation methods ............................................. 160

5.9.1. The considered calculation methods ...................................................... 160

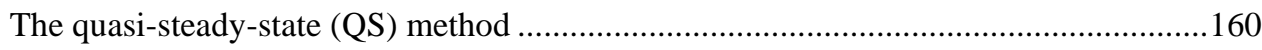

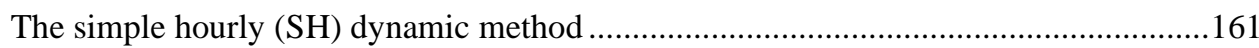

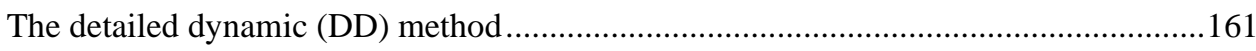

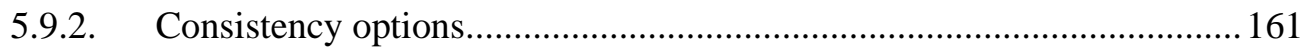

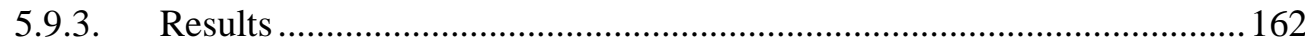

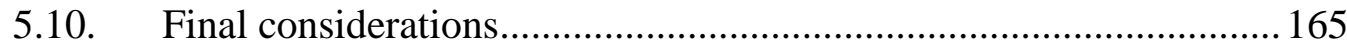

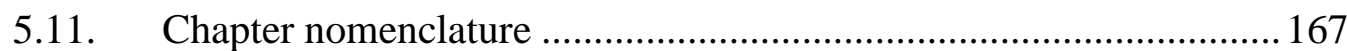

6. The role of envelope in livestock houses: a case study on broiler house

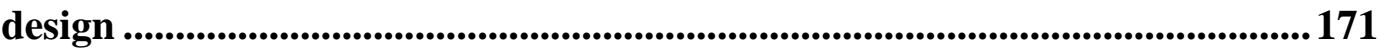

6.1. The importance of the primary energy approach in the envelope design 173

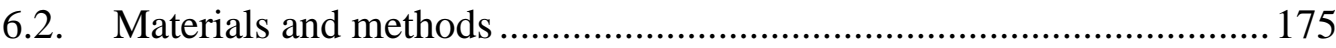

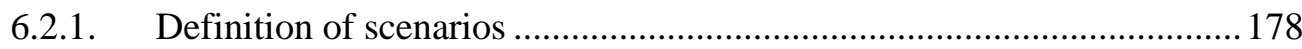

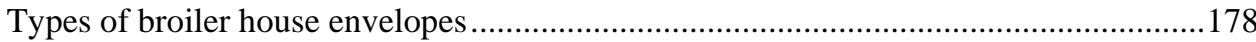


Outdoor weather conditions

6.2.2. Financial evaluation: global cost methodology ...................................... 181

6.3. Results and discussion............................................................... 183

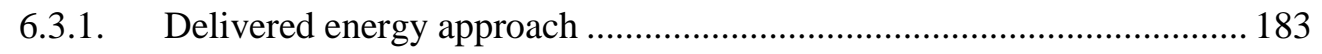

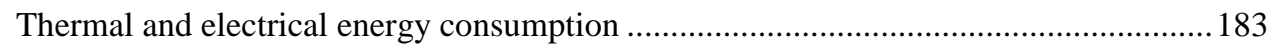

Reference values of delivered energy consumption......................................................185

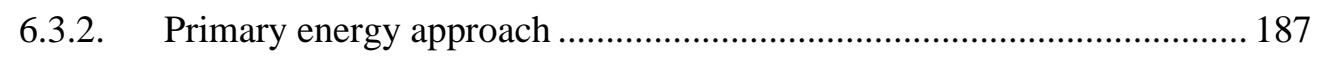

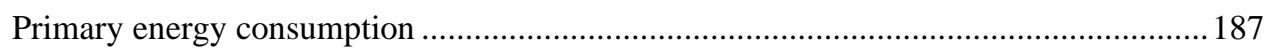

Reference values of primary energy consumption ................................................... 190

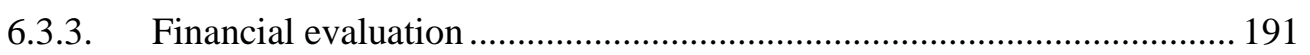

6.3.4. Comparison of indoor climate conditions .............................................. 192

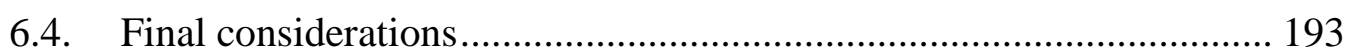

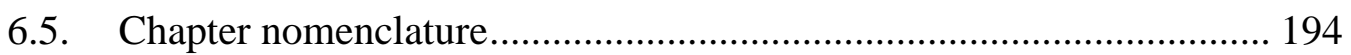

7. The role of ventilation in livestock houses: $I A Q$ improvements and energy

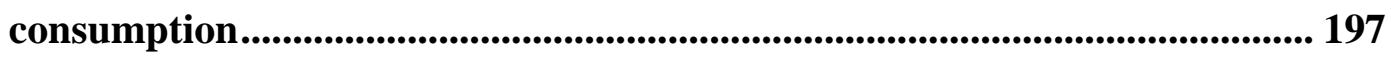

7.1. The detrimental effects of $\mathrm{NH}_{3}$ and $\mathrm{CO}_{2}$ on broiler health ................ 199

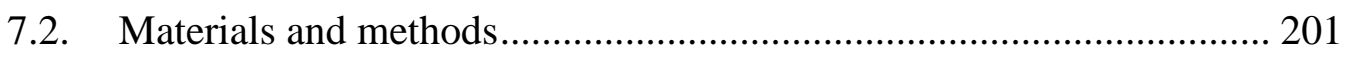

7.2.1. Overview on the experimental and simulation activity.......................... 201

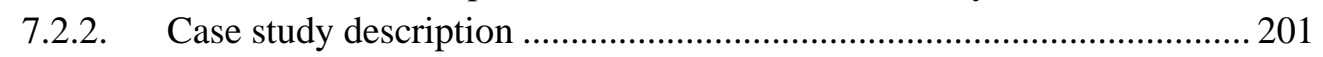

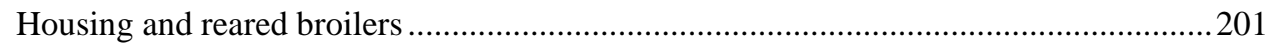

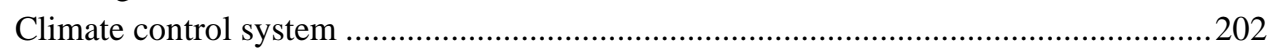

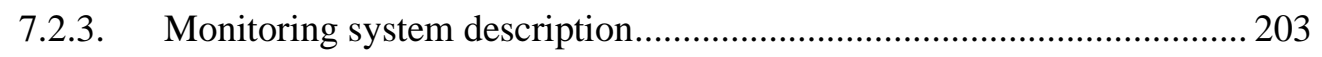

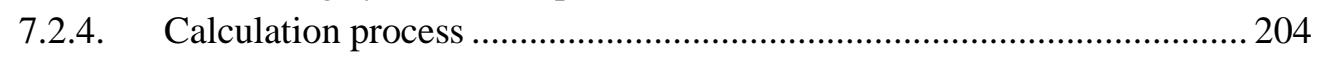

Estimation of the increased ventilation flow rate to fulfil the gas concentration requirements

$\ldots$

Estimation of the electrical and thermal energy consumption ......................................206

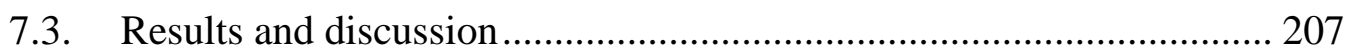

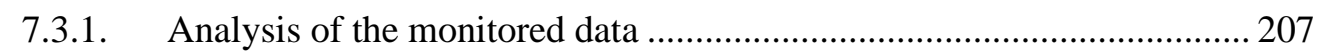

7.3.2. Evaluation of the theoretical ventilation increase ................................... 211

7.3.3. Evaluation of the energy consumption.................................................. 213

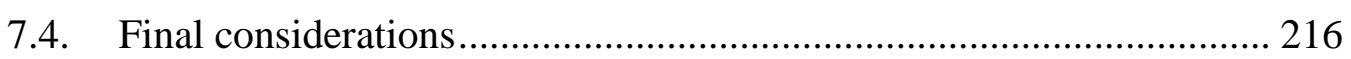

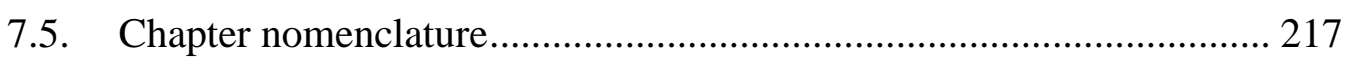

8. Conclusions ............................................................................................. 219

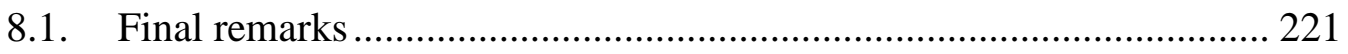

8.2. Future works ........................................................................... 222

8.3. Future perspectives ..................................................................... 222

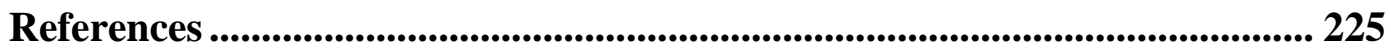


A. Tables of regression coefficients ...............................................................2243

A.1. Regression coefficients for Chapter 4 ............................................ 245

A.2. Regression coefficients for Chapter 5 ….......................................... 245

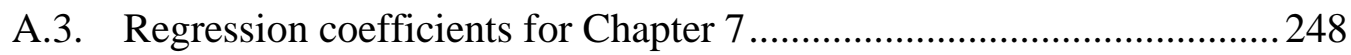

B. Set of equations for the application of the simple hourly method ........2249

B.1. Overview on the simple hourly method.......................................... 251

B.1.1. Setting the thermal balance ……............................................................252

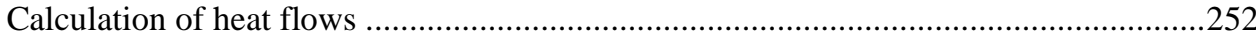

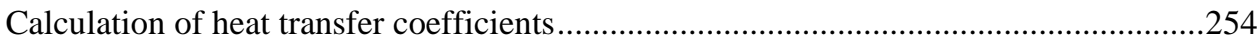

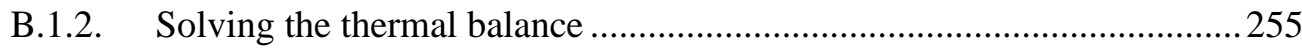

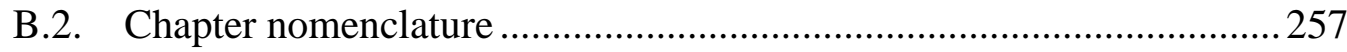

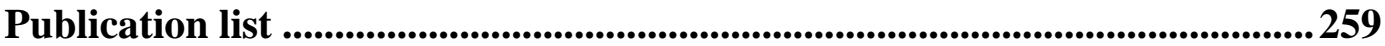




\section{List of Figures}

Figure 2.1 - Conceptualization of the network of relations between climate control and other topics of greenhouse crop production.

Figure 2.2 - Conceptualization of the network of relations between climate control and other domains of livestock production.

Figure 2.3 - Schematization of the Five Freedoms of animal welfare [82]. Climate control mainly affects the second freedom -freedom from discomfort- that is highlighted by a red contour..

Figure 2.4 - Relation between climate control and animal and human health..... 26

Figure 2.5 - Schematization of the positive impacts that an energy-efficient climate control of livestock houses could have on the three areas of sustainability, namely environmental, economic, and social sustainability.

Figure 3.1 - Schematic layout and main dimensions of the monitored greenhouse.

Figure 3.3 - Evaporative pads installed in the monitored greenhouse. 39

Figure 3.4 - Figure (a): three PT 1000 probes connected to an analog data logger enclosed in the electrical junction box. Figure (b): detail of greenhouse electrical panel with split-core current transformers and AC current switch sensors (in the center) and a $\mathrm{kWh}$ transducer (on the right).

Figure 3.5 - Hourly trends of $\theta$ air_i, $\theta$ air_o, $R H \mathrm{i}$ and $R H o$ during the monitored period. Three different subperiods (A, B and C) can be identified. 43

Figure 3.6 - Scatterplot of $\theta$ air_i ( $x$-axis) and $R H$ i ( $y$-axis) for the three considered subperiods

Figure 3.7 - Subplot (a): Oair_i (boxplot) and Oair_o. Subplot (b): Itot_hor (primary y-axis) and on/off status of evaporative cooling pump.

Figure 3.8 - Hourly differences ( $\Delta \theta$ air_i) between the $\theta$ air_i monitored by probes placed at different heights $(1.5,2$ and $2.5 \mathrm{~m})$ and the reference $\theta$ air_i placed at the bench level $(1 \mathrm{~m})$ during July.

Figure 3.9 - Carpet plot of the monitored electrical power absorbed by the greenhouse fans during July. Each cell of the plot represents the mean electrical power on a 15-minutes basis. 
Figure 3.10 - Subplot (a): Hourly energy consumption of fans. Subplot (b): Өair_o, Oair_i (primary $y$-axis) and Itot_hor (secondary $y$-axis) Subplot (c): Periods of

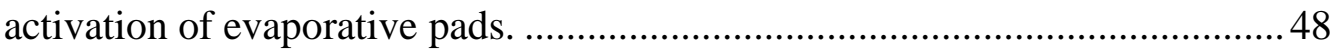

Figure 3.11 - Daily electrical energy consumption of fans. ..............................49

Figure 3.12 - Schematization of the farmstead context of the two monitored pig

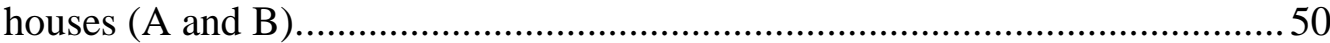

Figure 3.13 - Figure (a) external view of pig house A; figure (b) external view of pig house B; figure (c) internal view of pig house A; figure (d) internal view of pig house $B$. 50

Figure 3.14 - Figure (a) diesel fuel air heater adopted for the supplemental heating; Figure (b) fans for pit ventilation (detail of house B). 51

Figure 3.15 - Figure (a): PT 1000 probes connected to an analog data logger enclosed in an electrical junction box. Figure (b): datalogger with embedded thermistor and humistor in its protective case. 53

Figure 3.16 - Detail of the electrical panel with the $\mathrm{kW}$-transducer connected... 53

Figure 3.17 - Air temperature trends, UCT, LCT, TNZ visualization (primary $y$ axis) and pig live weight trend (secondary $y$-axes) .56

Figure 3.18 - Monthly heat-stress intensity for Pig House A and B during summer production cycle $(P 1)$.

Figure 3.19 - Indoor climate conditions of air temperature and relative humidity for pig house A (a) and B (b) for both the monitored periods ( $P 1$ and $P 2$ ) and

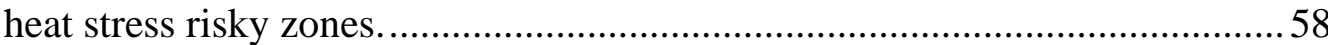

Figure 3.20 - Electrical power (10-seconds values) monitored in pig house A during the entire monitoring campaign 60

Figure 3.21 - Electrical power monitored during July in pig house A.................60

Figure 3.22 - Absolute frequencies of the electrical loads monitored during July in pig house A. The width of the classes is $30 \mathrm{~kW}$ and the logarithmic scale is used in $y$-axis. 61

Figure 3.23 - Daily electrical energy consumption for pig house A during (a) warm season (July) and (b) cool season (January).

Figure 3.24 - Relation between electric consumption due to feed distribution and average hourly indoor air temperature during the months of July 65

Figure 3.25 - Electrical energy consumption monitored during $P 1$ and $P 2$ in pig house A

Figure 4.1 - Classification (red dotted contour) of the energy simulation model presented in this work according to the existing literature. 78

Figure 4.2 - Model workflow through the calculation modules. The dotted contour represents the calculation loop that is repeated for each time-step of the simulation 80

Figure 4.3 - Evapotranspiration rates ( $m v a p$ ) calculated as a function of the solar radiation on the canopies ( $\phi$ sol_i) and the water Vapour Pressure Deficit (VPD) according to Eq. (15) ( $x$-axis is in logarithmic scale) 
Figure 4.4 - Analogy between the 5R1C electrical network and the thermal behavior of a greenhouse.

Figure 4.5 - Variation of the evaporative pad saturation efficiency $\varepsilon$ of different pad models as a function of the air velocity across them. The considered pad models are characterized by different thickness (100 and $150 \mathrm{~mm})$ and different flute angles $\left(30^{\circ} / 60^{\circ}\right.$ and $\left.15^{\circ} / 45^{\circ}\right)$. Authors elaboration on [215,216]. 87

Figure 4.6 - Control logic for the dehumidification ventilation adopted in the present model.

Figure 4.7 - Fixed speed fan (a) flowrate and (b) Specific Fan Performance (SFP) as function of fan static pressure.

Figure 4.8 - Variable speed fan (a) flowrate and (b) Specific Fan Performance $(S F P)$ as function of static pressure.

Figure 4.9 - Control logic for the cooling ventilation adopted in the present model.

Figure 4.10 - Static pressure drop generated by the cooling pad according to the model and thickness. Authors elaboration on [215,216]. 94

Figure 4.11 - Ventilation system performance, the fan operative condition is correlated to the type of cooling pad. 95

Figure 4.12 - Trends of monitored and simulated values of (a) indoor air temperature ( $\theta$ air_i $),(\mathrm{b})$ relative humidity $(\mathrm{RHi}),(\mathrm{c})$ and hourly electrical energy consumption. The outdoor air temperature ( $\theta$ air_o) and relative humidity $(\mathrm{RHo})$ are also showed.

Figure 4.13 - Absolute and cumulative frequencies of indoor air temperature for the considered scenarios of Verona (a), Seville (b) and Nantes (c). 106

Figure 4.14 - Cumulative electrical (a) and thermal (b) energy consumption for the considered climate scenarios.

Figure 5.1 - Calculation modules and workflow of the energy modelling framework proposed for livestock houses. The dotted contour represents the calculation loop that is repeated for each time-step of the simulation.

Figure 5.2 - Schematization of the base ventilation operating principle. Lateral exhaust fans create a negative pressure difference inside the broiler house expelling exhaust air (brown arrows). Supply fresh air (green arrows) inlets through the windows on the opposite wall, creating a cross ventilation flow to control $I A Q$

Figure 5.3 - Schematization of the tunnel ventilation operating principle. The fans placed at the end of the house exhaust hot air (red arrows), creating a negative pressure difference between inside and outside the broiler house. Fresh outdoor air (blue arrows) enters through the inlets placed across the longest sides of the broiler house due to the pressure difference, decreasing the indoor air temperature. 126

Figure 5.4 - Schematization of the evaporative cooling operating principle. The negative pressure difference inside the house created by tunnel ventilation fans forces the warm outdoor air through the wet evaporative pads decreasing its 
temperature (red/blue arrows). This supply air decreases the indoor air temperature and is expelled by the tunnel ventilation fans (red arrows)....... 127

Figure 5.5 - Trend of the optimal set point temperature (Өset_opt) with the dead band delimited by heating $(\theta$ set_H) and cooling set point temperature ( $\theta$ set_C). The trend of broiler live weight $(w \mathrm{~b})$ is shown on the secondary $y$-axis...... 129 Figure 5.6 - Moisture balance of a typical broiler house................................... 133

Figure 5.7 - Schematization of the layout of the broiler house selected as case study for the model validation.

Figure 5.8 - Daily trends of simulated ( $\theta$ air_i and $R H \mathrm{i}$ ) and monitored ( $\theta \mathrm{DL}, \theta \mathrm{CCU}$, $R H D L$, and $R H C C U$, ) values of indoor air temperature and relative humidity. The monitored trends of outdoor air temperature ( $\theta$ air_o) and relative humidity ( $R H \mathrm{Ho})$ are also presented

Figure 5.9 - Updated $(\varepsilon e c=0.6)$ daily trends of simulated ( $\theta$ air_i and $R H \mathrm{i})$ and monitored ( $\theta \mathrm{DL}, \theta \mathrm{CCU}, R H \mathrm{DL}$, and $R H C C U$,) values of indoor air temperature and relative humidity. The monitored trends of outdoor air temperature ( $\theta$ air_o) and relative humidity $(\mathrm{RHo})$ are also shown

Figure 5.10 - figure a): hourly trends of simulated ( $\theta$ air_i $)$, monitored $(\theta D L)$, and outdoor ( $\theta$ air_o) air temperature; figure b): hourly trends of simulated $(\mathrm{RHi})$, monitored $(R H D L)$, and outdoor $(R H o)$ relative humidity; figure $\mathrm{c})$ : simulated ventilation flow rate $(V$ act $)$

Figure 5.11 - Absolute (primary $y$-axis) and cumulative frequencies (secondary $y$ axis) of the relative humidity residual values $(\triangle R H \mathrm{i})$ calculated on hourly basis (1,200 values).

Figure 5.12 - Flow chart for the calculation of the actual ventilation flow rate (Vact) adopted in the presented energy simulation model.

Figure 5.13 - Schematization of pig house A, the one used for the model validation.

Figure 5.14 - Comparison between simulated and measured values of hourly indoor air temperature ( $\theta$ air_i) and relative humidity $(R H i)$. Outdoor monitored values of air temperature ( $\theta$ air_o $)$ and relative humidity $(\mathrm{RHo})$ are presented.

Figure 5.15 - Comparison between the daily monitored and estimated electrical energy consumption for ventilation. 156

Figure 5.16 - Hourly indoor climate conditions of air temperature and relative humidity for the considered scenarios. a) Italy: cool (IT-C) and warm (IT-W) seasons; b) Spain: cool (ES-C) and warm (ES-W) seasons; b) Germany: cool (DE-C) and warm (DE-W) seasons. 158

Figure 5.17 - Theoretical heating and cooling monthly energy needs from the considered models 163

Figure 5.18 - Hourly heating and cooling energy needs during a production cycle (February - April) 164

Figure 5.19 - Indoor air temperatures, set point temperatures and outdoor air temperature at the end of the analyzed production cycle (grey-filled area) and 
during the beginning of the following empty period (free running conditions).

Figure 6.1 - Schematization of the objective of Chapter 6 ........................... 175

Figure 6.2 - Schematization of the methodology workflow............................. 176

Figure 6.3 - Conceptualization of the differences between the delivered and the primary energy approach. 177

Figure 6.4 - Details of the building components of the three analyzed envelope types (A, B and C). The stationary thermal transmittances ( $U$-value), the internal areal heat capacities $(\kappa \mathrm{i})$ and the solar factors of the glazed surfaces $(g \mathrm{gl})$ are reported. 179

Figure 6.5 - Thermal ( $E$ th, figure a), and electrical energy consumption (figure b) both for ventilation (Eel_ven) and evaporative cooling (Eel_ec) from the 18 scenarios. 185

Figure 6.6 - Ranges of specific thermal (Emeat_th, figure a) and electrical energy consumption (Emeat_el, figure b) for the considered locations. 186

Figure 6.7 - Primary energy consumption Ep_glob of each scenario. In addition, the energy shares due to electrical (Ep_el) and thermal (Ep_th) energy consumptions are shown. 188

Figure 6.8 - Primary energy consumption for each production cycle (Ecycle_p_glob) and shares due and electrical (Ecycle_p_el) and thermal (Ecycle_p_th) energy from PL-C and ES-B scenario.

Figure 6.9 - Global cost $C G$ and shares due to envelope, climate control system and energy for each of the analyzed scenarios.

Figure 6.10 - Overheating index $(\Omega \mathrm{oH})$ of the analysed scenarios. 193

Figure 7.1 - Position of the sensors inside the monitored broiler house. Plan and cross section view -not at the same scale- show the main geometrical dimensions of the analyzed house. 204

Figure 7.2 - Flow chart of the calculation process........................................ 205

Figure 7.3 - a) monitored indoor ( $\theta$ air_i) and outdoor ( $\theta$ air_o) air temperatures; b) actual total ventilation flow rate $V \mathrm{l}+\mathrm{s}$; c) monitored indoor (Ci_NH3) and outdoor (Co_NH3) NH3 concentrations and indoor concentration limit (Clim_NH3); d) monitored indoor (Ci_CO2) and outdoor (Co_CO2) CO2 concentrations and indoor concentration limit (Clim_CO2)........................ 208

Figure 7.4 - Absolute and cumulative frequencies of: a) monitored indoor average NH3 concentration (Ci_NH3); b) monitored indoor average CO2 concentration (Ci_CO2). The arrows indicate the reference axis. 210

Figure 7.5 - Relative and absolute ventilation variation $\left(\Delta V l+s^{\prime}\right)$ between increased $\left(V l+s^{\prime}\right)$ and actual $(V l+s)$ ventilation flow rates (arrows indicate the reference axis).

Figure 7.6 - Trend of indoor air temperature ( $\theta$ air_i), indoor air temperature considering increased ventilation $\left(\theta\right.$ air_i $\left.{ }^{\prime}\right)$, heating $(\theta$ set_H) and cooling ( $\theta$ set_C) set point temperatures. On the secondary $y$-axis, heating load $(\phi H)$ and 
theoretical heating load $\left(\phi \mathrm{H}^{\prime}\right)$ are shown (arrows indicate the reference axis).

Figure 7.7 - Comparison between the total primary energy consumption and the shares due to heating and ventilation considering the actual and the increased ventilation flow rates.

Figure B.1 - General schematization of the equivalent 5R1C electrical network at the basis of the simple hourly method of ISO 13790. 251 


\section{List of Tables}

Table 1.1 - Summary of the structure of the thesis........................................... 8

Table 2.1 - Domains of crop production that have a mutual relation with climate control and scientific works from literature -with publication year and type of source- that highlight that mutual relation.

Table 2.2 - Domains of livestock production that have a mutual relation with climate control and scientific works from literature -with publication year and type of source- that highlight that mutual relation. ......................................... 19

Table 3.1 - Summary of the greenhouse monitoring campaign......................... 40

Table 3.2 - List of adopted instruments. ......................................................... 41

Table 3.3 - Summary of the pig houses monitoring campaign.......................... 51

Table 3.4 - List of adopted instruments. ............................................................ 52

Table 3.5 - Equipment and partial electrical loads preliminarily identified in pig house A

Table 3.6 - Main features of the monitored production cycles for both the houses.

Table 3.7 - Parameters for the Gompertz function of Eq.(1) adopted in this work.

Table 3.8 - Focus on the electrical energy consumption of pig house A during July.

Table 4.1 - Heat capacities of the greenhouse elements considered in this work.97

Table 4.2 - Values of the calibration parameters after the solution of the optimization problem.

Table 4.3 - Values (before and after the calibration) of goodness-of-fit indices and threshold values for the hourly validation of the presented energy simulation model, concerning indoor air temperature ( $\theta$ air_i $)$, relative humidity $(R H i)$ and hourly electrical energy consumption $(E \mathrm{el})$............................................ 104

Table 4.4 - Outdoor climate conditions used to perform the simulations.......... 105

Table 4.5 - Comparison between electrical energy consumption for ventilation considering variable and fixed angular speed fans.

Table 5.1 - Simulation models for livestock houses of monogastric animals considered in the literature review. 
Table 5.2 - Stationary thermal transmittance $(U-$ value $)$ and areal internal heat capacity ( $\kappa i$ ) of the building elements of the analyzed broiler house. ............ 136

Table 5.3 - Summary of the broiler house monitoring campaign. .................... 137

Table 5.4 - Summary of the dataset acquired in the broiler house.................... 137

Table 5.5 - Values before and after the calibration of goodness-of-fit indices and threshold values for the hourly and daily validation of the presented energy simulation model.

Table 5.6 - Monitored working times of the five gas heaters (I to V) of the monitored broiler house.

Table 5.7 - Stationary thermal transmittance $(U-$ value $)$ and internal areal heat capacities ( $\kappa i)$ of pig house A.

Table 5.8 - Goodness-of-fit indexes with their thresholds for indoor air temperature ( $\theta$ air_i) and relative humidity $(\mathrm{RHi})$.

Table 5.9 - Main features of the considered simulation scenarios.

Table 5.10 - Thermal (Eth), electrical $(E$ el) energy consumption and related financial costs of the considered scenarios.

Table 5.11 - Yearly theoretical energy needs for heating and cooling estimated by the three considered models.

Table 6.1 - The average stationary thermal transmittance of the entire envelope $U-$ value and total building fabric heat capacity $\mathrm{Cm}$ of the considered envelope types. 178

Table 6.2 - The locations used in this work with the reference cities, acronyms, and geographical regions. The average annual outdoor air temperature ( $\theta$ air_o) and the annual total solar radiation on horizontal surface (Hsol_hor) are shown for each location.

180

Table 6.3 - Costs of envelope and the climate control system elements and initial investment cost $(\mathrm{CI})$ referred to unit of useful floor area.

Table 6.4 - Considered cost conversion factor $(\gamma \mathrm{PLI})$ and costs of thermal $(C \mathrm{th})$ and electrical $(\mathrm{Cel})$ energy, including taxes.

Table 6.5 - Total -renewable and non-renewable- primary energy factors for thermal ( $f$ p_th_tot) and electrical ( $f$ p_el_tot) energy.

Table 6.6 - Primary energy consumption embedded in a unit of mass $(\mathrm{kg})$ of broiler meat (Emeat_p_glob) and shares due to heating, ventilation, and evaporative cooling.

Table 7.1 - Thermal transmittance $(U-$ value $)$ and internal areal heat capacity (кi) of the building components of the considered broiler house. 202

Table 7.2 - Detail of the monitored parameters. 204

Table 7.3 - Number of events and duration in which the indoor average NH3 (Ci_NH3) and CO2 (Ci_CO2) concentrations exceeded the established thresholds.

Table 7.4 - Comparison between the electrical (Eel) and thermal energy consumption $(E$ th $)$ considering the actual ventilation flow rate $(V l+s)$ and the 
electrical $\left(E \mathrm{el}^{\prime}\right)$ and thermal energy consumption $\left(E \mathrm{th}^{\prime}\right)$ considering the

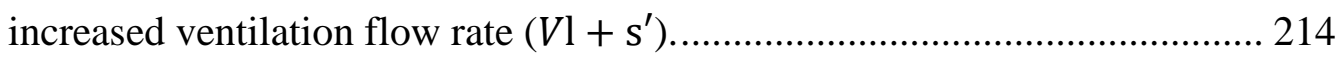

Table A.1 - Regression coefficients of Eqs. (17) and (18) ............................ 245

Table A.2 - Performance parameters of the fan model installed in the monitored greenhouse for the SFP calculation through Eq. (29) (data from manufacturer). 245

Table A.3 - Regression coefficients for the calculation of the broiler live weight as a function of the broiler age (Eq. (50)). 245

Table A.4 - Regression coefficients for the calculation of the optimal indoor air set point temperature as a function of the broiler age (Eq. (51)). 245

Table A.5 - Regression coefficients for the calculation of the dead band as a function of the broiler age (Eq. (52)). 246

Table A.6 - Regression coefficients for the calculation of sensible fraction of the broiler heat emission as a function of the optimal set point temperature (Eq. (56)). 246

Table A.7 - Regression coefficients for the calculation of the base ventilation flow rate emission as a function of the broiler age and weight (Eq. (60)). 246

Table A.8 - Regression coefficients for the calculation of the static pressure difference as a function of the air velocity (Eq. (69)). 246

Table A.9 - Regression coefficients for characterizing the fans installed in the considered broiler house through Eqs. (27) and (28).

Table A.10 - Regression coefficients for the calculation of the optimal indoor air set point temperature as a function of the pig live weight (Eq. (81)). 247

Table A.11 - Regression coefficients for the calculation of the base ventilation air flow rate as a function of the pig live weight (Eq. (83)). 247

Table A.12 - Regression coefficients for characterizing the fans installed in pig house A through Eqs. (27) and (28).

Table A.13 - Regression coefficients for the SFP of both the fan models....... 248 



\section{Chapter 1 \\ Introduction}

\begin{tabular}{c|l} 
Objective & $\begin{array}{l}\text { To provide a general framework about the importance of an energy-efficient } \\
\text { climate control for greenhouses and livestock houses. }\end{array}$ \\
\hline Outcome & $\begin{array}{l}\text { The overall objective, the three specific objectives and the outline of the thesis } \\
\text { are provided. }\end{array}$ \\
\hline Highlights & $\begin{array}{r}\text { - World food demand is expected to increase in the coming future. } \\
\text { - } \begin{array}{l}\text { Greenhouses and livestock houses can contribute to meet the future } \\
\text { food demand. } \\
\text { A more energy-efficient climate control is needed for greenhouses and } \\
\text { livestock houses. }\end{array}\end{array}$
\end{tabular}





\subsection{Meeting the future food demand}

According to the last estimations of United Nations, world population will rise from 7.7 to 9.7 billion between 2019 and 2050 [1]. A similar population growth would boost the world demand for agricultural products by at least $50 \%$ if compared to 2013 [2]. It means that a considerably higher amount of food should be produced to feed the future world population. This estimated increase of food demand will take place with a contemporary modification of the human diet, due to the expected economic growth and increasing urbanization -in 2050 more than two-thirds of people will live in urban settlements [3]- especially of low- and middle-income countries. Both these phenomena will lead to structural transformations of socioeconomic systems with consequent modifications also of food consumption patterns. The higher income typical of an urban population, in fact, favors the emergence of an urban middle class which demands mainly for meat, dairy products [4], vegetables and fruit, rather than cereals [2]. In 2050, it is expected an increase by $25 \%$ of the per-capita protein consumption (mainly from animal products) in low- and middle-income countries if compared to 2011 [5].

These increasing trends of food demand and modification of human diet emphasize the importance of one of the trickiest challenges for the next future: to produce enough food for future world population [6]. In this framework, climatecontrolled agricultural buildings- climate-controlled greenhouses and livestock houses- can play a primary role. Their production, in fact, is especially targeted on the agricultural products required by the future population -animal products, vegetables, and fruit- and they are characterized by a productivity considerably higher than on-field crop production and extensive animal farming. Even though, climate-controlled agricultural buildings can strongly contribute to feed the future population, they are also characterized by several issues, such as resource depletion and greenhouse gas emissions, that seriously jeopardize their sustainability, especially from the social and environmental points of view. Major transformations are then required to carry out the production in climate-controlled agricultural buildings in a sustainable manner [2]. One of the most critical aspects of those buildings is climate control since it provides several essential advantages to the production but, at the same time, it entails an important energy consumption, as shown in the following sections.

\subsubsection{Crop production in greenhouses}

Greenhouses are among the most widespread and efficient solutions for the Controlled Environment Agriculture. These agricultural buildings produce a wide variety of crops, mainly fruits and vegetables, that represent $60 \%$ of greenhousecultivated area [7].

Greenhouse crop cultivation is a very interesting alternative to the open field one since it improves weed control, pest management, irrigation process and 
harvesting operations [8]. In addition, the climate control system of fully mechanical controlled greenhouses -objective of this thesis- manages several indoor environmental parameters to provide the adequate indoor climate for crop growth also in climates and seasons in which the outfield cultivation would be otherwise impossible [9]. In this way, climate control of greenhouses enhances the possibility to cultivate crops near the locations of consumption reducing the transportation and, consequently, avoiding the related $G H G$ emissions and decreasing the food waste [9].

The precise control of the indoor environmental conditions brings each plant to its genetic potential [10], increasing the quality and especially the quantity of the production [11]. The greenhouse yield referred to the unit of productive surface is estimated to be between 10 and 20 times higher than the open-field one [12,13]. For example, the yield of strawberry production in greenhouses reaches up to $7.3 \mathrm{~kg} \mathrm{~m}^{-2}$ annum ${ }^{-1}$ against an open-field production of $0.5 \mathrm{~kg} \mathrm{~m}^{-2}$ annum ${ }^{-1}$ [14]. Tomato cultivation yield in greenhouses exceeds $68 \mathrm{~kg} \mathrm{~m}^{-2}$ annum ${ }^{-1}$, while the open-field one is around $7.5 \mathrm{~kg} \mathrm{~m}^{-2}$ annum ${ }^{-1}$ [15]. Similar increased cultivation yields are possible at the expense of a considerable energy consumption due to climate control. The open-field cultivation of one $\mathrm{kg}$ of strawberries, for example, needs around $0.20 \mathrm{kWh}$, while tomatoes cultivated in open field need $0.26 \mathrm{kWh} \mathrm{kg}^{-1}$. When the cultivation of these crops is carried out in climatecontrolled greenhouses, the related energy consumption dramatically increases, being $4.60 \mathrm{kWh} \mathrm{kg}^{-1}$ for strawberries and $17.50 \mathrm{kWh} \mathrm{kg}^{-1}$ for tomatoes $[14,15]$. This high energy consumption makes the greenhouse crop cultivation an energyintensive activity in the framework of the agricultural industry [9]. According to International Energy Agency, in the Netherlands, a country characterized by a high greenhouse production, the energy consumption of the agricultural sector is considerably increasing due to the expansion of greenhouse crop cultivation [16].

Greenhouses are characterized by an energy consumption referred to the unit of useful floor area that is by far higher than the one of other building types, such as residential, offices and retail buildings. Most of this energy consumption is due to heating which can need up to $530 \mathrm{kWh} \mathrm{m}^{-2}$ annum ${ }^{-1}$ in cool climates $[17,18]$ or up to $440 \mathrm{kWh} \mathrm{m}^{-2}$ annum ${ }^{-1}$ in warmer ones, such as in the Mediterranean area [17]. Heating represents between 65 and $85 \%$ of the total greenhouse energy consumption while the remaining share is due to electrical facilities, such as fans and actuators needed to cool the greenhouse [19]. The high solar radiation that enters the greenhouse through the glazed envelope, in fact, can considerably increase the indoor air temperature with detrimental effects for the cultivated crops. For this reason, cooling ventilation through fans and other cooling strategies are adopted in greenhouse, increasing even more the energy needed by this building type [20]. The high energy consumption proper of greenhouse crop production is not only an environmental issue, but also reflects on the production costs. The installation of the heating systems of greenhouses, in fact, represents between 30 and $60 \%$ of the total initial investment cost [21], while the use of energy is the 
second highest financial running cost after labor [9,19], accounting between 10 and $30 \%$ of the total production cost [17].

\subsubsection{Animal production in livestock houses}

Livestock products represent $18 \%$ of the kilocalories that are consumed worldwide and provides various micro-nutrients (e.g. vitamin A and iron) that are difficult to obtain in adequate quantities exclusively from plant-source food [22]. In addition, animal proteins are considered of a high quality with an amino acid pattern closer to the human body requirements [23] and they are more easily digestible and available for humans [24]. For these reasons, $25 \%$ of the total amount of protein consumed worldwide are derived from animals [22] and most of them are farmed in intensive livestock houses, which number has increased considerably in the last years [25]. Currently, more than $70 \%$ of poultry, about $55 \%$ of pork and over $60 \%$ of the eggs that are produced at a global level come from intensive livestock houses [26].

One of the greatest advantages of intensive livestock houses is their design and operation aimed at minimizing the costs and maximizing the production [27]. Fully mechanical controlled livestock houses (objective of this thesis) are equipped with climate control systems that manage the main indoor environmental parameters and that control the Indoor Air Quality (IAQ). The precise control of the indoor climate conditions brings the reared animals to express their genetic potential improving the production in both quantity [28,29] and quality [30] terms. In addition, fullymechanically controlled livestock houses are considered a resilient agricultural practice with a view on the climate change [31], representing an interesting solution for food security.

To guarantee the indoor climate conditions, mechanical systems are adopted inside fully mechanical controlled livestock houses. Those buildings, in fact, are usually equipped with heating systems for the general or specific heating, with ventilation fans for free cooling and $I A Q$ control and (in some cases) with evaporative pads that are used in certain climates to cool the animals during the warm season. All that equipment is responsible of an important on-farm energy consumption that depends on the considered animal production. For example, broiler houses need up to $140 \mathrm{kWh}_{\mathrm{th}} \mathrm{m}^{-2}$ yearly for general heating and $11 \mathrm{kWh}_{\mathrm{el}} \mathrm{m}^{-2}$ for ventilation and specific heating. These energy consumptions represent $96 \%$ of the total thermal energy and $65 \%$ of the total electrical energy that is used on farms, representing the main energy use in the broiler production [34]. Climate control represents a main energy use also in other livestock productions, such as laying hens and pigs [34]. In addition, most of the on-farm energy use is from fossil fuels [32], an issue that contributes to further worsen another primary problem of livestock production that are greenhouse gas $(G H G)$ emissions. Furthermore, fossil fuels are characterized by fluctuating price trends that expose 
farmers to significant business risks and have negative consequences from the food security point of view causing sudden increases of final product prices [26,33].

\subsection{Problem statement, aim and approach}

\subsubsection{The need of a transition toward sustainability}

As shown in the previous sections, climate control plays a dual role in climatecontrolled agricultural buildings. On the one hand, it has positive effects on the production providing useful advantages for meeting the future world food demand. On the other hand, climate control entails a high consumption especially of nonrenewable energy that are estimated to further increase in the coming future considering the rising trend of food production and the expansion of intensive agricultural systems $[25,34]$.

Similar energy consumptions represent an important issue that considerably affects the transition of the agricultural production toward the sustainability. It is evident that for moving toward more sustainable agricultural practices, the main sources of energy losses must be assessed [35] and an energy-efficient climate control is fundamental [36]. A more energy-efficient climate control, in fact, would improve the agricultural total factor productivity ([2]) that means to increase agricultural outputs through the increase of efficiency of production processes, rather than through the intensification of the inputs [2]. The improvement of the energy efficiency of climate-controlled agricultural buildings would have positive impacts on all the three pillars of sustainability. Environmental sustainability would increase since less resources would be used and less GHGs would be emitted. Financial sustainability would improve since the reduction of the energy consumption leads to lower production costs that, in turn, mean higher profitability for the farmers and lower food prices. Social sustainability would benefit since quality food at lower prices would be more easily accessible for people, improving food security and since more environmentally friendly agricultural systems would be more accepted by the society.

Improving the energy efficiency of climate-controlled agricultural buildings is a challenging task. Even though simulation methods and tools for assessing and improving the energy efficiency of buildings are present in literature and in normative frameworks, they cannot be tritely translated to greenhouses and livestock houses. This is because climate-controlled agricultural buildings are characterized by several peculiarities that should be accurately considered in the energy modelling, such as the adopted climate control systems and the interaction plant/animal-environment. Therefore, ad-hoc simulation models should be customized or developed specifically for greenhouses and livestock houses. These numerical models could strongly contribute to deepen the knowledge about climate control and energy consumption of these buildings, and they would enhance the assessment of the energy performance in standardized conditions, the setting of 
minimum requirements for envelope and systems and the evaluation of new technologies and solutions in several scenarios. In addition, energy models for greenhouses and livestock houses can also represent a powerful decision tool for stakeholders -farmers, engineers, and manufacturers- to be used in the design and operative stages for improving production while decreasing the energy consumption.

\subsubsection{Aim of the thesis}

Given the previous picture, the overall objective of this thesis is to contribute to the transition toward a sustainable agricultural production through the improvement of the energy performance of climate control in greenhouses and livestock houses.

To reach that overall objective, three main steps are followed, that represent as may specific objectives for this same thesis, namely:

a) the analysis of the tangle of mutual relations that interlaces energy, climate control and other relevant topics of agricultural production;

b) the development and validation of customized energy simulation frameworks for the estimation of the energy consumption and the average indoor environmental conditions of climate-controlled agricultural buildings;

c) the application of the developed simulation frameworks to propose new approach for achieving the sustainability of this sector and to analyze energy-related problems of climate-controlled agricultural buildings.

\subsubsection{Thesis outline and adopted approaches}

To achieve the overall objective of the thesis and to properly address the three established specific objectives -a), b) and c)- the thesis is structured as presented in Table 1.1. In Chapter 1 the general framework and the motivations that led to undertake this investigation are presented. In addition, the overall objective and the three specific objectives of the thesis are summarized and discussed.

Both Chapter 2 and Chapter 3 address the specific objective a). In Chapter 2, the mutual relations between energy consumption, climate control and other topics of intensive agricultural production -e.g. animal welfare and crop productivity- are analyzed through a deep analysis of the existing literature. In Chapter 3, those relations and further points of interest are underlined through the analyses of real datasets that were ad-hoc acquired during two long-term monitoring campaigns in a livestock house and in a greenhouse.

Chapter 4 and Chapter 5 are focused on the development and validation of $\mathrm{ad}$ hoc energy simulation models for climate-controlled agricultural buildings to address the specific objective b). These models are of a foremost importance to further investigate the nexus between climate control and energy consumption. In particular, Chapter $\mathbf{4}$ is focused on the development of a reliable energy simulation 
framework for mechanically ventilated greenhouses, while Chapter $\mathbf{5}$ provides a modeling framework for livestock houses that is then customized for broiler houses and growing-finishing pig houses. Both these chapters have a similar structure. First the main modelling issues are analyzed, then the model development is described and, finally, the validation procedure and results are presented. The model development is performed through a numerical approach, while the model validation adopts an experimental approach since the real datasets acquired in the case studies presented in Chapter 3 are adopted for this purpose.

In both Chapters 6 and 7, the developed energy simulation models are adopted to analyze energy-related problems, in accordance to objective c). In Chapter 6 the developed energy simulation model for broiler houses is used to investigate the role of the envelope in livestock houses, by assessing the delivered and primary energy consumption and global costs of different envelope types. In Chapter 7, the energy simulation model for broiler houses is adopted to investigate the role of ventilation, by assessing the variation of the energy consumption entailed by an improved ventilation strategy aimed at enhancing broiler welfare by reducing indoor noxious gas concentrations.

Finally, in Chapter 8 the conclusions and the final remarks of this thesis are presented and discussed.

Table 1.1 - Summary of the structure of the thesis.

\begin{tabular}{ccc} 
Chapter & Content & $\begin{array}{c}\text { Addressed } \\
\text { sub-objective }\end{array}$ \\
\hline Chapter 1 & Introduction and objectives of the thesis & - \\
Chapter 2 & Climate-environment nexus: results from literature analyses & a) \\
Chapter 3 & Climate-environment nexus: results from case studies & a) \\
Chapter 4 & Energy modelling of greenhouses & b) \\
Chapter 5 & Energy modelling of livestock houses & b) \\
Chapter 6 & Model application 1: envelope design through the primary & c) \\
Chapter 7 & Model application 2: extra-energy consumption for IAQ & c) \\
Chapter 8 & Conclusions and final remarks & - \\
\hline
\end{tabular}




\section{Chapter 2}

\section{Climate control in agricultural buildings: a tangle of relations}

\begin{tabular}{|c|c|}
\hline Objective & $\begin{array}{l}\text { To investigate the tangle of relations between climate control and other domains } \\
\text { of agricultural production in greenhouses and livestock houses. }\end{array}$ \\
\hline Outcome & $\begin{array}{l}\text { The central role of climate control in greenhouses and livestock houses is } \\
\text { outlined and the main relations with other domains are deeply analyzed. }\end{array}$ \\
\hline Highlights & $\begin{array}{l}\text { - Climate control has relations with various domains of agricultural } \\
\text { production. } \\
\text { - In greenhouses, the mutual relations are with productivity, water use, } \\
\text { health, and energy use. } \\
\text { - In livestock houses, the mutual relations are with animal welfare, air } \\
\text { emissions, productivity, health, and energy use. }\end{array}$ \\
\hline Notes & $\begin{array}{l}\text { Parts of this chapter are submitted to Applied Science Journal as: } \\
\text {-Costantino et al., "The role of climate control in monogastric animal farming: the } \\
\text { effects of indoor climate on animal welfare, air emissions, productivity, health, and } \\
\text { energy use", Applied Science, accepted manuscript. }\end{array}$ \\
\hline
\end{tabular}





\subsection{Climate control: a tangle of relations}

Climate control is fundamental in greenhouses and livestock houses since, as stated in the previous section, it contributes to improve considerably crop and animal productivity, at the expense of a large energy consumption due to the use of mechanical climate control equipment. Indeed, productivity and energy use are not the only research areas -domains- of agricultural production that are strongly affected by climate control. Several other domains of agricultural production, in fact, are interlaced with climate control, outlining a tangle of mutual relations that is worth of investigation. Before focusing specifically on energy-related aspects of climate control, this tangle of mutual relations is unpicked and investigated for both greenhouses and livestock houses through the analysis of the existing literature. In this way, the actual role of climate control in the considered agricultural buildings could be analyzed and the potentialities of investigations regarding climate control can be outlined.

\subsection{Unpicking the tangle of relations: greenhouses}

When humanity started to adopt greenhouse, they, at first, were used to accommodate rare and exotic plants during the cold season. Since this building type proved to guarantee almost the perfect conditions for the adequate plant growth and development, greenhouses become more and more employed for the cultivation of vegetables in not favorable climate conditions. For this reason, at the beginning, greenhouses were more common in severe climate conditions, such as Northern Europe. Nevertheless, the trend has changed in the last years and, nowadays, greenhouses have become more widespread in geographical areas with mild climates, for example the Mediterranean basin [37]. The reasons of this expansion can be attributable to several factors. One of them is the climate advantages of these areas which are characterized by mild winter temperatures and larger number of sunny days, entailing reduced supplemental heating costs. Another factor is the possibility of adopting low-cost materials, a feature that has boosted the expansion of plastic greenhouses at the expense of glasshouses, typical of Northern Europe. Finally, these geographical areas are characterized by an increasing demand for fresh vegetables and fruit caused by the rising income of local people [38], providing several market opportunities for greenhouse products.

The presented picture shows a strong relation between climate control and productivity in greenhouses. Nevertheless, further relations between climate control and other domains of crop productions can be highlighted and they outline a tangle of mutual relations. The objective of this section, hence, is to unpick this tangle by analyzing the existing mutual relations with the final aim of understanding the role of climate control in greenhouses. This objective is achieved by analyzing the existing scientific literature. 


\subsubsection{Analyzed works}

To show the mutual relations between climate control and other domains of crop production, the scientific literature was analyzed and the works reported in Table 2.1 were examined.

Table 2.1 - Domains of crop production that have a mutual relation with climate control and scientific works from literature -with publication year and type of source- that highlight that mutual relation.

\begin{tabular}{|c|c|c|c|}
\hline Domain & Reference & Year & Source* \\
\hline \multirow{13}{*}{ Productivity } & Bakker [39] & 1985 & $\mathrm{~J}$ \\
\hline & Mortensen [40] & 1987 & $\mathrm{~J}$ \\
\hline & Hicklenton [41] & 1988 & $\mathrm{~B}$ \\
\hline & Marcelis [42] & 1993 & $\mathrm{~J}$ \\
\hline & Rylski et al. [43] & 1994 & $\mathrm{P}$ \\
\hline & De Koning [44] & 1996 & $\mathrm{P}$ \\
\hline & Aloni et al. [45] & 1999 & $\mathrm{~J}$ \\
\hline & Baytorun et al. [46] & 1999 & $\mathrm{~J}$ \\
\hline & Ventura \& Mendlinger [47] & 1999 & $\mathrm{~J}$ \\
\hline & Dorais et al. [48] & 2000 & $\mathrm{~B}$ \\
\hline & Zipelevish et al. [49] & 2000 & $\mathrm{~J}$ \\
\hline & Kang et al. [50] & 2002 & $\mathrm{~J}$ \\
\hline & Gruda [38] & 2005 & $\mathrm{~J}$ \\
\hline \multirow{6}{*}{ Water use } & Blasco et al. [51] & 2007 & $\mathrm{~J}$ \\
\hline & Sabeh et al. [52] & 2007 & $\mathrm{P}$ \\
\hline & Hasani Balyani et al. [53] & 2015 & $\mathrm{~J}$ \\
\hline & O’Connor et al. [54] & 2016 & $\mathrm{P}$ \\
\hline & Omar et al. [55] & 2021 & $\mathrm{~J}$ \\
\hline & Tsafaras et al. [56] & 2021 & $\mathrm{~J}$ \\
\hline \multirow{3}{*}{ Health } & Cecchini et al. [57] & 2010 & $\mathrm{~J}$ \\
\hline & Callejon-Ferre et al. [58] & 2011 & $\mathrm{~J}$ \\
\hline & Marucci et al. [59] & 2012 & $\mathrm{~J}$ \\
\hline \multirow{12}{*}{ Energy use } & Canakci \& Akinci [60] & 2006 & $\mathrm{~J}$ \\
\hline & Sethi \& Sharma [61] & 2007 & $\mathrm{~J}$ \\
\hline & Najjar \& Hasan [62] & 2008 & $\mathrm{~J}$ \\
\hline & Djevic \& Dimitrijevic [63] & 2009 & $\mathrm{~J}$ \\
\hline & Runkle \& Both [19] & 2011 & $\mathrm{~J}$ \\
\hline & Qian et al. [64] & 2011 & $\mathrm{P}$ \\
\hline & Kittas et al. [17] & 2013 & $\mathrm{R}$ \\
\hline & Hemming et al. [65] & 2017 & $\mathrm{P}$ \\
\hline & Ntinas et al. [66] & 2017 & $\mathrm{~J}$ \\
\hline & Shen et el. [67] & 2018 & $\mathrm{~J}$ \\
\hline & Yano \& Cossu [68] & 2019 & $\mathrm{~J}$ \\
\hline & Ben Amara et al. [69] & 2021 & $\mathrm{~J}$ \\
\hline
\end{tabular}

* B: book, J: journal, P: conference proceeding, R: scientific report

Each work reported in Table 2.1 was analyzed to find the main domain of crop production that was highlighted to have a mutual relation with climate control. Four main domains were found to have such relation. These domains are reported in the 
first column of Table 2.1 and in the conceptualization of Figure 2.1. As visible from the figure, the analyzed domains are productivity, water use, health, and energy use. Nevertheless, additional mutual relations with further domains could be highlighted, but they are considered out of the scope of the present analysis.

Climate control has a strong relation with productivity, as previously stated. Indoor climate conditions, in fact, considerably affect productivity from a quantitative point of view by increasing the yield of harvested crops. Moreover, crops cultivated in an adequate thermal environment are usually characterized by better organoleptic characteristics, such as color and taste, guaranteeing high quality standards to the greenhouse production. This aspect is of the foremost importance in greenhouse production since greenhouse products usually have a higher visual quality than field-produced crops, a feature that justifies the extra production costs [70] and, at the same time, the extra cost on the market for the final customers.

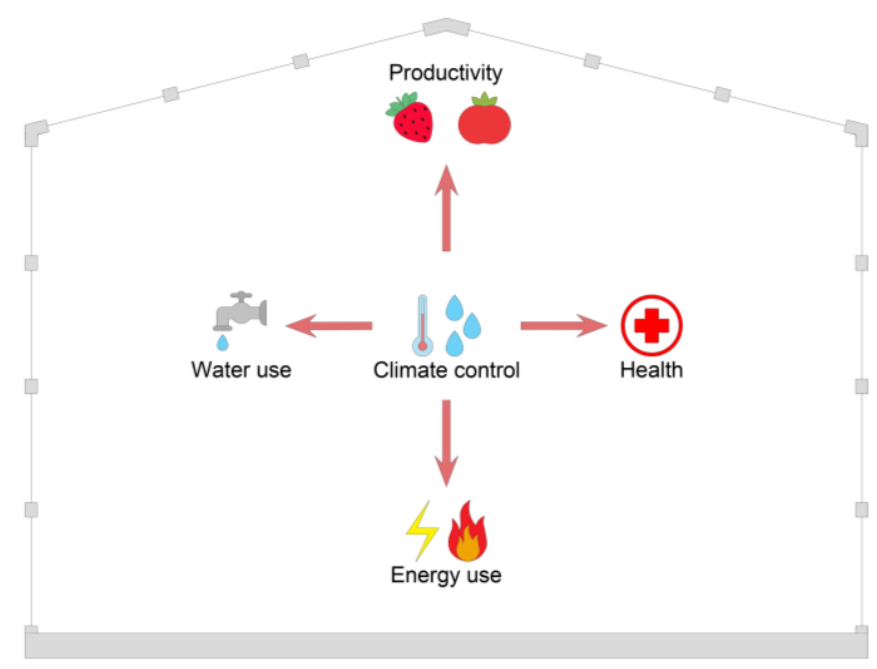

Figure 2.1 - Conceptualization of the network of relations between climate control and other topics of greenhouse crop production.

Climate control has also a strong relation with water use in greenhouses for a dual reason. On the one hand, a considerable amount of water -especially fresh water- is directly used by climate control system to cool the greenhouse, especially through equipment such as evaporative pads. On the other hand, indoor climate conditions affect plant evapotranspiration, a phenomenon which is strongly connected to irrigation, another main use of water in greenhouses.

Another relation shown by the schematization reported in Figure 2.1 is with health. Greenhouses, in fact, can be considered severe environments for workers that could suffer from heat stress, a serious threat for their health which could lead to cardiovascular and thermoregulatory disorders. Adequate indoor climate conditions could reduce these harmful situations for workers, improving the safety at the workplace.

The last relation that is shown by Figure 2.1 is with energy use. This relation is since a considerable amount of energy is needed in climate-controlled greenhouses 
to maintain the adequate indoor climate conditions. Since most of the energy used in greenhouse is mainly from fossil fuels, climate control can also have a negative effect on greenhouse gas $(G H G)$ emissions.

After this general overview, the relations between climate control and various domains of crop production are deepened in the following sections.

\subsubsection{The central role of climate control in greenhouses}

\section{Climate control and productivity}

In greenhouses, climate control has a strong relation with productivity. It favors plant development and avoid the unexpected and sudden changes of climate conditions, typical of open-field production which could be detrimental to cultivated crops. The effects of climate control on cultivated crops are considerable from both the quantitative and the qualitative points of view. Aspects such as crop yield and organoleptic characteristics, in fact, can be strongly affected by the indoor climate conditions [38].

Plant properties are affected by indoor air temperature at both the plant and cellular level. In general terms, the increase of indoor air temperature leads to an increased growth rate of vegetable fruits. The analyses on cucumbers performed by Marcelis [42], for example, show that the rise of indoor air temperature from $18{ }^{\circ} \mathrm{C}$ to $25^{\circ} \mathrm{C}$ increases the fruit biomass allocation at the expense of the other vegetative parts of the plants. Similar results were found by De Koning [44] in an analysis regarding tomatoes and by Ventura \& Mendlinger [47] in melon fruits. Indoor air temperature also affects the number of fruits produced by each plant since, when exposed to the increased indoor air temperature, plants start to abort flowers and to delay the growth of new fruits $[42,44]$. By contrast, low indoor air temperature causes small fruits [46] with malformations [45] and taste deterioration [43]. Low indoor air temperatures negatively affect also colors in tomatoes [48] and eggplants [49]. Finally, indoor air temperature -but also solar radiation- considerably affects the fruit temperature, a parameter that has a strong influence on the tolerance of fruits to postharvest chilling. For example, cucumbers that grown at a high fruit temperature $\left(32^{\circ} \mathrm{C}\right)$ were demonstrated to have a longer storage life than cucumbers that grown at a lower fruit temperature $\left(27^{\circ} \mathrm{C}\right)$ [50].

Indoor air relative humidity could also have detrimental effects on plants and not only on vegetable fruits. High relative humidity, in fact, reduces plant transpiration -a process that cools the plant- with a consequent increase of the occurrence of heat damages and limitation of ion translocation from roots to shoots. Furthermore, the changes in stomatal resistance produced by the high values of relative humidity can increase leaf injuries caused by air pollutants [39].

$\mathrm{CO}_{2}$ enrichment increases plant photosynthesis with positive effects on plant height, dry weight, leaf number and lateral branching [40]. $\mathrm{CO}_{2}$ enrichment practice has become more and more important in the last years since it is required by the increasingly widespread cultivations that use soilless growing media, such as peat 
bags, rockwool and nutrient films [38]. Since photosynthesis takes place mainly in leaves, the primary effects of $\mathrm{CO}_{2}$ enrichment are especially visible in leaf tissue that accumulates dry matter increasing their size [41]. This phenomenon represents an important advantage mainly in crops cultivated exclusively for their leaves, such as lettuce that can increase its weight up to $36 \%$ when $\mathrm{CO}_{2}$ enrichment is performed [38]. Furthermore, $\mathrm{CO}_{2}$ enrichment can mitigate the negative effects of other environmental factors, such as high salinity in irrigation water, low light conditions and high electrical conductivity levels of the adopted nutrient solutions [38].

\section{Climate control and water use}

Historically, water use has been one of the main concerns of agricultural production. Nowadays, it is estimated that $88 \%$ of the groundwater depletion is due to agriculture whose water use has dramatically increased by three times between 1980 and 2017 [56]. Greenhouses can be considered an agricultural practice that has several potentialities in saving water. This is since greenhouses reduce the evapotranspiration rate of the cultivated crops, even though the exact amount of water savings is difficult to be quantified [54]. Nevertheless, greenhouses are characterized by significant water uses for different purposes, mainly irrigation, fogging and cooling. Evaporative cooling systems, in fact, are considered the best cost-effective option for decreasing the indoor air temperature in greenhouses, especially in geographical contexts characterized by high outdoor air temperatures and low or medium outdoor relative humidity [53]. Unfortunately, evaporative cooling systems lead to a high freshwater consumption that, in certain geographical contexts such as arid and semi-arid regions, could exceed the freshwater consumption for irrigation, as reported by Sabeh et al. [52] for Southern Arizona (USA). For example, $16 \mathrm{~kg}$ of water are used for irrigation to produce one $\mathrm{kg}$ of tomatoes in a greenhouse in Saudi Arabia. In the same context, the amount of water used for evaporative cooling is around $89 \mathrm{~kg}$, more than 5 times higher [56].

Considering the environmental issues related to water depletion and the cost of water that is more and more noteworthy in some regions, such as Mediterranean basin due to the more frequent and intense drought [51], researchers are investigating improved climate control systems to decrease the water consumption in greenhouses. Blasco et al. [51], for example, proposed an improvement of the climate control systems of an hydroponic greenhouse through the implementation of a model-based predictive control optimized through genetic algorithms to minimize the costs for energy and nebulization water. Omar et al. [55] evaluated the effect of a solar-assisted evaporative cooling system coupled with a plastic coating of the cover that led to an increase of cucumber yield and a decrease of water use. Tsafaras et al. [56] demonstrated that a medium-technology greenhouse, equipped with reflective shading, variable angular speed fans and high pressure fogging systems, can reduce the water use for the production of $1 \mathrm{~kg}$ of tomatoes by about $40 \%$ if compared with a low-technology plastic greenhouse. The highest 
share of reduction was achieved for evaporative cooling water that decreased from $89 \mathrm{~kg}$ to $45 \mathrm{~kg}$ per $\mathrm{kg}$ of produced tomatoes.

\section{Climate control and health}

Greenhouse workers are exposed to the adequate climate conditions for crop growing but, usually, these climate conditions are not necessarily the best ones in which performing working activities. Greenhouse, especially the naturally ventilated ones, could be characterized by high indoor air temperatures and relative humidity that make them severely hot environments that could negatively affect worker thermoregulatory and cardiovascular systems, with consequent health problems. In this kind of environments, the thermoregulation system of human body is put under heavy strain and mechanisms such as perspiration and vasodilation are adopted to dissipate the excess of heat [57]. When the thermoregulatory system is not able to maintain the homeothermy, various health problems may occur, such as water/sodium deficiency, syncope, and heat stroke. Heat stroke, for example, is a disorder of body thermoregulation that leads to an increase of body temperature over $40{ }^{\circ} \mathrm{C}$ with harsh consequences for worker health, such as headache, dizziness, confusion and even coma [57]. The exposition of workers to high indoor air temperatures and relative humidity could lead to slighter consequences, such as aggressions, distractions, lack of precision and tremor with detrimental effects on greenhouse production [59]. The adoption of mechanical climate control systems, therefore, could avoid the extreme outdoor weather conditions that characterizes specific areas, contributing to decrease health risks for greenhouse workers.

For this reason, Authors in literature are focusing on assessing the heat stress and safety of workers inside greenhouses -especially naturally-ventilated onesthrough the adoption of different indices, such as the Predicted Mean Vote [71] and the Wet Bulb Globe Temperature index [72]. Marucci et al. [59], for example, evaluated the heat stress of workers of a greenhouse for vegetable grafting in Center Italy during a working year. Their analyses highlighted heat stress problems from April to October, while cold stress problems were evident in December and January. Cecchini et al. [57] assessed the health risk for workers of three greenhouses in central Italy, providing some guidelines to favor worker acclimatization, a strategy which is considered a fundamental element of prevention for people working in this type of environments. Callejon-Ferre et al. [58] focused their work on greenhouses of southeastern Spain, in Almería region. The results of their analyses individuated the hours of the day in which workers could be more exposed to heat stress and, consequently, they propose to modify the work timetable to avoid those hours.

\section{Climate control and energy use}

In greenhouses, climate control is strongly related with energy use. In several greenhouses, in fact, mechanical equipment is adopted for controlling the indoor climate conditions, entailing a significant thermal and electrical energy 
consumption. The greenhouse crop yield increases as a function of the total energy inputs [60], meaning that to achieve important production yields, high amount of energy are usually used. Furthermore, the energy consumption of greenhouses rises with the increase of the latitude since higher latitudes entail greater supplemental heating and lighting energy demands [68]. In this context, it is emblematic the situation of The Netherlands. The outdoor climate conditions of this country typical of Northern Europe- together with the high volume and production yields of Dutch greenhouse industry entail a considerable total energy consumption of greenhouse sector. This energy consumption is estimated to be around $10 \%$ of the total energy use of the country [64], being around 112 PJ in 2013 and the highest share of this energy (63\%) was for heating [65].

In mechanically controlled greenhouses, in fact, supplemental heating represents the highest share of energy consumption and it ranges between $65 \%$ and $85 \%$ of the total greenhouse energy consumption. The remaining share is due to electrical facilities, mainly for lighting and for cooling the greenhouse [19]. In literature, reference values of greenhouses energy consumption can be found. According to Kittas et al. [17], the thermal energy consumption for supplemental heating of mechanically controlled greenhouses in cool climates can be up to $530 \mathrm{kWh} \mathrm{m}^{-2}$ per year. In warmer climates, the thermal energy consumption for supplemental heating is lower, being up to $440 \mathrm{kWh} \mathrm{m}^{-2}$ per year. The analyses of Yano \& Cossu [68] show that greenhouses consume up to $55 \mathrm{kWh} \mathrm{m}^{-2}$ of electrical energy in hot regions. A higher electrical energy consumption -around $130 \mathrm{kWh} \mathrm{m}^{-2}$ - was reported by Ntinas et al. [66] for the interior area of Greece. Similar energy consumption values have also a considerable impact from the financial point of view since energy consumption is estimated to account for about $50 \%$ of the greenhouse production costs [67].

Energy consumption for climate control represents an important share also considering the total -operational plus embedded- energy consumption, as it stands out from the analyses of Canakci \& Akinci [60]. The energy consumption for heating represents around $20 \%$ of the total energy used in greenhouses, with a value that is of the same order of magnitude of the energy embedded in the greenhouse structure. Similar conclusions were obtained by Djevic \& Dimitrijevic [63] that compared the total energy consumption for different types of greenhouses.

To decrease this high energy consumption that characterizes greenhouses, several solutions are adopted, as shown by the analysis of the state of the art of Hemming et al. [65], such as the adoption of a heat exchanger system coupled with aquifers [61], phase change materials [62], photovoltaics systems [69] and geothermal heat exchangers [73]. To evaluate possible improvements of the energy performance of greenhouses through the adoption of new strategies and new technologies, energy simulation models for this specific type of agricultural buildings are essential and they were developed by various authors in literature, as better analyzed in section 4.3.1 of this thesis. 


\subsection{Unpicking the tangle of relations: livestock houses}

Animals are farmed by humanity since millennia for obtaining various products, such as meat, eggs, and milk. As animal farming developed, it became evident that controlling the thermal environment in which animals are farmed contributes materially to their production [74]. Consequently, animals had started to be farmed in confined systems -i.e. the livestock houses- for providing them an environment of controlled temperature and humidity. In this way, the environmental extremes -such as very low/high air temperatures- that are typical of the outdoor weather conditions, are considerably reduced, increasing productivity [29]. In the last decades, livestock houses have been subjected to an engineering process that has strongly transformed them, introducing new technologies and equipment. Consequently, current livestock houses are intensive livestock systems in which a fine-tuned climate control guarantees the adequate indoor climate conditions needed by animals to express their genetic potential and to increase the production $[28,29]$. These livestock houses are designed and operated to minimize costs and to maximize the production [27], respecting normative requirements, such as the minimum standards in terms of space allowance for animals [75-77]. The high productivity of livestock houses has led to an increase of their number in the last years [25] to cover the increasing demand of livestock products. Currently, more than $70 \%$ of poultry, about $55 \%$ of pork and over $60 \%$ of the eggs that are produced worldwide come from intensive livestock houses [26].

The presented picture shows a strong relation between climate control and productivity in livestock houses. Nevertheless, productivity is not the only domain of livestock production that is affected by climate control. Existing works in literature, in fact, highlighted relations between climate control and other domains of livestock production, such as animal welfare and air emissions. Consequently, a tangle of mutual relations between climate control and other domains of livestock production can be outlined, showing that the role of climate control in livestock houses is not trivial and it has not been totally understood. In the following sections, hence, the role of climate control in livestock houses and the mutual relations that it has with other domains of livestock production is analyzed. This objective is achieved through a literature review that is exclusively focused on monogastric animal farming, mainly poultry and pigs. This choice is since the high sensitivity to the thermal environment that characterizes monogastric animals makes climate control an essential element for their farming.

\subsubsection{Analyzed works}

To understand the mutual relations between climate control and other domains of livestock production, an analysis of the existing scientific literature was performed and the works reported in Table 2.2 were considered. As visible from the table, the analysis encompasses scientific works published in the last 25 years in international scientific journals, books, conference proceedings and scientific 
reports. Nevertheless, few older works -mainly handbooks- were included in this analysis since they are considered essential to the purpose of this work. As stated before, this literature review was focused only on monogastric animals due to their sensitivity to climate conditions. Nevertheless, climate conditions are also important for the farming of ruminants, but they are considered out of the scope of the present review.

Table 2.2 - Domains of livestock production that have a mutual relation with climate control and scientific works from literature -with publication year and type of source- that highlight that mutual relation.

\begin{tabular}{|c|c|c|c|}
\hline Domain & Reference & Year & Source* \\
\hline \multirow{8}{*}{ Animal welfare } & Newburgh et al. [78] & 1948 & $\mathrm{~B}$ \\
\hline & Hutchinson [79] & 1954 & B \\
\hline & Huges [80] & 1976 & $\mathrm{P}$ \\
\hline & Broom [81] & 1986 & $\mathrm{~J}$ \\
\hline & $\begin{array}{c}\text { Farm Animal Welfare } \\
\text { Council [82] }\end{array}$ & 1993 & $\mathrm{R}$ \\
\hline & Fregley [83] & 1996 & B \\
\hline & Fregley \& Blatteis [84] & 1996 & $\mathrm{~B}$ \\
\hline & Blokhuis et al. [85] & 2013 & $\mathrm{~B}$ \\
\hline \multirow{11}{*}{ Air emissions } & Carr et al. [86] & 1990 & $\mathrm{~J}$ \\
\hline & Aarnink et al. [87] & 1996 & $\mathrm{~J}$ \\
\hline & Groot Koerkamp et al. [88] & 1998 & $\mathrm{~J}$ \\
\hline & Huynh et al. [89] & 2005 & $\mathrm{~J}$ \\
\hline & Blanes-Vidal et al. [90] & 2008 & $\mathrm{~J}$ \\
\hline & Groot Koerkamp et al. [91] & 2008 & $\mathrm{P}$ \\
\hline & Knížatová et al. [92] & 2010 & $\mathrm{~J}$ \\
\hline & Banhazi [93] & 2013 & $\mathrm{~J}$ \\
\hline & Winkel et al. [94] & 2014 & $\mathrm{P}$ \\
\hline & Thorne [95] & 2019 & B \\
\hline & Rodriguez et al. [96] & 2020 & $\mathrm{~J}$ \\
\hline \multirow{9}{*}{ Productivity } & Grieve [97] & 2003 & $\mathrm{~J}$ \\
\hline & St-Pierre et al. [98] & 2003 & $\mathrm{~J}$ \\
\hline & Lu et al. [99] & 2007 & $\mathrm{~J}$ \\
\hline & Daramola et al. [30] & 2012 & $\mathrm{~B}$ \\
\hline & Kilic \& Simsek [100] & 2013 & $\mathrm{~J}$ \\
\hline & Barrett et al. [101] & 2019 & $\mathrm{~J}$ \\
\hline & Settar et al. [102] & 2019 & $\mathrm{~J}$ \\
\hline & Liu et al. [103] & 2020 & $\mathrm{~J}$ \\
\hline & Moreno et al. [104] & 2020 & $\mathrm{~J}$ \\
\hline \multirow[b]{8}{*}{ Health } & Kristensen \& Wathes [105] & 2000 & $\mathrm{~J}$ \\
\hline & McGovern et al. [106] & 2001 & $\mathrm{~J}$ \\
\hline & Donham et al. [107] & 2002 & $\mathrm{~J}$ \\
\hline & Beker et al. [108] & 2004 & $\mathrm{~J}$ \\
\hline & Olanrewaju et al. [109] & 2007 & $\mathrm{~J}$ \\
\hline & Olanrewaju et al. [110] & 2008 & $\mathrm{~J}$ \\
\hline & Smit et al. [111] & 2008 & $\mathrm{~J}$ \\
\hline & $\begin{array}{c}\text { European Commission } \\
{[112]}\end{array}$ & 2012 & $\mathrm{R}$ \\
\hline
\end{tabular}




\begin{tabular}{ccc} 
Aland \& Banhazi [113] & 2013 & B \\
Ngajilo [114] & 2014 & J \\
FAO [115] & 2016 & R \\
O’Neill [116] & 2016 & R \\
Yi et al. [117] & 2016 & J \\
Hristov et al. [118] & 2018 & J \\
Laurent [119] & 2018 & R \\
Ranjan et al. [120] & 2019 & J \\
Yasmeen et al. [121] & 2020 & J \\
\hline Thornton \& Herrero [122] & 2010 & R \\
El Mogharbel et al. [123] & 2014 & J \\
Fabrizio et al. [124] & 2014 & J \\
Zhou et al. [125] & 2017 & P \\
Xie et al. [126] & 2019 & J \\
Lee et al. [127] & 2020 & J \\
\hline
\end{tabular}

* B: book, J: journal, P: conference proceeding, R: scientific report

The selected works were analyzed with the aim of finding in each one of them the main domain of livestock production that was highlighted to have a mutual relation with climate control. Five main domains of livestock production were found to have such a relation -first column of Table 2.2- and they are schematized in the conceptualization of Figure 2.2. The considered domains are animal welfare, air emissions, productivity, health, and energy use. Other relations with further domains could be highlighted, but they are considered out of the scope of the present work.

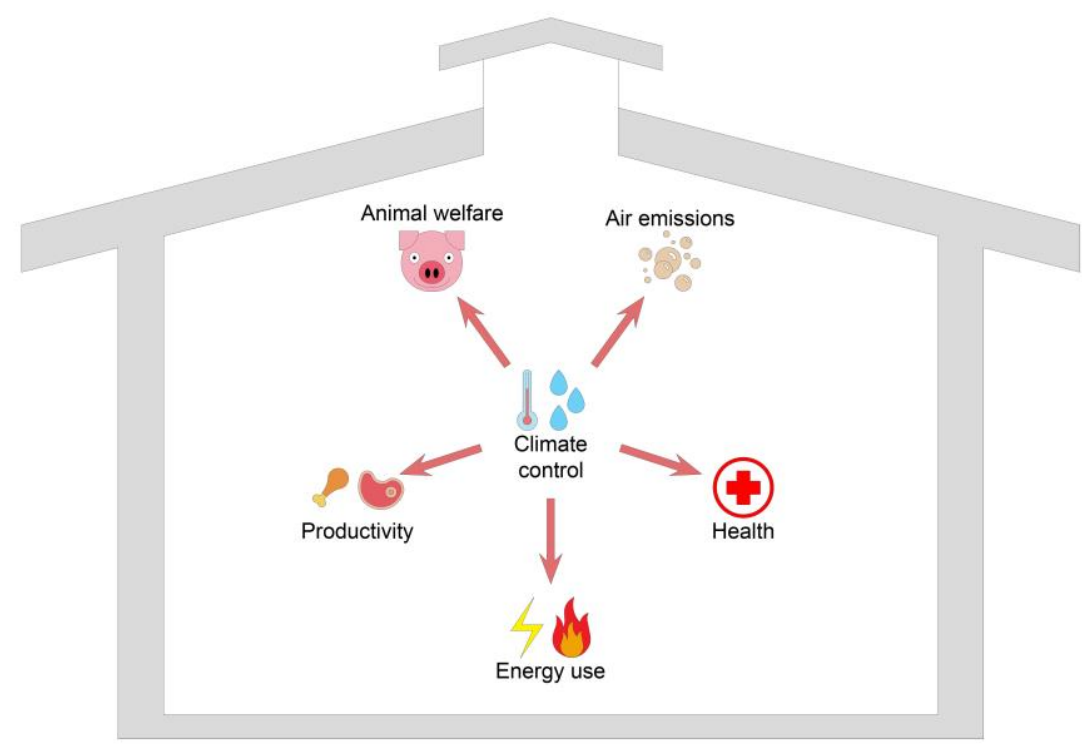

Figure 2.2 - Conceptualization of the network of relations between climate control and other domains of livestock production.

As visible from Figure 2.2, climate control has a mutual relation with animal welfare. This is since adequate indoor climate conditions are essential to improve the welfare of the farmed animals. An improved animal welfare could have positive impacts from the ethics point of view and it may contribute to increase the social 
acceptance of intensive animal farming systems that, nowadays, are more and more criticized. Animal welfare can have further connections with other two important pillars of livestock production, namely feeding and genetics. As an important component of animal environment, climate control critically affects how farmed animals express their genetic potential using feed efficiently and without disease. Therefore, investigations aimed at analyzing these three aspects -climate control, genetics, and feeding- should be performed considering all of them together in a holistic way.

From Figure 2.2, it stands out that there is a strong relation between climate control and air emissions. Ventilation, in fact, has a dual role in controlling the pollutant concentration and in affecting their emission rate. The same ventilation type and airflow rate- can modify emission patterns. Particularly, the $\mathrm{NH}_{3}$ emission process is enhanced when turbulence -air velocity- and temperature increase above manure surfaces. On the contrary, higher ventilation may reduce the humidity of litter inside livestock houses, thus reducing potential emissions in subsequent phases. This mutual relation and the real effect of ventilation, hence, is however difficult to predict since it depends on factors such as the airflow rate, building geometry and manure management system. Furthermore, it may be affected by other environmental parameters, such as temperature and relative humidity. These are relevant topics which need further research to be understood with the aim of improving emission abatement techniques.

Climate control has a mutual relation also with productivity and with health. The former relation -with productivity- is since not adequate indoor climate conditions can jeopardize farm production from the quantitative and the qualitative point. The latter relation -with health- is since climate control maintains adequate thermal and gaseous environments that contribute to ensure hygienic conditions and, hence, in reducing health risks for both animals and humans.

The last relation that is shown by the conceptualization of Figure 2.2 is the one with energy use. Many livestock houses for monogastric animal farming, in fact, are characterized by high energy consumption due to the adoption of mechanical equipment needed to maintain the adequate indoor climate conditions. Moreover, this energy consumption entails considerable $G H G$ emissions since fossil fuels are mostly adopted in the agricultural sector.

In this section a general overview about the mutual relations that exist between climate control and the previously presented domains of livestock production. The presented relations will be deepened in the following sections.

\subsubsection{The central role of climate control in livestock houses}

\section{Climate control and animal welfare}

Animal welfare has been always associated with environment, as highlighted by the definitions of animal welfare provided by Hughes [80] and Broom [81]. In addition, the second of the Five Freedoms of animal welfare established by Farm 
Animal Welfare Council in [82] -schematized in Figure 2.3- states that an appropriate environment should be provided to animals to avoid discomfort. In this context, hence, climate control is fundamental since it provides the adequate thermal and gaseous environments inside livestock houses. The importance of an adequate thermal environment in guaranteeing animal welfare is also highlighted by the protocol for the overall assessment of animal welfare developed by Welfare Quality Network [85]. One of the 12 principles at the basis of this protocol, in fact, specifically regards animal thermal comfort.

\section{Freedom from hunger or thirst \\ 2 Freedom from discomfort 9 \\ 3 Freedom from pain, injury and disease \\ 4 Freedom to express normal behavior

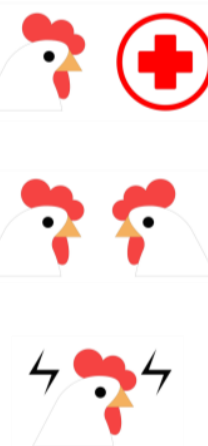 \\ 5 Freedom from fear and distress}

Figure 2.3 - Schematization of the Five Freedoms of animal welfare [82]. Climate control mainly affects the second freedom -freedom from discomfort- that is highlighted by a red contour.

To understand the deep relation between climate control and animal welfare, animal physiology should be analyzed since it can explain the changes that occur to the animal metabolism when the thermal environment is not adequate. The indoor effective environmental temperature is the main parameter that can be considered for evaluating if the thermal environment is adequate for animal farming. This parameter depends on air temperature, relative humidity and air velocity [128] and it has to be maintained within the zone of nominal losses -or Thermoneutral Zone (TNZ)- to guarantee the animal thermal comfort. $T N Z$ is a thermal neutral temperature range that is bounded by the Lower Critical Temperature (LCT) and the Upper Critical Temperature $(U C T)$, as reported in handbooks of animal physiology $[78,79]$. When the effective environmental temperature is within this range, the animal is in thermal comfort and its metabolism uses a minimum share of the energy intake from feed for maintaining homeothermy. In this situation, most of the intake energy is used for growth and production, for example of milk or eggs. When effective environmental temperature is out of the $T N Z$, the animal starts to adopt phenotypic responses, such as the reduction of feed intake and the alteration of physiological functions [84]. These phenotypic responses are part of a strategy 
called acclimation aimed at maintaining the animal thermal balance [83]. When the effective environmental temperature is lower than the $L C T$, the animal can suffer from cold stress -with potential hypothermia- and its rate of metabolic heat production must be increased adopting different strategies, such as behavioral modifications, increase of intake feed and shivering and/or non-shivering thermogenesis. By contrast, values of effective environmental temperature higher than UCT can cause heat stress, that can lead animal to potential hyperthermia. In this situation, the animal should increase its heat losses to maintain the thermal balance. To do so, the animal heat production decreases through behavioral strategies and through the reduction of the feed intake. Contemporarily, the animal increases its heat losses through, for instance, thermal tachypnea and sweating [129].

Another condition related to indoor climate that can jeopardize animal welfare is a poor Indoor Air Quality $(I A Q)$. The indoor air of livestock houses, in fact, is characterized by high concentrations of different types of pollutants such as gases, vapors, bioaerosols and particulate matter. These pollutants, are originated from animals, feed, manure and from microorganisms that are associated to the manure [95]. They can impair animal welfare with further negative consequences on health and productivity. To improve $I A Q$ and to consequently enhance animal welfare, European regulation set threshold limits for certain gases in livestock houses. For example, $\mathrm{NH}_{3}$ and $\mathrm{CO}_{2}$ concentrations should be maintained below $20 \mathrm{ppm}$ and 3,000 ppm, respectively, in European broiler houses with stocking densities higher than $33 \mathrm{~kg} \mathrm{~m}^{-2}$ [76]. Nevertheless, values over these limits were reported in commercial poultry houses. Knížatová et al. [92] measured $\mathrm{NH}_{3}$ concentrations up to $29 \mathrm{ppm}$ in a broiler house in different period of the year, a value similar to the one monitored by Groot Koerkamp et al. [88] in poultry houses of Northern Europe.

\section{Climate control and air emissions}

As just stated, gases, vapors, bioaerosols and particulate matter worsen $I A Q$ of livestock houses, with detrimental effects on animal welfare. To avoid similar problems and to improve $I A Q$, contaminant concentrations are usually controlled through natural or mechanical ventilation, a strategy that have a dual effect. On the one hand, in fact, ventilation dilutes and removes contaminants, improving $I A Q$. On the other hand, ventilation can increase the same air emissions, increasing the contaminants that are emitted inside and outside the livestock house. A clear example of this dual effect can be found, for example, in broiler houses. The high ventilation flow rates that are usually adopted in this type of livestock houses during warm season decrease the $\mathrm{NH}_{3}$ concentration but, at the same time, they favor the $\mathrm{NH}_{3}$ volatilization from litter, with a consequent increase of air emissions, as shown by the empirical models of Carr et al. [86]. By contrast, in cool periods, ventilation flow rates are considerably lower to minimize the ventilation heat losses. Consequently, $\mathrm{NH}_{3}$ is not diluted and concentration increases [92]. This dual effect shows that techniques for emission abatement should be implemented in broiler 
houses. Groot Koerkamp et al. [91], for example, proposed the installation of air circulation units for drying the litter and, hence, decreasing $\mathrm{NH}_{3}$ and odor emission. Winkel et al. [94] proposed to decrease the emission of particulate matter through an optimized oil spraying method.

A similar relation between the increase of ventilation and the consequent increase of air emissions can be found also in pig houses, especially in the ones that are equipped with a partly slatted floor. According to the analyses of Blanes-Vidal et al. [90], in fact, ventilation air flow is one of the three main parameters that affect the $\mathrm{NH}_{3}$ and $\mathrm{CH}_{4}$ emissions in pig houses, together with the type of rooting material and animal activity. High ventilation air flow rates entail high air speeds, a parameter that is positively related with the mass transfer coefficient from manure to air [130]. When air characterized by a high speed is over the free surface of the manure, hence, the emissions increase. Rodriguez et al. [96] found an inverse behavior between $\mathrm{NH}_{3}$ concentration and relative humidity and a direct relation between $\mathrm{NH}_{3}$ concentration and indoor air temperature in weaning rooms, results that are similar to the ones of Banhazi [93].

Air emissions inside livestock houses could increase also due to the adoption of mechanical equipment for providing supplemental heating to the farmed animals. A commonly adopted strategy to provide supplemental heating in livestock houses, in fact, is to place combustion air heaters directly inside the enclosure. This configuration is favorable since the installation is cheaper and all the heat produced is released directly inside the enclosure, with benefits from the energy and financial points of views. By contrast, this solution is detrimental for $I A Q$ since the combustion fumes are exhausted directly inside the enclosure, further increasing mainly $\mathrm{CO}_{2}$ emissions, a topic that will be deepened in Chapter 7. Better solutions, hence, should be considered for providing supplemental heating without further increasing the air emissions inside the same enclosure. Valuable options could be the adoption of other technologies, such as electrical heating lamps or radiant floors, or exhausting the fumes directly outside the enclosure.

Finally, indoor climate conditions can affect air emissions in an indirect way since they have a strong impact on the urination and defecation behavior of the reared animals. According to Huynh et al. [89], indoor air temperature is positively related to the pig urination and defecation frequencies that, in turn, are positively related with $\mathrm{NH}_{3}$ emissions [87].

\section{Climate control and productivity}

Climate control helps to guarantee the adequate thermal and gaseous environments with a consequent increase of the productivity in both quantity and quality terms. Animal productivity can be seriously jeopardized by heat stress that is particularly detrimental in poultry. Broilers and laying hens, in fact, are characterized by a low ability to dissipate body heat, a physiological feature that makes them extremely sensitive to heat stress [103]. Broilers exposed to heat stress decrease the feed intake with the aim of reducing the metabolic heat production, 
with a consequent lack of essential nutrients that causes a growth reduction. This condition is even more worsened considering that most of the energy intake from feed is expended in panting for dissipating the excess of heat [30]. Consequently, broilers that suffer from heat stress need more time to reach the target final live weight in comparison with broilers reared in a more adequate thermal environment. The work of Daramola et al. [30], for example, highlighted that broilers in heat stress conditions took 84 days instead of 42 days to reach a target final live weight fixed at around $4 \mathrm{~kg}$. This issue is particularly evident in broilers with high growth rate potential, as highlighted by the study of Settar et al. [102] on the effects of the interaction between genotype and environment on the performance of commercial broilers. In this sense, it is possible to state that a not adequate thermal environment frustrates the efforts carried out in the genetic selection of the reared breeds. In addition, the heat stress exposure of broilers could affect the quality of the production. According to Lu et al. [99] chronic heat stress can negatively affect the fat deposition in broiler meat. Furthermore, seasonal heat stress has been reported to accelerate postmortem glycolytic metabolism leading to biochemical changes in muscle and to the production of pale, soft exudative meat characteristics in chickens [30].

Heat stress is detrimental also in laying hen farming since it causes performance decreases, blood chemistry alterations and mortality increase, as reported by Kilic \& Simsek [100]. The effects of heat stress in laying hens is chronologic [30], meaning that the effects appear sequentially in time. First, heat stress causes a reduction in egg size, then a lowered egg production and, finally, a reduced quality of the egg shell [97]. The effect of ambient temperature on the average egg weight appears to be cumulative. When hens are kept at $26^{\circ} \mathrm{C}$, the average egg weight increases by $1 \mathrm{~g}$ per week whereas when kept at $35^{\circ} \mathrm{C}$, it remains constant for a period of six months [30].

Pig productivity can be also affected by heat stress. Growth performance and intestinal function of pigs, in fact, can be affected by the increased gut permeability and inflammation caused by heat stress [30]. Even in pigs, heat stress exposure can be detrimental for meat quality due to the high production of free radicals and Reactive Oxygen Substances [104] and by changes in the distribution of adipose tissues since body fat shifts toward internal sites [30].

Heat stress, hence, considerably affects farm productivity and the financial losses attributable to heat stress-related problems are considerable. According to St.-Pierre [98], around to $\$ 202$ million are losses each year in US in the growingfinishing pig sector. The economic losses are quite lower in poultry sector being around $\$ 98$ million in laying hen production and around $\$ 51.8$ million in broiler one $[98,101]$.

\section{Climate control and health}

Climate control has a strong relation with both animal and human health, as shown by the schematization presented in Figure 2.4. Climate control provides the 
adequate thermal and gaseous environments necessary to maintain animal health and avoiding problems, such as hypothermia and keratoconjunctivitis, as better described previously in this chapter. Furthermore, an adequate climate control considerably contributes to reducing the spread of infections inside livestock houses. This aspect is of the foremost importance for both animal and human health, especially considering the One Health approach, as specified later in this section. Finally, Figure 2.4 shows that climate control has further positive impacts on human health at a local level by reducing potential respiratory problems of farm workers.

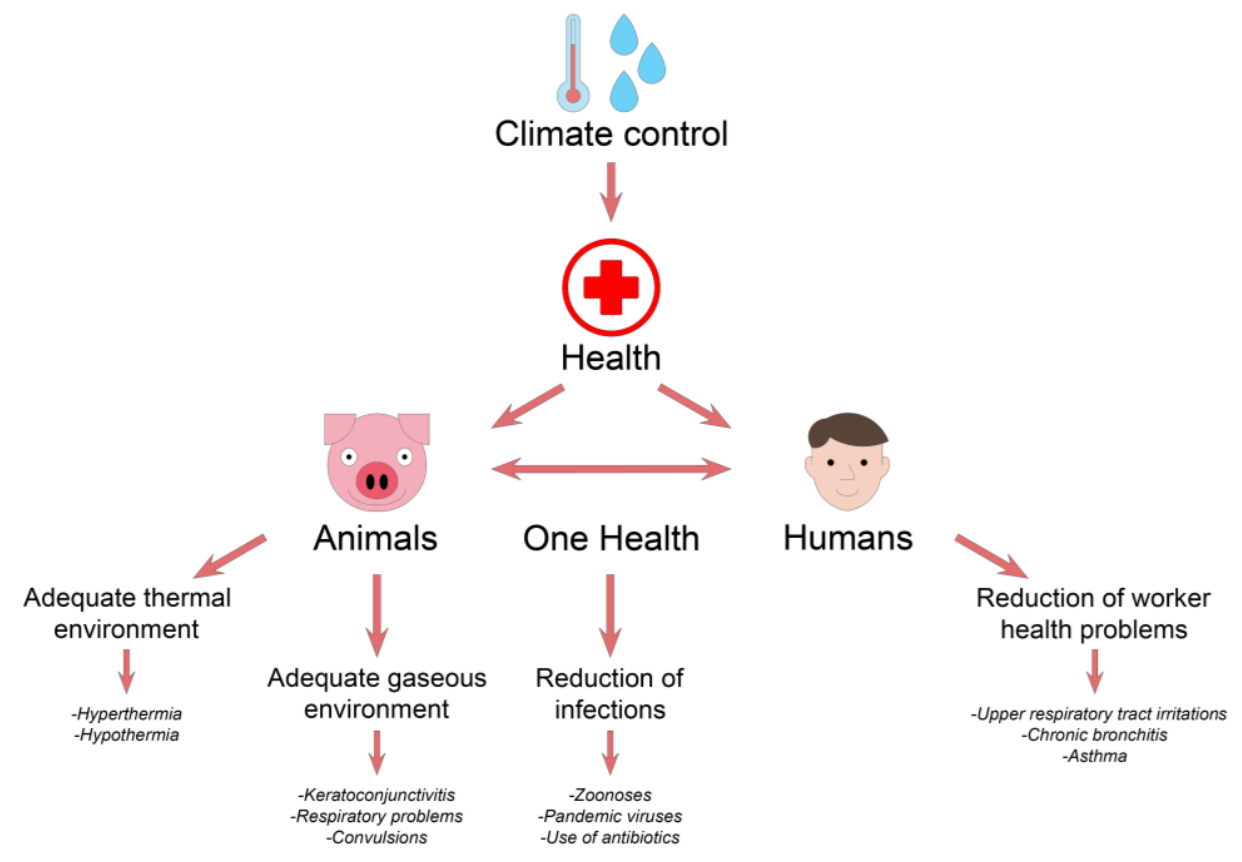

Figure 2.4 - Relation between climate control and animal and human health.

Climate control strongly contributes to maintain the health of farmed animals. As previously specified, a not adequate thermal environment can be detrimental for animal health leading them to hypothermia and hyperthermia with severe consequences, including death. A not adequate gaseous environment is also detrimental for animal health especially when high $\mathrm{NH}_{3}$ concentrations are present inside the house. Being a water soluble gas, $\mathrm{NH}_{3}$ can be absorbed into the mucus membrane and can increase the susceptibility of poultry to respiratory diseases [108] and to the development of infections [105]. High $\mathrm{NH}_{3}$ concentrations can also cause keratoconjunctivitis -ocular damages [109]- and other ocular disorders [108]. In addition, broilers exposed to high $\mathrm{NH}_{3}$ concentrations had a higher expression of genes potentially inhibiting both growth and development of breast muscle [117]. Even high $\mathrm{CO}_{2}$ concentrations can have negative consequences on broilers. This is due to both the negative effects of this gas and the consequent decrease in $\mathrm{O}_{2}$ concentration [106]. Concentrations of $\mathrm{CO}_{2}$ over 90,000 ppm can cause gasp and convulsions in broilers. Long exposure times, even in presence of lower $\mathrm{CO}_{2}$ concentrations, can decrease body weight and increase mortality [110], with negative effects on productivity. 
Climate control can further contribute to improve animal health by ensuring hygienic conditions inside livestock houses. In this way, the risk of introduction and spread of infections in herds and flocks can be reduced with positive impacts not only for animal health. By reducing the infections of farmed animals, in fact, the broad use of antibiotics in livestock sector could be cut down with potential benefits for human health at a global level [119]. According to the US Food and Drug Administration, in fact, over $70 \%$ percent by weight of the antibiotics that are considered as medically important for humans are sold to be used in animals, often with the aim of preventing infections or promoting growth rather than treating sick animals [116]. This massive use of antibiotics fosters the mechanism of resistance acquisition of bacteria [115] with the development of consequent drug-resistant infections in humans that kill at least 700,000 people die every year [116]. This shows that animal and human health are closely connected between them. According to the European Centre for Disease Prevention and Control [131], in fact, around $60 \%$ of all the human diseases have animal origins. For this reason, World Health Organization developed the One Health approach that considers human health, animal health and environmental health interconnected between them. The One Health approach aims at "designing and implementing programs, policies, legislation and research in which multiple sectors communicate and work together to achieve better public health outcomes" [132]. This approach is particularly focused on food safety, zoonoses control and antibiotic resistance with important impacts at a global level. The role of climate control in the framework of the One Health approach will be even most important considering that climate change is leading to the rise of new pathogens and diseases $[118,120]$. These diseases do not would be a problem only for livestock production, but also for humans. This is because there are high probabilities that emergence of new diseases may act as a mixing vessel between human and livestock, facilitating combination of new genetic material and their transmissibility [133].

Human health can benefit from climate control in livestock houses not only at a global level, as shown in the previous section, but positive effects can be obtained also at a local level. Climate control, in fact, can considerably contribute to guarantee the health of farm workers, as reported in the schematization of Figure 2.4. According to European Commission, being a farmer historically is one of the most hazardous occupations in the European Union with 400-500 fatalities a year, due to accidents with animals or zoonotic diseases [112]. Workers of intensive livestock houses, in fact, are particularly exposed to zoonosis with higher risk of contracting a pandemic virus, such as swine or avian flu and psittacosis. This risk can be minimized through frequent vaccinations, quarantine of sick animals and an efficient ventilation able to guarantee adequate $I A Q$ levels [112]. An efficient ventilation contributes also to decrease the respiratory exposures and health risks of farm workers. Workers of intensive livestock houses, in fact, are particularly exposed to respiratory problems, such as upper respiratory tract irritations, chronic bronchitis, and asthma [121]. This is since the enclosures of these buildings are 
characterized by high concentrations of noxious gases -e.g. $\mathrm{NH}_{3}$ and $\mathrm{H}_{2} \mathrm{~S}$ - and dust that represent potential health hazards also to humans. Inside livestock houses, gases are generated by the decomposition of animal urine and feces, while dust particles have different origins, such as animal dander, feed, and insects. The size of these dust particles goes from less than $2 \mu \mathrm{m}$ to $50 \mu \mathrm{m}$ in diameter and they can absorb noxious gases increasing the potential hazards of inhaling particles [113]. This potential hazard further increases considering that endotoxin and mycotoxin can be present within these particles [114]. Recent studies demonstrated that the exposure to this mix of gases and dust results in 2 to 4 times the respiratory health hazard -measured by the declining in pulmonary function over a period of workthan in normal conditions [107]. Undoubtedly, the risk of acute and chronic respiratory diseases in intensive livestock house workers depend on the individual relative genetic susceptibility to endotoxin [111] and other features such as the preexisting respiratory condition, the duration of the working time in the enclosure and the concentration of pollutants inside the house [113]. In this sense, an appropriate ventilation of the enclosure that is able to dilute the contaminant concentration can strongly contribute to the worker health and safety, providing an additional benefit for the farmer: healthy and safe workers, in fact, are more productive than stressed or injured ones [112,113].

\section{Climate control and energy use}

A strong mutual relation exists between climate control and energy use. In many cases, the only adoption of passive strategies, such as natural ventilation and envelope thermal insulation, would be not enough to guarantee the adequate indoor climate conditions, especially in certain periods of the year and in certain latitudes. Consequently, mechanical climate control systems -such as fans and air heaters- are adopted in livestock houses for monogastric animal farming. The use of mechanical equipment entails a considerable consumption of thermal and electrical energy. Very poor information about this energy consumption is present in literature and its quantification could be a complex task since several variables should be considered. In broilers houses, for example, $96 \%$ of the total on-farm thermal energy is for supplemental heating (up to $140 \mathrm{kWh} \mathrm{m}^{-2} \mathrm{y}^{-1}$ ), while $76 \%$ of the total on-farm electrical energy is for mechanical ventilation (up to $16 \mathrm{kWh} \mathrm{m}^{-2} \mathrm{y}^{-1}$ ). In laying hen houses, around $60 \%$ of the total on-farm electrical energy is for ventilation (up to $40 \mathrm{kWh} \mathrm{m}^{-2} \mathrm{y}^{-1}$ ). In pig houses, the thermal and electrical energy consumption for climate control -supplemental heating and ventilation- represent around 70\% and $50 \%$ of the total on-farm energy consumption, respectively [134]. Currently, this energy consumption is mainly from non-renewable energy sources, a negative aspect for the environmental, social, and economic sustainability of the livestock sector. In addition, the energy performance of agricultural buildings is usually low. According to OECD [135], the current energy performance of agricultural buildings in OECD countries, in fact, is still similar to the one of 1990s or 2000s since no substantial improvements occurred in the last years. Consequently, an energy- 
efficient climate control of livestock houses is of the foremost importance to move toward a more sustainable agriculture. This is especially true considering the expected rise of food demand and the consequent increase of the energy consumption due to food production [122].

Improvements of the energy performance for climate control of livestock houses have positive impacts also on GHG emissions. According to FAO [136], in fact, livestock supply chain accounts for 7.1 Gigatons of $\mathrm{CO}_{2}$-eq emissions, representing $14.5 \%$ of total anthropogenic $G H G$ emissions worldwide. $G H G$ emissions of the livestock sector, hence, has become an important concern in the last years and is more and more considered by the society as an enemy of the environment, with important social impacts. Even though most of the $G H G$ emissions of livestock sector are due to enteric fermentation and manure management, direct on-farm energy consumption represents a not negligible share of $G H G$ emissions [137]. The direct on-farm energy consumption is responsible of $7.6 \%$ of the total air emissions from chicken meat supply chain, $4.0 \%$ from eggs, $2.9 \%$ from pork supply chains. Even though the previously presented shares of emissions may seem small if compared with other ones, they are characterized by a considerable room for improvement since, currently, in livestock houses the most adopted energy sources are fossil fuels, while renewable energy accounts for less than $4 \%$ of the total energy consumed [32]. Therefore, an energy-efficient climate control based on the adoption of low-carbon and renewable energy sources could be one of the main research topics in the coming future.

In this context, energy simulation models could represent powerful tools to decrease the energy consumption for climate control of livestock houses. These models, in fact, enhance the evaluation of the energy performance of these buildings in standardized conditions, considering different climate change scenarios, different technologies and solutions. Nevertheless, few authors have been focused on this specific topic and few energy models that were ad-hoc developed and customized for the estimation of the energy consumption of livestock houses are present in literature, as deeply described in Chapter 5.

\subsubsection{Further considerations about climate control in livestock houses}

In the previous section, several relations between climate control and other domains of livestock production where shown, outlining the central role of climate control in livestock houses. This role may become even more central in the coming future. Climate change, in fact, will emphasize the importance of climate control of livestock houses since global warming is opening a new long-term challenge: avoiding a perpetual food crisis [138]. Global warming, in fact, increases the risk of food insecurity by intensifying the heat stress of livestock [133]. By controlling the indoor climate conditions, climate-controlled livestock houses are considered resilient buildings that can mitigate the impact of climate change [31], contributing 
to avoid food crises, especially in developing countries. These countries produce more than $50 \%$ of meat and $60 \%$ of milk that are consumed at a global level [139] and these percentages are increasing due to sociodemographic factors -such as population growth and urbanization- that foster the demand of animal products [140]. To meet this increasing demand and to guarantee the food security of these countries, climate control seems essential because most of the developing countries are in areas characterized by hot climates. Even though many factors -e.g. sanitary problems and quality of local feed- affect the productivity of livestock production in these geographical areas, adverse climatic conditions are among the most limiting factors [139]. In the past, these adverse climatic conditions had a lower impact on productivity since local livestock species, that easily acclimated to the local climate conditions, were farmed. Now, the increasing demand for livestock products is turning toward the adoption of high-performance animals, typical of industrial livestock systems, that are imported from developed countries [139]. These animals were genetically selected to increase their productivity, but they are very susceptible to high temperatures due to the strong relationship that exists between production level and metabolic heat production [139]. Mechanical climate control systems, hence, seem to spread in developing countries in the coming future. These systems would contribute to provide adequate farming conditions, but they would also entail important energy consumption in contexts where the energy supply is often problematic. In addition, this spread of climate-controlled livestock houses would further increase the overall energy consumption of livestock sector. One of the most urgent and arduous challenges, hence, is to develop an energyefficient climate control that would have positive impacts on all the three areas of sustainability, namely environment, economy, and society [141], as shown in the schematization of Figure 2.5. An energy-efficient climate control would entail a minimum energy consumption to maintain the adequate indoor climate conditions and it would integrate energy systems based on low-carbon and renewable energy sources. These features would lead to decrease the resource depletion and to reduce the anthropogenic GHG emissions from livestock sector, fighting climate change and the improving the environmental sustainability of livestock sector. The economic sustainability of the livestock sector would also benefit of an energyefficient climate control since a reduction of the energy consumption would lead to a consequent reduction of the farm running cost due to energy supply. The adoption of renewable energy sources represents an advantage for farmers since it would decrease their business risks in comparison to fossil fuels. Fossil fuels prices, in fact, are characterized by important fluctuations that expose farmers to significant business risks and can considerably increase production costs, with a consequent rise of the final product price [26,33]. Maintaining the final price stability, hence, the energy-efficient climate control could further improve food security, with positive impacts on social sustainability. 


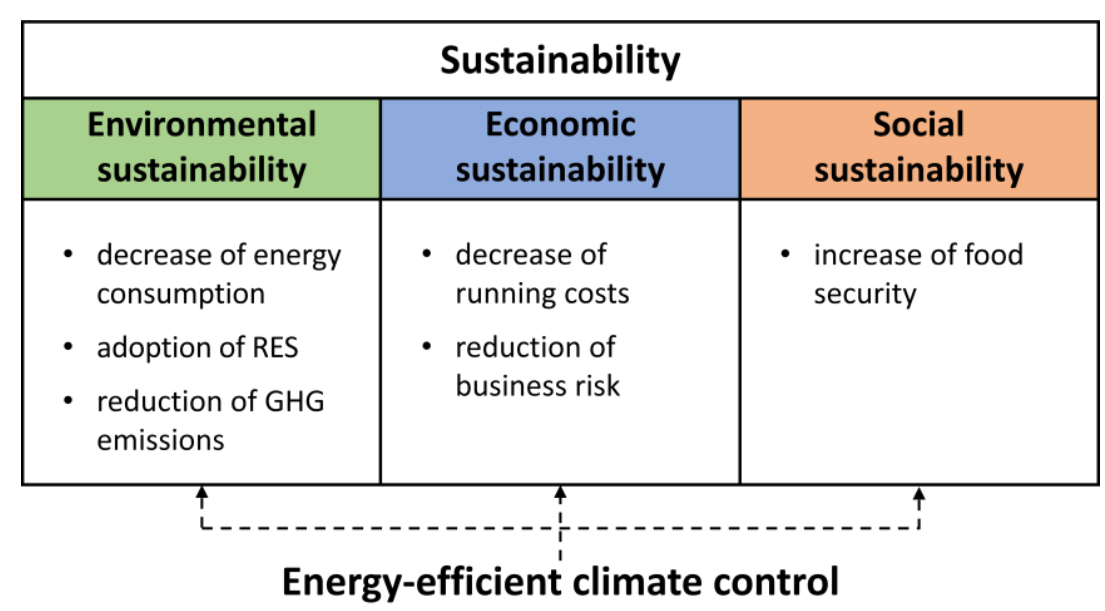

Figure 2.5 - Schematization of the positive impacts that an energy-efficient climate control of livestock houses could have on the three areas of sustainability, namely environmental, economic, and social sustainability.

\subsection{Final considerations}

In this chapter, the tangle of mutual relations between climate control of agricultural buildings -greenhouses and livestock houses- and other domains of livestock production was unpicked through a literature review. The results show the central role that climate control has in greenhouses and livestock houses, highlighting mutual relations with, for example, productivity, animal welfare, water use and energy use.

The tangle of relations that was presented in this chapter is the key to understand the potentialities that investigations specifically focused on climate control may have in improving different domains of crop and livestock production, with the final aim of enhancing the development of more sustainable agricultural systems. In this framework, climate control can become a driver to push the crop and livestock production in confined systems toward the sustainability. Nevertheless, deep transformations are need for climate control, especially from the energy point of view. A more energy-efficient climate control, in fact, is needed, especially considering the increasing trends of energy consumption caused by the rising demand for vegetables, fruit and livestock products. For this purpose, solutions, technologies, and strategy should be developed and tested to reduce the energy consumption. The first step toward this reduction is to develop reliable and robust simulation models for the estimation of indoor climate conditions inside different types of greenhouses and livestock houses. 



\section{Chapter 3}

\section{The nexus between climate control and energy: results from case studies}

\begin{tabular}{c|l} 
Objective & $\begin{array}{l}\text { To investigate the nexus between climate control and energy consumption } \\
\text { adopting an experimental approach. }\end{array}$ \\
\hline Outcome & $\begin{array}{l}\text { Analyses of real datasets from ad-hoc monitoring campaigns performed in two } \\
\text { climate-controlled agricultural buildings. }\end{array}$ \\
\hline \multirow{5}{*}{ Highlights } & $\begin{array}{l}\text { A greenhouse and two pig houses were monitored for long periods. } \\
\text { Data about indoor climate conditions and energy consumption were } \\
\text { acquired. }\end{array}$ \\
- High energy consumptions do not always entail adequate indoor \\
climate conditions.
\end{tabular}





\subsection{The need of an experimental approach}

In the previous chapter, a general overview about the tangle of relations that interlaces energy, climate control and other relevant topics of agricultural production was provided. This overview pointed out that maintaining the adequate indoor climate conditions using mechanical systems entails a considerable energy consumption in greenhouses and livestock houses, with negative consequences from the sustainability point of view. The nexus between indoor climate conditions and energy consumption in climate-controlled agricultural buildings, hence, is worth of investigation and an experimental approach could be useful to analyze this nexus. This experimental approach could rely on ad-hoc performed monitoring campaigns aimed at the acquisition of large datasets, as done in previous works present in literature. The analyses of such datasets can contribute to deepen the knowledge about the nexus between indoor climate conditions and energy consumption but also with further domains of agricultural production.

\subsubsection{Literature background}

In literature, the monitoring campaigns that concern indoor climate conditions and/or energy use in greenhouses and livestock houses are carried out mainly to acquire datasets for the experimental validation of new developed simulation models. The validation of a numerical simulation model with experimental data, in fact, is common methodological procedure in greenhouse modeling, as shown by the analysis performed by Taki et al. [142] and the review of Iddio et al. [9]. Mobtaker et al. [143], for example, validated their model against a dataset of indoor climate conditions acquired in a greenhouse without crops of around $15 \mathrm{~m}^{2}$. The dataset regarded the measurement of soil temperature, indoor air temperature and superficial temperature of cover during almost one year. Each one of the previous temperatures was monitored using two sensors set with a 1-minute time step. Joudi et Farhan [144] acquire a dataset of indoor climate conditions from an experimental greenhouse of around $8 \mathrm{~m}^{2}$. The dataset regarded indoor air and soil temperature and the acquisition time-step was set equal to 15 minutes. The indoor air temperature was monitored at $1.5 \mathrm{~m}$ of height by six sensors. Zhang et al. [145] acquired a validation dataset from a prototype greenhouse of $15 \mathrm{~m}^{2}$ without the presence of crops. The measure of the indoor air temperature was performed using two sensors placed at the center of the greenhouse at 0.5 and $1.5 \mathrm{~m}$ of height, while other sensors were used to measure the envelope and the soil temperatures.

A similar approach is used also for the validation of models for livestock houses. Lee et al. [127], for example, performed a monitoring campaign in a duck house during almost a year to acquire the needed dataset for validating their developed energy simulation model. To do so, 12 sensors for air temperature and relative humidity measurements were installed at $1.2 \mathrm{~m}$ and set with a 1-second acquisition time step. In addition, an electrometer and AC clamp sensors were 
installed to monitor the electric power of fans. Hamilton et al. [146] carried out a monitoring campaign to acquire the indoor air temperature and relative humidity in a broiler house during a 35-day production cycle with the aim of validating their energy model. The grid of air temperature and humidity sensors was placed at the broiler level. In addition, on/off data loggers were installed in the powerline of each fan. Xie et al. [126] used the data of indoor air temperature monitored by the climate control system of an experimental pig buildings to validate a developed energy simulation model. In addition, the fans of the considered pig houses were monitored through on/off status data loggers.

Besides being used for the acquisition of datasets for experimental validations, monitoring campaigns performed in greenhouses and livestock houses are also used to investigate specific research topics. Datasets acquired in greenhouses, for example, are used to evaluate the potential heat stress of greenhouse workers with a special focus on naturally ventilated greenhouse in Southern Europe. García-Ruiz et al. [147], for example, evaluated the thermal heterogeneity of a typical naturallyventilated greenhouse in Almería region (Southern Spain) on the basis of the ISO 7726 standard [148]. The greenhouse (around $1,000 \mathrm{~m}^{2}$ of floor area) was equipped with 12 measurement stations (which development and system architecture is described in [149]) for the acquisition of air temperature, black globe temperature, relative humidity and air velocity at three different heights $(0.23 \mathrm{~m}, 0.93 \mathrm{~m}$ and $1.56 \mathrm{~m}$ ). The monitoring campaign lasted around a year with an acquisition timestep of 30 seconds. A similar analysis was performed by Marucci et al. [59] considering a naturally-ventilated greenhouse located in Center Italy including the calculation of thermal comfort indices, such as the Predicted Mean Vote [150] and Wet Bulb Globe Temperature [151]. Datasets acquired through monitoring campaigns in greenhouse are also used to evaluate the performance of experimental energy systems. Bazgaou et al. [152], for example, analyze the effect of an active solar heating system on the greenhouse production evaluating, among others, the indoor climate conditions. To do so, two identical naturally ventilated greenhouses of around $165 \mathrm{~m}^{2}$ located in Canary Islands were monitored during a week in January. The indoor air temperature and relative humidity were measured at three different heights at the center of the greenhouses together with the soil temperature. Coomans et al. [153] compared the energy performance of naturally and mechanically ventilated experimentally greenhouses (two of $720 \mathrm{~m}^{2}$ and two of $482 \mathrm{~m}^{2}$ ) were monitored with a 1-minute logging time step through the same climate control systems of the greenhouses.

Few works that regard the monitoring campaigns carried out in livestock houses to investigate specific research topics are present in literature. Most of those works are focused on the monitoring of the gas emissions from livestock facilities and include the monitoring of indoor air temperature and relative humidity. For example. Calvet et al. [154] monitored a Mediterranean broiler farm during a summer and a winter production cycles with the aim of studying the gas emissions of the farm. Besides the gas concentrations, the monitored campaign also concerned 
the measurement of the indoor air temperature and relative humidity in four different spots inside the enclosure with a 30-minutes time step. The ventilation flow rates from the same case study were also monitored [155].

\subsubsection{Overview on the performed monitoring campaigns}

The previous background showed that most of the monitoring campaigns about indoor climate conditions and energy consumption of greenhouses and livestock houses were performed to acquire the datasets needed for the experimental validation of developed simulation models. On the contrary, very few works are performed with the main objective of analyzing specific topics, including the nexus between the indoor climate conditions and energy consumption of real commercial greenhouses and livestock houses. Most of the previously presented works are focused on small prototypes or naturally ventilated greenhouses neglecting, in some cases, the presence of crops representing a condition that could be quite far from the reality since plants could considerably affect both the indoor climate conditions and the energy consumption. The experimental campaigns regarding livestock are in general very few and mainly focused on aspects such as the gas emissions from livestock facilities, without providing more details about the nexus between the indoor climate conditions and the energy consumption. In addition, the monitoring campaigns in the previously presented works lack of a common and standardized methodological framework, as visible considering the configuration of the different systems configurations regarding number and positions of sensors, the adopted logging time step and duration of the same campaign.

This background promotes the possibility to increase the knowledge about the climate-controlled agricultural buildings through ad-hoc performed monitoring campaigns. For this reason, two long-term monitoring campaigns were performed in the framework of this thesis to acquire datasets which analyses could lead to better understand the nexus between climate control and energy consumption in agricultural buildings. The performed monitoring campaigns were carried out in selected case studies, namely a greenhouse and two growing-finishing pig houses that were monitored for four months and almost a year respectively acquiring data about the indoor climate conditions and the absorbed electrical power.

\subsection{Greenhouse monitoring campaign}

\subsubsection{Case study description}

One of the two long-term monitoring campaigns that were performed in the framework of the activities of this thesis regarded a fully mechanical controlled greenhouse. The considered building is a multi-span greenhouse part of a larger complex of about $250,000 \mathrm{~m}^{2}$ located in Northeast Italy. The considered building is devoted to experimental cultivation of new hybrid plants (small flower cuttings) that are very sensitive to the indoor climate conditions. Even though the selected 
greenhouse is not aimed at food production, the layout, the management, and the adopted climate control equipment are the same used for crop production. In addition, further interesting features led to the selection of this greenhouse as case study. A first reason is that the cultivation of sensitive cuttings emphasizes even more the importance of climate control since not adequate climate conditions could irreparably jeopardize the production, with detrimental effects also on the experimentation results and on the company investments. Another reason is that the selected case study was renovated just before the beginning of the monitoring campaign. The owner of the analyzed greenhouse, in fact, is a leading floricultural company at both national and international level that adopts state-of-the art technologies for improving the quantity and (especially) the quality of the production. Proof of this was the installation of new variable angular speed fans that are a promising energy-efficient technology for greenhouse production.

The schematic layout and the main geometrical dimensions of the monitored case study are presented in Figure 3.1. The greenhouse is composed by seven bays (6.4 $\mathrm{m}$ of width each one) with a metal frame structure and a single glazing envelope. The height of the bays is $5.15 \mathrm{~m}$ at the ridge level and $3.74 \mathrm{~m}$ at the eave level. Four of the bays are $36 \mathrm{~m}$ long while the remaining three are $40 \mathrm{~m}$ long. Thus, the useful floor area is approximately $1,690 \mathrm{~m}^{2}$ while the enclosed volume is around $7,510 \mathrm{~m}^{3}$. As visible from the picture, the main axis of the bays is aligned with northwest-southeast direction and the southwest wall is in direct contact with another building.

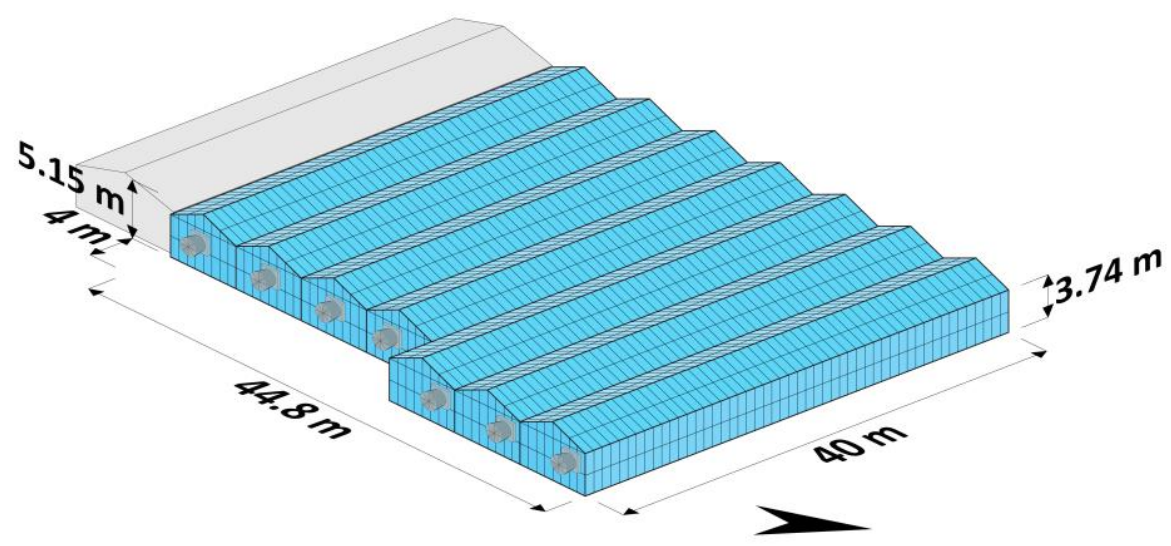

Figure 3.1 - Schematic layout and main dimensions of the monitored greenhouse.

In Figure 3.2 an internal view of the monitored building is presented and some of the main features of the greenhouse clearly stand out. Plants are cultivated on metal benches with an integrate irrigation system that occupy almost all the floor area of the analyzed building and insect proof screens are adopted to reduce the pest population and to reduce the incidence of insect-transmitted diseases [156]. The plant production cycle has an average duration of 60 days during which the plants increase their Leaf Area Index ( $L A I)$ approximatively from $0.4 \mathrm{~m}^{2} \mathrm{~m}^{-2}$ (beginning of the cycle) to $1.6 \mathrm{~m}^{2} \mathrm{~m}^{-2}$ (end of the cycle). 
The heating system of the greenhouse is centralized. A gas boiler ( $460 \mathrm{~kW}$ of heating capacity) produces the supplemental heat that is transferred and distributed into the enclosure through a hydronic pipe system hanging above the cultivation benches. The climate control system guarantees $\theta_{\text {set_H }}$ of $16^{\circ} \mathrm{C}$ during daytime and $14{ }^{\circ} \mathrm{C}$ during night-time (a sort of setback temperature). Figure 3.2 shows also that the monitored greenhouse is equipped with circulating fans to decrease the thermal stratification and with solar diffusing screens that provide the adequate light to the cultivated plants.

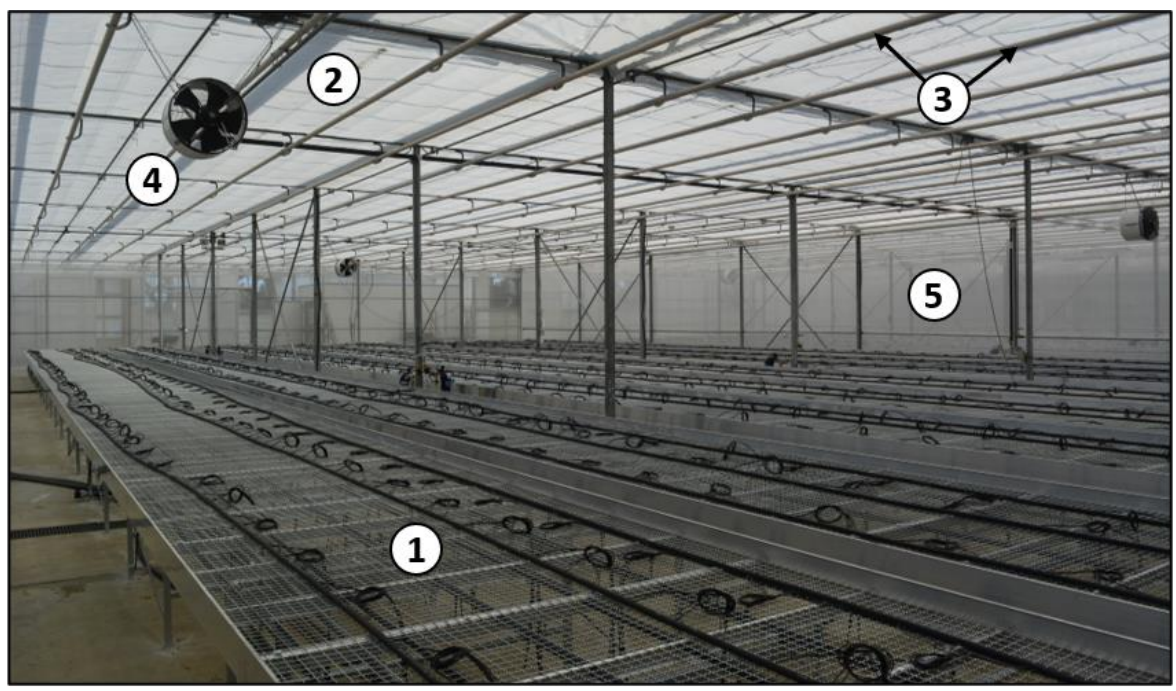
(1) Cultivation benches
(3) Heating pipe system
(5) Insect proof screen
(2) Diffusive screen
(4) Circulating fan

Figure 3.2 - Internal picture of the monitored greenhouse.

The exhaust ventilation system of the greenhouse deals with both dehumidification and cooling ventilation. The dehumidification ventilation is carried out to maintain a $R H_{\text {i_max }}$ of $65 \%$, while cooling ventilation is activated to maintain $\theta_{\text {set_c }}$ of $27.7^{\circ} \mathrm{C}$ and a maximum temperature gradient of $0.6^{\circ} \mathrm{C}$. The ventilation air flow rate is provided by seven variable angular speed fans with a diameter of 52', $(1.32 \mathrm{~m})$ that are placed on the southwest wall of the greenhouse (as visible in the previous Figure 3.1). In free delivery conditions $\left(\Delta p_{\mathrm{st}}=0 \mathrm{~Pa}\right)$ and at 495 RPM (the optimum energy efficiency), each one of the installed cone fans can provide a ventilation flow rate of $53,200 \mathrm{~m}^{3} \mathrm{~h}^{-1}$. When cooling or dehumidification ventilation is activated, the climate control system opens the top of the bays to let the outdoor air enter. This bay opening is managed by the climate control system to maintain the required $\Delta p_{\text {st }}$ of $22 \mathrm{~Pa}$.

When cooling ventilation is not enough to maintain $\theta_{\text {set_c }}$, evaporative cooling is activated, bay openings are closed and the outdoor air enters the greenhouse through the cellulose evaporative pads that are placed in the northwest wall, opposite to the fans. These pads (visible in Figure 3.3) are 0.15 m thick, with flute angles of $30^{\circ} / 60^{\circ}$, and a direct saturation effectiveness of $91 \%$ (considering an air velocity across the pads of $0.5 \mathrm{~m} \mathrm{~s}^{-1}$ ). To maintain the required $\theta_{\text {set_c }}$, the 
greenhouse is also equipped with shading screens that reduce the incoming solar radiation. The climate control system activates these screens when $\theta_{\text {air_i }}$ is higher than $26{ }^{\circ} \mathrm{C}$ and the outdoor solar radiation is higher than $600 \mathrm{~W} \mathrm{~m}^{-2}$.

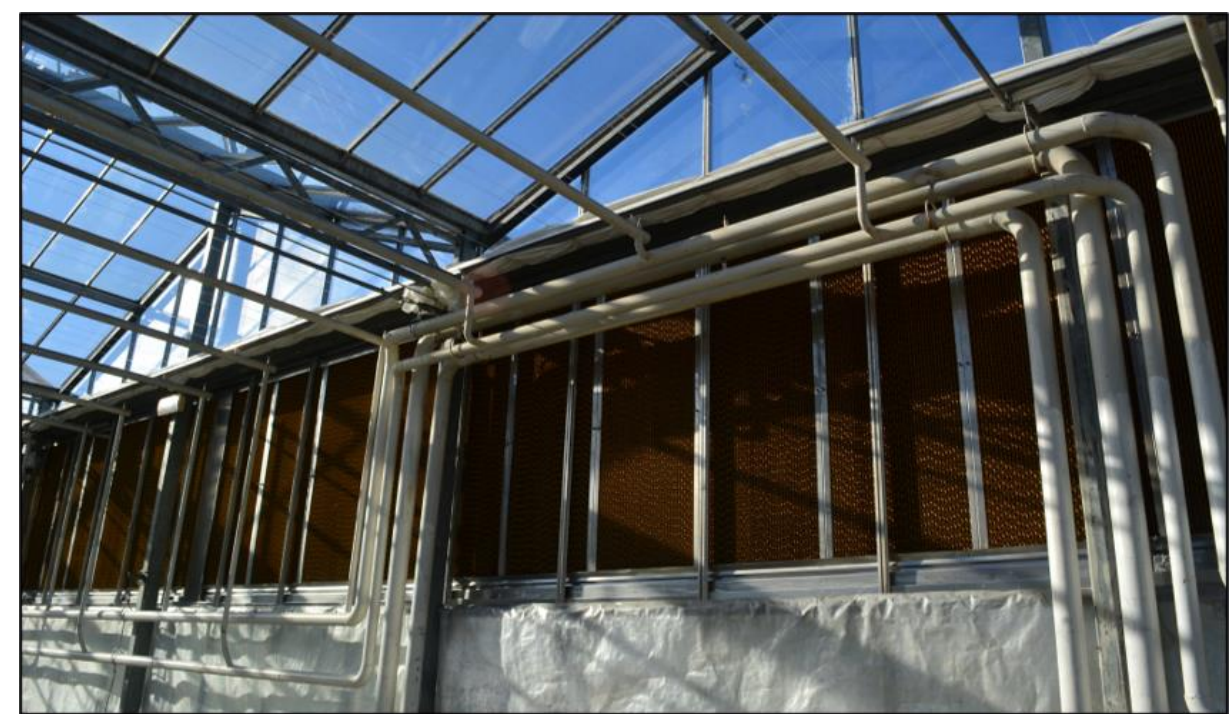

Figure 3.3 - Evaporative pads installed in the monitored greenhouse.

\subsubsection{Monitoring campaign description}

The monitoring campaign that was performed in the previously described greenhouse concerned the acquisition of the datasets that are summarized in Table 3.1 through the installation of an ad-hoc sensor network. The monitoring campaign acquired data about the indoor and outdoor climate conditions for four months and about the operations of climate control system during one month in the warm season.

Table 3.1 - Summary of the greenhouse monitoring campaign.

\begin{tabular}{ccc}
\hline Dataset & Monitored parameter & Monitoring period \\
\hline Indoor climate & $\theta_{\text {air_i }}$ & July $1^{\text {st }}-$ October $31^{\text {st }} 2018$ \\
conditions & $R H_{\mathrm{i}}$ & \\
\hline Outdoor climate & $\theta_{\text {air_o }}$ & July $1^{\text {st }}-$ October $31^{\text {st }} 2018$ \\
conditions & $R H_{\mathrm{o}}$ & \\
\hline Climate control & $I_{\text {tot_hor }}$ & \multirow{2}{*}{ July $1^{\text {st }}-$ July $31^{\text {st }} 2018$} \\
system & En/off state of evaporative pads & \\
\hline
\end{tabular}

*Part from ARPA Veneto

In Table 3.2, the list of the instruments adopted for the monitored campaign is presented. The monitoring of $\theta_{\text {air_i }}$ and $R H_{\mathrm{i}}$ was performed using the following instruments (accuracy noted in brackets):

- four portable loggers (USB communication protocol) that embed both a thermistor for the measurement of air temperature $\left( \pm 0.21^{\circ} \mathrm{C}\right)$ and a humistor for relative humidity $( \pm 2.5 \%)$; 
- 11 resistance temperature detector PT1000 $\left( \pm 0.15^{\circ} \mathrm{C}\right)$ connected to an analog portable logger (USB communication protocol).

The adopted $\theta_{\text {air_i }}$ and $R H_{\mathrm{i}}$ sensors are characterized by high accuracies that make them suitable to be used for the objective of this work, as done in similar works present in literature, as shown by the analysis present in [147]. Each datalogger was enclosed in an electrical junction box (as visible from Figure 3.4a) to avoid damages during the monitoring campaign and all the probes were shielded from the direct solar radiation. Using the previously described devices, $\theta_{\text {air_i }}$ was monitored in 15 different spots inside the enclosure and $R H_{\mathrm{i}}$ in four different spots. The sensors were spaced inside the enclosure (e.g. in the center, close to the pads and the fans) and at different heights from the floor $(0.5,1.0,1.5$ and $2.0 \mathrm{~m}$ ), as done in similar works presented in section 3.1.1. A similar numerosity of installed sensors was because greenhouses are characterized by a not homogenous indoor thermal environment and the indoor climate conditions may differ considerably between different spots of the enclosure [157]. The acquisition time-step was set from one to ten minutes, according to the memory capacity of the different devices.

The values of $\theta_{\text {air_o }}$ and $R H_{\mathrm{o}}$ were obtained through a portable datalogger arranged outside the building. In addition, further outdoor weather data were obtained from a third part weather station (Regional Agency for the Protection of the Environment of Veneto, ARPAV) near to the monitored greenhouse. ARPAV provided the hourly values of $\theta_{\text {air_o }}, R H_{\mathrm{o}}$ and total (beam and diffuse) solar radiation on horizontal plane ( $\left.I_{\text {tot_hor }}\right)$.

Table 3.2 - List of adopted instruments.

\begin{tabular}{ccc}
\hline $\begin{array}{c}\text { Monitored } \\
\text { parameter }\end{array}$ & Type of instrument & $\begin{array}{c}\text { Commercial product } \\
\text { (from Onset@) }\end{array}$ \\
\hline Air temperature & $\cdot$ Thermistor (embedded in logger) & UX100-011 \\
\hline Air temperature & $\cdot$ PT 1000 & TMCX-HD \\
& $\cdot$ Analog logger & UX120-006M \\
\hline Air relative humidity & $\cdot$ Humistor (embedded in logger) & UX100-011 \\
\hline Electrical power of & $\cdot$ Split-core current transformers & T-ACT-0750-020 \\
fans & $\cdot k W h$ transducer & T-WNB-3D-480 \\
\hline $\begin{array}{c}\text { On/off state of } \\
\text { evaporative pads }\end{array}$ & $\cdot$ Analog logger & UX120-006M \\
\hline
\end{tabular}

As visible from Table 3.2 different instruments were adopted for monitoring the climate control system operations. The electrical power absorbed by the fans was monitored using split-core current transformers $( \pm 0.75 \%$ of accuracy) placed in the electrical panel of the greenhouse and connected to kWh transducers (Figure $3.4 \mathrm{~b}$ ) and to an analog logger set with a 10-second logging time-step. The on/off state of the evaporative pads was monitored through an AC current switch connected to the power cable of the circulating pump of the evaporative pads. The signal was acquired and converted by a pulse data logger. 


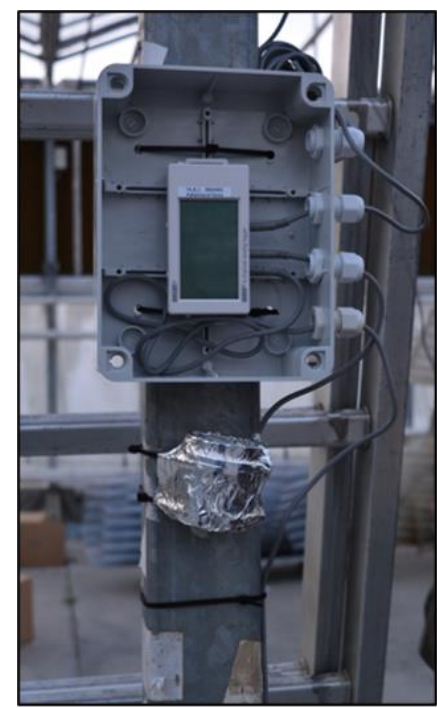

(a)

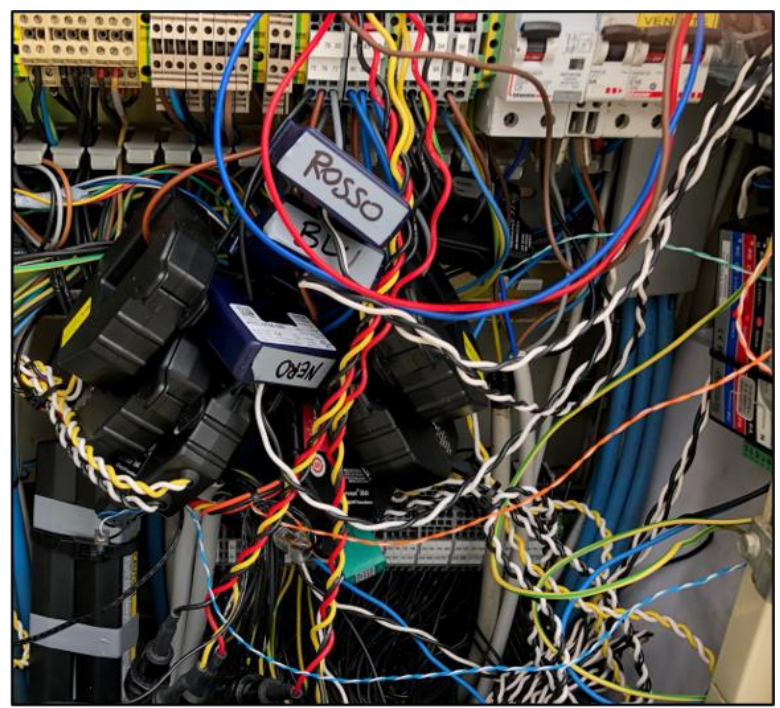

(b)

Figure 3.4 - Figure (a): three PT 1000 probes connected to an analog data logger enclosed in the electrical junction box. Figure (b): detail of greenhouse electrical panel with split-core current transformers and $\mathrm{AC}$ current switch sensors (in the center) and a $\mathrm{kWh}$ transducer (on the right).

\subsubsection{Main results from the monitoring campaign}

\section{Analyses of the monitored indoor climate conditions}

The acquired values of $\theta_{\text {air_i }}$ and $R H_{\mathrm{i}}$ were averaged first on a temporary basis to obtain hourly values. In turn, the obtained values were averaged between them to obtain a single value representative of the mean average $\theta_{\text {air_i }}$ and $R H_{\mathrm{i}}$ during the considered hour. The obtained trends are shown during the entire monitored period in Figure 3.5 together with the trends of $\theta_{\text {air_o }}$ and $R H_{\mathrm{o}}$. The graph shows that from July $1^{\text {st }}$ to $5^{\text {th }}$ the trends of $\theta_{\text {air }{ }_{-} \mathrm{i}}$ and $R H_{\mathrm{i}}$ are considerably different than during the remain period. This difference is because the production cycle started on July $6^{\text {th }}$ and, for this reason, climate control was not fully activated and extreme $\theta_{\text {air_i }}$ values with peaks of over $44{ }^{\circ} \mathrm{C}$ were monitored. Similar values of $\theta_{\text {air_i }}$ in free-floating conditions were reported in literature [158].

The graph shows that the geographical location of the analyzed greenhouse is very humid. The monitored values of $R H_{\mathrm{o}}$ often reach $100 \%$, especially during nighttime but high values of $R H_{\mathrm{o}}$ (higher than 90\%) were also monitored during

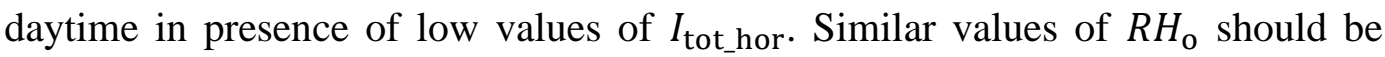
considered during the design stage of the climate control system because they can jeopardize the performance of the evaporative cooling system decreasing considerably the saturation effectiveness of the evaporative pads.

When the climate control system was activated, three different subperiods (A, $B$ and C) can be identified based on the variation of $\theta_{\text {air_o }}$ trend. Subperiod A is characterized by an average $\theta_{\text {air_o }}$ (calculated over the entire subperiod) of around $26^{\circ} \mathrm{C}$ and it goes from July $6^{\text {th }}$ to August $25^{\text {th }}$. During this subperiod $\theta_{\text {air_i }}$ was slightly lower than $\theta_{\text {air_o }}$ because evaporative pads were activated for maintaining 
adequate values of $\theta_{\text {air_i }}$. This activation of the evaporative pads was favored by the values of $R H_{\text {air_o }}$ that were lower than during the following days.

Subperiod B is from August $26^{\text {th }}$ to September $23^{\text {rd }}$, when the average $\theta_{\text {air_o }}$ decreased to around $24{ }^{\circ} \mathrm{C}$. In this subperiod, $\theta_{\text {air_i }}$ and $\theta_{\text {air_o }}$ were very similar. This similarity may depend on the high ventilation flow rates needed to guarantee the adequate $\theta_{\text {air_i }}$. In this subperiod, in fact, the high values of $R H_{\mathrm{o}}$ made the evaporative cooling less effective an issue that led to increase the ventilation flow rate. During the last subperiod (Subperiod C, September $24^{\text {th }}-$ October $31^{\text {st }}$ ), $\theta_{\text {air_o }}$ decreased to an average value of $21^{\circ} \mathrm{C}$. From the graph it stands out that in Subperiod $\mathrm{C} \theta_{\text {air_o }}$ was considerably lower than $\theta_{\text {air_i }}$ and supplemental heating was needed to maintain the indoor air set point temperature, especially during nighttime.

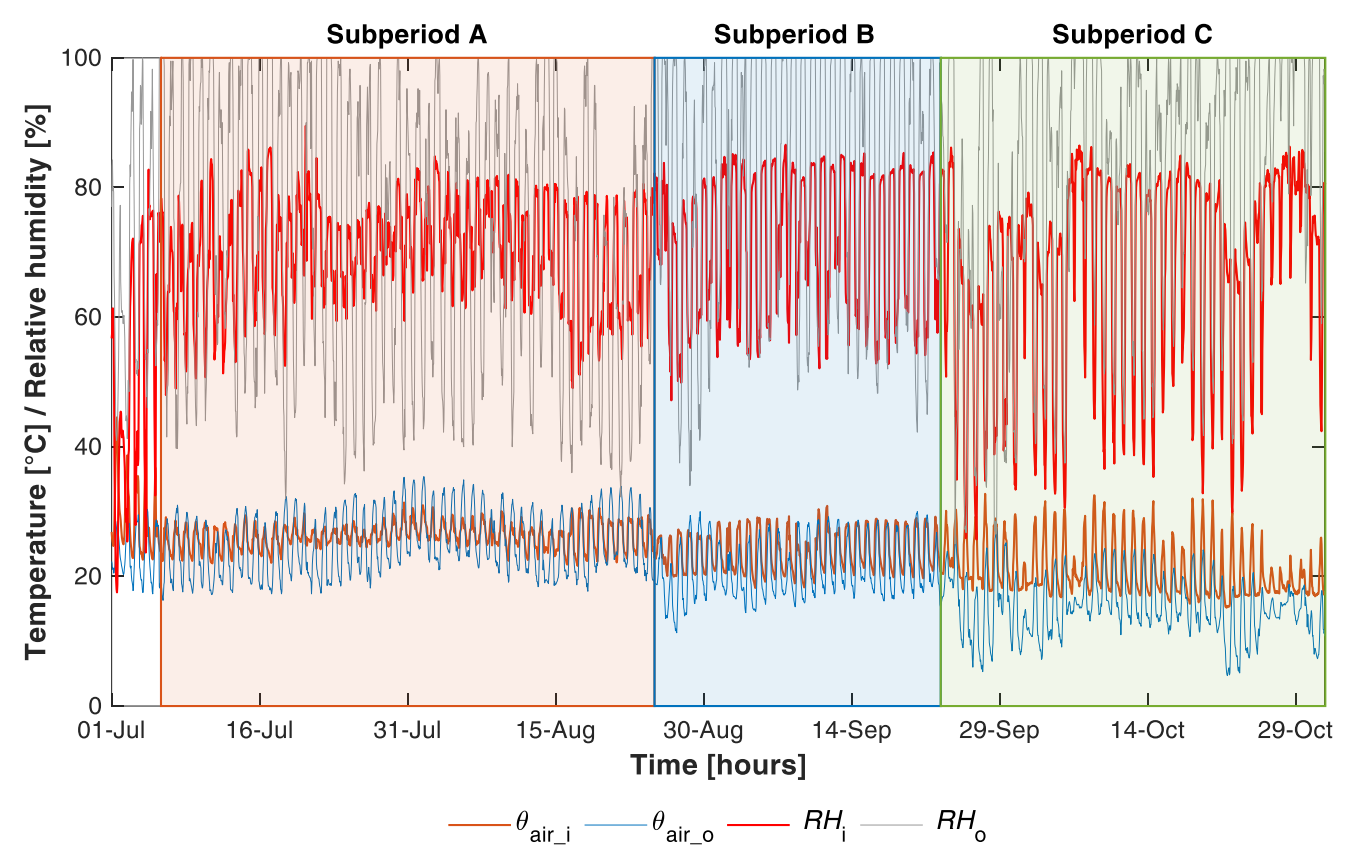

Figure 3.5 - Hourly trends of $\theta_{\text {air_i }}, \theta_{\text {air_o }}, R H_{\mathrm{i}}$ and $R H_{\mathrm{o}}$ during the monitored period. Three different subperiods (A, B and C) can be identified.

During the entire monitored period (with the exclusion of the first five days) $\theta_{\text {air_i }}$ was always in $15-33{ }^{\circ} \mathrm{C}$ range while $R H_{\mathrm{i}}$ was always between 40 and $90 \%$. Nevertheless, both the indoor environmental parameters varied considerably during each subperiod. This variation results more evident in the scatterplot of Figure 3.6, where the coordinates of each point are the average hourly values of $\theta_{\mathrm{i}}(x$-axis) and $R H_{\mathrm{i}}$ ( $y$-axis) monitored during the three subperiods. The values monitored through the dataloggers that embed both a humistors and a thermistor are considered in this analysis. The scatterplot shows that the point dispersion is lower in Subperiod A, increases in Subperiod B and it is even higher in Subperiod C. The $\theta_{\mathrm{i}}$ range, in fact, varies from a minimum of $15^{\circ} \mathrm{C}$ to a maximum of $33^{\circ} \mathrm{C}$ in Subperiod $\mathrm{C}$, from 18 to $31^{\circ} \mathrm{C}$ in Subperiod B and from 19 to $32{ }^{\circ} \mathrm{C}$ in Subperiod A. The range of $R H_{\mathrm{i}}$ is 
quite similar for Subperiod A and B (from 50 to $85 \%$ ), while a greater point dispersion characterizes Subperiod C (from 25 to $85 \%$ ).

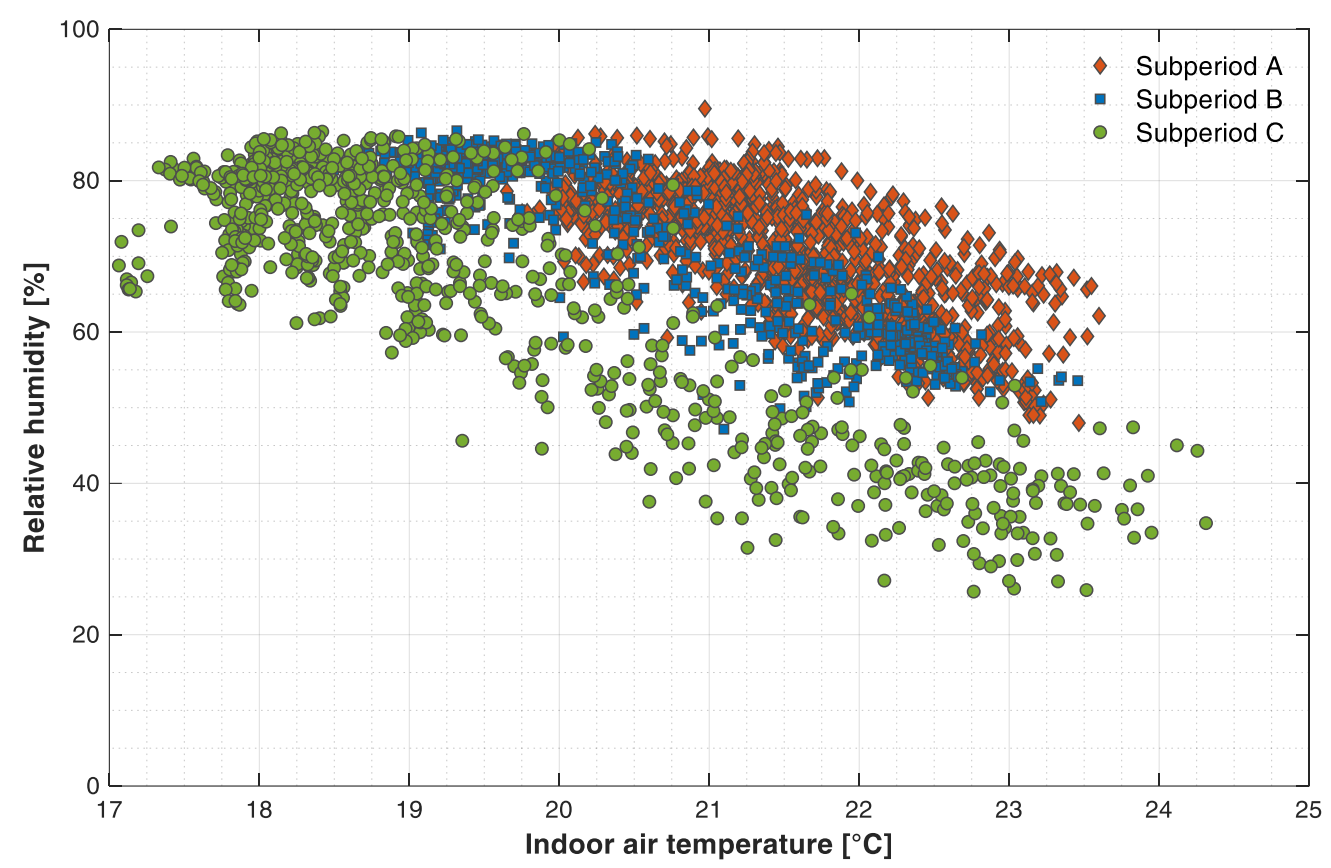

Figure 3.6 - Scatterplot of $\theta_{\text {air_i }}\left(x\right.$-axis) and $R H_{\mathrm{i}}$ (y-axis) for the three considered subperiods.

The previous analyses pointed out that the average indoor climate conditions of the monitored greenhouse vary significatively between the considered subperiods due to significant variations of the outdoor weather conditions. Nevertheless, important variations can be appreciated also in the same greenhouse enclosure, meaning that the thermal environment of this building type is not homogenous. Analyzing the measurements of $\theta_{\text {air_i }}$ that were collected in the different spots of the enclosure, considerable differences can be found. In Figure 3.7a, the hourly trend of $\theta_{\text {air }}$ i is displayed with a specific focus on three days (July $29^{\text {th }}-31^{\text {st }}$ ). In the graph, the trend of the hourly average value of $\theta_{\text {air_i }}$ is presented together with a boxplot that considers all the acquired measurements. The boxplot shows $75^{\text {th }}$ and $25^{\text {th }}$ percentiles of the considered measurements, the median, the upper and lower extremes and the outliers. A first element that stands out from that graph is that measured data have a larger dispersion during daytime than during nighttime. This issue could depend on the high values of solar radiation that were monitored during these days, which maximum exceeded $800 \mathrm{~W} \mathrm{~m}^{-2}$, as reported on the primary axis of Figure 3.7b. Solar radiation is the forcing that entails an increasing of $\theta_{\text {air_i }}$ especially due to the glazed envelope of the greenhouse.

This temperature increase is not uniform, as visible from the boxplot and it may depend by the zenith and azimuth angles of sun and on the presence of shadings (e.g. external elements or shading screens), a phenomenon that was also observed in [147]. Furthermore, the rise of $\theta_{\text {air_i }}$ increases the convective motion that favors the air stratification (vertical temperature gradient), a phenomenon that is further pronounced due to the height of the greenhouse. Furthermore, the presence of fans 
and of evaporative pads entails local differences in $\theta_{\text {air_i }}$ (horizontal temperature gradient). Considering all the previously mentioned conditions, the important variations of $\theta_{\text {air_i }}$ inside the enclosure could be explained. Considering the three analyzed days of Figure 3.7, the differences between the maximum and minimum monitored values of $\theta_{\text {air_i }}$ go from a maximum of $8{ }^{\circ} \mathrm{C}$ to a minimum of around $0.4{ }^{\circ} \mathrm{C}$, with important differences between daytime and nighttime. During daytime, the solar radiation causes higher differences between the values of $\theta_{\text {air_i }}$ measured in the various spots of the greenhouse, being the average difference between the maximum and the minimum values of $\theta_{\text {air_i }}$ was quite less than $5^{\circ} \mathrm{C}$, while during nighttime this difference decreases to less than $1^{\circ} \mathrm{C}$.

Another interesting aspect that stands out from Figure $3.7 \mathrm{a}$ is that $\theta_{\text {air_i }}$ was considerably lower than $\theta_{\text {air_o }}$ during all the three considered days. The graph shows, in fact, that during this period, the peak of $\theta_{\text {air_o }}$ was around $34-35^{\circ} \mathrm{C}$ while the corresponding $\theta_{\text {air_i }}$ peak was generally around $30^{\circ} \mathrm{C}$. To understand this temperature decrease, the on/off state of the evaporative pads is reported in the secondary axis of Figure 3.7b. The graph shows that the evaporative pads were activated almost without interruptions during all the daytime to guarantee an adequate value of $\theta_{\text {air_i }}$. During nighttime, the decrease of $\theta_{\text {air_o }}$ and the absence of solar radiation caused a reduction of $\theta_{\text {air_i }}$ that decreases up to around $23{ }^{\circ} \mathrm{C}$ without the use of evaporative cooling, as visible from Figure 3.7b.
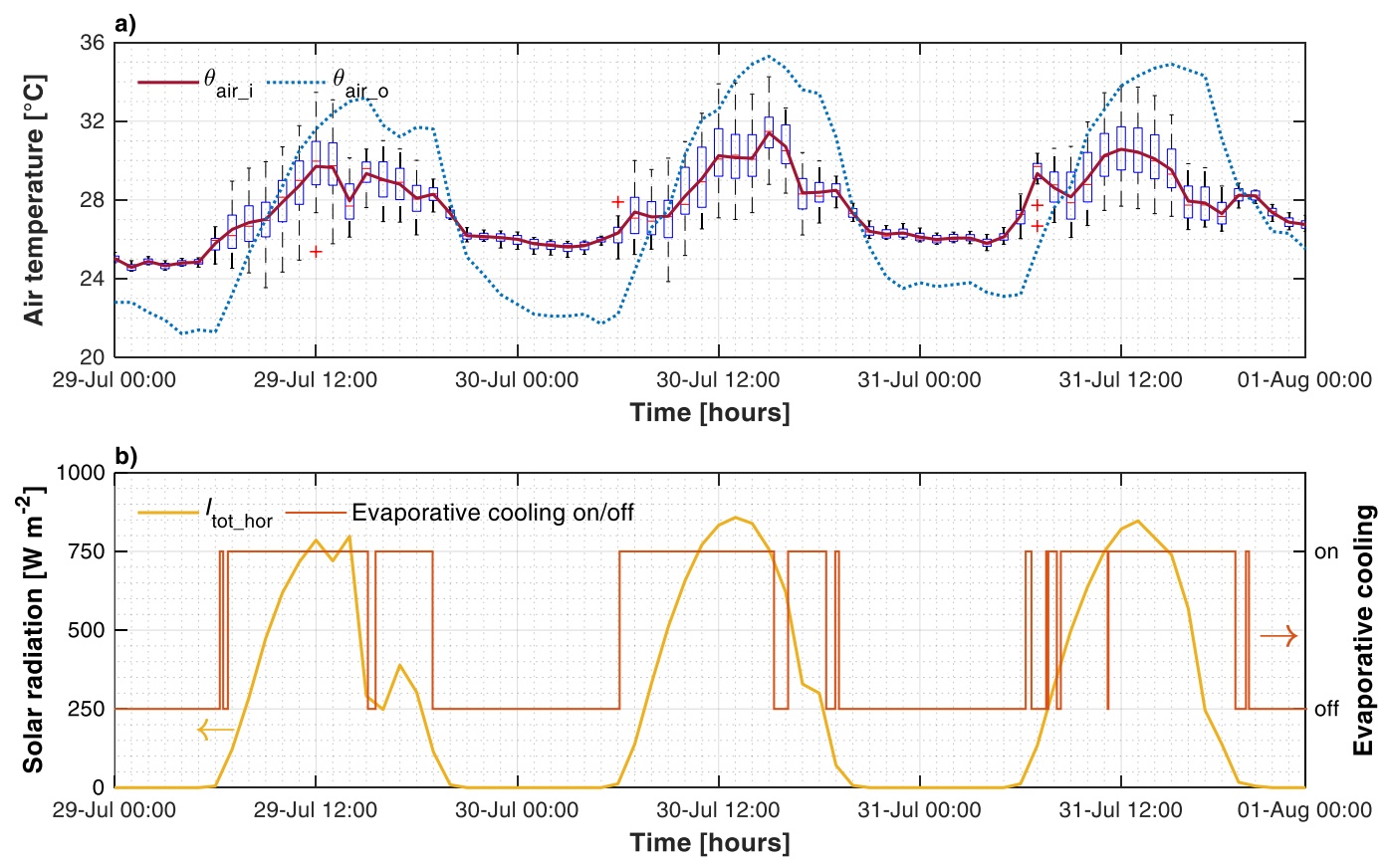

Figure 3.7 - Subplot (a): $\theta_{\text {air_i }}$ (boxplot) and $\theta_{\text {air_o }}$.

Subplot (b): $I_{\text {tot_hor }}$ (primary y-axis) and on/off status of evaporative cooling pump.

The assessment of the vertical variation of $\theta_{\text {air }}$ i (due to the thermal stratification) was performed evaluating the hourly differences $\Delta \theta_{\text {air_i }}$ between the $\theta_{\text {air_i }}$ values monitored by sensors placed at different heights $(1.5,2$ and $2.5 \mathrm{~m})$ and 
the reference $\theta_{\text {air_i }}$ measured at the bench level $(1 \mathrm{~m})$. The results of this analysis are presented in Figure 3.8 for the month of July. From the graph it stands out that $\Delta \theta_{\text {air_i }}$ is at a minimum value (around $0^{\circ} \mathrm{C}$ ) when the solar radiation is not present (nighttime). On the contrary, $\Delta \theta_{\text {air_i }_{i}}$ is considerably higher during daytime. The highest sensors $(2.5 \mathrm{~m})$, in fact, logged $\theta_{\text {air_i }}$ values that exceed $7{ }^{\circ} \mathrm{C}$ of difference if compared with the reference one. As an average, the daytime difference between the $2.5 \mathrm{~m}$-height probe and the reference one (bench level) is $3.5^{\circ} \mathrm{C}$. On the contrary, the average $\Delta \theta_{\text {air_i }}$ values calculated between the $2 \mathrm{~m}$-height and $1.5 \mathrm{~m}$ height probes with respect to the reference one are considerably lower, with average values during daytime of 1.8 and $1.5^{\circ} \mathrm{C}$. For both the probes, the maximum absolute $\Delta \theta_{\text {air_i }}$ does not exceed $4{ }^{\circ} \mathrm{C}$.

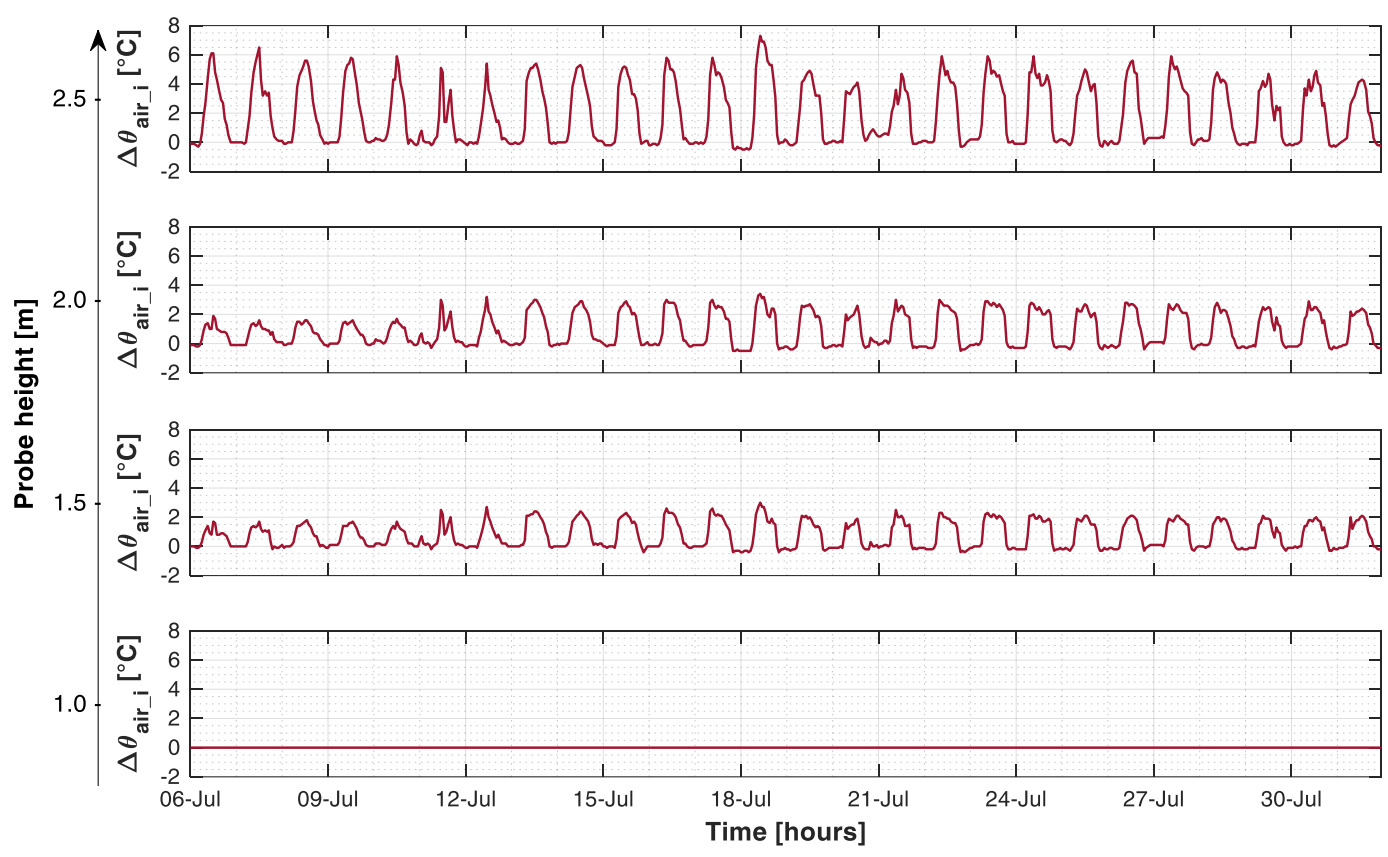

Figure 3.8 - Hourly differences $\left(\Delta \theta_{\text {air_i }}\right)$ between the $\theta_{\text {air_i }}$ monitored by probes placed at different heights $(1.5,2$ and $2.5 \mathrm{~m})$ and the reference $\theta_{\text {air_i }}$ placed at the bench level $(1 \mathrm{~m})$ during July.

\section{Analyses of the monitored electrical power absorbed by fans}

The monitored campaign also concerned the acquisition of data about the absorbed electrical power of fans during July (with a 10-second time step), as described in section 3.2.2. The monitored values were averaged to obtain the mean electrical power with a 15-minutes time basis and the results are reported in the carpet plot of Figure 3.9. Each column of $x$-axis of that graph represents a day of July, while on the $y$-axis the 24 hours of each day are represented with a time discretization of 15 minutes. Consequently, each cell indicates 15 minutes of July and its color tonality represents the value of the 15-minutes electrical power, being dark blue the lowest value and yellow the highest one (as indicated by the color bar on the right side of Figure 3.9).

The carpet plot shows that, during the monitored period, the highest monitored electrical power was around $8.5 \mathrm{~kW}$ and the fans were activated only during the 
central hours of daytime. The greenish and yellowish cells, in fact, can be found only all along the central part of the carpet plot, meaning that the fans were activated approximatively from 09:00 to 19:00 of each day, while during nighttime fans were not operative. The carpet plot of Figure 3.9 shows also that fans were activated almost always at their maximum power, as visible by the predominance of yellow cells.

Analyzing the various days of July, it stands out that during the first three days of the considered period (July $1^{\text {st }}-3^{\text {th }}$ ), no absorbed power was monitored, this is since the production cycle started on July $6^{\text {th }}$, as previously stated. In the following two days (July $4^{\text {th }}$ and $5^{\text {th }}$ ), fans were activated for some hours during the day, probably to test the correct working of fans and to prepare the adequate indoor climate for the beginning of the production cycle. From July $6^{\text {th }}$ to $31^{\text {st }}$, fans were always operative to maintain the required indoor climate conditions and the working time sensibly increases during the month. This is particularly evident comparing the last days of July (e.g. $29^{\text {th }}, 30^{\text {th }}$ and $31^{\text {st }}$ ) with the first days of the production (e.g. $6^{\text {th }}, 7^{\text {th }}$ and $8^{\text {th }}$ ). This increase of working time of the fans can be attributable to the increase of $\theta_{\text {air_o }}$ at the end of July that is visible in the previously presented graph of Figure 3.5.

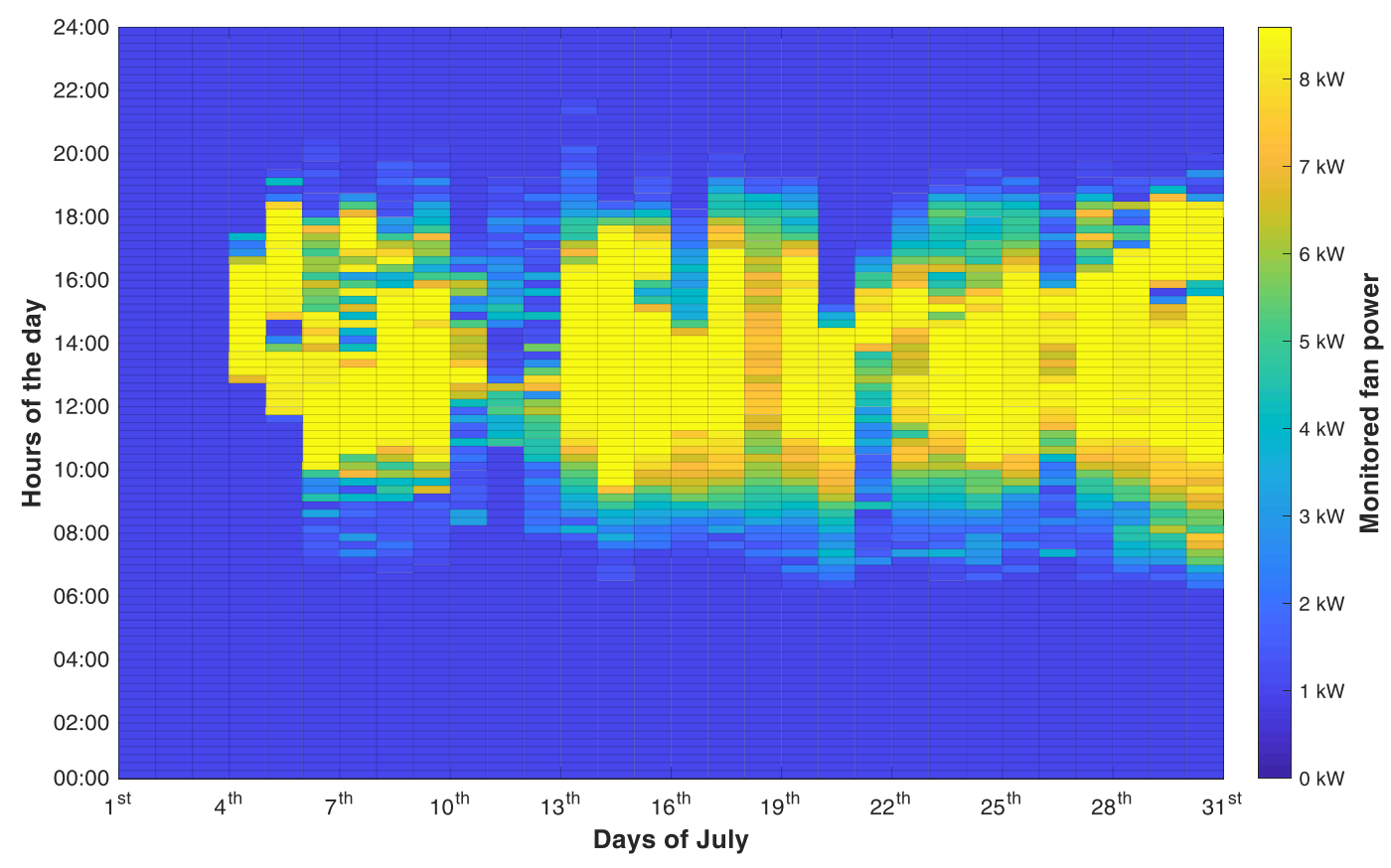

Figure 3.9 - Carpet plot of the monitored electrical power absorbed by the greenhouse fans during July. Each cell of the plot represents the mean electrical power on a 15-minutes basis.

Another interesting element that stands out from the carpet plot of Figure 3.9 is a different trend of absorbed electrical power in the period July $10^{\text {th }}-12^{\text {th }}$. To understand the cause of that difference, in Figure 3.10 a focus on the first two weeks of July is presented through three different subplots. Subplot (a) shows the hourly electrical energy consumption of fans (obtained as the integration of the monitored power in time), subplot (b) shows the trends of $\theta_{\text {air_o }}, \theta_{\text {air_i }}$ and $I_{\text {tot_hor }}$, while 
subplot (c) shows the time during which evaporative pads were activated. Subplot (a) confirms that during the period July $10^{\text {th }}-12^{\text {th }}$ an energy consumption quite lower than in the other days occurred. This decrease of the energy consumption can be attributable to a reduced use of fans due to more favorable outdoor climate conditions. Analyzing subplot (b), in fact, it stands out that in the period July $10^{\text {th }}$ $12^{\text {th }}$ a slight decrease of $\theta_{\text {air_o }}$ and $I_{\text {tot_hor }}$ trends can be appreciated entailing lower ventilation flow rates and a reduced use of evaporative cooling. In particular, on July $11^{\text {th }}$, the evaporative pads were almost not activated, as stands out from Figure 3.10c.

The graphs of Figure 3.10 are also interesting to analyze the dynamics of the greenhouse before the beginning of the production cycle, when the climate control system was not already activated. The importance of controlling the climate using mechanical systems is especially evident analyzing the trends of $\theta_{\text {air_i }}$ on July $1^{\text {st }}$ and $2^{\text {nd }}$. During those days, in fact, $\theta_{\text {air_i }}$ was in free-floating conditions reaching approximately $45^{\circ} \mathrm{C}$, a temperature that is not suitable for any crop production. The activation of fans in the following days considerably reduces $\theta_{\text {air_i }}$, a reduction that is furtherly enhanced by the adiabatic saturation performed by the activated evaporative pads.
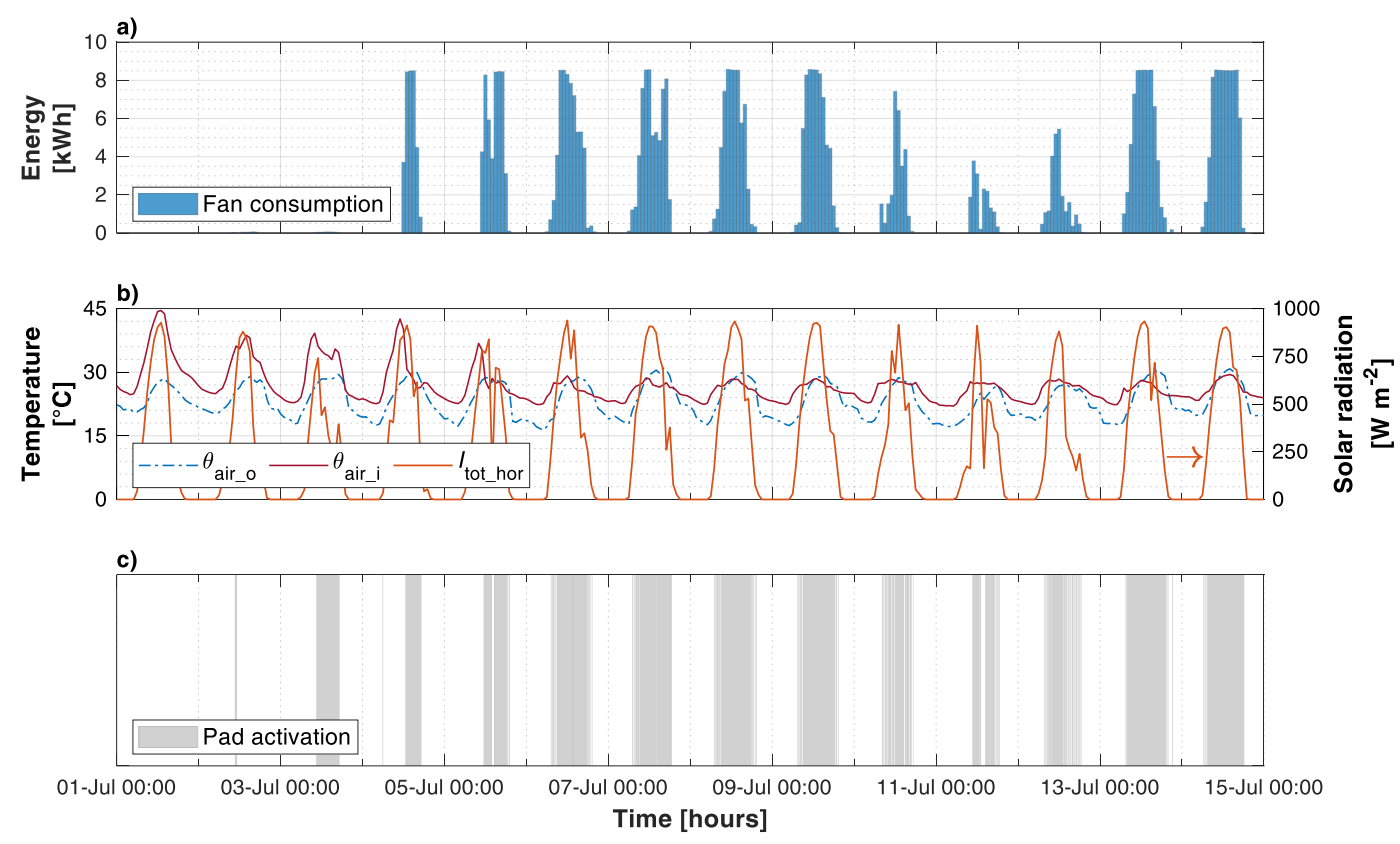

Figure 3.10 - Subplot (a): Hourly energy consumption of fans. Subplot (b): $\theta_{\text {air_o }}, \theta_{\text {air_i }}$ (primary $y$-axis) and $I_{\text {tot_hor }}$ (secondary $y$-axis) Subplot (c): Periods of activation of evaporative pads.

As shown by Figure 3.10a, the electrical energy consumption due to fan operations can vary considerably depending on the outdoor weather conditions. In the bar chart of Figure 3.11, the daily electrical energy consumption for the operation of fans of the monitored greenhouse is presented. The chart shows that (not considering the first four days of the monitored period), the electrical energy consumption of the greenhouse goes from a minimum of around $16 \mathrm{kWh}$ (July $11^{\text {th }}$ ) 
to a maximum of more than $90 \mathrm{kWh}\left(\mathrm{July} 30^{\text {th }}\right)$, showing an increasing trend, as previously observed. The average monitored electrical energy consumption during the period in which the production was carried out (July $6^{\text {th }}-31^{\text {st }}$ ) was approximately $62.5 \mathrm{kWh}$, while the total energy consumption over the entire monitored period was around 1,710 kWh.

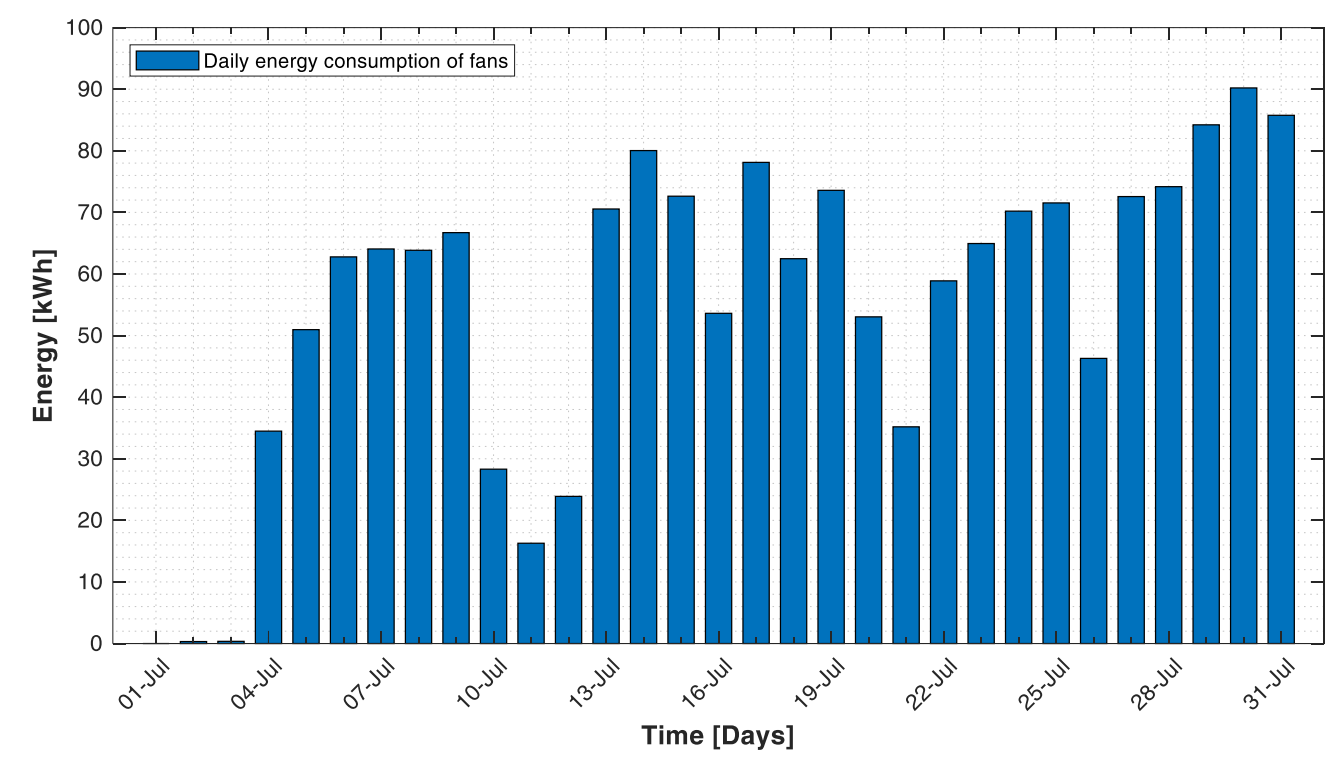

Figure 3.11 - Daily electrical energy consumption of fans.

\subsection{Livestock house monitoring campaign}

\subsubsection{Case study description}

The second monitoring campaign that was performed in the framework of the thesis aimed at acquiring data about climate-controlled livestock houses. For this purpose, two pig houses were selected as case studies and they were monitored during almost a year.

The monitored buildings are two growing-finishing pig houses that are part of a larger farmstead, which schematization is presented in Figure 3.12. The farmstead is composed by several buildings -e.g. warehouses and sheds for agricultural machineries- and three growing-finishing pig houses, as visible from Figure 3.12. Pig house A and B are the smallest ones and were selected for the monitoring campaign. The other pig house (the light blue building in Figure 3.12) was not monitored because it was considered out of the scope of this work since it has a natural ventilation system and a layout typical of a dairy house (its original function). 


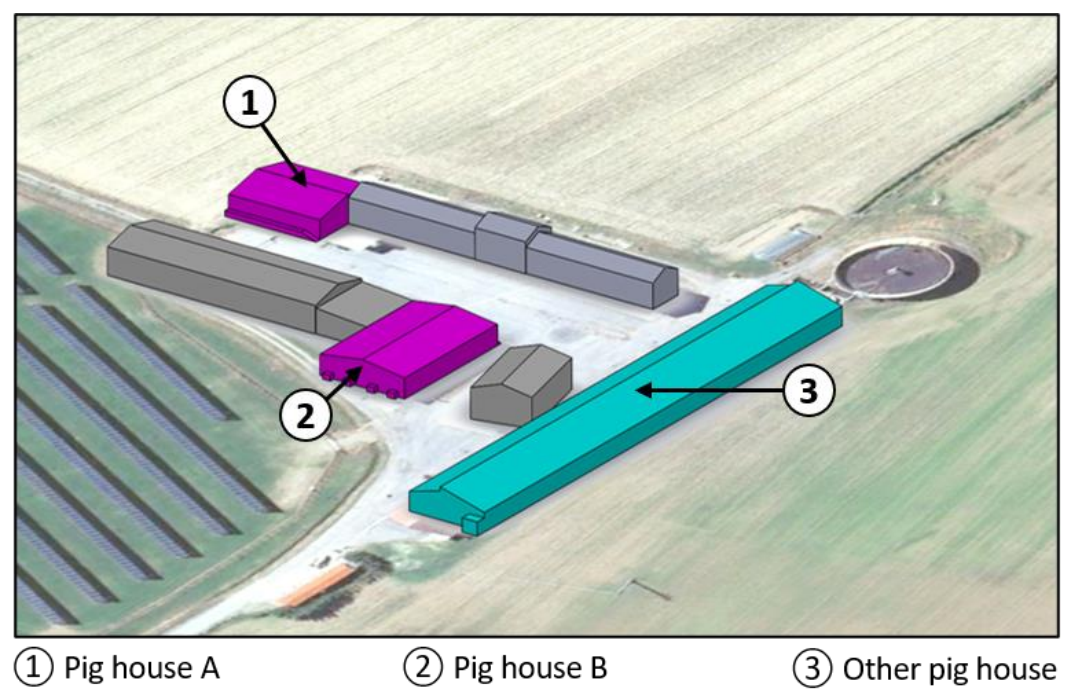

Figure 3.12 - Schematization of the farmstead context of the two monitored pig houses (A and B).

As visible from Figure 3.13, the monitored growing-finishing pig houses have similar configurations. Their walls are made of concrete piled hollow blocks, the rooves are prefabricated sandwich panels and the air inlets are made of polycarbonate hollow sheets with metal frames. Inside, both the buildings are divided into pens with partially slatted floors with slurry pits below. The structural building elements (e.g. slurry pits, pillars, beams and floor) are made of reinforced concrete. Pig house A has a useful floor area of $280 \mathrm{~m}^{2}$ and a volume of $1,000 \mathrm{~m}^{3}$. Pig house B has greater useful floor area and volume $\left(400 \mathrm{~m}^{2}\right.$ and $2,400 \mathrm{~m}^{3}$, respectively) but inside it is divided into two different rearing areas by a bearing wall.

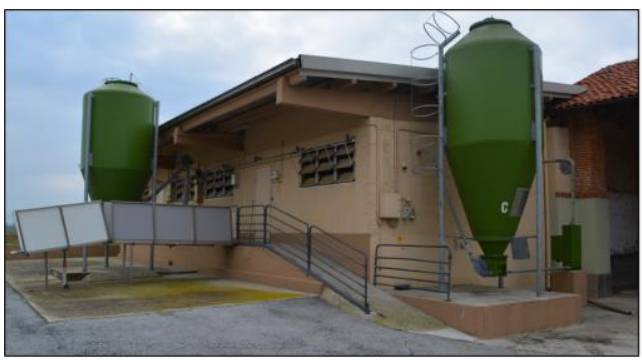

(a)

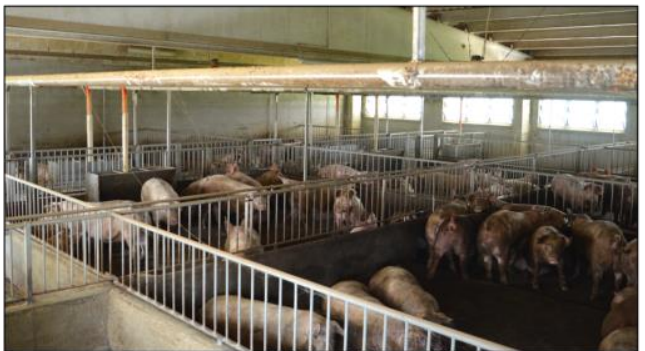

(c)

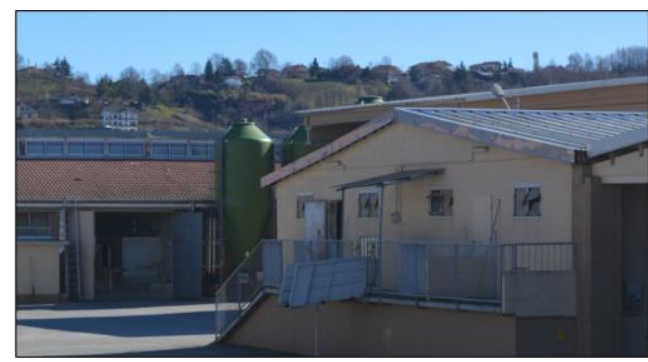

(b)

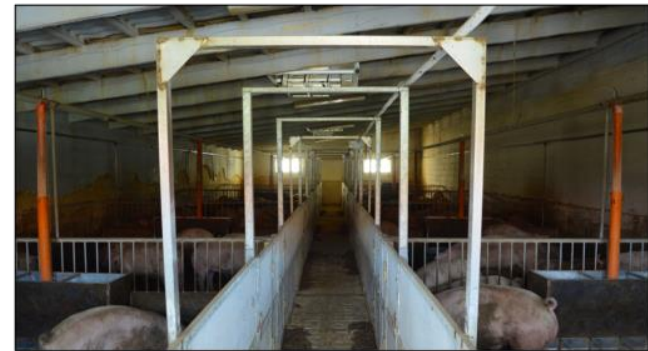

(d)

Figure 3.13 - Figure (a) external view of pig house A; figure (b) external view of pig house B; figure (c) internal view of pig house A; figure (d) internal view of pig house B.

Both the pig houses are also equipped with a similar climate control system which main components are presented in Figure 3.14. The supplemental heating of 
each house is provided by two moveable diesel fuel air heaters (Figure 3.14a) of $67 \mathrm{~kW}$ of maximum heating capacity that are placed inside the houses only when they are needed. The ventilation of the houses is provided by direct driven axial extractors that are placed at the pit level (Figure 3.14b) adopting the so-called "pit ventilation" configuration. In this configuration, fans exhaust the indoor air directly from the pits, avoiding the spreading of the contaminants (e.g. $\mathrm{NH}_{3}$ and $\mathrm{H}_{2} \mathrm{~S}$ in the enclosure. The installed fans can operate at different propeller speed (four steps) through a transformer speed controller. In this way, low ventilation flow rates can be provided in cool season to control the $I A Q$ (base ventilation) and higher ones during the warm season for cooling ventilation.

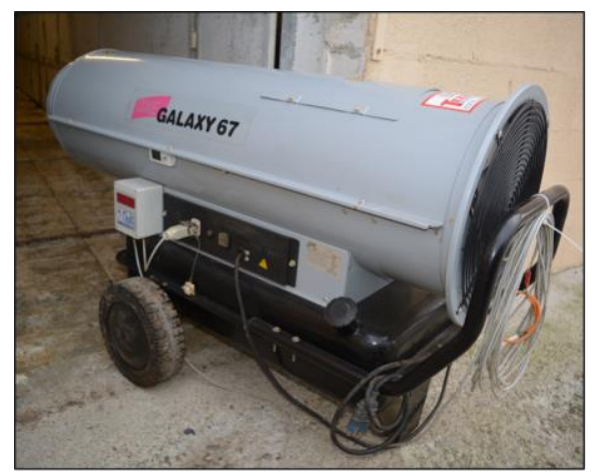

(a)

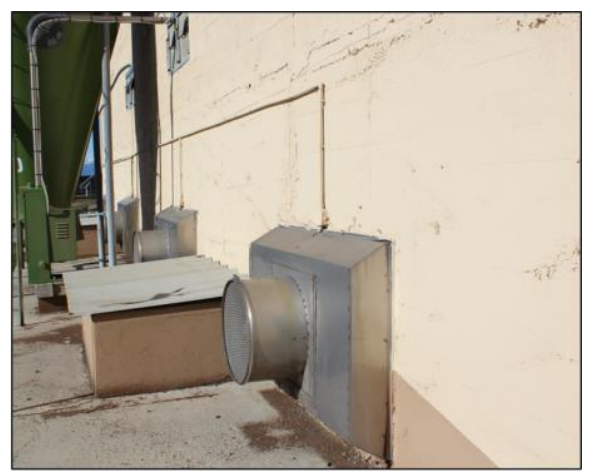

(b)

Figure 3.14 - Figure (a) diesel fuel air heater adopted for the supplemental heating; Figure (b) fans for pit ventilation (detail of house B).

\subsubsection{Monitoring campaign description}

The monitoring campaign that was performed in pig house A and pig house $\mathrm{B}$ concerned the acquisition of the datasets summarized in Table 3.3 through the installation of an ad-hoc sensor network in each one of the pig houses. As visible from the table, the main difference between the datasets acquired in the pig houses is that in pig house A both indoor climate conditions and electrical power were monitored, while in pig house B the monitoring campaign regarded only the climate conditions. The duration of the monitoring campaign was more than a year for the indoor and outdoor climate conditions and around nine months for the monitoring of electrical power.

Table 3.3 - Summary of the pig houses monitoring campaign.

\begin{tabular}{|c|c|c|c|}
\hline Pig house & Dataset & Monitored parameter & Monitoring period \\
\hline A \& B & $\begin{array}{c}\text { Indoor climate } \\
\text { conditions }\end{array}$ & $\begin{array}{c}\theta_{\text {air_i }} \\
R H_{\mathrm{i}} \\
\end{array}$ & $\begin{array}{c}\text { March } 21^{\text {st }} 2017-\text { April } \\
13^{\text {th }} 2018\end{array}$ \\
\hline A \& B & $\begin{array}{l}\text { Outdoor climate } \\
\text { conditions }\end{array}$ & $\begin{array}{c}\theta_{\text {air_o }} \\
R H_{\mathrm{o}} \\
I_{\text {tot_hor }}\end{array}$ & $\begin{array}{c}\text { March } 21^{\text {st }} 2017-\text { April } \\
13^{\text {th }} 2018\end{array}$ \\
\hline A & $\begin{array}{c}\text { Climate control } \\
\text { system }\end{array}$ & $\begin{array}{l}\text { Electrical power of the } \\
\text { house }\end{array}$ & $\begin{array}{c}\text { June } 28^{\text {th }} 2017-\text { April } 13^{\text {th }} \\
2018\end{array}$ \\
\hline
\end{tabular}

*Part from ARPA Piemonte 
In Table 3.4 the instruments used for the monitoring campaign are presented. The instruments for the monitoring of climate conditions are the same ones used in the monitoring campaign of the greenhouse presented in section 3.2.2. The sensors for the acquisition of indoor climate conditions were placed in both the pig houses. In pig house $A$, five points of measurement for $\theta_{\text {air_i }}$ and four points of measurement for $R H_{\mathrm{i}}$ were set in the enclosure. A slightly different strategy was adopted in pig house B because, being the two rearing areas very similar between them, the sensors were placed only in one of them and the acquired data are considered representative of the entire enclosure. In pig house $\mathrm{B}$, therefore, five points of measurement for $\theta_{\text {air_i }}$ and three for $R H_{\mathrm{i}}$ were set in only one of the two rearing areas. All the monitoring devices were set with a 10 -minute logging time step and they were enclosed in electrical junction boxes or protective cases to avoid damages (Figure 3.15). In both the pig houses, the sensors were installed on existing supports at $2 \mathrm{~m}$ of height to avoid possible interactions with the reared animals.

The values of $\theta_{\text {air_o }}$ and $R H_{\mathrm{o}}$ were obtained through a portable data logger arranged outside the pig house $\mathrm{B}$. The obtained weather data were also integrated using the hourly data from a third part weather station (Regional Agency for the Protection of the Environment of Piemonte, ARPA Piemonte) that includes also Itot_hor.

Table 3.4 - List of adopted instruments.

\begin{tabular}{|c|c|c|c|c|}
\hline $\begin{array}{l}\text { Monitored } \\
\text { parameter }\end{array}$ & Type of instrument & $\begin{array}{c}\text { Commercial } \\
\text { product } \\
\text { (from Onset }(\text { ) }\end{array}$ & $\begin{array}{c}\text { Pig house } \\
\text { A }\end{array}$ & $\begin{array}{c}\text { Pig house } \\
\text { B }\end{array}$ \\
\hline $\begin{array}{c}\text { Air } \\
\text { temperature }\end{array}$ & $\begin{array}{c}\text { ·Thermistor } \\
\text { (embedded in logger) }\end{array}$ & UX100-011 & 4 & 3 \\
\hline \multirow{2}{*}{$\begin{array}{c}\text { Air } \\
\text { temperature }\end{array}$} & $\cdot \mathrm{PT} 1000$ & TMCX-HD & 1 & 2 \\
\hline & $\cdot$ Analog logger & UX120-006M & 1 & 1 \\
\hline $\begin{array}{l}\text { Air relative } \\
\text { humidity }\end{array}$ & $\begin{array}{c}\text { ·Humistor } \\
\text { (embedded in logger) }\end{array}$ & UX100-011 & 4 & 3 \\
\hline \multirow{2}{*}{$\begin{array}{c}\text { Electrical } \\
\text { power of } \\
\text { fans }\end{array}$} & $\begin{array}{l}\text {-AC kilowatt transducer } \\
\text { with incorporated sensors }\end{array}$ & T-VER-8044-100 & 1 & - \\
\hline & Analog logger & UX120-006M & 1 & - \\
\hline
\end{tabular}

The performed monitoring campaign aimed also at acquiring data about the electrical power absorbed in pig house A. For this purpose, an AC kilowatt transducer that incorporates one split-core AC current sensor (Figure 3.16) and two voltage leads was installed in the main electrical panel of the house. The datalogger connected to the AC kilowatt transducer was set with a 10-second logging time step. The electric panel of pig house A distributes the power to different equipment inside the pig house. Consequently, the total monitored electrical power -or the total electrical load- is due to the sum of the partial electrical loads of the pig house A equipment. 


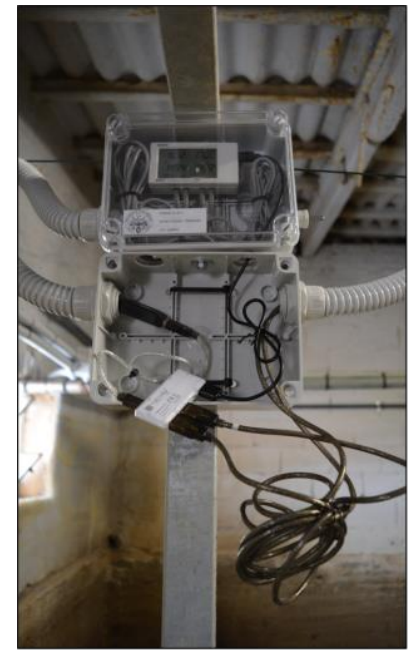

(a)

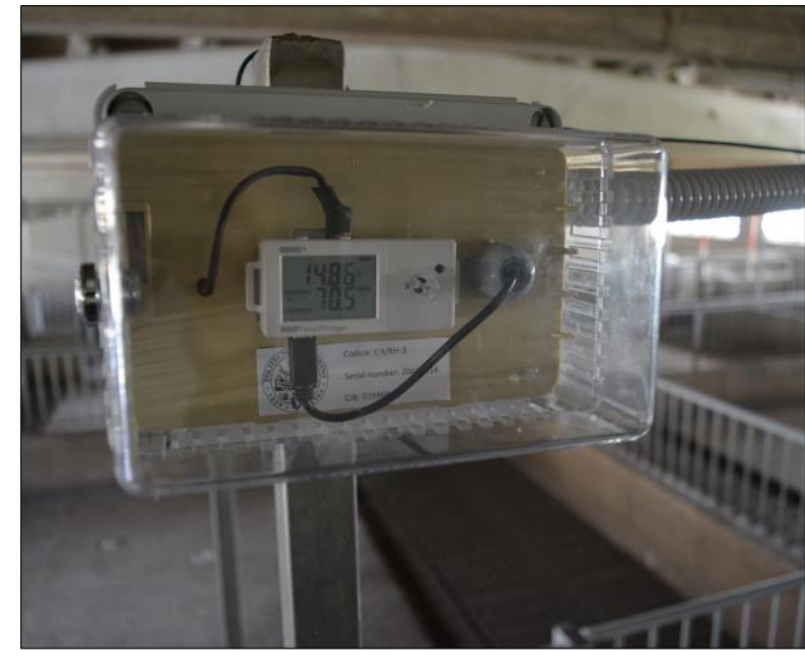

(b)

Figure 3.15 - Figure (a): PT 1000 probes connected to an analog data logger enclosed in an electrical junction box. Figure (b): datalogger with embedded thermistor and humistor in its protective case.

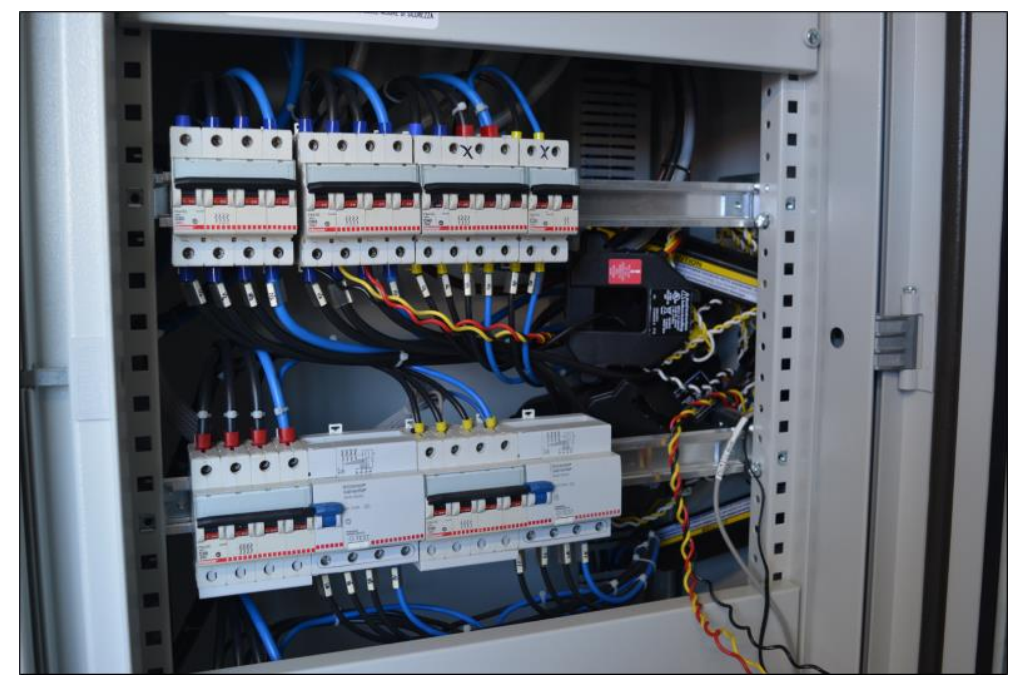

Figure 3.16 - Detail of the electrical panel with the kW-transducer connected.

Before the beginning of the monitoring campaign a preliminary operation was carried out with the aim of estimating the electrical power absorbed by each equipment -the partial electrical loads- present in pig house A. The results of this operation are summarized in Table 3.5. Three main equipment were present in the considered pig house, namely feed distribution system, lighting, and ventilation. The feed distribution system needs electrical power to work since it automatically fills the pigs' feeders through an auger when the feed falls below a certain threshold (pigs were feed ad-libitum). The auger is equipped with an electrical motor that absorbs $0.861 \mathrm{~kW}$, as reported in Table 3.5. The lighting system of pig house A is divided in two subsystems which partial electrical loads were estimated to be $0.224 \mathrm{~kW}$ and $0.126 \mathrm{~kW}$, respectively. Finally, the last partial electrical loads are represented by ventilation since fans can work at different speeds absorbing a different power as presented in Table 3.5. 
Table 3.5 - Equipment and partial electrical loads preliminarily identified in pig house A.

\begin{tabular}{cc}
\hline Equipment & $\begin{array}{c}\text { Partial electrical load } \\
{[\mathbf{k W}]}\end{array}$ \\
\hline Feed distribution system & 0.861 \\
Light 1 & 0.224 \\
Light 2 & 0.126 \\
Fan: speed 1 & 1.022 \\
Fan: speed 2 & 1.436 \\
Fan: speed 3 & 1,534 \\
Fan: speed 4 & 1.839 \\
\hline
\end{tabular}

The previous operation was carried out before the beginning of the first monitored production cycle (P1) that started at the end of March 2017 and lasted all the warm season for both the pig houses, as visible from Table 3.7 where the main features of the two monitored production cycles are presented. The second production cycle (P2) took place between October 2017 and March/April 2018, during the cool season.

The pig final live weights presented in Table 3.7 (170 kg in $P 1$ and more than $180 \mathrm{~kg}$ in P2) are higher than the standard final live weights that are common in European pig production. Similar final live weights, in fact, are because the considered farm rear pigs for cured ham production (i.e. prosciutto crudo), therefore heavier pigs are needed.

Table 3.6 - Main features of the monitored production cycles for both the houses.

\begin{tabular}{cccc}
\hline Cycles & Parameters & Pig house A & Pig house B \\
\hline & Start & March $22^{\text {nd }} 2017$ & March $29^{\text {th }} 2017$ \\
& End & August $27^{\text {th }} 2017$ & September $9^{\text {th }} 2017$ \\
$1^{\text {st }}$ production cycle & Duration & 153 days & 160 days \\
(warm season) & Number of heads & 155 heads & 250 heads \\
$P 1$ & Mortality & $3.9 \%$ & $3.6 \%$ \\
& Live weight (start) & $25.4 \mathrm{~kg}$ & $25.1 \mathrm{~kg}$ \\
& Live weight (end) & $169.3 \mathrm{~kg}$ & $170.0 \mathrm{~kg}$ \\
\hline $2^{\text {nd }}$ production cycle & Start & October $20^{\text {th }} 2017$ & October $27^{\text {th }} 2017$ \\
(cool season) & End & March $15^{\text {th }} 2018$ & April $3^{\text {rd }} 2018$ \\
$P 2$ & Duration & 147 days & 159 days \\
& Number of heads & 155 heads & 252 heads \\
& Mortality & $0.0 \%$ & $1.2 \%$ \\
& Live weight (start) & $28.9 \mathrm{~kg}$ & $27.3 \mathrm{~kg}$ \\
& Live weight (end) & $181.9 \mathrm{~kg}$ & $184.6 \mathrm{~kg}$ \\
\hline
\end{tabular}

\subsubsection{Main results from the monitoring campaign}

\section{Analyses of the monitored indoor climate conditions}

Figure 3.17 shows the variation of the hourly mean $\theta_{\text {air_i }}$ (obtained as the arithmetic mean among the 10-minute acquired data) for both the analyzed pig houses, together with the trend of $\theta_{\text {air_o }}$ (black dotted line). The limits (in terms of 
time duration) of the two monitored production cycles ( $P 1$ and $P 2)$ for pig house A are highlighted by the red vertical dashed lines. Between $P 1$ and $P 2$ a sanitary empty period was present. The graph highlights that the indoor climate conditions are very different between $P 1$, carried out during the warm season, and $P 2$ that took place in the cool season. In the warm season, pigs were exposed to a mean $\theta_{\text {air_i }}$ that often exceeded $\theta_{\text {air_o }}$. This issue indicates the difficulty of the climate control system (not equipped with evaporative cooling) in dissipating the heat produced by the animals. On the other hand, during the winter months $(P 2)$ the effect of a thermal regulation is evident since the climate control system maintained an average $\theta_{\text {air_i }}$ always around $21^{\circ} \mathrm{C}$ (more constantly in house $\mathrm{A}$ ), a value that is considerably higher than $\theta_{\text {air_o }}$.

To have a more complete view about the animal welfare during the monitored period, the thermoneutral zone (TNZ) of the pigs [159] was studied. To do so, the trend of the pig body mass (also known as live weight, $w_{\mathrm{p}}$ ) was expressed as a function of the animal age through a Gompertz function [160] that, according to different studies present in literature $[161,162]$, is the best solution to estimate $w_{\text {pig }}$ as a function of the pig age and reads

$$
w_{\mathrm{p}}=W_{\mathrm{p}} \cdot e^{\left(-e^{\left(-\delta_{\mathrm{p}} \cdot\left(\mathrm{ap}_{\mathrm{p}}-\mathrm{a}_{-} \mathrm{max}\right)\right)}\right)} \quad[\mathrm{kg}]
$$

where $e$ is the Euler's number and $\mathrm{a}_{\mathrm{p}}$ the pig age expressed in days. The terms $W_{\mathrm{p}}$, $\delta_{\mathrm{p}}$ and $\mathrm{a}_{\mathrm{p}_{-} \max }$ (which value is presented in Table 3.7) are three characteristic parameters evaluated fitting the curve on the data of age and weight provided by the farmer. The term $W_{\mathrm{p}}$ indicates the theoretical maximum weight achievable by the pig, $\delta_{\mathrm{p}}$ is the pig growing rate and $\mathrm{a}_{\mathrm{p}_{-} \max }$ is the pig age at which the maximum theoretical weight is achieved. The trend of $w_{\mathrm{p}}$ over the monitored periods is also shown in Figure 3.17.

Table 3.7 - Parameters for the Gompertz function of Eq.(1) adopted in this work.

\begin{tabular}{cc}
\hline Parameter & Value \\
\hline$W_{\mathrm{p}}$ & $218.16 \mathrm{~kg}$ \\
$\delta_{\mathrm{p}}$ & 0.0142 days $^{-1}$ \\
$\mathrm{a}_{\mathrm{p} \_ \text {max }}$ & 143.10 days \\
\hline
\end{tabular}

The ideal set point temperature $\theta_{\text {set_id }}$ can be expressed as a function of $w_{\mathrm{p}}$ through a regression from values reported in [163]. This temperature is supposed to guarantee the animal welfare while maximizing the growth rate and reads

$$
\theta_{\text {set_id }}=36.734 \cdot\left(w_{\mathrm{p}}\right)^{-0.147} \quad\left[{ }^{\circ} \mathrm{C}\right]
$$

The function described by Eq.(2) is also represented in Figure 3.17 by the solid green line. Comparing $\theta_{\text {set_id }}$ with the trend of the average $\theta_{\text {air_i }}$ of both the pig 
houses, a marked deviation during $P 1$ clearly stands out. This marked temperature difference might induce excessive physiological heat stress in pigs.

To better understand the welfare conditions of pig related to the $\theta_{\text {air_i }}$, the $T N Z$ is analysed. To do so, the Upper Critical Temperature $\left(\theta_{\mathrm{UCT}}\right)$ and the Lower Critical Temperature $\left(\theta_{\mathrm{LCT}}\right)$ [159] are evaluated according to the punctual values provided by previous studies [164]. Starting from these values, $\theta_{\mathrm{UCT}}$ and $\theta_{\mathrm{LCT}}$ curves were obtained as a function of $w_{\text {pig }}$, fitting the available data to a mathematical law similar to the one that governs the trend of $\theta_{\text {set_id }}$. The formulations to obtain $\theta_{\text {UCT }}$ and $\theta_{\mathrm{LCT}}$ read

$$
\begin{aligned}
& \theta_{\mathrm{UCT}}=32.898 \cdot\left(w_{\mathrm{p}}\right)^{-0.056} \quad\left[{ }^{\circ} \mathrm{C}\right] \\
& \theta_{\mathrm{LCT}}=33.212 \cdot\left(w_{\mathrm{p}}\right)^{-0.230} \quad\left[{ }^{\circ} \mathrm{C}\right]
\end{aligned}
$$

Please note that different values of $\theta_{\mathrm{UCT}}$ and $\theta_{\mathrm{LCT}}$ can be found considering different rearing conditions (e.g. floor type, air speed and skin wetness) and different pig breeds.

The obtained $T N Z$ is represented in Figure 3.17 by the green area delimited by a solid red line $\left(\theta_{\mathrm{UCT}}\right)$ and a blue one $\left(\theta_{\mathrm{LCT}}\right)$. The analysis of the graph shows that the climate conditions of both the monitored case studies are not adequate during the warm season since $\theta_{\text {air_i }}$ is not only quite far from $\theta_{\text {set_id }}$ values, but it is out of the $T N Z$ for several weeks exposing the reared pigs to potential heat stress conditions.

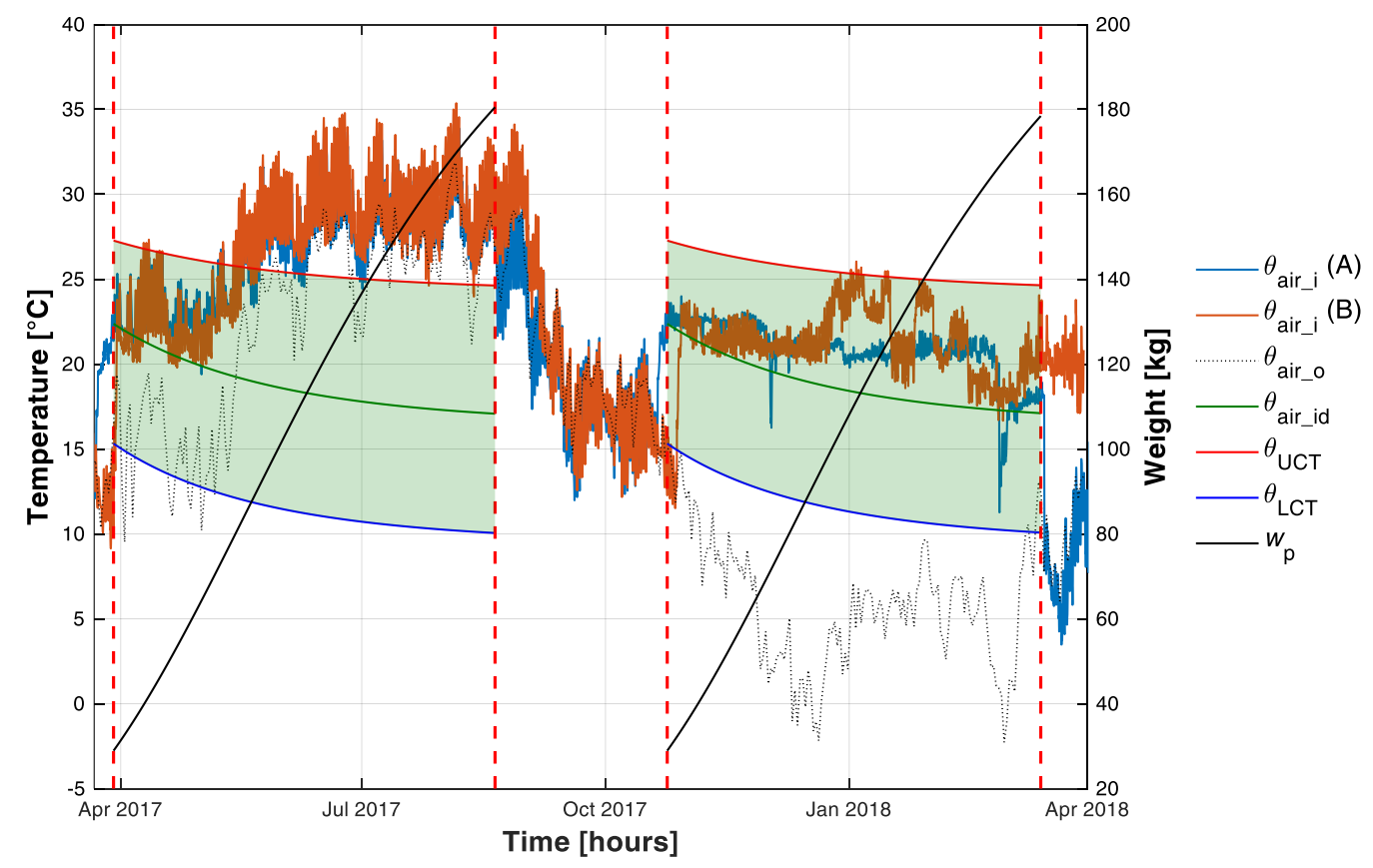

Figure 3.17 - Air temperature trends, UCT, LCT, TNZ visualization (primary $y$-axis) and pig live weight trend (secondary $y$-axes). 
To numerically evaluate the potential heat stress due to the not adequate conditions during $P 1$ that were shown in Figure 3.17, the apparent heat-stress intensity index $\left(I_{\mathrm{hs}}\right)$ can be adopted. This index is developed on the basis of the formulations proposed in [165] and [124] reads

$$
I_{\mathrm{hs}}=\sum_{j=1}^{n_{\text {step }}}\left(\Delta \theta_{\text {air, }} \cdot \Delta \tau_{\mathrm{j}}\right) \quad\left[{ }^{\circ} \mathrm{Ch}\right]
$$

where $\Delta \theta_{\text {air,j }}$ is the positive difference between $\theta_{\text {air_i }}$ and $\theta_{\text {UCT }}$ at $j$-th time step, $\Delta \tau_{j}$ is the duration of $j$-th time step and $n_{\text {step }}$ is the number of considered time steps.

During the entire $P 1, I_{\mathrm{hs}}$ was equal to $2,251^{\circ} \mathrm{C} \mathrm{h}$ in pig house $\mathrm{A}$ and $2,324{ }^{\circ} \mathrm{C} \mathrm{h}$ in pig house $\mathrm{B}$, confirming the not adequate indoor climate conditions of the monitored pig houses. The heat stress risk is more evident during the month of June and July, as visible from the bar charts of Figure 3.18 that show the monthly values of $I_{\text {hs }}$ during $P 1$ for both the pig houses. The chart shows, in fact, that June and July were characterized by extremely high values of $I_{\text {hs }}$ (higher than $700{ }^{\circ} \mathrm{C} \mathrm{h}$ ). The situation is quite better during May and August when $I_{\mathrm{hs}}$ is around $400-450{ }^{\circ} \mathrm{C} \mathrm{h}$ in both the pig houses. In April, the heat stress was apparently not a problem since $I_{\mathrm{hs}}$ is almost zero (few ${ }^{\circ} \mathrm{C} \mathrm{h}$ values were monitored only in pig house B). The bar charts of Figure 3.18 do not show the values of $I_{\mathrm{hs}}$ during $P 2$ since in that period $\theta_{\text {air_i }}$ falls almost always in the $T N Z$, entailing lower heat stress risk. During $P 2$, in fact, $I_{\mathrm{hs}}$ was $0{ }^{\circ} \mathrm{C} \mathrm{h}$ for pig house $\mathrm{A}$ and $23{ }^{\circ} \mathrm{C} \mathrm{h}$ for pig house B.
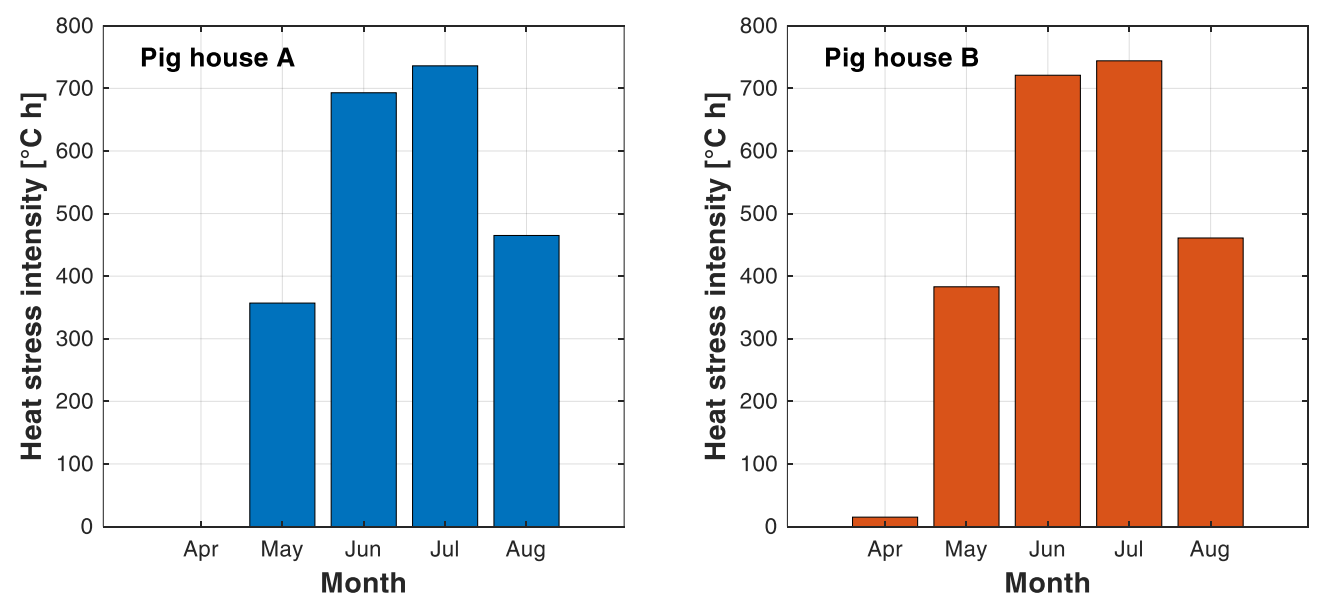

Figure 3.18 - Monthly heat-stress intensity for Pig House A and B during summer production cycle $(P 1)$.

Indoor air temperature is not the only parameter that has to be considered when the indoor climate conditions of a livestock house are evaluated since also high $R H_{\mathrm{i}}$ could increase pig heat stress and, consequently, it should be carefully evaluated. To analyze the monitored pig houses from a thermo-hygrometric point of view, the average monitored $R H_{\mathrm{i}}$ is plotted against the contemporary average monitored value of $\theta_{\text {air }}$ i in the scatterplots of Figure 3.19 for both the pig houses in both the monitored periods. The graphs show that the data representing the production cycle 
during the warm season $(P 1)$ are characterized by a greater dispersion than the data referring to the winter cycle $(P 2)$ that are less dispersed being grouped around the set point temperature. Figure 3.19 is also interesting since it enhances the evaluation of heat stress risk using threshold values provided in literature.In the presented scatter plot, the three risky zones for heat stress reported in [166] are presented using different background colors. In alert zone, yellow background, pig may start to suffer from heat stress. For this reason, ventilation should be increased and pigs should be monitored to detect possible signs of heat stress, such as panting. In danger zone, orange background, additional cooling systems should be adopted, such as water spraying or misting. In the emergency zone, red background, pigs are suffering from heat stress and their activity should be reduced by withdrawing feed and reducing light level.
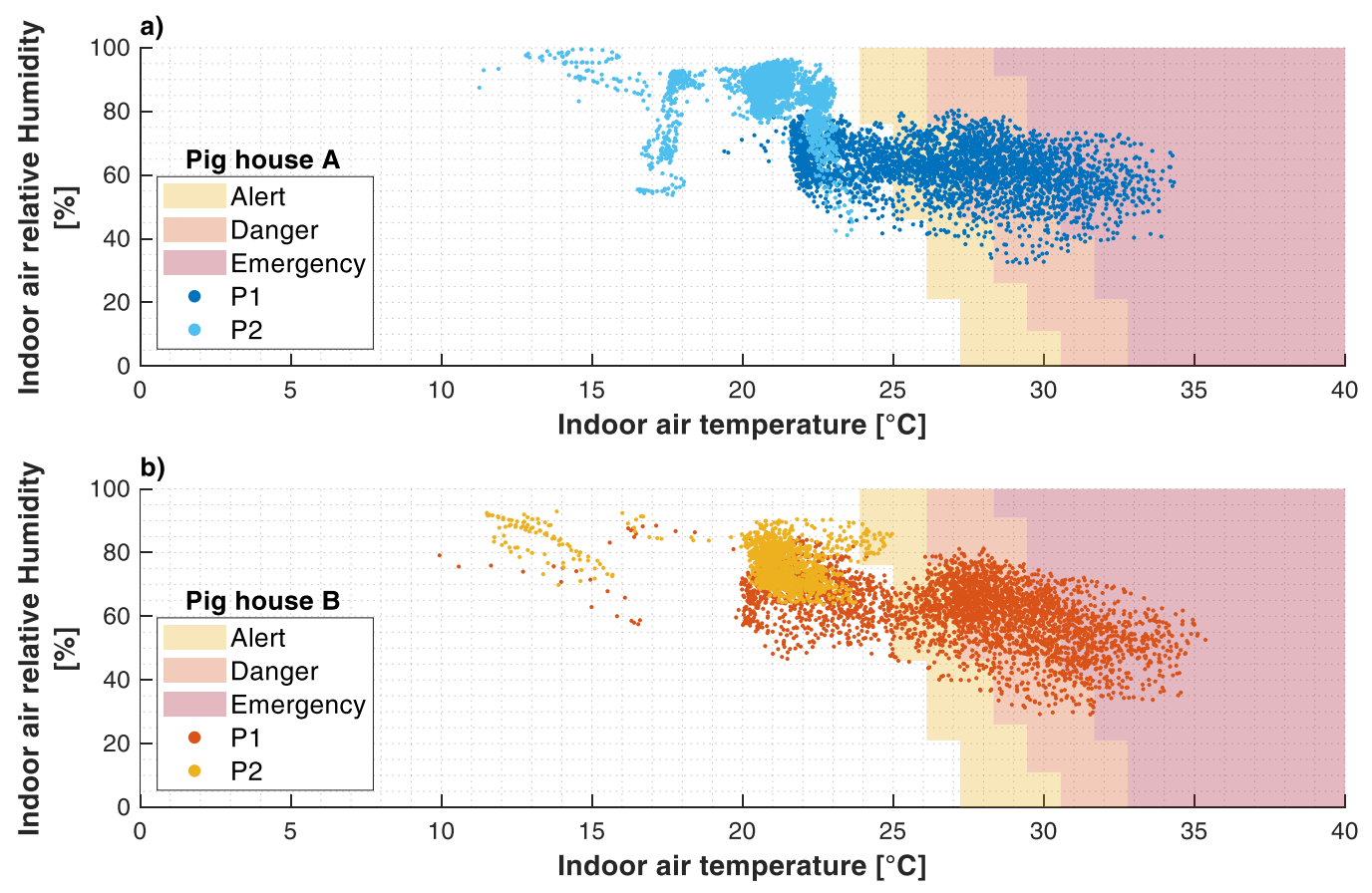

Figure 3.19 - Indoor climate conditions of air temperature and relative humidity for pig house A

(a) and $\mathrm{B}(\mathrm{b})$ for both the monitored periods ( $P 1$ and $P 2)$ and heat stress risky zones.

As visible from Figure 3.19, most of the points representing the indoor climate conditions of $P 1$ indicate a risky situation for pigs. It means that the climate control systems that are adopted in both the pig houses are not very effective in providing the adequate indoor climate conditions to the reared pigs, especially during the warm season. Similar inadequate indoor climate conditions that characterized $P 1$ had consequences on the mortality of the animals. During $P 1$, in fact, the mortality among the animals was $3.9 \%$ in pig house A and $3.6 \%$ in pig house B. Since no cooling systems were present inside the house, pigs wet themselves using the drinking water to decrease their body temperature. This behavior has detrimental consequences for the on-farm use of water and on the related energy consumption of the submerged pumps used to obtained water from the water table (not monitored in the framework of this work), as confirmed by the electrical bills of the farmer. 
This detrimental situation would be improved by evaluating the possible installation of evaporative pads or fogging systems that could reduce the heat stress of the reared pigs.

\section{Analyses of the monitored electrical power}

As described in section 3.3.2, the monitoring campaign regarded the acquisition of the electrical power absorbed only by pig house A. For this reason, in this section pig house B will be not analyzed since no values of electrical power are available. The trend of electrical power of pig house A is reported in Figure 3.20 with a 10second time discretization, that is the acquisition time step. The first element that stands analyzing this graph is that the maximum power monitored in pig house A is slightly around $3 \mathrm{~kW}$. The monitored electrical power is higher during $P 1$ (July - August) than in P2 (October - April). This is because, in $P 1$, fans were working at their maximum capacity during almost all the time to decrease $\theta_{\text {air_i }}$ and maintaining adequate farming conditions. Figure 3.20 shows a considerable decrease of the use of electrical energy during September and October, when the monitored electrical power was almost $0 \mathrm{~kW}$. This decrease can be attributable to the sanitary empty period that took place between $P 1$ and $P 2$, as visible from Figure 3.17. During that period, in fact, both the houses were empty and all the equipment for pig production were turned off. The only exception is represented by important peaks of electrical power that were monitored just after the end of the production cycle. Those peaks are around $8.5 \mathrm{~kW}$, they can be also found at the end of $P 2$ and they represent the maximum monitored values during the entire campaign. The duration of these peaks -only few hours- indicates the use of electrical equipment that absorbs a great amount of power, but that is used for a short amount of time and in specific periods, at the end of the production cycle. These features suggest that those peaks can be attributable to the major sanitization tasks that usually take place during the sanitary empty period. As confirmed by the farmer, in fact, after each production cycle the slurry collected in the pits of the pig houses is mechanically flushed and the same houses are sanitized through pressure washers which use entails a considerable increase of the absorbed electrical power. The last element that could be highlighted analyzing the trend of Figure 3.20 is that the electrical power monitored in $P 2$ is considerably lower than in $P 1$. This difference can be explained considering the milder outdoor climate conditions in which the use of fans and the consequent use of electrical energy is very reduced. 


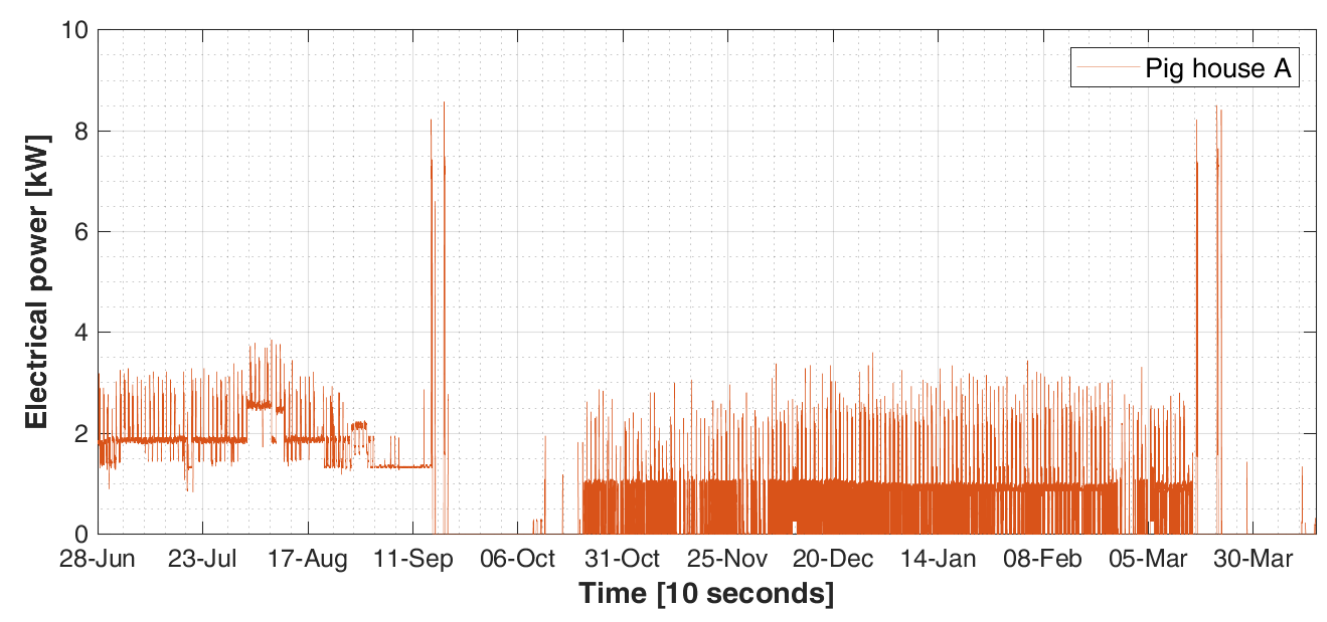

Figure 3.20 - Electrical power (10-seconds values) monitored in pig house A during the entire monitoring campaign.

More information about the dynamics of pig house A can be obtained analyzing specific monitored periods. In Figure 3.21, an example of focus on data acquired during July is presented. July is an interesting month to be analyzed since it was characterized by the highest $I_{\mathrm{hs}}$ (Figure 3.18) and by an important use of fans, as estimated from Figure 3.20. The focus shown in Figure 3.21 confirms that during July the ventilation system worked at its full capacity since the average monitored power was around $1.8 \mathrm{~kW}$. This value is attributable to the fans working at their maximum speed, as reported in Table 3.5. The trend of Figure 3.21 is also interesting since it presents a pattern of monitored electrical power that is very similar with a daily basis. This is particularly evident considering the recurrent peaks of power of around $2.6 \mathrm{~kW}$ that could be due to the contemporary activation of the fans at the maximum speed and of the automatic feeding system (always referring to the values reported in Table 3.5).

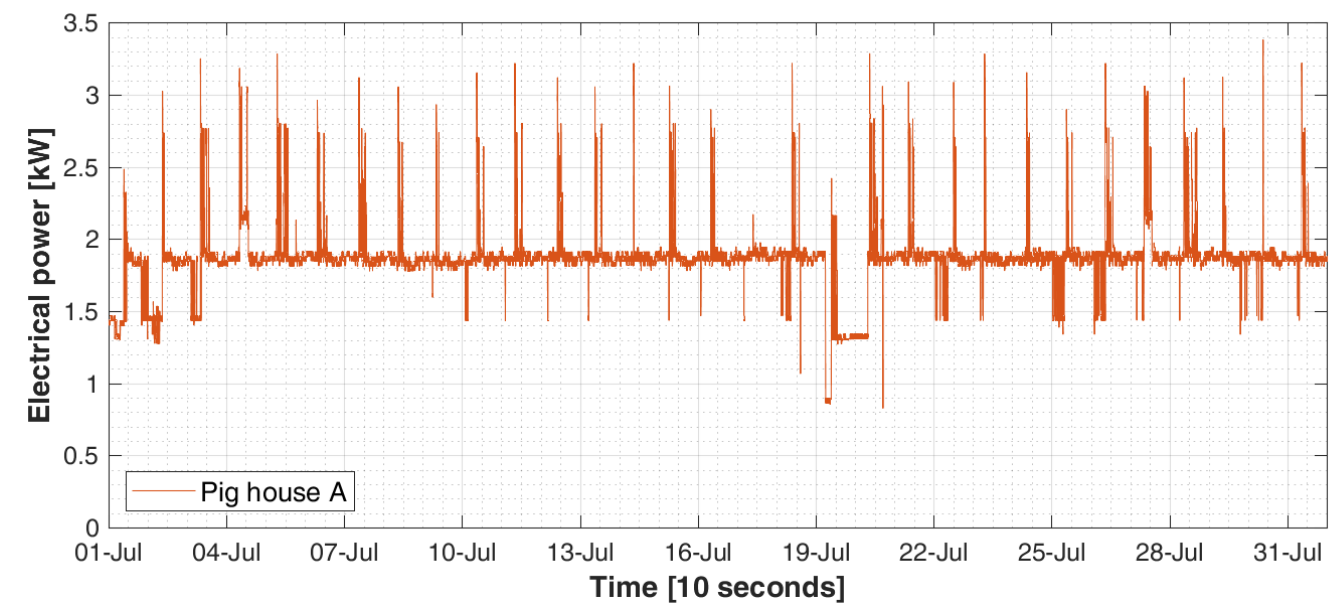

Figure 3.21 - Electrical power monitored during July in pig house A.

The presence of a pattern in the absorbed electrical power is even more evident representing the frequencies of the monitored electrical power. In the histogram of Figure 3.22, the electrical powers acquired during July in pig house A are grouped in classes of $30 \mathrm{~W}$ of width and their absolute frequencies are presented using a 
logarithmic scale. From the histogram some clusters of total electrical loads that are characterized by high absolute frequency stand out. The identification of these clusters is possible referring to the values previously identified in Table 3.5. The highest frequency presented in Figure 3.22 regards a total electrical load of about $1.8 \mathrm{~kW}$ that can be attributable, as already stated, to the activation of fans at the maximum speed (speed 4). The second highest frequency is related to a total electrical load of about $1.4 \mathrm{~kW}$ and could be related to the activation of fans at speed 2. The other more relevant frequencies are around $2.2 \mathrm{~kW}$ and $2.6 \mathrm{~kW}$. These monitored powers can be due to the contemporary activation of fans at speed 2 $(1.436 \mathrm{~kW})$ or $4(1.839 \mathrm{~kW})$ with the feed distribution system $(0.861 \mathrm{~kW})$. The feed distribution itself has a considerable absolute frequency (around $0.8 \mathrm{~kW}$ ) and can be appreciated on the left of the histogram.

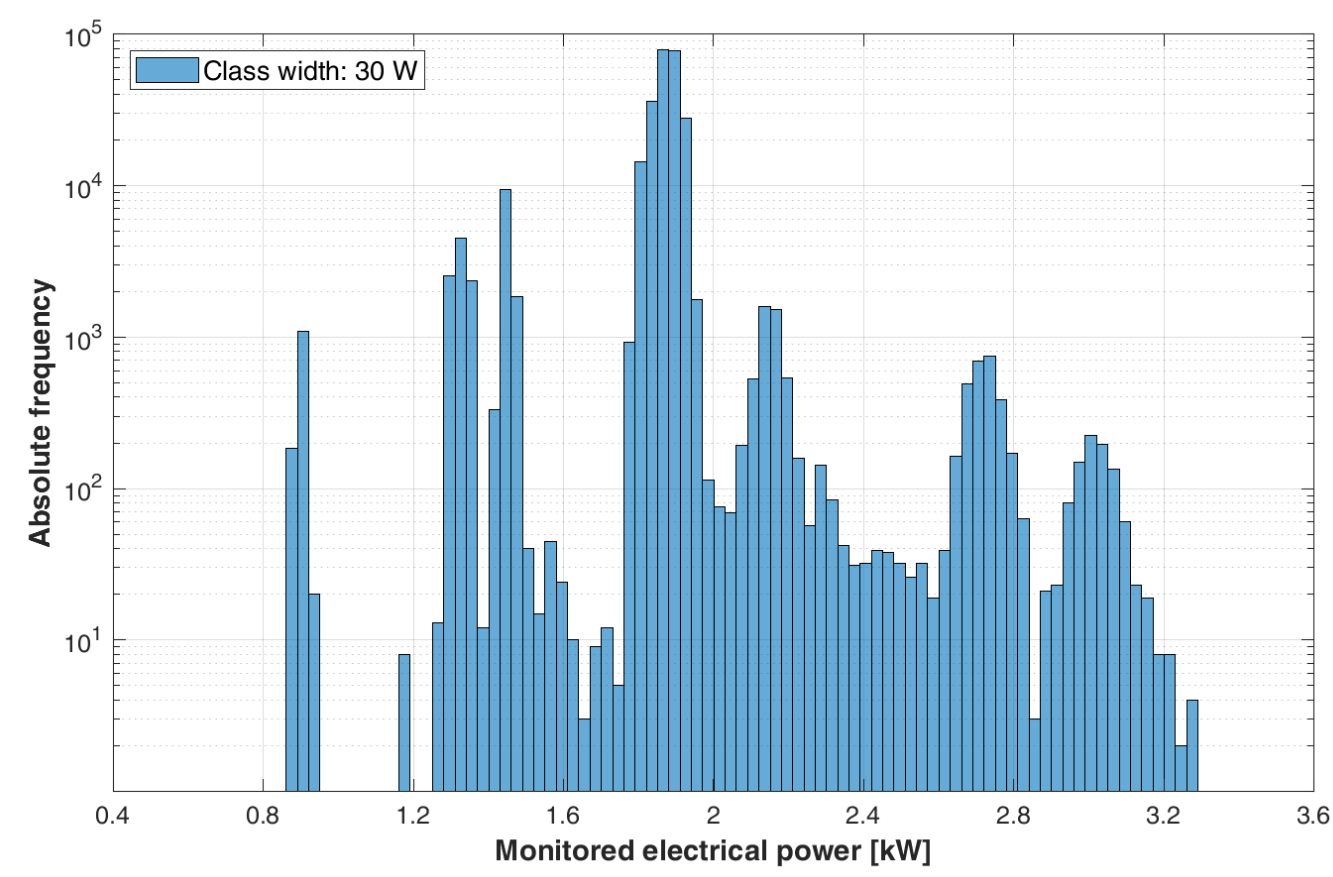

Figure 3.22 - Absolute frequencies of the electrical loads monitored during July in pig house A. The width of the classes is $30 \mathrm{~kW}$ and the logarithmic scale is used in $y$-axis.

As visible from the histogram of Figure 3.22, the total electrical load that is monitored by the AC kilowatt transducer is the combination of the partial electrical load that were presented in Table 3.5. This makes it possible to develop a specific algorithm able to unbundle and to identify the partial loads $\left(l_{\mathrm{el}}\right)$ that compose the monitored total electrical load $\left(L_{\mathrm{el}}\right)$. At each monitored time step $j$, in fact, the total monitored electrical load $L_{\mathrm{el}}(j)$ can be defined as

$$
L_{\mathrm{el}}(j)=\vec{a}(j)^{t} \cdot \vec{l}+e_{\mathrm{err}}\left(\|\vec{a}(j)\|_{1}\right) \quad[\mathrm{kW}]
$$

where $\vec{a}(j)$ is a column vector which elements are Boolean variables $\pi_{1} \in$ $\{0,1\}$. The values of the $\vec{a}(j)$ elements depend on the presence at time $j$ of the partial load $l_{\mathrm{el}}$ (with $i=1, \ldots, n_{\mathrm{l}}$ ) that, in turn, are organized in the vector $\vec{l}$. The term $n_{\mathrm{l}}$ is 
the cardinality of the set of the known partial electrical loads that were obtained with preliminary analysis and are reported in Table 3.5. The addend $e_{\text {err }}$ of Eq. (6) represents the total error of the measurement performed at each time step $\tau$ and is due to, for example, the accuracy of the adopted instruments. This error is related to both the measurement of $L_{\mathrm{el}}(j)$ and of every partial load $l_{\mathrm{el}}$ being, thus, function of the number of the detected active loads. Furthermore, $e_{\mathrm{err}}$ also includes the presence of partial loads that were not considered a priori and, hence, that were not measured with the preliminary measurements.

For pig house A, vectors $\vec{a}(j)$ reads

$$
\vec{a}(j)=\left[\begin{array}{c}
\pi_{\text {feed }} \\
\pi_{\text {light_1 }} \\
\pi_{\text {light_2 }} \\
\pi_{\text {fan_1 }} \\
\pi_{\text {fan_2 }} \\
\pi_{\text {fan_3 }} \\
\pi_{\text {fan_4 }}
\end{array}\right]
$$

and $\vec{l}$ reads

$$
\vec{l}=\left[\begin{array}{c}
l_{\text {feed }} \\
l_{\text {light_1 }} \\
l_{\text {light_2 }} \\
l_{\text {fan_1 }} \\
l_{\text {fan_2 }} \\
l_{\text {fan_3 }} \\
l_{\text {fan_4 }}
\end{array}\right]
$$

To unbundle the partial electrical loads and to calculate $e$ at each logging time step, an algorithm was implemented in MATLAB ${ }^{\circledR}$ environment. The algorithm is based on the following optimization function

$$
\hat{\vec{a}}(j)=\min _{\vec{a}(j)}\left(e_{\mathrm{err}}\right)
$$

where $\hat{\vec{a}}(j)$ is the $\vec{a}(j)$ vector that minimizes the $e_{\mathrm{err}}$ function obtained from Eq. (6) as

$$
e_{\mathrm{err}}=\vec{a}^{t} \cdot \overrightarrow{l_{\mathrm{el}}}-L_{\mathrm{el}} \quad[\mathrm{kW}]
$$

with

$$
\pi_{1} \in\{0,1\}
$$

and

$$
\sum_{n=4}^{7} \pi_{1} \leq 1
$$


set as constraints of the minimization procedure. The condition of Eq. (12) should be fulfilled because $l_{\text {fan_1 }}, l_{\text {fan_2 }}, l_{\text {fan_3 }}$ and $l_{\text {fan_4 }}$ represent the partial loads due to different velocities of the same fan that, thus cannot coexist at the same time step $j$.

The previously presented procedure was then applied to the month of July to unbundle and identify the partial electrical loads and the precision of the unbundle process was assessed through the mean total error $\bar{e}_{\text {err }}$ as

$$
\bar{e}_{\text {err }}=\frac{\sum_{j=1}^{n_{\text {mea }}}\left|e_{\text {err, } \mathrm{j}}\right|}{n_{\text {mea }}} \quad[\mathrm{kW}]
$$

where $e_{\mathrm{err}, \mathrm{j}}$ is the error obtained from Eq. (10) at the $j$ time step and $n_{\text {mea }}$ is the total number of measurements that are considered for July $(267,840)$. For pig house A and for July, $\bar{e}_{\text {err }}$ is equal to $126 \mathrm{~W}$, meaning a slight error during the unbundle procedure.

The results of the load unbundle and identification procedure are aggregated to obtain the electrical energy consumptions that are presented in Table 3.8, where $e_{\text {err }}$ is omitted for the sake of clarity. During the monitored period, the electrical energy consumption of pig house A was $1377 \mathrm{kWh}$. Most of this energy consumption was due to the fans (96.3\%), while feed distribution and light represented a minor energy electrical consumption share. This analysis also confirm that fans were activated for almost all the time during July (734 h).

Table 3.8 - Focus on the electrical energy consumption of pig house A during July.

\begin{tabular}{cccc}
\hline Energy use & $\begin{array}{c}\text { Energy } \\
\text { consumption } \\
{[\mathbf{k W h}]}\end{array}$ & $\begin{array}{c}\text { Share on the } \\
\text { total } \\
{[\%]}\end{array}$ & $\begin{array}{c}\text { Working } \\
\text { time } \\
{[\mathbf{h}]}\end{array}$ \\
\hline Feed distribution & 10.7 & 0.8 & 12.4 \\
Light 1 & 34.1 & 2.5 & 152.2 \\
Light 2 & 5.8 & 0.4 & 46.0 \\
Fans (speed 1) & 30.7 & 2.2 & 30.0 \\
Fans (speed 2) & 50.8 & 3.7 & 35.4 \\
Fans (speed 3) & 8.8 & 0.6 & 5.7 \\
Fans (speed 4) & 1236.4 & 89.8 & 672.3 \\
\hline Total & 1377.3 & $100 \%$ & - \\
\hline Whereof fans & 1326.7 & 96.3 & 743.4 \\
\hline
\end{tabular}

The developed methodology makes it possible also to compare the trends of energy consumption during the warm and the cool season. For this purpose, in Figure 3.23 the daily electrical energy consumption during July and January are presented. The considered months are interesting for performing this analysis since they are representative of $P 1$ and $P 2$, and because the age of the reared pigs was similar. The daily energy consumptions presented in Figure 3.23 are in accordance with the outdoor climate conditions that characterize the considered months. During July, in fact, the monitored energy consumption is always around $44 \mathrm{kWh}_{\mathrm{el}}$, with few exceptions (July $1^{\text {st }}-3^{\text {rd }}$ and July $19^{\text {th }}$ and $10^{\text {th }}$ ). These variations could be 
attributable to significative variations of $\theta_{\text {air_o }}$. On the contrary, in January (Figure $3.6 \mathrm{~b})$ the monitored electrical energy consumption is lower than $20 \mathrm{kWh}_{\mathrm{el}}$, almost the half of the energy consumption monitored in July. In January, the monitored energy consumption for ventilation not only decreases but is also less constant if compared to July. This pattern shows that in colder months, the ventilation system does not operate at its maximum capacity since its main task is to ensure the required fresh air supply to control the $I A Q$. In both the periods, lighting and feeding have a significatively lower impact on the global energy consumption, furtherly pointing out that the increasing of the energy-efficiency for climate control is fundamental for increasing the overall energy performance of livestock houses.
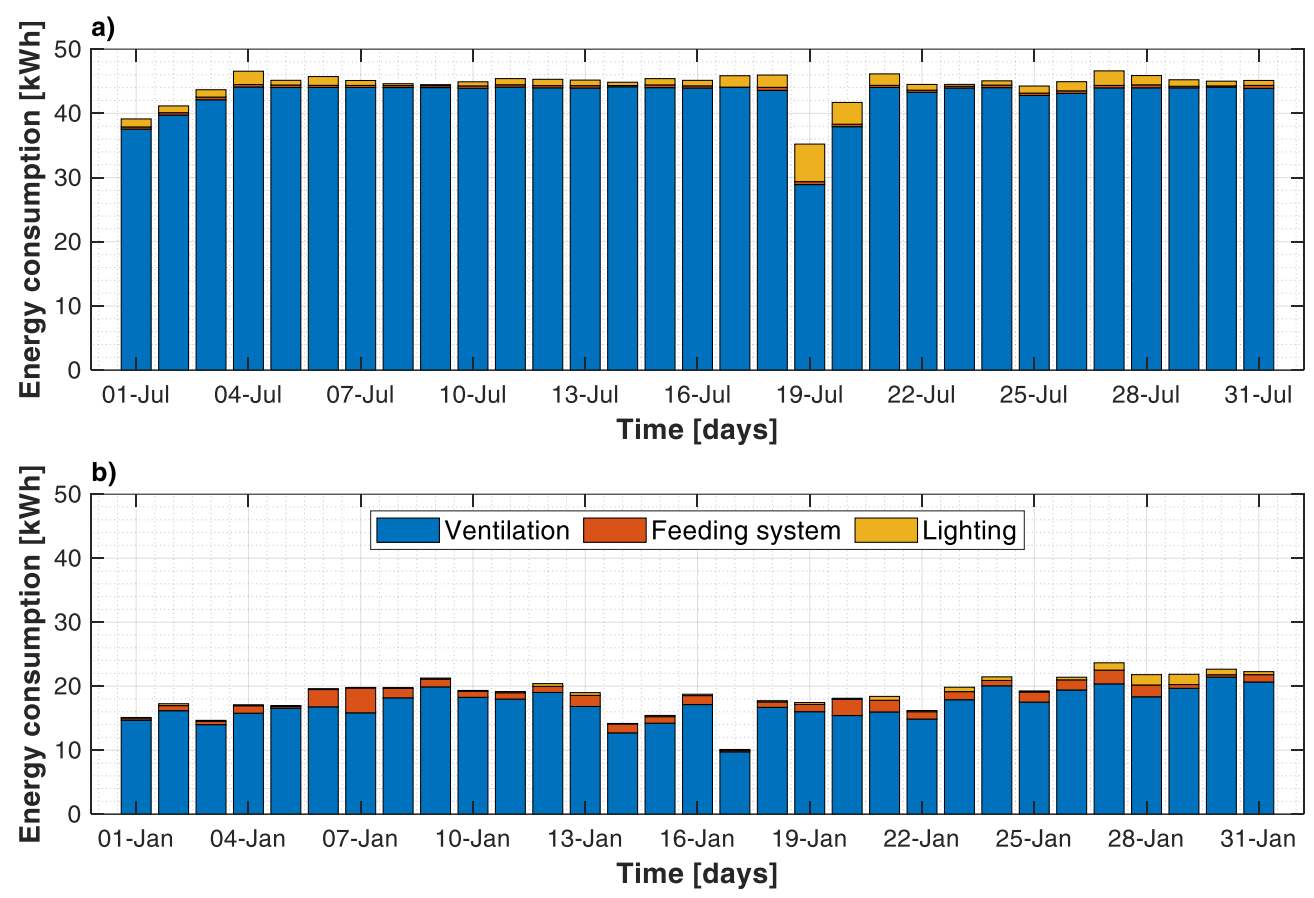

Figure 3.23 - Daily electrical energy consumption for pig house A during (a) warm season (July) and (b) cool season (January).

The analyzed months are also interesting to perform analysis about the effects that indoor climate conditions have on pig behavior. Figure 3.18 and Figure 3.19 highlighted that July was a very critical month for what it concerns heat stress. The consequence of the indoor climate conditions on animal behavior can be appreciated in Figure 3.24 where the relations between $\theta_{\text {air_i }}$ and feeding activity is presented. The $x$-axis of the chart represents the hour of the day, while the sum of the hourly electrical energy consumption due to the automatic feeding system is reported on the primary $y$-axis. The secondary $y$-axis reports the average hourly trend of $\theta_{\text {air_i }}$ during the analyzed month. From Figure 3.24, it is evident that, during July, almost all consumption connected to the feed distribution took place in the morning (between 07:00 and 11:00), when $\theta_{\text {air_i }}$ reaches its minimum, around $27^{\circ} \mathrm{C}$. During the rest of the day $\theta_{\text {air_i }}$ increases considerably up to $30^{\circ} \mathrm{C}$, a value that is not in the pig TNZ (as visible from the previous Figure 3.17). Consequently, pigs adopt physiological responses for decreasing their metabolism and the 
ingestion of feed, as demonstrated by the electrical energy consumption due to feed distribution that is almost null during the afternoon. The existence of a possible correlation between indoor air temperature and feeding behavior of pigs may be studied in future works through deepen statistical analyses.

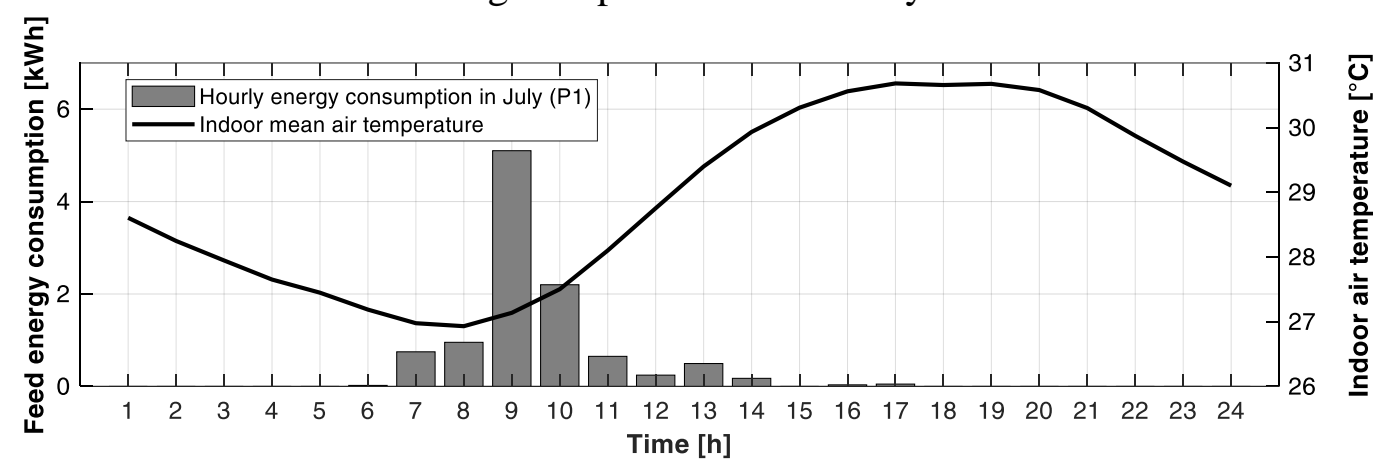

Figure 3.24 - Relation between electric consumption due to feed distribution and average hourly indoor air temperature during the months of July.

Finally, the load unbundle and identification algorithm can be extended to both the entire production cycles for estimating the total electrical energy consumption of pig house A. The results (reported in Figure 3.25) show that in both the considered periods, the greatest share of electrical energy consumption is for ventilation (in both the cases 89\%) but the absolute energy consumption is considerably different. $P 1$, in fact, is characterized by an electrical energy consumption for ventilation of around 2,232 kWh, while in $P 2$ it is 1,439 kWh. The importance of the electrical energy consumption for ventilation in pig house is further evident if it is considered that while $P 2$ was entirely monitored, the first three months of $P 1$ were not monitored for what it concerns the electrical power, as visible comparing Table 3.3 and Table 3.6. The results presented in Figure 3.25 show also that the energy consumption for feed distribution and lighting are an order of magnitude lower than the one for ventilation.

P1

(Warm season)

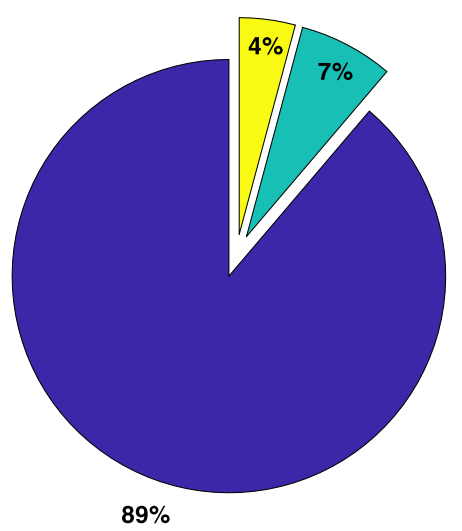

Ventilation $=2231.74 \mathrm{kWh}$

Feed distribution $=177.14 \mathrm{kWh}$

Lighting $=104.81 \mathrm{kWh}$
P2

(Cool season)

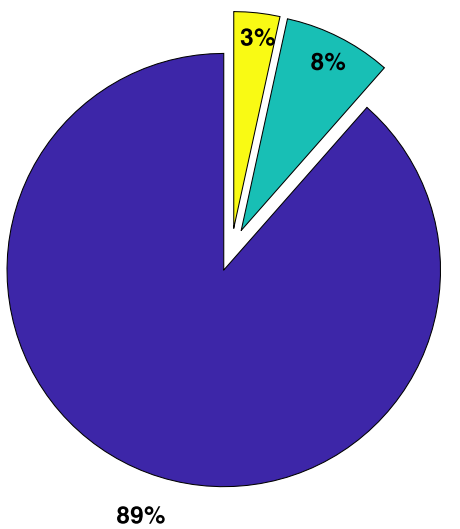

Ventilation $=1439.01 \mathrm{kWh}$

Feed distribution $=131.05 \mathrm{kWh}$

Lighting $=55.66 \mathrm{kWh}$

Figure 3.25 - Electrical energy consumption monitored during $P 1$ and $P 2$ in pig house A. 


\subsection{Final considerations}

The results provided by the analyses of the datasets acquired through the monitoring campaigns outlines the strong nexus that exist between the control of the indoor climate conditions and the energy consumption in greenhouses and livestock houses. The performed analyses highlighted that both the monitored agricultural buildings were characterized by high electrical energy consumption for ventilation which represented one of the main energy shares, especially in the pig house. Nevertheless, the analyses highlighted that a high energy consumption does not always guarantee the adequate indoor climate conditions, especially during the warm season. The glazed envelope of the monitored greenhouse, in fact, contributed to considerable gradients of indoor air temperatures across the building enclosure, favoring the presence of spots not adequate for plant growing. In a similar way, the high electrical energy consumption for ventilation in the monitored pig houses does not reflect in adequate indoor climate conditions. Excessive indoor air temperatures, in fact, were monitored during the warm season in both the pig houses, with a consequent increase of the heat stress risk for the farmed pigs. The provided picture shows that several improvements in climate-controlled agricultural buildings are needed, especially for what it concerns maintaining adequate indoor climate conditions and decreasing the energy performance for climate control. These improvements could be achieved through the adoption of new technologies, new strategies, and new solutions. Their implementation in greenhouses and livestock houses could be challenging and their effectiveness could be complex to be evaluated. For this purpose, a numerical approach is strongly needed with the aim of developing novel ad-hoc energy simulation frameworks for greenhouses and livestock houses, as it will be better described in the following chapters.

The performed monitoring campaigns were also interesting since they show the potentialities of data analysis in improving the production of climate-controlled agricultural buildings. The diffusion of low-cost monitoring technologies, in fact, may favor the installation of sensor networks in agricultural buildings, enhancing data analysis with several positive impacts. Future works, hence, may be focused on the development of new powerful algorithms based on artificial intelligence that could help farmers and other stakeholders in individuating potential inefficiencies in the production and in improving their decision-making process.

\subsection{Chapter nomenclature}

$\begin{array}{ll}\vec{a} & \text { Column vector of Boolean variables } \\ \overrightarrow{\vec{a}} & \text { Optimized vector of Boolean variables } \\ \mathrm{a}_{\mathrm{p}} & \text { Pig age [days] } \\ \mathrm{a}_{\mathrm{p} \_ \text {max }} & \text { Pig age when the maximum theoretical weight is achieved [days] } \\ e & \text { Euler's number [-] }\end{array}$




\begin{tabular}{|c|c|}
\hline$e_{\text {err }}$ & Total error of the electrical load measurement [kW] \\
\hline $\bar{e}_{\mathrm{err}}$ & Mean total error of the electrical load measurement $[\mathrm{kW}]$ \\
\hline$I_{\mathrm{hs}}$ & Apparent heat stress index $\left[{ }^{\circ} \mathrm{C} \mathrm{h}\right]$ \\
\hline$I_{\text {tot_hor }}$ & Total solar radiation on horizontal plane $\left[\mathrm{W} \mathrm{m}^{-2}\right]$ \\
\hline$j$ & Considered time step \\
\hline$I A Q$ & Indoor Air Quality \\
\hline$L_{\mathrm{el}}$ & Total monitored electrical load $[\mathrm{kW}]$ \\
\hline$\vec{l}$ & Vector of the partial electrical loads \\
\hline$l_{\mathrm{el}}$ & Partial electrical load [kW] \\
\hline$l_{\text {feed }}$ & Partial electrical load of feeding system [kW] \\
\hline$l_{\text {light_1 }}$ & Partial electrical load of the first lighting system [kW] \\
\hline$l_{\text {light_2 }}$ & Partial electrical load of the second lighting system [kW] \\
\hline$l_{\text {fan_1 }}$ & Partial electrical load of fans (velocity 1 ) [kW] \\
\hline$l_{\text {fan } \_2}$ & Partial electrical load of fans (velocity 2 ) [kW] \\
\hline$l_{\text {fan_3 }}$ & Partial electrical load of fans (velocity 3 ) [kW] \\
\hline$l_{\text {fan_4 }}$ & Partial electrical load of fans (velocity 4) [kW] \\
\hline$L A I$ & Leaf Area Index $\left[\mathrm{m}^{2} \mathrm{~m}^{-2}\right]$ \\
\hline$n_{1}$ & Cardinality of the set of partial electrical load \\
\hline$n_{\text {mea }}$ & Total number of considered measurement $[-]$ \\
\hline$n_{\text {step }}$ & Number of considered time steps \\
\hline$P 1$ & First pig production cycle (warm season) \\
\hline$P 1$ & Second pig production cycle (cool season) \\
\hline$R H_{\mathrm{i}}$ & Indoor air relative humidity [\%] \\
\hline$R H_{\text {i_max }}$ & Maximum indoor air relative humidity [\%] \\
\hline$R H_{\mathrm{o}}$ & Outdoor air relative humidity [\%] \\
\hline THI & Thermal-Humidity Index \\
\hline$T N Z$ & Thermoneutral zone \\
\hline$W_{\mathrm{p}}$ & Theoretical maximum pig live weight $[\mathrm{kg}]$ \\
\hline$w_{\mathrm{p}}$ & Pig body mass (live weight) $[\mathrm{kg}]$ \\
\hline$\Delta p_{\text {st }}$ & Static pressure difference between inside and outside $[\mathrm{Pa}]$ \\
\hline$\Delta \theta_{\text {air_i }}$ & Air temperature difference $\left[{ }^{\circ} \mathrm{C}\right]$ \\
\hline$\Delta \tau$ & Time step duration $[\mathrm{h}]$ \\
\hline$\delta_{\mathrm{p}}$ & Pig growing rate $\left[\mathrm{kg}^{-1}\right]$ \\
\hline$\theta_{\text {air_i }}$ & Indoor air temperature $\left[{ }^{\circ} \mathrm{C}\right]$ \\
\hline$\theta_{\text {air_o }}$ & Outdoor air temperature $\left[{ }^{\circ} \mathrm{C}\right]$ \\
\hline$\theta_{\mathrm{LCT}}$ & Lower Critical Temperature $\left[{ }^{\circ} \mathrm{C}\right]$ \\
\hline$\theta_{\text {set_C }}$ & Air set point temperature for cooling $\left[{ }^{\circ} \mathrm{C}\right]$ \\
\hline$\theta_{\text {set_H }}$ & Air set point temperature for heating $\left[{ }^{\circ} \mathrm{C}\right]$ \\
\hline$\theta_{\text {set_id }}$ & Ideal set point temperature $\left[{ }^{\circ} \mathrm{C}\right]$ \\
\hline$\theta_{\mathrm{UCT}}$ & Upper Critical Temperature $\left[{ }^{\circ} \mathrm{C}\right]$ \\
\hline$\pi_{\text {fan_1 }}$ & Boolean variable of the partial electrical load of fans (velocity 1) \\
\hline$\pi_{\text {fan_2 }}$ & Boolean variable of the partial electrical load of fans (velocity 2) \\
\hline
\end{tabular}


$\pi_{\text {fan_3 }} \quad$ Boolean variable of the partial electrical load of fans (velocity 3)

$\pi_{\text {fan_4 }}$

Boolean variable of the partial electrical load of fans (velocity 4)

$\pi_{\text {feed }}$

Boolean variable of the partial electrical load of feeding system

$\pi_{1}$

Boolean variable of the partial electrical load

$\pi_{\text {light_1 }}$

Boolean variable of the partial electrical load of the first lighting system

$\pi_{\text {light_2 }}$

Boolean variable of the partial electrical load of the second lighting system 


\section{Chapter 4}

\section{A new modelling framework for fully mechanically controlled greenhouses}

\begin{tabular}{|c|c|}
\hline Objective & $\begin{array}{l}\text { To investigate the nexus between climate control and energy consumption in } \\
\text { fully mechanically controlled greenhouses through a numerical approach. }\end{array}$ \\
\hline Outcome & $\begin{array}{l}\text { A dynamic energy simulation model for greenhouses that can estimate the } \\
\text { indoor climate conditions and the thermal and electrical energy consumption } \\
\text { for climate control. }\end{array}$ \\
\hline Highlights & $\begin{array}{l}\text { - A new model for estimating the energy consumption of greenhouses } \\
\text { is provided. } \\
\text { - A plant model is coupled to consider the crop effects on thermal and } \\
\text { mass balances. } \\
\text { - The proposed model enhances the simulation of variable angular speed } \\
\text { fans. } \\
\text { - Electrical energy consumption decreases by } 25 \% \text { using variable } \\
\text { angular speed fans. }\end{array}$ \\
\hline Notes & $\begin{array}{l}\text { Parts of this chapter have been published in: } \\
\text {-Costantino et al., "Energy performance and climate control in mechanically } \\
\text { ventilated greenhouses: A dynamic modelling-based assessment and investigation", } \\
\text { Applied Energy 2021, 288: } 116583 \text {. }\end{array}$ \\
\hline
\end{tabular}





\subsection{The need of a numerical approach}

As shown by the framework presented in section 2.2 and by the experimental activity presented in section 3.2, fully mechanically controlled greenhouses are characterized by considerably thermal and electrical energy consumption due to climate control. The reduction of this energy consumption of greenhouses can be identified as a key industry sustainable development goal [9] since it involves the three pillars of sustainability. The reduction of this energy consumption, in fact, would increase the environmental sustainability (lower use of resource), the financial sustainability (lower financial cost) and social sustainability (higher food security). For this reason, a great attention is being paid on producing greenhouse crops in an energy-efficient manner [19], reducing the use of fossil fuels [13], replacing them by renewable energy sources through the use, for example, of heat pumps [167], biomass [168] or anaerobic digestion [17].

Ad-hoc developed energy simulation models for greenhouses are needed to assess the effectiveness of energy-efficient solutions for greenhouse design and retrofit. The dynamic behavior of greenhouse indoor climate is a combination of physical processes involving energy and mass transfer and is strongly affected by several time-varying features, such as the outside weather conditions, the type and state of the cultivated crops, the adopted climate control system and its operation logic [169]. The development of these models is a complex task because a normative framework lacks at European level. The European Union standard EN13031-1 [170], in fact, provides only the rules for structural design and construction of greenhouses without giving any indications for the assessment of the greenhouse energy performance. In addition, ready to use building energy simulation tools such as TRNSYS and EnergyPlus are not suitable for simulating this building type since they do not adequately describe the physical processes of heat and mass transfer which occur in a greenhouse [171] and very complicated modifications are needed for this purpose [172]. For example, the effects of plant transpiration are omitted or excessively simplified connecting external models to the building energy simulation tool for simulating this phenomenon, but this solution does not make it possible to consider the plant-environment interaction. To fill this gap, several authors in literature developed customized energy simulation models with different purposes. Most of these models are simplified in some features -e.g. control, modelling of the thermal inertia and system operation- or, on the contrary, are very complex. Complex models require several iterations that weigh the calculation down preventing them to be used to perform simulations in several scenarios characterized by different greenhouse configurations, an issue that considerably limits the use of these models among stakeholders, that are mainly practitioners, farmers, and industry. In addition, most of the developed models enhance the improvement of the greenhouse energy performance optimizing the control strategy during the operational stage, while few of them improve the energy performance focusing on an energy-efficient selection of the envelope and equipment during the 
design stage. The energy design of greenhouse, in fact, is usually a sort of "preselected scheme" in which fundamental issues, such as the several possibilities that are provided by envelope and system technologies, are not considered in detail. Reliable energy simulation models can break that "pre-selected scheme" since they can evaluate the effectiveness of new technologies and of innovative solutions, providing to stakeholders a clearer idea of the typical energy performance -and running cost- of the considered greenhouse under typical conditions. Such simulation models, therefore, could significatively improve the energy design of new greenhouses and enhance the retrofit of old ones, increasing the energy saving and the crop production.

The objective of this chapter is to develop and validate a dynamic energy simulation model for assessing the indoor environmental conditions and the energy performance for climate control of fully-mechanically ventilated greenhouses. The present modelling framework is developed for being a decision support tool for stakeholders in the energy design and retrofit stages of greenhouses. The novelty of this work is to propose a reliable energy model able to simulate the greenhouse dynamics -e.g. thermal and hygric behavior of the building, dynamic response of the crops- and the consequent dynamic response of the climate control systems. A deep attention is paid in modelling the climate control and the climate equipment that is mainly adopted in fully-mechanically ventilated greenhouses, particularly to variable angle speed fans. This type of fans represents a new promising energyefficient technology for the greenhouses sector, but reliable energy simulation models that integrate them are not present in literature. The present model integrates them, representing a novelty in literature and a first step toward the improvement of the knowledge about their effectiveness and their sizing.

This chapter is organized as it follows. The dynamics that characterize the indoor environment of a greenhouse that should be considered during the development of an energy simulation model of such enclosures are described in section 4.2. In section 4.3, the developed energy simulation model is described together with the different calculation modules and the related equations. In section 4.4, the reliability of the presented model is proved through a validation against a real dataset. In section 4.5, the potentialities of the presented energy simulation model are highlighted through a numerical example comparing the indoor environmental conditions and energy performance of similar greenhouses in different climate conditions. The final considerations are presented in section 4.6.

\subsection{Overview on greenhouse modelling issues}

The energy modelling of greenhouses is challenging since this type of climatecontrolled agricultural building is characterized by peculiar features that are uncommon in other building types, such as the dimension of the enclosure, a total glazed envelope that entails high solar heat gains and high transmission heat losses. Furthermore, greenhouses are densely populated by plants which react in a specific 
way mainly to indoor air temperature $\left(\theta_{\text {air_i }_{-}}\right)$, relative humidity $\left(R H_{\mathrm{i}}\right), \mathrm{CO}_{2}$ concentration $\left(\left\langle C_{\mathrm{CO}_{2} \mathrm{i}}\right\rangle\right)$, and solar radiation entering in the greenhouse $\left(\phi_{\text {sol_i }}\right)$ [9].

A fundamental interaction between plants and the greenhouse environment is plant transpiration, a process that converts between $30 \%$ and $50 \%$ of the incoming solar radiation into latent heat. The driver of the transpiration is the Vapor Pressure Deficit $(V P D)$, with the "deficit" that is defined as the difference between the vapor pressure in the air and the saturated vapor pressure value. The smaller the difference, the more moisture-laden the air will be. The larger the difference, the drier the air will be. The use of $V P D$ is widespread in the greenhouse production since this parameter is independent from $\theta_{\text {air_i }}$ and $R H_{\mathrm{i}}$ [173]. Crop foliage surface deeply affects the transpiration rate and its extension is evaluated through the Leaf Area Index ( $L A I)$, defined as leaf area per unit of greenhouse surface [174].

Active climate control systems enhance a precise control of the indoor climate conditions of the greenhouse. These systems provide supplemental heat through equipment such as gas air heaters or boilers. In this way, $\theta_{\text {air_i }}$ can be maintained over the minimum indoor air temperature $\left(\theta_{\text {set_H }}\right)$. On the contrary, mechanical cooling ventilation is activated when $\theta_{\text {air_i }}$ has to be maintained below a maximum indoor air temperature $\left(\theta_{\text {set_c }}\right)$. Cooling ventilation is supplied by a set of box or cone extraction fans that provide a bay-flow or a cross-bay flow using outdoor fresh air maintaining the air speed below $0.75 \mathrm{~m} \mathrm{~s}^{-1}$ to avoid negative effects on $\mathrm{CO}_{2}$ uptake of plants due to high air velocities [175]. Another strategy to decrease $\theta_{\text {air_i }}$ is the reduction of the solar radiation that enters inside the greenhouse $\left(\phi_{\text {sol_i }}\right)$. In greenhouses, $\phi_{\text {sol_i }}$ is maximized during the cool season for enhancing plant photosynthesis and reducing the supplemental heating need, but it must be controlled during the warm season to avoid the overheating of the enclosure. For this purpose, reflective-diffusive screen systems, mixed glass-photovoltaic panels [176] or external films of calcium carbonate are adopted [177]. When cooling ventilation and solar radiation reduction through shading screens are not enough to maintain $\theta_{\text {air_i }}$ below $\theta_{\text {set_c }}$, evaporative cooling is adopted.

$R H_{\mathrm{i}}$ is another parameter that is carefully controlled inside greenhouses. $R H_{\mathrm{i}}$ is maintained above $50 \%$ since lower $R H_{\mathrm{i}}$ values would increase the plant evaporation losses beyond its capacity of replacing the water lost, resulting in wilting, and burning of growing tips. Values of $R H_{\mathrm{i}}$ higher than $80 \%-90 \%$ should be avoided since they would favour the proliferation of fungal pathogenic organisms [175]. $R H_{\mathrm{i}}$ is controlled through extraction fans that are used to provide an airflow of fresh outdoor air which enters through a set of upper gable shutters automatically opened and closed to maintain a constant value of static pressure between inside and outside the greenhouse $\left(\Delta p_{\text {st }}\right)$. In some situations, outdoor air can be characterized by a higher value of humidity ratio than indoor air. In these situations, ventilation cannot be used to decrease $R H_{\mathrm{i}}$ since the introduction of outdoor air in the enclosure would further increase $R H_{\mathrm{i}}$. The only solutions to decrease $R H_{\mathrm{i}}$, hence, is the activation of the heating system: the increase of $\theta_{\text {air_i }}$ causes a consequent decrease of $R H_{\mathrm{i}}$ since 
the humidity ratio of indoor air remains constant in this psychrometric transformation.

The indoor $\mathrm{CO}_{2}$ concentration $\left(\left\langle C_{\mathrm{CO}_{2} \mathrm{i}}\right\rangle\right)$ is also controlled in greenhouses to avoid $\mathrm{CO}_{2}$ compensation point of plants. This condition occurs when the amount of $\mathrm{CO}_{2}$ absorbed by photosynthesis is the same released by plant respiration, with detrimental consequences for plant growth [178]. In greenhouses, $\left\langle C_{\mathrm{CO}_{2-} \mathrm{i}}\right\rangle$ is maintained at adequate levels through ventilation with the exception of cold days in which $\mathrm{CO}_{2}$ enrichment -a direct injection of $\mathrm{CO}_{2}$ inside the enclosure- is preferred [179]. $\mathrm{CO}_{2}$ enrichment is also performed to enhance plant growth over a normal level [179].

\subsection{Model structure}

\subsubsection{Literature background on existing greenhouse models}

As just shown, the dynamics inside a greenhouse are several and complex. The climate control systems that are adopted in greenhouses to control the indoor environmental conditions are different not only from the ones of other building types, but several differences can be found also between the ones of different types of greenhouses. For these reasons, standardized calculation models for the estimation of the overall energy consumption for climate control in greenhouses do not exist. On the contrary, various customized energy simulations models for this purpose have been developed, as described by the history of greenhouse model development presented in [180]. Analyzing the recent scientific literature and the main reviews on this topic $[9,181]$, different models developed for different and specific purposes can be found. Van Beveren et al. [182,183] developed a dynamic energy simulation model for optimizing the energy inputs of greenhouses working on the indoor environmental conditions. Lin et al. [184] applied the energy model developed by Van Beveren et al. [182,183] for improving the energy efficiency and the operating costs of Venlo-type greenhouses in South Africa, analyzing different control strategies. Chen et al. [185] developed a model for estimating the energy consumption of greenhouses through a model-optimized prediction methodology in which the uncertain parameters of a physical model of the greenhouse were calibrated using optimization algorithms. Altes-Buch et al. [186] developed an open-source model in Modelica for simulating greenhouse climate and its complex interactions with thermal systems (e.g. CHP and heat pumps). Ahamed et al. [172] modelled the dynamic requirements of a solar greenhouse using TRNSYS and highlighted that this simulation tool is not suitable for simulating the greenhouse thermal environment since very complicated modifications are needed for this purpose. Similarly, Vadiee and Martin [13] developed an energy simulation model in TRNSYS to improve the overall energy performance of Swedish greenhouses. Taki et al. [142] developed a dynamic simulation model to estimate the indoor air temperature in six spots of the greenhouse with the aim of analyzing the effects of 
thermal screen on the greenhouse energy consumption and on the indoor environmental conditions. Mobtaker et al. [143] developed a dynamic energy simulation model to predict the main greenhouse indoor temperature (e.g. air, soil and walls) with the aim of analyzing the thermal energy losses and solar heat gains of different greenhouses shapes. A model for a similar purpose (the estimation of the main indoor temperatures of greenhouses) was developed by Joudi and Farhan [144]. Also the dynamic energy model of Reyes-Rosas et al. [187] was developed for a similar purpose (the estimation of greenhouse indoor air, soil and cover temperatures), but it was tailored for naturally ventilated greenhouses. Zhang et al. [145] developed a dynamic energy model in MATLAB $^{\circledR}$ environment that incorporates the dynamic absorbance and transmittance values of the greenhouse cover. Golzar et al. [181] proposed a coupled model to assess the greenhouse energy demand and crop yield for analyzing the potential of renewable energy use and the effects of different indoor environmental conditions on the crop yield with a high temporal resolution. The work of Ward et al. [171] is different from the other ones since it adopts the energy simulation model developed by Brown et al. [188] to analyze the retrofit opportunities for historic ornamental greenhouses (also known as "glasshouses") in United Kingdom. Recently, greenhouse energy models have been coupled with building energy model with the aim of exploring the potentiality of Urban-Integrated Agriculture. For example, Jans-Singhet al. [189] co-simulated a rooftop greenhouse integrated on the top of a school building. The co-simulation was performed through EnergyPlus (school building simulation) and a MATLAB ${ }^{\circledR}$ model (greenhouse simulation). A similar analysis was carried out through WUFI commercial software by Gholami et al. [190]. These studies are of a foremost importance since they improve the integration of greenhouses in human buildings making it possible fine-tuning the exploitation of building waste streams (e.g. $\mathrm{CO}_{2}$ and exhausted warm air) as input of the greenhouse and, contemporarily, to evaluate the extent to which greenhouses can contribute to decrease the building cooling and heating energy demand.

This literature analysis shows that different types of greenhouse energy simulation models are present in literature. Some models are mainly focused on estimating indoor temperatures (e.g. air and soil temperatures) while others aim at decreasing the energy consumption of greenhouses but, in many cases, they were tailored for a specific greenhouse. In addition, those models are frequently developed to be used during the operative stage of the greenhouses since they aim at optimizing the climate control strategies once selected a given envelope and climate control system. On the contrary, the energy simulation model that is presented in this chapter aims at improving the energy performance of the greenhouses through an energy conscious design and/or retrofit, enhancing the comparison between a wide range of configurations of envelope and systems of the considered greenhouse.

As just presented, several greenhouse energy simulation models developed for different purposes are present in literature. Despite the differences, all the energy 
simulation models for greenhouses (and more in general for climate-controlled agricultural buildings) can be grouped in three different categories, as reported in [9]: first-principle, data-driven and hybrid energy models, as schematized in Figure 4.1. First-principle energy models (also known as white-box models) relies on a mathematical set of physical and empirical equations that describe the thermal behavior of the greenhouse. The development of a first-principle energy model depends on a deep knowledge of the system physics and of the properties of both envelope and HVAC system. A negative aspect of first-principle energy models is that a great effort is required in the calibration stage. Instead, data-driven energy models (also known as black-box models) avoid these problems since they are based on large datasets of real measured data that are used to formulate a prediction using algorithms (such as Bayesian network [191] or machine learning [192]) to seek relations between input and output data. Data-driven energy models can simulate with a good accuracy the thermal behavior of an existing building, but they are unsuitable for the design stage since measured data are not available and since it is complex to obtain generalized results that does not refer to an existing specific case study. Hybrid energy models (also known as grey-box models) [51,158] are a compromise between the previously presented models (white-box models) since they rely on both physical equations and real datasets. The adoption of hybrid energy models represents an interesting choice when the knowledge of the problem physics is incomplete or there is a lack of data. Since the objective of this work is to develop an energy simulation model with a detailed modelling of HVAC system (especially for implementing the new variable angular speed fans into the model) to be used to obtain generalized results also for design purposes, data-driven and hybrid energy models are not considered the best solutions for the present work and first-principle energy models are preferred.

First-principle energy models (within which the presented model falls) can be divided in two subgroups: steady-state and dynamic energy models, as visible in the schematization of Figure 4.1. The steady-state models, in turn, can be further classified in:

- fully-steady-state models;

- quasi-steady-state models.

Fully-steady-state models adopt a very large time-step (up to one month) and consider only the steady-state part of the energy balance equation, neglecting any transient term, such as the energy storage in the building thermal mass. Jolliet et al. [193] developed a steady-state model to study the thermal energy balance of greenhouses, that represented an intermediate solutions between very simple models of low precision and precise (but time consumptive) dynamic models. Singh and Tiwari [194] performed steady-state analyses to determine the best shape of the greenhouses to maintain the adequate indoor air temperature and to minimize the energy consumption. Campiotti et al. [195] developed a fully-steady-state model for greenhouses for calculating the reduction of the energy consumption in the framework of Italian legislation. 
The complexity of steady-state models increases in quasi-steady-state models [196] since an adjusting parameter is introduced to consider the heat storage phenomenon.

Dynamic energy models are more complex to implement, are characterized by short time-steps (one hour or less) and provide more reliable results. They can be classified in:

- dynamic energy models with one lumped temperature;

- dynamic energy models with more than one lumped temperature;

- detailed dynamic simulation models.

Dynamic energy models with lumped temperatures (one or more) are usually customized models implemented in different codes to solve a set of energy balance equations [144]. In this type of energy model, HVAC system is usually not modelled in detail due to its complexity [9]. To enhance the simulation of HVAC systems, detailed dynamic simulations performed in Building Energy Simulation tools (BES), such as EnergyPlus and TRNSYS, are preferred. Chen et al. [197] developed a numerical model in EnergyPlus to study the thermal performance of a passive solar greenhouse. Rasheed et al. [198] developed a dynamic energy simulation model of a greenhouse to study the effect of screens (characterized by different materials and control strategies) on the thermal energy requirements of greenhouses. Bambara and Athienitis [199] developed a dynamic energy model of a greenhouse in TRNSYS to identify the most cost-effective cladding design for a specific greenhouse. BES tools enable accurate simulation of the most common types of HVAC systems, but they are not suitable for simulating the greenhouse environment and the new technologies and HVAC systems typical of greenhouses since they were developed for "civil" buildings and since their level of customizability is low [172,200]. Furthermore, BES tools do not account for peculiar phenomena that usually take place inside greenhouses and strongly influence the energy balance, such as plant transpiration and plant growth. To consider the effects of these phenomena, models that simulate them are integrated into the energy model, originating the so-called coupled energy models $[9,196]$.

In this framework, the energy model presented in this thesis can be classified as a first-principle coupled dynamic energy simulation model, as shown by the red dotted contour present in Figure 4.1. This classification depends on the fact that the core of the developed model is a set of physical equations that are used for solving a dynamic energy balance characterized by one lumped temperature $\left(\theta_{\text {air_i }}\right)$. The presented model is also considered coupled since integrates a plant transpiration model for correctly setting the moisture balance and estimating the reduction of the solar radiation heat gain. Furthermore, in the present model the HVAC system is modelled in detail considering the presence of several equipment, with a particular focus on variable angular speed fans, a new energy-efficient technology that is spreading in greenhouses. The modelling of this technology is a novelty in literature. 


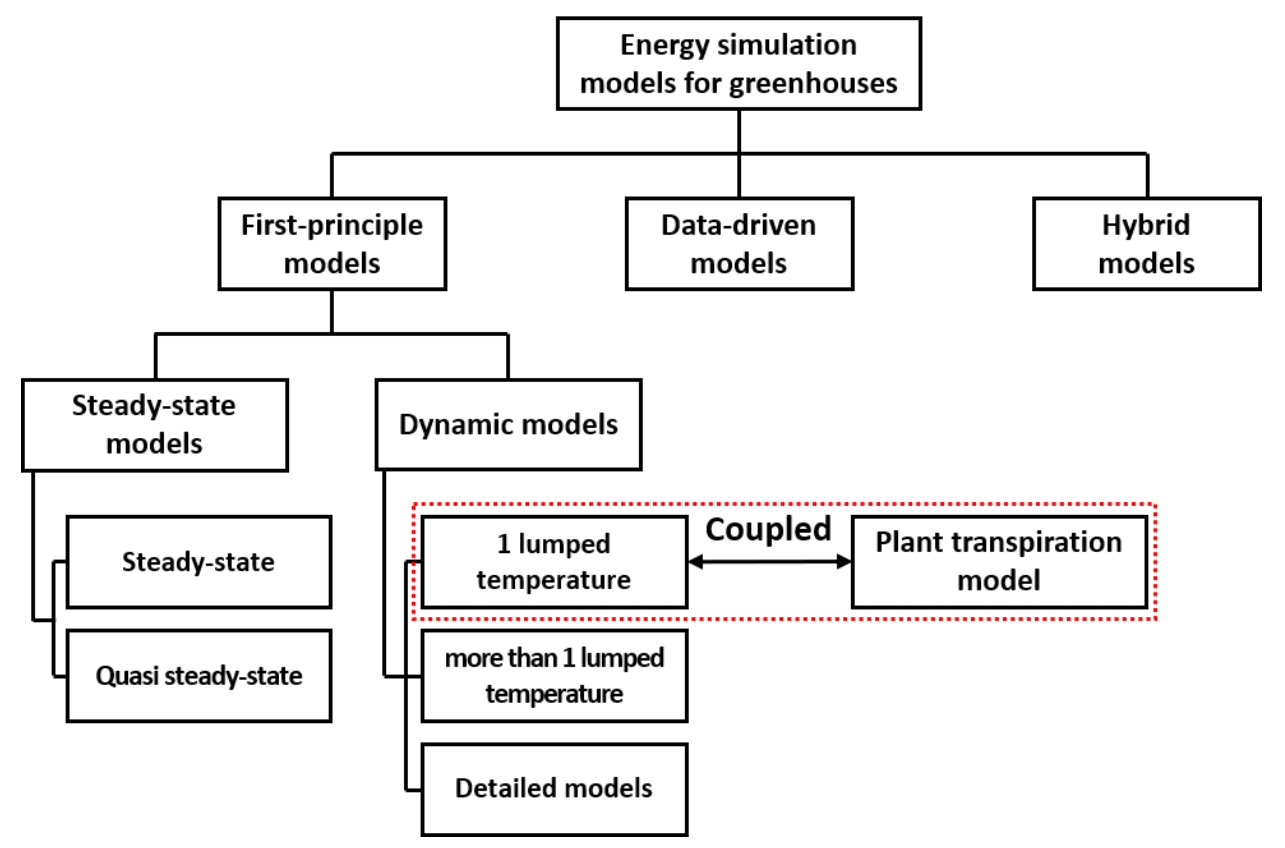

Figure 4.1 - Classification (red dotted contour) of the energy simulation model presented in this work according to the existing literature.

\subsubsection{Model workflow}

The presented energy simulation model was developed in a spreadsheet environment and it is made by nine calculation modules that were developed for modelling all the relevant greenhouse subsystems and the plant transpiration. The developed calculation modules are the following:

- Preliminary calculation module

- Solar radiation module

- Plant transpiration module

- Thermal balance module

- Moisture balance module

- Heating system module

- Cooling pad efficiency module

- Dehumidification ventilation systems module

- Cooling ventilation system module

The previously presented modules are organized as shown in Figure 4.2, where the entire workflow of the developed simulation model is presented. Preliminary stage of the simulation is the user input of constant parameter (block "Input data" in the workflow of Figure 4.2), such as the thermo-physical and optical properties of the envelope, the geographical location of the greenhouse and the climate control features (e.g. air set point temperatures and fan models). Some details about the crop type, such as the $L A I$, are also requested in this phase. In the following stage, the model starts with the "Preliminary calculations module" to determine all the variables that are needed for the subsequent steps, such as the heat transfer coefficients and the total building fabric heat capacity. After the preliminary 
calculations, a calculation loop (represented in Figure 4.2 by a dotted contour) is repeated for each time-step of the simulation. Each loop begins with the calculations of the "Solar radiation module" aimed at determining the hourly solar angles to estimate the total solar radiation reaching the crops. This value is an input of the "Plant transpiration module" that estimates the rate of water vapor released by the crops and the reduction of sensible heat from solar radiation due to crop transpiration. Using these values, the sensible energy balance is solved ("Thermal balance module") for providing the inputs for the estimation of $R H_{\mathrm{i}}$ ("Moisture balance module"). If $R H_{\mathrm{i}}$ exceeds the maximum limit value $\left(R H_{\mathrm{i} \_ \text {max }}\right)$, the model calculates the needed dehumidification ventilation flow rate $\left(\dot{V}_{\text {deh }}\right.$, in "Dehumidification ventilation system module") and then the electrical energy consumption for dehumidification. The obtained $\dot{V}_{\text {deh }}$ is used to update the thermal and moisture balances. If $R H_{\mathrm{i}}$ is below the limit, the model evaluates if $\theta_{\text {air_i }}$ is

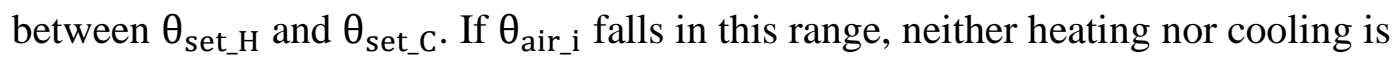
needed and $\theta_{\text {air_i }}$ is in free-floating conditions. If $\theta_{\text {air_i } i}$ falls out of the range and heating is needed $\left(\theta_{\text {air_i }_{-}}<\theta_{\text {set_H }_{-}}\right)$, the model updates the thermal balance, calculates the theoretical thermal energy need ("Heating system module") and the actual thermal energy consumption (considering the heating system efficiency). If cooling is needed $\left(\theta_{\text {air_i }}>\theta_{\text {set_c }}\right)$, the model updates the thermal balance calculating the cooling load that has to be provided to the greenhouses to reach $\theta_{\text {set_c }}$. This estimated cooling load is only theoretical since the model considers that no mechanical cooling system is present in the simulated greenhouse and $\theta_{\text {air_i }}$ is decreased using cooling ventilation. For this reason, the obtained theoretical cooling load is converted in a ventilation air flow rate ("Cooling ventilation system module") considering also the activation of evaporative pads ("Cooling pad efficiency module"). After this stage, the actual electrical energy consumption is calculated, and the current iteration of the loop calculation ends. The loop, starting from the "Solar radiation module", is thus repeated for the following hourly step. In the meanwhile, the thermal and electrical energy consumption calculated at each time-step are integrated along the simulation time period, to obtain the yearly thermal and electrical energy consumption. Hourly time profiles of $\theta_{a_{-} i_{-} i}$ and $R H_{\mathrm{i}}$ are additional valuable outputs of the model. 


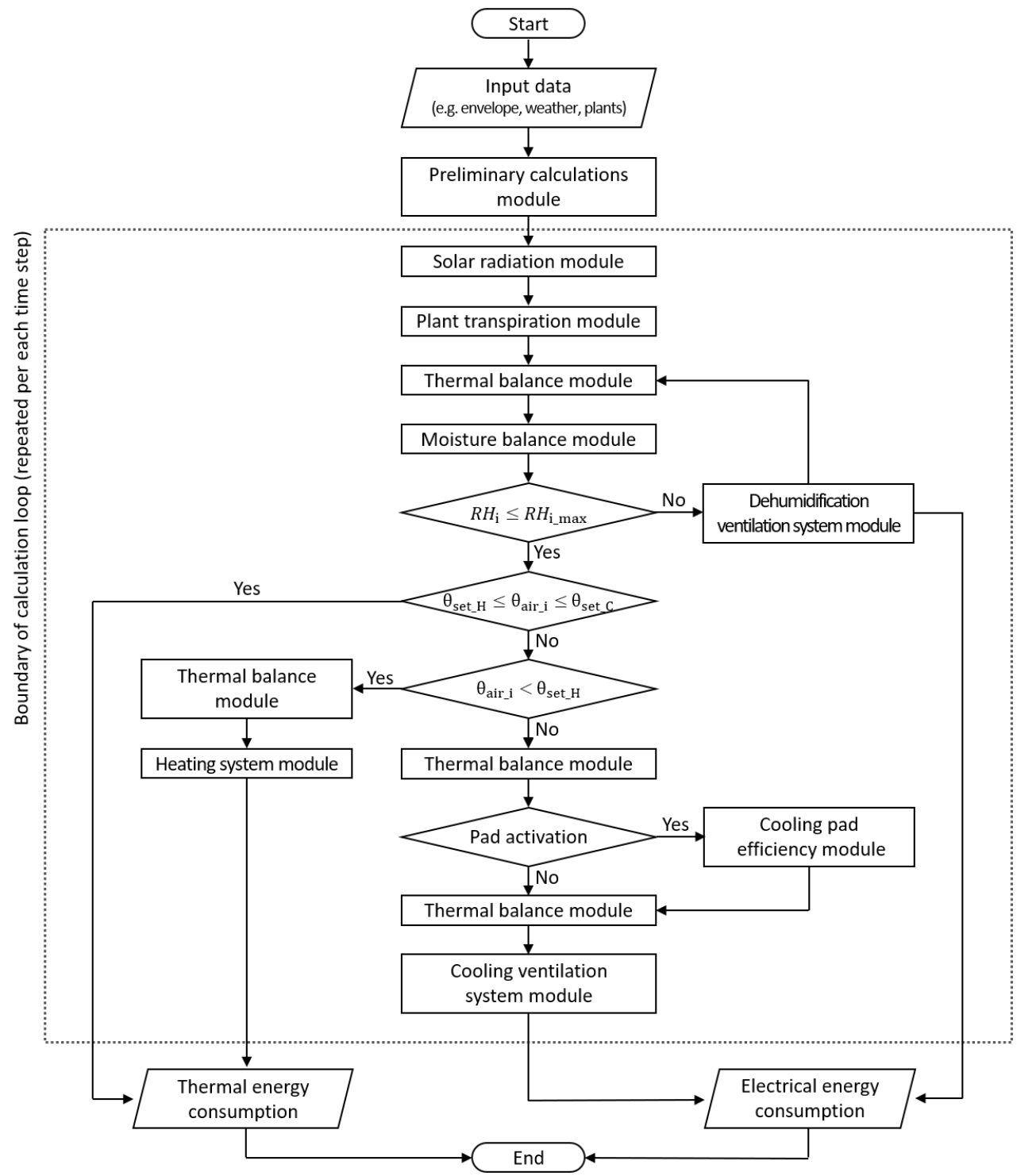

LEGEND

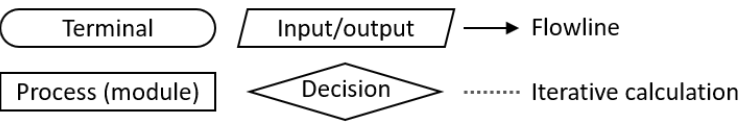

Figure 4.2 - Model workflow through the calculation modules. The dotted contour represents the calculation loop that is repeated for each time-step of the simulation.

\subsubsection{Calculation modules}

\section{Preliminary calculation module}

In the preliminary calculation module, all the variables needed for the following calculations are calculated starting from the input data. Among the most important variables that are calculated in this module, the heat transfer coefficients needed to solve the thermal balance can be mentioned. 


\section{Solar radiation module}

This module estimates the actual solar radiation $\phi_{\text {sol_i }}$ that enters inside the greenhouse and can reach the crop canopies. The timely solar position in the sky is calculated (using the solar equations of [201]) with the aim of considering in the model the effect of the optical properties of the glazed envelope as a function of the angle of incidence of solar radiation on the glazed surface. Furthermore, in this way, the effect of possible solar screens can be properly modelled, considering that they can be opened or closed depending on the solar radiation intensity. At time-step $j$, the total solar radiation that enters in the greenhouse $\phi_{\text {sol_i,j }}$ is calculated as

$$
\begin{gathered}
\phi_{\mathrm{sol} \_\mathrm{i}, \mathrm{j}}=\sum_{k=1}^{n_{\text {sur }}}\left\{A _ { \mathrm { gl } l \mathrm { k } } \cdot g _ { \mathrm { sc } , \mathrm { j } } \cdot \left[\phi_{\mathrm{sol} \_\mathrm{b}, \mathrm{j}} \cdot R_{\mathrm{b}, \mathrm{k}}\left(\mu_{\mathrm{j}}\right) \cdot\right.\right. \\
\left.\left.\operatorname{SHGC}_{\mathrm{k}}\left(\mu_{\mathrm{j}}\right)+\phi_{\mathrm{sol} \_\mathrm{d}, \mathrm{j}} \cdot F_{\mathrm{v}, \mathrm{k}}\left(\mu_{\mathrm{j}}\right) \cdot \operatorname{SHGC} C_{\mathrm{k}}\left(\mu_{\mathrm{j}}\right)\right]\right\} \quad[\mathrm{W}]
\end{gathered}
$$

where $A_{\mathrm{gl}, \mathrm{k}}$ is the generic $k$-th surface of the glazed envelope exposed to the solar radiation, $n_{\text {sur }}$ is the total number of these surfaces, $g_{\mathrm{sc}, \mathrm{j}}$ is the total solar transmission coefficient of the screen (dimensionless) at the $j$-th time-step (the screen can be opened or closed), while $\phi_{\text {sol }_{b}, j}$ and $\phi_{\text {sol_d,j }}$ are the beam and diffuse solar radiation on the horizontal external plane $\left(\mathrm{W} \mathrm{m}^{-2}\right)$, respectively, at the considered time-step. The tipping coefficient $R_{\mathrm{b}, \mathrm{k}}$ (dimensionless) identifies the rate between the solar radiation hitting a generically oriented surface $k$ and the solar radiation on a horizontal plane. The term $F_{\mathrm{v}, \mathrm{k}}$ is the view factor (dimensionless) between a generically oriented surface $k$ of the envelope and the sky. The term $S H G C_{\mathrm{k}}$ (dimensionless) is the Solar Heat Gain Coefficient that estimates the total thermal solar radiation that crosses the glazed surface $k$. In Eq. (14), the terms $R_{\mathrm{b}, \mathrm{k}}$, $F_{\mathrm{v}, \mathrm{k}}$ and $S H G C_{\mathrm{k}}$ are expressed as function of $\mu_{\mathrm{j}}$, that represents the angle between the direction of the beam solar radiation and the normal to the glazed surface calculated at the $j$-th time-step.

\section{Plant transpiration module}

This calculation module aims at estimating the amount of water vapor that is transpired by the cultivated crops. This is a crucial aspect to be considered when a greenhouse is analyzed from the thermal and hygrometric point of view since plant transpiration considerably affects the greenhouse thermal and moisture balances.

Plant transpiration is a complex phenomenon that is related to several parameters, such as the stomatal resistance [202]. In literature, several plant transpiration models were proposed, such as the Stanghellini's one [203], the "big leaf" model of Penman-Monteith [204,205], models based on new algorithms (such as the random forest regression one [206]) or models that estimates the effects of transpiration starting from the outdoor conditions [207]. Even though several models to predict transpiration of greenhouse crops are present in literature, it is still not clear which model is more appropriate [208]. Among them, the Stanghellini's model [203] is one of the most established and widely used. In the presented model, the latent heat released by the crop due to transpiration is 
calculated through a rearrangement of the diffusion equation. The resistances to diffusion were modelled as a function of the indoor environmental conditions inside the greenhouse, described by the already cited quantities $\phi_{\text {sol_i }_{1},}, \theta_{\text {air_i }_{i}},\left\langle C_{\mathrm{CO}_{2} \mathrm{i}}\right\rangle$ and $V P D$. Stanghellini's model has been proven to be highly accurate, but it requires to solve a convergence problem that involves complex computation and numerous inputs, requiring a considerable computing time. For this reason, the simplified model by Jolliet [209] was implemented in the presented energy simulation model, being an effective trade-off between affordable computing time and accuracy of results. This latter transpiration model was obtained by linearizing the Stanghellini's one according to the method proposed in [210] that consists in a nonlinear regression on the results obtained with the Stanghellini's model and a set of 168 different boundary conditions obtained varying $\phi_{\text {sol_i }}, V P D$ and $L A I$. The results of this linearization of Stanghellini's model show that transpiration can be approximated with a good accuracy through Eq. (15). At each analyzed time-step $j$, the plant transpiration water vapor flow $\left(\dot{m}_{\mathrm{vap}}\right)$ per unit of cultivated area is calculated as

$$
\dot{m}_{\mathrm{vap}, \mathrm{j}}=\frac{\delta}{\lambda} \cdot \frac{\phi_{\mathrm{sol} \_\mathrm{i}, \mathrm{j}}}{A_{\mathrm{gh}}}+\frac{h_{\mathrm{t}, \mathrm{j}}}{\lambda \cdot \sigma} \cdot V P D_{\mathrm{j}} \quad\left[\frac{\mathrm{mg}_{\mathrm{vap}}}{\mathrm{m}^{2} \mathrm{~s}}\right]
$$

where $\lambda$ is the latent heat of vaporisation of water $\left(2.5 \mathrm{MJ} \mathrm{kg}^{-1}\right.$ at $\left.20^{\circ} \mathrm{C}\right), \sigma$ is a psychrometric constant $\left(66 \mathrm{~Pa} \mathrm{~K}^{-1}\right)$ and $V P D$ is calculated as

$$
V P D_{\mathrm{j}}=p_{\mathrm{vs}, \mathrm{j}}-p_{\mathrm{v}, \mathrm{j}} \quad[\mathrm{Pa}]
$$

where $p_{\mathrm{vs}, \mathrm{j}}$ is the saturation water vapour pressure and $p_{\mathrm{v}, \mathrm{j}}$ is the water vapour pressure at time-step $j$, both expressed in Pa. The term $A_{\text {gh }}$ is the greenhouse floor area (input data) expressed in $\mathrm{m}^{2}$. The term $\delta$ is a dimensionless coefficient that characterises the influence of $\phi_{\text {sol_i }}$ on transpiration, while $h_{\mathrm{t}, \mathrm{j}}$ is the sensible heat transfer coefficient due to transpiration. These coefficients are calculated as

$$
\delta=z_{1} \cdot \ln \left(1+z_{2} \cdot L A I_{\mathrm{j}}^{z_{3}}\right) \quad[-]
$$

and

$$
h_{\mathrm{t}, \mathrm{j}}=z_{4} \cdot L A I_{\mathrm{j}} \cdot\left(1-z_{5} \cdot e^{\left(-\frac{\phi_{\mathrm{sol}} \mathrm{i}, \mathrm{j}}{z_{6}}\right)}\right) \quad\left[\frac{\mathrm{W}}{\mathrm{m}^{2} \mathrm{~K}}\right]
$$

where $z_{1}-z_{6}$ are the regression coefficients reported in Table A.1. The term $L A I_{\mathrm{j}}$ represents the $L A I$ of the crops present inside the greenhouse at the $j$-th time step of the simulation. The presented energy model, in fact, simulates the plant growth linearly varying the $L A I$ during the crop production cycle.

In Figure 4.3, an example of calculation of $\dot{m}_{\text {vap }}$ according to Eq. (15) was performed considering $L A I$ equal to $3 \mathrm{~m}^{2} \mathrm{~m}^{-2}$ and four different values of $V P D$. 
The results show that in presence of high $\phi_{\text {sol_i }}\left(\right.$ above $100 \mathrm{~W} \mathrm{~m}^{-2}$ ), $\dot{m}_{\text {vap }}$ is affected mainly by $V P D$, while in presence of low $\phi_{\text {sol_i }}, \dot{m}_{\text {vap }}$ is mostly affected by the same solar radiation.

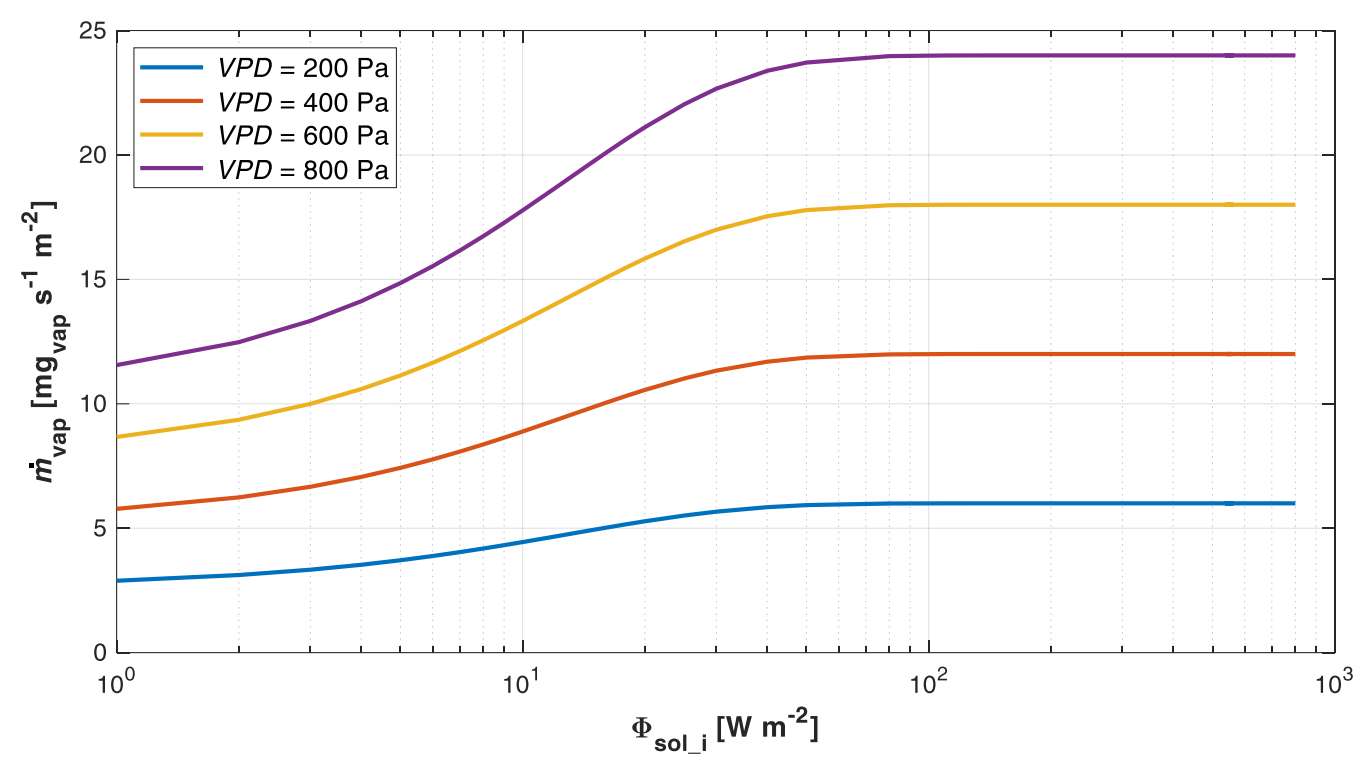

Figure 4.3 - Evapotranspiration rates $\left(\dot{m}_{\text {vap }}\right)$ calculated as a function of the solar radiation on the canopies $\left(\phi_{\text {sol_i }}\right)$ and the water Vapour Pressure Deficit $(V P D)$ according to Eq. (15) ( $x$-axis is in logarithmic scale).

The term $\dot{m}_{\mathrm{vap}, \mathrm{j}}$ estimates the amount of water vapor that the plants transpire to the surrounding air per unit of cultivated floor area at the $j$-th time step. Knowing $\dot{m}_{\text {vap,j }}$, the equivalent latent heat load $\left(\phi_{\text {lat }_{i}, \mathrm{j},}\right)$ can be estimated as

$$
\phi_{\text {lat } \_, j}=\frac{A_{\text {gh }} \cdot \dot{m}_{\mathrm{vap}, \mathrm{j}} \cdot \lambda}{10^{3}} \quad[\mathrm{~W}]
$$

The plant transpiration converts a share of the solar radiation (sensible heat) that has entered the greenhouse $\left(\phi_{\text {sol_i } i, j}\right)$ in latent heat. The remaining solar sensible heat gain $\left(\phi_{\text {sens_i,j }}\right)$ can be calculated at each time-step $j$ as

$$
\phi_{\text {sens_i,j }_{-}}=\phi_{\text {sol_i,j }}-\phi_{\text {lat_ } \_, j_{j}}[\mathrm{~W}]
$$

The calculated values of $\phi_{\text {sens_i,j }}$ and $\dot{m}_{\text {vap }}$ are inputs data for the thermal and the moisture balance solution modules, respectively.

\section{Thermal balance module}

The thermal balance module represents the core of the energy model and it is used at each simulation stage in which $\theta_{\text {air_i }}$ has to be estimated. The thermal balance integrated in this simulation model is a customization of the simple hourly method (SH) of ISO 13790 standard [211]. The method consists in the thermalelectrical analogy between the analyzed building and a resistance-capacitance ( $\mathrm{R}-$ C) electrical network characterised by five resistances and one capacitance (5R1C), 
as shown in Figure 4.4. In the thermal analogy, the resistances represent the heat transfer resistances, and the capacitor represents the entire building fabric heat capacity. The $S H$ method embeds the advantage of adopting an hourly time-step for the simulation, that is adequate to follow the variation of both solar radiation and ventilation flow rate that are typical of greenhouses. This simulation method is considered reliable by many previous studies especially focused on civil buildings $[212,213]$.

As shown in Figure 4.4 (where a schematization of the present energy simulation method is presented), the supply air temperature $\theta_{\text {air_sup }}$ and the outdoor air temperature $\theta_{\text {air_o }}$ are connected to the node $\theta_{\text {air_i }}$ through the heat transfer coefficient $H_{\mathrm{ve}}$, meaning that ventilation can be carried out considering $\theta_{\text {air_o }}$ or

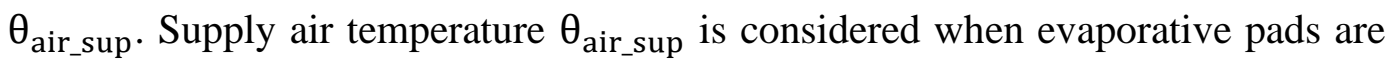
activated, and it is the temperature of the air exiting the pads after the adiabatic saturation. The supplemental heat load $\phi_{\mathrm{H} / \mathrm{C}_{-} \text {nd }}$ is directly applied on the node $\theta_{\text {air_i }}$. This configuration of the thermal network entails that $\phi_{\mathrm{H} / \mathrm{C}_{-} n d}$ and the ventilation thermal load directly affects the value of $\theta_{\text {air } \mathrm{i}}$ without any time delay.

The heat conduction through glazed surfaces has the same effect (no time delay) on $\theta_{\text {air_i }}$, since the $\theta_{\text {air_o }}$ node is linked to the $\theta_{\text {air_i }}$ through the heat transfers coefficients $H_{\text {tr_fen }}$ and $H_{\text {tr_is }}$. The heat transfer coefficient $H_{\text {tr_fen }}$ represents the heat conduction across the glazed surfaces while $H_{\text {tr_is }}$ represents the natural convection between the glazed surface and the indoor air. Conversely, the heat conduction through the opaque envelope (quite negligible in greenhouses) involves the phenomenon of heat storage and release. For this reason, the total building fabric heat capacity of the greenhouse $\left(C_{\mathrm{gh}}\right)$ is placed between the heat transfer coefficients $H_{\text {tr_em }}$ and $H_{\text {tr_ms }}$. The heat transfer coefficient $H_{\text {tr_em }}$ considers the heat conduction occurring from the external environment to the building thermal mass. The $H_{\text {tr_ms }}$ considers the heat transfer between the building thermal mass and the building surface, characterized by $\theta_{\mathrm{s}}$ that averages the temperature of the glazed and opaque envelope.

The developed model considers that only a fraction of the outdoor beam and diffuse solar radiation $\left(\phi_{\text {sol_b }}\right.$ and $\left.\phi_{\text {sol_d }}\right)$ enters inside the greenhouse $\left(\phi_{\text {sol_i }}\right)$. Once entered in the greenhouse enclosure, $\phi_{\text {sol_i }}$ is in part converted by the plants into latent heat $\left(\phi_{\text {lat_i}_{i}}\right)$, while the remaining sensible part $\left(\phi_{\text {sens_i }_{i}}\right)$ is considered in the thermal balance. A visible in Figure $4.4, \phi_{\text {sens_i }_{-}}$is split into three additional heat flows, namely:

- $\phi_{\mathrm{ia}}$ : convective heat flow directly applied to $\theta_{\mathrm{air}_{\mathrm{i}}}$;

- $\phi_{\mathrm{st}}$ : radiative heat flow directly applied to $\theta_{\mathrm{s}}$;

- $\phi_{\mathrm{im}}$ : radiative heat flow directly applied to $\theta_{\mathrm{m}}$ (building mass temperature) and subjected to a time delay.

In the developed simulation model, the $S H$ method is applicated for estimating the supplemental heating/cooling theoretical thermal load $\phi_{\mathrm{H} / \mathrm{C} \_n d}$ to reach the 
fixed set point temperatures. If neither supplemental heating nor cooling is needed (free-floating conditions), the solution of the energy balance provides $\theta_{\text {air_i }}$. The main equations adopted for solving the energy balance set in this calculation module are reported in Appendix A, while the complete set of equations can be found in paragraph C.3 of Annex C of ISO 13790 [211].

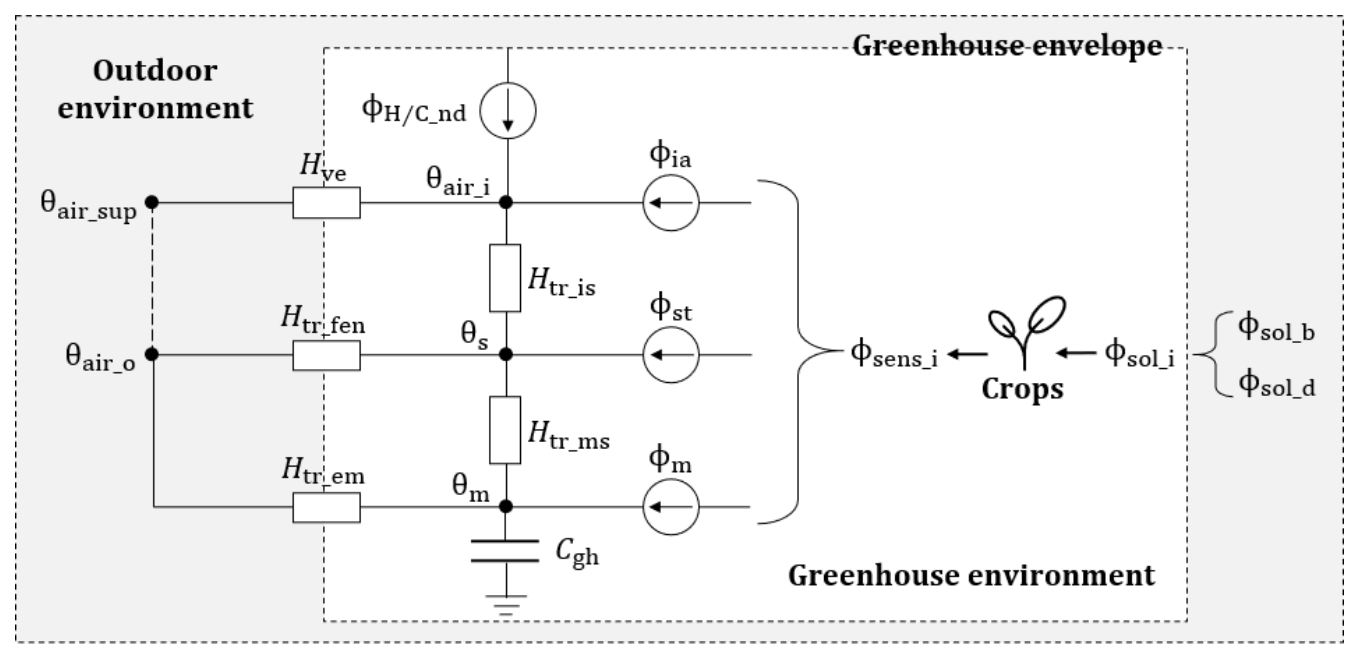

Figure 4.4 - Analogy between the 5R1C electrical network and the thermal behavior of a greenhouse.

\section{Moisture balance module}

In this module, the indoor air water content (or humidity ratio) $x_{\text {air }_{-} \mathrm{i}}$ is studied through the following mass balance ordinary differential equation that describes the water vapor balance inside the greenhouse in non-steady state conditions

$$
\begin{aligned}
& \frac{d x_{\text {air_i }}}{d \tau} \cdot V_{\text {gh }} \cdot \rho_{\text {air }}=\dot{m}_{\text {vap }} \cdot A_{\text {gh }} \cdot 10^{3}+ \\
& \frac{\dot{V}_{\text {air }} \cdot \rho_{\text {air }} \cdot\left(x_{\text {air_sup }}-x_{\text {air_i }}\right)}{3.6 \cdot 10^{3}} \quad\left[\frac{\mathrm{g}_{\text {vap }}}{\mathrm{s}}\right]
\end{aligned}
$$

where $\frac{d x_{\text {air_i }}}{d \tau}$ represents the variation rate of $x_{\text {air_i }}\left(g_{v} \mathrm{~kg}_{\text {air }}^{-1}\right)$ in time $\tau(\mathrm{s}), V_{\mathrm{gh}}$ is the greenhouse net volume $\left(\mathrm{m}^{3}\right)$ and $\rho_{\text {air }}$ is the volumetric mass density of air $\left(\mathrm{kg} \mathrm{m}^{-3}\right)$. The term $\dot{m}_{\text {vap }}$ is the transpiration water vapour flow $\left(\mathrm{mg}_{\mathrm{vap}} \mathrm{m}^{-2} \mathrm{~s}^{-1}\right)$, $A_{\text {gh }}$ the greenhouse floor area $\left(\mathrm{m}^{2}\right), \dot{V}_{\text {air }}$ is the ventilation flow rate $\left(\mathrm{m}^{3} \mathrm{~h}^{-1}\right)$ and $x_{\text {air_sup }}$ is the humidity ratio of the supply air $\left(\mathrm{g}_{\text {vap }} \mathrm{kg}_{\text {air }}^{-1}\right)$.

The solution of the ordinary differential Eq. (21) is

$$
\begin{aligned}
& x_{\text {air_i }_{-}}(\tau+\Delta \tau)=x_{\text {sup }}+\frac{\dot{m}_{\text {vap }} \cdot A_{\text {gh }}}{n_{\text {ach }} \cdot V_{\text {gh }} \cdot \rho_{\text {air }}} \cdot 3.6 \cdot 10^{6}+\left[x_{\text {air_i }_{-}}(\tau)+\right. \\
& \left.-x_{\text {air_sup }}-\frac{\dot{m}_{\text {vap }} \cdot A_{\text {gh }}}{n_{\text {ach }} \cdot V_{\text {gh }} \cdot \rho_{\text {air }}} \cdot 3.6 \cdot 10^{6}\right] \cdot e^{-\left(\frac{n_{\text {ach }}}{3600 \cdot \omega}\right) \cdot \Delta \tau} \quad\left[\frac{g_{\text {vap }}}{\mathrm{kg} g_{\text {air }}}\right]
\end{aligned}
$$

where $\Delta \tau$ is the time-step of simulation and $n_{\text {ach }}$ is the number of ventilation air exchanges per hour $\left(\mathrm{h}^{-1}\right)$. The term $\omega$ is a dimensionless multiplier that is introduced to lump the effect of water vapor sorption and storage of the greenhouse elements in the air node. 
For each simulation time-step, $x_{\text {air_i }}$ is estimated through Eq. (22), while $R H_{\mathrm{i}}$ is obtained through a psychrometric equation from $x_{\text {air_i }}$ and $\theta_{\text {air_i }}$.

\section{Heating system module}

This calculation module estimates the thermal energy consumption needed to maintain $\theta_{\text {set_H }}$ in the analyzed greenhouse $\left(E_{\text {th }}\right)$ as

$$
E_{\mathrm{th}}=\frac{\sum_{j=1}^{n_{\text {sim }}}\left(\phi_{\mathrm{H} \_n d, j} \cdot \Delta \tau\right)}{\eta_{\mathrm{H}} \cdot 10^{3}} \quad[\mathrm{kWh}]
$$

The value of $E_{\text {th }}$ is calculated considering $\phi_{\mathrm{H}_{-} \text {nd,j }}$ (the needed thermal load at $j$-th time-step), the duration of the $j$-th time-step $\Delta \tau$ (one hour) and considering the global efficiency of the heating system $\eta_{H}$ (a preliminary model input). The term $n_{\text {sim }}$ is the number of the simulation time-steps.

\section{Cooling pad efficiency module}

This calculation module estimates the supply air temperature exiting from the evaporative pads. The direct saturation effectiveness of the evaporative pad $(\varepsilon)$ indicates the extent to which the complete saturation of the inletting air is approached [214] and is influenced by various parameters, mainly:

- pad model: this affects $\varepsilon$ since the air path through the pad is different according to its geometrical features, such as the pad depth and flute angle. Flute angles can be defined as the angle between the pad flutes (in which the air flows through the pads) and the vertical axis of the same pad. For example, a flute angle of $0^{\circ}$ means that the flute is horizontal. Cellulose pads are made by vertical array of flutes with alternate angles (e.g. $30^{\circ} / 60^{\circ}$ or $\left.45^{\circ} / 15^{\circ}\right)$.

- $\quad$ airspeed across the pad: low airspeeds entail high $\varepsilon$.

Figure 4.5 (Authors elaboration on [215,216]) shows the variation of $\varepsilon$ for different cellulose pad models as a function of the air velocity across them. The considered models differ for the thickness $(100 \mathrm{~mm}$ and $150 \mathrm{~mm})$ and for the flute angles that are $30^{\circ} / 60^{\circ}$ for models 1 and 2 , while they are $45^{\circ} / 15^{\circ}$ for models 3 and 4. The graph shows that $\varepsilon$ decreases considerably as a function of the air speed across the pads while it increases in thicker pads and in presence of higher flute angles $\left(30^{\circ} / 60^{\circ}\right)$. 


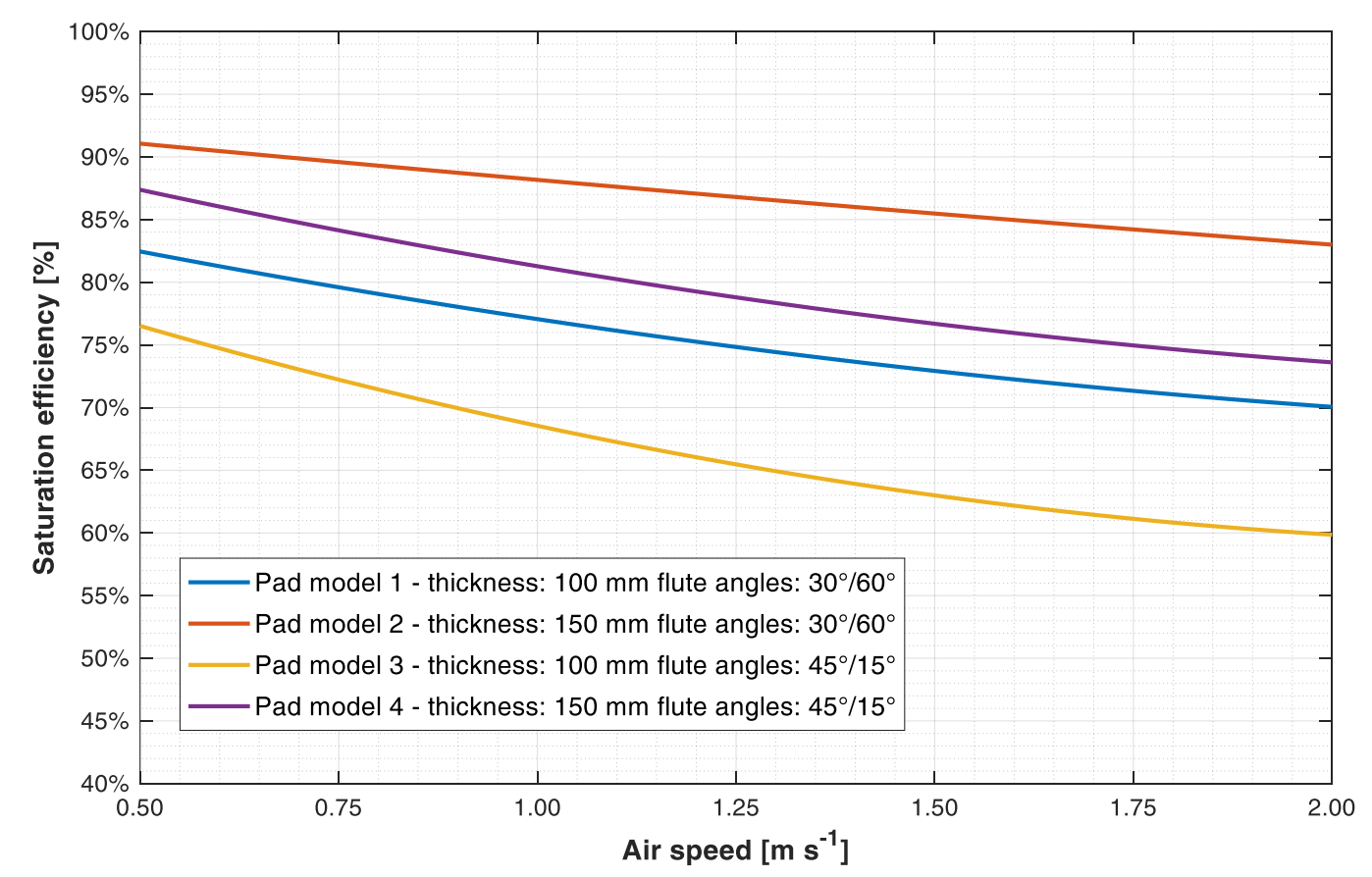

Figure 4.5 - Variation of the evaporative pad saturation efficiency $\varepsilon$ of different pad models as a function of the air velocity across them. The considered pad models are characterized by different thickness $(100$ and $150 \mathrm{~mm})$ and different flute angles $\left(30^{\circ} / 60^{\circ}\right.$ and $\left.15^{\circ} / 45^{\circ}\right)$. Authors elaboration on $[215,216]$.

In the calculation model, the user selects the pad model and, at each time-step, $\varepsilon$ is calculated as a function of the airspeed across the pads that is estimated as the ratio between the total ventilation air flow rate and the pad area.

The calculation model activates the evaporative cooling only in the time-steps in which $\theta_{\text {air_o }}$ is higher than $\theta_{\text {set_c }}$. At each time-step, the supply air temperature $\theta_{\text {air_sup,j }}$ is thus calculated as

$$
\begin{gathered}
\theta_{\text {air_sup,j }}= \\
\left\{\begin{array}{cc}
\theta_{\text {air_o_db,j }}-\varepsilon \cdot\left(\theta_{\text {air_o_db,j }}-\theta_{\text {air_o_wb,j }}\right) & \text { if } \theta_{\text {air_sup,j }}>\theta_{\text {set_C }} \\
\theta_{\text {air_o_db,j }} & \text { if } \theta_{\text {air_sup,j }} \leq \theta_{\text {set_C }}
\end{array}\right.
\end{gathered}
$$

where $\theta_{\text {air_o_db }}$ and $\theta_{\text {air_o_wb }}$ are the dry-bulb and the wet-bulb temperatures of the outdoor air, respectively. Please note that, even if the evaporative cooling is not activated, the inletting air crosses the pads to enter inside the greenhouse, therefore the pressure drop due to the pad presence should be always considered.

\section{Dehumidification ventilation system module}

In mechanically ventilated greenhouses, two main configurations of the ventilation system can be adopted. The first configuration relies in two different sets of fans, one for dehumidification and the other for cooling ventilation. This choice is since dehumidification usually needs lower ventilation flow rates than cooling ventilation, hence smaller fans can be installed. In the second configuration, a single set of fans deals with both dehumidification and cooling ventilation. 
The calculations for estimating the ventilation flow rate and electrical energy consumption for dehumidification and cooling ventilation are presented in this section and in the following one. This division is since, even though the process is quite similar, these calculations are characterized by a main difference. When dehumidification ventilation is activated, in fact, the greenhouse climate control system manages the inlet opening for maintaining a fixed static pressure difference between inside and outside $\Delta p_{\text {st }}$. Therefore, $\Delta p_{\text {st }}$ in ventilation for dehumidification is an input data of the model. On the contrary, when cooling ventilation is activated, $\Delta p_{\text {st }}$ is unknown and it has to be estimated by the model considering, for example, the pressure drop due to the evaporative pads, as described in the following section.

This calculation module simulates the control logic of dehumidification ventilation and estimates the consequent volumetric ventilation airflow rate for dehumidification $\left(\dot{V}_{\text {deh }}\right)$ needed to maintain $R H_{\mathrm{i}}$ below the threshold value $R H_{\mathrm{i} \_m a x}$ (input data). The module also estimates the electrical energy consumption resulting from the use of fans.

Depending on the values of $x_{\text {air_sup }}$ (supply air humidity ratio) and $x_{\text {air_i_MAX }}$ (the maximum $x_{\text {air_i }}$ that ensures to maintain $R H_{\mathrm{i}}$ below $R H_{\mathrm{i}_{-} \max }$ ), different conditions may occur as visible in Figure 4.6, where the ventilation logic implemented in the model is schematized. According to that diagram, three different situations can occur at each simulation time step depending on the value of $x_{\text {air_sup }}$. The first situation (A) is typical of a winter day with $x_{\text {air_sup }}$ lower than $x_{\text {air_i_MAX }}$. In this situation, the outdoor supply air can be used to maintain $R H_{\text {i_max }}$. In this situation, the ventilation airflow rate for dehumidification $\left(\dot{V}_{\mathrm{deh}}\right)$ is calculated as

$$
\dot{V}_{\text {deh }}=\min \left[\frac{\dot{m}_{\text {vap }} \cdot A_{\text {gh }} \cdot 3.6}{\rho_{\text {air }} \cdot\left(x_{\text {air____MAX }}-x_{\text {air_sup }}\right)} ; \dot{V}_{\text {inst }}\right] \quad\left[\frac{\mathrm{m}^{3}}{\mathrm{~h}}\right]
$$

where $x_{\text {air_sup }}$ is the humidity ratio of the supply air and $x_{\text {air_i_MAX }}$ is the maximum value of $x_{\text {air_i }}$ that ensures to maintain $R H_{\mathrm{i}}$ below $R H_{\mathrm{i}_{-} \max }$ (both expressed in $\mathrm{g}_{\text {vap }} \mathrm{kg}_{\mathrm{air}}^{-1}$ ). $\dot{V}_{\text {inst }}$ represents the maximum ventilation capacity (for dehumidification) installed in the greenhouse and it is considered because $\dot{V}_{\text {deh }}$ can never be higher than $\dot{V}_{\text {inst }}$. The value of $x_{\text {air_i_max }}$ (needed in Eq. (25)) is calculated using the following psychrometric equation

$$
x_{\text {air____MAX }}=0.622 \cdot \frac{R H_{\text {i_MAX }} \cdot p_{\text {vs }}\left(\theta_{\text {air_i }}\right)}{p_{\text {atm }}-R H_{\text {i__MAX }} \cdot p_{\text {vs }}\left(\theta_{\text {air_i }}\right)} \quad\left[\frac{g_{\text {vap }}}{\mathrm{kg}_{\text {air }}}\right]
$$

where $p_{\text {vs }}\left(\theta_{\text {air_i }}\right)$ is water saturated vapour pressure at $\theta_{\text {air_i }}$ and $p_{\text {atm }}$ is the atmospheric pressure (in $\mathrm{Pa}$ ). In the time-steps in which $\theta_{\text {air_i }}$ is not know (freefloating conditions), the value of $x_{\text {air_i_MAX }}$ cannot be calculated directly through Eq. (26) and the model performs an iterative procedure up to convergence. This iterative procedure consists in the application of the thermal balance module using 
the output value of $\theta_{\text {air_i }}$ to estimate the $x_{\text {air_i_MAX }}$ using Eq. (26). Once $x_{\text {air_i_MAX }}$ is known, the module re-applies Eq. (25) and (26) in loop until the convergence.

The second situation presented in Figure 4.6 (B) is common in autumn, spring, and summer. Since $x_{\text {air_sup }}$ and $x_{\text {air_i_MAX }}$ are very close between them, a high dehumidification ventilation flow rate is needed. For this reason, the maximum ventilation capacity for dehumidification installed in the greenhouse ( $\dot{V}_{\text {inst }}$, commonly a 5-6 ach) is provided. The last situation (C) may also happen during autumn, spring, and summer (like the previous conditions). When $x_{\text {air_sup }}$ is higher than $x_{\text {air_i_MAX }}$, ventilation cannot reduce $R H_{\mathrm{i}}$ (as visible from Eq. (25)) and the only way to decrease the $R H_{\mathrm{i}}$ is by increasing $\theta_{\text {air_i }}$. This strategy is suitable during autumn and spring, but it increases the greenhouse thermal energy consumption, and its adoption is led by economic considerations. During summer, the increase of $\theta_{\text {air_i }}$ to reduce $R H_{\mathrm{i}}$ is not adopted since it has the opposite effect of cooling ventilation.

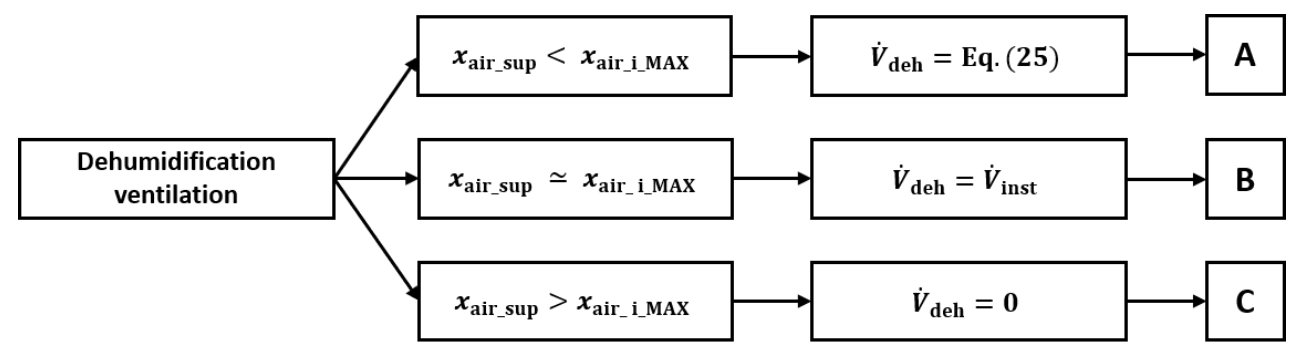

Figure 4.6 - Control logic for the dehumidification ventilation adopted in the present model.

The presented energy model was developed to simulate greenhouses equipped with fixed and/or variable angular speed fans, therefore the greenhouses can be simulated considering two sets of fans that carry out, respectively, dehumidification and cooling ventilation, or a single set that deals with both the tasks. Fixed angular speed fans cannot control the propeller speed and they provide a single value of airflow as function only of the fan operative static pressure $\Delta p_{\text {st }}$, that is the difference between the pressure that would be measured upstream and downstream of the fan (inside and outside the greenhouse). To obtain the desired ventilation rate, fixed angular speed fans are operated according to a duty cycle (intermittent activation). On the contrary, variable angular speed fans can modulate the propeller speed for providing exactly the needed ventilation rate.

This difference should be considered when fans are modelled. In particular, the ventilation flow rate $\dot{V}_{\text {fan_fix }}$ for a fixed angular speed fan reads

$$
\dot{V}_{\text {fan_fix }}=a_{\text {flow }} \cdot \Delta p_{\text {st }}^{2}+b_{\text {flow }} \cdot \Delta p_{\text {st }}+c_{\text {flow }} \quad\left[\frac{\mathrm{m}^{3}}{\mathrm{~h}}\right]
$$

where $a, b$ and $c$ are interpolation parameters for ventilation rate (subscript flow).

To estimate the electrical energy consumption for ventilation $E_{\mathrm{el}}$, the Specific Fan Performance $(S F P)$ is considered. The $S F P$ represents the hourly flowrate 
delivered by the fan per each watthour of electrical energy consumption. For a fixed angular speed fan, the $S F P$ reads

$$
S F P_{\text {fix }}=a_{\text {perf }} \cdot \Delta p_{\mathrm{st}}^{2}+b_{\text {perf }} \cdot \Delta p_{\mathrm{st}}+c_{\text {perf }} \quad\left[\frac{\mathrm{m}^{3}}{\mathrm{Wh}}\right]
$$

where $a, b$ and $c$ are interpolation parameters for $S F P$ (subscript perf).

Eq. (27) and (28) show that for fixed angular speed fans, both the flowrate and the $S F P$ vary only on a single curve as a function of $\Delta p_{\text {st }}$ only, as shown in Figure 4.7. As stated before, in dehumidification ventilation, $\Delta p_{\text {st }}$ is known since the automatic climate control system of the greenhouse maintains $\Delta p_{\text {st }}$ constant at the established value (usually $20 \mathrm{~Pa}$ ) by opening and closing the fan shutters and the greenhouse openings. In the simulation model, the user can set the value of $\Delta p_{\text {st }}$ that has to be maintained by the dehumidification ventilation.
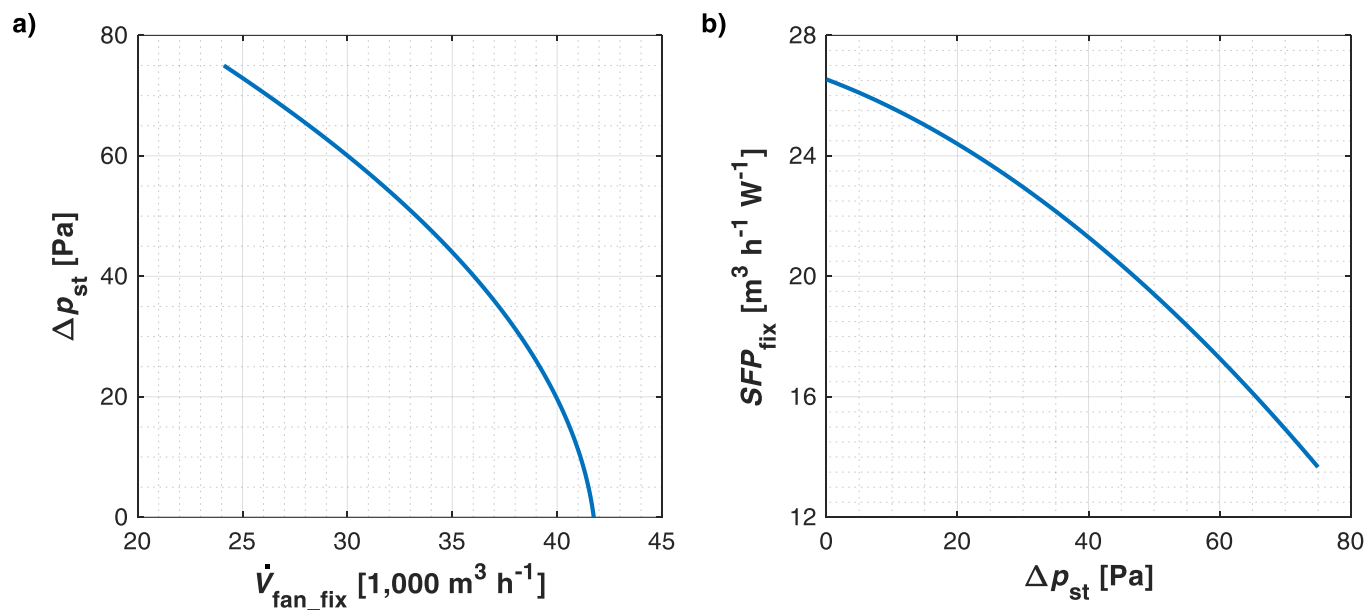

Figure 4.7 - Fixed speed fan (a) flowrate and (b) Specific Fan Performance (SFP) as function of fan static pressure.

Conversely, a variable angular speed fan operates with a set of operative curves depending on the propeller speed and, thus, both the flowrate and the SFP (at the same value of $\Delta p_{\text {st }}$ ) can get different values depending on the propeller speed, as shown in Figure 4.8. The graph shows that when a variable angular speed fan is operated at a low propeller speed (such as $60 \%$ of the maximum speed), the flowrate (Figure 4.8a) is lower if compared with high propeller speeds (such as $100 \%$ of the maximum speed), but the specific performance (Figure 4.8b) increases considerably (at the same $\Delta p_{\text {st }}$ ) and less energy is needed by the fan to deliver the same amount of air. For this reason, climate control systems of greenhouses usually share the ventilation flow rate between the installed fans with the aim of making them work at low angular speeds (usually around 60-70\% of the maximum speed). Higher angular speeds are reached only when high ventilation flow rates are needed.

The estimation of the propeller speed needed to ensure the required flowrate is not an easy task and, consequently, the calculation of the SFP of a variable angular speed fan is more complex than for a fixed angular speed fan. The solution for calculating the SFP consists in generating a set of additional fictitious variables 
defined as a combination of the flowrate $\dot{V}_{\text {fan_var }}$ and $\Delta p_{\text {st }}$ to interpolate the energy consumption of the fan at different propeller speed. An example of that a process is

$$
\begin{gathered}
S F P_{\text {var }}=d_{\text {perf }} \cdot \dot{V}_{\text {fan_var }}+e_{\text {perf }} \cdot \dot{V}_{\text {fan_var }}^{2}+f_{\text {perf }} \cdot \Delta p_{\text {st }}+ \\
g_{\text {perf }} \cdot \Delta p_{\text {st }}^{2}+h_{\text {perf }} \cdot \Delta p_{\text {st }} \cdot \dot{V}_{\text {fan_var }}+i_{\text {perf }}\left[\frac{\mathrm{m}^{3}}{\mathrm{wh}}\right]
\end{gathered}
$$

where $d_{\text {perf }}, e_{\text {perf }}, f_{\text {perf }}, g_{\text {perf }}, h_{\text {perf }}$ are interpolation coefficients that depend on the model of variable speed fans. In this case, $\dot{V}_{\text {fan_var }}$ has the same value of $\dot{V}_{\text {deh }}$ since this fan type provides exactly the required ventilation flow rate.

a)

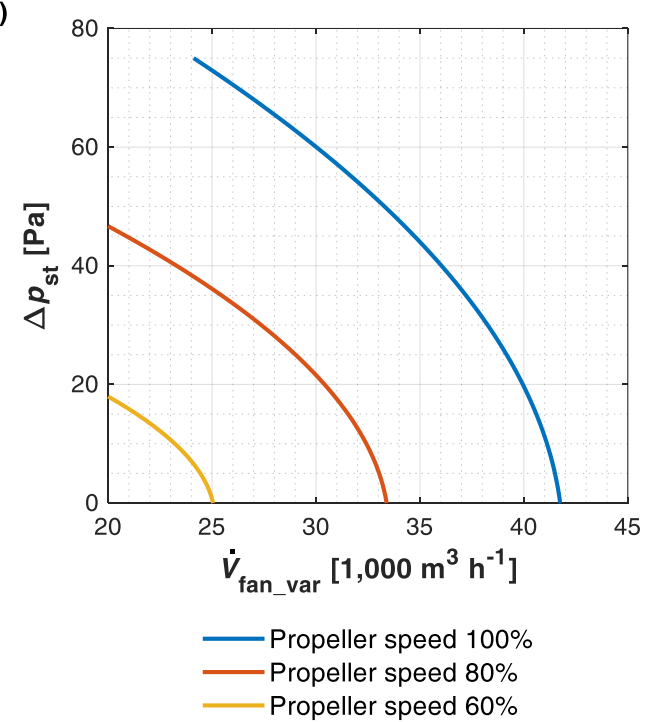

b)

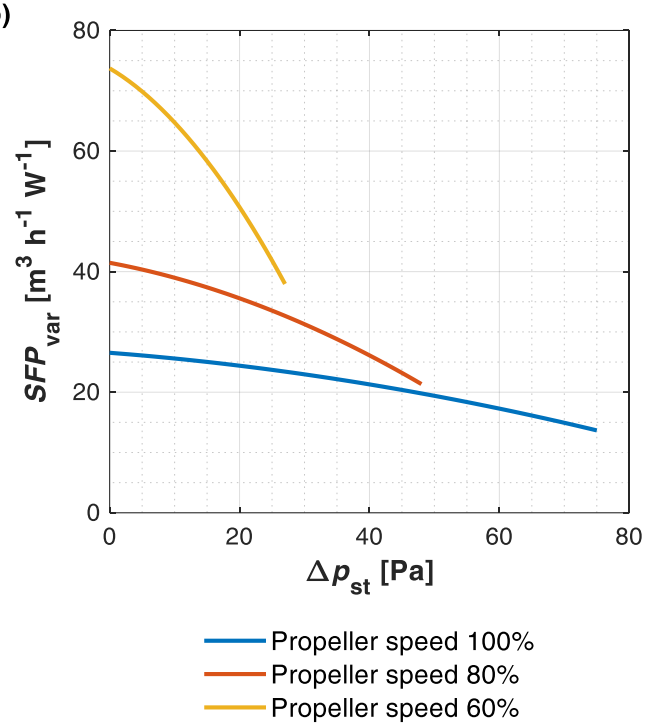

Figure 4.8 - Variable speed fan (a) flowrate and (b) Specific Fan Performance (SFP) as function of static pressure.

Knowing the SFP of both fixed and variable angular speed fans, the electrical energy consumption for dehumidification ventilation $E_{\text {el_deh }}$ is calculated as

$$
E_{\text {el_deh }}=\sum_{i=1}^{n_{\text {fan }}}\left(\frac{\dot{V}_{\text {fan_fix } / \mathrm{var}, \mathrm{z}} \cdot \Delta \tau}{S F P_{\mathrm{fix} / \mathrm{var}, \mathrm{z}} \cdot 10^{3}}\right) \quad[\mathrm{kWh}]
$$

where $S F P_{\mathrm{fix} / \mathrm{var}, \mathrm{z}}$ and $\dot{V}_{\mathrm{fan} \_\mathrm{fix} / \mathrm{var}, \mathrm{z}}$ are the $S F P$ and the ventilation flow rate of the $i$-th fixed or variable angular speed fan. The term $\Delta \tau$ is the duration of the simulation time step and $n_{\mathrm{fan}}$ indicates number of fans that are present in the ventilation system.

\section{Cooling ventilation system module}

This calculation module simulates the control logic of the cooling ventilation and estimates the ventilation air flow rate needed to maintain the required $\theta_{\text {air_i }}$ and the resulting electrical energy consumption. The previously obtained value of $\phi_{\mathrm{C}_{-} n d}$ (sensible cooling load) is used to calculate the hourly ventilation rate needed for cooling $\dot{V}_{\text {cool }}$. 
The cooling ventilation logic implemented in this model as schematized in Figure 4.9. Two different types of control can be performed inside greenhouses. The first type of control is the temperature control, and it maintains a fixed $\theta_{\text {set_c }}$ in a certain spot of the greenhouse (where the climate control probe is placed). When temperature control is performed, two different situations can occur depending on $\theta_{\text {air_sup. If }} \theta_{\text {air_sup }}$ is lower than $\theta_{\text {set_c }}, \dot{V}_{\text {cool }}$ (situation A of Figure 4.9) is calculated from $\phi_{\mathrm{C}_{-} \text {nd }}$ as

$$
\dot{V}_{\text {cool }}=\min \left[\frac{\phi_{\mathrm{C}_{\_} \text {nd }} \cdot 3.6 \cdot 10^{3}}{\rho_{\text {air }} \cdot c_{\text {air }} \cdot\left(\theta_{\text {air_i }}-\theta_{\text {air_sup }}\right)} ; \dot{V}_{\text {inst }}\right] \quad\left[\frac{\mathrm{m}^{3}}{\mathrm{~h}}\right]
$$

where $c_{\text {air }}$ is the specific heat capacity of the air (in $\mathrm{J} \mathrm{kg}^{-1} \mathrm{~K}^{-1}$ ) and $\rho_{\text {air }}$ its volumetric mass density $\left(\mathrm{kg} \mathrm{m}^{-3}\right)$. The term $\dot{V}_{\text {inst }}$ represents the maximum ventilation capacity (for cooling) actually installed in the greenhouse. This term is considered in Eq. (31) since $\dot{V}_{\text {cool }}$ can never be higher than $\dot{V}_{\text {inst }}$. If $\theta_{\text {air_sup }}$ is higher than $\theta_{\text {set_c }}, \theta_{\text {set_c }}$ cannot be maintained and $\dot{V}_{\text {inst }}$ is provided (situation B of Figure 4.9).

The second type of temperature control maintains a minimum fixed value of temperature gradient $\left(\Delta \theta_{\text {air_i }}\right.$, of 3-4 $\left.{ }^{\circ} \mathrm{C}\right)$ between two spots of the greenhouse (usually the beginning and the end) in addition to guarantee $\theta_{\text {set_c }}$. This temperature control criterion is adopted to prevent the crop from being subject to different temperatures and, thus, different growing conditions depending on their position in the greenhouse. In the first situation of temperature gradient control presented in Figure 4.9 (situation C), $\theta_{\text {air_sup }}$ is smaller than the set point gradient, therefore $\dot{V}_{\text {cool }}$ can decrease $\theta_{\text {air_i }}$. In the second situation (D), $\Delta \theta_{\text {air_i }}$ (an input data of the model and of the greenhouse climate control system) should be reduced to make it

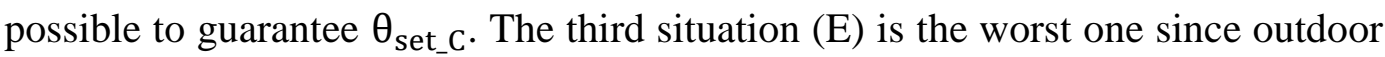
air cannot be used to achieve $\Delta \theta_{\text {air_i }}$. In this situation, the maximum cooling ventilation capacity $\dot{V}_{\text {inst }}$ is used or evaporative cooling is activated. Last situation $(\mathrm{F})$ is the one in which $\theta_{\text {air_sup }}$ has the same value of the $\theta_{\text {set_c }}$ considering also $\Delta \theta_{\text {air_i }}$. Please note that, when it is present, evaporative cooling can be activated in each one of situations presented in Figure 4.9. Its activation, in fact, reduces $\theta_{\text {air_sup }}$ and, consequently, also $\dot{V}_{\text {cool }}$ and $E_{\text {el_deh }}$. 


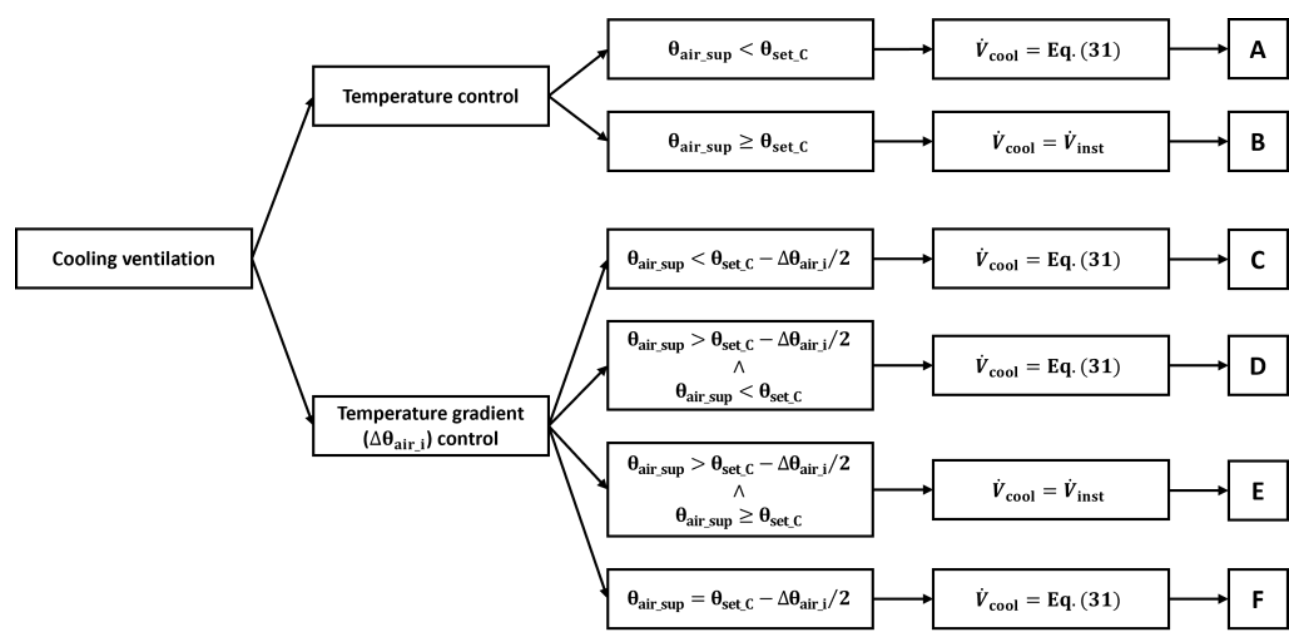

Figure 4.9 - Control logic for the cooling ventilation adopted in the present model.

In the calculation of the electrical energy consumption for cooling ventilation $E_{\text {el_cool }}$, the main difference with respect of the dehumidification ventilation calculation (as stated before) is that in cooling ventilation $\Delta p_{\text {st }}$ is unknow, since is not maintained constant by the climate control system but depends on the air speed through the pads and, consequently by the ventilation rate.

To estimate $\Delta p_{\mathrm{st}}$, the pressure drop due to the presence of evaporative pads is considered. Inlet air, in fact, enters through the pads, even when they are not activated. The static pressure that is generated by the air flow passing through the cooling pad system (15-20 $\mathrm{Pa}$ at maximum airflow) can be estimated by the data provided by the manufacturers of the pads that express the static pressure drop as a function of the air velocity across the pad, as reported in Figure 4.10 (Authors elaboration on [215,216]), where the same pad models of Figure 4.5 are presented. The graph shows that pad models with higher flute angles (i.e. $30^{\circ} / 60^{\circ}$ ) are responsible of higher static pressure drops.

The pressure drop due to pads presence is the main component for the calculation of $\Delta p_{\text {st }}$ since the distributed static pressure drop due to the airflow crossing the greenhouse can be neglected. The low airspeed inside the greenhouse (usually does not overcome $0.75 \mathrm{~m} \mathrm{~s}^{-1}$ ), in fact, entails negligible values of pressure drops around 1 or $2 \mathrm{~Pa}$. 


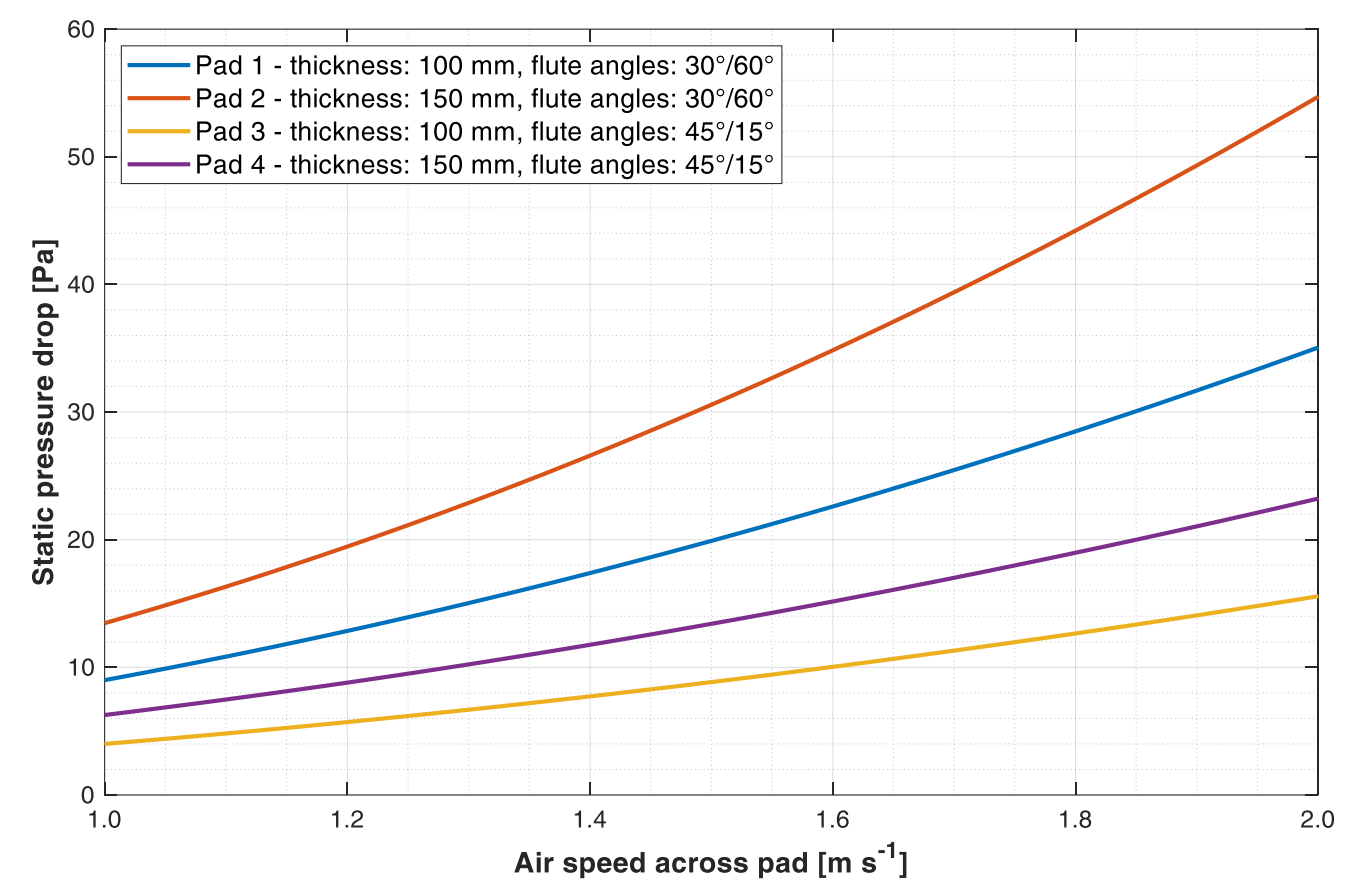

Figure 4.10 - Static pressure drop generated by the cooling pad according to the model and thickness. Authors elaboration on [215,216].

To calculate $E_{\text {el_cool }}$, two different approaches are followed by the model depending on the type of fan used. For cooling purposes, in fact, both fixed and variable angular speed fans can be used, similarly to what happens for dehumidification ventilation.

When fixed angular speed fans are used, the aeraulic circuit resistance curve (pad curve of Figure 4.10) and the fans performances curves of Figure 4.7 are crossed to estimate the ventilation flowrate generated by the fixed angular speed fans during cooling ventilation (solution of a system of two equations in two variables). Figure 4.11 represents the approach followed by the calculation model to estimate the ventilation capacity of the system according to the number of fans that are activated. A higher number of fans means a higher ventilation rate but also a higher $\Delta p_{\text {st }}$ and, thus, a lower ventilation capacity of each fan.

Once the ventilation capacity of the system is calculated, $E_{\text {el_cool }}$ is estimated knowing $\Delta p_{\text {st }}$ using the $S P F$, with an equation similar to Eq. (30). 


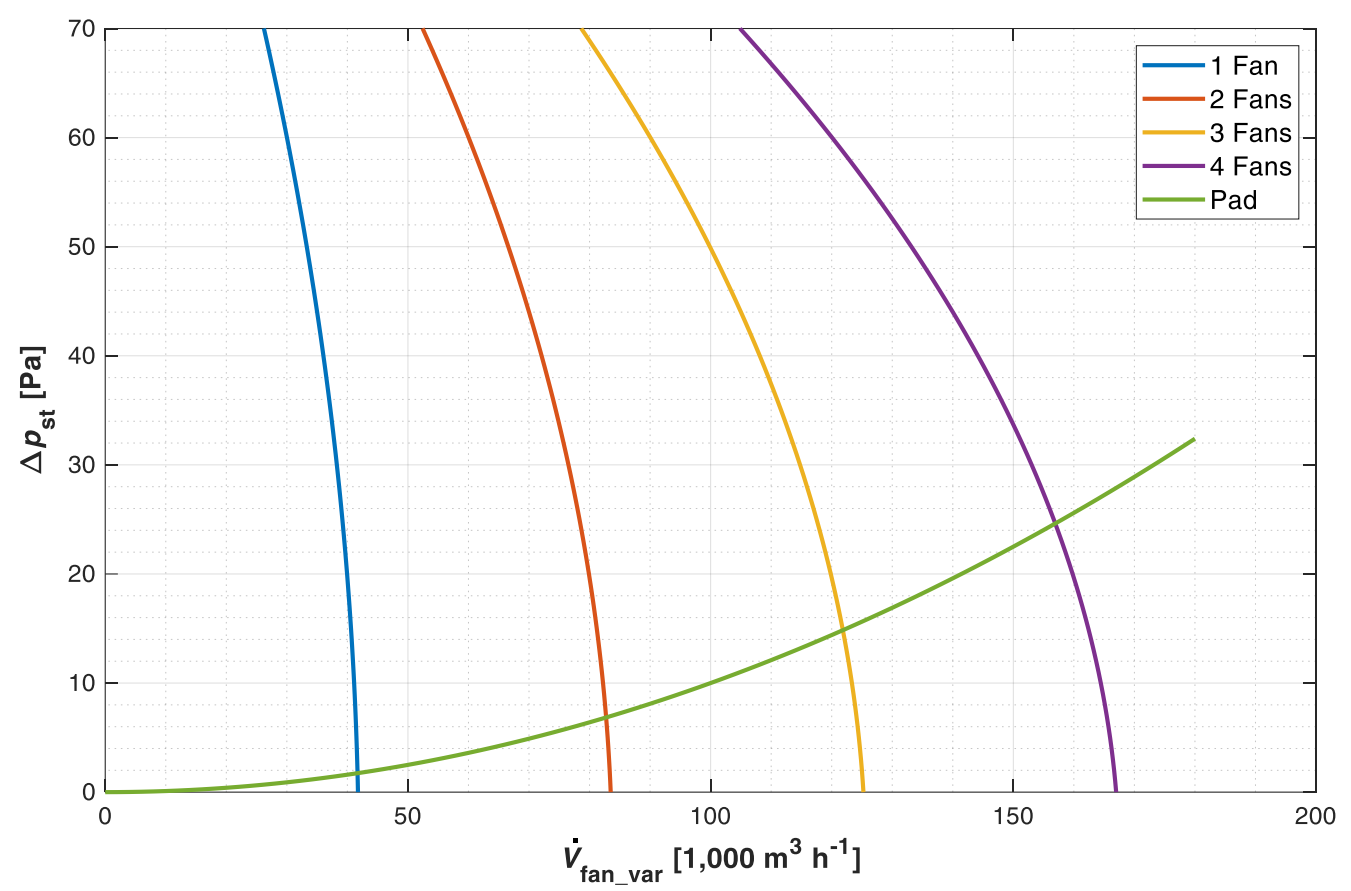

Figure 4.11 - Ventilation system performance, the fan operative condition is correlated to the type of cooling pad.

When variable speed fans are used, the calculation is simpler since the ventilation provided by fans is exactly $\dot{V}_{\text {cool }}$ calculated through Eq. (31) as fans can modulate their propeller speed. In addition, also the static pressure is easily calculated since it consists in applying the pad curve equation with the airspeed resulting from the $\dot{V}_{\text {cool }}$ flowrate. $S F P$ and $E_{\text {el_cool }}$ are calculated in a similar way to the dehumidification ventilation, referring to Eq. (29) and (30).

Finally, the overall electrical energy consumption $E_{\mathrm{el}}$ for ventilation (dehumidification and cooling) is calculated as

$$
E_{\mathrm{el}}=\sum_{\mathrm{j}=1}^{n_{\text {sim }}}\left(E_{\mathrm{el} \_d e h, \mathrm{j}}+E_{\text {el_cool, } \mathrm{j}}\right) \quad[\mathrm{kWh}]
$$

where $E_{\text {el_deh,j }}$ and $E_{\text {el_cool,j }}$ are the electrical energy consumption for dehumidification and cooling at the $j$-th time-step, respectively and $n_{\text {sim }}$ is the number of the time-steps of the simulation period.

\subsection{Model calibration and validation}

\subsubsection{Calibration and validation overview}

The presented energy simulation model is validated against real monitored data for guaranteeing the reliability of the results. Before the validation, a calibration process is carried out since mathematical models for predicting greenhouse climate conditions need a calibration of their parameters before their validation [217]. This is especially true in first principles models because they rely on physical equations 
based on several parameters (e.g. $U$ - value and greenhouse thermal capacity) that could be difficult to adjust [51]. Calibration process alters the model parameters making them more similar to the ones of the physical world and obtaining a better fit between simulated and measured data [218].

\subsubsection{Case study}

\section{Case study description}

The presented energy simulation model was validated and calibrated using part of the dataset obtained from the monitoring campaign carried out in the greenhouse presented in section 3.2.

The main description of the adopted case study was provided in section 3.2.1. Nevertheless, few additional data should be added for running the simulations with the aim of calibrating and validating the energy simulation model. One of the main inputs of the model are the thermophysical properties of the greenhouses envelope that were estimated for both the glazed surfaces and the floor. The $U-$ value of the single glazed envelope (including the metal frame) is equal to $6.3 \mathrm{~W} \mathrm{~m}^{-2} \mathrm{~K}^{-1}$ as reported in [175,219], while the internal areal heat capacity is considered negligible due to its minor relevance. The floor is a concrete slab $(0.2 \mathrm{~m}$ of thickness) and its $U-$ value was estimated to be $3.7 \mathrm{~W} \mathrm{~m}^{-2} \mathrm{~K}^{-1}$, while its internal areal heat capacity is $181.2 \mathrm{~kJ} \mathrm{~m}^{-2} \mathrm{~K}^{-1}$.

To calculate the total heat capacity of the greenhouse, the heat storage property of the main elements contained inside the greenhouse (e.g. soil and cultivation benches) are considered. Table 4.1 shows the heat capacity of the different elements considered for this calculation. The total heat capacity of the greenhouse $\left(C_{\mathrm{gh}}\right)$ is estimated to be $476,957 \mathrm{~kJ} \mathrm{~K}^{-1}$. Nevertheless, $C_{\mathrm{gh}}$ is characterized by a great uncertainty since the estimation of the total amount of the elements present inside the greenhouse, their volumetric mass density and their specific heat value is a complex task. For this reason, a calibration parameter will be applied to $C_{\mathrm{gh}}$, as shown later in the text.

In section 3.2.1, the main features of the climate control system of the considered case study were presented. In that section it was stated that the monitored greenhouse is equipped with seven variable angular speed fans placed in the southwest wall of the greenhouse that deal with both dehumidification and cooling ventilation. To properly simulate those fans, the performance parameters typical of the installed model presented in Table A.2 (Appendix A) are adopted. 
Table 4.1 - Heat capacities of the greenhouse elements considered in this work.

\begin{tabular}{cc}
\hline Element & $\begin{array}{c}\text { Heat capacity value } \\
{\left[\mathrm{kJ} \mathrm{K}^{-1}\right]}\end{array}$ \\
\hline Greenhouse floor & 147,875 \\
Aluminum cultivation benches & 14,500 \\
Soil for plant cultivation & 288,990 \\
Water in hydronic pipe systems & 15,052 \\
Cultivated plants & 1,437 \\
Air inside the enclosure & 9,102 \\
\hline Total & 476,957 \\
\hline
\end{tabular}

\section{Calibration and validation dataset}

From the larger datasets presented in section 3.2, the data collected during 15 days of July $\left(6^{\text {th }}-20^{\text {th }}\right)$ were selected to calibrate and validate the presented energy simulation model. The selected data have been processed to be comparable with the simulation outputs obtained for the same period. Since the developed energy simulation model is a lumped parameter one with an hourly time step, the values of $\theta_{\text {air_i }}$ and $R H_{\mathrm{i}}$ that were monitored in the different spots of the enclosure were first spatially averaged (through the arithmetic mean) between them to obtain single values properly representative of the indoor environmental conditions of the entire enclosure at each logging time step. Then, the time profiles of the measured variables were temporally averaged (also through the arithmetic mean) over one hour obtaining three measured-based temporal profiles: (1) the $\tilde{\mathcal{A}}$ set constituted by the hourly average of the measured $\theta_{\text {air_i }}$, (2) the $\widetilde{\mathcal{B}}$ set constituted by the hourly average of the measured $R H_{\mathrm{i}}$ and the $\tilde{\mathcal{C}}$ set constituted by the hourly values of monitored electrical energy consumption. The $\tilde{\mathcal{A}}, \widetilde{\mathcal{B}}$ and $\tilde{\mathcal{C}}$ time profiles were thus divided into two disjoint subsets each one: the first one (72 hours) is used to calibrate the model, while the second one ( 288 hours) is used to validate it through a calibrated simulation.

\subsubsection{Model calibration}

\section{Calibration parameters definition}

In the present work, an optimization-based calibration [82,83] is adopted and, for this aim, an optimization problem is set, defining the optimization parameters (even called calibration parameters), the objective functions and constrains of the problem. The selection of parameters to be calibrated was performed considering the aspects of the model that are characterized by a higher uncertainty, due to modelling simplifications (e.g. plant transpiration and greenhouse heat storage phenomena) or the use of literature data instead of measured ones. In addition, the adopted calibration parameters were selected on purpose among the input data (that are constant during the entire simulation) with the aim of not affecting the dynamics of any physical phenomenon. 
The thermal transmittances of the glazed surfaces and of the floor, which were estimated from on-site inspections, are characterized by a high uncertainty. For this reason, the calibration parameters $\gamma_{\text {glass }}$ and $\gamma_{\text {floor }}$ are introduced. Both the defined parameters are dimensionless multiplicative factors of the $U$-values of glazed surfaces and floor (constant input data), respectively.

The calibration stage also concerns the heat and moisture storage property since, as previously stated, the estimation of heat and moisture capacity is deeply affected by the properties of the elements contained inside the building that, in a complex environment such a greenhouse, are difficult to be properly determined. Since several parameters affect the preliminary assessment of heat and moisture capacity, the dimensionless calibration parameter $\gamma_{\mathrm{th}}$ and $\gamma_{\mathrm{hig}}$ are defined. The calibration parameter $\gamma_{\mathrm{th}}$ is a multiplier of $C_{\mathrm{gh}}$, while $\gamma_{\mathrm{hig}}$ is a multiplier of $\omega$ presented in Eq. (9). Both the terms $C_{\text {gh }}$ and $\omega$ are input data that are constant during the entire simulation.

Another source of uncertainty in the model is the plant $L A I$ dynamics of the grown experimental cultivations, the accurate measurement of which is destructive [223] or very difficult [224]. In this work, the $L A I$ variation in time was modelled with a linear function characterised by the slope $m_{\mathrm{LAI}}$ and the y-intercept $q_{\mathrm{LAI}}$. In the calibration process, $m_{\mathrm{LAI}}$ and $q_{\mathrm{LAI}}$ are corrected by the two dimensionless multiplicative parameters $\gamma_{\mathrm{m}_{-} \mathrm{LAI}}$ and $\gamma_{\mathrm{q}_{-} \mathrm{LAI}}$, respectively. The calibration parameter $\gamma_{\mathrm{q}_{-} \mathrm{LAI}}$, therefore, modifies the $L A I$ value of the plants at the beginning of the simulation, while $\gamma_{m_{\text {LLAI }}}$ calibrates the velocity of plant growth during the same simulation. The introduction of $\gamma_{\mathrm{q}_{-} \mathrm{LAI}}$ and $\gamma_{\mathrm{m}_{-} \mathrm{LAI}}$ do not affect the dynamics of the plant growth since $L A I$ still changes with an hourly basis.

\section{Objective function definition}

The previously defined set of calibration parameters is organized in two column vectors $(\Psi$ and $\Omega$ ) since the optimization process is performed in two consecutive steps. In the first step, the calibration parameters related to the sensible heat (vector $\Psi)$ are optimized for minimizing the deviation between the monitored and the measured indoor air temperatures. In the second step, the set of calibration parameters mainly related with the indoor air humidity (vector $\Omega$ ) are optimized for minimizing the deviation between the monitored and the measured indoor air relative humidity. Vectors $\Psi$ and $\Omega$ read

$$
\begin{gathered}
\Psi=\left[\begin{array}{c}
\gamma_{\text {glass }} \\
\gamma_{\text {floor }} \\
\gamma_{\text {th }}
\end{array}\right] \\
\Omega=\left[\begin{array}{c}
\gamma_{\text {m_LAI }} \\
\gamma_{\text {_LLAI }} \\
\gamma_{\text {hig }}
\end{array}\right]
\end{gathered}
$$


The deviation between the simulated and measured values is quantified through the Root Mean Square Error (RMSE) calculated between the simulated and measured values of $\theta_{\text {air_i }}$ and $R H_{\mathrm{i}}$. The $R M S E$ is defined as

$$
\operatorname{RMSE}(X, \tilde{X})=\sqrt{\frac{\sum_{\mathrm{j}=1}^{n_{\mathrm{set}}\left(\chi_{\mathrm{j}}-\tilde{\chi}_{\mathrm{j}}\right)^{2}}}{n_{\mathrm{set}}}} \quad\left[{ }^{\circ} \mathrm{C}\right]
$$

where $(X)$ is the vector representing the simulated time profiles and $\tilde{X}$ the vector representing the measured ones. In Eq. (35), $\chi_{\mathrm{j}}$ and $\tilde{\chi}_{\mathrm{j}}$ are the simulated and measured values, respectively, while $n_{\text {set }}$ represents the cardinality of the considered subset ( 72 for the calibration phase).

In the first step of the optimization process, first, a Generalized Reduced Gradient $(G R G)$ nonlinear algorithm is used to solve the following optimization problem

$$
\widehat{\Psi}=\min _{\Psi}[\operatorname{RMSE}(\mathcal{A}(\Psi), \tilde{\mathcal{A}})]
$$

to find the optimal set of parameter values $\widehat{\Psi}$ for $\theta_{\text {air_i }}$. Then, in the second step, the $G R G$ nonlinear algorithm was used to solve the following optimisation problem

$$
\widehat{\Omega}=\min _{\Omega}[\operatorname{RMSE}(\mathcal{B}(\Omega), \widetilde{\mathcal{B}})]
$$

where $\widehat{\Omega}$ is the vector of the set of the calibration parameters that minimizes the $R M S E$ for $R H_{\mathrm{i}}$, similarly to Eq. (36).

A set of constrains are fixed for the two considered optimization problems to decrease the calculation time and to ensure to obtain results that are reliable from a physical point of view and that respect the assumptions that are presented later in the text.

The defined constrains are the following:

$$
\begin{gathered}
0.75 \leq \gamma_{\text {glass }} \leq 1.25 \\
0.75 \leq \gamma_{\text {floor }} \leq 1.25 \\
\gamma_{\text {th }} \geq 1 \\
\gamma_{\text {LAI_ang }}>0 \\
\gamma_{\text {hig }} \geq 1
\end{gathered}
$$

The constrains of Eq. (38) and (39) are set considering that an error by $\pm 25 \%$ can be present in the estimation of the U-values from literature. The constraint for $\gamma_{\text {th }}$ (Eq. (40)) is needed since the total greenhouse heat capacity must be positive 
$\left(\gamma_{\text {th }}>0\right)$ and because its first estimation was precautionary, therefore it is assumed that a lower value is very improbable $\left(\gamma_{\mathrm{th}} \geq 1\right)$. The constraint related to $L A I$ calibration parameter $\left(\gamma_{\text {LAI_ang }}\right)$ is needed since the $L A I$ value should increase as a function of time and the function should be bijective (Eq. (41)). No constrains were defined for $\gamma_{\mathrm{q}_{-} \text {LAI }}$. The constrain of the calibration parameter $\gamma_{\mathrm{hig}}$ is set to have a value higher than one (Eq. (42)) since the first approximation of the hygric capacity of the greenhouse only considered the hygric capacity of the air inside the greenhouse (the $\omega$ factor of Eq. (22) was set equal to one). This choice was because no reliable data concerning the moisture buffer value of greenhouse are available in literature, therefore the estimation of the final value of $\omega$ is performed through the calibration process.

The results of the optimization process that are then used for the calibrated simulation for the model validation are presented in Table 4.2. In the first instance, the $L A I$ was considered equal to $0.4 \mathrm{~m}^{2} \mathrm{~m}^{-2}$ at the beginning of the production cycle and $1.6 \mathrm{~m}^{2} \mathrm{~m}^{-2}$ at the end of it, with a linear increase. The optimization process changed those values and in the calibrated model the $L A I$ is equal to $0.15 \mathrm{~m}^{2} \mathrm{~m}^{-2}$ at the beginning of the production cycle and $1.14 \mathrm{~m}^{2} \mathrm{~m}^{-2}$ at the end of it.

Table 4.2 - Values of the calibration parameters after the solution of the optimization problem.

\begin{tabular}{cc}
\hline Coefficient & Value \\
\hline$\gamma_{\text {glass }}$ & 1.25 \\
$\gamma_{\text {floor }}$ & 0.99 \\
$\gamma_{\text {th }}$ & 3.83 \\
$\gamma_{\text {m_LAI }}$ & 0.82 \\
$\gamma_{\text {q_LAI }}$ & 0.36 \\
$\gamma_{\text {hig }}$ & 1.48 \\
\hline
\end{tabular}

\subsubsection{Model validation}

\section{Goodness-of-fit indexes}

The presented model is validated comparing the results carried out through a calibrated simulation with the data acquired through the monitoring campaign.

The differences in terms of $\theta_{\text {air_i }}, R H_{\mathrm{i}}$ and $E_{\mathrm{el}}$ between the measured and the estimated values are evaluated using two different goodness-of-fit indices that are calculated with an hourly basis. The first index is the Mean Bias Error $(M B E)$ that reads

$$
M B E=\frac{\sum_{\mathrm{j}=1}^{n_{\mathrm{set}}}\left(\tilde{\chi}_{\mathrm{j}}-\chi_{\mathrm{j}}\right)}{\sum_{\mathrm{j}=\mathrm{j}}^{n_{\mathrm{set}}} \tilde{\chi}_{\mathrm{i}}} \cdot 100 \quad[\%]
$$


where $\chi_{\mathrm{j}}$ and $\tilde{\chi}_{\mathrm{j}}$ are the simulated and measured values at the hourly time-step $j$, respectively, while $n_{\text {set }}$ is the number of hourly values considered in the validation period.

The other chosen calculated goodness-of-fit index is the Coefficient of variation of the RMSE ( $C v(R M S E))$ that reads

$$
C v(R M S E)=\frac{R M S E}{\left(\sum_{\mathrm{j}=1}^{n_{\mathrm{set}}} \tilde{\chi}_{\mathrm{j}}\right) \cdot \frac{1}{n_{\mathrm{set}}}} \cdot 100 \quad[\%]
$$

where RMSE is the Root Mean Square Error calculated similarly to Eq. (35).

The reliability of the model in estimating the electrical energy consumption due to dehumidification and cooling ventilation over long periods of simulation is estimated also considering the deviation of the simulated energy consumption from the monitored one $\left(\Delta E_{\mathrm{el}}\right)$ over the validation period as

$$
\Delta E_{\mathrm{el}}=\frac{\left(\sum_{\mathrm{j}=1}^{n_{\mathrm{set}}} \chi_{\mathrm{j}}\right)-\left(\sum_{\mathrm{j}=1}^{n_{\text {set }}} \tilde{\chi}_{\mathrm{j}}\right)}{\left(\sum_{\mathrm{j}=1}^{n_{\mathrm{set}}} \tilde{\chi}_{\mathrm{j}}\right)} \quad[\%]
$$

\section{Validation results}

In Figure 4.12 the hourly trends of simulated values of $\theta_{\text {air_i }}, R H_{\mathrm{i}}$ and $E_{\mathrm{el}}$ are displayed against the measured ones during the validation period. In addition, the monitored values of $\theta_{\text {air_o }}$ and $R H_{\mathrm{o}}$ are also displayed. During the considered period (July), both $\theta_{\text {air_o }}$ and $R H_{\mathrm{o}}$ are characterised by considerably high values. In particular, $\theta_{\text {air_o }}$ ranges between 17.1 and $33.2^{\circ} \mathrm{C}$, while $R H_{\mathrm{o}}$ values are between 50 and $90 \%$. These outdoor air external conditions entail high values of $\theta_{\text {air_i }}$ and $R H_{\mathrm{i}}$ and, consequently, high $E_{\mathrm{el}}$ due to fan activation.

Figure 4.12 shows that the model is reliable (from a qualitative point of view) in estimating the indoor environmental conditions and electrical energy consumption of the monitored greenhouse. The measured and simulated trends of $\theta_{\text {air_i }}$ (Figure 4.12a) are very similar between them, especially during nighttime, when $\theta_{\text {air_i }}$ is in free-floating conditions due to the absence of solar radiation and the lower value of $\theta_{\text {air_o }}$ (no cooling is needed). During daytime, the higher $\theta_{\text {air_o }}$ and the presence of solar radiation cause the activation of the installed fans (as visible from the $E_{\text {el }}$ trends of Figure 4.12c) and slight differences between the two $\theta_{\text {air_i }}$ trends (the measured and simulated ones) stand out. These differences are especially evident on July $9^{\text {th }}$ and $10^{\text {th }}$ when (at around 12:00) the simulated $\theta_{\text {air }} \mathrm{i}$ suddenly decreases while the measured $\theta_{\text {air_i }}$ follows rising. This discrepancy is due to slight differences in the modelling of the evaporative cooling system.

The difference in evaporative pad activation also explains the small spikes that characterize the simulated trend of $\theta_{\text {air_i }}$ that have a major effect on the trend of simulated $R H_{\mathrm{i}}$, shown in Figure $4.12 \mathrm{~b}$. The simulated $R H_{\mathrm{i}}$ trend, in fact, is 
characterized by spikes that are not present in the measured one. Those spikes are caused by the sudden activation of the evaporative cooling pads that enhances the inlet of fresh saturated cool air inside the greenhouse. The inlet of this air causes a consequent decrease of $\theta_{\text {air_i }}$ (as visible in Figure 4.12a) that reflects in the sudden increase of $R H_{\mathrm{i}}$. In addition, it has to be considered the incoming air is characterized by a high $x_{\text {air_sup }}$ (due to the adiabatic cooling process that takes place inside the pads) that increases $x_{\text {air_i }}$ and, consequently, $R H_{\mathrm{i}}$. The $R H_{\mathrm{i}}$ spikes are present in the trend estimated by model since it considers that the pads are activated/deactivated with an hourly time step. In the real greenhouses the situation is quite different since pads are activated/deactivated with sub-hourly time steps, avoiding the presence of similar spikes in the monitored trend.

Figure $4.12 \mathrm{c}$ shows the comparison between the simulated and measured hourly $E_{\text {el }}$ due to fan activation. As visible from the chart, the main difference between the measured and simulated energy trends regards the maximum of energy consumption that is achieved daily. The measured $E_{\mathrm{el}}$, in fact, achieves a maximum daily value higher than the simulated $E_{\mathrm{el}}$. This difference is slight (less than $1 \mathrm{kWh}$ ) and it seems a sort of systematic error since it is appreciable during most of the days of the validation period, except July $10^{\text {th }}, 11^{\text {th }}, 12^{\text {th }}$, and $18^{\text {th }}$. This systematic error could be ascribable to a slight difference between the fan implemented in the energy model and the real ones installed in the monitored greenhouse. This difference may be due how the fan was implemented in the energy model or due some discrepancies between the specifications reported in the technical datasheet of the fans and their real performance once installed on field.

Another interesting element that stands out from the analysis of Figure 4.12c is the trend of both monitored and simulated $E_{\mathrm{el}}$ on July $11^{\text {th }}$ and $12^{\text {th }}$ that is considerably different from the other days. This difference is due to the $\theta_{\text {air_o }}$ values (visible in Figure 4.12a) that, on July $11^{\text {th }}$ and $12^{\text {th }}$, is at the minimum values of the analyzed period. The cooler $\theta_{\text {air_o }}$ makes it possible to maintain $\theta_{\text {set_c }}\left(27.7^{\circ} \mathrm{C}\right)$ without activating cooling ventilation. Therefore, during July $11^{\text {th }}$ and $12^{\text {th }}$ only dehumidification ventilation was activated, requiring a lower electrical power.

The reliability of the model that is proved from a qualitative point of view by Figure 4.12 , is also analyzed from a quantitative point of view comparing the calculated $M B E$ and $C v(R M S E)$ with the main thresholds for validating energy simulation models for buildings through calibrated simulations, as recommended in [220]. The sources of thresholds considered in this work are:

- American Society of Heating, Refrigerating and Air-Conditioning Engineers (ASHRAE) Guidelines 14 [225];

- International Performance Measurements and Verification protocol (IPMVP) [226];

- Federal Energy Management Program (FEMP) Measurements and Verification $(\mathrm{M} \& \mathrm{~V})$ guidelines [227]. 

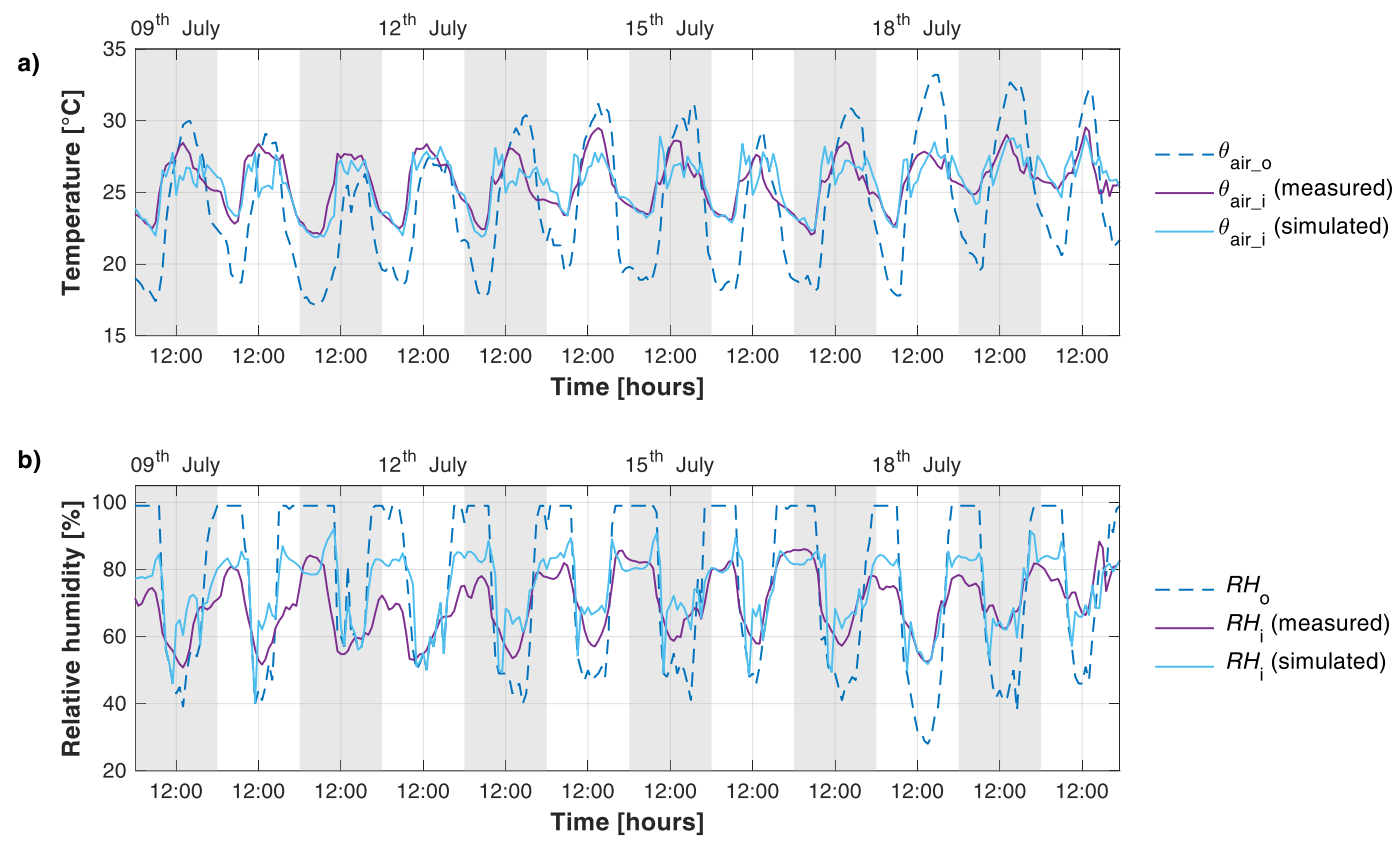

c)

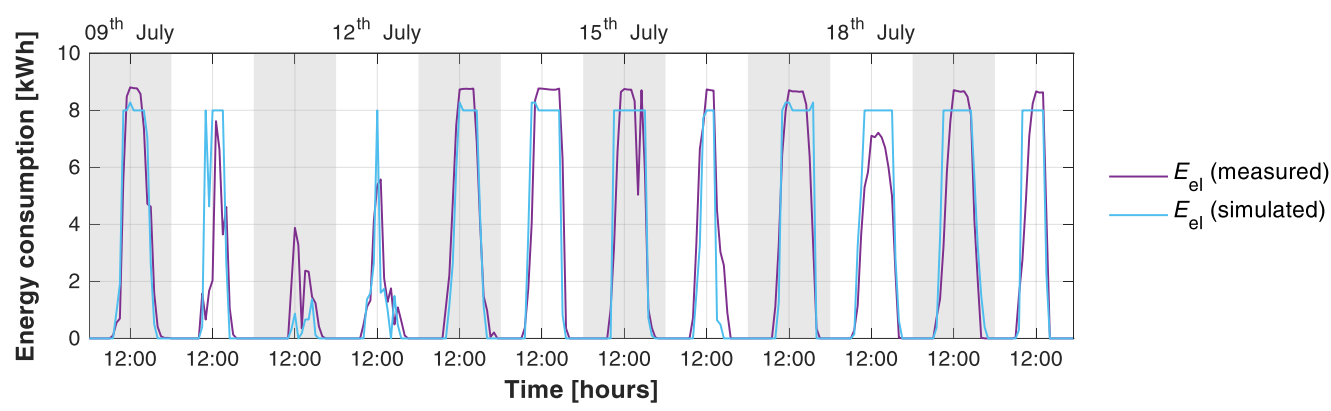

Figure 4.12 - Trends of monitored and simulated values of (a) indoor air temperature $\left(\theta_{\text {air_i }}\right)$, (b) relative humidity $\left(R H_{\mathrm{i}}\right),(\mathrm{c})$ and hourly electrical energy consumption. The outdoor air temperature $\left(\theta_{\text {air_o }}\right)$ and relative humidity $\left(R H_{\mathrm{o}}\right)$ are also showed.

In Table 4.3 , the values of $M B E$ and $C v(R M S E)$ for $\theta_{\text {air_i }}, R H_{\mathrm{i}}$ and $E_{\mathrm{el}}$ calculated before and after the calibration are shown together with the respective threshold values for hourly validation. In addition, the RMSE is also presented since even though ASHRAE Guidelines 14 [225], IPMVP [226] and FEMP [227] do not provide threshold values for this index, it represents a good measure of the extent of the error between the estimated trend and the simulated one. Please note that the goodness-of-fit indices reported in Table 4.3 were calculated considering the hours of the validation period only. The hours that were used for the model calibration were not considered for the calculation of those indices.

The values reported in Table 4.3 show that the calculated goodness-of-fit indices respect all the considered threshold values for both $\theta_{\text {air_i }}$ and $R H_{\mathrm{i}}$ (even the most restrictive ones from IPMVP), while $E_{\text {el }}$ does not respect only the $C v(R M S E)$ thresholds. The $R M S E$ is equal to $1.16^{\circ} \mathrm{C}$ for $\theta_{\text {air_i }}$ and $9.1 \%$ for $R H_{\mathrm{i}}$ demonstrating that the error of the model in estimating these two indoor environmental parameters is small during the validation period, confirming the reliability of the presented model. The obtained RMSE are similar to the ones found in other similar works in 
the literature [12,145]. The $R M S E$ for $E_{\mathrm{el}}$ is $1.35 \mathrm{kWh}$ a value that would further decrease if the systematic error that was highlighted in Figure $4.12 \mathrm{c}$ is not considered. This error could appear slightly high, but it should be considered that the developed model adopts an hourly simulation time step. To improve the energy consumption prediction, lower simulation time steps should be adopted to improve the simulation of the dynamics of fan activation. Nevertheless, lower simulation time steps would increase the computation time reducing the usability of the model.

The reliability of the model from the energy point over long periods of simulation can be also evaluated comparing the simulated and measured energy consumption over the entire validation period. The model, in fact, estimates an electrical energy consumption for dehumidification and cooling ventilation of $711 \mathrm{kWh}$, while the monitoring campaign provided an electrical energy consumption of $703 \mathrm{kWh}$. According to the formulation of Eq. (45), a $\Delta E_{\mathrm{el}}$ of roughly $1.1 \%$ can be calculated, meaning that there is just a slight overestimation of the electrical energy consumption. The model estimates that during the validation period no thermal energy was needed to heat the enclosure, a result that is confirmed by the monitoring campaign in which, the heating system was not operative.

The previous analyses show that the model is reliable for the purpose of this work and it can be adopted to perform long term simulations (for example, one year) considering different configurations of the greenhouses systems at both the envelope and system level to find the best configuration for improving the greenhouse energy performance. An example of model application is presented in the following section.

Table 4.3 - Values (before and after the calibration) of goodness-of-fit indices and threshold values for the hourly validation of the presented energy simulation model, concerning indoor air temperature $\left(\theta_{\text {air_i }}\right)$, relative humidity $\left(R H_{\mathrm{i}}\right)$ and hourly electrical energy consumption $\left(E_{\mathrm{el}}\right)$.

\begin{tabular}{|c|c|c|c|c|c|c|}
\hline \multirow{2}{*}{ Parameter } & \multirow{2}{*}{$\begin{array}{l}\text { Goodness- } \\
\text { of-fit index }\end{array}$} & \multicolumn{2}{|c|}{ Calculated value } & \multicolumn{3}{|c|}{$\begin{array}{c}\text { Threshold value } \\
\text { (hourly validation) }\end{array}$} \\
\hline & & $\begin{array}{c}\text { Before } \\
\text { calibration }\end{array}$ & $\begin{array}{c}\text { After } \\
\text { calibration }\end{array}$ & $\begin{array}{c}\text { ASHRAE } \\
{[225]}\end{array}$ & $\begin{array}{c}\text { IPMVP } \\
{[226]}\end{array}$ & $\begin{array}{c}\text { FEMP } \\
{[227]}\end{array}$ \\
\hline \multirow{3}{*}{$\theta_{\text {air_i }}$} & $M B E^{a}$ & $0.7 \%$ & $0.3 \%$ & $\pm 10 \%$ & $\pm 5 \%$ & $\pm 10 \%$ \\
\hline & $C v(R M S E)^{\mathrm{b}}$ & $5.2 \%$ & $4.5 \%$ & $30 \%$ & $20 \%$ & $30 \%$ \\
\hline & $R M S E^{\mathrm{c}}$ & $1.35^{\circ} \mathrm{C}$ & $1.16^{\circ} \mathrm{C}$ & - & - & - \\
\hline \multirow{3}{*}{$R H_{\mathrm{i}}$} & $M B E$ & $-10.6 \%$ & $-6.1 \%$ & $\pm 10 \%$ & $\pm 5 \%$ & $\pm 10 \%$ \\
\hline & $C v(R M S E)$ & $18.2 \%$ & $13.1 \%$ & $30 \%$ & $20 \%$ & $30 \%$ \\
\hline & RMSE & $12.7 \%$ & $9.1 \%$ & - & - & - \\
\hline \multirow{3}{*}{$E_{\mathrm{el}}$} & $M B E$ & $-33.2 \%$ & $-1.2 \%$ & $\pm 10 \%$ & $\pm 5 \%$ & $\pm 10 \%$ \\
\hline & $C v(R M S E)$ & $83.7 \%$ & $55.3 \%$ & $30 \%$ & $20 \%$ & $30 \%$ \\
\hline & RMSE & $2.04 \mathrm{kWh}$ & $1.35 \mathrm{kWh}$ & - & - & - \\
\hline
\end{tabular}

\footnotetext{
${ }^{a}$ Mean Bias Error

${ }^{\mathrm{b}}$ Coefficient of Variation of the Root Mean Square Error

${ }^{\mathrm{c}}$ Root Mean Square Error
} 


\subsection{Model Application}

The potentialities of the presented energy simulation model are several since it enhances the possibility to simulate different types of greenhouses in different climate conditions and specially to evaluate the effect of different types of control systems and new equipment. The results provide interesting information about the indoor environmental conditions and the related energy performance.

To exploit the potentialities of the presented model, the greenhouse described in section 3.2.1 is simulated in three different scenarios considering the climate conditions of three different locations presented in Table 4.4 (data from the Test Meteorological Year).

Table 4.4 - Outdoor climate conditions used to perform the simulations.

\begin{tabular}{|c|c|c|c|}
\hline Scenario & Location & $\begin{array}{c}\theta_{\text {air_o }} \\
\text { (average) }^{\mathrm{a}}\end{array}$ & $\begin{array}{c}\text { Annual solar } \\
\text { radiation }^{\mathrm{b}}\end{array}$ \\
\hline Verona (Italy) & Southern Europe & $12.3^{\circ} \mathrm{C}$ & $1,070 \mathrm{kWh} \mathrm{m}^{-2}$ \\
\hline Seville (Spain) & Southwestern Europe & $18.4^{\circ} \mathrm{C}$ & $1,769 \mathrm{kWh} \mathrm{m}^{-2}$ \\
\hline Nantes (France) & Northwestern Europe & $12.2^{\circ} \mathrm{C}$ & $1,180 \mathrm{kWh} \mathrm{m}^{-2}$ \\
\hline
\end{tabular}

In Figure 4.13, the absolute and cumulative frequencies of the simulated $\theta_{\text {air_i }}$ for the three climate scenarios are presented. The frequencies of Verona and Nantes scenarios are quite similar between them, while important differences stand out comparing those climate scenarios with the Sevilla one. Verona and Nantes scenarios, in fact, are characterized by a higher frequency of lower $\theta_{\text {air_i }}$ since the cumulative frequency of the class $20{ }^{\circ} \mathrm{C}$ is higher than $70 \%$ in both the climate scenarios. On the contrary, in Sevilla scenario higher temperatures can be observed and the cumulative frequency of $20{ }^{\circ} \mathrm{C}$ is $50 \%$, considerably lower than in the other considered climate scenarios. This different distribution of $\theta_{\text {air_i }}$ frequency will reflect also in different thermal and electrical energy consumption that are showed later in the text.

The absolute frequency distributions presented in Figure 4.13 show that $\theta_{\text {air_i }}$ is always higher than $14{ }^{\circ} \mathrm{C}$. The most frequent value of $\theta_{\text {air_i }}$ is $16^{\circ} \mathrm{C}$ for all the climate scenarios and its absolute frequency ranges between around 2,100 (Seville) and 3,200 (Nantes). This high absolute frequency is explained considering that $16^{\circ} \mathrm{C}$ is the set point temperature that is maintained by the climate control system during the day. During nighttime, the climate control system maintains a setback temperature of $14^{\circ} \mathrm{C}$. Consequently, 14 and $16^{\circ} \mathrm{C}$ are characterized by very high absolute frequencies. On the contrary, $15^{\circ} \mathrm{C}$ has a very low absolute frequency since this $\theta_{\text {air_i }}$ value can occur only in certain conditions during nighttime and in those hours in which $\theta_{\text {air_i }}$ increases from 14 to $16^{\circ} \mathrm{C}$ and vice versa. 

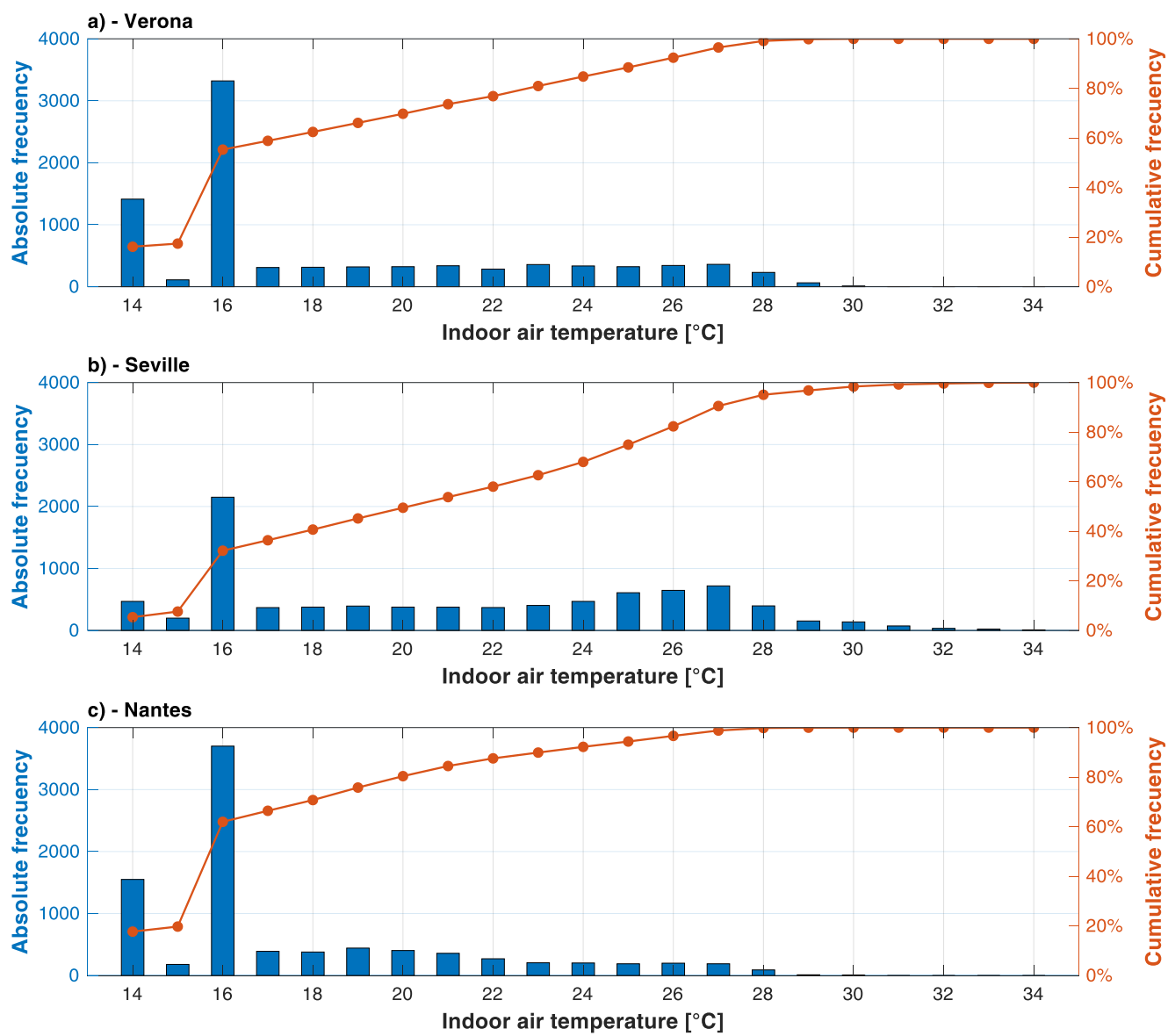

Figure 4.13 - Absolute and cumulative frequencies of indoor air temperature for the considered scenarios of Verona (a), Seville (b) and Nantes (c).

In Figure 4.14, the cumulative electrical and thermal energy consumption for heating and ventilation in the simulated climate scenarios are presented. Figure 4.14a shows that the higher electrical energy consumption is from Seville scenario where the warm outdoor weather conditions entail a considerably electrical energy consumption for fan activation $\left(10,180 \mathrm{kWh}_{\mathrm{el}}, 6.02 \mathrm{kWh}_{\mathrm{el}} \mathrm{m}^{2}\right)$. That energy consumption value is considerably higher than the ones of Verona $\left(2,161 \mathrm{kWh}_{\mathrm{el}}\right.$, $1.28 \mathrm{kWh}_{\mathrm{el}} \mathrm{m}^{2}$ ) and Nantes $\left(534 \mathrm{kWh}_{\mathrm{el}}, 0.32 \mathrm{kWh}_{\mathrm{el}} \mathrm{m}^{2}\right)$.

An opposite trend regards the thermal energy consumption, as visible from Figure $4.14 \mathrm{~b}$. Seville scenario, in fact, is characterized by a yearly thermal energy consumption of $57,063 \mathrm{kWh}_{\mathrm{th}}$ (around $33.77 \mathrm{kWh}_{\mathrm{th}} \mathrm{m}^{2}$ ) a value considerably lower than the one found for Nantes scenario $\left(199,397 \mathrm{kWh}_{\mathrm{th}}\right.$, around $\left.117.99 \mathrm{kWh}_{\mathrm{th}} \mathrm{m}^{2}\right)$ and Verona one $\left(269,528 \mathrm{kWh}_{\mathrm{th}}\right.$, around $\left.159.48 \mathrm{kWh}_{\mathrm{th}} \mathrm{m}^{2}\right)$.

The presented results agree with other studies present in scientific literature that underline how most of the energy consumption of greenhouse is due to space heating [17,19]. For this reason, future investigations should aim at reducing heating energy consumption exploiting energy simulation tools such the one presented in this work. The estimated thermal energy consumption results considerably higher than the one of other agricultural building characterized by high values of energy consumption for climate control, such as livestock houses [134]. 

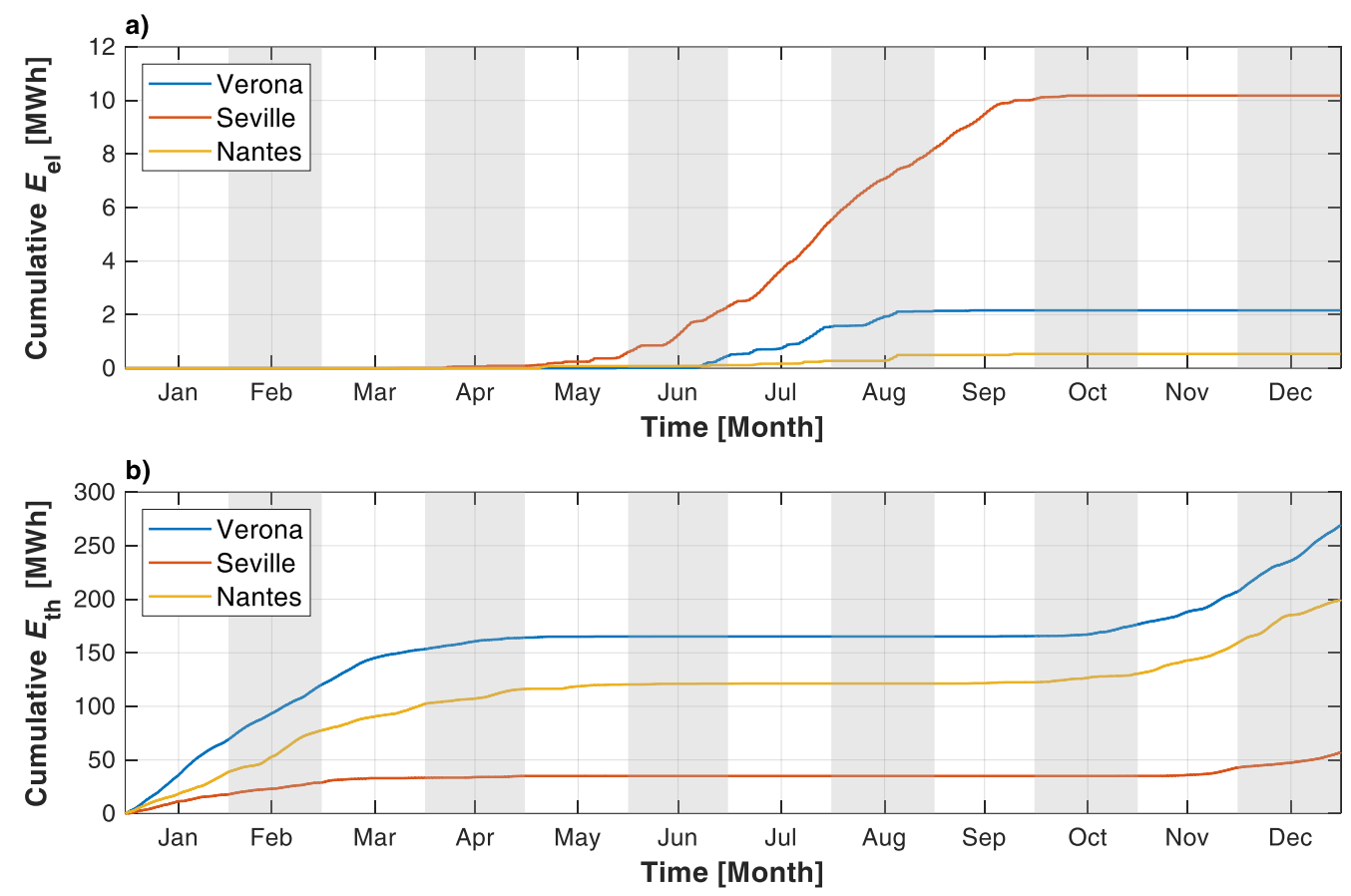

Figure 4.14 - Cumulative electrical (a) and thermal (b) energy consumption for the considered climate scenarios.

The previously presented electrical energy consumption was estimated considering variable angular speed fans installed in the simulated greenhouse, through the procedure described in section 4.3.3. In Table 4.5, the previously obtained electrical energy consumption are compared with the ones that were obtained considering a set of 15 fixed angular speed fans of $0.56 \mathrm{~kW}(0.75 \mathrm{hp})$ and $19,100 \mathrm{~m}^{3} \mathrm{~h}^{-1}$ of maximum flow rate installed in the greenhouse, as it can be observed in many existing structures. As visible from the table, variable angular speed fans entail a decrease of the electrical energy consumption for ventilation between 24 and $34 \%$ if compared with fixed angular speed fans.

Table 4.5 - Comparison between electrical energy consumption for ventilation considering variable and fixed angular speed fans.

\begin{tabular}{cccc}
\hline Scenario & $\begin{array}{c}\boldsymbol{E}_{\text {el }} \\
\text { (variable angular } \\
\text { speed fans) }\end{array}$ & $\begin{array}{c}\boldsymbol{E}_{\text {el }} \\
\text { (fixed angular } \\
\text { speed fans) }\end{array}$ & $\begin{array}{c}\text { Energy saving due } \\
\text { to variable angular } \\
\text { speed fans }\end{array}$ \\
\hline Verona (Italy) & $2,161 \mathrm{kWh}_{\mathrm{el}}$ & $2,958 \mathrm{kWh}_{\mathrm{el}}$ & $-27 \%$ \\
Seville (Spain) & $10,180 \mathrm{kWh}_{\mathrm{el}}$ & $13,441 \mathrm{kWh}_{\mathrm{el}}$ & $-24 \%$ \\
Nantes (France) & $534 \mathrm{kWh}_{\mathrm{el}}$ & $810 \mathrm{kWh}_{\mathrm{el}}$ & $-34 \%$ \\
\hline
\end{tabular}

\subsection{Final considerations}

In this chapter a coupled first-principle dynamic energy simulation model for the calculation of energy consumption and indoor environmental conditions of fully mechanically ventilated greenhouses was elaborated and presented. The model was calibrated and validated against a subset of the real monitored from the case study presented in Chapter 3 in compliance with the main protocols for building energy 
simulation present in literature. The model proved to be reliable in providing the estimation of time profiles of the indoor air temperature and relative humidity in accordance with those measured in the experimentation. The model also properly estimates the electrical energy consumption for dehumidification and cooling ventilation.

The main strength of the presented model lies in its integrated approach in simulating the greenhouse dynamics (e.g. thermal and hygric behavior of the building) and the consequent dynamic response of the climate control systems. The presented energy model integrates the most adopted climate control equipment in large multi-span greenhouses, including the new variable angular speed fans, a promising energy-efficient technology for greenhouses that has yet to be exploited in this sector. Integration of such fans in this simulation model, represents a novelty in literature.

The presented model could represent a decision support tool for the stakeholders in the energy design and retrofit stage of fully-mechanically ventilated greenhouses. Stakeholders, in fact, will use this energy simulation model to create a greenhouse "digital mock-up" to test a wide range of configuration creating scenarios characterized by different solutions with different solutions at both envelope and system level, by different features production cycle (e.g. cultivated crop and cycle length), and by different settings of climate control system (e.g. set point temperatures and minimum ventilation). The results of those simulations could lead stakeholders to adopt the most energy-efficient solution to improve the energy performance for climate control of greenhouses. An example of the application of this model was presented in this work, considering various solutions at system level (variable and fixed angular speed fans) in different outdoor climate conditions.

Further improvements and fine-tuning calibrations could convert the presented model also in a digital twin of existing greenhouses, providing analytics useful for improving the greenhouse management and further improving the energy performance during the operational stage. Future model improvements may integrate additional equipment for climate control, new technologies and new calculation modules for different purposes (e.g. simulation of natural ventilation, the estimation of on-site energy renewable energy production and the assessment of greenhouse gas emissions).

\subsection{Chapter nomenclature}

$\begin{array}{ll}\mathcal{A}, \tilde{\mathcal{A}} & \text { Sets of simulated and measured values (indoor air temperature) } \\ \mathcal{B}, \widetilde{\mathcal{B}} & \text { Sets of simulated and measured values (indoor relative humidity) } \\ \mathcal{C}, \tilde{\mathcal{C}} & \text { Sets of simulated and measured values (electrical energy consumption) } \\ A_{\mathrm{gh}} & \text { Greenhouse floor area }\left[\mathrm{m}^{2}\right] \\ A_{\mathrm{gl}} & \text { Area of a surface of the greenhouse envelope }\left[\mathrm{m}^{2}\right] \\ a_{\mathrm{flow}}-c_{\text {flow }} & \text { Regression coefficients for fan ventilation flow rate } \\ a_{\text {perf }}-i_{\text {perf }} & \text { Regression coefficients for fan performance }\end{array}$




\begin{tabular}{|c|c|}
\hline$\left\langle C_{\mathrm{CO}_{2 \mathrm{i}} \mathrm{i}}\right\rangle$ & Indoor $\mathrm{CO}_{2}$ concentration $[\mathrm{ppm}]$ \\
\hline$C_{\mathrm{gh}}$ & Greenhouse heat capacity $\left[\mathrm{kJ} \mathrm{K}^{-1}\right]$ \\
\hline$c_{\text {air }}$ & Air specific heat capacity $\left[\mathrm{J} \mathrm{kg}^{-1} \mathrm{~K}^{-1}\right]$ \\
\hline$C v(R M S E)$ & Coefficient of variation of the $R M S E[\%]$ \\
\hline$E_{\mathrm{el}}$ & Electrical energy consumption [kWh] \\
\hline$E_{\text {el_cool }}$ & Electrical energy consumption for cooling ventilation [kWh] \\
\hline$E_{\text {el_deh }}$ & Electrical energy consumption for dehumidification [kWh] \\
\hline$E_{\text {th }}$ & Thermal energy consumption [kWh] \\
\hline$e$ & Euler's number \\
\hline$F_{\mathrm{v}}$ & View factor $[-]$ \\
\hline$g_{\mathrm{sc}}$ & Total solar transmission coefficient of the screen $[-]$ \\
\hline$H_{\text {tr_em }}$ & Heat transfer coefficient $\left[\mathrm{W} \mathrm{K}^{-1}\right]$ \\
\hline$H_{\text {tr_fen }}$ & Heat transfer coefficient $\left[\mathrm{W} \mathrm{K}^{-1}\right]$ \\
\hline$H_{\text {tr_is }}$ & Heat transfer coefficient $\left[\mathrm{W} \mathrm{K}^{-1}\right]$ \\
\hline$H_{\text {tr_ms }}$ & Heat transfer coefficient $\left[\mathrm{W} \mathrm{K}^{-1}\right]$ \\
\hline$H_{\mathrm{ve}}$ & Ventilation heat transfer coefficient $\left[\mathrm{W} \mathrm{K}^{-1}\right]$ \\
\hline$h_{\mathrm{t}}$ & Sensible heat transfer coefficient due to transpiration $\left[\mathrm{W} \mathrm{m}{ }^{-2} \mathrm{~K}^{-1}\right]$ \\
\hline$i$ & $i$-th fan of the greenhouse \\
\hline$j$ & $j$-th simulation time-step \\
\hline$k$ & $k$-th surface of the greenhouse envelope \\
\hline$L A I$ & Leaf Area Index $\left[\mathrm{m}^{2} \mathrm{~m}^{-2}\right]$ \\
\hline$m_{\mathrm{LAI}}$ & Slope of the $L A I$ function $\left[\mathrm{m}^{2} \mathrm{~m}^{-2}\right]$ \\
\hline$\dot{m}_{\text {vap }}$ & Plant transpiration water vapor flow $\left[\mathrm{mg}_{\mathrm{vap}} \mathrm{m}^{-2} \mathrm{~s}^{-1}\right]$ \\
\hline$M B E$ & Mean Bias Error [\%] \\
\hline$n_{\mathrm{ach}}$ & Ventilation air changes $\left[\mathrm{h}^{-1}\right]$ \\
\hline$n_{\text {fan }}$ & Number of adopted fans \\
\hline$n_{\text {set }}$ & Cardinality of a set of elements \\
\hline$n_{\text {sim }}$ & Number of simulation time-steps \\
\hline$n_{\text {sur }}$ & Number of envelope surfaces \\
\hline$p_{\text {atm }}$ & Atmospheric pressure $[\mathrm{Pa}]$ \\
\hline$p_{\mathrm{v}}$ & Water vapor pressure $[\mathrm{Pa}]$ \\
\hline$p_{\mathrm{vs}}$ & Saturation water vapor pressure $[\mathrm{Pa}]$ \\
\hline$q_{\mathrm{LAI}}$ & $y$-intercept of $L A I$ function $\left[\mathrm{m}^{2} \mathrm{~m}^{-2}\right]$ \\
\hline$R_{\mathrm{b}}$ & Tipping coefficient of the solar radiation $[-]$ \\
\hline$R H_{\mathrm{i}}$ & Indoor air relative humidity [\%] \\
\hline$R H_{\text {i_max }}$ & Maximum indoor air relative humidity [\%] \\
\hline$R H_{\mathrm{o}}$ & Outdoor air relative humidity [\%] \\
\hline$R M S E$ & Root Mean Square Error \\
\hline$S F P$ & Specific fan performance $\left[\mathrm{m}^{3} \mathrm{Wh}^{-1}\right]$ \\
\hline$S F P_{\text {fix }}$ & Specific fan performance of fixed angular speed fans $\left[\mathrm{m}^{3} \mathrm{Wh}^{-1}\right]$ \\
\hline$S F P_{\text {var }}$ & Specific fan performance of variable angular speed fans $\left[\mathrm{m}^{3} \mathrm{Wh}^{-1}\right]$ \\
\hline SH & Simple hourly method \\
\hline$S H G C$ & Solar Heat Gain Coefficient $[-]$ \\
\hline$U$-value & Stationary thermal transmittance $\left[\mathrm{W} \mathrm{m} \mathrm{m}^{-2} \mathrm{~K}^{-1}\right]$ \\
\hline$V_{\mathrm{gh}}$ & Greenhouse net volume $\left[\mathrm{m}^{3}\right]$ \\
\hline$\dot{V}_{\text {air }}$ & Ventilation air flow $\left[\mathrm{m}^{3} \mathrm{~h}^{-1}\right]$ \\
\hline$\dot{V}_{\text {cool }}$ & Ventilation air flow for cooling $\left[\mathrm{m}^{3} \mathrm{~h}^{-1}\right]$ \\
\hline$\dot{V}_{\mathrm{deh}}$ & Ventilation air flow for dehumidification $\left[\mathrm{m}^{3} \mathrm{~h}^{-1}\right]$ \\
\hline$\dot{V}_{\text {fan_fix }}$ & Ventilation flow rate of fixed angular speed fans $\left[\mathrm{m}^{3} \mathrm{~h}^{-1}\right]$ \\
\hline
\end{tabular}




\begin{tabular}{|c|c|}
\hline$\dot{V}_{\text {fan_var }}$ & Ventilation flow rate of variable angular speed fans $\left[\mathrm{m}^{3} \mathrm{~h}^{-1}\right]$ \\
\hline$\dot{V}_{\text {inst }}$ & Maximum greenhouse ventilation capacity $\left[\mathrm{m}^{3} \mathrm{~h}^{-1}\right]$ \\
\hline$V P D$ & Vapor Pressure Deficit $[\mathrm{Pa}]$ \\
\hline$x_{\text {air_i }}$ & Indoor air humidity ratio $\left[\mathrm{g}_{\text {vap }} \mathrm{kg}_{\text {air }}\right]$ \\
\hline$x_{\text {air_i_MAX }}$ & Maximum indoor air humidity ratio $\left[\mathrm{g}_{\mathrm{vap}} \mathrm{kg}_{\text {air }}\right]$ \\
\hline$x_{\text {air_sup }}$ & Supply air humidity ratio $\left[\mathrm{g}_{\mathrm{vap}} \mathrm{kg}_{\mathrm{air}}\right]$ \\
\hline$z_{1-6}$ & Regression coefficients \\
\hline$\gamma_{\text {floor }}$ & Calibration parameter for the floor $[-]$ \\
\hline$\gamma_{\text {glass }}$ & Calibration parameter for glazed surfaces $[-]$ \\
\hline$\gamma_{\text {hig }}$ & Calibration parameter for the greenhouse hygric capacity $[-]$ \\
\hline$\gamma_{\mathrm{m} \_\mathrm{LAI}}$ & Calibration parameter for $L A I$ function slope $[-]$ \\
\hline$\gamma_{q_{-} \text {LAI }}$ & Calibration parameter for $L A I$ function y-intercept [-] \\
\hline$\gamma_{\text {th }}$ & Calibration parameter for the greenhouse thermal capacity [-] \\
\hline$\Delta E_{\mathrm{el}}$ & Energy consumption deviation $[\%]$ \\
\hline$\Delta p_{\text {st }}$ & Static pressure difference between inside and outside $[\mathrm{Pa}]$ \\
\hline$\Delta \theta_{\text {air_i }}$ & Thermal gradient inside the greenhouse $\left[{ }^{\circ} \mathrm{C}\right]$ \\
\hline$\Delta \tau$ & Time step duration $[s]$ \\
\hline$\delta$ & Dimensionless coefficient for plant transpiration $[-]$ \\
\hline$\varepsilon$ & Direct saturation effectiveness of the evaporative pads [-] \\
\hline$\eta_{H}$ & Global efficiency of the heating system $[-]$ \\
\hline$\theta_{\text {air_i }}$ & Indoor air temperature $\left[{ }^{\circ} \mathrm{C}\right]$ \\
\hline$\theta_{\text {air_o }}$ & Outdoor air temperature $\left[{ }^{\circ} \mathrm{C}\right]$ \\
\hline$\theta_{\text {air_o_db }}$ & Dry-bulb temperature of outdoor air $\left[{ }^{\circ} \mathrm{C}\right]$ \\
\hline$\theta_{\text {air_o_wb }}$ & Wet-bulb temperature of outdoor air $\left[{ }^{\circ} \mathrm{C}\right]$ \\
\hline$\theta_{\text {air_sup }}$ & Supply air temperature $\left[{ }^{\circ} \mathrm{C}\right]$ \\
\hline$\theta_{\mathrm{m}}$ & Building mass temperature $\left[{ }^{\circ} \mathrm{C}\right]$ \\
\hline$\theta_{\mathrm{s}}$ & Temperature of the indoor building surface $\left[{ }^{\circ} \mathrm{C}\right]$ \\
\hline$\theta_{\text {set_c }}$ & Air set point temperature for cooling $\left[{ }^{\circ} \mathrm{C}\right]$ \\
\hline$\theta_{\text {set_H }}$ & Air set point temperature for heating $\left[{ }^{\circ} \mathrm{C}\right]$ \\
\hline$\lambda$ & Latent heat of vaporization of water $\left[\mathrm{MJ} \mathrm{kg}^{-1}\right]$ \\
\hline$\mu$ & Angle between beam solar radiation and the normal to the surface $\left[^{\circ}\right]$ \\
\hline$\rho_{\text {air }}$ & Volumetric mass density of air $\left[\mathrm{kg}^{3} \mathrm{~m}^{3}\right]$ \\
\hline$\sigma$ & Psychrometric constant $\left[\mathrm{Pa} \mathrm{K}^{-1}\right]$ \\
\hline$\tau$ & Time instant $[\mathrm{s}]$ \\
\hline$\phi_{\mathrm{H} / \mathrm{C}_{n} \mathrm{nd}}$ & Supplemental heat load for heating or cooling [W] \\
\hline$\phi_{\text {ia }}$ & Convective heat flow [W] \\
\hline$\phi_{\mathrm{m}}$ & Radiative heat flow [W] \\
\hline$\phi_{\text {lat_i }}$ & Latent heat load due to plant transpiration $[\mathrm{W}]$ \\
\hline$\phi_{\text {sens_i }}$ & Solar sensible heat gain (after plant transpiration) [W] \\
\hline$\phi_{\text {st }}$ & Radiative heat flow $[\mathrm{W}]$ \\
\hline$\phi_{\text {sol_b }}$ & Beam outdoor solar radiation on horizontal plane $\left[\mathrm{W} \mathrm{m}^{-2}\right]$ \\
\hline$\phi_{\text {sol_d }}$ & Diffuse outdoor solar radiation on horizontal plane $\left[\mathrm{W} \mathrm{m}^{-2}\right]$ \\
\hline$\phi_{\text {sol_i }}$ & Solar radiation that enters inside the greenhouse $[\mathrm{W}]$ \\
\hline$X, \tilde{X}$ & Simulated and measured generic time profiles \\
\hline$\chi_{\mathrm{j}}, \tilde{\chi}_{\mathrm{j}}$ & Simulated and measured generic value \\
\hline$\Psi, \widehat{\Psi}$ & Initial and optimal set of calibration parameters \\
\hline$\Omega, \widehat{\Omega}$ & Initial and optimal set of calibration parameters \\
\hline$\omega$ & Coefficient for water vapor sorption and storage $[-]$ \\
\hline
\end{tabular}




\section{Chapter 5}

\section{A new modelling framework for fully mechanically controlled livestock houses}

\begin{tabular}{c|c} 
Objective & $\begin{array}{l}\text { To investigate the nexus between climate control and energy consumption in } \\
\text { fully mechanically controlled livestock houses through a numerical approach. }\end{array}$ \\
\hline Outcome & $\begin{array}{l}\text { Two dynamic energy simulation models for estimating the indoor climate } \\
\text { conditions and the thermal and electrical energy consumption for climate } \\
\text { control of broiler houses and pig houses. }\end{array}$ \\
\hline Highlights & $\begin{array}{l}\text { Three main categories of energy models for livestock houses are } \\
\text { present in literature. }\end{array}$ \\
- & $\begin{array}{l}\text { A new modelling framework for mechanically controlled livestock } \\
\text { houses is presented. }\end{array}$ \\
The developed framework is customized and validated for broiler \\
houses and pig houses. \\
The adopted simulation method is compared with two alternative \\
simulation methods. \\
The adopted simulation method is a good compromise between \\
reliability and customizability.
\end{tabular}





\subsection{A numerical approach for livestock houses}

As presented in the general framework of Chapter 2 and remarked by the results of the experimental activity performed in the pig houses of section 3.3.3, climatecontrolled livestock house are characterized by a high energy consumption for climate control. This energy consumption represents an important obstacle in the path toward the sustainability of these agricultural systems. For this reason, improvements of the energy performance of climate-controlled livestock house are needed and, similarly to what it was stated for greenhouses (section 4.1), numerical models are fundamentals for this purpose. This is since they enhance the assessment of the effectiveness of energy-efficient solutions for livestock houses design and retrofit in standardized conditions, representing important decision tools for stakeholders.

The objective of this chapter, hence, is to develop an energy simulation framework for fully mechanically controlled livestock houses that could be customized for specific livestock productions. For achieving this objective, a review about the energy models for livestock houses present in literature is performed (section 5.2). Then, the general modelling framework for livestock houses is set (section 5.3) and then it is customized and validated for broiler houses (sections 5.4 and 5.5) and growing-finishing pig houses (sections 5.6 and 5.7). These two animal productions were selected since they are characterized by high shares of energy consumption for climate control (section 2.3.2.) and since they are the livestock production with the greatest volume of produced meat at a global level [228]. Finally, the energy simulation method on which the developed models rely is compared with other two alternative methods to evaluate the main differences in the final results (section 5.9).

\subsection{Literature review: energy models for livestock houses}

Specific models for the simulation of the thermal behavior of livestock houses aimed at estimating thermal loads, energy consumption and indoor climate conditions are present in literature. These specific models were found through a specific literature review focused on monogastric animals -similarly to what it was done in section 2.3- and they are summarized in Table 5.1. The table shows that the considered simulation models can be grouped in three main categories, namely steady-state energy models, dynamic energy models and Computational Fluid Dynamics ( $C F D)$ models. Steady-state energy models are usually provided by agricultural engineering handbooks and they are generally used for design purposes and for analyzing the animal heat stress risk in specific periods, using, for example, the Temperature Humidity Index (THI) [166]. Dynamic energy models are used for the estimation of the energy performance of livestock houses and for the assessment of the indoor climate conditions inside the enclosure. Since these models usually adopt lumped parameters, the estimated indoor climate conditions are the average 
ones of the enclosure, without the possibility of estimating, for example, the gradients of these parameters. To have a more detailed view about the indoor climate conditions of livestock houses, $C F D$ models are preferred since they enable more detailed analyses by considering the spatial distribution of indoor environmental parameters, such as indoor air temperature and air velocity. From Table 5.1, it stands out that very few simulation models enable the estimation of the energy consumption for climate control, representing an important gap in literature.

Table 5.1 - Simulation models for livestock houses of monogastric animals considered in the literature review.

\begin{tabular}{|c|c|c|c|c|c|c|}
\hline & Reference & Year & Source* $^{*}$ & Type $^{* *}$ & Outputs ${ }^{* * * *}$ & Validation \\
\hline \multirow{6}{*}{ 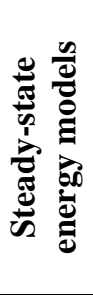 } & Albright [229] & 1990 & $\mathrm{H}$ & GH & $\mathrm{TL}$ & No \\
\hline & Carvalho et al. [230] & 2008 & $\mathrm{P}$ & $\mathrm{BH}$ & ASI+IEC & Yes \\
\hline & Esmay and Dixon [159] & 1986 & $\mathrm{H}$ & $\mathrm{GH}$ & $\mathrm{TL}$ & No \\
\hline & Hamilton et al. [146] & 2016 & $\mathrm{~J}$ & $\mathrm{BH}$ & $\mathrm{EC}+\mathrm{IEC}+\mathrm{TL}$ & Yes \\
\hline & Lindley and Whitaker [128] & 1996 & $\mathrm{H}$ & $\mathrm{GH}$ & $\mathrm{TL}$ & No \\
\hline & Midwest Plan Service [231] & 1983 & $\mathrm{H}$ & $\mathrm{GH}$ & $\mathrm{TL}$ & No \\
\hline \multirow{13}{*}{ 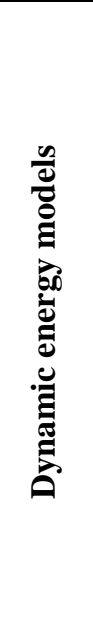 } & Axaopoulos et al. [232] & 2014 & $\mathrm{~J}$ & $\mathrm{PH}$ & $\mathrm{IEC}+\mathrm{TL}$ & No \\
\hline & Daskalov et al. [233] & 2006 & $\mathrm{~J}$ & GH & IEC+TL & Yes \\
\hline & Daskalov [234] & 1997 & $\mathrm{~J}$ & $\mathrm{PH}$ & $\mathrm{IEC}+\mathrm{TL}$ & Yes \\
\hline & El Mogharbel et al. [123] & 2014 & $\mathrm{~J}$ & $\mathrm{BH}$ & $\mathrm{EC}+\mathrm{IEC}+\mathrm{TL}$ & No \\
\hline & Fabrizio et al. [124] & 2014 & $\mathrm{~J}$ & $\mathrm{PH}$ & ASI+EC+IEC & No \\
\hline & Jackson et al. [235] & 2017 & $\mathrm{~J}$ & $\mathrm{PH}$ & IEC & Yes \\
\hline & Jackson et al. [236] & 2018 & $\mathrm{~J}$ & $\mathrm{PH}$ & IEC & Yes \\
\hline & Lee et al. [127] & 2020 & $\mathrm{~J}$ & DH & $\mathrm{IEC}+\mathrm{TL}$ & Yes \\
\hline & Liberati and Zappavigna [237] & 2005 & $\mathrm{P}$ & GH & AWI+IEC & Yes \\
\hline & Panagakis and Axaopoulos [165] & 2008 & $\mathrm{~J}$ & $\mathrm{PH}$ & ASI+IEC & No \\
\hline & Seo et al [238] & 2009 & $\mathrm{~J}$ & $\mathrm{BH}$ & $\mathrm{IEP}+\mathrm{TL}$ & Yes \\
\hline & Xie et al. [126] & 2019 & $\mathrm{~J}$ & $\mathrm{PH}$ & $\mathrm{EC}+\mathrm{IEC}+\mathrm{TL}$ & Yes \\
\hline & Zhou et al. [125] & 2017 & $\mathrm{P}$ & $\mathrm{BH}$ & EC+IEC & No \\
\hline \multirow{14}{*}{ S } & Bjerg et al. [239] & 2018 & $\mathrm{~J}$ & $\mathrm{PH}$ & ASI+IEC & No \\
\hline & Blanes-Vidal et al. [240] & 2008 & $\mathrm{~J}$ & BH & IEC & Yes \\
\hline & Bustamante et al. [241] & 2017 & $\mathrm{~J}$ & $\mathrm{BH}$ & IEC & Yes \\
\hline & Fidaros et al. [242] & 2018 & $\mathrm{~J}$ & $\mathrm{BH}$ & IEC & Yes \\
\hline & Guerra-Galdo et al. [243] & 2015 & $\mathrm{~J}$ & $\mathrm{BH}$ & ASI+IEC & No \\
\hline & Kwon et al. [244] & 2015 & $\mathrm{~J}$ & $\mathrm{BH}$ & IEC & Yes \\
\hline & Mostafa et al. [245] & 2012 & $\mathrm{~J}$ & $\mathrm{BH}$ & IEC & Yes \\
\hline & Qin et al. [246] & 2020 & $\mathrm{~J}$ & $\mathrm{PH}$ & IEC & Yes \\
\hline & Rojano et al. [247] & 2015 & $\mathrm{~J}$ & $\mathrm{BH}$ & IEC & Yes \\
\hline & Rong [248] & 2020 & $\mathrm{~J}$ & $\mathrm{PH}$ & IEC & Yes \\
\hline & Rong and Aarnink [249] & 2019 & $\mathrm{~J}$ & $\mathrm{PH}$ & IEC & Yes \\
\hline & Seo et al. [250] & 2012 & $\mathrm{~J}$ & $\mathrm{PH}$ & IEC & Yes \\
\hline & Tabase et al. [251] & 2020 & $\mathrm{~J}$ & $\mathrm{PH}$ & IEC & Yes \\
\hline & Zhu et al. [252] & 2012 & $\mathrm{P}$ & $\mathrm{BH}$ & IEC & No \\
\hline
\end{tabular}

*Journal (J), Proceedings (P), Handbook (H)

${ }^{* *}$ Generic animal house $(\mathrm{GH})$, Broiler house $(\mathrm{BH})$, Pig house $(\mathrm{PH})$, Duck house (DH)

***A Animal stress indexes (ASI), Energy consumption (EC), Indoor environmental conditions (IEC), Thermal loads (TL) 


\subsubsection{Steady-state energy models}

In reference handbooks of agricultural engineering about environmental control, various Authors presented different formulations of the steady-state heat balance that were specifically developed for livestock houses. Those heat balances were not addressed at estimating or improving the energy performance of these buildings, but they are mainly used by agricultural engineers for sizing the climate control system, such as the number of fans and the heating capacity of the air heaters. In addition, these models can be also adopted for assessing the potential heat stress risk for the reared animals in specific periods of the year, such as the warm season.

In literature, the reference formulation of the sensible heat balance in steadystate conditions for a generic livestock house was provided by Albright [229] and it reads:

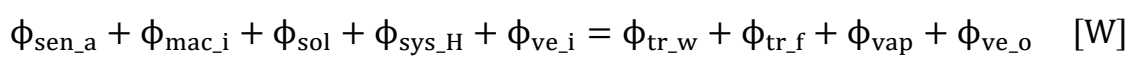

In Eq. (46) the term $\phi_{\text {sen_a }}$ represents the sensible heat flow from animals inside the enclosure and it mainly depends on the considered animal species, being related to animal body mass. Data about animal sensible heat production can be found in handbooks [159] or in technical reports [253]. If referred to unit of useful floor area, $\phi_{\text {sen_a }}$ is considerably higher than civil buildings: for example, in broiler house $\phi_{\text {sen_a }}$ can reach values around $180 \mathrm{~W} \mathrm{~m}^{-2}$, while in residential buildings -such as houses and restaurants- this value rarely exceeds $20 \mathrm{~W} \mathrm{~m}^{-2}$ [211].

The term $\phi_{\text {mac } \_i}$ is the sensible heat flow from internal machineries, such as fan motors and lights. According to the formulation of the heat balance of Midwest Plan Service [231], this term can be neglected in the balance of a livestock house due to its minor relevance. This simplification is furtherly encouraged by the current widespread use of energy-efficient technologies -e.g. led/gas-discharge lamps and brushless motors- that enables high performance with a minimum overheating of the devices and a consequent lower release of heat inside the enclosure.

The term $\phi_{\text {sol }}$ represents the heat flow due to the solar radiation, while $\phi_{\text {sys_H }}$ is the supplemental heating heat flow provided by supplemental heating systems, such as air heaters or heating lamps. The terms $\phi_{\mathrm{ve}_{-} \mathrm{i}}$ and $\phi_{\mathrm{ve} \mathrm{e}_{\mathrm{o}}}$ are sensible heat flows due to the ventilation air entering and leaving the enclosure, respectively. These terms play a fundamental role in the energy balance of livestock houses because in these buildings high ventilation rates are needed for removing the high concentration of contaminants -e.g. $\mathrm{CO}_{2}$ and $\mathrm{NH}_{3}$ - and to cool animals [159] since no mechanical cooling is usually present inside livestock houses. The increase of $\phi_{\mathrm{ve}_{-} \mathrm{i}}$ and $\phi_{\mathrm{ve} \_\mathrm{o}}$ usually enhances an improvement of the Indoor Air Quality (IAQ) at the expenses of a higher thermal and electrical energy consumption, an issue that will be deepened in Chapter 7 of this thesis. 
In Eq. (46), the heat losses due to transmission through the building envelope are split into two terms. The term $\phi_{\text {tr_w }}$ represents the heat losses through the walls and roof, while $\phi_{\mathrm{tr}_{-} \mathrm{f}}$ represents the heat loss through the floor. Even though $\phi_{\mathrm{tr}-\mathrm{w}}$ and $\phi_{\text {tr_f }}$ represent transmission heat flows through the building envelope, various Authors [165,229] separated these terms because the heat transfer via the ground constitutes a challenging issue due to its complexity, especially in livestock houses. In pig houses, for example, the presence of slatted or partially slatted floors and manure pits may complicate the estimation of the heat transfer via the ground. Panagakis and Axaopoulos [165] solved this problem calculating firstly the heat transfer coefficient of the pit walls and then the heat transfer coefficient of the pit floor. For this calculation, they applied a series of thermal resistances to the various layers -the air inside the pit, the manure, and the floor of the pit- that divide the thermal zone from the ground.

The term $\phi_{\text {vap }}$ represents the sensible heat flow that is needed to evaporate the water inside the enclosure, considering the presence, for example, of waterers, feed, and slurry. In literature, there is not a common agreement on how to consider $\phi_{\text {vap }}$. Hamilton et al. [146] developed a steady-state model for broiler houses to demonstrate the considerable energy savings that can be achieved through the thermal insulation of the house. In their steady-state energy balance, Hamilton et al. [146] considered the term $\phi_{\text {vap. }}$ Pedersen and Sällvik [253] in their formulation of heat production at house level accounted $\phi_{\text {vap }}$ directly in the share of heat produced by the reared animals considering, for instance, the evaporation of water from waterers and feed. On the contrary, according to Midwest Plan Service [231], $\phi_{\text {vap }}$ can be considered negligible due do its minor relevance.

As just stated, the steady-state heat balance of Eq. (46) can be simplified neglecting the terms $\phi_{\text {mac }_{-} \text {i }}$ and $\phi_{\text {vap }}$, as stated in Midwest Plan Service [231]. In addition, it is possible to integrate the heat balance of Eq. (46) with further terms introduced in similar formulations provided by other Authors. For example, Daskalov et al. [233], Carvalho et al. [230], and Panagakis and Axaopoulos [165] consider in their works the presence of the term $\phi_{\text {fog }}$ that represents the sensible heat flow due to the fogging system installed inside the building. In certain livestock houses, especially growing-finishing pig houses, fogging and sprinkling systems can be installed to mitigate the heat stress of the animals. Panagakis and Axaopoulos [165] introduced the Boolean logic $\gamma_{\text {fog }}$ to consider the activation $\left(\gamma_{f o g}=1\right)$ or deactivation $\left(\gamma_{\mathrm{fog}}=0\right)$ of the fogging system.

Liberati and Zappavigna [237] underlined the importance of considering the sensible heat exchange between manure and the air inside the enclosure, an issue that could be interesting especially in those livestock houses where is collected in pits. For this reason, the term $\phi_{\operatorname{man}}$ could be considered in the formulation of a steady-state heat balance, especially in the large-scale growing-finishing pig houses that are equipped with pits where manure is not frequently flushed. Even in this 
case, the Boolean logic $\gamma_{\text {man }}$ may be used: $\gamma_{\text {man }}$ could be considered equal to one in livestock houses where $\phi_{\text {man }}$ is considered significant.

Considering all the previously mentioned aspects, the energy balance of Eq. (46) can be reformulated as

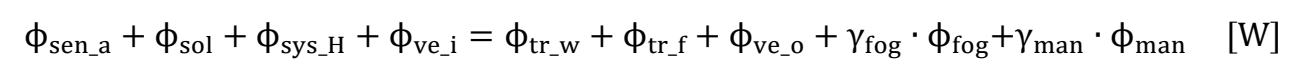

Due the considerable production of water vapor that characterizes livestock houses, the mass balance should be also considered. In literature, the formulations of mass balances of livestock houses are widespread because they are often used to study the contaminant concentrations. Albright [229] reports the usual steady-state mass balance for a generic material of interest that for water vapor reads

$$
\dot{m}_{\mathrm{i}}+\dot{m}_{\mathrm{ve} \_ \text {sup }}=\dot{m}_{\mathrm{ve} \_\mathrm{i}} \quad\left[\frac{\mathrm{kg}_{\mathrm{vap}}}{\mathrm{h}}\right]
$$

where $\dot{m}_{\mathrm{i}}$ represents the total water vapor mass flow rate that is produced within the space $\left(\mathrm{kg}_{\mathrm{vap}} \mathrm{h}^{-1}\right), \dot{m}_{\mathrm{ve} \_ \text {sup }}$ and $\dot{m}_{\mathrm{ve} \_\mathrm{i}}$ are the water vapor mass flow rate that is carried into and carried out of the enclosure by ventilation air, both expressed in $\mathrm{kg}_{\text {vap }} \mathrm{h}^{-1}$. A more specific formulation -derived from Eq. (48)- for the moisture balance can be found in $[159,231]$ and it reads

$$
\left(\dot{m}_{\text {vap_a }}+\dot{m}_{\text {ev }}\right)+\left(\dot{q}_{\text {air }} \cdot x_{\text {air_sup }}\right)=\left(\dot{q}_{\text {air }} \cdot x_{\text {air_i }}\right) \quad\left[\frac{\mathrm{kg}_{\text {vap }}}{\mathrm{h}}\right]
$$

where $\dot{m}_{\text {vap_a }}$ is the water vapor mass flow rate from animals $\left(\mathrm{kg}_{\text {vap }} \mathrm{h}^{-1}\right), \dot{m}_{\mathrm{ev}}$ is the water vapor mass flow rate from surfaces water evaporations and fogging $\left(\mathrm{kg}_{\text {vap }} \mathrm{h}^{-1}\right), \dot{q}_{\text {air }}$ is the ventilation rate $\left(\mathrm{kg} \mathrm{h}^{-1}\right)$ and $x_{\text {air_sup }}$ and $x_{\text {air_i }}$ are the specific humidity of the incoming and exhaust air $\left(\mathrm{kg}_{\mathrm{vap}} \mathrm{kg}_{\text {air }}^{-1}\right)$.

\subsubsection{Dynamic energy models}

The use of steady-state models can be a reliable and effective solution for the climate control system design. When the aim of the simulation is the assessment of the energy performance of livestock houses, dynamic models are needed. In dynamic models, the heat capacity of the building elements is usually considered. Even though the heat balance proposed by Lindley and Whitaker [128] was in steady-state conditions, they introduced a further term to consider the heat stored in the building materials and in the equipment. This term was not added in Eq. (47) because the heat storage capacity of the building should be considered only in dynamic or quasi-steady state energy balances.

Panagakis and Axaopoulos [165] introduced the lumped effective building capacitance in their model based on two time-dependent equations, one for the energy balance and the other for the mass balance. The objective of their work was assessing the performance of two different fogging strategies inside pig houses to 
decrease the heat stress of the reared animals. Panagakis and Axaopoulos [165] did not estimate the energy consumption of the pig house, but they introduced two heat stress indices -regarding duration and intensity- that, together with $T H I$, could be implemented in new energy simulation models to provide interesting information about the thermal stress risk of the reared animals. Liberati and Zappavigna [237] presented a dynamic simulation model that is based on two time-dependent equations for describing the energy and the mass balance inside a livestock house. In their work, each term of the heat balance -both sensible and latent- is explicitly described focusing on detailed aspects, such as the manure-air heat exchange calculation and floor modelling. The model was validated against real monitored data. Xie et al. [126] developed a customized dynamic energy model for improving animal welfare and energy performance of pig houses considering three different conditions of ventilation.

In literature, the use of $B E S$ (Building Energy Simulation) tools for carrying out dynamic simulations is also present. Fabrizio et al. [124] used a BES tool (EnergyPlus) to simulate the indoor climate conditions and the energy consumption of a sow farrowing room. In that work, the BES tool was used for performing dynamic simulations to compare different solutions in terms of climate control system and building envelope. The final aim was to find out the best solution from the point of view of energy consumption -heating, cooling, and primary energy- and animal welfare -overheating index- for the analyzed sow farrowing room. Axaopoulos et al. [232] developed an energy simulation model in TRNSYS to evaluate the optimum insulation thickness of the walls of a growing-finishing pig house considering different orientations and compositions. Jackson et al. [235] developed an EnergyPlus model for improving the design of pig housing to promote an efficient use of the resources and enhance animal welfare. This EnergyPlus model was also adopted by Jackson et al. [236] to improve the pig house design including passive design techniques aimed at reducing the time that pigs spend in not adequate indoor climate conditions. Zhou et al. [125] carried out a similar analysis using the same BES tool (EnergyPlus) focusing on a broiler house in New South Wales, Australia. The analysis aimed at decreasing the energy consumption and the operating costs for heating and cooling of the analyzed broiler house, including an optimization in the farm operational plan, by varying the starting dates of the production cycles. Lee et al. [127] used TRNSYS to develop a dynamic energy model for analyzing the thermal and hygroscopic environment of mechanically ventilated duck houses.

In literature, $B E S$ are also coupled with $C F D$. Seo et al. [238] coupled $B E S$ with $C F D$ with the aim of improving the ventilation system of a naturally ventilated broiler house. $C F D$ evaluated the indoor air temperature and the ventilation efficiency, while BES model computed the heating load. Through this model, various types of openings were analyzed to find the best solution in terms of energy consumption. El Mogharbel et al. [123] coupled an energy model with CFD to evaluate the performance of an innovative localized solar-assisted heating system 
for broiler brooding. $C F D$ was used to simulate the air flow rate and the supply air temperature inside the house, while the performance of the components, such as collector-tank system and solar concentrator, was simulated through a set of timedependent equations.

Finally, Daskalov [234] adopted a different approach to the problem of the energy simulation of livestock houses, developing a dynamic discrete autoregressive moving average model. The model investigates the main indoor climate parameters, e.g. indoor air temperature and relative humidity, that have to be considered inside a livestock house. The main findings of that work were used by Daskalov et al. (2006) for designing a non-linear proportional integral control to be applied to the climate control system of livestock houses.

\subsubsection{Computational Fluid Dynamics (CFD)}

For the detailed analyses that concern the estimation of the indoor climate conditions, CFD models are preferred to lumped parameter models, as clearly visible from Table 5.1. This is since $C F D$ can analyze more in detail the entire spatial domain of the enclosure, enabling the assessment of the spatial distribution and gradient of indoor climate parameters, such as indoor air temperature and air velocity. 2D or 3D CFD models are applied to livestock houses especially for:

- the prediction of the indoor climate conditions;

- the evaluation and improvement of ventilation;

- the evaluation of the emissions of contaminants.

An accurate and complete prediction of the indoor climate conditions inside livestock houses is fundamental because the breeds that had been genetically selected for being reared inside intensive livestock houses had lost their adaptability to the environment variations and are more sensitive to the thermal stress [243]. For this reason, adequate indoor climate conditions should be guaranteed and CFD is especially suitable for estimating and evaluating them. For example, Kwon et al. [244] adopted $C F D$ to analyze jet-drop-distances in a commercial broiler house with multiple slot-openings. Rojano et al. [247] used CFD to model the indoor climate conditions and $I A Q$ in naturally ventilated broiler houses. Bjerg et al. [239] used $C F D$ simulations to predict the indoor effective temperature in the lying area of a growing-finishing pig house equipped with hinged ceiling flap inlet. $C F D$ is also suitable to study the effects of evaporative pads on the indoor climate conditions of broiler houses, as shown by Fidaros et al. [242].

As previously stated, $C F D$ is spread in literature also for analyzing ventilation and its effects on $I A Q$, energy efficiency and animal thermal comfort [243]. Mostafa et al. [245], for example, used CFD to investigate the difference between four configurations of duct ventilation systems in broiler houses by assessing thermal and humidity gradients of the entire domain. CFD models are used for the assessment of the air velocities inside broiler houses -as shown by the works of 
Bustamante et al. [241] and Blanes-Vidal et al. [240]- also considering different building configurations, as done by Guerra-Galdo et al. [243]. Seo et al. [250] use $C F D$ for evaluating the indoor climate conditions, but the focus of the work is pig houses.

Finally, in many works, $C F D$ is used to investigate aspects such as $\mathrm{NH}_{3}$ emissions [254] and the removal of gaseous pollutants. For example, Tabase et al. [251] developed a CFD model to predict the indoor airflow and the distribution of $\mathrm{NH}_{3}$ and $\mathrm{CO}_{2}$ in a pig house equipped with an underfloor air distribution system. Qin et al. [246] used CFD to investigate the effects of slatted floor layouts on the airflow pattern in a manure pit and the consequent $\mathrm{NH}_{3}$ emissions. Zhu et al. [252] used $C F D$ simulations to optimize the ventilation system of broiler houses in removing gaseous pollutants. Rong [248] applied a validated $C F D$ model to a pig house with pit ventilation for investigating the removal ratio of $\mathrm{NH}_{3}$ emissions from four different emission surfaces, namely top, side, bottom surfaces of the slatted floor and slurry manure surface. Rong and Aarnink [249] used CFD simulations to derive the $\mathrm{NH}_{3}$ mass transfer coefficients above metal and concrete slatted floor in an experimental pig house. This widespread use of $C F D$ models for investigating issues related to $\mathrm{NH}_{3}$ and other gaseous emissions is due to the high cost that characterizes the experimental measurements of $\mathrm{NH}_{3}$ concentration. To obtain reliable results, in fact, specialized measurement tools [255] and a considerable number of samples are needed, entailing a not negligible financial cost [256]. The advantage of $C F D$ models relies on the possible combination with experimental campaigns, enabling the extension of the performed measurements to the entire enclosure. Furthermore, CFD enables more reliable results because the entire domain of the enclosure is deeply analyzed and the measurements by agent, that may cause distort outputs, are minimized. Furthermore, CFD can analyse also experimental solutions without the need of adopting real test sites [90].

\subsection{An energy modelling framework for climate- controlled livestock houses}

As just shown, different type of livestock houses models can be found in literature, but very few of them are dynamic energy models specifically developed for the estimation of the energy consumption for climate control. Furthermore, the performed literature analysis showed that neither standardized calculation procedures nor common frameworks are present, outlining a significant gap in literature. For this reason, an energy modelling framework suitable for the application to different types of climate-controlled livestock houses is proposed in this chapter with the aim of filling the outlined gap.

Each type of climate-controlled livestock houses has several specificities that can be attributable mainly to the farmed animal species since they are characterized by different thermal and vapor emissions, and they require different indoor climate conditions. Nevertheless, different types of climate-controlled livestock houses 
have also many common features, such as a comparable building thermal behaviors and similar climate control systems. These similarities enhance the possibility to provide a general modelling framework for livestock houses that could be then customized for developing ad-hoc energy simulation models for specific types of livestock houses, such as broilers, growing-finishing pigs, laying hens and ducks.

The energy modelling framework for livestock houses that is proposed in this thesis adopts a dynamic energy simulation method that is considered the most suitable option for the energy simulation of livestock houses, as previously shown in the review presented in section 5.2. The proposed energy modelling framework is structured in different calculation modules that are developed for simulating the most relevant phenomena that occur inside livestock houses. These modules can be easily customized to be adapted to the considered type of livestock houses and they are

- Initialization module

- Animal modelling module

- Thermal balance module

- Cooling ventilation and evaporative cooling module

- Moisture balance module

- System performance module

The presented calculation modules are structured in the workflow schematized in Figure 5.1. A deepen description of each calculation module will be provided in the next sections where the energy modelling framework will be customized for broiler houses and growing-finishing pig houses.

As visible from the schematization of Figure 5.1, input data should be provided to start the simulation. These data mainly regard the geometrical and thermophysical properties of the analyzed livestock houses, the farming features, and the outdoor weather conditions. Starting from the input data, all the variables needed in the following calculation modules -e.g. heat transfer coefficients and the total building fabric heat capacity- are preliminary calculated in the "Initialization module" that is the first calculation module of the presented workflow. Then, the model starts a calculation loop that is repeated per each simulation time step. This loop begins with the "Animal modelling module" that estimates the time-dependent variables related to the farmed animals, such as animal live weight and heat production. All these variables, as visible later in the text, are calculated as a function of animal age through numerical relations obtained from technical handbooks -regarding animal physiology or environmental control- or from farming guides provided by suppliers of breeding stocks.

Once defined the needed boundary conditions related to farmed animals, the sensible heat balance is solved to estimate $\theta_{\text {air_i }}$ at the analyzed time step in the "Thermal balance module". As visible from Figure 5.1, three different situations can occur at each time step. The first situation is $\theta_{\text {air_i }}$ in free-floating condition $\left(\theta_{\text {set_H }} \leq \theta_{\text {air_i }} \leq \theta_{\text {set_C }}\right)$, meaning that neither heating nor cooling is needed. The 
simulation model stores the estimated value of $\theta_{\text {air_i }}$ and moves on to the following step, the "Moisture balance module" to evaluate $R H_{\mathrm{i}}$. The second possible situation is the need of a supplemental heating load $\left(\theta_{\text {air_i }}<\theta_{\text {set_H }}\right)$. In this case, the model estimates and stores the theoretical supplemental heating load $\left(\phi_{\mathrm{H}_{-} n d}\right)$ that is needed to maintain $\theta_{\text {set_H }}$, before moving on to the "Moisture balance module". The last possible situation occurs when a cooling load is needed $\left(\theta_{\text {air_i }}>\theta_{\text {set_C }}\right)$. In this third case, the model estimates a theoretical cooling load $\left(\phi_{\mathrm{C}_{-} n d}\right)$ needed to maintain the required $\theta_{\text {set_c. }}$. This cooling load is the input for the following step that is the "Cooling ventilation and evaporative cooling module". In this calculation module, the ventilation air flow rate equivalent to the theoretical cooling load calculated in the previous step $\left(\phi_{\mathrm{C}_{-} n \mathrm{nd}}\right)$ is estimated considering the possible presence and activation of evaporative cooling pads. The calculated ventilation air flow rate is used to update the thermal balance and, consequently, to estimate the actual $\theta_{\text {air_i }}$, that is stored by the model.

As visible from Figure 5.1, all the three situations converge in the "Moisture balance module" in which the water vapor mass balance is solved to obtain the indoor air humidity ratio $\left(x_{\text {air_i }_{-}}\right)$and , then, $R H_{\mathrm{i}}$ through psychrometric formulations as a function of the previously estimated $\theta_{\text {air_i }}$. An interesting difference that exists between this modelling framework and the energy simulation model for greenhouses (Chapter 4 ) is $R H_{\mathrm{i}}$ control. The greenhouse model, as shown in the workflow of Figure 4.2, simulates a precise control -with a feedback loop- of $R H_{\mathrm{i}}$ that is precisely maintained below a certain pre-set threshold. By contrast, this type of $R H_{\mathrm{i}}$ control is not typical in livestock houses and, therefore, it was not integrated in the proposed modelling framework. In livestock houses, in fact, $R H_{\mathrm{i}}$ is usually controlled through base ventilation which flow rate is calculated only considering the total animal live weight present inside the house, without a feedback loop.

Once estimated the $R H_{\mathrm{i}}$ value, the simulation of the analyzed time step ends and the model starts another loop to calculate the following time step beginning from the "Animal modelling module". When the simulation of all the time steps is ended, the model moves on to the "System performance module" that provides the total thermal and electrical energy consumption for climate control during the simulated period. The thermal energy consumption for supplemental heating and the electrical energy consumption for ventilation are obtained considering the efficiency of the heating and ventilation systems of the analyzed livestock house.

At the end of the simulation, several valuable outputs are obtained, such as the total thermal and electrical energy consumption for climate control, the ventilation flow rate at each time step, and the time profiles of $\theta_{\text {air_i }}$ and $R H_{\mathrm{i}}$. 


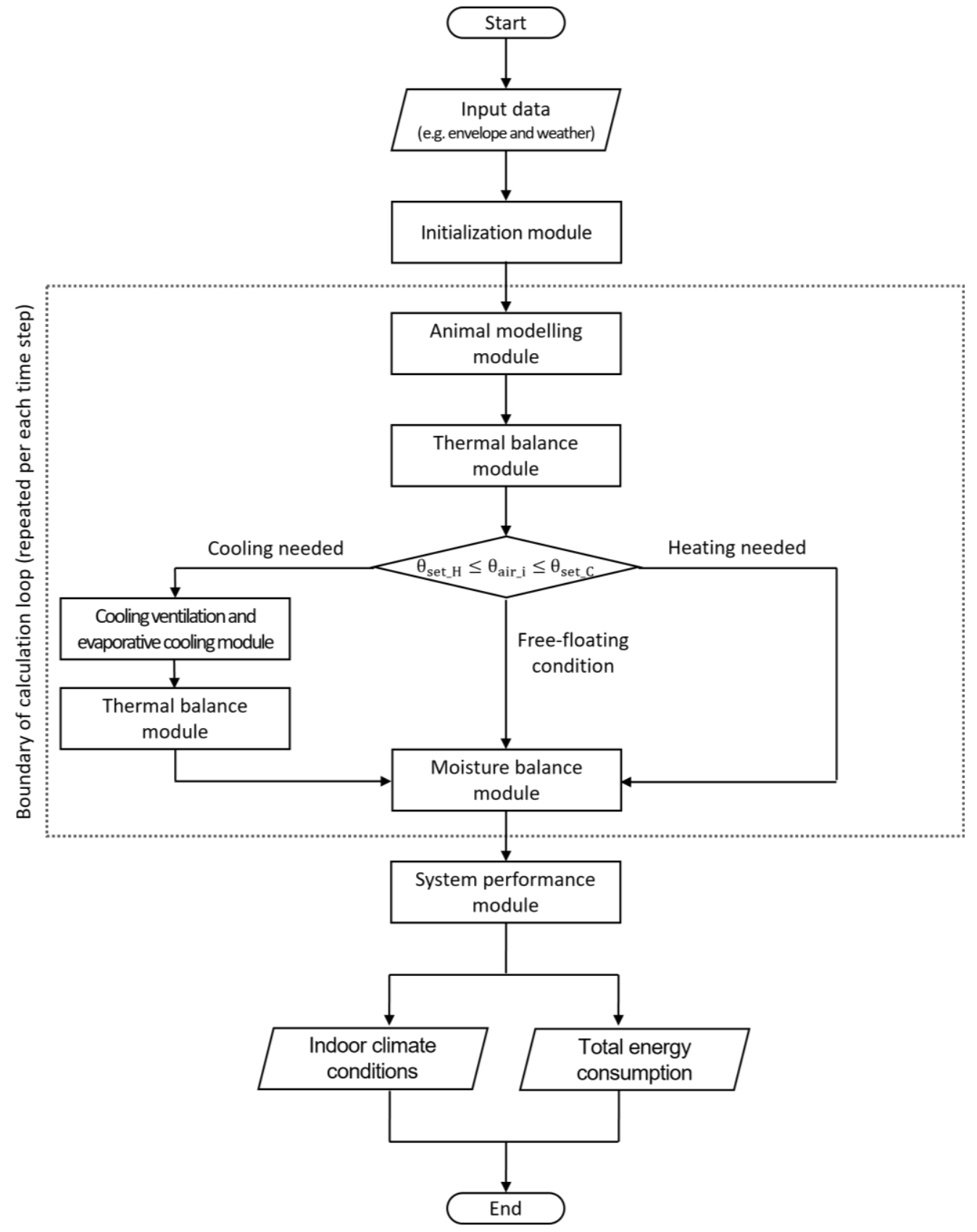

LEGEND

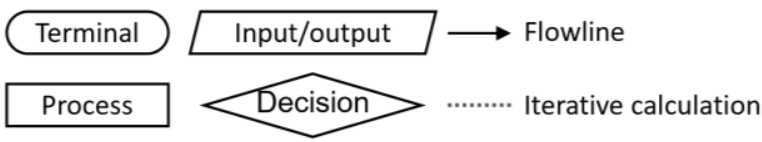

Figure 5.1 - Calculation modules and workflow of the energy modelling framework proposed for livestock houses. The dotted contour represents the calculation loop that is repeated for each timestep of the simulation.

As previously stated, the presented energy modelling framework for livestock houses can be customized to develop energy simulation models for specific types of climate-controlled livestock houses. For this aim, the previously presented calculation modules should be customized according to the specificities of the considered type of livestock house. In the next sections, two examples of model 
customization will be presented. The first customization regards broiler houses and the second one growing-finishing pig houses. Both the obtained simulation models are validated against real monitored data to prove their reliability.

\subsection{Model customization for broiler houses: development}

\subsubsection{The need of a broiler house energy model}

Broiler houses have been chosen to customize the energy modelling framework presented in section 5.3 since an improvement of their energy performance would have an important positive impact on the energy consumption of the entire livestock sector. This is so since more than $70 \%$ of the broilers that are currently produced at a global level are reared in intensive broiler houses [257] and the number of these agricultural buildings has been increasing in the last years [25]. The mechanical control of the indoor climate conditions that is needed to guarantee broiler health and to improve the production entails a considerable energy consumption that represents the highest direct energy use in this animal production, as shown in section 2.3.2. Another element that makes interesting the development of an energy simulation model for broiler houses is the amount of poultry production at a global level. Poultry, in fact, represents the greatest meat production worldwide together with pork [228]. According to FAO, the population growth and the modification of human diet will entail an increase of poultry meat consumption by $125 \%$, referring to 2010-2050 time span [258], an issue that will make poultry production higher than pork one before 2030 [228].

\subsubsection{Overview on broiler houses modelling issues}

Some issues specific of broiler production should be considered to customize the energy modelling framework for this livestock production. The energy modelling of a broiler house is a challenging task since this type of livestock house is usually characterized by a high volume of the enclosure, by important changes of the required indoor climate conditions over the production cycle and by the presence of thousands of broilers which thermal and vapor emissions considerably affect the thermal and moisture balances of the house.

Broiler houses are quite standardized buildings with a width usually between 10 and $15 \mathrm{~m}$ and a length that may exceed $100 \mathrm{~m}$. The covering can be a gable roof or a barrel vault that in the highest point reaches 4 or $5 \mathrm{~m}$ of height. The windows and the opening systems depend on the adopted ventilation scheme, but generally they are made of polycarbonate hollow sheets and placed on the longest walls of the house. The $U$-value of the envelope is usually high since walls and roof are poorly thermally insulated with a consequent increase of the thermal energy consumption, an issue that will be deeply analyzed later in this thesis (Chapter 6). 
Broilers are reared in production cycles, also known as "batches", that start when few-days-aged chicks are carried in the house and end 40-50 days later, when broilers achieve the target final live weight. The rapid growth that characterizes broilers during the production cycle entails important variations of the needed climate conditions inside the house. The heating set point temperature $\left(\theta_{\text {set_H }}\right)$ is at a maximum at the beginning of the batch since few-days-aged chicks need high indoor air temperatures $\left(\theta_{a_{i} r_{i}}\right)$ to maximize their growth avoiding health problems. In this period, the supplemental heating system -gas or diesel oil air heaters- is usually activated inside the house to maintain the required $\theta_{\text {set_H }}$. As broilers grow, the $\theta_{\text {set_H }}$ decreases and supplemental heating is no more needed since the same heat emission of broilers can maintain the adequate $\theta_{\text {air_i }}$. Heat and vapor emissions of broilers, in fact, change significantly during the production cycle. On the first day of the production cycle, the total heat emission of one broiler chick can be estimated around about $1 \mathrm{~W}$ while the vapor emission is around $1 \mathrm{~g} \mathrm{~h}^{-1}$, considering $\theta_{\text {air_i }}$ equal to $32.0^{\circ} \mathrm{C}$. At the end of the batch $\left(50^{\text {th }}\right.$ day), these values increase up to $26 \mathrm{~W}$ and $16 \mathrm{~g} \mathrm{~h}^{-1}$, respectively considering $\theta_{\text {air_i }}$ equal to $16.8^{\circ} \mathrm{C}$ $[159,259]$. These high values of thermal and vapor emissions highlight the importance of the ventilation system that controls $I A Q, R H_{\mathrm{i}}$ and $\theta_{\text {air_i }}$. Base ventilation (Figure 5.2) is required for controlling $R H_{\mathrm{i}}$ and $I A Q$, that are strongly affected by broiler metabolism. Broilers, in fact, consume $\mathrm{O}_{2}$ and produce $\mathrm{CO}_{2}$ and water vapor, increasing their concentrations inside the house with potential health risks for the same broilers. $I A Q$ is also affected by broiler activity and by the same ventilation that can enhance the emissions of microscopic particles of dust from bedding, feed, and fecal material [27], as previously discussed in section 2.3.2. In addition, $I A Q$ is also negatively affected by the decomposition of broilers waste products that generates $\mathrm{CH}_{4}, \mathrm{H}_{2}, \mathrm{H}_{2} \mathrm{~S}$ and $\mathrm{NH}_{3}$ that are gases that could be particularly detrimental for broilers health, as deeply described later in section 7.1. Furthermore, high $\mathrm{NH}_{3}$ concentration can affect the health of the workers present inside the broiler house, as previously mentioned in section 2.3.2.

Base ventilation is very effective to dilute contaminant gas concentrations, but it may not be sufficient for dust control because pockets with high concentrations of dust are common in livestock houses and different strategies -e.g. spraying and sprinkling- should be adopted [260]. To provide base ventilation, several fans are spaced uniformly along one of the largest sides of the house. On the opposite side, or on the roof ridge, various openings are present with different inlet configurations to provide a cross ventilation flow $[27,175]$. Base ventilation may be positive or negative pressure, depending on the adopted scheme. 


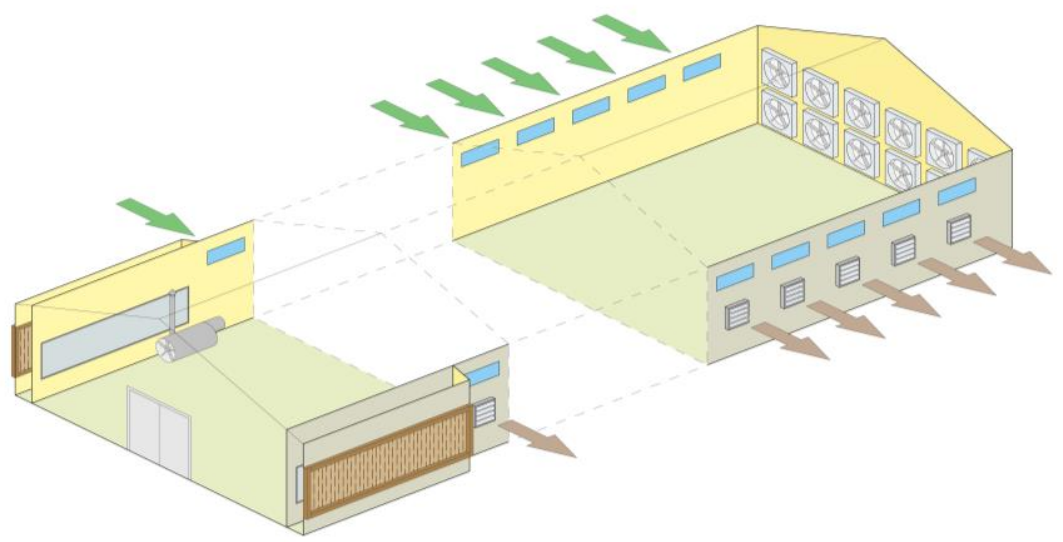

Figure 5.2 - Schematization of the base ventilation operating principle. Lateral exhaust fans create a negative pressure difference inside the broiler house expelling exhaust air (brown arrows). Supply fresh air (green arrows) inlets through the windows on the opposite wall, creating a cross ventilation flow to control $I A Q$.

The second type of ventilation adopted in broiler houses aims at controlling the $\theta_{\text {air_i }}$ and is a cooling ventilation that, in this type of livestock house, is usually known as tunnel ventilation (Figure 5.3) since fans -situated in one of the two shortest sides of the building- move the fresh air along the length of the house, as it would be a tunnel. Tunnel ventilation fans are larger than the ones used for base ventilation and usually are exhaust fans. This type of ventilation is intended to decrease $\theta_{\text {air_i }}$ by removing the thermal emission of broilers and providing them a wind-chill effect. The air speed of tunnel ventilation in broiler areas cannot be excessive (2.5-3 $\mathrm{m} \mathrm{s}^{-1}$ ) especially in cold season to avoid health problem to the reared broilers. In some configurations of broiler houses, the same tunnel ventilation fans carry out also base ventilation, without the need of installing the smaller fans on the largest walls.

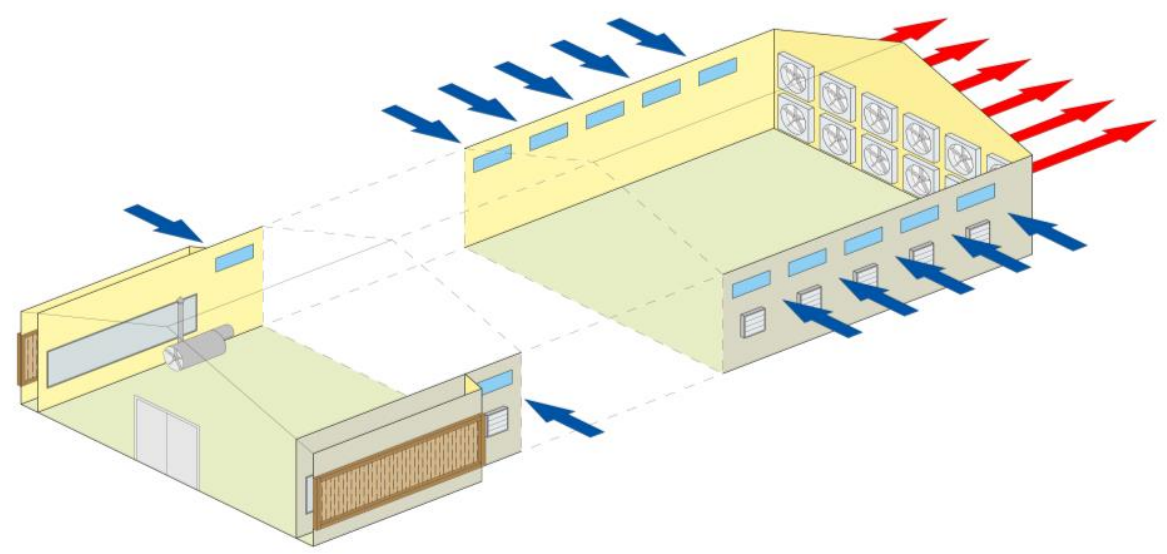

Figure 5.3 - Schematization of the tunnel ventilation operating principle. The fans placed at the end of the house exhaust hot air (red arrows), creating a negative pressure difference between inside and outside the broiler house. Fresh outdoor air (blue arrows) enters through the inlets placed across the longest sides of the broiler house due to the pressure difference, decreasing the indoor air temperature. 
During the warmest periods of the year, tunnel ventilation could not maintain $\theta_{\text {set_H }}$ and evaporative cooling should be activated to prevent heat prostration mortality of broilers [27]. This strategy is common in poultry houses (Figure 5.4) and makes it possible to provide a ventilation flow rate with a supply air temperature $\left(\theta_{\text {air_sup }}\right)$ lower than the outdoor one $\left(\theta_{\text {air_o }}\right)$, similarly to what was previously explained for greenhouses in section 4.3.3.

In broiler houses, cooling pads are placed on the largest walls opposite to the tunnel ventilation fans, as schematized in Figure 5.4, for letting the cooled airflow cross the entire house. The evaporative pads used in broiler houses are blocks of corrugated materials as plastic, fiberglass or cellulose treated to increase their water absorption to increase their efficiency. Few information are present concerning water demand and usage of evaporative pads in broiler houses since this consumption depends on several factors, such as pad thickness and the outdoor climate conditions. In literature, a value of about $1.22 \cdot 10^{-2} \mathrm{~m}^{3} \mathrm{~h}^{-1}$ per unit of pad surface is estimated as an average [261].

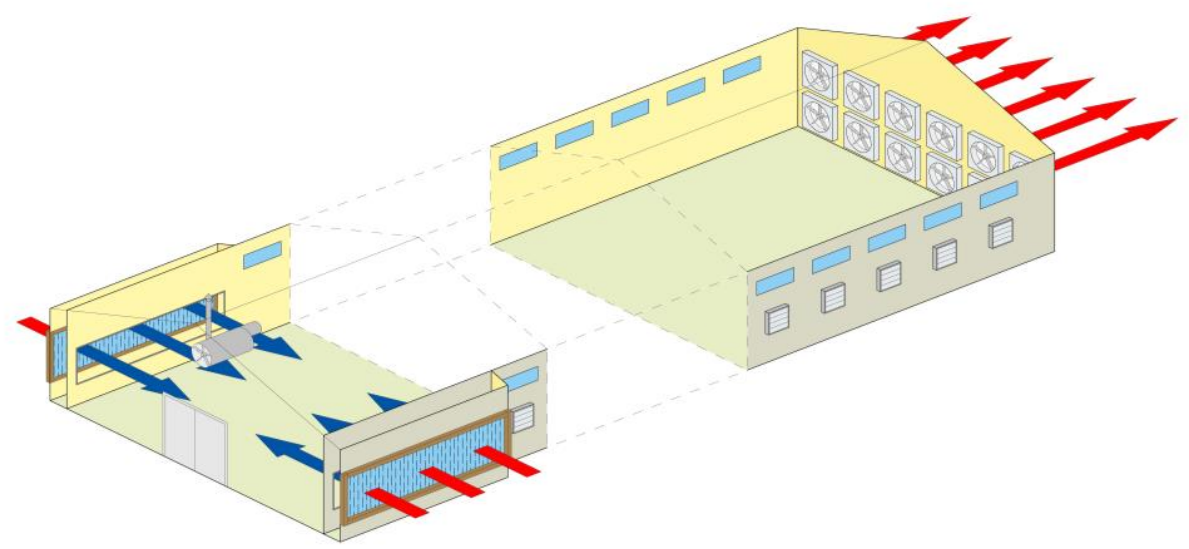

Figure 5.4 - Schematization of the evaporative cooling operating principle. The negative pressure difference inside the house created by tunnel ventilation fans forces the warm outdoor air through the wet evaporative pads decreasing its temperature (red/blue arrows). This supply air decreases the indoor air temperature and is expelled by the tunnel ventilation fans (red arrows).

\subsubsection{Calculation modules}

The calculation modules that are part of the workflow of the general modelling framework for livestock houses presented in section 5.3 are now customized for the specific simulation of broiler houses, considering the peculiarities of these buildings that were presented in section 5.4.2.

\section{Initialization module}

The "Initialization module" is needed to perform preliminary calculations for estimating all the variables that are not time-dependent that are needed in the following calculation modules, such as the heat transfer coefficients and the total building fabric heat capacity. 


\section{Broiler modelling module}

The "Animal modelling module" presented in Figure 5.1 is customized to be specific for broiler houses and, thus, for calculating all the time-variables related to broilers. The first variable that is calculated is broiler body mass, commonly known as live weight, that is calculated as a function of the broiler age as

$$
w_{\mathrm{b}}=k_{\mathrm{wb}_{-} 3} \cdot \mathrm{a}_{\mathrm{b}}^{3}+k_{\mathrm{wb}_{-} 2} \cdot \mathrm{a}_{\mathrm{b}}^{2}+k_{\mathrm{wb}_{-} 1} \cdot \mathrm{a}_{\mathrm{b}}+k_{\mathrm{wb}_{-} 0} \quad[\mathrm{~kg}]
$$

where $w_{\mathrm{b}}$ is the broiler live weight $(\mathrm{kg})$ and $\mathrm{a}_{\mathrm{b}}$ is the broiler age (in days). The terms $k_{\mathrm{wb}_{3} 3}-k_{\mathrm{wb}_{-} 0}$ are regression coefficients that were determined reducing the last square error from data provided in [262] and their values are reported in Table A.3 of Appendix A.

The adequate $\theta_{\text {air_i }}$ for broiler farming is function of $a_{b}$. The optimal indoor air set point temperature $\left(\theta_{\text {set_opt }}\right)$ is calculated as

$$
\begin{aligned}
\theta_{\text {set_opt }}= & k_{\theta \mathrm{b}_{-} 6} \cdot \mathrm{a}_{\mathrm{b}}^{6}+k_{\theta \mathrm{b}_{-} 5} \cdot \mathrm{a}_{\mathrm{b}}^{5}+k_{\theta \mathrm{b}_{4} 4} \cdot \mathrm{a}_{\mathrm{b}}^{4}+k_{\theta \mathrm{b}_{-} 3} \cdot \mathrm{a}_{\mathrm{b}}^{3}+ \\
& +k_{\theta \mathrm{b}_{-} 2} \cdot \mathrm{a}_{\mathrm{b}}^{2}+k_{\theta \mathrm{b}_{-}} \cdot \mathrm{a}_{\mathrm{b}}+k_{\theta \mathrm{b}_{-} 0} \quad\left[{ }^{\circ} \mathrm{C}\right]
\end{aligned}
$$

where the terms $k_{\theta \mathrm{b}_{-} 6}-k_{\theta \mathrm{b} \_0}$ are regression coefficients obtained from [263] which value is reported in Table A.4 (Appendix A). Once defined $\theta_{\text {set_opt }}$, the heating $\left(\theta_{\text {set_H }}\right)$ and the cooling $\left(\theta_{\text {set_C }}\right)$ set point temperatures are established considering a dead band ( $\left.\Delta \theta_{\text {band }}\right)$ in which $\theta_{\text {air_i }}$ fluctuates in free-floating conditions that for $\mathrm{a}_{\mathrm{b}}$ lower than 41 days is calculated as

$$
\Delta \theta_{\text {band }}=k_{\Delta_{-} 6} \cdot \mathrm{a}_{\mathrm{b}}^{6}+k_{\Delta_{-} 5} \cdot \mathrm{a}_{\mathrm{b}}^{5}+k_{\Delta_{-} 4} \cdot \mathrm{a}_{\mathrm{b}}^{4}+k_{\Delta_{-} 3} \cdot \mathrm{a}_{\mathrm{b}}^{3}+k_{\Delta_{-} 2} \cdot \mathrm{a}_{\mathrm{b}}^{2}+k_{\Delta_{-} 1} \cdot \mathrm{a}_{\mathrm{b}}+k_{\Delta_{-} 0} \quad\left[{ }^{\circ} \mathrm{C}\right]
$$

where $k_{\Delta_{-} 6}-k_{\Delta_{-} 0}$ are the regression coefficients presented in Table A.5 (Appendix A) calculated from the data reported in [263]. If $\mathrm{a}_{\mathrm{b}}$ is equal or higher than 41 days, $\Delta \theta_{\text {band }}$ is equal to $0 \mathrm{~K}$.

The two set point temperatures $\theta_{\text {set_H }}$ and $\theta_{\text {set_C }}$ are finally obtained as

$$
\begin{aligned}
& \theta_{\text {set_H }}=\theta_{\text {set_opt }}-\Delta \theta_{\text {band }} \quad\left[{ }^{\circ} \mathrm{C}\right] \\
& \theta_{\text {set_C }}=\theta_{\text {set_opt }}+\Delta \theta_{\text {band }} \quad\left[{ }^{\circ} \mathrm{C}\right]
\end{aligned}
$$

In Figure 5.5 , the trends of $\theta_{\text {set_H }}, \theta_{\text {set_opt }}$ and $\theta_{\text {set_C }}$ during a generic production cycle are shown on the primary $y$-axis as function of the broiler age, while $w_{\mathrm{b}}$ trend is reported in the secondary $y$-axis. From the chart, it stands out that all the set point temperatures decrease as broiler weight increases because, as previously stated, broiler chicks need higher $\theta_{\text {air_i }}$ than older broilers. 


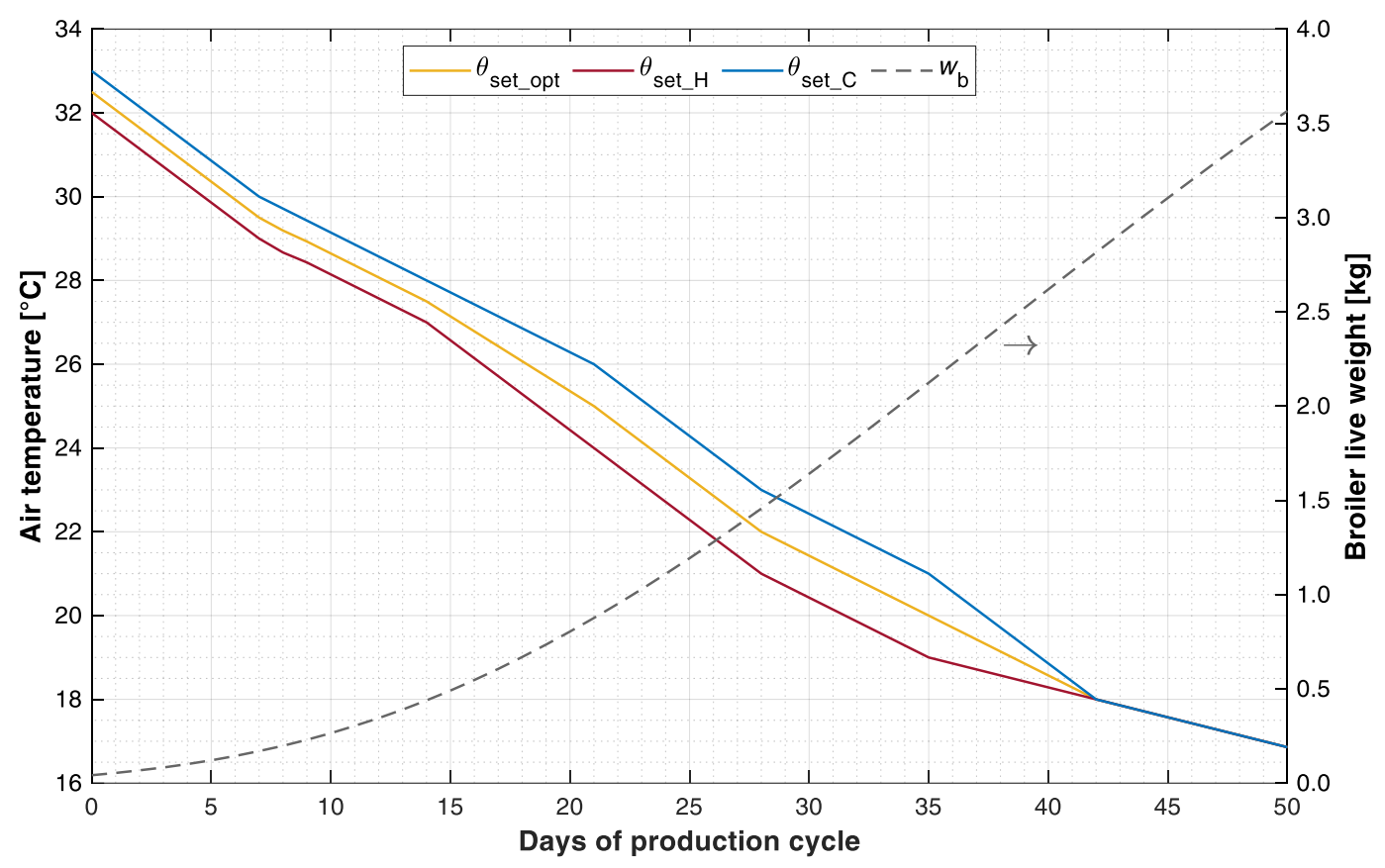

Figure 5.5 - Trend of the optimal set point temperature $\left(\theta_{\text {set_opt }}\right)$ with the dead band delimited by heating $\left(\theta_{\text {set_H }}\right)$ and cooling set point temperature $\left(\theta_{\text {set_C }}\right)$. The trend of broiler live weight $\left(w_{\mathrm{b}}\right)$ is shown on the secondary $y$-axis.

This calculation module embeds the estimation of broiler heat emission that is an issue of a foremost importance, as stated in section 5.4.2, because it considerably affects the thermal and moisture balances. The broiler thermal emission is a function of the broiler body area, a parameter that could be quite complex to be correctly estimated since body area per unit of body volume or weight is not constant. For this reason, it is preferred to express the broiler thermal emissions as a function of $w_{\mathrm{b}}$ [159]. In the framework of this work, the total -sensible plus latentheat emission of the entire broiler flock $\left(\phi_{s+l_{-}}\right)$is calculated through the following formulation, adapted from [259]

$$
\phi_{\mathrm{s}+l_{-} \mathrm{f}}=10 \cdot w_{\mathrm{b}}^{0.75} \cdot n_{\mathrm{b}} \quad[\mathrm{W}]
$$

where $w_{\mathrm{b}}$ is the broiler weight and $n_{\mathrm{b}}$ is the number of broilers present in the house.

The ratio between sensible and total heat emission $\left(R_{\mathrm{S}}\right)$ is inversely proportional to $\theta_{\text {air_i }}$. To avoid iterative calculations, $R_{\mathrm{S}}$ is calculated as a function of $\theta_{\text {set_opt }}$ as

$$
\begin{gathered}
R_{\mathrm{s}}=k_{\mathrm{R} \_6} \cdot \theta_{\text {set_opt }}^{6}+k_{\mathrm{R}_{\_} 5} \cdot \theta_{\text {set_opt }}^{5}+k_{\mathrm{R} \_4} \cdot \theta_{\text {set_opt }}^{4}+ \\
+k_{\mathrm{R}_{-} 3} \cdot \theta_{\text {set_opt }}^{3}+k_{\mathrm{R}_{-} 2} \cdot \theta_{\text {set_opt }}^{2}+k_{\mathrm{R}_{-} 1} \cdot \theta_{\text {set_opt }}+k_{\mathrm{R}_{-} 0} \quad[-]
\end{gathered}
$$

where $k_{\mathrm{R}_{-} 6}-k_{\mathrm{R}_{-} 0}$ are regression coefficients calculated from [259] and reported in Table A.6 of Appendix A.

Once calculated $R_{\mathrm{S}}$, the sensible ( $\left.\phi_{\mathrm{S}_{-} \mathrm{f}}\right)$ and latent $\left(\phi_{\mathrm{l}_{-}} \mathrm{f}\right)$ heat production of the entire broiler flock are calculated as 


$$
\begin{gathered}
\phi_{\mathrm{s}_{-} \mathrm{f}}=R_{\mathrm{S}} \cdot \phi_{\mathrm{s}+\mathrm{l}_{-} \mathrm{f}} \quad[\mathrm{W}] \\
\phi_{\mathrm{l}_{-} \mathrm{f}}=\phi_{\mathrm{s}+\mathrm{l}_{-} \mathrm{f}}-\phi_{\mathrm{S}_{-} \mathrm{f}} \quad[\mathrm{W}]
\end{gathered}
$$

The water vapor emission from the entire broiler flock $\dot{m}_{\text {iff }_{f}}$ can be calculated from $\phi_{l_{-} f}$ as

$$
\dot{m}_{\text {i_f }}=\frac{\phi_{\text {l_f }_{f}} \cdot 10^{-3}}{h_{\text {vap }} \cdot\left(\theta_{\text {set_opt }}\right)} \quad\left[\frac{\mathrm{kg}_{\text {vap }}}{\mathrm{s}}\right]
$$

where $h_{\mathrm{vap}}$ is the specific enthalpy of vaporization of water $\left(\mathrm{kJ} \mathrm{kg}^{-1}\right)$ evaluated at $\theta_{\text {set_opt }}$.

As stated in section 5.4.2, the control of $R H_{\mathrm{i}}$ and $I A Q$ is performed through base ventilation which flow rate is a function of the total live weight of broilers present inside the house. Knowing broiler age $\left(\mathrm{a}_{\mathrm{b}}\right)$, broiler live weight $\left(w_{\mathrm{b}}\right)$ and the number of broilers present inside the house $\left(n_{b}\right)$, the base ventilation flow rate $\left(\dot{V}_{\mathrm{bs}}\right)$ can be calculated as

$$
\dot{V}_{\mathrm{bs}}=\left(k_{\mathrm{Vb}_{-} 4} \cdot \mathrm{a}_{\mathrm{b}}^{4}+k_{\mathrm{Vb}_{-} 3} \cdot \mathrm{a}_{\mathrm{b}}^{3}+k_{\mathrm{Vb}_{-} 2} \cdot \mathrm{a}_{\mathrm{b}}^{2}++k_{\mathrm{Vb}_{-} 1} \cdot \mathrm{a}_{\mathrm{b}}+k_{\mathrm{Vb}_{-} 0}\right) \cdot w_{\mathrm{b}} \cdot n_{b} \quad\left[\frac{\mathrm{m}^{3}}{\mathrm{~h}}\right]
$$

where $k_{\mathrm{Vb}_{-} 4}-k_{\mathrm{Vb} \_0}$ are regression coefficients obtained from [263] and presented in Appendix A (Table A.7).

\section{Thermal balance module}

Once defined all the needed boundary conditions related to broilers, the energy simulation model solves the thermal balance of the broiler house to estimate $\theta_{\text {air_i }}$ and the theoretical heating $\left(\phi_{\mathrm{H}_{-} n d}\right)$ and cooling $\left(\phi_{\mathrm{C} \_n d}\right)$ loads, when needed. The thermal balance module integrates a customization of the simple hourly $(\mathrm{SH})$ method of ISO 13790 standard [211] which complete description and full set of equations is reported in Appendix B of this thesis.

\section{Cooling ventilation and evaporative cooling module}

This calculation module is needed in those time steps in which the solution of the thermal balance highlights a cooling need to maintain $\theta_{\text {set_c }}$. As stated in section 5.3, this cooling load should be converted in an equivalent cooling ventilation flow rate because broiler houses are not equipped with mechanical cooling. Since cooling ventilation in broiler houses is usually known as "tunnel ventilation", this term will be used instead of "cooling ventilation" in this specific energy model.

The proposed energy simulation model considers that tunnel ventilation is activated when all the following conditions are fulfilled:

- broilers are present in the house since tunnel ventilation is not activated during sanitary empty periods; 
- a cooling load is needed $\left(\phi_{\mathrm{C}_{-} \text {nd }}<0\right)$;

- $\theta_{\text {air_o }}$ is sufficiently lower than $\theta_{\text {set_c }}\left(\theta_{\text {air_o }} \ll \theta_{\text {set_C }}\right)$.

The last condition has to be imposed because for cooling the enclosure using tunnel ventilation, $\theta_{\text {air_o }}$ has to be lower than $\theta_{\text {set_c }}$ of a certain temperature difference $\left(\Delta \theta_{\mathrm{tv}}\right.$.) This condition is implemented in the model through the following formulation

$$
\theta_{\text {set_C }}-\theta_{\text {air_o }} \geq \Delta \theta_{\text {tv }} \quad\left[{ }^{\circ} \mathrm{C}\right]
$$

where $\Delta \theta_{\mathrm{tv}}$ is the minimum difference between $\theta_{\text {set_c }}$ and $\theta_{\text {air_o }}$ for activating tunnel ventilation. In broiler houses, $\Delta \theta_{\mathrm{tv}}$ is a parameter that usually can be set in the climate control unit and varies between 0.5 and $3{ }^{\circ} \mathrm{C}$. In the developed model, $\Delta \theta_{\mathrm{tv}}$ is an input data that is constant over the entire simulation period.

When the previous conditions are fulfilled, tunnel ventilation air flow rate $\left(\dot{V}_{\mathrm{tv}}\right)$ is calculated as

$$
\dot{V}_{\mathrm{tv}}=\min \left[\frac{\left|\phi_{\mathrm{C}_{\_} \text {nd }}\right|}{c_{\text {air }} \cdot\left(\theta_{\text {set_c }}-\theta_{\text {air_o }}\right)} \cdot \frac{3.6 \cdot 10^{3}}{\rho_{\text {air }}} ; \dot{V}_{\text {max }}\right]\left[\frac{\mathrm{m}^{3}}{\mathrm{~h}}\right]
$$

where $c_{\text {air }}$ is the specific heat capacity of air $\left(\mathrm{J} \mathrm{kg}^{-1} \mathrm{~K}^{-1}\right), \rho_{\text {air }}$ is air volumetric mass density $\left(\mathrm{kg} \mathrm{m}^{-3}\right)$ and $\dot{V}_{\max }$ is the maximum ventilation capacity installed inside the broiler house $\left(\mathrm{m}^{3} \mathrm{~h}^{-1}\right)$.

The term $\Delta \theta_{\mathrm{tv}}$ is also a condition that guarantees the feasibility of the ventilation, as it stands out from Eq. (61). If the difference between $\theta_{\text {set_c }}$ and $\theta_{\text {air_o }}$ is close to zero, $\dot{V}_{\mathrm{tv}}$ increases, reaching excessively high values that are not feasible or that entail air velocities that could negative affect the health of the farmed broilers. From Eqs. (61) and (62) it stands out that, for a given value of $\phi_{\mathrm{C}_{-} \text {nd }}$, small values of $\Delta \theta_{\mathrm{tv}}$ (e.g. 0.5 or $1.0^{\circ} \mathrm{C}$ ) entail a maximum flow rate of tunnel ventilation larger than the one that may be obtained assuming greater values of $\Delta \theta_{\mathrm{tv}}$, such as 2.5 or $3.0^{\circ} \mathrm{C}$.

During the warm season, $\theta_{\text {air_o }}$ may rise above $\theta_{\text {set_c }}$ and Eq. (61) cannot be fulfilled. In this situation, tunnel ventilation cannot maintain $\theta_{\text {set_c }}$ and high $\theta_{\text {air_i }}$ can occur inside the broiler house, a situation similar to the one of the monitored pig houses in section 3.3.3. To decrease the potential heat stress of the farmed broilers, evaporative cooling is activated, reducing the supply air temperature $\left(\theta_{\text {air_sup }}\right)$.

The model simulates the activation of the evaporative cooling system when all the following conditions are fulfilled:

- broilers are present in the house since evaporative cooling is not activated during sanitary empty periods;

- a cooling load is needed $\left(\phi_{\mathrm{C}_{-} \text {nd }}<0\right)$;

- the condition of Eq. (61) is not fulfilled; 
- the simulated broiler house is equipped with evaporative pads.

When evaporative cooling is activated, evaporative pads cool the outdoor air that passes through them by adiabatic saturation. The value of $\theta_{\text {air_sup }}$ is determined as a function of $\theta_{\text {air_o }}$, the outdoor humidity -expressed through the wet-bulb temperature- and the direct saturation effectiveness $\varepsilon_{\text {ec }}$ of the cooling pad. The saturation effectiveness indicates the extent to which complete saturation is approached [11], that is the percentage of the closeness between the dry-bulb temperature of the air leaving the cooling pad $\left(\theta_{\text {air_sup }}\right)$ and the wet-bulb temperature of the air entering in them, that is the outdoor one $\left(\theta_{\text {air_o,wb }}\right)$. Usually, $\varepsilon_{\mathrm{ec}}$ varies between 0.70 and 0.95 as a function of the air velocity through the pad values between 1.0 and $1.4 \mathrm{~m} \mathrm{~s}^{-1}$ produce the highest efficiencies [27]-, the thickness of the pad -between 0.1 and $0.3 \mathrm{~m} \mathrm{[214]-} \mathrm{and} \mathrm{the} \mathrm{maintenance} \mathrm{since} \mathrm{dust,}$ particles and algae decrease the efficiency. In a generic cooling pad, $\varepsilon_{\mathrm{ec}}$ can be expressed as

$$
\varepsilon_{\mathrm{ec}}=\frac{\theta_{\text {air_o }}-\theta_{\text {air_sup }}}{\theta_{\text {air_o }}-\theta_{\text {air_o,wb }}} \quad[-]
$$

When evaporative cooling is activated, the model determines $\theta_{\text {air_sup }}$ as

$$
\theta_{\text {air_sup }}=\theta_{\text {air_o }}-\varepsilon_{\text {ec }} \cdot\left(\theta_{\text {air_o }}-\theta_{\text {air_o,wb }}\right) \quad\left[{ }^{\circ} \mathrm{C}\right]
$$

And the tunnel ventilation with the activation of evaporative pads $\left(\dot{V}_{\text {ec }}\right)$ as

$$
\dot{V}_{\text {ec }}=\min \left[\frac{\left|\phi_{\text {C_nd }}\right|}{c_{\text {air }} \cdot\left(\theta_{\text {set_C }}-\theta_{\text {air_sup }}\right)} \cdot \frac{3.6 \cdot 10^{3}}{\rho_{\text {air }}} ; \dot{V}_{\text {max }}\right] \quad\left[\frac{\mathrm{m}^{3}}{\mathrm{~h}}\right]
$$

After the estimation of $\dot{V}_{\mathrm{tv}}$ or $\dot{V}_{\mathrm{ec}}$, the energy simulation model updates the thermal balance -as shown by the workflow of Figure 5.1- to correctly estimate the actual value of $\theta_{\text {air_i }}$, needed to set the moisture balance in the following calculation module.

\section{Moisture balance module}

At each simulation time step, the energy simulation model solves the following moisture balance which schematization is presented in Figure 5.6

$$
\dot{V}_{\text {act }} \cdot \rho_{\text {air }} \cdot\left(x_{\text {air_sup }}-x_{\text {air_i }}\right)+\dot{m}_{\text {i_f }_{-}} \cdot 3.6 \cdot 10^{3}=0 \quad\left[\frac{\mathrm{kg}_{\text {vap }}}{\mathrm{h}}\right]
$$

where $\dot{V}_{\text {act }}$ is the actual ventilation air flow rate $-\dot{V}_{\mathrm{bs}}, \dot{V}_{\mathrm{tv}}$ or $\dot{V}_{\mathrm{ec}}$ - estimated by the model in the considered time step $\left(\mathrm{m}^{3} \mathrm{~h}^{-1}\right), \rho_{\text {air }}$ is the volumetric mass density of the ventilation air $\left(\mathrm{kg} \mathrm{m}^{-3}\right), x_{\text {air_sup }}$ and $x_{\text {air_i }}$ are the humidity ratio of supply and indoor air, respectively $\left(\mathrm{kg}_{\text {vap }} \mathrm{kg}^{-1}\right)$. The term $\dot{m}_{\mathrm{i}_{\mathrm{f}}}$ is the water vapor emission from the entire flock $\left(\operatorname{kg}_{\mathrm{vap}} \mathrm{s}^{-1}\right)$. The moisture storage capacity of the envelope 
and the materials contained inside the enclosure -e.g. animals' plumage and litter straw- are not considered in the framework of the present work.

The moisture balance of Eq. (66) is solved by the model to determine $x_{\text {air_i }}$ needed to estimate $R H_{\mathrm{i}}$ as a function of $\theta_{\text {air_i }}$ through psychrometric formulations.

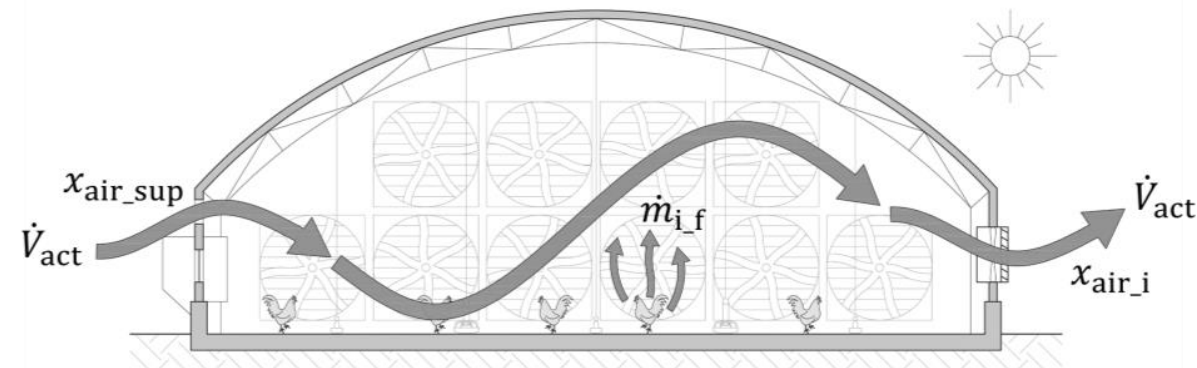

Figure 5.6 - Moisture balance of a typical broiler house.

\section{System performance module}

The "System performance module" is the last step of the model workflow and estimates the total thermal and electrical energy consumption due to supplemental heating and ventilation. To do so, the performance of the climate control system of the simulated broiler house should be considered.

The thermal energy consumption for supplemental heating over the entire simulation period $\left(E_{\mathrm{th}}\right)$ is calculated as

$$
E_{\text {th }}=\sum_{k=1}^{n_{\mathrm{k}}}\left(\frac{\phi_{\mathrm{H}_{\_} \mathrm{nd}, \mathrm{k}} \cdot \Delta \tau}{\eta_{\mathrm{H}} \cdot 10^{3}}\right)[\mathrm{kWh}]
$$

where $\phi_{\mathrm{H}_{-} n d}(\mathrm{~W})$ is the theoretical heating load estimated at each $k$-th simulation time step, $\eta_{H}$ is the global efficiency of the supplemental heating system $(-), \Delta \tau$ is the duration of the simulation time step (h) and $n_{\mathrm{k}}$ is the number of time steps of the simulation period.

To calculate the electrical energy consumption of the fans for both base and tunnel ventilation, the model estimates the static pressure difference between outside and inside air pressure $\left(\Delta p_{\text {st }}\right)$ for the following three cases

$$
\Delta p_{\mathrm{st}}=\left\{\begin{array}{lll}
\Delta p_{\mathrm{bs}} & \text { if } & \dot{V}_{\mathrm{bs}}>0 \\
\Delta p_{\mathrm{tv}} & \text { if } & \dot{V}_{\mathrm{tv}}>0 \\
\Delta p_{\mathrm{ec}} & \text { if } & \dot{V}_{\mathrm{ec}}>0
\end{array} \quad[\mathrm{~Pa}]\right.
$$

where $\Delta p_{\mathrm{bs}}, \Delta p_{\mathrm{tv}}$ and $\Delta p_{\mathrm{ec}}$ are $\Delta p_{\mathrm{st}}$ calculated considering the presence of base ventilation, tunnel ventilation and evaporative cooling, respectively.

When base ventilation is activated, $\Delta p_{\mathrm{st}}$ is considered equal to $\Delta p_{\mathrm{bs}}$, an input data. This is so, since the simulation model simulates the real operation of a broiler house where climate control system manages the inlet opening to maintain a fixed value of $\Delta p_{\mathrm{st}}$. When tunnel ventilation is activated, $\Delta p_{\mathrm{st}}$ is equal to $\Delta p_{\mathrm{tv}}$ that is 
estimated as a function of air velocity $\left(v_{\text {air }}\right)$ and the length of the broiler house $\left(l_{\text {hou }}\right)$ as

$$
\Delta p_{\mathrm{tv}}=\left(k_{\Delta \mathrm{p}_{-} 2} \cdot v_{\text {air }}^{2}+k_{\Delta \mathrm{p}_{-} 1} \cdot v_{\text {air }}+k_{\Delta \mathrm{p}_{0} 0}\right) \cdot l_{\mathrm{hou}}[\mathrm{Pa}]
$$

where $k_{\Delta \mathrm{p}_{-} 2}-k_{\Delta \mathrm{p}_{-} 0}$ are regression coefficient obtained from [262] and reported in Table A.8 of Appendix A.

When the evaporative cooling is activated, the presence of the pads entails a further pressure drop that should be considered. For this reason, to calculate $\Delta p_{\mathrm{ec}}$, the $\Delta p_{\mathrm{tv}}$ value obtained through Eq. (69) is increased by a further pressure drop that is introduced as an input data.

To calculate the electrical energy consumption due to ventilation $\left(E_{\mathrm{el}}\right)$, the fans present in the broiler houses are modelled similarly to what it was done in greenhouse model (Eqs. (27) - (29)). For this purpose, the fans for base and tunnel ventilation are characterized expressing their ventilation flow rate $\left(\dot{V}_{\text {fan }}\right)$ and their Specific Fan Performance $(S P F)$ as a function of $\Delta p_{\mathrm{st}}$. The activation of fans is simulated by the model allocating the ventilation flow rate to the first fan and then, sequentially, to the remaining ones. In this way, the first fan is always working base ventilation is always present- while the remaining ones are activated only when the needed ventilation flow rate cannot be provided by the previous ones.

Considering this control logic, at each $k$-th time step, $E_{\text {el }}$ reads

$$
E_{\mathrm{el}, \mathrm{k}}=\sum_{j=1}^{n_{\mathrm{fan}}}\left(\frac{\dot{V}_{\mathrm{fan}, \mathrm{j}}}{S F P_{\mathrm{j}}} \cdot \Delta \tau\right) \cdot 10^{-3}[\mathrm{kWh}]
$$

where $j$ indicates the $j$-th fan present in the broiler house and $n_{\text {fan }}$ is the total number of fans present inside the house.

The total electrical energy consumption over the simulation period reads

$$
E_{\mathrm{el}}=\sum_{k=1}^{n_{\mathrm{k}}} E_{\mathrm{el}, \mathrm{k}}[\mathrm{kWh}]
$$

where $n_{\mathrm{k}}$ is the number of the simulation time steps.

\subsection{Model customization for broiler houses: validation}

The presented energy simulation model is validated against a real dataset acquired through a monitoring campaign carried out during an entire production cycle in a broiler house. Before the model validation, an optimization-based calibration is performed. 


\subsubsection{Case study description}

\section{Broiler house description}

The selected case study for the model validation is a gable roof broiler house located in North of Italy which layout is schematized in Figure 5.7. The house has a useful floor area of $1,200 \mathrm{~m}^{2}$, being $120 \mathrm{~m}$ long and $10 \mathrm{~m}$ wide. The height of the house is $4.4 \mathrm{~m}$ at the ridge level and decreases until $2.1 \mathrm{~m}$ at the eave level. The useful volume is around $3,900 \mathrm{~m}^{3}$. The main orientation of the building is EastWest since its longest axis is aligned on the North-South direction.

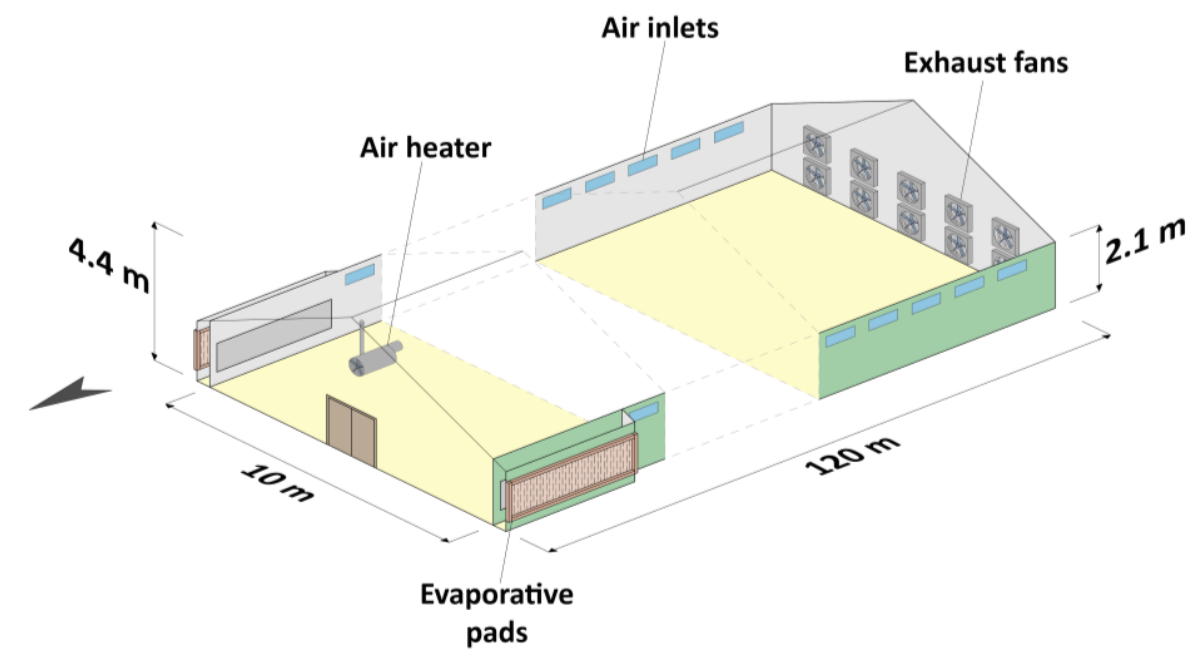

Figure 5.7 - Schematization of the layout of the broiler house selected as case study for the model validation.

Walls are prefabricated sandwich panels made up of a double layer of prepainted steel sheets with a high density spread polyurethane layer interposed of $0.04 \mathrm{~m}$ of thickness. The mean stationary thermal transmittance $(U-$ value $)$ of the walls is $0.81 \mathrm{~W} \mathrm{~m}^{-2} \mathrm{~K}^{-1}$. This value is obtained considering that part of the opaque envelope -about $6 \%$ of the north and south walls- is made of corrugated cellulose evaporative pads that are characterized by a higher $U-$ value. The windows are polycarbonate alveolar panels with a $U-$ value of $3.60 \mathrm{~W} \mathrm{~m}^{-2} \mathrm{~K}^{-1}$. The roof is composed by the same prefabricated panels used for the walls, but the interposed polyurethane layer is $0.02 \mathrm{~m}$ thick, thus a $U$-value of $1.17 \mathrm{~W} \mathrm{~m}^{-2} \mathrm{~K}^{-1}$ is estimated. The floor is a reinforced concrete screed above a waterproofing sheet in direct contact with the ground. The thermal effect of the ground was considered by adding a $1.5 \mathrm{~m}$ layer of soil to the original construction of the floor and adopting $\theta_{\text {air_o }}$ as the outdoor boundary condition. The internal heat capacity of the opaque elements $\left(\kappa_{\mathrm{i}}\right)$ was calculated in compliance with ISO 13786 Standard [264]. The main thermo-physical properties of the analyzed broiler house are summarized in Table 5.2. 
Table 5.2 - Stationary thermal transmittance $(U-$ value $)$ and areal internal heat capacity $\left(\kappa_{\mathrm{i}}\right)$ of the building elements of the analyzed broiler house.

\begin{tabular}{|c|c|c|}
\hline Element & $\begin{array}{c}U-\text { value } \\
{\left[\mathrm{W} \mathbf{m}^{-2} \mathbf{K}^{-1}\right]}\end{array}$ & {$\left[\mathrm{kJ} \mathrm{m}^{-2} \mathbf{K}^{-1}\right]$} \\
\hline Walls & 0.81 & 4.7 \\
\hline Roof & 1.17 & 4.0 \\
\hline Floor & 0.94 & 79.9 \\
\hline Windows & 3.60 & - \\
\hline
\end{tabular}

The batches carried out in the house have a duration of 50 days and the target final live weight of broiler is $3.6 \mathrm{~kg}$. The mean animal stocking density is 12 broilers per square meter of usable floor area, meaning that about 14,500 broilers are reared per batch. After each production cycle, a sanitary empty period of 11 days is considered for sanitization tasks. Six production cycles are completed each year.

The considered broiler house is mechanically ventilated through a tunnel ventilation configuration, one of the most common strategy adopted in broiler house design. On the south wall, ten fixed angular speed exhaust fans deal with both Indoor Air Quality (IAQ) control -base ventilation- and tunnel ventilation. The mechanical power of the installed fan model is $0.75 \mathrm{~kW}(1 \mathrm{hp})$ and the diameter of the six-blade propeller is $1.27 \mathrm{~m}$. The maximum flow rate of the fan in free air delivery conditions $\left(\Delta p_{\text {st }}=0 \mathrm{~Pa}\right)$, is around $42,000 \mathrm{~m}^{3} \mathrm{~h}^{-1}$. In Table A.9 (Appendix A), the regression coefficients for Eqs. (27) and (28) needed to characterize $\dot{V}_{\text {fan }}$ and $S F P$ as a function of $\Delta p_{\text {st }}$ are reported.

When cooling ventilation cannot maintain $\theta_{\text {set_c }}$, evaporative cooling is activated and $\theta_{\text {air_sup }}$ is decreased through the adiabatic saturation performed by the evaporative pads installed in the north part of the longest walls. Climate control system activates the evaporative cooling when the difference between $\theta_{\text {set_c }}$ and outdoor air temperature $\theta_{\text {air_o }}$ is lower than $3^{\circ} \mathrm{C}$. The evaporative pads are $150 \mathrm{~mm}$ thick and are made of impregnated and corrugated cellulose paper sheets. The direct saturation effectiveness of the pads -as defined by [214] and Eq. (63)- is equal to $87 \%$, as reported in the technical datasheet provided by the manufacturer. Two submersible pumps are used to pump the water from the tanks at the basis of the pads to the top of them. The electrical motor of each pump is estimated to deliver $0.55 \mathrm{~kW}(0.75 \mathrm{hp})$ of mechanical power and to absorb $0.85 \mathrm{~kW}$ of electrical power.

The supplemental heating system is made by five natural gas air heaters with $10 \mathrm{~kW}$ of heating capacity each one.

\section{Monitoring campaign description}

The previously described broiler house was monitored during an entire production cycle of 50 days (1,200 hours) carried out between May and June. During this period, indoor and outdoor climate conditions were monitored together with the working time of the gas heaters and the electrical energy consumption of fans, as summarized in Table 5.3. The considered period results adequate for the 
model validation and calibration since all the equipment for climate control -gas air heaters, fans, and evaporative pads- were activated and quite different outdoor weather conditions occurred.

Table 5.3 - Summary of the broiler house monitoring campaign.

\begin{tabular}{ccc}
\hline Dataset & Monitored parameter & Monitoring period \\
\hline $\begin{array}{c}\text { Indoor climate } \\
\text { conditions }\end{array}$ & $\theta_{\text {air_i }}$ & May $5^{\text {th }}-$ June $23^{\text {rd }}$ \\
\hline Outdoor climate & $R H_{\text {i }}$ & \\
conditions & $\theta_{\text {air_o }}$ & May $5^{\text {th }}-$ June $23^{\text {rd }}$ \\
\hline $\begin{array}{c}\text { Climate control } \\
\text { system }\end{array}$ & $R H_{\mathrm{o}}$ \\
$I_{\text {tot_hor }}$ & Working time of gas heaters & May $5^{\text {th }}-$ June $23^{\text {rd }}$ \\
\hline
\end{tabular}

*Part from third-party weather station

In Table 5.4, the summary of the dataset acquired during the monitoring campaign is presented. Two points of measurements for $\theta_{\text {air_i }}$ and $R H_{\mathrm{i}}$ were set inside the house. For this purpose, two data loggers that embed a thermistor (accuracy: $\pm 0.21^{\circ} \mathrm{C}$ ) and a humistor (accuracy: $\pm 2.5 \%$ ) were installed at the beginning and at the end of the broiler house at $0.35 \mathrm{~m}$ of height from floor level. The acquisition time step was set to two minutes. Additional data were provided with a daily basis by the house climate control unit that measured and logged the daily maximum, minimum and mean $\theta_{\text {air_i }}$ and $R H_{\mathrm{i}}$. A data logger was arranged outside the house to monitor $\theta_{\text {air_o }}$ and $R H_{\mathrm{o}}$, while the hourly solar radiation on the horizontal plane ( $I_{\text {tot_hor }}$ ) was obtained from a third-party weather station near the broiler house.

The thermal energy consumption was indirectly calculated knowing the heat capacity of the gas heaters and the daily working time of each one that was retrieved from the climate control unit. The electrical energy consumption for ventilation was obtained by installing an energy meter in the powerline of the fans that provided the cumulative electrical energy consumption of all the fans over the entire period.

Table 5.4 - Summary of the dataset acquired in the broiler house.

\begin{tabular}{cccc}
\hline Monitored parameter & Source & $\begin{array}{c}\text { Number } \\
\text { of data }\end{array}$ & $\begin{array}{c}\text { Acquisition } \\
\text { time step }\end{array}$ \\
\hline Indoor air temperature & Data loggers & 72,000 & 2 minutes \\
Indoor relative humidity & Data loggers & 72,000 & 2 minutes \\
Outdoor air temperature & Data logger & 36,000 & 2 minutes \\
Outdoor relative humidity & Data logger & 36,000 & 2 minutes \\
Outdoor solar radiation & Weather station & 1,200 & 1 hour \\
Indoor air temperature & Climate control unit & 150 & 1 day \\
Indoor relative humidity & Climate control unit & 150 & 1 day \\
Working time of each gas heaters & Climate control unit & 250 & 1 day \\
Cumulative fans energy consumption & Energy meter & 1 & 50 days \\
\hline
\end{tabular}

To calibrate and validate the developed model, the acquired data were averaged to obtain a single value that represents the mean $\theta_{\text {air_i }}$ and $R H_{\mathrm{i}}$ of the enclosure at each hourly time step. For this purpose, the data acquired at each logging time step 
from the data loggers were first averaged between them and then they were averaged on a time basis to obtain hourly and daily values. The obtained $\theta_{\text {air_i }}$ and $R H_{\mathrm{i}}$ are identified with the subscript $D L\left(\theta_{\mathrm{DL}}\right.$ and $\left.R H_{\mathrm{DL}}\right)$. For the calibration and validation of the model, only the daily mean values of $\theta_{\text {air_i }}$ and $R H_{\mathrm{i}}$ obtained from climate control unit are considered and they are identified as $\theta_{\mathrm{CCU}}$ and $R H_{\mathrm{CCU}}$.

\subsubsection{Model calibration and validation}

\section{Preliminary assessment of model reliability}

The previously described case study was simulated to provide a first evaluation of the model reliability. In Figure 5.8, the daily values of $\theta_{\text {air_i }}$ and $R H_{\mathrm{i}}$ estimated by the model and the values obtained from the data loggers $\left(\theta_{\mathrm{DL}}\right.$ and $\left.R H_{\mathrm{DL}}\right)$ and from climate control unit $\left(\theta_{\mathrm{CCU}}\right.$ and $\left.R H_{\mathrm{CCU}}\right)$ are shown during the entire monitored production cycle together with $\theta_{\text {air_o }}$ and $R H_{\mathrm{o}}$. Analyzing the trend of $\theta_{\text {air_o }}$ and $R H_{\mathrm{o}}$, the monitored period results relevant for the model validation, as previously stated. The first part of the production cycle, in fact, is characterized, by lower $\theta_{\text {air_o }}$, being the minimum value $-18^{\text {th }}$ day of the batch- $15.7^{\circ} \mathrm{C}$. The low $\theta_{\text {air_o }}$, and the presence of the few-days old broiler chicks inside the house, entailed a supplemental heating need to maintain $\theta_{\text {set_H }}$.

During the second part of the monitored production cycle, the higher $\theta_{\text {air_o }}$-the maximum value is $29.0^{\circ} \mathrm{C}, 31^{\text {st }}$ day of the batch- and the increased heat production of heavier birds entail the need to cool the broilers through the activation of both tunnel ventilation and evaporative cooling. The trends of all the presented indoor air temperatures $\left(\theta_{\mathrm{air}_{-} \mathrm{i}}, \theta_{\mathrm{DL}}\right.$, and $\left.\theta_{\mathrm{CCU}}\right)$ are similar between them, while some differences stand out between the indoor air relative humidity trends $\left(R H_{\mathrm{i}}, R H_{\mathrm{DL}}\right.$, and $\left.R H_{\mathrm{CCU}}\right)$. The trend estimated by the simulation model $\left(R H_{\mathrm{i}}\right)$ is higher than the monitored values $\left(R H_{\mathrm{DL}}\right.$ and $\left.R H_{\mathrm{CCU}}\right)$ during almost all the days of the monitoring campaign, being the only exception day 22 . The differences between the simulated and monitored values are higher especially during the second part of the monitored period, when cooling is needed. This difference may be explained analyzing the evaporative pads modeling. This cooling system, in fact, considerably influences $R H_{\mathrm{i}}$ since pads tent to saturate the inletting air, increasing its humidity ratio. For preforming the simulation, the $\varepsilon_{\mathrm{ec}}$ value from the technical datasheet of the panel model provided by the manufacturer was used. The chosen value, hence, is representative of the $\varepsilon_{\mathrm{ec}}$ of a new pad. Nevertheless, it has to be considered that $\varepsilon_{\mathrm{ec}}$ tends to decrease over its lifetime as a result of the degradation process of the material caused by factors such as dust, solar radiation and chemical components that could be present in the water used to wet the pad. Fort this reason, $\varepsilon_{\mathrm{ec}}$ is chosen as calibration parameter. 


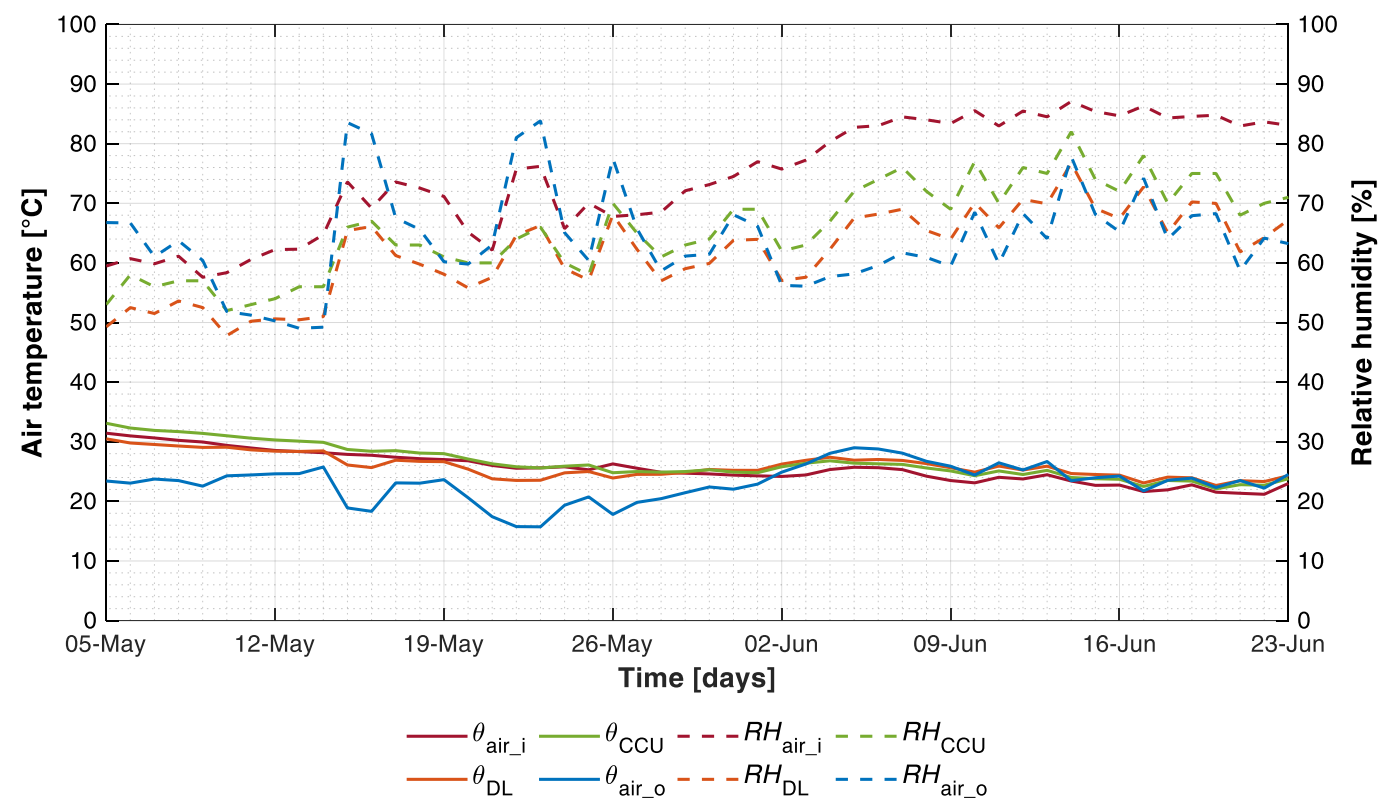

Figure 5.8 - Daily trends of simulated $\left(\theta_{\mathrm{air}_{\mathrm{i}} \mathrm{a}}\right.$ and $\left.R H_{\mathrm{i}}\right)$ and monitored $\left(\theta_{\mathrm{DL}}, \theta_{\mathrm{CCU}}, R H_{\mathrm{DL}}\right.$, and $R H_{\mathrm{CCU}}$, ) values of indoor air temperature and relative humidity. The monitored trends of outdoor air temperature $\left(\theta_{\text {air_o }}\right)$ and relative humidity $\left(R H_{0}\right)$ are also presented.

\section{Calibration of the model}

For increasing the reliability of the model, an optimization-based calibration [220] is performed to fine-tune $\varepsilon_{\mathrm{ec}}$. For this purpose, the dimensionless calibration parameter $\gamma_{\varepsilon}$ that multiplies $\varepsilon_{\mathrm{ec}}$ is introduced. The calibration process is based on the minimization of the Root Mean Square Error ( $R M S E$, previously defined in Eq. (35)) varying $\gamma_{\varepsilon}$ with a procedure similar to the one previously presented in section 4.4.3. The optimization problem, hence, reads

$$
\hat{\gamma}_{\varepsilon}=\min _{\gamma_{\varepsilon}}\left[\operatorname{RMSE}\left(\mathcal{A}\left(\gamma_{\varepsilon}\right), \tilde{\mathcal{A}}\right)\right]
$$

where $\hat{\gamma}_{\varepsilon}$ is the optimum value of $\gamma_{\varepsilon}$ that minimizes the $R M S E$ calculated between the simulated hourly profile of $\theta_{\text {air_i }}(\mathcal{A})$ and the measured one $(\tilde{\mathcal{A}})$.

The optimization procedure is performed setting the following constraint

$$
0 \leq \gamma_{\varepsilon} \leq 1
$$

since the calibrated value of $\varepsilon_{\mathrm{ec}}$ cannot be higher than the $\varepsilon_{\mathrm{ec}}$ value provided by the pad technical datasheet $\left(\gamma_{\varepsilon} \leq 1\right)$ and because $\varepsilon_{\mathrm{ec}}$ should be positive or equal to $0\left(0 \leq \gamma_{\varepsilon}\right)$. A Generalized Reduced Gradient $(G R G)$ nonlinear algorithm is used to solve Eq. (72), providing a value of $\hat{\gamma}_{\varepsilon}$ of 0.69 . Considering the obtained value, the optimum $\varepsilon_{\mathrm{ec}}$ is 0.6 , meaning that the performance decay of the pads is around $30 \%$. Once obtained the calibrated $\varepsilon_{\mathrm{ec}}$, a new simulation is performed to validate the model. 


\section{Validation of the model: indoor climate conditions}

In Figure 5.9, the daily trends of $\theta_{\text {air_i }}$ and $R H_{\mathrm{i}}$, previously presented in Figure 5.8, are updated considering the calibrated $\varepsilon_{\mathrm{ec}}$. The new trends better fit the measured data. The new trend of $\theta_{\text {air_i }}$ is slightly higher than the one presented in Figure 5.8 since the reduced $\varepsilon_{\mathrm{ec}}$ makes the evaporative pads less effective in decreasing the temperature of the inletting air. The new trend of $R H_{\mathrm{i}}$ is considerably different than the one presented in Figure 5.8, especially in the second half when evaporative pads were activated. This difference is due to the lower capacity of the pads of saturating the inletting air that, consequently, has a lower humidity ratio.

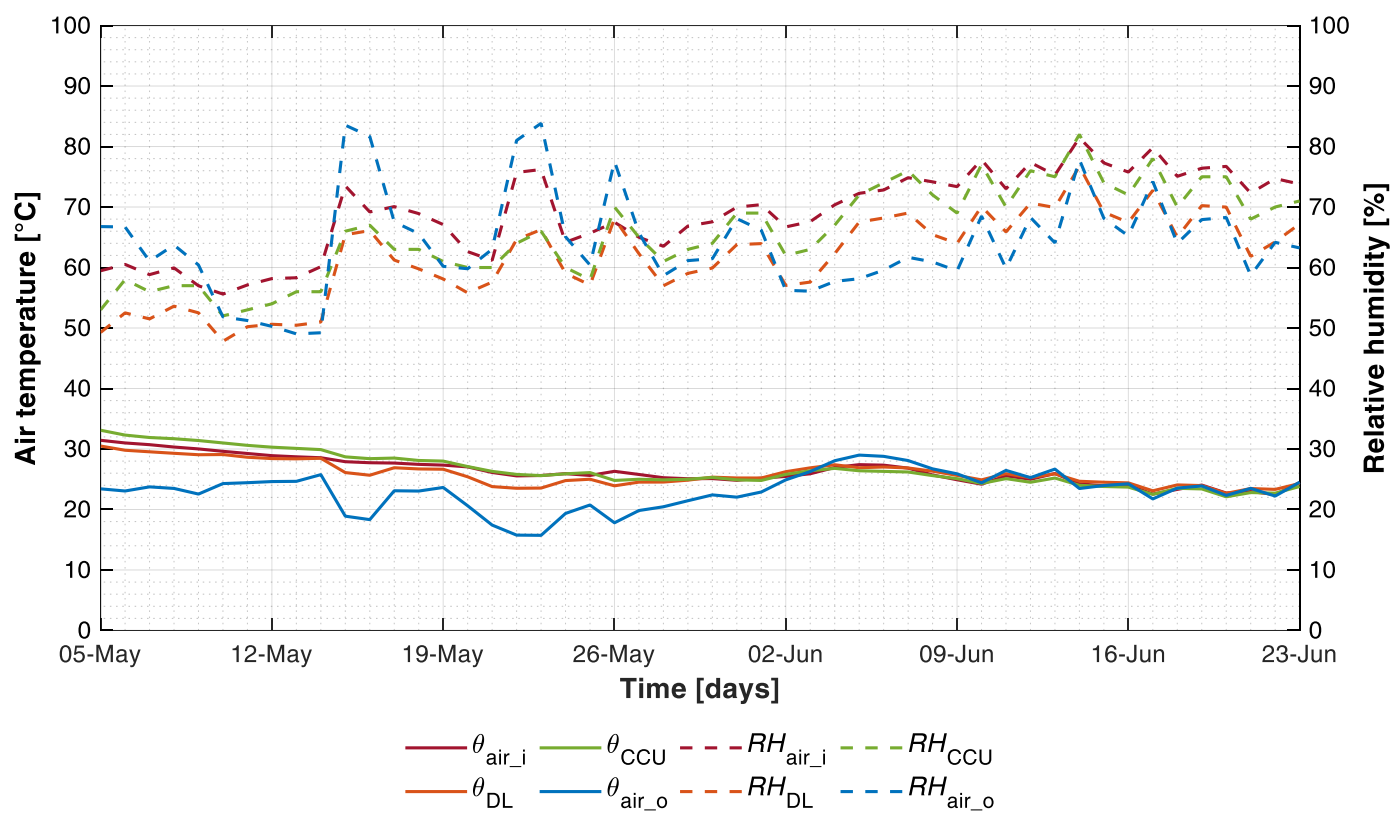

Figure 5.9 - Updated $\left(\varepsilon_{\mathrm{ec}}=0.6\right)$ daily trends of simulated $\left(\theta_{\text {air_i }}\right.$ and $\left.R H_{\mathrm{i}}\right)$ and monitored $\left(\theta_{\mathrm{DL}}\right.$, $\theta_{\mathrm{CCU}}, R H_{\mathrm{DL}}$, and $R H_{\mathrm{CCU}}$, ) values of indoor air temperature and relative humidity. The monitored trends of outdoor air temperature $\left(\theta_{\text {air_o }}\right)$ and relative humidity $\left(R H_{\mathrm{o}}\right)$ are also shown.

In Figure 5.10, the hourly trend of the simulated $\theta_{\text {air_i }}, R H_{\mathrm{i}}$ and $\dot{V}_{\text {act }}$ are displayed together with the monitored $\theta_{\mathrm{DL}}, R H_{\mathrm{DL}}, \theta_{\text {air_o }}, R H_{\mathrm{o}}$. The graph shows that, during the first days of the batch, $\dot{V}_{\text {act }}$ is at a minimum (Figure 5.10c) since only base ventilation is activated and no cooling was needed. Since base ventilation flow rate is a function of broiler weight (as shown in Eq. (60)), low flow rates are expected in that period because broiler chicks are present in the house. As time goes on, $\dot{V}_{\text {act }}$ increases because heavier birds require higher ventilation flow rate for $I A Q$ control and for cooling them during the warmest period.

Figure 5.10 shows also that the energy simulation model estimates with a good reliability the trend of $\theta_{\text {air_i }}$ (Figure 5.10a) since slight differences stand out with $\theta_{\mathrm{DL}}$ trend. During the second part of the monitoring period, $\theta_{\text {air_i }}$ is characterized by a higher daily variation than $\theta_{\mathrm{DL}}$. This difference could be explained considering a slight difference between the modelled and real broiler house total heat capacity. The graph shows also that the model is reliable for estimating $R H_{\mathrm{i}}$ with a slight overestimation over the entire monitored period (Figure 5.10b). That 
overestimation may be due to the hygroscopic storage capacity of the materials present inside the house that was not considered in the moisture balance of Eq. (66).
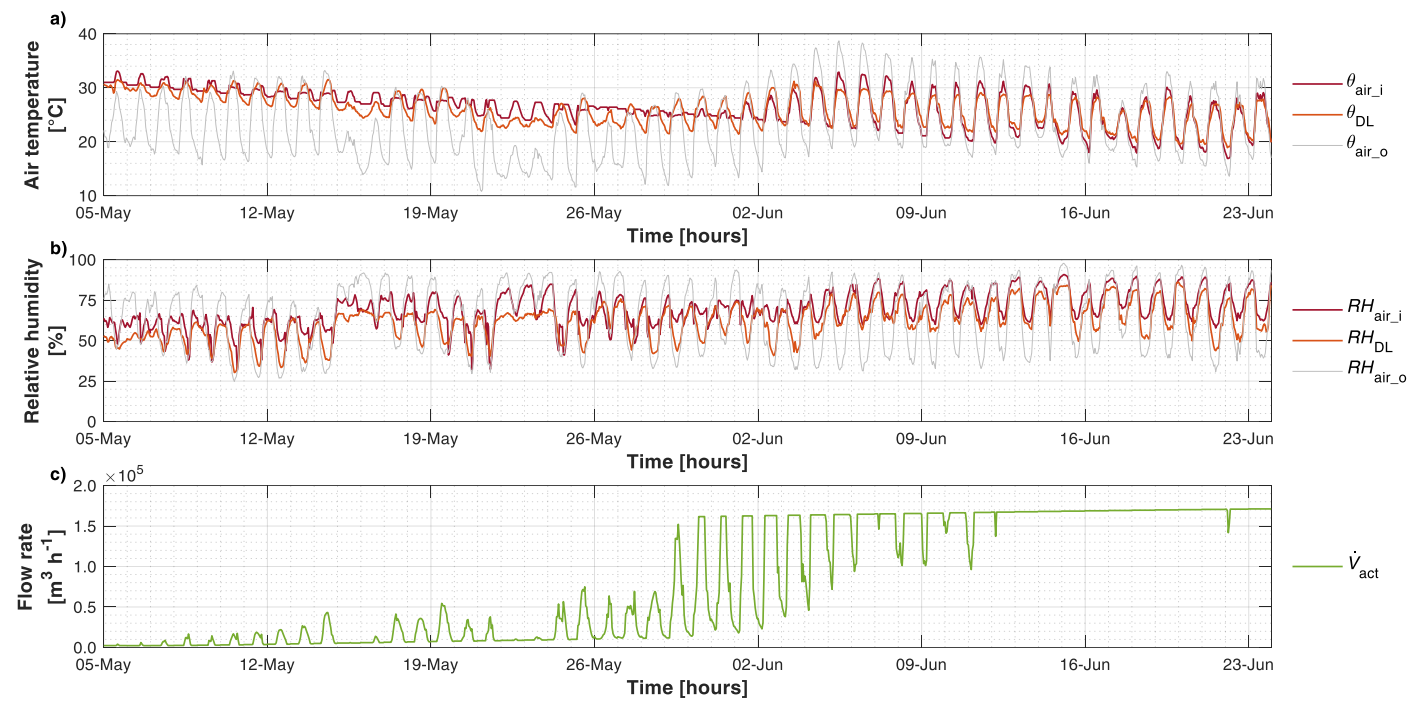

Figure 5.10 - figure a): hourly trends of simulated $\left(\theta_{\text {air_i }}\right)$, monitored $\left(\theta_{D L}\right)$, and outdoor $\left(\theta_{\text {air_o }}\right)$ air temperature; figure b): hourly trends of simulated $\left(R H_{\mathrm{i}}\right)$, monitored $\left(R H_{\mathrm{DL}}\right)$, and outdoor $\left(R H_{\mathrm{o}}\right)$ relative humidity; figure c): simulated ventilation flow rate $\left(\dot{V}_{\text {act }}\right)$.

The proposed energy model is validated also from a numerical point of view, adopting goodness-of-fit-indexes, similarly to what it was done for greenhouse model (section 4.4.4). For this aim, the Mean Bias Error ( $M B E$, defined in Eq. (43)) and the Coefficient of variation of the RMSE (CvRMSE, defined in Eq. (44)) are calculated over the entire monitored period with an hourly basis and compared with the main thresholds present in literature (ASHRAE Guidelines 14 [225], IPMVP [226] and FEMP [227]). In Table 5.5, the goodness-of-fit indexes calculated before and after the calibration and their thresholds -provided only for hourly validationare presented. In the same table, the hourly and daily $R M S E$ values calculated considering the measured data obtained from data loggers $\left(\theta_{\mathrm{DL}}\right.$ and $\left.R H_{\mathrm{DL}}\right)$ and from climate control unit $\left(\theta_{\mathrm{CCU}}\right.$ and $\left.R H_{\mathrm{CCU}}\right)$ are also presented.

From Table 5.5, it stands out that the model estimation of $\theta_{\text {air_i }_{i}}$ is very reliable. On an hourly basis, in fact, the RMSE -calculated considering the data obtained from the data loggers- is around $1.65^{\circ} \mathrm{C}$, a value that has considerably been improved by the calibration process, since originally it was $2.01{ }^{\circ} \mathrm{C}$. The goodnessof-fit indexes concerning $\theta_{\text {air_i }}$ are considerably below all the thresholds, including the most restrictive ones of IPMVP. The model estimation of $R H_{\mathrm{i}}$ is also good, being the RMSE after the calibration less than $10 \%$. The model respects all the thresholds of $C v(R M S E)$, while the obtained $M B E(-11.73 \%)$ is slightly below the ASHRAE and FEMP thresholds $( \pm 10 \%)$ while it does not respect the IPMVP one $( \pm 5 \%)$.

The model reliability on a daily basis is also good. The $R M S E$, is lower than $1{ }^{\circ} \mathrm{C}$ for $\theta_{\text {air_i }}$ and lower than $8 \%$ for $\theta_{\text {air_i }}$, considering the measured data from both the data loggers and the climate control unit. Comparing the calculated RMSE, the 
model estimation is more similar to the data obtained from the climate control unit than the ones from data loggers.

Table 5.5 - Values before and after the calibration of goodness-of-fit indices and threshold values for the hourly and daily validation of the presented energy simulation model.

\begin{tabular}{|c|c|c|c|c|c|c|}
\hline & \multirow{2}{*}{$\begin{array}{l}\text { Measured } \\
\text { value }\end{array}$} & \multirow{2}{*}{$\begin{array}{l}\text { Goodness- } \\
\text { of-fit index }\end{array}$} & \multicolumn{2}{|c|}{ Calculated value } & \multicolumn{2}{|c|}{$\begin{array}{l}\text { Threshold value }^{\mathrm{d}} \\
\text { (hourly validation) }\end{array}$} \\
\hline & & & $\begin{array}{c}\text { Before } \\
\text { calibration }\end{array}$ & $\begin{array}{c}\text { After } \\
\text { calibration }\end{array}$ & $\begin{array}{c}\text { ASHRAE } \\
\text { and } \\
\text { FEMP }\end{array}$ & IPMVP \\
\hline \multirow{6}{*}{ 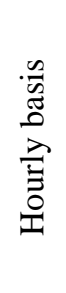 } & \multirow{3}{*}{$\theta_{\mathrm{DL}}$} & $M B E^{\mathrm{a}}$ & $1.30 \%$ & $-1.51 \%$ & $\pm 10 \%$ & $\pm 5 \%$ \\
\hline & & $C v(R M S E)^{\mathrm{b}}$ & $7.76 \%$ & $6.35 \%$ & $30 \%$ & $20 \%$ \\
\hline & & $R M S E^{\mathrm{c}}$ & $2.01{ }^{\circ} \mathrm{C}$ & $1.65^{\circ} \mathrm{C}$ & - & - \\
\hline & \multirow{3}{*}{$R H_{\mathrm{DL}}$} & $M B E$ & $-20.49 \%$ & $-11.73 \%$ & $\pm 10 \%$ & $\pm 5 \%$ \\
\hline & & $C v(R M S E)$ & $25.85 \%$ & $15.19 \%$ & $30 \%$ & $20 \%$ \\
\hline & & $R M S E$ & $16.00 \%$ & $9.38 \%$ & - & - \\
\hline \multirow{4}{*}{$\begin{array}{l}\frac{n}{\tilde{E}} \\
\frac{0}{0} \\
\stackrel{2}{\Xi} \\
\tilde{0}\end{array}$} & $\theta_{\mathrm{DL}}$ & $R M S E$ & $1.46^{\circ} \mathrm{C}$ & $0.99^{\circ} \mathrm{C}$ & - & - \\
\hline & $R H_{\mathrm{DL}}$ & $R M S E$ & $13.47 \%$ & $7.59 \%$ & - & - \\
\hline & $\theta_{\mathrm{CCU}}$ & $R M S E$ & $1.13^{\circ} \mathrm{C}$ & $0.78^{\circ} \mathrm{C}$ & - & - \\
\hline & $R H_{\mathrm{CCU}}$ & $R M S E$ & $9.44 \%$ & $4.21 \%$ & - & - \\
\hline
\end{tabular}

To understand the model estimation regarding $R H_{\mathrm{i}}$, an analysis of the $R H_{\mathrm{i}}$ residual values $\left(\Delta R H_{\mathrm{i}}\right)$ calculated as the hourly difference between $R H_{\mathrm{i}}$, estimated by the model, and $R H_{\mathrm{DL}}$ was performed. The results are presented in the histogram of Figure 5.11, where the absolute (primary $y$-axis) and relative (secondary $y$-axis) $\Delta R H_{\mathrm{i}}$ frequencies are presented. The graph highlights that most of the $\Delta R H_{\mathrm{i}}$ values are positive, meaning that the model overestimates $R H_{\mathrm{i}}$ during $88 \%$ of the hours of the simulation period. This sort of "systematic error" may be due to the hygric material properties. As stated before, in fact, the model does not consider that the water vapor present in the indoor air could be partially absorbed by the broiler plumage and the bedding straw, decreasing the humidity ratio and, consequently, $R H_{\mathrm{i}}$. Further developments of the model may include the hygric capacity of broiler house -a topic currently not present in literature- for improving the $R H_{\mathrm{i}}$ estimation. 


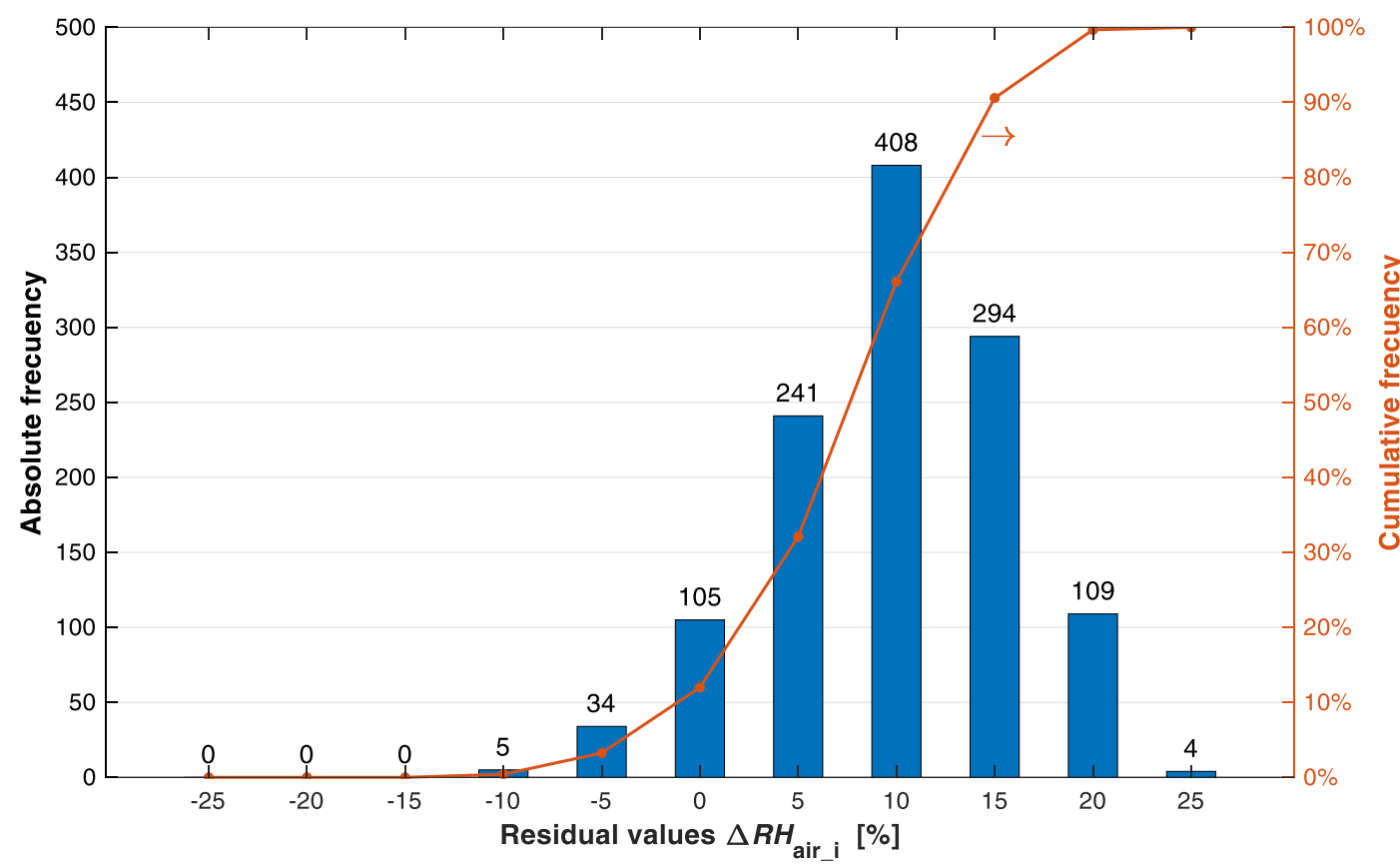

Figure 5.11 - Absolute (primary $y$-axis) and cumulative frequencies (secondary $y$-axis) of the relative humidity residual values $\left(\Delta R H_{\mathrm{i}}\right)$ calculated on hourly basis $(1,200$ values $)$.

\section{Validation of the model: energy consumption}

The last part of the model validation concerns the thermal energy consumption for supplemental heating and the electrical energy consumption for ventilation.

The monitored working times of each gas heater (I to V) of the house, obtained from climate control unit, are reported in Table 5.6. The acquired data show that gas heaters I and $\mathrm{V}$ are the ones with the highest working times, probably since they are placed at the head and bottom of the broiler house where the thermal losses due to transmission and infiltration are higher than in other spots of the house. Since the maximum heat capacity of each gas heater is known $(10 \mathrm{~kW})$, the total thermal energy consumption over the entire period for supplemental heating is estimated to be $3,551 \mathrm{kWh}_{\mathrm{th}}$. The model estimates a thermal energy consumption for supplemental heating of $3,184 \mathrm{kWh}_{\mathrm{th}}$, meaning a slightly underestimation by around $10 \%$. The estimation of electrical energy consumption is also good since the monitored consumption for ventilation is $5,061 \mathrm{kWh}_{\mathrm{el}}$ while the model estimated it around $5,463 \mathrm{kWh}_{\mathrm{el}}$, meaning a slight overestimation by around $8 \%$. 
Table 5.6 - Monitored working times of the five gas heaters (I to V) of the monitored broiler house.

\begin{tabular}{|c|c|c|c|c|c|}
\hline \multirow{2}{*}{$\begin{array}{l}\text { Day of the } \\
\text { batch }\end{array}$} & \multicolumn{5}{|c|}{ Gas heater monitored working time (minutes) } \\
\hline & I & II & III & IV & $\mathbf{V}$ \\
\hline 1 & 365 & 125 & 8 & 9 & 386 \\
\hline 2 & 712 & 264 & 8 & 7 & 600 \\
\hline 3 & 612 & 307 & 12 & 9 & 566 \\
\hline 4 & 574 & 315 & 3 & 6 & 571 \\
\hline 5 & 506 & 256 & 3 & 0 & 525 \\
\hline 6 & 435 & 224 & 0 & 3 & 441 \\
\hline 7 & 370 & 212 & 0 & 0 & 407 \\
\hline 8 & 290 & 285 & 0 & 0 & 369 \\
\hline 9 & 181 & 232 & 0 & 0 & 274 \\
\hline 10 & 169 & 208 & 0 & 0 & 179 \\
\hline 11 & 415 & 496 & 27 & 239 & 452 \\
\hline 12 & 444 & 408 & 8 & 2 & 509 \\
\hline 13 & 201 & 229 & 4 & 1 & 321 \\
\hline 14 & 160 & 189 & 5 & 30 & 246 \\
\hline 15 & 128 & 197 & 0 & 0 & 52 \\
\hline 16 & 145 & 187 & 14 & 197 & 181 \\
\hline 17 & 190 & 251 & 0 & 0 & 210 \\
\hline 18 & 422 & 401 & 34 & 355 & 93 \\
\hline 19 & 380 & 393 & 66 & 653 & 48 \\
\hline 20 & 132 & 155 & 8 & 1 & 3 \\
\hline 21 & 95 & 100 & 3 & 40 & 25 \\
\hline 22 & 56 & 81 & 1 & 328 & 155 \\
\hline 23 & 25 & 14 & 0 & 45 & 0 \\
\hline 24 & 11 & 6 & 0 & 0 & 1 \\
\hline 25 & 6 & 4 & 2 & 0 & 0 \\
\hline 26 & 0 & 0 & 0 & 0 & 0 \\
\hline 27 & 0 & 0 & 0 & 0 & 0 \\
\hline 28 & 0 & 0 & 0 & 0 & 0 \\
\hline 29 & 0 & 0 & 0 & 0 & 0 \\
\hline $30-50$ & 0 & 0 & 0 & 0 & 0 \\
\hline Total & 7,024 & 5,539 & 206 & 1,925 & 6,614 \\
\hline
\end{tabular}

\subsection{Model customization for pig houses: development}

In the following sections, the energy modelling framework for climatecontrolled livestock houses (section 5.3) is customized to obtain a second energy simulation model specific for growing-finishing pig houses. For this purpose, the calculation modules presented in Figure 5.1 are now customized to be suitable for the simulation of the considered type of livestock houses, similarly to what it has been previously done for broiler houses (section 5.4.3). 


\subsubsection{The importance of a pig house model}

Pig houses were chosen for the customization of a second energy simulation model from the general energy framework due to the implications that pig production has at a global level. Pork, in fact, is one of the most important sources of animal proteins [265] and it represents over $40 \%$ of the total meat that is produced worldwide [228]. The spreading of pig farming mostly depends on the high feed efficiency that characterizes pigs, which are considered the most efficient in converting feed into meat amongst the large animals [128]. Over their production cycle, pigs, in fact, have an average feed-conversion ratio of $3.3 \mathrm{~kg}_{\text {feed }} \mathrm{kg}_{\text {weight }}^{-1}$, meaning that $3.3 \mathrm{~kg}$ of feed are needed to increase the pig live weight of $1 \mathrm{~kg}$ [266]. The low feed-conversion ratio that makes pigs interesting from the productive point of view clashes with the high amount of energy that is needed for their farming, especially in climate-controlled pig houses, as previously shown in Chapter 2. In European context, in fact, pig farming is the second most energy consuming activity of livestock sector -after milk production- with a specific total primary energy consumption -referred to pig live weight- that goes from $14.5 \mathrm{MJ} \mathrm{kg}_{\text {weight }}^{-1}$ to 22.6 MJ kg -1 are estimated to increase in the coming future [34] since pork production will rise by $7 \%$ just in the decade $2018-2028$ due to the world population growth [228]. Furthermore, the important transformations caused by agricultural mechanization will increase the share of pig farming carried out in intensive livestock system, especially in low-GDP countries [26] entailing a further increase of the energy consumption related to this livestock production [268].

The energy performance of pig houses can be improved, for example, by adopting passive strategies, such as the thermal insulation of the building envelope or passive heat recovery systems [269]. Active strategies are also suitable for this purpose and energy-efficient equipment can be adopted in pig houses, such as the variable angular speed fans that were previously presented in Chapter 4. The effectiveness of both active and passive strategies should be evaluated considering different boundary conditions, such as the geographical context and the expected climate changes. Therefore, the adoption of ad-hoc energy simulation models can be considered fundamental also for pig houses. Unfortunately, the literature review presented in section 5.2 showed that a common framework for the energy simulation of pig houses is far from being established. Furthermore, most of the existing pig house models are more focused on the estimation of the indoor climate conditions than on the energy consumption, outlining an important gap in literature.

Given this framework, in this section the energy simulation framework presented in section 5.3 is customized and validated for mechanically ventilated growing-finishing pig houses. This specific building type was selected among other pig buildings -e.g. farrowing houses and pig nursery houses- because growingfinishing pig houses are very widespread and mechanical systems entail higher energy consumption than naturally ventilated houses. In this customization, the 
peculiarities of pig houses have been addressed to properly model this complex thermodynamic system that deeply differ from other building types, similarly to what it was previously done for broiler houses. These peculiarities are, for instance, the time variable set point temperatures, the presence of free cooling systems and the high values of internal heat and moisture production from internal sources. For example, a $170 \mathrm{~kg}$ pig reared at $20{ }^{\circ} \mathrm{C}$ of indoor air temperature can produce up to $150 \mathrm{~W}$ of sensible heat and up to $130 \mathrm{~g} \mathrm{~h}^{-1}$ of water vapour, according to the formulations provided by Pedersen \& Sällvik [253].

\subsubsection{Overview on pig houses modelling issues}

In this section, the main peculiarities that have to be considered in the energy simulation of growing-finishing pig houses are presented. These peculiarities regard both the building and the climate control systems typical of growingfinishing pig houses.

\section{Peculiarities of buildings for growing-finishing pigs}

Pigs are farmed in growing-finishing pig houses during the last stage of the production cycle to reach the target final live weight that can be around $100 \mathrm{~kg}$ for butcher's meat production or around $160 \mathrm{~kg}$ for cured meat production, depending on the market and the country needs. Usually, intensive growing-finishing pig houses are totally confined systems that, inside, are divided in pens in which pigs are hosted in groups kept together since weaning stage, to decrease fights and stress problems [128].

The opaque envelope of growing-finishing pig houses could be made of masonry -outdated houses- or prefabricated panels -recently built houses- that are more and more preferred due to the easy installation, high durability, good thermal properties, and low cost. Windows are made up of polycarbonate hollow sheet panels and their opening can be managed by automatized electric systems to maintain a constant value of static pressure difference $\left(\Delta p_{\mathrm{st}}\right)$ between inside and outside the house. Partially or completely slatted floor systems are widespread in growing-finishing pig houses because they allow manure to be easily collected into pits under the floor, reducing the labor requirements [231]. Once in the pits, manure can be removed at the end of the production cycle or it can be frequently flushed, minimizing the bacterial digestion and the consequent gas production with positive effects on the $I A Q$ of the house [128].

\section{Peculiarities of climate control in growing-finishing pig houses}

In mechanically ventilated growing-finishing pig houses, climate control systems maintain the adequate indoor climate conditions needed to guarantee animal welfare and to improve the production. From an operative point of view, a $\theta_{\text {air_i }}$ range between 21 and $16^{\circ} \mathrm{C}$ is considered the optimal one to improve pig welfare and to increase their productivity [270]. Nevertheless, it could be difficult to guarantee these $\theta_{\text {air_i }}$ values especially true during the warm season since only 
free cooling systems are present in pig houses. The optimal range of relative humidity $\left(R H_{\mathrm{i}}\right)$ is between $60 \%$ and $75 \%$ [270,271]. Lower values of $R H_{\mathrm{i}}$ should be avoided since they could cause airway dryness and dehydration in pigs, facilitating the occurrence of respiratory problems. Higher $R H_{\mathrm{i}}$ values combined with low $\theta_{\text {air_i }}$ can rise the skin thermal conductivity, increasing the occurrence of cold stress situations during the cool season. During the warmer season, higher $R H_{\mathrm{i}}$ values with high $\theta_{\text {air_i }}$ can hinder the heat dissipation of pigs, increasing the occurrence of heat stress situations [163]. Heat stress is a detrimental condition for pigs from the ethic point of view since animal welfare can be considerably affected. Heat stress is also negative from the financial point of view, since it decreases productive performance -i.e., worse feed conversion ratio- and may lead to an increase mortality [272], as described in section 2.3. This is since pigs suffering from heat stress adopt phenotypic responses, such as a reduction of feed intake. In addition, most of the energy obtained by the intake feed is used to maintain homeothermy and not for growth, with a consequent decrease in weight gain [84]. St-Pierre et al. [98] estimated that, in USA, heat stress causes around $0.6 \%$ of the death among growing-finishing pigs and a reduction in weight gain up to $7 \mathrm{~kg} \mathrm{head}^{-1}$ each year. The economic loss due to the consequences of heat stress can be estimated around $\$ 202$ million yearly [98].

To maintain the previously presented adequate indoor climate conditions, mechanical systems are usually adopted in growing-finishing pig houses. Supplemental heating is provided by air heaters or hot water systems. In many growing-finishing pig houses, mechanical ventilation is adopted to cool pigs. During the warmest periods, high ventilation air flow rates are provided to remove the heat produced by pigs and to decrease $\theta_{\text {air_i }}$ by inletting cooler outdoor air. Mechanical ventilation is also a good strategy to control $I A Q$ by diluting and removing the contaminants through fresh outdoor air. The high indoor concentration of aerial dust particles, gases and odorous vapors, in fact, can affect pig health and can create a potentially hazardous environment for workers [159]. In growing-finishing pig houses equipped with slatted floor, exhaust ventilation systems are the most widespread ones [175], especially the so-called "pit ventilation" strategy. In pit ventilation, indoor air is exhausted by fans placed below the slatted floor level, enhancing the fresh air to inlet from openings placed in the rearing area [175]. Being exhausted below the floor level, the contact between noxious gases -originated in the pits- and the pigs' snouts -that are close to the flooris avoided [159].

Since mechanical ventilation is performed, air velocity inside the pig house should be carefully controlled to avoid drafts. Pigs, in fact, are strongly affected by temperature variations and draft due to the lack of a protective layer on their skin due to the absence of hair [128]. Usually, the air velocity around pigs should be between 0.2 and $1.5 \mathrm{~m} \mathrm{~s}^{-1}$ as a maximum value to avoid welfare problems. Higher air speeds are well tolerated in presence of high $\theta_{\text {air_i }}$-summer conditions- because 
they enhance the heat dissipation from the pig body [175], decreasing the heat stress risk.

\subsubsection{Calculation modules}

The calculation modules of the general modelling framework for livestock houses presented in section 5.3 are now customized for being suitable for the simulation of growing-finishing pig houses, considering the peculiarities of these buildings that were presented in section 5.6.2.

\section{Initialization module}

This module is needed to perform preliminary calculations for the estimation of the variables that are not time-dependent and that are needed in the following calculation modules, such as the equivalent solar areas and the stationary thermal transmittance.

\section{Pig modelling module}

The "Animal modelling module" presented in Figure 5.1 is customized to be specific for growing-finishing pig houses. The time-dependent variables specifically related to pigs are calculated in this module. Aspects such as pig thermal and vapor emissions, in fact, should be accurately estimated to solve the thermal and moisture balances.

In the developed model, all the needed boundary conditions are expressed as a function of pig body mass $\left(w_{\mathrm{p}}\right)$, commonly known as pig live weight. Since the presented model is dynamic, $w_{\mathrm{p}}$ is calculated as a time-dependant variable for accurately considering the variations of the boundary conditions that are dependent on pig growth. As reported in section 3.3.3, Gompertz function [160] was proved by different Authors $[162,273]$ to be reliable for the estimation of $w_{\mathrm{p}}$ as a function of pig age $\left(a_{p}\right)$. Therefore, the Gompertz function reported in Eq. (1) is implemented in this calculation module.

Heat and moisture production from internal sources can be expressed as a function of $w_{\mathrm{p}}$. In the framework of this model, heat and moisture production are estimated referring to the specific formulations for growing-finishing pig houses provided in [253]. These formulations estimate heat and moisture production at house level. Therefore, they include not only heat and moisture produced directly by pigs but even water evaporation from feed, waterers, and manure. The total sensible plus latent- thermal emission from internal sources $\left(\phi_{\text {tot } \mathrm{i}}\right)$ can be expressed at each time step through the following formulation adapted from [253]

$$
\phi_{\text {tot_i }}=\frac{\left\{\left[\phi_{\mathrm{m}_{\_} \mathrm{p}}+\left(1-K_{\mathrm{y}}\right) \cdot\left(\phi_{\mathrm{d}_{-} \mathrm{p}}-\phi_{\mathrm{m}_{\_} \mathrm{p}}\right)\right] \cdot\left(1240-12 \cdot \theta_{\mathrm{air}_{-} \mathrm{i}}\right)\right\} \cdot n_{\mathrm{p}}}{1000} \quad[\mathrm{~W}]
$$

where $\phi_{\mathrm{m}_{-} \mathrm{p}}$ is the heat dissipated by a single pig due to maintenance $(\mathrm{W}), K_{\mathrm{y}}$ is the dimensionless coefficient of efficiency at weight gain, $\phi_{\mathrm{d}_{-} p}$ is daily feed 
energy intake by a pig $(\mathrm{W}), \theta_{\text {air_i }}$ is the indoor air temperature $\left({ }^{\circ} \mathrm{C}\right)$ and $n_{\mathrm{p}}$ is the number of pigs farmed inside the house. The term $\phi_{m_{-}}$is a function of $w_{p}$ and reads

$$
\phi_{\mathrm{m} \_\mathrm{p}}=5.09 \cdot w_{\mathrm{p}}^{0.75} \quad[\mathrm{~W}]
$$

The dimensionless coefficient $K_{\mathrm{y}}$ is also function of $w_{\mathrm{p}}$ and reads

$$
K_{\mathrm{y}}=0.47+0.003 \cdot w_{\mathrm{p}} \quad[-]
$$

The daily feed energy intake by a pig can be expressed as

$$
\phi_{\mathrm{d} \_\mathrm{p}}=n_{\text {feed }} \cdot \phi_{\mathrm{m} \_\mathrm{p}} \quad[\mathrm{W}]
$$

where $n_{\text {feed }}$ is a dimensionless feed factor which values for country and rate of gain are reported in [253]. Please note that being $\phi_{\text {tot_i }}$ function of $\theta_{\text {air_i }}$, the computation of this last parameter by solving the thermal balance is performed iteratively.

According to [253], the sensible heat emission from internal sources $\left(\phi_{\text {sen }_{-}}\right)$ can be calculated as

$$
\phi_{\text {sen_i }_{-}}=\left\{\left[0.62 \cdot\left(1240-12 \cdot \theta_{\text {air__i }_{i}}\right)\right]-1.15 \cdot 10^{7} \cdot \theta_{\text {air__ }_{-}^{6}}\right\} \cdot n_{p} \quad[\mathrm{~W}]
$$

Once obtained $\phi_{\text {tot } \_i}$ and $\phi_{\text {sen_i }}$, the latent heat emission from internal sources $\left(\phi_{\text {lat_i }}\right)$ can be calculated as the difference between $\phi_{\text {tot_i }}$ and $\phi_{\text {sen_i }}$. Knowing $\phi_{\text {lat } \_\mathrm{i}}$, the vapor emission from internal sources $\left(\dot{m}_{\mathrm{i}}\right)$ is obtained as

$$
\dot{m}_{\mathrm{i}}=\frac{\phi_{\text {lat } \mathrm{i}} \cdot 3.6}{h_{\text {vap }}} \quad\left[\frac{\mathrm{kg}_{\text {vap }}}{\mathrm{h}}\right]
$$

where $h_{\text {vap }}$ is the enthalpy of vaporization of water $\left(\mathrm{kJ} \mathrm{kg}^{-1}\right)$ calculated at $\theta_{\text {air_i }}$ temperature.

At each simulation time step, the model estimates the optimal set point temperature $\left(\theta_{\text {set_opt }}\right)$ as a function of $w_{\mathrm{p}}$ through the following piecewise-defined function

$$
\theta_{\text {set_opt }}=\left\{\begin{array}{cc}
g\left(w_{\mathrm{p}}\right) & w_{\mathrm{p}}<90 \\
14.4 & w_{\mathrm{p}} \geq 90
\end{array}\right.
$$

with

$$
g\left(w_{\mathrm{p}}\right)=k_{\theta \mathrm{p}_{-} 3} \cdot w_{\mathrm{p}}^{3}+k_{\theta \mathrm{p}_{2} 2} \cdot w_{\mathrm{p}}^{2}+k_{\theta \mathrm{p}_{1} 1} \cdot w_{\mathrm{p}}+k_{\theta \mathrm{p}_{-} 0} \quad\left[{ }^{\circ} \mathrm{C}\right]
$$

where $k_{\theta \mathrm{p}_{3} 3}-k_{\theta \mathrm{p} \_0}$ are the polynomial regression coefficients obtained from [270] and reported in Appendix A (Table A.10). The heating $\left(\theta_{\text {set_H }}\right)$ and cooling 
$\left(\theta_{\text {set_C }}\right)$ set point temperatures are obtained considering a constant dead band of $\pm 2{ }^{\circ} \mathrm{C}$ from $\theta_{\text {set_opt }}$.

The base ventilation flow rate needed at the $k$-th time step for $I A Q \operatorname{control}\left(\dot{V}_{\mathrm{bs}}\right)$ can be calculated through the following piecewise-defined function

$$
\dot{V}_{\mathrm{bs}}=\left\{\begin{array}{cc}
f\left(w_{\mathrm{p}}\right) \cdot n_{\mathrm{p}} \cdot w_{\mathrm{p}} & w_{\mathrm{p}}<50 \\
0.17 \cdot w_{\mathrm{p}} \cdot n_{\mathrm{p}} & w_{\mathrm{p}} \geq 50
\end{array}\right.
$$

with

$$
\begin{aligned}
f\left(w_{\mathrm{p}}\right)= & \left(k_{\mathrm{Vp} \_6} \cdot w_{\mathrm{p}}^{6}+k_{\mathrm{Vp}_{5} 5} \cdot w_{\mathrm{p}}^{5}+k_{\mathrm{Vp}_{-} 4} \cdot w_{\mathrm{p}}^{4}+k_{\mathrm{Vp}_{-} 3} \cdot w_{\mathrm{p}}^{3}+\right. \\
& \left.+k_{\mathrm{Vp} \__{-} 2} \cdot w_{\mathrm{p}}^{2}+k_{\mathrm{Vp}_{-} 1} \cdot w_{\mathrm{p}}+k_{\mathrm{Vp} \_0}\right) \quad\left[\frac{\mathrm{m}^{3}}{\mathrm{~h}}\right]
\end{aligned}
$$

where $k_{\mathrm{Vp}_{-} 6}-k_{\mathrm{Vp} \_0}$ are the polynomial regression coefficients obtained from [270] and reported in Table A.11 of Appendix A.

\section{Thermal balance module}

Once defined all the needed boundary conditions and all the variables referred to pigs, the energy simulation model solves the thermal balance of the growingfinishing pig house for estimating $\theta_{\text {air_i }}$ and the theoretical heating $\left(\phi_{\mathrm{H}_{-} n d}\right)$ and cooling $\left(\phi_{\mathrm{C}_{\mathrm{n} n d}}\right)$ loads, when needed. The thermal balance module integrates a customization of the $S H$ method of ISO 13790 standard [211]. For the complete description of the adopted simulation method and the full set of equations, please refer to Appendix B of this thesis.

\section{Cooling ventilation calculation module}

This calculation module estimates the cooling ventilation air flow rate that is needed to maintain $\theta_{\text {set_c }}$ inside the house. In this module, the presence of evaporative cooling systems is not considered. The equivalent cooling ventilation air flow rate $\left(\dot{V}_{\text {cool }}\right)$ is estimated from the theoretical cooling load $\left(\phi_{\mathrm{C}_{-} \text {nd }}\right)$ estimated by the solution of the thermal balance as

$$
\dot{V}_{\text {cool }}=\min \left[\frac{\left|\phi_{C_{\text {nnd }}}\right|}{\left(\theta_{\text {set_C }}-\theta_{\text {air_o }}\right)} \cdot \frac{3.6 \cdot 10^{3}}{\rho_{\text {air }} \cdot c_{\text {air }}} ; \dot{V}_{\text {max }}\right] \quad\left[\frac{\mathrm{m}^{3}}{\mathrm{~h}}\right]
$$

where $\dot{V}_{\text {max }}$ is the maximum ventilation air flow rate that is installed in the growing-finishing pig house. Since no evaporative cooling systems are considered, $\dot{V}_{\text {cool }}$ is always performed with $\theta_{\text {air_sup }}$ equal to $\theta_{\text {air_o }}$.

\section{Moisture balance module}

At each simulation time step, the moisture balance of the pig house is solved to find the indoor air humidity ratio $\left(x_{\mathrm{air}_{-} \mathrm{i}}\right)$ and the hourly value of $R H_{\mathrm{i}}$. Knowing the vapor production from internal sources $\left(\dot{m}_{\mathrm{i}}\right)$ calculated through Eq. (79), the 
moisture balance in dynamic conditions can be described through the following ordinary pure-time differential equation

$$
\frac{d x_{\text {air_i }}}{d \tau} \cdot V \cdot \rho_{\text {air }}=\dot{m}_{\mathrm{i}}+\dot{V}_{\text {act }} \cdot \rho_{\text {air }} \cdot\left(x_{\text {air_o }}-x_{\text {air_i }}\right) \quad\left[\frac{\mathrm{kg}_{\text {vap }}}{\mathrm{h}}\right]
$$

where $V$ is the pig house net volume $\left(\mathrm{m}^{3}\right), \rho_{\text {air }}$ is the volumetric mass density of air $\left(\mathrm{kg} \mathrm{m}^{-3}\right), x_{\text {air_o }}$ is the outdoor air humidity ratio $\left(\mathrm{kg}_{\text {vap }} \mathrm{kg}_{\text {air }}^{-1}\right)$ and $\dot{V}_{\text {act }}$ is the actual ventilation flow rate $\left(\mathrm{m}^{3} \mathrm{~h}^{-1}\right)$ present at the considered time step inside the house. The energy model, in fact, simulates the ventilation depending on the boundary conditions and three main cases can occur at each time step, as schematized by flowchart of Figure 5.12. In the times steps in which pigs are not present inside the house -e.g. sanitary empty periods-, $\dot{V}_{\text {act }}$ is equal to $\dot{V}_{\min }$ (case A) that is a minimum ventilation air flow rate that is maintained inside the house to guarantee a safety environment for workers. The value of $\dot{V}_{\min }$ is an input data of the model. If pigs are present in the house, two different cases may occur depending on $\theta_{\text {air_i }}$ value at the considered time step. If $\theta_{\text {air_i }} \leq \theta_{\text {set_c }}$, ventilation is only needed to control $I A Q$ (case B). In this case, $\dot{V}_{\text {act }}$ is equal to $\dot{V}_{\mathrm{bs}}$ that is calculated according to Eq. (82). The last case presented in Figure 5.12 (case C) regards those time steps in which pigs are present inside the house and a theoretical cooling load is needed. In this case, $\dot{V}_{\text {act }}$ is equal to $\dot{V}_{\text {cool }}$ that can be calculated through Eq. (84).

The solution of the previous Eq. (85) is

$$
x_{\text {air_i }}\left(\tau_{\mathrm{k}}+\Delta \tau\right)=x_{\text {air_o }}+\frac{\left(\dot{m}_{\mathrm{i}}\right)}{\dot{V}_{\text {act }} \rho_{\text {air }}}++\left[x_{\text {air_i }}\left(\tau_{\mathrm{k}}\right)-x_{\text {air_o }}-\frac{\left(\dot{m}_{\mathrm{i}}\right)}{\dot{V}_{\text {act }} \rho_{\text {air }}}\right] \cdot e^{-\left(\frac{\dot{V}_{\text {act }}}{V}\right) \cdot \Delta \tau} \quad\left[\frac{\mathrm{kg}_{\mathrm{vap}}}{\mathrm{kg}}\right]
$$

where $\Delta \tau$ is the duration of the time step and $e$ is the Euler's number.

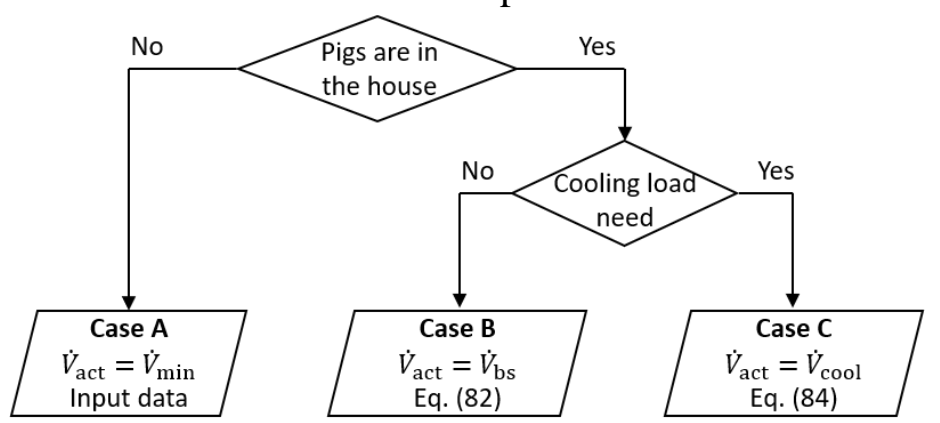

Figure 5.12 - Flow chart for the calculation of the actual ventilation flow rate $\left(\dot{V}_{\text {act }}\right)$ adopted in the presented energy simulation model.

\section{System performance module}

This module is needed to estimate the total thermal and electrical energy consumption of the analyzed growing-finishing pig house due to supplemental heating and ventilation. These calculations are performed according to Eq. (67) and (71), adopting the same procedure described for the broiler house model. 


\subsection{Model customization for pig houses: validation}

The developed energy simulation model is validated against real monitored data to assess its reliability in estimating the indoor climate conditions and the energy consumption for climate control. The acquired data and the simulation results are used to calculate goodness-of-fit indexes that are then compared to threshold values established by international guidelines and protocols, similarly to what it was done in sections 4.4.4 and 5.5.2.

\subsubsection{Case study description}

\section{Pig house description}

The presented energy simulation model is validated using part of the dataset obtained from the monitoring campaign carried out in pig house A that was previously presented in section 3.3 and which schematization is reported in Figure 5.13 .

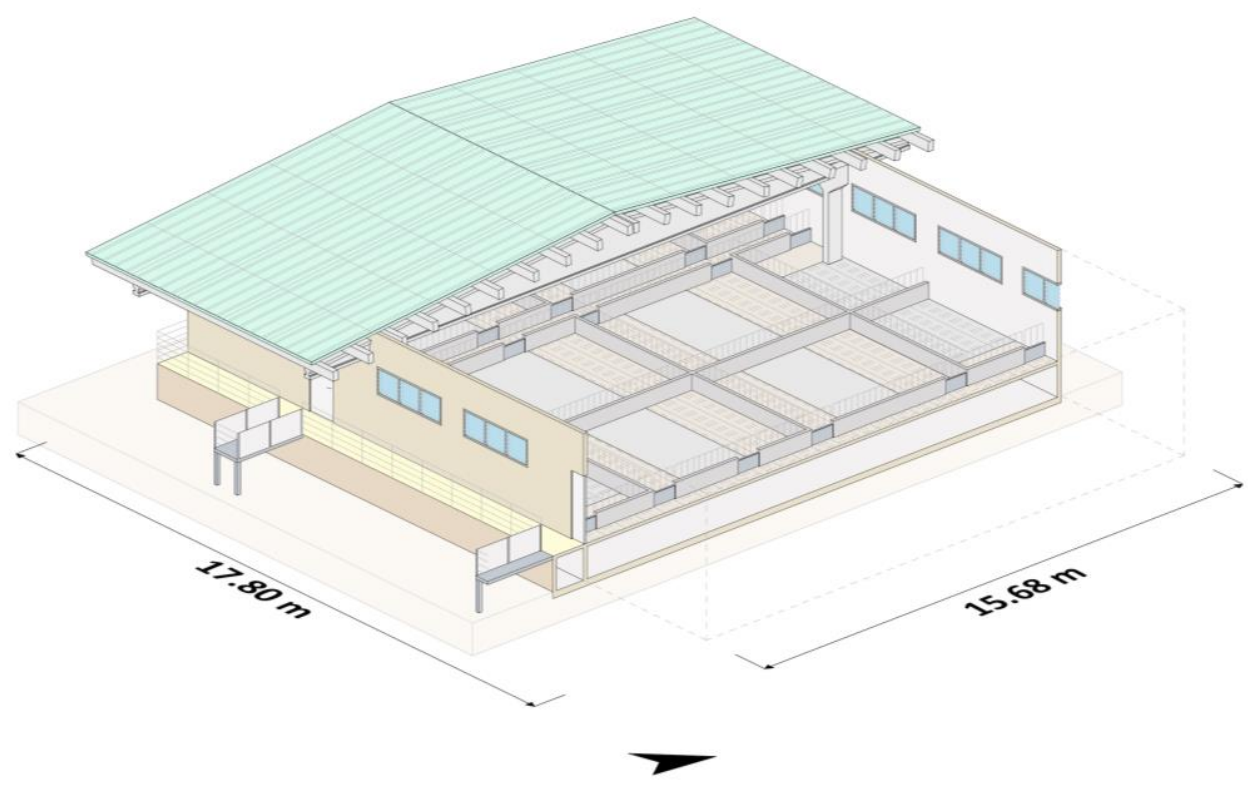

Figure 5.13 - Schematization of pig house A, the one used for the model validation.

The main description of the case study was provided in section 3.3.1. Nevertheless, some additional details are here provided to give a complete picture about all the data needed for running the simulation for the model validation. As stated before, the analyzed pig house has a reinforced concrete structure with prefabricated beams and pillars. The walls are composed by piled hollow blocks and the roof is composed by prefabricated sandwich panels. The air inlets are polycarbonate hollow sheets with metal frames. The thermal transmittances ( $U-$ value) of these building elements are presented in Table 5.7. As visible from the table, all these elements are characterized by high $U$-value, with the only exception of the roof that is the only envelope element with a thermal insulation layer. The $\kappa_{\mathrm{i}}$ presented in Table 5.7 are needed for the calculation of the total 
building fabric heat capacity $\left(C_{\mathrm{m}}\right)$ of the pig house. For this purpose, the presence of internal structural elements and of the pit was considered.

Table 5.7 - Stationary thermal transmittance $(U-$ value $)$ and internal areal heat capacities $\left(\kappa_{\mathrm{i}}\right)$ of pig house A.

\begin{tabular}{ccc}
\hline Building element & $\begin{array}{c}\boldsymbol{U}-\text { value } \\
{\left[\mathbf{W} \mathbf{~ m}^{-\mathbf{2}} \mathbf{K}^{-\mathbf{1}}\right]}\end{array}$ & $\begin{array}{c}\mathbf{K}_{\mathbf{i}} \\
{\left[\mathbf{k J ~ ~ ^ { - 2 }} \mathbf{K}^{-\mathbf{1}}\right]}\end{array}$ \\
\hline Walls & 2.18 & 55.8 \\
Roof & 0.64 & 3.8 \\
Partially slatted floor & 2.88 & 60.2 \\
Air inlets & 3.40 & - \\
\hline
\end{tabular}

As described in section 3.3.1, the ventilation system of the analyzed growingfinishing pig house is composed by three exhaust fans placed at the pit level that are used to control both $I A Q$ and $\theta_{\text {air_i }}$. Each 6-blade fan $-0.5 \mathrm{~m}$ of diameter- has $0.43 \mathrm{~kW}$ of mechanical power and its maximum airflow in free delivery conditions $\left(\Delta p_{\mathrm{st}}=0 \mathrm{~Pa}\right.$ ) is around $6,500 \mathrm{~m}^{3} \mathrm{~h}^{-1}$. In Table A.12 (Appendix A) the regression coefficients for Eqs. (27) and (28) needed to characterize $\dot{V}_{\text {fan }}$ and $S F P$ as a function of $\Delta p_{\text {st }}$ are reported. The installed fans are controlled by a climate control unit that also manages the inlet opening to maintain a constant $\Delta p_{\text {st }}$ of $20 \mathrm{~Pa}$ during the production cycle.

\section{Monitoring campaign description}

From the larger dataset presented in section 3.3, the data collected during 31 days of July ( $1^{\text {th }}-31^{\text {st }}, 744$ hours) were selected to validate the proposed energy simulation model. The selected dataset has been processed to be comparable with the simulation outputs obtained for the same time period. For this purpose, the values of $\theta_{\text {air_i }}$ and $R H_{\mathrm{i}}$ that were monitored in the different spots of the pig house enclosure were first spatially averaged between them -through the arithmetic meanto obtain single values properly representative of the indoor climate conditions of the entire enclosure at each logging time step. Then, the time profiles of the measured variables were temporally averaged -also through the arithmetic meanover the hour to be comparable with the model output.

\subsubsection{Model validation}

In Figure 5.14, the monitored trends of $\theta_{\text {air_i }}$ and $R H_{\mathrm{i}}$ are presented with an hourly time basis together with the trends of $\theta_{\text {air }{ }_{i} \text { and }} R H_{\mathrm{i}}$ estimated by the model. The trends of the monitored $\theta_{\text {air_o }}$ and $R H_{\mathrm{o}}$ during the considered period are also presented in the figure. The presented graph shows that, during the considered period, $\theta_{\text {air_o }}$ was considerably high, with values that often exceed $30^{\circ} \mathrm{C}$ during daytime. During nighttime, $\theta_{\text {air_o }}$ decreased considerably, especially during the first days, when it reached a minimum of $14^{\circ} \mathrm{C}$. In the following days, $\theta_{\text {air_o }}$ was almost always higher than $20^{\circ} \mathrm{C}$. These high values of $\theta_{\text {air_o }}$, explain the higher values of monitored $\theta_{\text {air_i }}$ that, as stated in section 3.3.3, may be detrimental for pig health. 
The chart shows that the simulated and monitored trends of $\theta_{\text {air_i }}$ are quite similar between them during the entire analyzed period. The main difference that can be noticed between the considered trends regards the peaks that can be observed during daytime. The energy simulation model, in fact, estimates maximum $\theta_{\text {air_i }}$ during daytime that are slightly higher than the monitored ones. A similar pattern can be observed also for the minimum $\theta_{\text {air_i }}$ values estimated during nighttime since the model estimates lower $\theta_{\text {air_i }}$ than the monitored ones. These differences are more evident, for example, in the period between July $23^{\text {rd }}$ and $28^{\text {th }}$ and they can be attributable to a slight underestimation of the building fabric heat capacity $\left(C_{\mathrm{m}}\right)$.

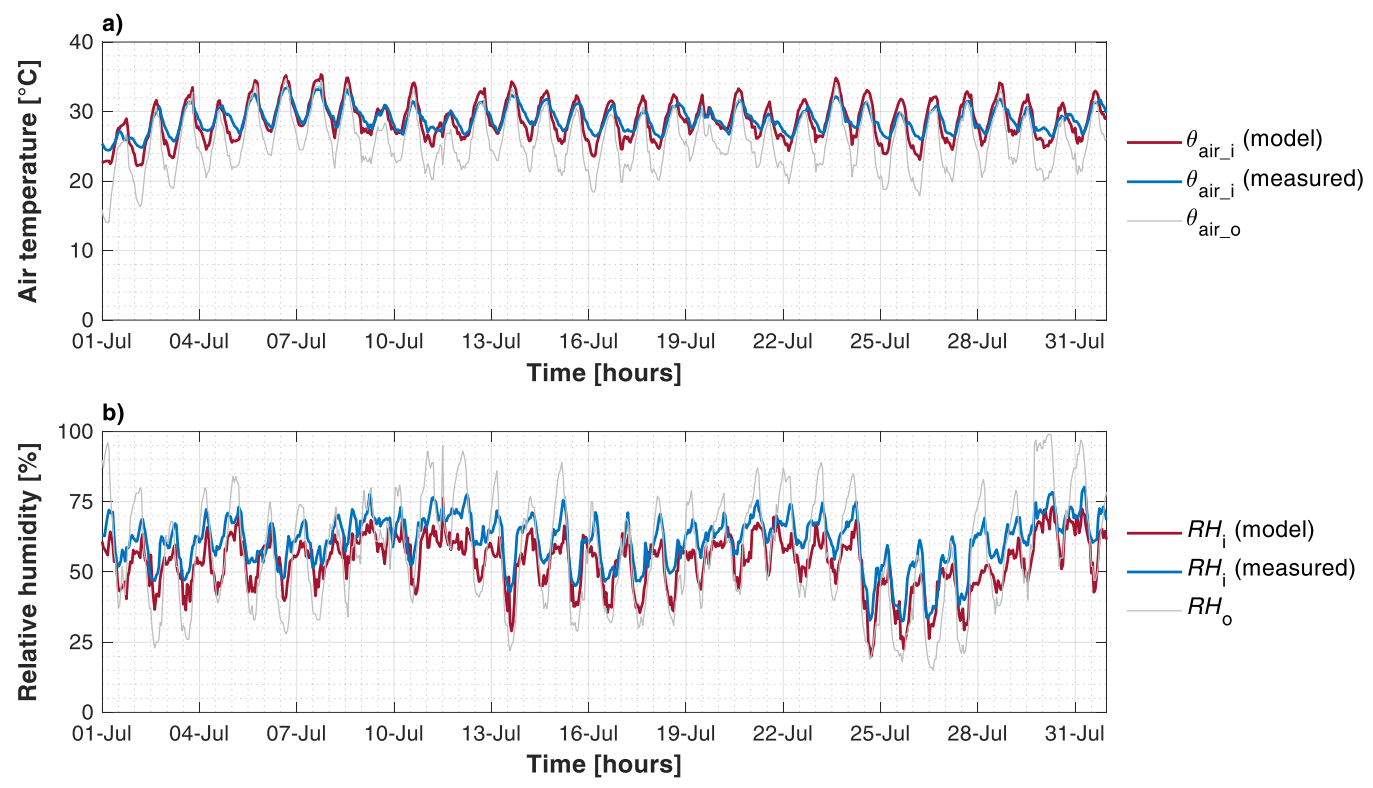

Figure 5.14 - Comparison between simulated and measured values of hourly indoor air temperature $\left(\theta_{\text {air_i }}\right)$ and relative humidity $\left(R H_{\mathrm{i}}\right)$. Outdoor monitored values of air temperature $\left(\theta_{\text {air_o }}\right)$ and relative humidity $\left(R H_{\mathrm{o}}\right)$ are presented.

Figure 5.14 enhances the possibility to compare the monitored and simulated trends of $R H_{\mathrm{i}}$. The model estimates with a good approximation the trend of the monitored $R H_{\mathrm{i}}$, but an underestimation of $R H_{\mathrm{i}}$ stands out. Part of this difference could be due to the previously presented deviation between the estimated and monitored $\theta_{\text {air_i }}$ since -as it is well known- $R H_{\mathrm{i}}$ is function of the saturated water vapor pressure and, in turn, of $\theta_{\text {air_i }}$. Therefore, the differences between $\theta_{\text {air_i }}$ trends reflect on the considered $R H_{\mathrm{i}}$ trends. The deviation between the estimated and the monitored $R H_{\mathrm{i}}$ trends can be also attributable to an underestimation of the water vapor emission from internal sources. Even though the formulations that are used in this work estimate the vapor emissions at house level including feed, waterers and manure, the vapor emission from the pit may be underestimated since, in the analyzed pig house, manure is flushed only at the end of the production cycle. In addition, the monitored period was characterized by high values of $\theta_{\text {air_o }}$ that may have contributed to increase the moisture production from manure. Even though pit ventilation was adopted in the considered case study, air stagnation pockets may 
have been present favoring the mass transportation from pit to enclosure. Further works may deepen the analysis of this specific issue with the aim of understanding the dynamics of ventilation air and contaminants between the enclosure and the pit adopting, for example, zonal or CFD models [274].

The proposed model is validated also from a numerical point of view, adopting the same goodness-of-fit-indexes that were evaluated for greenhouse and broiler house models, in sections 4.4.4 and 5.5.2, respectively. In Table 5.8, the $M B E$ (Eq. (43), the CvRMSE (Eq. (44), and the RMSE (Eq. (35)) calculated over the entire monitored period with an hourly basis are presented with their respective thresholds, from ASHRAE [225], FEMP [227] and IPMVP [226]. The numerical results provided in the table confirm what it was stated comparing the estimated and monitored trends of Figure 5.14. The model, in fact, is reliable for the estimation of $\theta_{\text {air_i }}$. The RMSE between the estimated and monitored trends over the 744 hours of simulation is $1.42{ }^{\circ} \mathrm{C}$. The model estimation of $\theta_{\text {air_i }}$ widely respects the established threshold values, even the more restrictive of IPMVP. The $M B E$, in fact, is $0.72 \%$, a value considerably lower than the ASHRAE and FEMP threshold $( \pm 10 \%)$ and IPMVP threshold $( \pm 5 \%)$.

The reliability of the model regarding $R H_{\mathrm{i}}$ can be considered good, even though the $M B E$ value (12.19\%) is slightly higher than the established thresholds ( $\pm 10 \%$ and $\pm 5 \%$ ), as visible in Table 5.8. Nevertheless, the model estimation is characterized by a low $R M S E$ of $8.79 \%$, over the entire period. The model respects all the thresholds for the $C v(R M S E)$. The calculated $C v(R M S E)$, in fact, is $14.38 \%$, while the most restrictive threshold (IPMVP) is $20 \%$.

Table 5.8 - Goodness-of-fit indexes with their thresholds for indoor air temperature $\left(\theta_{\text {air } \_ \text {i }}\right)$ and relative humidity $\left(R H_{\mathrm{i}}\right)$.

\begin{tabular}{ccccc}
\hline \multirow{2}{*}{ Parameter } & $\begin{array}{c}\text { Goodness-of- } \\
\text { fit index }\end{array}$ & $\begin{array}{c}\text { Calculated } \\
\text { value }\end{array}$ & $\begin{array}{c}\text { Threshold value } \\
\text { (hourly validation) }\end{array}$ \\
\cline { 4 - 5 } & $M B E^{\mathrm{a}}$ & $0.72 \%$ & $\pm 10 \%$ & $\begin{array}{c}\text { ASHRAE and } \\
\text { FEMP }\end{array}$ \\
\hline \multirow{2}{*}{$\theta_{\text {air_i }}$} & $C v(R M S E)^{\mathrm{b}}$ & $4.91 \%$ & $30 \%$ & $\pm 5 \%$ \\
& $R M S E^{\mathrm{c}}$ & $1.42{ }^{\circ} \mathrm{C}$ & - & $20 \%$ \\
\hline \multirow{2}{*}{$R H_{\mathrm{i}}$} & $M B E$ & $12.08 \%$ & $\pm 10 \%$ & $\pm 5 \%$ \\
& $C v(R M S E)$ & $14.38 \%$ & $30 \%$ & $20 \%$ \\
\hline
\end{tabular}

${ }^{a}$ Mean Bias Error

${ }^{\mathrm{b}}$ Coefficient of Variation of the Root Mean Square Error

${ }^{\mathrm{c}}$ Root Mean Square Error

${ }^{d}$ ASHRAE [225], FEMP [227], IPMVP [226]

The last evaluation of model reliability regards the estimation of the electrical energy consumption for ventilation. In the bar chart of Figure 5.15, the monitored and estimated electrical energy consumption for ventilation are compared on a daily basis. The graph shows that the daily electrical energy consumption of the monitored growing-finishing pig house was between around 28 and $44 \mathrm{kWh}$ during the monitored period. This energy consumption shows that fans operate during most 
of the time to guarantee adequate $\theta_{\text {air_i }}$ values in a period in which $\theta_{\text {air_o }}$ was considerably high, as shown in Figure 5.14. The bar chart shows that the model correctly estimates the electrical energy consumption with few exceptions. The main deviation between the estimated and the monitored electrical energy consumption is on July $19^{\text {th }}$, where the monitored electrical energy consumption was around $28 \mathrm{kWh}$ while the estimated one was around $44 \mathrm{kWh}$. This difference may be attributable to a manual deactivation of the ventilation system by farm workers to perform specific tasks inside the house, a hypothesis that was not possible to verify with certainty.

The total energy consumption that was acquired during the considered period was around 1,329 $\mathrm{kWh}$ of electrical energy, while the model estimated 1,361 kWh. It means that the energy simulation model overestimates the energy consumption over the entire period by less than $3 \%(32 \mathrm{kWh})$, an error that can be considered acceptable for the purpose of the present work.

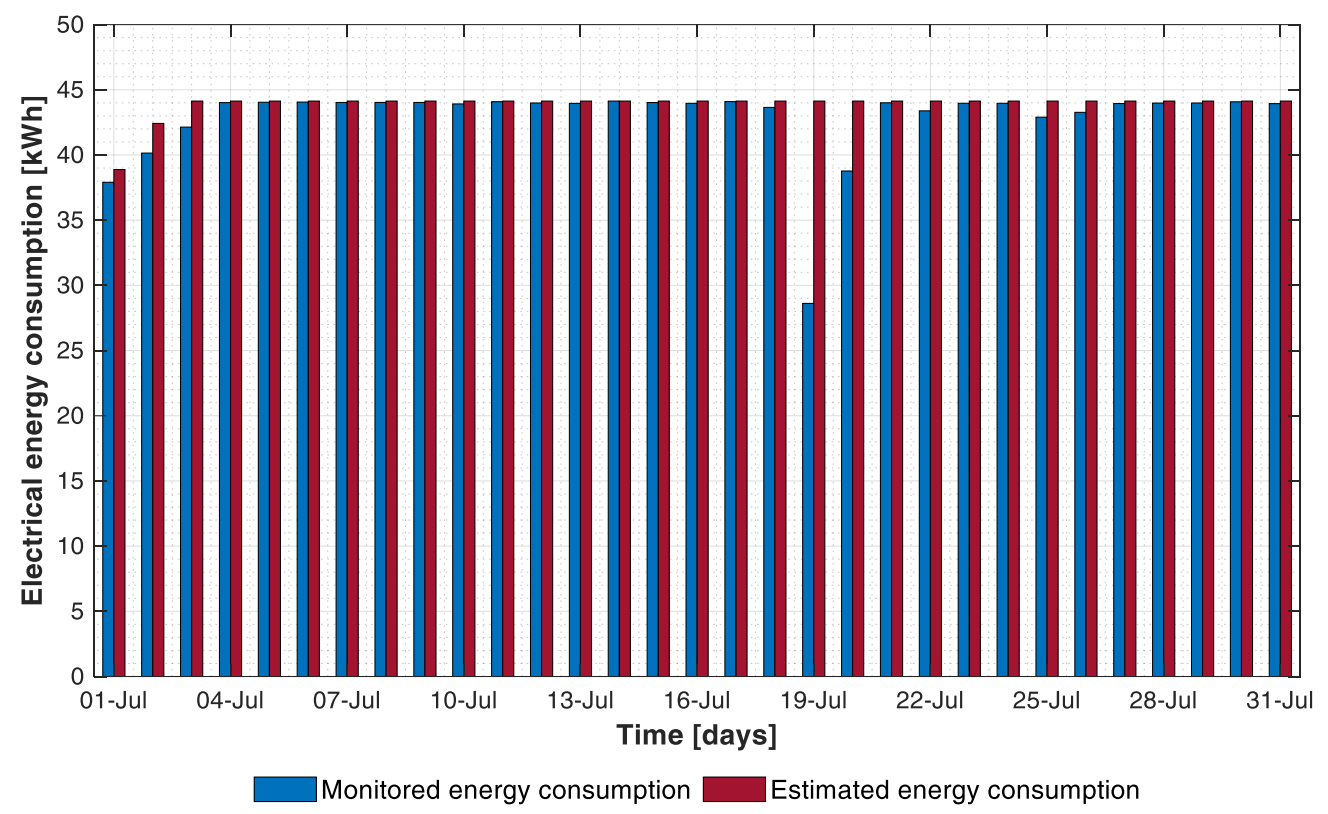

Figure 5.15 - Comparison between the daily monitored and estimated electrical energy consumption for ventilation.

\subsection{Model application}

The proposed energy simulation models have several potentialities for the analysis of indoor climate conditions and energy consumption of broiler houses and growing-finishing pig houses. In the next chapters (6 and 7), the potentialities of these models will be widely shown with a main focus on the broiler house model. In this section, a brief overview on the opportunities provided by the pig house model is provided. For this purpose, the same case study used for the model validation is simulated in six different scenarios characterized by specific geographical contexts (Table 5.9). Each scenario represents a pig production cycle of 135 days carried out during the cool and the warm season. At the end of the 
production cycle, pigs reach a final live weight of around $160 \mathrm{~kg}$. The considered countries -Italy, Spain, and Germany- are chosen since they are the most important European producers of pigs for cured meat production, as reported in a survey of the European Commission [275]. A reference city is selected for each geographical context and its Typical Meteorological Year (TMY) is adopted for performing the simulation. As visible from Table 5.9, each scenario is characterized by quite different values of average hourly $\theta_{\text {air_o }}$ over the production cycle, being the minimum value $2.4{ }^{\circ} \mathrm{C}$ from DE-C scenario and the maximum one $22.2^{\circ} \mathrm{C}$ from ESW scenario.

Table 5.9 - Main features of the considered simulation scenarios.

\begin{tabular}{cccc}
\hline Scenario & Season & $\begin{array}{c}\text { Geographical context } \\
\text { (reference city) }\end{array}$ & $\begin{array}{c}\text { Average hourly } \\
\boldsymbol{\theta}_{\text {air oo }}\end{array}$ \\
\hline IT-C & Cool season $^{\mathrm{a}}$ & Italy (Bologna) & $3.3^{\circ} \mathrm{C}$ \\
IT-W & Warm season $^{\mathrm{b}}$ & Italy (Bologna) & $20.2^{\circ} \mathrm{C}$ \\
ES-C & Cool season & Spain (Barcelona) & $10.0^{\circ} \mathrm{C}$ \\
ES-W & Warm season & Spain (Barcelona) & $22.2^{\circ} \mathrm{C}$ \\
DE-C & Cool season & Germany (Bremen) & $2.4^{\circ} \mathrm{C}$ \\
DE-W & Warm season & Germany (Bremen) & $15.3^{\circ} \mathrm{C}$ \\
\hline
\end{tabular}

a November $1^{\text {st }}-$ March $16^{\text {th }}$

${ }^{\mathrm{b}}$ June $1^{\text {st }}-$ October $14^{\text {th }}$

The first assessment that can be carried out through the energy simulation model is an estimation of the differences regarding heat stress risk between the considered scenarios with the same procedure that was adopted in section 3.3.3. The cartesian coordinates of each point of the scatterplot of Figure 5.16 are the hourly values of $\theta_{\text {air_i }}$ and $R H_{\mathrm{i}}$ simulated for the analyzed scenarios. From the graph, it is evident that scenarios IT-C and ES-C are the ones characterized by the highest risk of heat stress since animals are in alert, danger, or emergency situations during several hours of the production cycles. By contrast, heat stress seems to be a minor issue in DE-W scenario since the farmed pigs are in alert or danger situation during only few hours of the production cycle. This difference between the scenarios is attributable to the different $\theta_{\text {air_o }}$, as reported in Table 5.9. During cool season, heat stress is not an issue in none of the considered scenarios, namely ITC, ES-C and DE-C. Nevertheless, the results of the simulations highlight that IT-C and $\mathrm{DE}-\mathrm{C}$ scenarios could be characterized by significative humidity problems since $R H_{\mathrm{i}}$ is often over $70 \%$. These humidity problems may lead to an increase of heating energy consumption, as reported by Fernandez et al. [276]. The presented model, hence, can be used to numerically estimate the needed increase of ventilation air flow rate to decrease $R H_{\mathrm{i}}$ considering the consequent increase of electrical energy consumption due to fan activation and thermal energy consumption due to the increased heat losses. In this way, it could be possible to find a trade-off between improving the indoor climate conditions for pig farming and decreasing the energy consumption for climate control of the pig house. Animal welfare, hence, could be improved by increasing ventilation, a strategy that would also increase thermal and electrical energy consumption, an issue that will be deepened in Chapter 7. By 
contrast, the humidity problem is not present in scenario ES-W, as visible from Figure $5.16 \mathrm{~b}$. The high $\theta_{\text {air_o }}$ typical of this scenario, in fact, entails a higher ventilation flow rate to decrease $\theta_{\text {air_i }}$ with a consequent decrease of $R H_{\mathrm{i}}$.
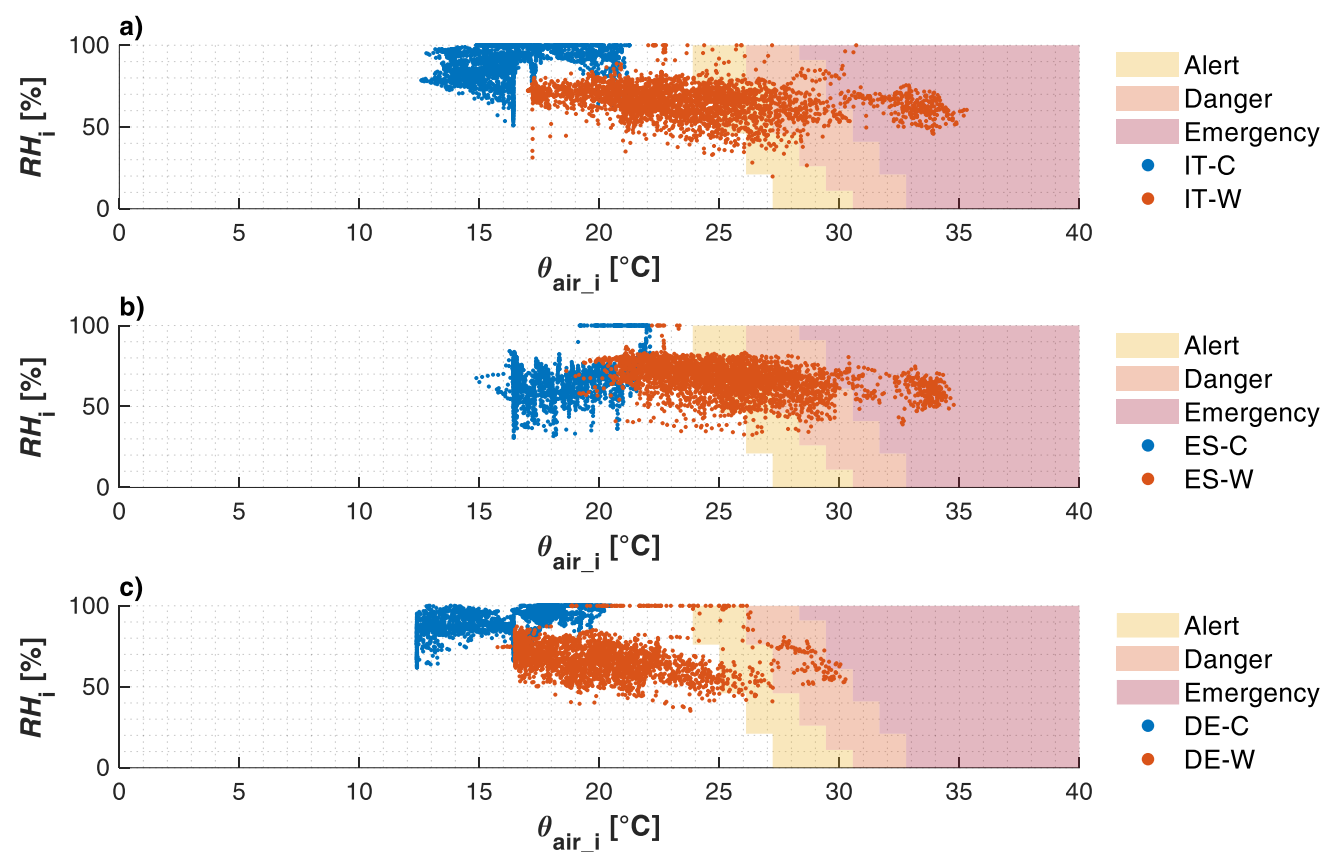

Figure 5.16 - Hourly indoor climate conditions of air temperature and relative humidity for the considered scenarios. a) Italy: cool (IT-C) and warm (IT-W) seasons; b) Spain: cool (ES-C) and warm (ES-W) seasons; b) Germany: cool (DE-C) and warm (DE-W) seasons.

The different outdoor climate conditions in which the production cycles take place have also important consequences on the energy consumption for maintaining adequate $\theta_{\text {air_i }}$ inside the analyzed pig house, as visible from Table 5.10. In the table, the thermal energy consumption for supplemental heating $\left(E_{\mathrm{th}}\right)$ and the electrical energy consumption for ventilation $\left(E_{\mathrm{el}}\right)$ are shown for each one of the considered scenarios. Supplemental heating can be considered a minor issue in almost all the considered scenarios. No supplemental heating, in fact, is needed in the scenarios that consider the warm season -IT-W and ES-W- with the only exception of DE-W, where a slight value of $E_{\text {th }}$ is estimated. The situation in the scenarios that consider the cool season -IT-C, ES-C and DE-C- is quite different. In ES-C scenario, the mild outdoor weather conditions of the considered area of Spain and the pig thermal emissions are enough to maintain adequate value of $\theta_{\text {air_i }}$ without using mechanical heating systems. Therefore no $E_{\mathrm{th}}$ is estimated. The value of $E_{\mathrm{th}}$ is higher in IT-C scenario $\left(279 \mathrm{kWh}_{\mathrm{th}}\right)$ and especially in DE-C, where it is the highest one $\left(2,974 \mathrm{kWh}_{\mathrm{th}}\right)$.

As visible from Table 5.10, electrical energy consumption due to ventilation is present in all the scenarios. The lowest $E_{\mathrm{el}}$ values are evaluated in IT-C and DE-C scenarios and they are due to the base ventilation that is performed during the cool season. The $E_{\mathrm{el}}$ value of ES-C scenario is considerably higher $\left(1,542 \mathrm{kWh}_{\mathrm{el}}\right)$ and it is due to both base ventilation and cooling ventilation. The $E_{\mathrm{el}}$ values of the 
scenarios that consider the warm season is relevant, being $3,117 \mathrm{kWh}_{\mathrm{el}}$ the minimum (DE-W) and 5,047 $\mathrm{kWh}_{\mathrm{el}}$ the maximum (ES-W).

Table 5.10 - Thermal $\left(E_{\mathrm{th}}\right)$, electrical $\left(E_{\mathrm{el}}\right)$ energy consumption and related financial costs of the considered scenarios.

\begin{tabular}{|c|c|c|c|c|c|}
\hline \multirow[b]{2}{*}{ Scenario } & \multirow[b]{2}{*}{$\begin{array}{c}E_{\text {th }} \\
{\left[\mathbf{k W h} \mathbf{h}_{\mathrm{th}}\right]}\end{array}$} & \multirow[b]{2}{*}{$\begin{array}{c}\boldsymbol{E}_{\mathrm{el}} \\
{\left[\mathbf{k} \mathbf{W h}_{\mathrm{el}}\right]}\end{array}$} & \multicolumn{3}{|c|}{ Financial costs $[€]$} \\
\hline & & & $\begin{array}{l}\text { Thermal } \\
\text { energy }\end{array}$ & $\begin{array}{c}\text { Electrical } \\
\text { energy }\end{array}$ & Total \\
\hline IT-C & 279 & 614 & 19.50 & 135.19 & 154.69 \\
\hline IT-W & 0 & 4,292 & 0.00 & 944.42 & 944.42 \\
\hline ES-C & 0 & 1,542 & 0.00 & 339.27 & 339.27 \\
\hline ES-W & 0 & 5,047 & 0.00 & $1,110.41$ & $1,110.41$ \\
\hline DE-C & 2,974 & 613 & 178.44 & 183.89 & 362.33 \\
\hline DE-W & 4 & 3,117 & 0.22 & 925.20 & 935.42 \\
\hline
\end{tabular}

The energy simulation model can be also useful to perform financial evaluations regarding the running costs of the pig house due to energy consumption. In Table 5.10, the total financial costs due to energy consumption and the shares for thermal and electrical energy are presented. The cost of energy was obtained multiplying the energy consumption by the cost of energy -including taxes- reported in Eurostat [277,278]. The cost of thermal energy was assumed equal to $0.07 € \mathrm{kWh}_{\mathrm{th}}^{-1}$ for Italy and Spain, and $0.06 € \mathrm{kWh}_{\mathrm{th}}^{-1}$ for Germany. The cost of electrical energy was assumed equal to $0.22 € \mathrm{kWh}_{\mathrm{el}}^{-1}$ for Italy and Spain, and $0.30 € \mathrm{kWh}_{\mathrm{el}}^{-1}$ for Germany. The table shows that the financial costs vary considerably between the analyzed scenarios, being the range between $154.69 €$ (IT-C) and 1,110.41 € (ES-W). The production cycles carried out in the warm season are the ones characterized by the highest costs that goes between 935 and $1,110 €$. By contrast, the production cycles performed during the cool season are characterized by lower costs that do not exceed $362 €$. A potential improvement of the energy performance for ventilation, hence, would decrease the running costs of the pig house. In cool climate conditions, such as the ones of Germany, the running costs would benefit also from a reduction of the thermal energy consumption for supplemental heating. This is since the thermal energy share represents almost a half of the total financial cost of scenario DE-C, as visible from Table 5.10. This last solution should be carefully evaluated since an increased thermal insulation of the envelope could lead to a potential overheating of the enclosure during the warm season and to a consequent rise of the electrical energy consumption for ventilation. The overheating risk and the potential increase of electrical energy consumption could be evaluated through the proposed energy simulation model through a procedure described in Chapter 6. 


\subsection{Alternative energy simulation methods}

The presented energy simulation models for livestock houses are based on a dynamic method in compliance with ISO 13790 Standard [211]. As shown by the literature review of section 5.2, other simulation methods -steady-state and detailed dynamic methods- would have been implemented in the proposed models, with consequent differences on the obtained results. Therefore, it seems worth investigating the magnitude of those differences with the aim of understanding which methods are more adequate for modelling the thermal behavior of climatecontrolled livestock houses. For this purpose, the broiler house model presented in section 5.4 is modified to implement quasi-steady-state $(Q S)$ and the detailed dynamic $(D D)$ energy simulation methods of ISO 13790 Standard [211]. The results provided by these methods are compared with the model based on the simple hourly $\mathrm{SH}$ ) method described in section 5.4. The chosen simulation methods differ each other for the chosen time step, the considered dynamic parameters and the different detail of the needed input data, therefore important difference are expected. The three energy simulation models are used to simulate a case study similar to the one described in section 5.5.1.

\subsubsection{The considered calculation methods}

The considered calculation methods used to implemented as many simulation models are the ones of ISO 13790 Standard [211] which main features are described in the following sub-sections.

\section{The quasi-steady-state (QS) method}

The quasi-steady-state $(Q S)$ calculation method is based on balance of heat losses -transmission plus ventilation- and heat gains -solar plus internal- assessed in monthly average conditions. The dynamic effects on the theoretical energy needs for heating and cooling are considered introducing a utilization factor for the mismatch between transmission plus ventilation heat losses and solar plus internal heat gains that lead to heating/cooling energy needs. The utilization factor is a function of the building time constant, of the ratio between heat gains and heat losses, and of the occupancy/system management schedules.

At each month, the theoretical energy needs for space heating $\left(Q_{\mathrm{H}_{-} \text {nd }}\right)$ and cooling $\left(Q_{\mathrm{C}_{-} \text {nd }}\right)$ are calculated as:

$$
\begin{gathered}
Q_{\mathrm{H} \_ \text {nd }}=Q_{\mathrm{ls}}-\eta_{\mathrm{gn}} \cdot Q_{\mathrm{gn}} \quad[\mathrm{kWh}] \\
Q_{\mathrm{C} \_ \text {nd }}=Q_{\mathrm{gn}}-\eta_{\mathrm{ls}} \cdot Q_{\mathrm{ls}} \quad[\mathrm{kWh}]
\end{gathered}
$$

where $Q_{\text {ls }}(\mathrm{kWh})$ represents the total -transmission plus ventilation- heat losses, $Q_{\mathrm{gn}}(\mathrm{kWh})$ represents the total -internal plus solar- heat gains, $\eta_{\mathrm{gn}}$ is the utilization factor of the heat gains (-) and $\eta_{\mathrm{ls}}$ is the utilization factor of the heat losses (-). 
The durations of the heating and cooling seasons are determined using the limit value of the dimensionless heat-balance ratio for the heating mode and the cooling mode, respectively. This limit value is expressed as a function of a dimensionless numerical parameter depending on the time constant of the analyzed building.

\section{The simple hourly (SH) dynamic method}

The simple hourly method $(\mathrm{SH})$ is the dynamic method that was used to develop the broiler house simulation model presented in section 5.4. More details about this method and the full set of equations are reported in Appendix B of this thesis.

\section{The detailed dynamic (DD) method}

To implement the detailed dynamic $(D D)$ method, EnergyPlus software tool was used. The calculation method of the building thermal zone of EnergyPlus is the air heat balance model. This model is based on the assumptions that the air in the thermal zone has a uniform temperature, the temperature of each surface is uniform, the long-wave and short-wave radiation is uniform, the surface irradiation is diffusive and the heat conduction through the surfaces is one-dimensional. For a generic thermal zone, the air heat balance -neglecting the heat transfer due to infiltration and to inter-zone air mixing- can be written as:

$$
C_{\mathrm{m}} \frac{d \theta_{\text {air_i }}}{d \tau}=\sum_{q=1}^{n_{\text {loads }}} \phi_{\text {conv }, \mathrm{q}}+\sum_{t=1}^{n_{\text {sup }}} \phi_{\text {sup }, \mathrm{t}}+\phi_{\text {vent }}+\phi_{\text {sys }} \quad[\mathrm{kW}]
$$

where $C_{\mathrm{m}}$ is the building fabric thermal capacity of the considered thermal zone $\left(\mathrm{kJ} \mathrm{K}^{-1}\right), \theta_{\text {air_i }}$ is the indoor air temperature of the considered thermal zone $\left({ }^{\circ} \mathrm{C}\right)$, $n_{\text {loads }}$ is the number of the internal convective heat sources, $\phi_{\text {conv }}$ is the heat flow from each $q$-th convective heat source $(\mathrm{kW}), n_{\text {sup }}$ is the number of surfaces of the thermal zone, $\phi_{\text {sup }}$ is the heat flow from the $t$-th surface of the thermal zone $(\mathrm{kW})$, $\phi_{\text {vent }}$ is the ventilation heat flow $(\mathrm{kW})$ and $\phi_{\text {sys }}$ is the heat flow from the climate control system $(\mathrm{kW})$.

To determine the broiler house theoretical energy needs under ideal conditions and to make the results independent from the system features, the so- called "Ideal Loads Air System", which can be operated with infinite heating and cooling capacity, was applied. A time step of fifteen minutes was set for the simulation.

\subsubsection{Consistency options}

To compare the theoretical energy needs -without considering the system efficiency- obtained with the different methods, the modelling procedures should be made consistent, as shown in $[279,280]$. In the considered models, the following consistency options are applied:

- the hourly weather data -e.g. outdoor air temperature and solar radiation- used in the $D D$ and $S H$ simulation come from IWEC 
(International Weather for Energy Calculations) dataset. The monthly average values of the same data were applied in the $Q S$ model;

- hourly schedules of heating and cooling set-point temperatures, internal heat sources -sensible heat emission of broilers- and ventilation flow rate were assumed in $D D$ and $S H$ models, while monthly averages of the same quantities were used in $Q S$ model.

- the opaque and transparent building components were modelled in $D D$ model by defining detailed thermo-physical parameters of their materials, such as thermal conductivity, density, specific heat capacity and spectral features. The resulting values of thermal transmittance of the envelope components and the total solar energy transmittance of glazing were applied in $S H$ and in $Q S$ models.

\subsubsection{Results}

In Table 5.11, the theoretical yearly energy needs for heating and for cooling estimated by the three models are reported referring to the unit of floor area. The table shows that $Q S$ model estimates the highest yearly value for heating $\left(168.1 \mathrm{kWh} \mathrm{m}^{-2}\right)$ and the lowest one for cooling $\left(187.5 \mathrm{kWh} \mathrm{m}^{-2}\right)$. On the contrary, $\mathrm{SH}$ model estimates the lowest energy need for heating $\left(84.2 \mathrm{kWh} \mathrm{m}^{-2}\right)$ and the highest one for cooling $\left(205.7 \mathrm{kWh} \mathrm{m}^{-2}\right)$. The theoretical energy needs estimated by the $D D$ model are between the values obtained by $Q S$ and $S H$ models, for both heating and cooling.

Focusing on the heating energy needs, the differences between the results from the three models are considerable. Table 5.11 shows that, assuming the values from $D D$ model as reference, the heating energy need estimated by $S H$ model is smaller by $17.0 \mathrm{kWh} \mathrm{m}^{-2}(-17 \%)$, while the value estimated by $Q S$ model is greater than $D D$ by $66.9 \mathrm{kWh} \mathrm{m}^{-2}$ (+66\%). By contrast, all the estimated theoretical yearly energy needs for cooling are quite similar between them. Considering the results from $D D$ model as a reference, the estimation of $Q S$ model is lower by $18.2 \mathrm{kWh} \mathrm{m}^{-2}(-9 \%)$, while $S H$ model value is greater by $6.7 \mathrm{kWh} \mathrm{m}^{-2}(+3 \%)$.

Table 5.11 - Yearly theoretical energy needs for heating and cooling estimated by the three considered models.

\begin{tabular}{cccc}
\hline Energy use & $\begin{array}{c}\text { Quasi-steady-state } \\
(\boldsymbol{Q S}) \text { model }\end{array}$ & $\begin{array}{c}\text { Simple hourly } \\
(\boldsymbol{S H}) \text { model }\end{array}$ & $\begin{array}{c}\text { Detailed dynamic } \\
(\boldsymbol{D D}) \text { model }\end{array}$ \\
\hline $\begin{array}{c}\text { Heating } \\
{\left[\mathrm{kWh} \mathrm{m}^{-2}\right]}\end{array}$ & 168.1 & 84.2 & 101.2 \\
$\begin{array}{c}\text { Cooling } \\
{\left[\mathrm{kWh} \mathrm{m}^{-2}\right]}\end{array}$ & 187.5 & 205.7 & 199.0 \\
\hline
\end{tabular}

The significant differences that exist especially between the heating energy needs of $Q S$ model and the other two models can be explained analyzing the monthly energy needs reported in the bar chart of Figure 5.17. The graph shows that $Q S$ model greatly overestimates the heating needs during the cool season, especially in January, February, and December. Another interesting element that 
stands out from Figure 5.17 is that $Q S$ model cannot consider the contemporary of heating and cooling energy needs during the same month. The only exception is in the months in which heating and cooling seasons -or vice versa- change, as it occurs in October. This issue has important consequences on the estimation of the energy needs since $Q S$ model neglects important shares of energy needs when there is a contemporaneity of heating and cooling need in the same month, as it happens in February and March. For this reason, $Q S$ model is considered to be not reliable for the estimation of the energy consumption of livestock houses.

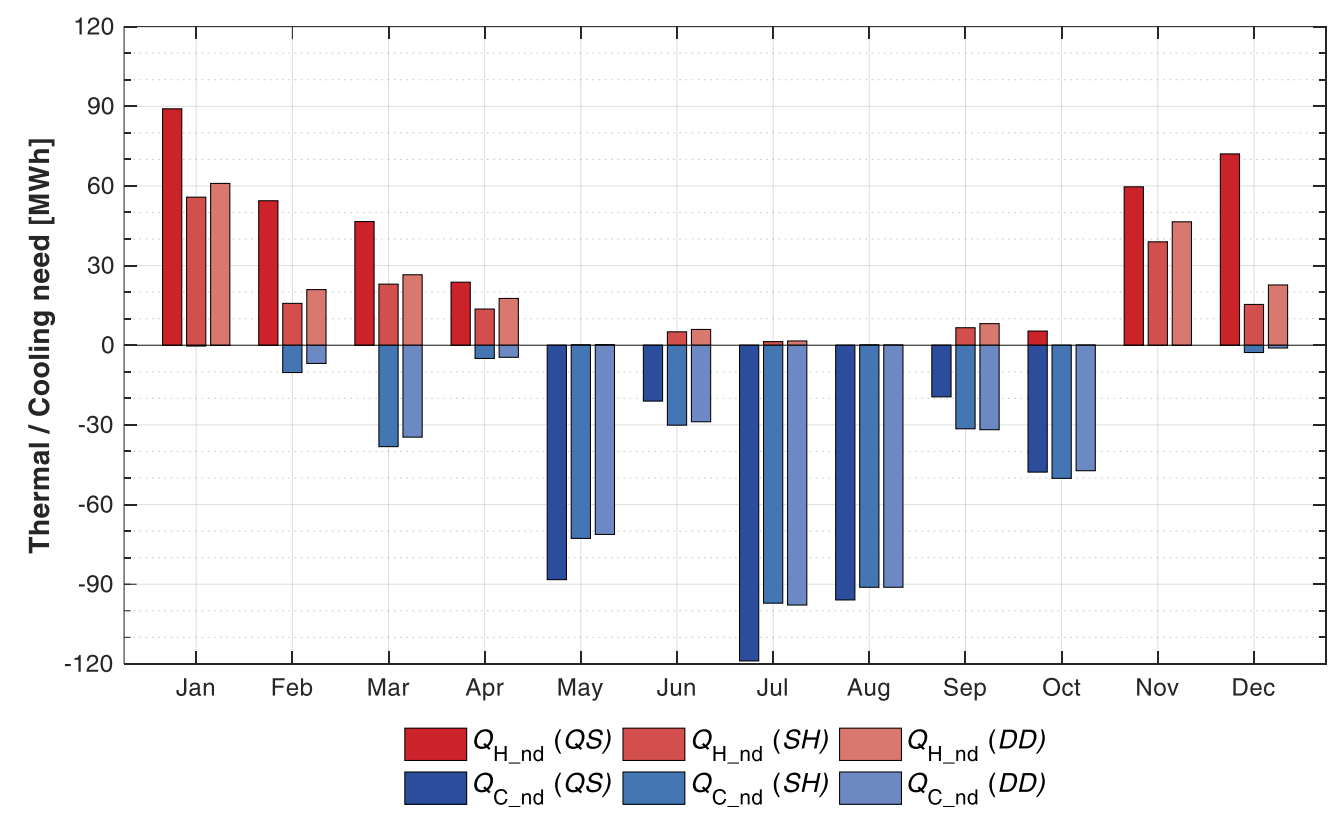

Figure 5.17 - Theoretical heating and cooling monthly energy needs from the considered models.

In Figure 5.18 the hourly trends of heating and cooling energy needs estimated by the two dynamic models ( $S H$ and $D D$ models) are shown during an entire production cycle carried out between February and April. The graph also includes parts of the sanitary empty periods performed before and after the considered production cycle, in which neither heating nor cooling energy needs are present since $\theta_{\text {air_i }}$ is in free-floating conditions.

At the beginning of the production cycle, a peak of thermal energy need is estimated by both the models. This peak is needed since an important amount of thermal energy is needed to reach the needed $\theta_{\text {set_H }}$ for broiler chicks after the empty period. After this peak, both the trends of heating energy needs decrease but some differences can be noticed since the decrease is slower for $D D$ model than $S H$ one. This difference may be attributable to a difference in the modelling of the total building fabric heat capacity of the broiler house. After some hours, the trends are almost aligned and the difference between them are negligible also when cooling needs are need, in the second half of the production cycle.

To evaluate the differences between the trends of the energy needs presented in Figure 5.18, the RMSE (Eq. (35)) is calculated between the trends provided by the two considered models. The RMSE calculated between the estimated heating 
energy needs is $22.0 \mathrm{kWh}$ and it is $8.1 \mathrm{kWh}$ for the cooling energy need. The higher difference between the RMSE for the heating period is mainly due to the deviation that exists at the beginning of the production cycle. If the first hours of the production cycle are excluded from the calculation, the RMSE decreases to $7.3 \mathrm{kWh}$.

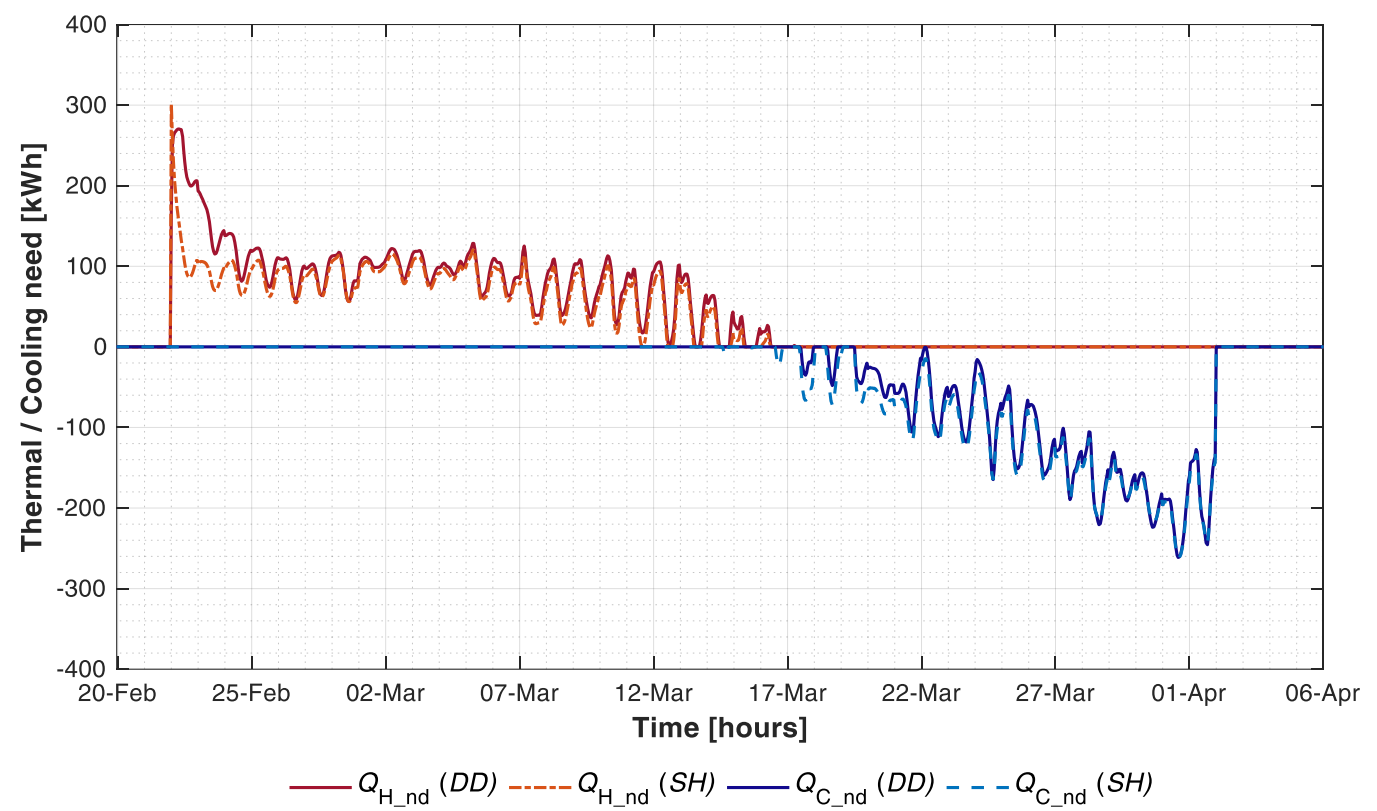

Figure 5.18 - Hourly heating and cooling energy needs during a production cycle (February April).

To deepen the analysis between the results provided by the $D D$ and $S H$ models, the $\theta_{\text {air_i }}$ trends estimated by the models are presented in Figure 5.19 during the last days of the production cycle (grey-filled area), together with $\theta_{\text {set_H }}, \theta_{\text {set_c }}$ and $\theta_{\text {air_o }}$. The chart shows that during the last days of the production cycle, the $\theta_{\text {air_i }}$ values estimated by both the models follow the $\theta_{\text {set_c }}$ trend. When the production cycle ends, no $\theta_{\text {set_c }}$ is set and $\theta_{\text {air_i }}$ fluctuates in free-running conditions. The presented trends of $\theta_{\text {air_i }}$ are quite similar between them some days after the end of the production cycle. On the contrary, some differences can be noticed just after the end of the cycle. The $\theta_{\text {air_i }}$ estimated by $S H$ model, in fact, suddenly starts to follow the trend of $\theta_{\text {air_o }}$, while the $\theta_{\text {air_i }}$ estimated by $S H$ model takes some hours more to follow $\theta_{\text {air_o }}$ trend. This behavior is similar to the one that was previously described in Figure 5.18 regarding the heating energy needs. Even in this case, the deviation between the presented trends may be attributable to a different modeling of the total building fabric heat capacity that characterize the adopted simulation methods.

The presented analyses show that $Q S$ method is not a good option for being implemented in an energy simulation model for livestock houses. This is since the large simulation time step -a month- does not make it possible to describe with a good detail the boundary conditions. Furthermore, $Q S$ method cannot estimate the contemporaneity of heating and cooling energy needs. On the contrary, $D D$ and $S H$ 
methods are good options since they provide quite similar results, and the main deviations are due to the different modelling of the total building fabric thermal capacity. The $S H$ method could be preferred since it is characterized by a high customizability that enhances the development of ad-hoc calculation modules and that favors the modeling of the specific climate control system adopted in livestock houses. This last issue is not immediate in $D D$ methods implemented in ready-touse simulation tools, such as EnergyPlus.

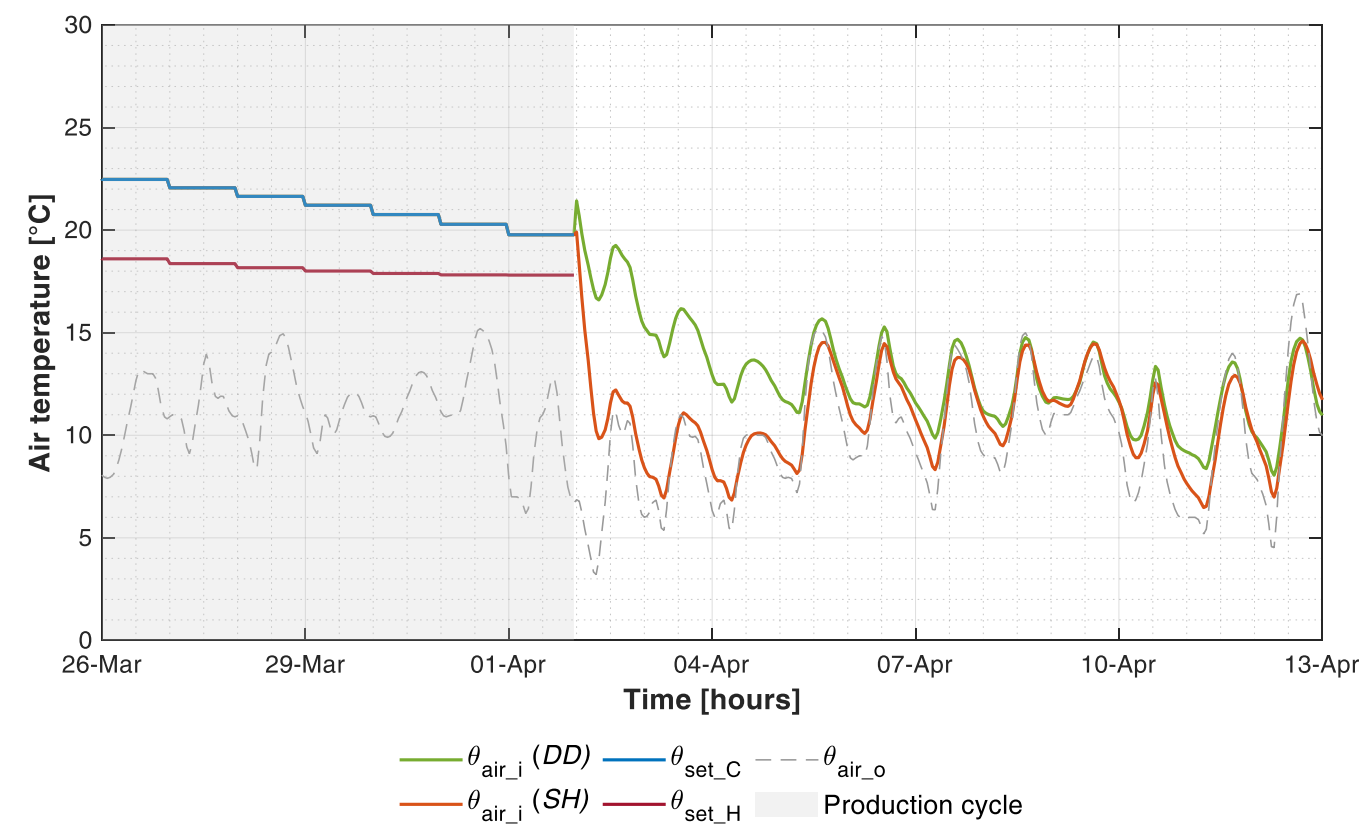

Figure 5.19 - Indoor air temperatures, set point temperatures and outdoor air temperature at the end of the analyzed production cycle (grey-filled area) and during the beginning of the following empty period (free running conditions).

\subsection{Final considerations}

In this chapter, an energy modelling framework for fully mechanically controlled livestock houses was presented. This framework was then customized for the specific energy simulation of broiler houses and growing-finishing pig houses. Both the obtained models were validated with good results against real monitored data in compliance with the main protocols regarding the energy simulation of buildings that are available and well established in literature. The models, in fact, resulted to be reliable in the estimation of the time profiles of the indoor climate conditions, namely air temperature and relative humidity. In addition, the models estimate with a good approximation the energy consumption. Finally, the simulation method on which the proposed modelling framework is based -the simple hourly method- was compared with the quasi-steady-state and detailed dynamic methods to investigate the main differences. The simple hourly method was highlighted to have slight differences compared with the dynamic detailed energy simulation method, a further confirmation of its reliability in the simulation of mechanically ventilated livestock houses. 
The proposed energy simulation framework may fill the gap in literature that was outlined at the beginning of this chapter, by setting a common methodology for the simulation of mechanically ventilated livestock houses. Further customization of this simulation framework could lead to the development of further simulation models for other livestock houses, such as laying hen houses. These simulation models, in fact, are essential for improving the energy performance of livestock houses and, hence, increasing the sustainability of the livestock sector. The primary role of these models is further enhanced considering the expected population growth and the increase of animal protein consumption. From a practical point of view, the developed modelling framework could represent a powerful decision support tool for the stakeholders involved in intensive livestock production since it enhances the assessment of the energy performance of mechanically ventilated livestock houses in standardized conditions. In this way, the effectiveness of new solutions, technologies and strategies aimed at increasing the energy performance of this building type can be evaluated considering specific outdoor weather conditions, different features of the building and the climate control system. This is of the foremost importance at the design and retrofit stages, especially considering the need of increasing the resiliency of livestock houses to climate changes. The customized models could be adopted even at the operation stage of livestock houses since they could provide useful data for farm management, such as running costs for energy supply and potential heat stress situations. Nevertheless, future works may improve the presented energy simulation framework by implementing additional calculation modules for the estimation of the energy production from renewable energy sources, such as photovoltaics and solar thermal, and for the estimation of the amount of greenhouse gas emissions due to the direct on-farm energy consumption. Furthermore, future works may couple the presented energy simulation framework with a $\mathrm{NH}_{3}$-emission model that considers further aspects of pig farming, such as feeding and other farming practices. In this way, it would be possible to make long-term estimations of $\mathrm{NH}_{3}$ emissions with the aim of evaluating the effectiveness of different emission abatement techniques.

In this chapter, the potentialities of the customized energy simulation methods were briefly shown through an application of the energy simulation model of growing-finishing pig houses, providing useful information about energy consumption and financial costs in different scenarios. In the following chapters, the potentialities of the broiler house model will be deeply explored. In Chapter 6, the broiler house model will be used to compare different solutions in terms of building envelope to decrease the overall energy consumption for climate control. In Chapter 7, the same model will be adopted to evaluate the differences in terms of energy consumption of two different ventilation strategies. 


\subsection{Chapter nomenclature}

\begin{tabular}{|c|c|}
\hline $\mathcal{A}, \tilde{\mathcal{A}}$ & Sets of simulated and measured values of indoor air temperature \\
\hline$a_{b}$ & Broiler age [days] \\
\hline$a_{p}$ & Pig age [days] \\
\hline $\mathrm{C}$ & Cool season (scenario) \\
\hline$c_{\text {air }}$ & Specific heat capacity of air $\left[\mathrm{Jg}^{-1} \mathrm{~K}^{-1}\right]$ \\
\hline$C_{\mathrm{m}}$ & Total building fabric heat capacity $\left[\mathrm{kJ} \mathrm{K}^{-1}\right]$ \\
\hline$C v R M S E$ & Coefficient of variation of the $R M S E$ [\%] \\
\hline$D D$ & Detailed dynamic energy simulation method \\
\hline $\mathrm{DE}$ & Germany (scenario) \\
\hline$E_{\mathrm{el}}$ & Electrical energy consumption for ventilation [kWh] \\
\hline$E_{\text {th }}$ & Thermal energy consumption for supplemental heating [kWh] \\
\hline ES & Spain (scenario) \\
\hline$h_{\text {vap }}$ & Specific enthalpy of water vapor $\left[\mathrm{kJ} \mathrm{kg}^{-1}\right]$ \\
\hline$I_{\text {tot_hor }}$ & Hourly solar radiation on the horizontal plane $\left[\mathrm{W} \mathrm{m}^{-2}\right]$ \\
\hline IT & Italy (scenario) \\
\hline$j$ & $j$-th fan of the livestock house \\
\hline$K_{\mathrm{y}}$ & Coefficient of efficiency at weight gain for pigs [-] \\
\hline$k$ & $k$-th simulation time step \\
\hline$k_{\Delta \mathrm{p}_{-} 2}-k_{\Delta \mathrm{p}_{-} 0}$ & Regression coefficients for $\Delta p_{\mathrm{tv}}$ \\
\hline$k_{\mathrm{R} \_6}-k_{\mathrm{R} \_0}$ & Regression coefficients for $R_{\mathrm{S}}$ \\
\hline$k_{\mathrm{Vb}_{-} 4}-k_{\mathrm{Vb} \__{0}}$ & Regression coefficients for base ventilation air flow rate \\
\hline$k_{\mathrm{Vp} \_6}-k_{\mathrm{Vp} \__{0}}$ & Regression coefficients for base ventilation air flow rate \\
\hline$k_{\mathrm{wb}_{3} 3}-k_{\mathrm{wb} \__{0}}$ & Regression coefficients for broiler live weight \\
\hline$k_{\Delta_{-} 6}-k_{\Delta_{-} 0}$ & Regression coefficients for dead band \\
\hline$k_{\theta \mathrm{b} \_6}-k_{\theta \mathrm{b} \_0}$ & Regression coefficients for $\theta_{\text {set_opt }}$ of broilers \\
\hline$k_{\theta \mathrm{p}_{-} 3}-k_{\theta \mathrm{p}_{\_} 0}$ & Regression coefficients for $\theta_{\text {set_opt }}$ of pigs \\
\hline$l_{\text {hou }}$ & Length of the broiler house $[\mathrm{m}]$ \\
\hline$\dot{m}_{\mathrm{ev}}$ & Water vapor mass flow rate for evaporation from internal sources $\left[\mathrm{kg}_{\mathrm{vap}} \mathrm{h}^{-1}\right]$ \\
\hline$\dot{m}_{\mathrm{i}}$ & Water vapor mass flow rate from internal sources $\left[\mathrm{kg}_{\mathrm{vap}} \mathrm{h}^{-1}\right]$ \\
\hline$\dot{m}_{\text {vap_a }}$ & Water vapor mass flow rate from animals $\left[\mathrm{kg}_{\mathrm{vap}} \mathrm{h}^{-1}\right]$ \\
\hline$\dot{m}_{\mathrm{ve} \_\mathrm{i}}$ & Water vapor mass flow rate carried out by ventilation air $\left[\mathrm{kg}_{\text {vap }} \mathrm{h}^{-1}\right]$ \\
\hline$\dot{m}_{\text {ve_sup }}$ & Water vapor mass flow rate carried in by ventilation air $\left[\mathrm{kg}_{\mathrm{vap}} \mathrm{h}^{-1}\right]$ \\
\hline$\dot{m}_{\mathrm{i}_{-} \mathrm{f}}$ & Water vapor mass flow rate from the entire broiler flock $\left[\mathrm{kg}_{\mathrm{vap}} \mathrm{s}^{-1}\right]$ \\
\hline$M B E$ & Mean Bias Error [\%] \\
\hline$n_{\mathrm{b}}$ & Number of broilers present in the house \\
\hline$n_{\text {fan }}$ & Number of fans present inside the house \\
\hline$n_{\text {feed }}$ & Feed factor $[-]$ \\
\hline$n_{\mathrm{k}}$ & Number of simulation time steps \\
\hline$n_{\text {loads }}$ & Number of the internal convective heat sources \\
\hline$n_{\mathrm{p}}$ & Number of pigs present in the house \\
\hline$n_{\text {sup }}$ & Number of surfaces of the thermal zone \\
\hline$q$ & $q$-th convective heat source \\
\hline$\dot{q}_{\text {air }}$ & Ventilation air mass flow rate $\left[\mathrm{kg} \mathrm{h}^{-1}\right]$ \\
\hline$Q S$ & Quasi-steady-state energy simulation method \\
\hline$Q_{\mathrm{C} \_ \text {nd }}$ & Monthly theoretical energy needs for space cooling [kWh] \\
\hline$Q_{\mathrm{gn}}$ & Monthly heat gains $[\mathrm{kWh}]$ \\
\hline$Q_{\mathrm{H}_{\text {nnd }}}$ & Monthly theoretical energy needs for space heating [kWh] \\
\hline
\end{tabular}


$Q_{\mathrm{ls}} \quad$ Monthly heat losses [kWh]

$R_{\mathrm{S}}$

$R H_{\mathrm{CCU}}$

Ratio between sensible and total heat emission [-]

$R H_{\mathrm{DL}}$

Indoor air relative humidity monitored by climate control unit [\%]

$R H_{\mathrm{i}}$

$R H_{\mathrm{o}}$

RMSE

$S H$

$S P F$

$t$

$U-$ value

V

$\dot{V}_{\text {act }}$

$\dot{V}_{\text {bs }}$

$\dot{V}_{\text {cool }}$

$\dot{V}_{\text {ec }}$

$\dot{V}_{\text {fan }}$

$\dot{V}_{\text {max }}$

$\dot{V}_{\text {min }}$

$\dot{V}_{\mathrm{tv}}$

$v_{\text {air }}$

$\mathrm{W}$

$w_{\mathrm{b}}$

$w_{\mathrm{p}}$

$x_{\text {air_i }}$

$x_{\text {air_o }}$

$x_{\text {air_sup }}$

$\gamma_{\text {fog }}$

$\gamma_{\text {man }}$

$\gamma_{\varepsilon}, \hat{\gamma}_{\varepsilon}$

$\Delta p_{\text {bs }}$

$\Delta p_{\text {ec }}$

$\Delta p_{\mathrm{st}}$

$\Delta p_{\mathrm{tv}}$

$\Delta R H_{\mathrm{i}}$

$\Delta \theta_{\text {band }}$

$\Delta \theta_{\mathrm{tv}}$

$\Delta \tau$

$\varepsilon_{\text {ec }}$

$\theta_{\text {air_i }}$

$\theta_{\text {air_sup }}$

$\theta_{\text {air_o }}$

$\theta_{\text {air_o,wb }}$

$\theta_{\mathrm{CCU}}$

$\theta_{\mathrm{DL}}$

$\theta_{\text {set_C }}$

$\theta_{\text {set_H }}$

$\theta_{\text {set_opt }}$

$\kappa_{\mathrm{i}}$

Averaged indoor air relative humidity obtained by data loggers [\%]

Indoor air relative humidity [\%]

Outdoor air relative humidity [\%]

Root Mean Square Error

Simple hourly energy simulation method

Specific Fan Performance $\left[\mathrm{m}^{3} \mathrm{Wh}^{-1}\right]$

$t$-th surface of the thermal zone

Stationary thermal transmittance $\left[\mathrm{W} \mathrm{m}^{-2} \mathrm{~K}^{-1}\right.$ ]

Pig house volume $\left[\mathrm{m}^{3}\right]$

Actual ventilation air flow rate $\left[\mathrm{m}^{3} \mathrm{~h}^{-1}\right]$

Base ventilation air flow rate $\left[\mathrm{m}^{3} \mathrm{~h}^{-1}\right]$

Cooling ventilation air flow rate $\left[\mathrm{m}^{3} \mathrm{~h}^{-1}\right]$

Tunnel ventilation air flow rate with evaporative pad activation $\left[\mathrm{m}^{3} \mathrm{~h}^{-1}\right]$

Air flow rate of fans $\left[\mathrm{m}^{3} \mathrm{~h}^{-1}\right]$

Maximum ventilation air flow rate installed in the house $\left[\mathrm{m}^{3} \mathrm{~h}^{-1}\right]$

Minimum ventilation air flow rate inside the house $\left[\mathrm{m}^{3} \mathrm{~h}^{-1}\right]$

Tunnel ventilation air flow rate $\left[\mathrm{m}^{3} \mathrm{~h}^{-1}\right]$

Air velocity $\left[\mathrm{m} \mathrm{s}^{-1}\right]$

Warm season (scenario)

Broiler live weight (or body mass) $[\mathrm{kg}]$

Pig live weight (or body mass) [kg]

Indoor air humidity ratio $\left[\mathrm{kg}_{\mathrm{vap}} \mathrm{kg}_{\text {air }}^{-1}\right]$

outdoor air humidity ratio $\left[\mathrm{kg}_{\text {vap }} \mathrm{kg}_{\text {air }}^{-1}\right]$

Humidity ratio of supply air $\left[\mathrm{kg}_{\mathrm{vap}} \mathrm{kg}\right]$

Boolean variable for the presence of fogging system [-]

Boolean variable associated to manure heat flow [-]

Initial and optimum value of the calibration parameter for $\varepsilon_{\mathrm{ec}}[-]$

$\Delta p_{\text {st }}$ value in presence of base ventilation [Pa]

$\Delta p_{\text {st }}$ value in presence of evaporative cooling [Pa]

Static pressure difference between outside and inside air pressure [Pa]

$\Delta p_{\text {st }}$ value in presence of tunnel ventilation [Pa]

Residual values between simulated and monitored $R H_{\mathrm{i}}$ [\%]

Dead band for set point temperatures $\left[{ }^{\circ} \mathrm{C}\right]$

Minimum temperature difference for tunnel ventilation activation $\left[{ }^{\circ} \mathrm{C}\right]$

Duration of the simulation time step [h]

Direct saturation effectiveness of evaporative pads [-]

Indoor air temperature $\left[{ }^{\circ} \mathrm{C}\right]$

Supply air temperature $\left[{ }^{\circ} \mathrm{C}\right]$

Outdoor air temperature $\left[{ }^{\circ} \mathrm{C}\right]$

Wet-bulb temperature of outdoor air $\left[{ }^{\circ} \mathrm{C}\right]$

Indoor air temperature monitored by climate control unit $\left[{ }^{\circ} \mathrm{C}\right]$

Averaged indoor air temperature obtained by data loggers $\left[{ }^{\circ} \mathrm{C}\right]$

Air set point temperature for cooling $\left[{ }^{\circ} \mathrm{C}\right]$

Air set point temperature for heating $\left[{ }^{\circ} \mathrm{C}\right]$

Optimal indoor air set point temperature $\left[{ }^{\circ} \mathrm{C}\right]$

Areal internal heat capacity of building components $\left[\mathrm{kJ} \mathrm{m}^{-2} \mathrm{~K}^{-1}\right]$ 


\begin{tabular}{|c|c|}
\hline$\eta_{\text {gn }}$ & Utilization factor of the heat gains $[-]$ \\
\hline$\eta_{\mathrm{H}}$ & Global efficiency of the supplemental heating system [-] \\
\hline$\eta_{\text {ls }}$ & Utilization factor of the heat losses $[-]$ \\
\hline$\rho_{\text {air }}$ & Air volumetric mass density $\left[\mathrm{kg} \mathrm{m}^{-3}\right]$ \\
\hline$\tau_{\mathrm{k}}$ & $k$-th simulation time step \\
\hline$\phi_{\text {fog }}$ & Heat flow due to the fogging system [W] \\
\hline$\phi_{\mathrm{C}_{\text {nnd }}}$ & Theoretical cooling load [W] \\
\hline$\phi_{\text {conv }}$ & Convective heat flow [W] \\
\hline$\phi_{\mathrm{d} \_\mathrm{p}}$ & Daily feed energy intake by a pig [W] \\
\hline$\phi_{\mathrm{H}_{\mathrm{n} n d}}$ & Theoretical supplemental heating load [W] \\
\hline$\phi_{\text {lat_i }}$ & Latent heat emission from internal sources [W] \\
\hline$\phi_{\mathrm{m} \_\mathrm{p}}$ & Heat dissipated by a pig due to maintenance [W] \\
\hline$\phi_{\text {mac_i }}$ & Sensible heat flow from internal machineries [W] \\
\hline$\phi_{\text {man }}$ & Heat flow associated to manure [W] \\
\hline$\phi_{l_{f} f}$ & Latent heat production of the broiler flock [W] \\
\hline$\phi_{\text {s+l_f }}$ & Total -sensible plus latent- thermal emission of the broiler flock [W] \\
\hline$\phi_{s_{-} f}$ & Sensible heat production of the broiler flock [W] \\
\hline$\phi_{\text {tot_i }}$ & Total -sensible plus latent- thermal emission from internal sources [W] \\
\hline$\phi_{\text {sen_i }}$ & Sensible heat emission from internal sources [W] \\
\hline$\phi_{\text {sen_a }}$ & Sensible heat flow from animals [W] \\
\hline$\phi_{\text {sys }}$ & Heat flow from climate control system [W] \\
\hline$\phi_{\text {sys_H }}$ & Heat flow from the supplemental heating system [W] \\
\hline$\phi_{\text {sol }}$ & Solar radiation heat flow [W] \\
\hline$\phi_{\text {sup }}$ & Heat flow from the surfaces of the thermal zone [W] \\
\hline$\phi_{\text {tr_f }}$ & Transmission heat losses through the floor [W] \\
\hline$\phi_{\text {tr_w }}$ & Transmission heat losses through walls and roof [W] \\
\hline$\phi_{\text {vap }}$ & Heat flow for water evaporation inside the enclosure [W] \\
\hline$\phi_{\mathrm{ve} \_\mathrm{i}}$ & Sensible heat flows due to ventilation air entering in the house [W] \\
\hline$\phi_{\text {ve_o }}$ & Sensible heat flows due to ventilation air leaving the house [W] \\
\hline$\phi_{\text {vent }}$ & Ventilation heat flow [W] \\
\hline
\end{tabular}





\section{Chapter 6}

\section{The role of envelope in livestock houses: a case study on broiler house design}

\begin{tabular}{c|c} 
Objective & $\begin{array}{l}\text { To highlight the importance of using primary energy approach in design } \\
\text { livestock house envelope. }\end{array}$ \\
\hline Outcome & $\begin{array}{l}\text { Comparison between delivered and primary energy consumption, global cost } \\
\text { and indoor climate conditions of a broiler house analyzed in different scenarios. }\end{array}$ \\
\hline Highlights & $\begin{array}{l}\text { Primary energy is proposed as a new approach in energy assessment } \\
\text { of animal houses. } \\
\text { The energy performance for climate control of a typical broiler house } \\
\text { is assessed. }\end{array}$ \\
- $\begin{array}{l}\text { High insulation envelope decreases energy consumption but has a high } \\
\text { global cost. } \\
\text { Medium insulated envelope is favorable for energy consumption and } \\
\text { global cost. } \\
\text { Reference values of energy consumption in standardized conditions } \\
\text { are provided }\end{array}$ & $\begin{array}{l}\text { Parts of this chapter have been published in Journal of Cleaner Production as: } \\
\text {-Costantino et al., "Identification of energy-efficient solutions for broiler house } \\
\text { envelopes through a primary energy approach", Journal of Cleaner Production 2021, } \\
\text { 312: 127639. }\end{array}$
\end{tabular}





\subsection{The importance of the primary energy approach in the envelope design}

Poultry production is often considered the most environmentally efficient type of livestock production [281]. However, increasing environmental concerns have raised questions about the sustainability of livestock production systems [282]. One of the main concerns regarding broiler production is the high use of energy required to farm the animals, e.g. thermal and electrical energy, or to provide the inputs, e.g. machinery and feed. According to Heidari et al. [283], the highest indirect energy input of poultry production is feed, that represents around $32 \%$ of the total energy inputs. Other energy inputs, e.g. for machinery and human labor, are negligible. The importance of feed as an energy input for broiler production has been underlined in literature by emergy analyses, which are analyses that assess the overall energy inputs of broiler production as units of equivalent solar energy [284]. Castellini et al. [285], for example, compared conventional and organic broiler farming in terms of emergy inputs. Allegretti et al. [286] performed an emergy assessment to show the potentialities of insect-based feed for broiler production.

As stated in Chapter 2, the highest direct energy inputs in broiler production are fuel and electrical energy needed in broiler houses, that represent around 59\% and $9 \%$ of the total -direct plus indirect- energy inputs, respectively [283]. Fuel and electrical energy are mainly used on farms for climate control, that is by far the highest share of on-farm energy consumption. According to the analysis presented in section 2.3, in fact, around $96 \%$ of thermal energy and around $76 \%$ of electrical energy are used for maintaining adequate indoor climate conditions. Such high shares of energy consumption highlight how an energy-efficient climate control of livestock houses could contribute to improving the environmental sustainability of livestock sector with a view to climate change [287]. In literature, several works have investigated solutions to decrease the energy consumption for climate control of broiler houses. Most of these works focus on the improvement of the climate control system performance through the use of aerothermal heat pumps [288], geothermal heat pumps [289], solar systems [290] including those based on experimental parabolic concentrators [123], and heat recovery systems [291].

Whilst some research has been carried out on the improvement of the energy performance of climate control systems, there have been few investigations into the improvement of the energy performance of broiler house envelopes [232]. The envelope is composed of the outer elements of a broiler house, i.e. walls, roof, floor and windows. It constitutes the boundary of thermodynamic system of the broiler house that modulates the exchange of energy -e.g. heat and solar irradiation- and mass -e.g. ventilation air and moisture- between the indoor environment -the enclosure- and the outdoor. The design of the envelope, hence, should aim at improving the energy performance for climate control through the decrease of the overall consumption of thermal and electrical energy. By contrast, in current 
practice, the envelope design of a broiler house is often a shallow process that provides standardized solutions for contexts that are considerably different. Therefore, there is a strong need for a design process targeted at improving the energy performance of the broiler house envelope. Energy analysis [292] is a powerful method to evaluate improvements of the energy performance, but research has pointed out that the robustness of this method may need to be improved [293]. Most of the energy analyses described above, in fact, evaluated the energy performance of broiler houses focusing only on thermal and electrical energy delivered on farms. Thus, the current state of the art adopts a delivered energy approach that focuses only on the very last stages of the energy supply chain, neglecting the energy consumption that occurs in the previous stages. A new approach based on primary energy could encompass all the stages of the energy supply chain. Primary energy assessment, in fact, is a single metric for assessing all forms of direct energy, e.g. thermal and electrical, that are supplied to the broiler house. Primary energy accounts for the energy losses - e.g. due to conversion and transportation - and for the energy embedded in the infrastructures - e.g. in turbines and pipes - along the energy supply chain in addition to the on-farm energy consumption. Furthermore, primary energy focuses on the adopted energy carrier, e.g. natural gas or electricity from grid, and on the considered country [294].

The importance of primary energy is testified by its adoption as major metric by the Energy Performance of Buildings Directive of European Union [295] and it is becoming widely adopted in the energy assessment of residential [296] and office [297] buildings and industrial processes [298]. By contrast, there are few primary energy analyses of broiler houses in literature and they focus on very specific case studies and geographical contexts. Baxevanou et al. [299], for example, used the primary energy approach to evaluate the energy consumption of eight broiler houses in different Greek climate contexts. Thus, improving the energy performance of broiler house envelopes through the assessment of primary energy could contribute to decreasing the energy consumption of this production system and of the entire livestock sector.

In this chapter, delivered energy and primary energy approaches are adopted to identify the most energy-efficient solution for envelopes in typical European broiler houses, as schematized in Figure 6.1. For this purpose, 18 different scenarios characterized by three different envelope types and six different outdoor weather conditions are simulated. The results of the simulations are evaluated from the financial point of view and considering the heat stress risk. 


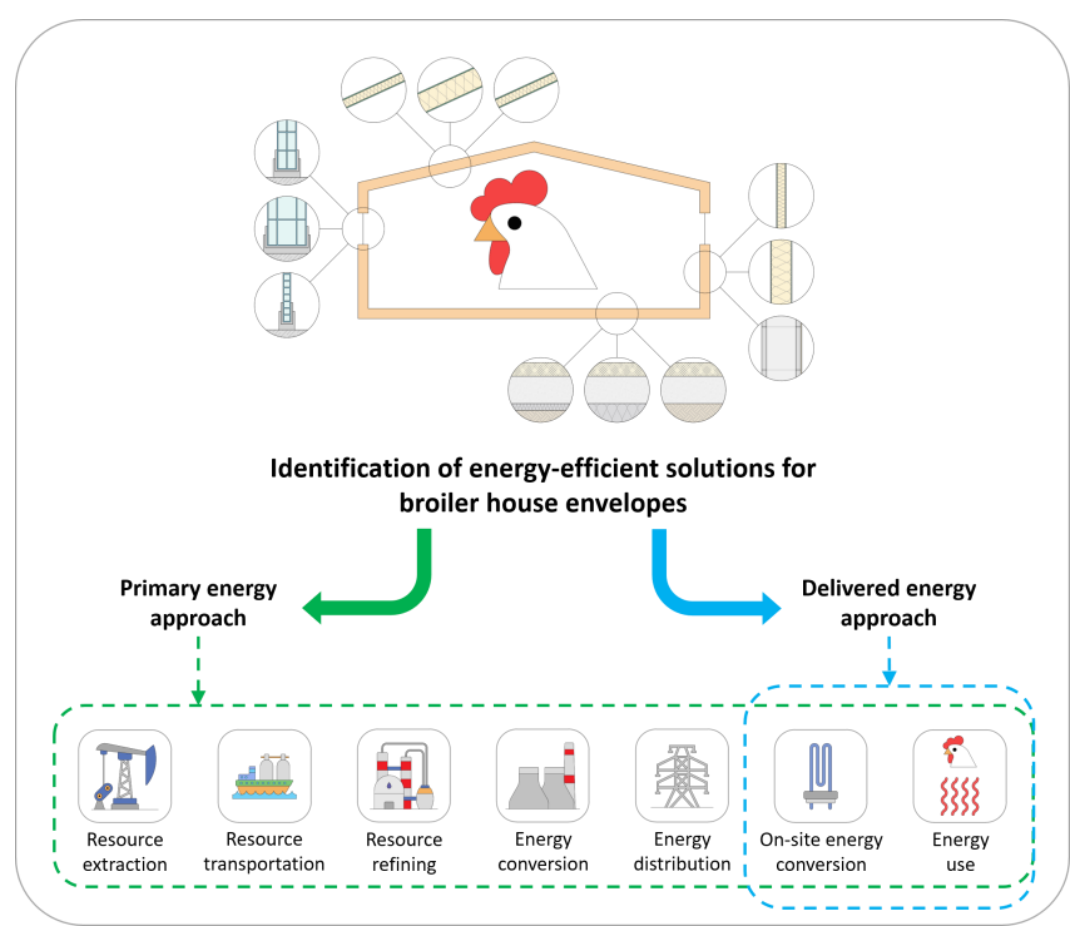

Figure 6.1 - Schematization of the objective of Chapter 6.

\subsection{Materials and methods}

To achieve the previously presented objective, the methodology workflow schematized in Figure 6.2 is adopted. The calibrated energy simulation model for broiler houses -presented in section 5.4- is used to simulate the case study presented in section 5.5.1, that is considered a typical broiler house of the European context. The simulations are performed in different scenarios that are set in the preprocessing stage, defining different envelope types and different outdoor weather conditions (section 6.2.1). For each defined scenario, a typical year of broiler production is simulated, obtaining the following results:

- energy consumption for climate control, namely

- thermal energy for supplemental heating

- electrical energy for ventilation and evaporative cooling

- indoor climate conditions, namely

- indoor air temperature

- indoor air relative humidity. 


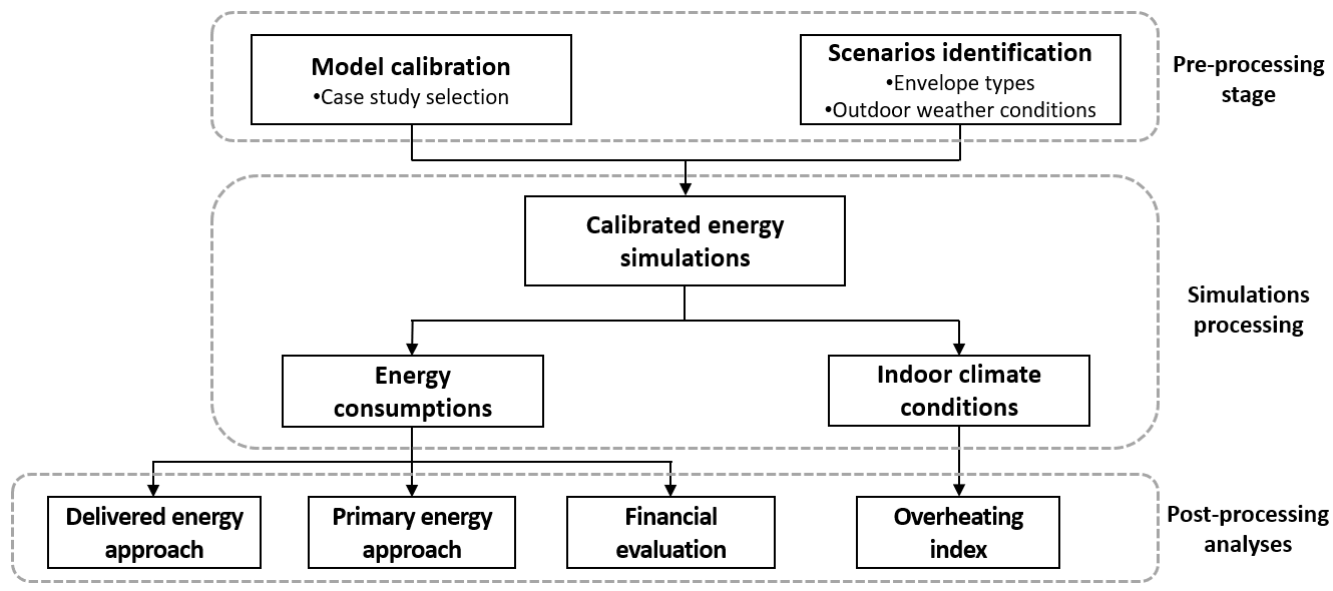

Figure 6.2 - Schematization of the methodology workflow.

The obtained energy consumption is analyzed adopting both the delivered and the primary energy approaches and the results are presented in sections 6.3.1 and 6.3.2, respectively, where, additionally, reference values of energy consumption are provided. The main difference between delivered and primary energy approach is conceptualized in Figure 6.3. As shown in the figure, the delivered energy approach accounts exclusively for the energy that is converted and used on farm. In this work, the delivered energy consumption of the analyzed broiler house is provided directly by the energy simulation model. By contrast, the primary energy approach encompasses all the stages of the energy supply chain, from the resource extraction to the final on-farm use, as visible in Figure 6.3. The primary energy consumption of the analyzed scenarios is calculated from the simulation results through ad-hoc conversion factors. The global primary energy consumption $E_{\mathrm{p}_{\text {glob }}}$, is calculated as the sum of primary energy consumption due to thermal $E_{\mathrm{p}_{-} \text {th }}$ and electrical energy $E_{\mathrm{p}_{-} \mathrm{el}}$, as

$$
E_{\mathrm{p}_{\text {glob }}}=E_{\mathrm{p} \_t h_{1}}+E_{\mathrm{p} \_ \text {el }_{1}}\left[\mathrm{kWh}_{\mathrm{p}}\right]
$$

where

$$
\begin{gathered}
E_{\mathrm{p} \_t h_{1}}=E_{\mathrm{th}} \cdot f_{\mathrm{p} \_ \text {th_tot }}\left[\mathrm{kWh}_{\mathrm{p}}\right] \\
E_{\mathrm{p} \_ \text {el }}=\left(E_{\text {el_ven }}+E_{\text {el_ec }}\right) \cdot f_{\mathrm{p} \_ \text {el_tot }_{1}}\left[\mathrm{kWh}_{\mathrm{p}}\right]
\end{gathered}
$$

where $f_{\mathbf{p}_{-} \text {th_tot }}$ is the total primary energy conversion factor for thermal energy and $f_{\mathrm{p}_{-} \text {el_tot }}$ is the total primary energy conversion factor for electrical energy. These factors depend on the considered energy carrier since the overheads for extracting, refining, converting, and transporting energy change significatively depending on it. The primary energy factors are calculated at a national level since each country should consider its own energy mix. The terms $f_{\mathrm{p}_{-} \text {th_tot }}$ and $f_{\mathrm{p}_{-} \text {el_tot }}$ are "total" conversion factors since they account for the renewable and nonrenewable primary energy shares. 


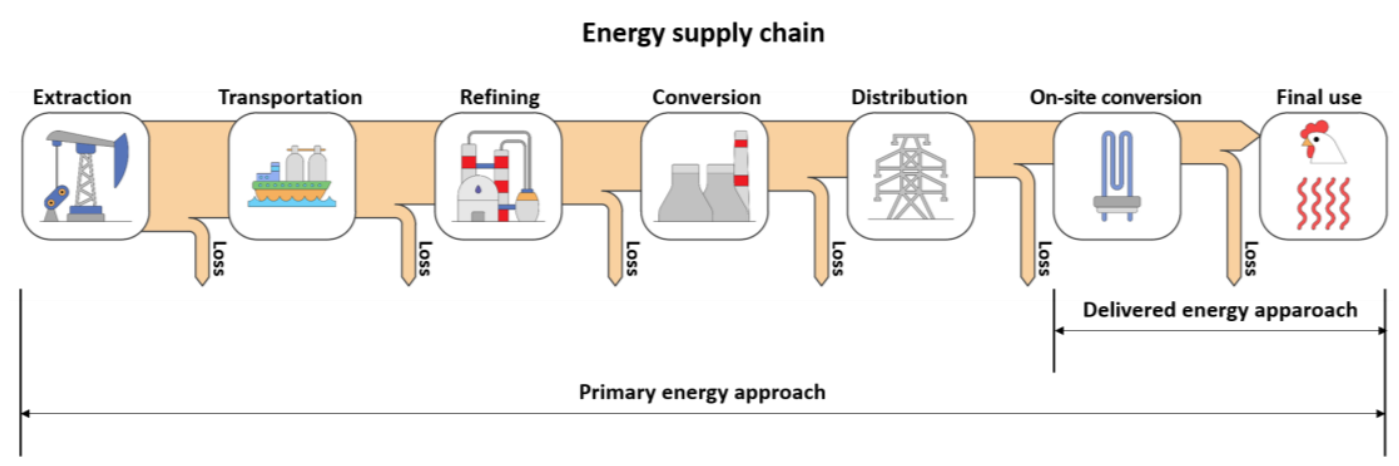

Figure 6.3 - Conceptualization of the differences between the delivered and the primary energy approach.

As shown in Figure 6.1, the scenarios are analyzed from a financial point of view according to the methodology provided in section 6.2.2. The financial evaluation estimates how the considered types of envelope affect the global cost of the broiler house over its lifespan and the results are presented in section 6.3.3.

Finally, a comparison of the scenarios regarding the indoor climate conditions to assess the potential heat stress risk for broilers is performed. For this purpose, the overheating index $\Omega_{\mathrm{OH}}$ is assessed, as similarly done in previous works [124]. The overheating index indicates the extent to which indoor air temperature $\theta_{\text {air_i }}$ exceeds the set point temperature $\theta_{\text {set_c }}$ during a considered time interval $\Delta \tau$. It is calculated similarly to Eq. (5) and reads

$$
\Omega_{\mathrm{oH}}=\sum_{k=1}^{n_{\text {step }}}\left(\Omega_{\mathrm{oH}, \mathrm{k}} \cdot \Delta \tau\right) \quad\left[{ }^{\circ} \mathrm{C} \mathrm{h}\right]
$$

with

$$
\Omega_{\mathrm{oH}, \mathrm{k}} \in \mathcal{R}^{+}
$$

where

$$
\Omega_{\mathrm{oH}, \mathrm{k}}=\theta_{\text {air_i, }}-\theta_{\text {set_C,k }} \quad\left[{ }^{\circ} \mathrm{C}\right]
$$

where $\mathcal{R}^{+}$is the set of positive real numbers, $\Omega_{\mathrm{oH}, \mathrm{k}}$ is the overheating index calculated at the $k$-th hour and $n_{\text {step }}$ is the number of hours in which broilers are present inside the house. The value of $n_{\text {step }}$ in this work is 7,200 h (the total hours of the years minus the hours of sanitary empty periods) and $\Delta \tau$ is equal to one hour (the simulation time step). The terms $\theta_{\text {air_i,k }}$ and $\theta_{\text {set_c,k }}$ are the indoor air temperature and the cooling set point temperature at the $k$-th hour, respectively. The results of this analysis are presented in section 6.3.4. 


\subsubsection{Definition of scenarios}

\section{Types of broiler house envelopes}

Three types of building envelope that are commonly used in typical European broiler houses are considered in this work and they are presented in Table 6.1. The considered envelopes are characterized by different values of average stationary thermal transmittance ( $\bar{U}$-value) and total building fabric heat capacity $\left(C_{\mathrm{m}}\right)$. The term $\bar{U}$-value reported in Table 6.1 represents the averaged stationary thermal transmittance of the entire building envelope and is calculated as

$$
\bar{U}-\text { value }=\frac{\sum_{j=1}^{n_{\text {comp }}}\left(U-\text { value }_{\mathrm{j}} \cdot A_{\mathrm{j}}\right)}{\sum_{j=1}^{n_{\text {comp }}} A_{\mathrm{j}}}\left[\frac{\mathrm{W}}{\mathrm{m}^{2} \mathrm{~K}}\right]
$$

where $U$-value -calculated in compliance with [300]- is the stationary thermal transmittance of the $j$-th element of the building envelope $\left(\mathrm{W} \mathrm{m}^{-2} \mathrm{~K}^{-1}\right)$ and $A_{\mathrm{j}}$ is its area $\left(\mathrm{m}^{2}\right)$. The term $n_{\mathrm{comp}}$ is the number of building components of the envelope.

The total building fabric heat capacity $\left(C_{\mathrm{m}}\right)$ reported in Table 6.1 is calculated as

$$
C_{\mathrm{m}}=\sum_{j=1}^{n_{\text {comp }}}\left(\kappa_{\mathrm{i}, \mathrm{j}} \cdot A_{\mathrm{j}}\right)\left[\frac{\mathrm{kJ}}{\mathrm{K}}\right]
$$

where $\kappa_{\mathrm{i}, \mathrm{j}}\left(\mathrm{kJ} \mathrm{m}^{-2} \mathrm{~K}^{-1}\right)$ is the internal heat capacity of the $j$-th opaque element -calculated according to EN ISO 13786 standard [264]- and $A_{\mathrm{j}}$ is its area. The term $n_{\text {comp }}$ is the number of building components that are considered in the calculation of $C_{\mathrm{m}}$. In this work, $\kappa_{\mathrm{i}}$ of the transparent elements is considerably lower than the one of the opaque ones, thus it was neglected in the simulations.

Table 6.1 - The average stationary thermal transmittance of the entire envelope $\bar{U}-$ value and

\begin{tabular}{|c|c|c|c|c|}
\hline Envelope & Envelope features & Use & $\begin{array}{c}\bar{U} \text {-value } \\
{\left[\mathbf{W} \mathbf{m}^{-2} \mathbf{K}^{-1}\right]}\end{array}$ & $\begin{array}{c}C_{\mathbf{m}} \\
{\left[\mathrm{kJ} \mathrm{K} \mathrm{K}^{-1}\right]}\end{array}$ \\
\hline Type-A & $\begin{array}{c}\text { Medium insulation and } \\
\text { low mass }\end{array}$ & $\begin{array}{l}\text { Modern broiler } \\
\text { houses }\end{array}$ & 0.69 & 24,231 \\
\hline Type-B & $\begin{array}{c}\text { High insulation and } \\
\text { low mass }\end{array}$ & $\begin{array}{l}\text { Modern broiler } \\
\text { houses }\end{array}$ & 0.36 & 24,045 \\
\hline Type-C & $\begin{array}{c}\text { Low insulated and } \\
\text { high mass }\end{array}$ & $\begin{array}{l}\text { Older broiler } \\
\text { houses }\end{array}$ & 1.15 & 49,322 \\
\hline
\end{tabular}
total building fabric heat capacity $C_{\mathrm{m}}$ of the considered envelope types.

The $U$-values (Eq. (96)) and the values of $\kappa_{\mathrm{i}}$ (Eq. (97)) for each considered envelope that are used in this work are reported in Figure 6.4 with the solar factors of the glazed surfaces $\left(g_{\mathrm{gl}}\right)$. All the adopted thermo-physical properties were calculated from the values reported in international standards [300], technical handbooks [301] or technical datasheets of commercial products. 


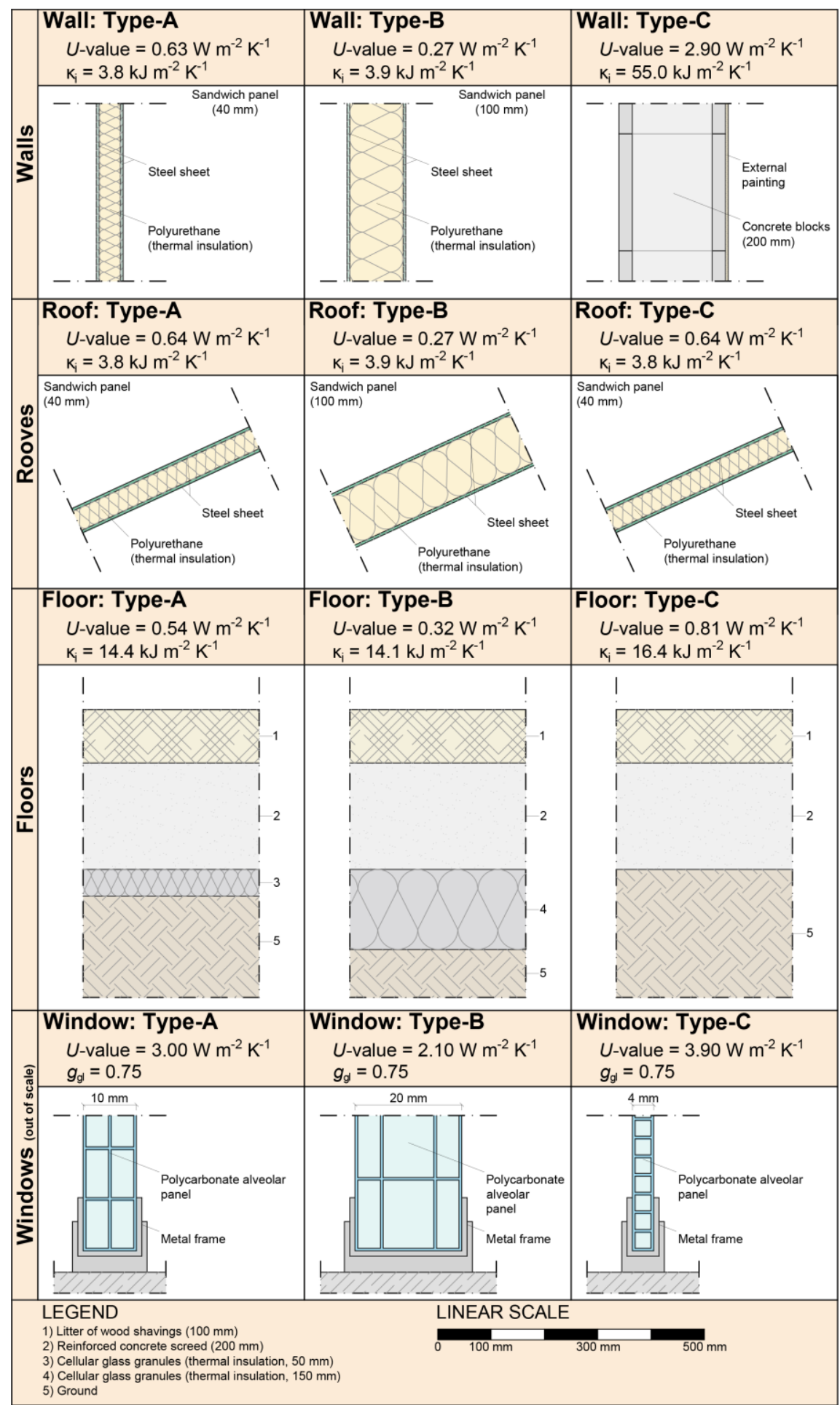

Figure 6.4 - Details of the building components of the three analyzed envelope types (A, B and C). The stationary thermal transmittances ( $U$-value), the internal areal heat capacities $\left(\kappa_{\mathrm{i}}\right)$ and the solar factors of the glazed surfaces $\left(g_{\mathrm{gl}}\right)$ are reported.

The walls of type-A and type-B envelopes and all the rooves are sandwich panels made of a double pre-painted steel sheet with the thermal insulation layer interposed (high density spread polyurethane). The panel thickness changes according to the envelope type. The walls of type-C envelope are made up of hollow concrete blocks. The outdoor surface of all the walls is painted of a light color (solar 
absorption coefficient $\alpha_{\text {sol }}$ equal to 0.3 ), while the roof has an intermediate colour $\left(\alpha_{\text {sol }}=0.6\right)$.

The floors of the three envelopes are made by a reinforced concrete screed with litter of wood shavings above. The thermo-physical properties of the litter are the ones presented in [302]. A thermal insulation layer of cellular glass granules is considered below the concrete screed in type-A and type-B envelopes (with different thickness), while the floor of type-C envelope has no thermal insulation.

The windows of the broiler house are considered with metal frames and polycarbonate alveolar panels of different thicknesses. The value of $g_{\mathrm{gl}}$ is 0.75 for all the envelopes.

\section{Outdoor weather conditions}

The energy performance of the analyzed broiler house was assessed considering different outdoor weather conditions of the European context. The chosen weather conditions are proper of geographical locations characterized by the highest poultry production in Europe and are Poland (PL), France (FR), United Kingdom (UK), Germany (DE), Spain (ES), and Italy (IT). In these six countries more than $70 \%$ of the European poultry meat is produced [303]. For each country, the region with the highest poultry production at a national level was individuated to perform the simulations. A reference city representative of each one of these regions was selected for obtaining the Typical Meteorological Year (TMY), needed for the simulation inputs. In Table 6.2, the six selected locations with their countries and geographical regions are presented. In addition, the main parameters useful to characterize their weather conditions are shown. The reference locations are characterized by different values of average annual outdoor air temperature $\left(\bar{\theta}_{\text {air_o }}\right)$ and annual total solar radiation on horizontal surface $\left(H_{\text {sol_hor }}\right)$. In the framework of the present work, $\bar{\theta}_{\text {air_o }}$ is the arithmetic mean of the hourly $\theta_{\text {air_o }}$ values over the entire year, while $H_{\text {sol_hor }}$ is the integral of the hourly values of solar irradiance over the entire year. From Table 6.2, it stands out that Barcelona is characterized by the highest value of $\bar{\theta}_{\text {air_o }}\left(15.7^{\circ} \mathrm{C}\right)$ and the highest $H_{\text {sol_hor }}\left(5.2 \mathrm{GJ} \mathrm{m}^{-2} \mathrm{y}^{-1}\right)$. Warsaw results the location with the lowest $\bar{\theta}_{\text {air_o }}\left(8.4^{\circ} \mathrm{C}\right)$, while Finninglay and Bremen are the ones characterized by the lowest $H_{\text {sol_hor }}\left(3.4 \mathrm{GJ} \mathrm{m}^{-2} \mathrm{y}^{-1}\right)$.

Table 6.2 - The locations used in this work with the reference cities, acronyms, and geographical regions. The average annual outdoor air temperature $\left(\bar{\theta}_{\text {air_o }}\right)$ and the annual total solar radiation on horizontal surface $\left(H_{\text {sol hor }}\right)$ are shown for each location.

\begin{tabular}{ccccc}
\hline Location (reference city) & Acronym & $\begin{array}{c}\text { Geographical } \\
\text { region }\end{array}$ & $\begin{array}{c}\overline{\boldsymbol{\theta}}_{\text {air_o }} \\
{\left[{ }^{\circ} \mathbf{C}\right]}\end{array}$ & $\begin{array}{c}\boldsymbol{H}_{\text {sol_hor }} \\
{\left[\mathbf{G J ~ m}^{-\mathbf{2}} \mathbf{y}^{\mathbf{- 1}}\right]}\end{array}$ \\
\hline Poland (Warsaw) & PL & Central Europe & 8.4 & 3.6 \\
France (Brest) & FR & Western Europe & 11.2 & 3.9 \\
United Kingdom (Finningley) & UK & Western Europe & 9.5 & 3.4 \\
Germany (Bremen) & DE & Central Europe & 8.9 & 3.4 \\
Spain (Barcelona) & ES & Southwest Europe & 15.7 & 5.2 \\
Italy (Verona) & IT & Southern Europe & 12.3 & 3.9 \\
\hline
\end{tabular}


Considering the six different locations and the three envelope types (A, B and C), 18 simulation scenarios are formulated. Each scenario is identified by a code in which the first two characters indicate the reference country (acronyms from Table 6.2), while the last one, separated by a dash, indicates the considered envelope type (A, B or C, Figure 6.4).

\subsubsection{Financial evaluation: global cost methodology}

After the delivered and primary energy analyses, the scenarios are analyzed from a financial point of view to estimate how the considered types of envelope affect the global cost of the broiler house over its lifespan. This analysis is performed in compliance with the EN 15459 international standard [304]. The global cost $\left(C_{G}\right)$, here referred to the unit of useful floor area, is the sum of the present value of all the costs estimated during the lifespan $\left(\tau_{\mathrm{ls}}\right)$ of the broiler house and reads

$$
C_{\mathrm{G}}\left(\tau_{\mathrm{ls}}\right)=C_{\mathrm{I}}+\sum_{l=1}^{n_{\text {com }}}\left[\sum_{q=1}^{\tau_{\mathrm{ls}}}\left(C_{\mathrm{a}, \mathrm{q}, \mathrm{l}} \cdot R_{\mathrm{d}, \mathrm{q}}\right)-V_{\mathrm{f}, \tau_{\mathrm{ls}}, \mathrm{l}}\right] \quad\left[€ \mathrm{~m}^{-2}\right]
$$

where $C_{\mathrm{I}}$ is the initial investment cost $\left(€ \mathrm{~m}^{-2}\right), C_{\mathrm{a}, \mathrm{q}, \mathrm{l}}$ is the annual cost regarding the $l$-th component of cost calculated at the $q$-th year $\left(€ \mathrm{~m}^{-2}\right)$ of broiler house lifespan while $V_{\mathrm{f}, \tau_{\mathrm{ls}},}$ is the final value of the $l$-th component at the end of its lifespan $\tau_{\mathrm{ls}}\left(€ \mathrm{~m}^{-2}\right)$. The term $R_{\mathrm{d}, \mathrm{q}}$ is the discount rate (\%) introduced to refer the value of money of the $q$-th year at the present. It reads

$$
R_{\mathrm{d}}(q)=\left(\frac{1}{1+R_{\mathrm{R}}}\right)^{q} \cdot 100 \quad[\%]
$$

where $R_{\mathrm{R}}$ is the real interest rate (\%) that considers the market and inflation rates. In this work, The global cost $C_{\mathrm{G}}$ of each proposed solution is evaluated considering $\tau_{\mathrm{ls}}$ equal to 30 years and $R_{\mathrm{R}}$ equal to $3.5 \%$ [305].

The initial investment cost $\left(C_{\mathrm{I}}\right)$ for IT-A, IT-B, and IT-C scenarios was estimated through an analysis on the Italian market aimed at finding the final costs (product plus installation plus taxes) of each considered element of the envelope and climate control system of the broiler house. These costs are presented in Table 6.3 referring to the unit of useful floor area. Other costs, such as feeders and lighting system, are not considered since they negligibly affect the energy performance of the broiler house. 
Table 6.3 - Costs of envelope and the climate control system elements and initial investment cost $\left(C_{\mathrm{I}}\right)$ referred to unit of useful floor area.

\begin{tabular}{cccc}
\hline Element & $\begin{array}{c}\text { IT-A } \\
{\left[€ \mathbf{~ m}^{-2}\right]}\end{array}$ & $\begin{array}{c}\text { IT-B } \\
{\left[€ \mathbf{~ m}^{-2}\right]}\end{array}$ & $\begin{array}{c}\text { IT-C } \\
{\left[€ \mathbf{~ m}^{-2}\right]}\end{array}$ \\
\hline Walls & 17.49 & 32.07 & 21.60 \\
Roof & 45.25 & 76.95 & 45.25 \\
Floor & 107.93 & 208.43 & 53.72 \\
Windows & 4.03 & 5.03 & 3.39 \\
Fans & 4.37 & 4.37 & 4.37 \\
Gas air heaters & 6.51 & 6.51 & 7.81 \\
Evaporative pads & 3.30 & 3.30 & 3.30 \\
Pad pumps and pipelines & 4.55 & 4.55 & 4.55 \\
\hline$C_{\mathrm{I}}$ & 193.43 & 341.21 & 143.99 \\
\hline
\end{tabular}

The $C_{\mathrm{I}}$ values for the other considered countries can be estimated assuming that the difference between the $C_{\mathrm{I}}$ values of two countries depends on the difference between their purchasing powers due to the fluctuations in currency exchange rates, as reported in Eurostat [306]. Hence, the $C_{\mathrm{I}}$ values for the other considered countries are obtained by multiplying $C_{\mathrm{I}}$ values for the Italian context -last row of Table 6.3by the dimensionless cost conversion factor $\gamma_{\mathrm{PLI}}$. This factor is the ratio between the construction price level of the considered European country and the Italian one. In this work, $\gamma_{\mathrm{PLI}}$ values are obtained by elaborating the Price Level Indices for non-residential buildings construction provided by Eurostat [306]. The considered $\gamma_{\text {PLI }}$ values are presented in Table 6.4.

Table 6.4 - Considered cost conversion factor $\left(\gamma_{\mathrm{PLI}}\right)$ and costs of thermal $\left(C_{\mathrm{th}}\right)$ and electrical $\left(C_{\mathrm{el}}\right)$ energy, including taxes.

\begin{tabular}{cccc}
\hline Country & $\begin{array}{c}\boldsymbol{\gamma}_{\text {PLI }} \\
{[-]}\end{array}$ & $\begin{array}{c}\boldsymbol{C}_{\text {th }} \\
{[€ \mathbf{k W h}}\end{array}$ & $\begin{array}{c}\boldsymbol{C}_{\text {el }} \\
{\left[€ \mathbf{k W h}_{\mathrm{el}}^{-\mathbf{1}}\right]}\end{array}$ \\
\hline PL & 0.78 & 0.04 & 0.15 \\
FR & 1.23 & 0.08 & 0.19 \\
UK & 1.38 & 0.05 & 0.22 \\
DE & 1.67 & 0.06 & 0.30 \\
ES & 0.95 & 0.07 & 0.22 \\
IT & 1.00 & 0.07 & 0.22 \\
\hline
\end{tabular}

The considered annual costs $\left(C_{\mathrm{a}}\right)$ over the broiler house lifespan are due to energy and due to the replacement of the elements of climate control system. Other annual costs, such as insurances and ordinary maintenance, are considered out of the scope of this work. The annual cost of energy is estimated multiplying the yearly thermal and electrical energy consumption obtained from the simulations by the cost of thermal $\left(C_{\mathrm{th}}\right)$ and electrical $\left(C_{\mathrm{el}}\right)$ energy for the considered country. The costs of energy adopted in this work were obtained from Eurostat [277,278] and are reported in Table 6.4. The annual cost of element replacement for climate control system is estimated considering the initial costs presented in Table 6.3 and estimating a lifespan of 15 years for fans, gas air heaters and pumps and pipeline of the evaporative cooling system. The lifespan of the evaporative pads was estimated 
equal to five years. At the end of the broiler house lifespan, no final value $V_{\mathrm{f}}$ (Eq. (98)) is considered for envelope and climate control system elements.

\subsection{Results and discussion}

Each one of the 18 considered scenarios is simulated in standardized conditions using the calibrated energy model. The results of the simulations are here analyzed to identify the best envelope solution in terms of delivered and the primary energy performance. In addition, the results are compared in terms of global cost and overheating index.

\subsubsection{Delivered energy approach}

The delivered energy consumption is evaluated considering the thermal energy consumption for heating $\left(E_{\mathrm{th}}\right)$, the electrical energy consumption for ventilation $\left(E_{\text {el_ven }}\right)$ and for evaporative cooling $\left(E_{\text {el_ec }}\right)$. The values of $E_{\text {th }}$ and $E_{\text {el_ven }}$ are calculated by the model considering the efficiency of the heating system and the features of the ventilation system, as described in section 5.4.3. The value of $E_{\text {el_ec }}$ is calculated by the model activation time and the electrical power of the circulation pumps.

\section{Thermal and electrical energy consumption}

In the bar charts of Figure $6.5, E_{\mathrm{th}}, E_{\text {el_ven }}$ and $E_{\text {el_ec }}$ are presented normalized per unit of floor area. The graph shows that important differences in terms of $E_{\text {th }}$ (Figure 6.5a) stand out among the analyzed scenarios. The highest $E_{\text {th }}$ values are from PL-C (163.7 $\left.\mathrm{kWh}_{\mathrm{th}} \mathrm{m}^{-2} y^{-1}\right)$, DE-C $\left(142.7 \mathrm{kWh}_{\mathrm{th}} \mathrm{m}^{-2} y^{-1}\right)$ and UK-C $\left(119.0 \mathrm{kWh}_{\mathrm{th}} \mathrm{m}^{-2} y^{-1}\right)$ scenarios, respectively. The lowest values of $E_{\mathrm{th}}$ result from ES-B (19.6 $\left.\mathrm{kWh}_{\mathrm{th}} \mathrm{m}^{-2} y^{-1}\right)$, FR-B $\left(29.3 \mathrm{kWh}_{\mathrm{th}} \mathrm{m}^{-2} y^{-1}\right)$ and ES-A (36.3 $\mathrm{kWh}_{\mathrm{th}} \mathrm{m}^{-2} y^{-1}$ ). The lowest values of $E_{\mathrm{th}}$ (ES-B scenario) is $88 \%$ lower than the highest $E_{\text {th }}$ (PL-C scenario) highlighting the effects that outdoor weather conditions and envelope type have in terms of thermal energy consumption of broiler houses.

Looking at the values of $\bar{\theta}_{\text {air_o }}$ presented in Table 6.2 , it stands out that the highest $E_{\text {th }}$ values come from the outdoor weather conditions characterized by the lowest $\bar{\theta}_{\text {air_o }}$. Solar radiation seems to not have the same influence of $\theta_{\text {air_o }}$ on $E_{\text {th }}$ because, even though PL-C is characterized by a slightly higher value of $H_{\text {sol_hor }}$ than DE-C, its $E_{\mathrm{th}}$ is considerably higher than the one of DE-C. An interesting analysis in this sense is the comparison between the sensible heat load from broilers with the heat load from solar radiation. Considering the last day of the production cycle in August, the maximum solar heat load that should be removed from the enclosure per unit of useful floor area is $47 \mathrm{~W}$ in scenario ES-C. At the same moment, the sensible heat load due to the animals is $176 \mathrm{~W} \mathrm{~m}^{-2}$ of useful floor area, a value that is nearly four times higher the one of the solar heat load. This difference means that sensible heat load from animals represents the major issue for 
cooling ventilation broiler houses, even in mild climates such as the one of ES-C scenario. Please note that in this work, the total solar radiation on any surface was calculated from the hourly values of direct normal radiation and diffuse horizontal solar radiation reported in the TMY adopting the transposition model of ASHRAE [301]. The calculation of the solar gains from the solar irradiance on opaque and transparent envelope components was performed in compliance with EN ISO 13790 standard [211].

The results of the simulations show that, from the delivered energy point of view, the adoption of the high-insulation and low-massive building envelope (typeB) represents an interesting strategy to reduce $E_{\text {th }}$ in all the considered weather conditions, because the type-B envelope entails the lowest $E_{\mathrm{th}}$. The relative differences between the thermal energy performance of the considered envelopes in the same weather conditions are important. The choice of a high-insulation building envelope (type-B) reduces $E_{\text {th }}$ between 63 and 67\% if compared to a noninsulated envelope (type-C). The increase of the thermal insulation layer, from typeA to type-B envelope, entails a decrease of $E_{\text {th }}$ between 41 and $46 \%$.

High-insulation building envelope (type-B) resulted the best option for decreasing $E_{\text {th }}$, but the better thermal insulation properties favor the overheating of the enclosure. Consequently, a higher electrical energy consumption for ventilation $E_{\text {el_ven }}$ and evaporative cooling $E_{\text {el_ec }}$ is expected compared to the other envelope types. In Figure $6.5 \mathrm{~b}$, the electrical energy consumptions $E_{\text {el_ven }}$ and $E_{\text {el_ec }}$ are presented and the bar chart indicates that, actually, $E_{\text {el_ven }}$ is higher when type-B envelope is considered. The highest value of $E_{\text {el_ven }}$ comes from Spain (ES-B, $15.5 \mathrm{kWh}_{\mathrm{el}} \mathrm{m}^{-2} y^{-1}$ ) while the lowest one from United Kingdom (UK-C, $\left.5.8 \mathrm{kWh}_{\mathrm{el}} \mathrm{m}^{-2} y^{-1}\right)$. Even in this case, the higher $E_{\mathrm{el} \_v e n}$ values come from the weather conditions characterized by the higher $\bar{\theta}_{\text {air_o }}$, namely Spain $\left(15.7^{\circ} \mathrm{C}\right)$ and Italy $\left(12.3^{\circ} \mathrm{C}\right)$.

The $E_{\text {el_ec }}$ values presented in Figure $6.5 \mathrm{~b}$ are the same for each considered geographical location regardless of the analyzed envelope type. This is because the adopted energy model simulates the activation of the evaporative cooling only depending on the temperature difference between $\theta_{\text {set_c }}$ and $\theta_{\text {air_o }}$. The bar chart of Figure $6.5 \mathrm{~b}$ shows greater $E_{\mathrm{el} \_e c}$ for those scenarios where the $E_{\mathrm{el} \_v e n}$ is higher, such as Spain and Italy. The estimated $E_{\text {el_ec }}$ values are considerably smaller than $E_{\text {el_ven }}$, being $2.5 \mathrm{kWh}_{\mathrm{el}} \mathrm{m}^{-2} y^{-1}$, or lower, for all the considered scenarios.

The total electrical energy consumption $E_{\mathrm{el}}$ (sum of $E_{\text {el_ven }}$ and $E_{\text {el_ec }}$ ) ranges between $18.0 \mathrm{kWh}_{\mathrm{el}} \mathrm{m}^{-2} y^{-1}$ and $6.4 \mathrm{kWh}_{\mathrm{el}} \mathrm{m}^{-2} y^{-1}$. The adoption of a low insulated envelope (type-C) decreases it from 6 to $13 \%$ if compared to a highinsulation envelope (type-B). 


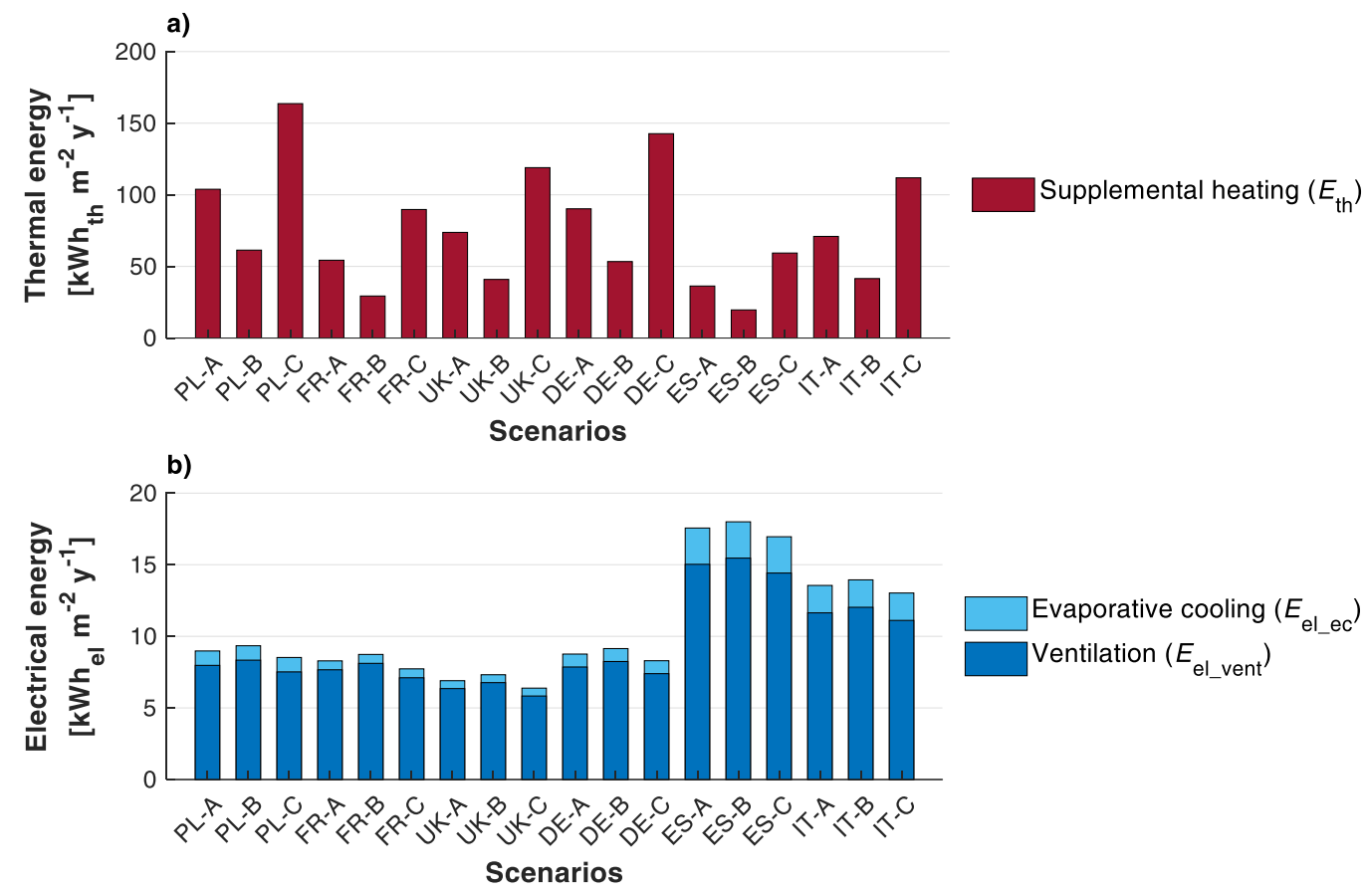

Figure 6.5 - Thermal ( $E_{\text {th }}$, figure a), and electrical energy consumption (figure b) both for ventilation $\left(E_{\text {el_ven }}\right)$ and evaporative cooling $\left(E_{\text {el_ec }}\right)$ from the 18 scenarios.

\section{Reference values of delivered energy consumption}

The delivered energy consumption values are now used to provide reference values about the use of energy in broiler houses. Similar values are interesting from the scientific point of view with a perspective on the improvement of the energy efficiency of broiler production, but very few of them are present in literature. Most of the existing reference values, in fact, refers to specific case studies or geographical contexts, as done by Hörndahl [307] for the Swedish context, by the Technical Institute of Poultry [308] for France, and by Rossi et al. [309] for Italy. In addition, those reference values were not assessed in standardized conditions, a feature that may jeopardize their reliability. By contrast, the reference values present in this section were calculated in standardized conditions, refer to different European context and consider different types of building envelope. Nevertheless, more accurate results would be obtained performing simulations using Monte Carlo method to consider a higher variations of boundary conditions. Furthermore, sensitivity analyses could be performed to better investigate the influence of the various parameters on the final results.

The results obtained from the simulated scenarios are normalized on the $\mathrm{kg}_{\text {meat }}$ and grouped to obtain ranges of delivered energy consumption for climate control. This normalization is necessary to make the results independent from the assumptions made for the analysis, such as the farming features. Furthermore, the adopted unit of measure ( $\mathrm{Wh} \mathrm{kg}_{\text {meat }}^{-1}$ ) is useful for engineers and farmers since they can refer production costs and revenues to the unit of final product. The saleable meat from each broiler is calculated considering a carcass yield, percentage of the saleable meat over the final live weight, of $73 \%$. Consequently, a meat production 
of $2.60 \mathrm{~kg}_{\text {meat }}$ per harvested broiler is estimated. The main limitation in the formulation of these reference values is the estimation of the broiler final live weight that does not consider potential decrease of weight gain due to, for example, heat stress. This issue could be considered in future works using the formulations provided by St-Pierre, Cobanov, \& Schnitkey [98].

In Figure 6.6, the ranges of the specific thermal $E_{\text {meat_th }}$ (Figure 6.6a) and electrical energy consumption $E_{\text {meat_el }}$ (Figure $6.6 \mathrm{~b}$ ) referred to the selected countries are presented. The values of $E_{\text {meat_th }}$ and $E_{\text {meat_el }}$ were calculated dividing the yearly thermal and electrical energy consumption by the meat production over the entire year. The presented ranges consider the minimum and the maximum values of $E_{\text {meat_th }}$ and $E_{\text {meat_el }}$ (sum of electrical energy consumption for ventilation and evaporative cooling) of each country considering the three envelope types.
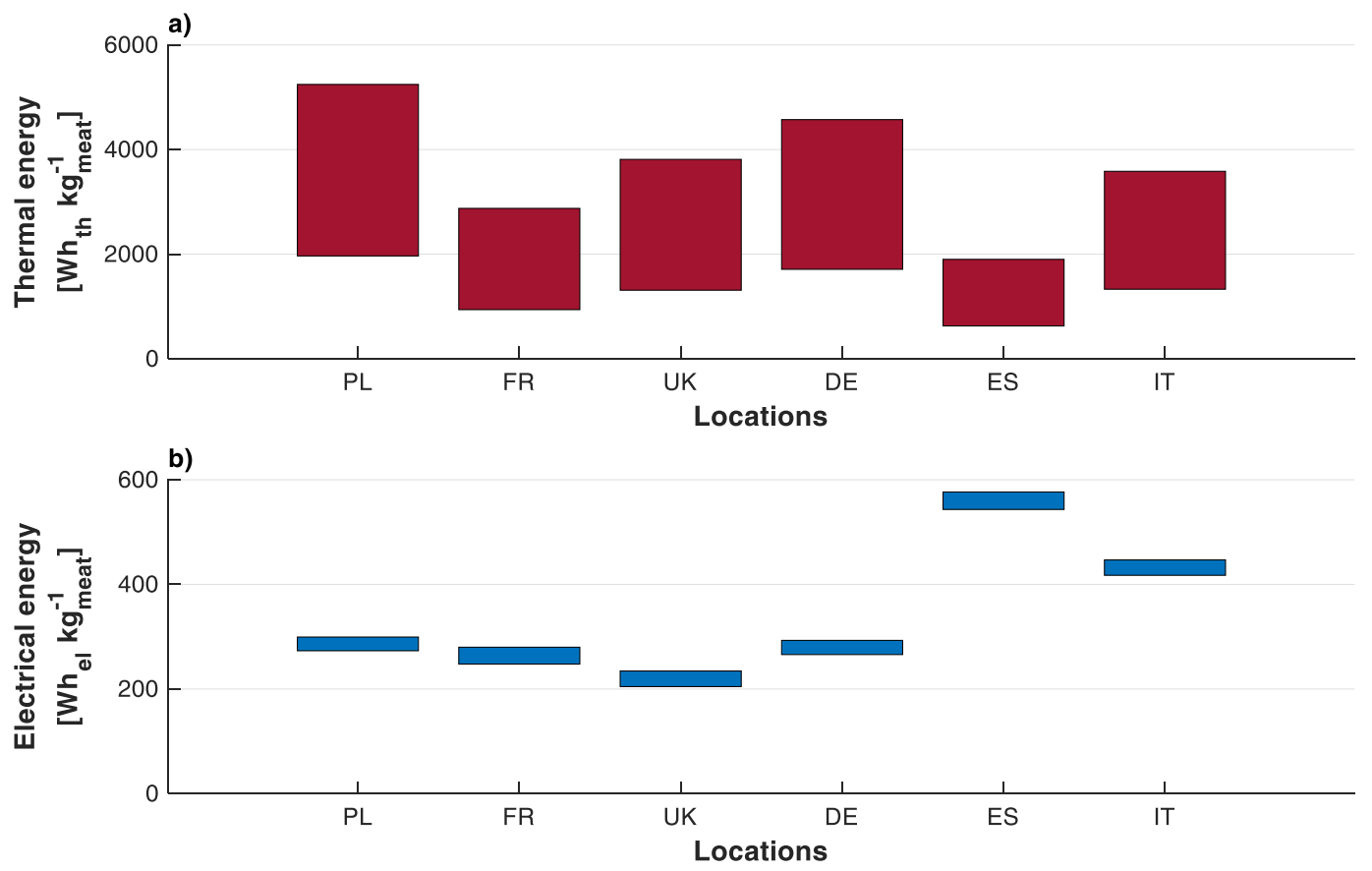

Figure 6.6 - Ranges of specific thermal ( $E_{\text {meat_th }}$, figure a) and electrical energy consumption ( $E_{\text {meat_el }}$, figure b) for the considered locations.

The range of $E_{\text {meat_th }}$ goes from $628 \mathrm{Wh}_{\text {th }} \mathrm{kg}_{\text {meat }}^{-1}$ (Spain) to $5,245 \mathrm{Wh}_{\mathrm{th}} \mathrm{kg}_{\text {meat }}^{-1}$ (Poland). Three countries -France, United Kingdom, and Italyare in the range from 940 to $3,812 \mathrm{Wh}_{\text {th }} \mathrm{kg}_{\text {meat }}^{-1}$, while the $E_{\text {meat_th }}$ of Germany and Poland is between the range $1,711-5,245 \mathrm{Wh}_{\mathrm{th}} \mathrm{kg}_{\text {meat }}^{-1}$. Spain is the country with the narrower range of $E_{\text {meat }}$ th that goes from 628 to $1,901 \mathrm{Wh}_{\text {th }} \mathrm{kg}_{\text {meat }}^{-1}$.

The ranges presented in Figure $6.6 \mathrm{~b}$ are narrower and of an order of magnitude lower than the ones of Figure 6.6a. The difference between the highest and the lowest value of each country presented in Figure 6.6b is between 26 and $33 \mathrm{Wh}_{\mathrm{el}} \mathrm{kg}_{\text {meat }}^{-1}$. The lowest $E_{\text {meat_el }}$ is the one from Great Britain $\left(205 \mathrm{Wh}_{\mathrm{el}} \mathrm{kg}_{\text {meat }}^{-1}\right)$ while the greatest one is from Spain $\left(577 \mathrm{Wh}_{\mathrm{el}} \mathrm{kg}_{\text {meat }}^{-1}\right)$. $E_{\text {meat_el }}$ of four countries -Poland, France, United Kingdom, and Germany- is 
between 205 and $299 \mathrm{Wh}_{\mathrm{el}} \mathrm{kg}_{\text {meat }}^{-1}$. The $E_{\text {meat_el }}$ value from Italy is between 417 and $447 \mathrm{Wh}_{\mathrm{el}} \mathrm{kg}_{\text {meat }}^{-1}$, while Spain has the wider $E_{\text {meat_el }}$ range (543 $577 \mathrm{Wh}_{\mathrm{el}} \mathrm{kg}_{\text {meat }}^{-1}$ ).

\subsubsection{Primary energy approach}

The previous analysis assessed the delivered energy consumption. Type-B envelope resulted the best solution to decrease $E_{\mathrm{th}}$, while type-C envelope was the worst one by far in all the considered locations. On the contrary, type-C envelope was characterized by the best performance considering the electrical energy consumption for ventilation and evaporative cooling. Type-A envelope is the intermediate solution for both thermal and electrical energy consumption.

To identify the best global solution, the primary energy performance is assessed for the 18 scenarios. In this way, the thermal and electrical energy consumption can be correctly weighted considering their respective energy overheads for extracting, refining, converting, and transporting energy.

\section{Primary energy consumption}

The conversion from delivered energy to primary energy can be performed according to Eqs. (90)-(92) using the total (renewable and non-renewable) primary energy consumption factors $f_{\mathrm{p}_{-} \text {th_tot }}$ and $f_{\mathrm{p}_{\text {_el_tot }}}$ reported in Table 6.5. The energy carriers that are considered are natural gas and electrical energy from the national grid. From Table 6.5, two main aspects can be highlighted. The first aspect is that $f_{\mathrm{p}_{-} \text {el_tot }}$ is always higher than $f_{\mathrm{p}_{-} \text {th_tot }}$. This difference is since the production and transport of electrical energy is characterized by higher energy overheads than the thermal one. The second aspect is that quite important differences stand out among the considered countries especially concerning $f_{\mathrm{p}_{-} \text {el_tot }}$. These differences could be attributable to the different energy mixes proper of each country and, consequently, different energy overheads.

Table 6.5 - Total -renewable and non-renewable- primary energy factors for thermal $\left(f_{\mathrm{p}_{-} \text {th_tot }}\right)$ and electrical $\left(f_{\text {p_el_tot }}\right)$ energy.

\begin{tabular}{|c|c|c|c|}
\hline Country & $\begin{array}{c}\boldsymbol{f}_{\mathbf{p}_{-} \text {th_tot }} \\
\text { (natural gas) } \\
{\left[\mathbf{k W h} \mathbf{W}_{\mathbf{p}} \mathbf{k} \mathbf{W h}_{\mathrm{th}}^{-1}\right]}\end{array}$ & $\begin{array}{c}\boldsymbol{f}_{\mathbf{p}_{\text {_el_tot }}} \\
\text { (electrical grid) } \\
{\left[\mathbf{k W h} \mathbf{W W h}_{\mathrm{p}} \mathbf{k} \mathbf{h}_{\mathrm{el}}^{-1}\right]}\end{array}$ & Source \\
\hline Poland & 1.10 & 3.03 & {$[310]$} \\
\hline France & 1.00 & 2.58 & [311] \\
\hline United Kingdom & 1.02 & 2.92 & [312] \\
\hline Germany & 1.10 & 2.80 & [313] \\
\hline Spain & 1.195 & $2.368^{\mathrm{a}}$ & [314] \\
\hline Italy & 1.05 & 2.42 & [315] \\
\hline
\end{tabular}

In Figure $6.7, E_{\mathrm{p}_{-} \text {glob }}$ and its shares $E_{\mathrm{p}_{-} \text {th }}$ and $E_{\mathrm{p}_{-} \text {el }}$ from the analysed scenarios are presented. The graph shows that PL-C is characterized by the highest $E_{\text {p_glob }}$ 
(205.9 $\left.\mathrm{kWh}_{\mathrm{p}} \mathrm{m}^{-2} \mathrm{y}^{-1}\right)$. This is since the considered Polish weather conditions entail a considerable high $E_{\mathrm{th}}$ that represents around $87 \%$ of $E_{\mathrm{p} \_ \text {glob }}$.

In all the considered weather conditions, type-B envelope provides the best global primary energy performance entailing the minimum $E_{\mathrm{p}_{\text {glob }}}$. In particular, the scenario characterized by the lowest value of $E_{\mathrm{p}_{\text {gglob }}}$ is FR-B $\left(51.9 \mathrm{kWh}_{\mathrm{p}} \mathrm{m}^{-2} \mathrm{y}^{-1}\right)$. This scenario, in fact, is characterized by a quite low $E_{\text {th }}$ the lowest one after ES-B- that is not increased by $f_{\mathrm{p}_{-} \text {th_tot }}$ that, for France, is equal to $1 \mathrm{kWh}_{\mathrm{p}} \mathrm{kWh}_{\mathrm{el}}^{-1}$. Furthermore, $\bar{\theta}_{\text {air_o }}$-the highest one after ES and IT- entails a reduced $E_{\text {el_vent }}\left(8.1 \mathrm{kWh}_{\mathrm{el}} \mathrm{m}^{-2} \mathrm{y}^{-1}\right)$ that, converted in $E_{\mathrm{p}_{-} \text {el }}$, represents $43 \%$ of $E_{\text {p_glob. }}$.

The analysis of the primary energy consumption highlights that type-B envelope is the actual best solution to decrease the energy consumption for climate control of the analyzed broiler house in all the outdoor weather conditions. The thermal energy analysis showed that type-B envelope can reduce $E_{\text {th }}$ between 63 and $67 \%$ if compared to type-C envelope. This result is quite misleading since the actual decrease of that energy consumption (evaluated through the primary energy consumption) is lower, being between 41 and 55\%.

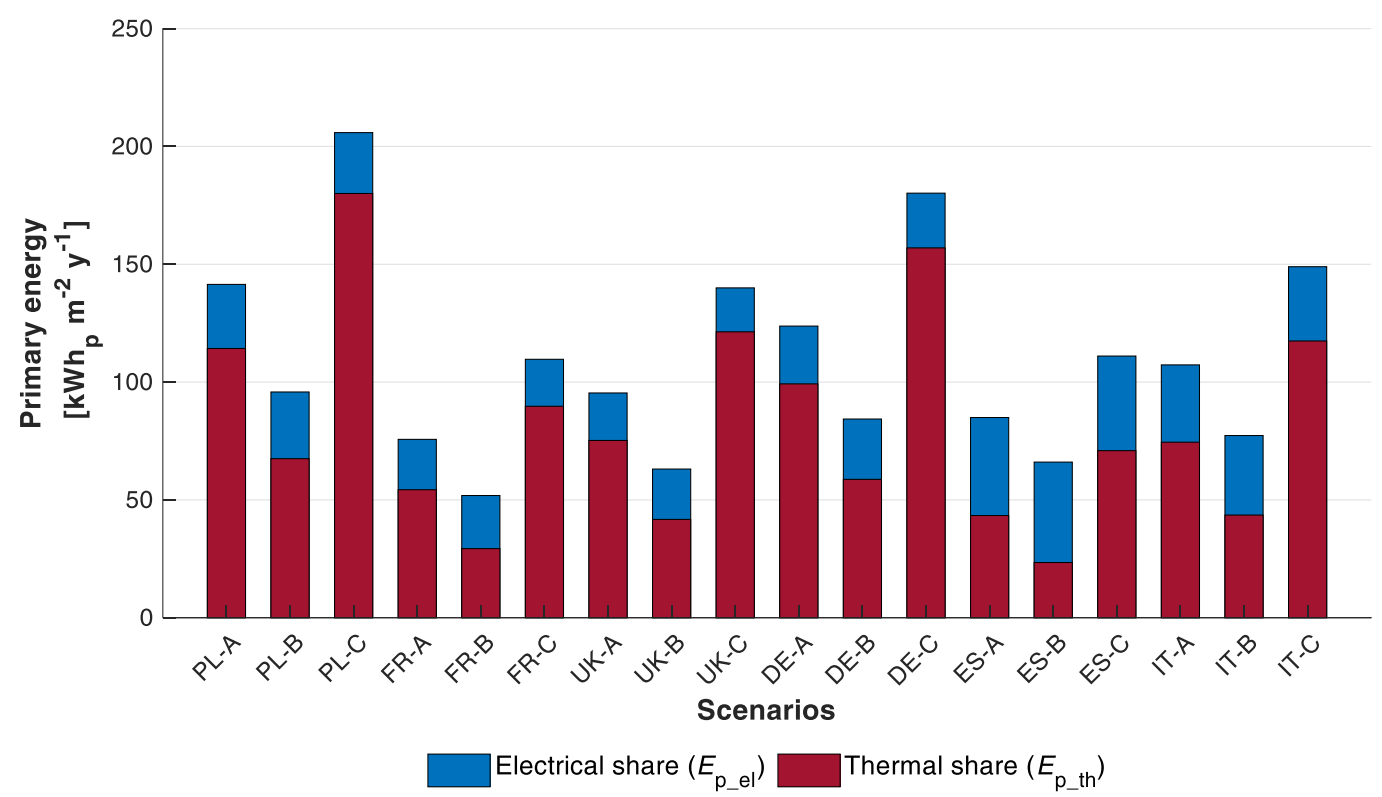

Figure 6.7 - Primary energy consumption $E_{\mathrm{p} \_ \text {glob }}$ of each scenario. In addition, the energy shares due to electrical $\left(E_{\mathrm{p}_{-} \mathrm{el}}\right)$ and thermal $\left(E_{\mathrm{p}_{-} \text {th }}\right)$ energy consumptions are shown.

The values of $E_{\text {p_glob }}$ presented in Figure 6.7 refer to the entire year but each production cycle could be characterized by considerably different values of primary energy consumption, if compared to the other cycles, depending on the period of the year in which is carried out.

To analyze these differences, the global primary energy consumption of each production cycle $E_{\text {cycle_p_glob }}\left(\mathrm{kWh}_{\mathrm{p}} \mathrm{m}^{-2}\right.$ cycle $\left.^{-1}\right)$ from PL-C and ES-B scenarios are shown in Figure 6.8. The comparison between PL-C and ES-B is interesting 
since these scenarios are characterized by the highest $E_{\mathrm{p}_{-} \text {th }}$ and $E_{\mathrm{p}_{-} \mathrm{el}}$, respectively. The sum of $E_{\text {cycle_p_glob }}$ of each production cycle is equal to $E_{\mathrm{p}_{-} \text {glob }}$ reported in Figure 6.7. In Figure 6.8, the primary energy shares due to thermal $E_{\text {cycle_p_th }}$ and electrical $E_{\text {cycle_p_el }}$ energy are reported. In addition, the average $E_{\text {cycle_p_glob }}$ calculated over the six production cycles is provided for both the considered scenarios.

The bar chart of Figure 6.8 shows that the average $E_{\text {cycle_p_glob }}$ values of the considered scenarios are different, being $E_{\text {cycle_p_glob }}$ of PL-C scenario around $19.8 \mathrm{kWh}_{\mathrm{p}} \mathrm{m}^{-2}$ cycle $^{-1}$ (around $87 \%$ due to $E_{\text {cycle,p,th }}$ and $13 \%$ due to $E_{\text {cycle,p,el }}$ ), while $E_{\text {cycle_p_glob }}$ of the ES-B scenario is $6.4 \mathrm{kWh}_{\mathrm{p} \mathrm{m}} \mathrm{m}^{-2}$ cycle ${ }^{-1}(35 \%$ due to $E_{\text {cycle_p_th }}$ and $65 \%$ due to $\left.E_{\text {cycle_p_el }}\right)$.

From Figure 6.8, important differences between the production cycles of the warm and the cool seasons can be highlighted. Analyzing the Polish scenario, it stands out that the production cycles of the cool season $\left(1^{\text {st }}, 2^{\text {nd }}\right.$, and $\left.6^{\text {th }}\right)$ are characterized by $E_{\text {cycle_p_tot }}$ values that are higher than $23.0 \mathrm{kWh}_{\mathrm{p}} \mathrm{m}^{-2} \mathrm{cycle}^{-1}$. This energy consumption is greater than the one from the $3^{\text {rd }}, 4^{\text {th }}$, and $5^{\text {th }}$ production cycles, that is always lower than $10.0 \mathrm{kWh}_{\mathrm{p}} \mathrm{m}^{-2}$ cycle $^{-1}$. Looking at the shares of $E_{\text {cycle_p_glob }}$, in $1^{\text {st }}, 2^{\text {nd }}, 5^{\text {th }}$ and $6^{\text {th }}$ production cycles in PL-C scenario, $E_{\text {cycle_p_th }}$ is always higher than $80 \%$ of the total, with a maximum value of $98 \%$ during the $1^{\text {st }}$ production cycle. In $3^{\text {rd }}$ and $4^{\text {th }}$ production cycles, during the warm season, $E_{\text {cycle_p_th }}$ is lower, being around $60 \%$ and $40 \%$, respectively.

In PL-C scenario, great differences stand out between the production cycles that are carried out during the warm and the cool season, while in ES-B scenario this difference is negligible. In ES-B scenario, in fact, $E_{\text {cycle_p_glob }}$ is quite constant during all the year being the minimum and the maximum values 3.9 and $8.7 \mathrm{kWh}_{\mathrm{p}} \mathrm{m}^{-2}$ cycle $^{-1}$, respectively. Another difference between the PL-C and ES-B scenarios concerns the shares of $E_{\text {cycle_p_th }}$ and $E_{\text {cycle_p_el }}$. In PL-C scenario $E_{\text {cycle_p_el }}$ is the lowest one in all the production cycles with the only exception of the $4^{\text {th }}$ one. In ES-B scenario, $E_{\text {cycle_p_el }}$ is the highest share during warm season production cycles $\left(3^{\text {rd }}, 4^{\text {th }}\right.$, and $\left.5^{\text {th }}\right)$, reaching the maximum relative value of $97 \%$ during the $4^{\text {th }}$ production cycle. 


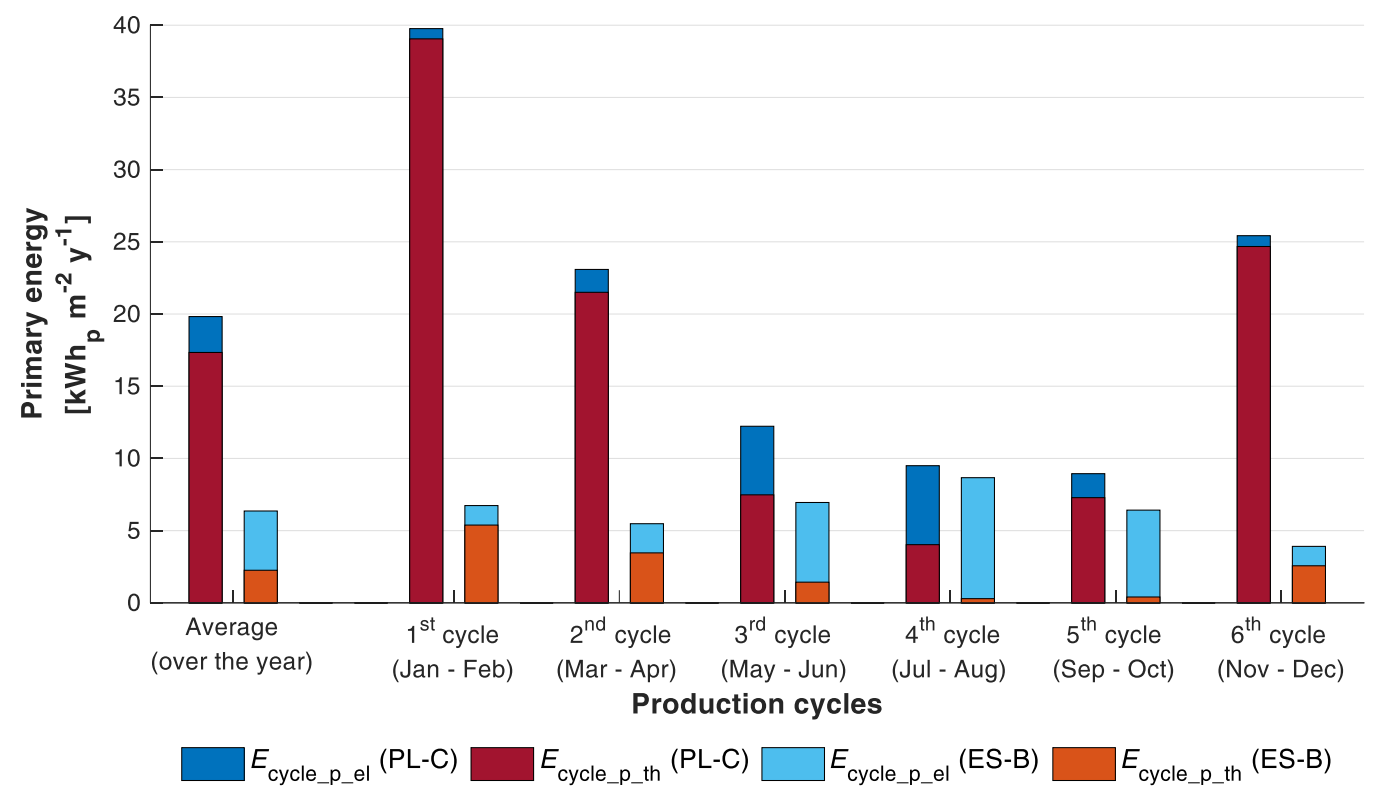

Figure 6.8 - Primary energy consumption for each production cycle $\left(E_{\text {cycle_p_glob }}\right)$ and shares due and electrical $\left(E_{\text {cycle_p_el }}\right)$ and thermal $\left(E_{\text {cycle_p_th }}\right)$ energy from PL-C and ES-B scenario.

\section{Reference values of primary energy consumption}

Reference values are provided for primary energy consumption, considering the global energy performance of the broiler houses. In Table 6.6, the primary energy consumption for climate control needed to produce a unit of mass of broiler meat $\left(E_{\text {meat_p_glob }}\right)$ is presented with the shares due to heating, ventilation, and evaporative cooling. The results show that the range of $E_{\text {meat_p_glob }}$ values goes from 1.7 to $6.6 \mathrm{kWh}_{\mathrm{p}} \mathrm{kg}_{\text {meat }}^{-1}$. Heating represents the highest share of $E_{\text {meat_p_glob }}$ in almost all the scenarios (the only exceptions is ES-B) being between 51 and 87\% of the total. Ventilation goes from 11 to $55 \%$ of $E_{\text {meat_p_glob. Evaporative cooling }}$ is equal or lower than $6 \%$ in all the scenario except for ES-A and ES-B where it represents $7 \%$ and $9 \%$, respectively. This result proves that in the assessment of the energy performance of a broiler house, the energy consumption for evaporative cooling can be neglected due to its minor relevance, especially in cool climate conditions and in presence of low-insulated envelopes. 
Table 6.6 - Primary energy consumption embedded in a unit of mass $(\mathrm{kg})$ of broiler meat $\left(E_{\text {meat_p_glob }}\right)$ and shares due to heating, ventilation, and evaporative cooling.

\begin{tabular}{ccccc}
\hline Scenario & $\begin{array}{c}\boldsymbol{E}_{\text {meat_p_glob }} \\
{\left[\mathbf{k W h} \mathbf{W h}_{\mathbf{m} \text {-1 }} \text { ] }\right.}\end{array}$ & $\begin{array}{c}\text { Heating } \\
{[\%]}\end{array}$ & $\begin{array}{c}\text { Ventilation } \\
{[\%]}\end{array}$ & $\begin{array}{c}\text { Evaporative } \\
\text { cooling } \\
{[\%]}\end{array}$ \\
\hline PL-A & 4.5 & $81 \%$ & $17 \%$ & $2 \%$ \\
PL-B & 3.1 & $71 \%$ & $26 \%$ & $3 \%$ \\
PL-C & 6.6 & $87 \%$ & $11 \%$ & $2 \%$ \\
\hline FR-A & 2.4 & $72 \%$ & $26 \%$ & $2 \%$ \\
FR-B & 1.7 & $57 \%$ & $40 \%$ & $3 \%$ \\
FR-C & 3.5 & $82 \%$ & $17 \%$ & $1 \%$ \\
\hline UK-A & 3.1 & $79 \%$ & $19 \%$ & $2 \%$ \\
UK-B & 2.0 & $66 \%$ & $31 \%$ & $3 \%$ \\
UK-C & 4.5 & $87 \%$ & $12 \%$ & $1 \%$ \\
\hline DE-A & 4.0 & $80 \%$ & $18 \%$ & $2 \%$ \\
DE-B & 2.7 & $70 \%$ & $27 \%$ & $3 \%$ \\
DE-C & 5.8 & $87 \%$ & $12 \%$ & $1 \%$ \\
\hline ES-A & 2.7 & $51 \%$ & $42 \%$ & $7 \%$ \\
ES-B & 2.1 & $36 \%$ & $55 \%$ & $9 \%$ \\
ES-C & 3.6 & $64 \%$ & $31 \%$ & $5 \%$ \\
\hline IT-A & 3.4 & $70 \%$ & $26 \%$ & $4 \%$ \\
IT-B & 2.5 & $56 \%$ & $38 \%$ & $6 \%$ \\
IT-C & 4.8 & $79 \%$ & $18 \%$ & $3 \%$ \\
\hline
\end{tabular}

\subsubsection{Financial evaluation}

The previously presented scenarios are analyzed from the financial point of view to understand the differences in terms of cost-benefit analysis. The global cost $C_{\mathrm{G}}$ of each scenario was estimated according to the methodology described in section 6.2.2.

In Figure 6.9, the shares of $C_{\mathrm{G}}$ due to envelope, climate control system and energy of each considered scenario are presented in a stacked bar chart. The graph shows that the highest overall $C_{\mathrm{G}}$ is $714 € \mathrm{~m}^{-2}$ of DE-B scenario, while the lowest one is $272 € \mathrm{~m}^{-2}$ of PL-A scenario. These absolute values can be explained with a view on Table 6.4 since $\gamma_{\mathrm{PLI}}, C_{\mathrm{th}}$ and $C_{\mathrm{el}}$ considerably affects the difference between countries. Germany, in fact, is characterized by the highest $\gamma_{\mathrm{PLI}}(1.67)$ that entails considerably higher $C_{\mathrm{I}}$ and $C_{\mathrm{a}}$ (due to climate control system replacement) than the other countries, especially, Poland where $\gamma_{\mathrm{PLI}}$ is only 0.78. A similar difference can be found analyzing $C_{\mathrm{th}}$ and $C_{\mathrm{el}}$ that are the lowest ones for Poland ( $0.04 € \mathrm{kWh}_{\mathrm{th}}^{-1}$ and $0.15 € \mathrm{kWh}_{\mathrm{el}}^{-1}$, respectively), while Germany is characterized by the highest $C_{\mathrm{el}}$.

The results of the global cost analysis presented in Figure 6.9 show that, in all the considered countries, type-B envelope is characterized by the highest $C_{\mathrm{G}}$, while type-A and type-C envelopes are characterized approximatively by the same $C_{\mathrm{G}}$, with a maximum relative difference of $8 \%$ (UK-A and UK-C scenarios). The relative difference between type-B envelope and the other two types is 
considerable, being between 29\% (IT-C) and 58\% (UK-C). The stacks of the bar chart explain why type-B envelope is characterized by a considerably high $C_{\mathrm{G}}$ although it was characterized by the best primary energy performance, as previously shown in Figure 6.7. The costs related to the building envelope, in fact, represent between $68 \%$ and $79 \%$ of $C_{\mathrm{G}}$ in the considered countries. The good energy performance of type-B envelope reflects on very low shares of $C_{\mathrm{G}}$ for energy (between $12 \%$ and $21 \%$ ) but it is not enough to make type-B envelope a good option from the financial point of view. In this sense, type-A envelope could represent a good compromise since it is a solution that guarantee a favorable primary energy performance (considerably better than the one of type-C, as visible in Figure 6.7) and a $C_{\mathrm{G}}$ similar to the one of type-C envelope, with a good impact form the financial sustainability point of view.

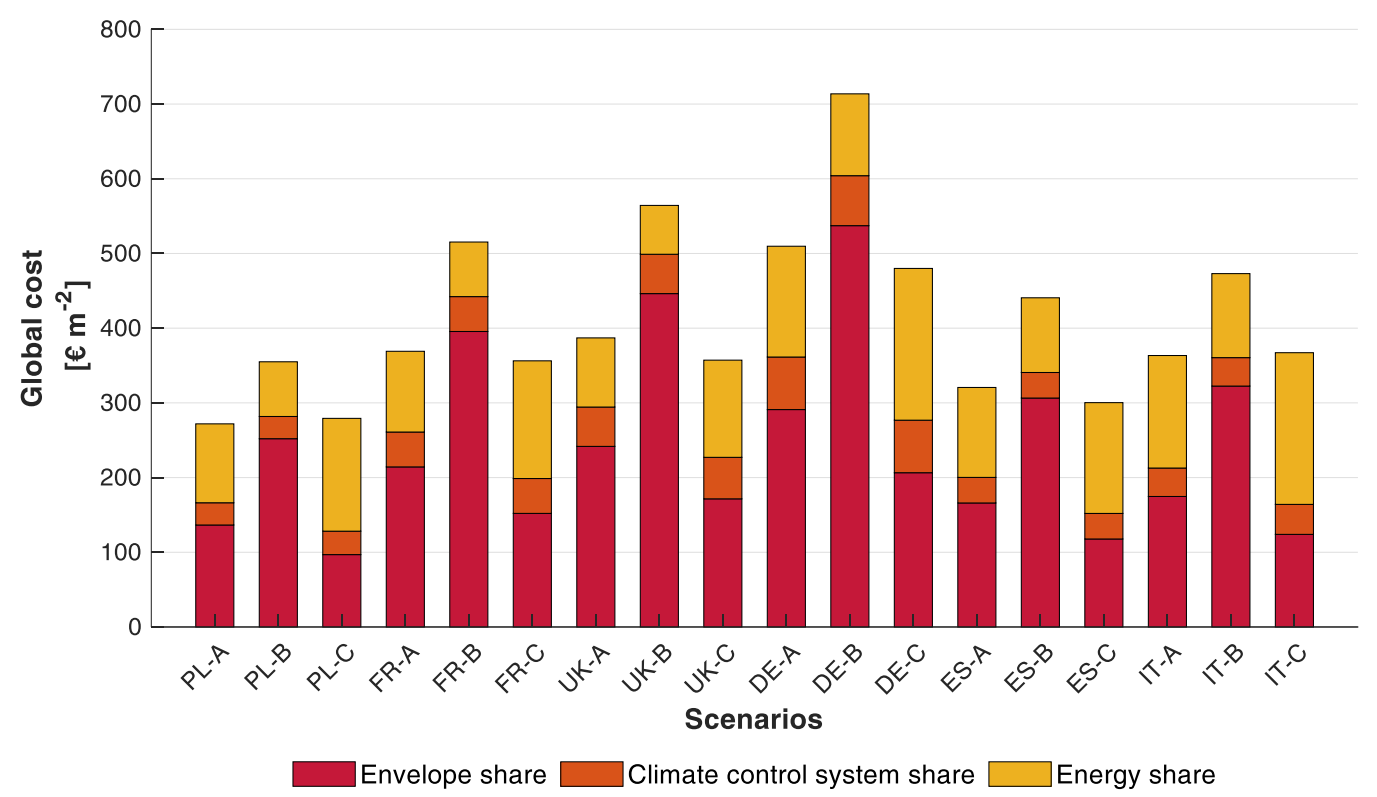

Figure 6.9 - Global cost $C_{\mathrm{G}}$ and shares due to envelope, climate control system and energy for each of the analyzed scenarios.

\subsubsection{Comparison of indoor climate conditions}

The free cooling systems with which broiler houses are usually equipped could be not able to maintain the required $\theta_{\text {set_c }}$ especially in warm season and broilers can be exposed to heat stress especially in presence of thermal insulated envelopes. For this reason, it is important to evaluate the envelope considering the indoor climate conditions to ensure that a low energy consumption is not related to excessively poor indoor climate conditions.

For this purpose, the overheating index $\Omega_{\mathrm{OH}}$ is calculated according to Eq. (93) for the considered scenarios and the results are presented in the bar chart of Figure 6.10. From the bar chart, it stands out that overheating problems are evident in the scenarios with the outdoor weather conditions of Spain and Italy, while the other scenarios are characterized by low $\Omega_{\mathrm{oH}}$. The minimum $\Omega_{\mathrm{oH}}$ value is from UK-C scenario. 
Through the bar chart of Figure 6.10, the differences between the three types of envelope in the same outdoor weather conditions in terms of $\Omega_{\mathrm{oH}}$ can be assessed. In the same outdoor weather conditions, the maximum $\Omega_{\mathrm{oH}}$ come from the scenarios with type-B envelope, while the minimum $\Omega_{\mathrm{oH}}$ comes from the scenario with type$\mathrm{C}$ envelope. The higher thermal insulation of the type-B envelope, in fact, decreases the energy need for heating but does not foster the heat losses through transmission, increasing the cooling need. During the warm season (or in presence of high thermal load from the animals) these transmission heat losses would decrease $\theta_{\text {air_i }}$ mitigating the overheating of the enclosure. In the scenarios characterized by milder weather conditions (Spain and Italy), the relative difference between the type-B envelope (with the maximum $\Omega_{\mathrm{oH}}$ ) and type-A and type-C envelopes (with the minimum $\Omega_{\mathrm{oH}}$ ) is equal or less than $6 \%$. In the scenarios with cooler outdoor weather conditions, those differences are higher. The greatest difference is from United Kingdom scenarios where the maximum relative difference between type-C and type-B is around $30 \%$. In all the other weather conditions this difference is always lower than $20 \%$, but in absolute terms, $\Omega_{\mathrm{oH}}$ is low.

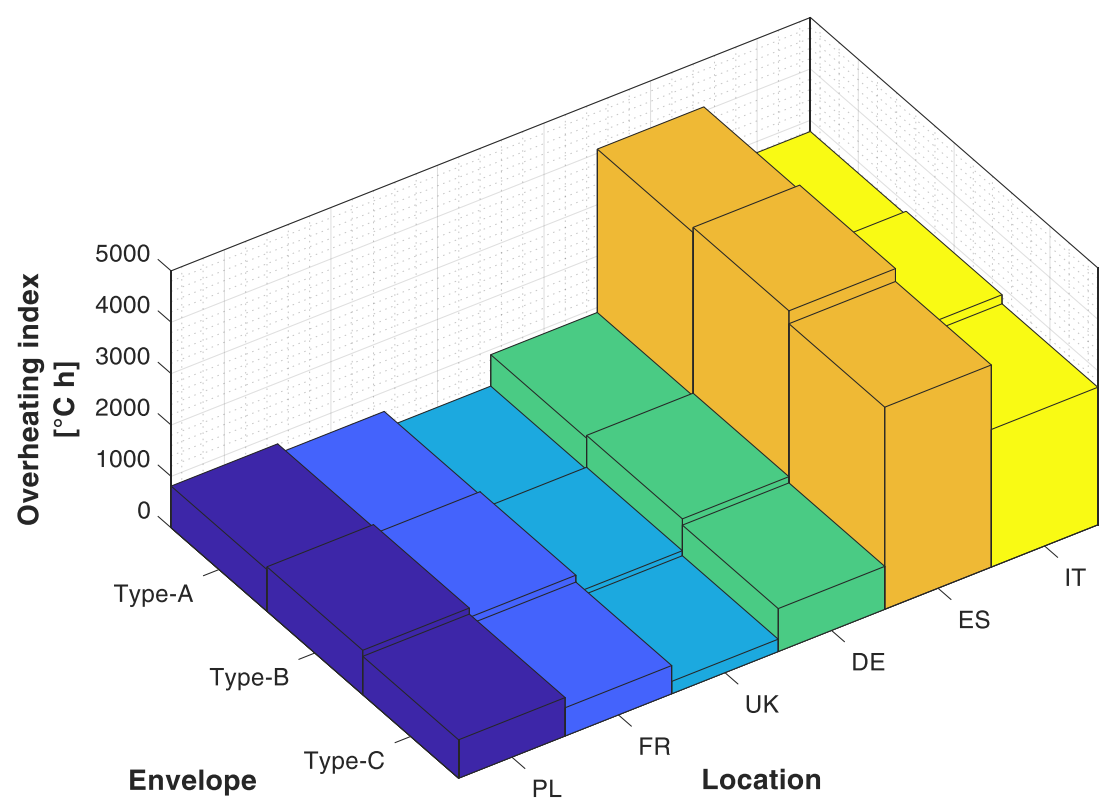

Figure 6.10 - Overheating index $\left(\Omega_{\mathrm{oH}}\right)$ of the analysed scenarios.

\subsection{Final considerations}

In this chapter, the best energy-efficient solution in terms of envelope for a typical broiler house in the European context was identified in different scenarios. This identification was performed through the assessment of the delivered energy consumption -state of the art- and the primary energy consumption -new proposed approach-. The results highlight that, from the delivered and the primary energy points of view, a high-insulated envelope is strongly recommended for all the analyzed outdoor weather conditions, but it is not sustainable from a financial point of view. This is because the financial savings due to the reduction of energy 
consumption enhanced by the improved energy performance do not pay back the high initial investment cost of the envelope. By contrast, a medium insulated envelope could be interesting since is a compromise between a good energy performance and a sustainable cost without increasing considerably the overheating of the enclosure.

The previous analyses lay the groundwork for future research into the energy efficiency of livestock house through two main contributions. First, this work shows the importance of a case-by-case design of the building envelope in improving the energy performance of broiler houses, while in literature most of the works are focused on the improvement of climate control systems. The second contribution relies in the methodology that is adopted in this paper to evaluate the energy performance. The performed energy analyses are not limited to the delivered energy consumed on farm, but they encompass the entire energy supply chain adopting an approach based on primary energy. In this way, important issues can be considered such as the energy losses along the energy supply chain of the considered energy carrier and different energy mixes proper of the country. This last aspect is essential to evaluate how the transition toward cleaner energy mixes undertaken by several countries affects the sustainability of the livestock production. To do so, future works could further deepen the energy analysis based on the primary energy approach to assess the share of primary energy from renewable and non-renewable sources. That distinction would considerably improve the assessment of the environmental sustainability of livestock production. In addition, primary energy approach could represent the core of a new energy certification scheme ad-hoc developed for livestock houses. It would represent the first step of new legislation frameworks that, establishing minimum energy performances and incentive systems, could boost to a cleaner livestock production through a top-down approach.

\subsection{Chapter nomenclature}

$A$
$C_{\mathrm{a}}$
$C_{\mathrm{el}}$
$C_{\mathrm{m}}$
$C_{\mathrm{G}}$
$C_{\mathrm{I}}$
$C_{\mathrm{th}}$
$\mathrm{DE}$
$E_{\text {cycle_p_el }}$
$E_{\text {cycle_p_glob }}$
$E_{\text {cycle_p_th }}$
$E_{\text {p_el }}$
$E_{\text {p_glob }}$
$E_{\mathrm{p} \_t h}$
$E_{\text {el }}$
$E_{\text {el_ec }}$

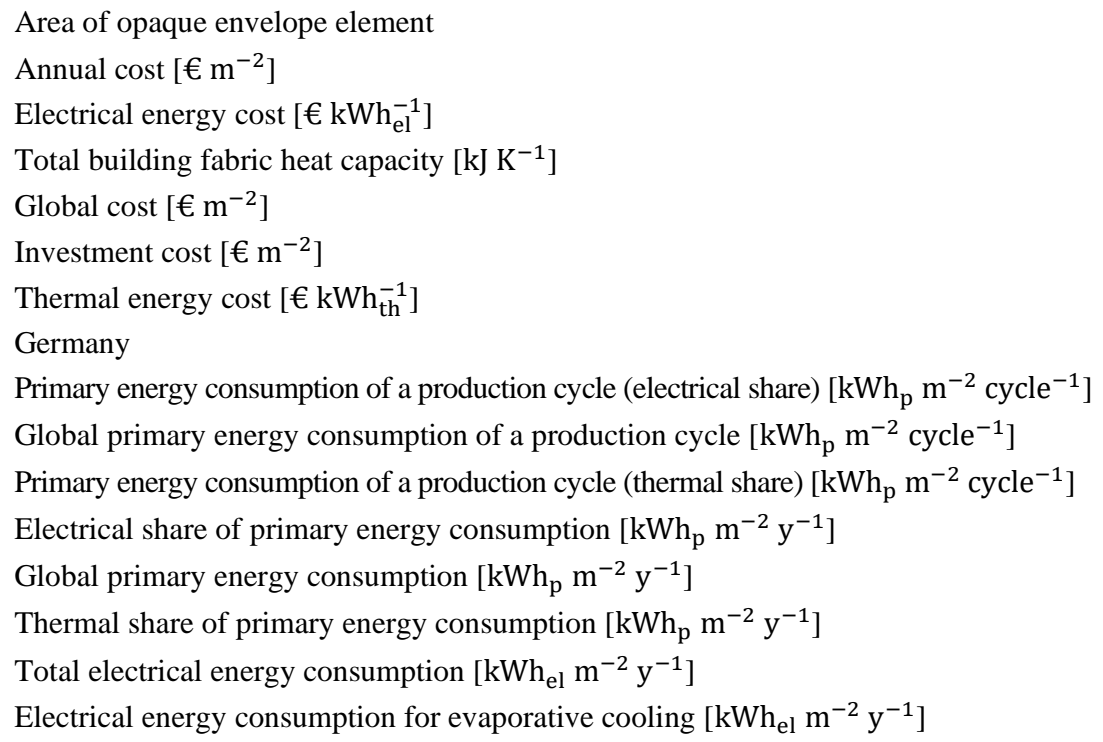




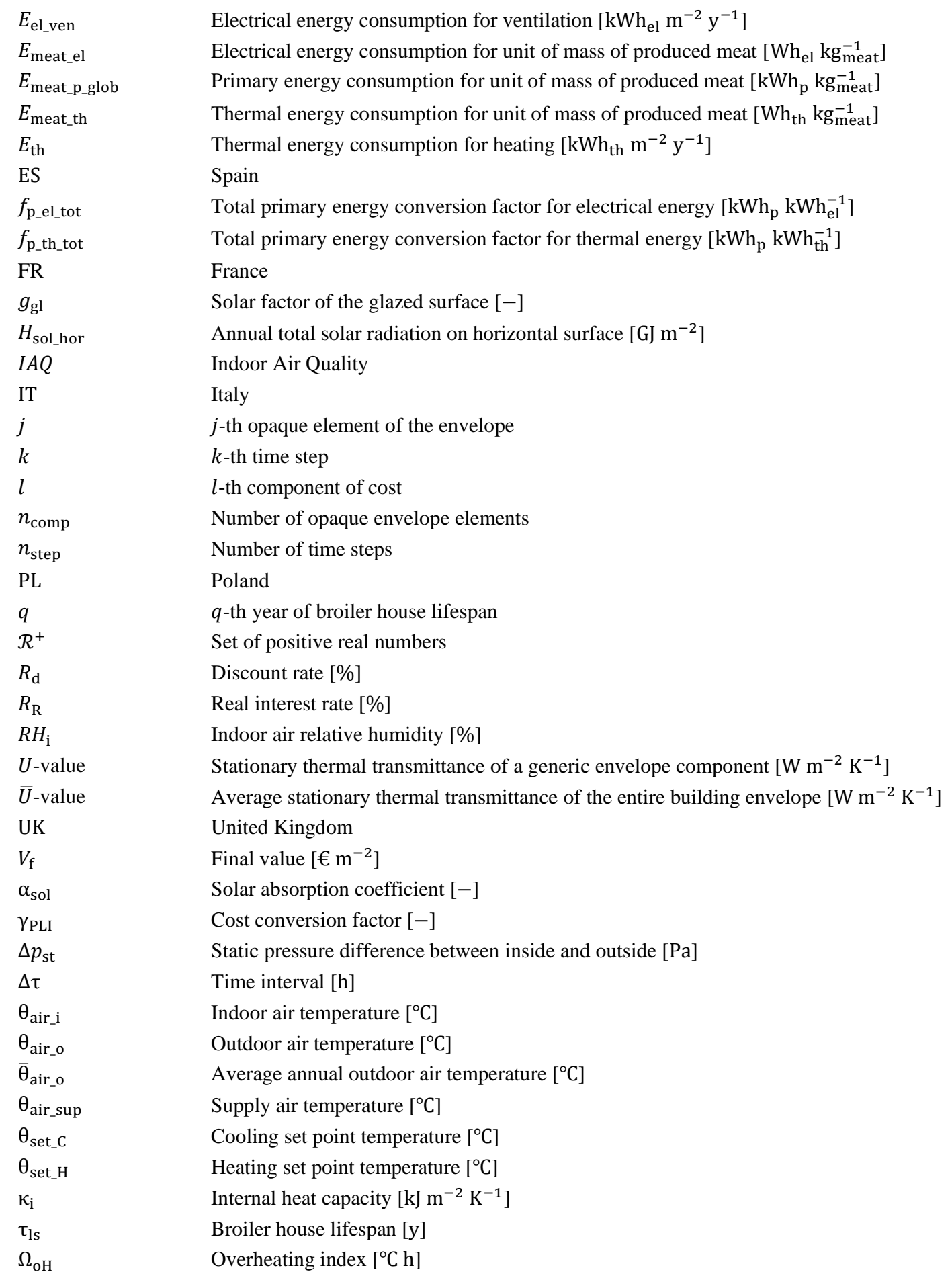





\section{Chapter 7}

\section{The role of ventilation in livestock houses: $I A Q$ improvements and energy consumption}

\begin{tabular}{c|c} 
Objective & $\begin{array}{l}\text { To investigate how energy consumption is affected by the increase of } \\
\text { ventilation rates to fulfil the recommended thresholds of gas concentrations in } \\
\text { a commercial broiler house. }\end{array}$ \\
\hline Outcome & $\begin{array}{l}\text { The energy consumption of a broiler house is assessed through numerical } \\
\text { simulations based on real monitored data considering two different ventilation } \\
\text { strategies. }\end{array}$ \\
\hline Highlights & $\begin{array}{l}\text { In a monitored broiler house, gas concentrations exceed the limits for } \\
60 \% \text { of time. } \\
\text { Increasing ventilation to control gas concentration increases energy } \\
\text { consumption. } \\
\text { Electrical energy consumption increases by } 10 \% \text { and thermal energy } \\
\text { by 14\%. } \\
\text { The financial cost for ventilation increases by }+14 \% \text { (+0.02 } € \text { per } \\
\text { broiler). }\end{array}$ \\
Notes & $\begin{array}{l}\text { Parts of this chapter have been published in: } \\
\text { - Costantino et al., "The reduction of gas concentrations in broiler houses through } \\
\text { ventilation: Assessment of the thermal and electrical energy consumption", } \\
\text { Biosystems Engineering 2020, 199: 135-148. }\end{array}$
\end{tabular}





\subsection{The detrimental effects of $\mathrm{NH}_{3}$ and $\mathrm{CO}_{2}$ on broiler health}

The accumulation of aerial pollutants inside animal farms impairs animal health and welfare and reduces farm efficiency and productivity. The most relevant among the harmful gases in broiler houses are ammonia $\left(\mathrm{NH}_{3}\right)$ and carbon dioxide $\left(\mathrm{CO}_{2}\right)$. Their effects on broilers depend on their concentration as well as on the exposure duration.

Atmospheric $\mathrm{NH}_{3}$ in poultry facilities has been recognized as a significant environmental problem, as well as a detriment to poultry health, performance, and welfare [316]. It causes ocular damages when broilers are exposed to 25 and $50 \mathrm{ppm}\left(1 \mathrm{ppm}\right.$ of $\mathrm{NH}_{3}$ is $0.7 \mathrm{mg} \mathrm{m}^{-3}$ at atmospheric pressure and $25{ }^{\circ} \mathrm{C}$ of gas temperature) for 14 days [109], and keratoconjunctivitis and other eye disorders when exposed to $60 \mathrm{ppm}[108,317]$. Ammonia is also absorbed by the distal airway mucus, which enhances mucosal inflammation and bacterial contamination of the lungs [318]. Moreover, exposure to $\mathrm{NH}_{3}$ also promotes the development of infections [105] and enhances susceptibility to respiratory diseases [108]. Breast blisters have also been found in environments of 25 and $50 \mathrm{ppm}$ of $\mathrm{NH}_{3}$ [319]. More recently, it was found that broilers exposed to $25 \mathrm{ppm}$ of $\mathrm{NH}_{3}$ had a higher expression of genes potentially inhibiting growth and development of breast muscle, compared to broilers exposed to $3 \mathrm{ppm}$ [117].

High $\mathrm{CO}_{2}$ concentrations have negative consequences on broilers due to both the direct effect of this gas and the consequent decrease in the oxygen $\left(\mathrm{O}_{2}\right)$ concentration [106]. According to Gerritzen et al. [320], broilers start to notice instantaneously the presence of $\mathrm{CO}_{2}$ at $24,000 \mathrm{ppm}\left(1 \mathrm{ppm}\right.$ of $\mathrm{CO}_{2}$ is $1.8 \mathrm{mg} \mathrm{m}^{-3}$ at atmospheric pressure and $25^{\circ} \mathrm{C}$ of gas temperature). Higher concentration values in the breathing air may cause gasp $(92,000 \mathrm{ppm})$ and convulsions $(300,000 \mathrm{ppm})$. Lower concentrations of $\mathrm{CO}_{2}$ could affect broiler health when they are in contemporaneity with high exposure times. For example, when broilers are exposed to $\mathrm{CO}_{2}$ concentrations between 3,000 and 6,000 ppm for 14 days, body weight is depressed and late mortality increases [110].

According to these findings, it is recommended to maintain $\mathrm{NH}_{3}$ and $\mathrm{CO}_{2}$ concentrations below certain limits. In some regions, welfare regulations have established concentration limits. European Council Directive 2007/43/EC [76] sets the minimum requirements for the protection of broilers kept for meat production and, among these rules, it establishes the maximum density for reared broilers at $33 \mathrm{~kg} \mathrm{~m}^{-2}$. However, the maximum rearing density can be increased up to $42 \mathrm{~kg} \mathrm{~m}^{-2}$ when specific environmental control requirements are accomplished. Among these requirements, $\mathrm{NH}_{3}$ concentration must be kept below $20 \mathrm{ppm}$ and $\mathrm{CO}_{2}$ concentration below 3,000 ppm at the level of broilers' heads. It has been reported that most commercial farms across Europe rear broilers at densities higher than $33 \mathrm{~kg} \mathrm{~m}^{-2}$ [321]. However, gas concentrations exceeding the limits 
established by the 2007/43/EC Directive have also been reported in commercial poultry houses for both $\mathrm{NH}_{3}$ [88] and $\mathrm{CO}_{2}$ [322].

Ventilation design and operation is critical to maintain gas concentrations below harmful levels. Increasing the ventilation rate reduces gas concentration by dilution, which is simple in terms of management and could be easily carried out by the automatic climate control systems installed in farms. However, increasing the ventilation rates boosts the energy consumption and, consequently, the production costs. This is due to the extra electrical energy needed for operating the fans and to the extra supplemental heating load needed to maintain the indoor air set point temperature, particularly in cold conditions [269]. Furthermore, climate control systems are mostly programmed to control only air temperature and relative humidity inside livestock houses [323] and the installation of specific sensors would be required.

As previously mentioned in Chapter 2 of this thesis, rearing broilers involves a high energy consumption compared with other livestock farms. The energy consumption for climate control, in fact, represents $96 \%$ of the total thermal energy and $75 \%$ of the total electrical energy consumption of broiler houses. These high energy consumptions reflect in the running costs of the farm: in the European context, the energy share represents $20 \%$ of the total production cost of a broiler excluding feedstuff- and can be estimated between 0.04 and $0.09 €$ per harvested broiler [324]. For these reasons, quantifying potential impacts of increasing ventilation on energy consumption is of a foremost importance also considering the expected increase of the overall energy consumption in the agricultural sector that was mentioned in section 1.1.

The objective of this chapter is to explore how energy consumption is affected by the increase of ventilation rates in a commercial broiler house to fulfil the recommended thresholds of gas concentrations. This kind of analysis is not present in literature and may be useful for both engineers and farmers.

To carry out this work, $\mathrm{NH}_{3}$ and $\mathrm{CO}_{2}$ concentrations and their thresholds established by the European regulation -20 and 3,000 ppm in mass, respectivelyare considered. For the analysis, a mechanically ventilated broiler house located in a Mediterranean area was selected as a case study (section 7.2.2) and was monitored during a production cycle carried out in cool season (section 7.3.3). The monitoring campaign provided the gas concentrations and the needed inputs for performing simulations through the energy model for broiler houses presented in section 5.4 that is adopted for estimating the thermal and electrical energy consumption of two different ventilation strategies. 


\subsection{Materials and methods}

\subsubsection{Overview on the experimental and simulation activity}

The experimental activity concerned the monitoring of indoor and outdoor $\mathrm{NH}_{3}$ and $\mathrm{CO}_{2}$ concentrations, indoor and outdoor environmental conditions, static pressure difference between inside and outside the broiler house and the working time of the fans. The monitoring campaign concerned 40 days out of 47 of a production cycle that was carried out during the cool season, in December and January. The first week of the production cycle was not monitored. When $\mathrm{NH}_{3}$ and $\mathrm{CO}_{2}$ concentrations exceeded 20 and $3,000 \mathrm{ppm}$, respectively, the theoretical extra ventilation flow rate needed to maintain the $\mathrm{NH}_{3}$ and $\mathrm{CO}_{2}$ concentrations below the established limits was estimated through a gas mass balance.

The variation of the energy consumption was then assessed considering the electrical energy consumption for the operation of the fans and the thermal energy consumption for the supplemental heating of the enclosure. The electrical energy consumption was calculated through the Specific Fan Performance (SFP) obtained through regressions on technical datasheets of the fans. The thermal energy consumption was estimated through dynamic energy simulations.

\subsubsection{Case study description}

\section{Housing and reared broilers}

The experiment was carried out in a commercial mechanically ventilated broiler house located in Vila-real, Castellon province in eastern Spain, a geographical location in a Mediterranean climate. The province of Castellon is classified as an hot-humid climate zone [325] characterized by a mild climate with no dry season and hot summer. The heating degree days are $1579{ }^{\circ} \mathrm{C} \mathrm{d}$ calculated considering $20^{\circ} \mathrm{C}$ as baseline temperature and the entire year as calculation period, in compliance with EN ISO 15927-6 [326].

The selected case study can be considered representative of the commercial broiler farms of that region. The building floor area is $1,430 \mathrm{~m}^{2}$, being $110 \mathrm{~m}$ length and $13 \mathrm{~m}$ width. The building has a gable roof and its height is $2.5 \mathrm{~m}$ at the eave level, and $4.5 \mathrm{~m}$ at the ridge level. The broiler house net volume is approximately $5,000 \mathrm{~m}^{3}$. The perimetral walls are made of concrete hollow blocks $(150 \mathrm{~mm}$ of thickness) and cement plaster (20 mm of thickness). Part of these walls is insulated through polyurethane sandwich panels (30 $\mathrm{mm}$ of thickness). The roof is made of corrugated fiber-cement sheets with fiberglass insulation panels $(30 \mathrm{~mm}$ of thickness) and polyurethane foam (20 mm of thickness) that was applied on the inner face. The floor is a lightweight reinforced concrete screed $(100 \mathrm{~mm}$ of thickness) in direct contact with the ground. A layer of rice hulls of about $100 \mathrm{~mm}$ is used as bedding material and the litter is removed at the end of each production cycle. To perform the energy simulations, an additional $1.5 \mathrm{~m}$ of soil layer is added 
to the previously described floor layers to consider the effect of the ground on the building thermal behavior. The heat flow via the ground was calculated using as thermodynamic driving force the difference between the indoor air temperature $\left(\theta_{\text {air_i }}\right)$ and the outdoor air temperature $\left(\theta_{\text {air_o }}\right)$.

The thermal transmittance $(U-$ value $)$ and the internal areal heat capacity $\left(\kappa_{\mathrm{i}}\right)$ of the broiler house envelope were calculated in compliance with ISO 6946 [300] and ISO 13786 [264] standards. The calculated values are reported in Table 7.1 and are the inputs for performing the needed energy simulations.

Table 7.1 - Thermal transmittance $(U-$ value $)$ and internal areal heat capacity $\left(\kappa_{\mathrm{i}}\right)$ of the building components of the considered broiler house.

\begin{tabular}{|c|c|c|}
\hline $\begin{array}{c}\text { Building } \\
\text { component }\end{array}$ & $\begin{array}{c}U-\text { value } \\
{\left[\mathrm{W} \mathbf{m}^{-2} \mathbf{K}^{-1}\right]}\end{array}$ & {$\left[\begin{array}{c}\kappa_{i} \\
{\left[k J ~ m^{-2} K^{-1}\right]}\end{array}\right.$} \\
\hline Not insulated walls & 2.40 & 56.3 \\
\hline Insulated walls & 0.67 & 13.3 \\
\hline Roof & 0.42 & 3.4 \\
\hline Floor & 0.44 & 16.3 \\
\hline
\end{tabular}

The production cycle started on December $15^{\text {th }}$ with 12,000 male and 12,000 female broiler chicks and ended on January $31^{\text {st }}$, after 7 weeks. The monitoring campaign started on the $7^{\text {th }}$ day of the production cycle (December $22^{\text {nd }}$ ) and lasted 967 hours, around 40 days, until the end of the production cycle. On January $24^{\text {th }}$, $15 \%$ of the 42-day-old broilers were harvested with an average weight of $2.33 \mathrm{~kg}$ per broiler. Total mortality during the growing period was $3.28 \%$. The final production was 23,212 broilers with a total final live weight of $62,534 \mathrm{~kg}$, meaning an average live weight of $2.69 \mathrm{~kg}$ per 48 -day-old broiler. The feedstuff consumption was $114,000 \mathrm{~kg}$ and the feed conversion rate 1.82 . Rearing density at the end of the cycle was $37.05 \mathrm{~kg} \mathrm{~m}^{-2}$, a value higher than the threshold of $33 \mathrm{~kg} \mathrm{~m}^{-2}$ established by the European Council Directive 2007/43/EC [76]. Therefore, the specific environmental control requirements regarding gas concentration should be accomplished.

\section{Climate control system}

The analyzed broiler house is mechanically ventilated using a cross ventilation configuration. Air inlets are placed on one of the larger walls and are automatically controlled for maintaining a constant static pressure difference between inside and outside the house $\left(\Delta p_{\mathrm{st}}\right)$ during the same day. On the opposite wall, there are 16 lateral exhaust fans that deal with both Indoor Air Quality $(I A Q)$ control and cooling ventilation. The 16 fans are of two different models: nine of them are larger than the other seven. The larger fans have a maximum electrical power of $0.75 \mathrm{~kW}$ and in free air delivery conditions $\left(\Delta p_{\mathrm{st}}=0 \mathrm{~Pa}\right)$ the maximum declared airflow is around $35,000 \mathrm{~m}^{3} \mathrm{~h}^{-1}$. The remaining seven fans are smaller with a maximum electrical power of $0.59 \mathrm{~kW}$ and their maximum declared airflow in free air delivery conditions is roughly $12,750 \mathrm{~m}^{3} \mathrm{~h}^{-1}$. Both fan models are three-phase and fixed 
propeller speed fans. Their airflow flow and $S F P$, hence, vary as a function of $\Delta p_{\text {st }}$ only on a single curve, as previously described by Eq. (28).

In the analyzed broiler house, a commercial automatic control system measures the value of $\theta_{\text {air_i }}$ through a probe inside the house and maintains it between the heating $\left(\theta_{\text {set_H }}\right)$ and the cooling $\left(\theta_{\text {set_C }}\right)$ set point temperatures in a dead band of $2{ }^{\circ} \mathrm{C}$ of range. When supplemental heating is needed to maintain $\theta_{\text {air_i }}$ above $\theta_{\text {set_H }}$, the farm automatic control system activates two propane air heaters of $85 \mathrm{~kW}$ of heating capacity each one. Both the air heaters are placed inside the building and a global conversion efficiency $\left(\eta_{\mathrm{H}}\right)$ of $100 \%$ is considered. Since the air heaters emit the exhaust fumes directly inside the enclosure, they contribute to further increase the indoor $\mathrm{CO}_{2}$ concentration.

When cooling is needed to maintain $\theta_{\text {air_i }}$ below $\theta_{\text {set_c }}$, cooling ventilation and evaporative pads are activated. The climate control system also provides a minimum ventilation flow rate, based on the animal stocking density, to control the $I A Q$. The ventilation is managed through the activation of the 16 fans according to two different activation cycles. When low ventilation flow rates are needed, usually for $I A Q$ control, the activation cycle lasts $15 \mathrm{~s}$. When higher ventilation flow rates are needed, usually for cooling ventilation, the control system manages the fans with activation cycles of $100 \mathrm{~s}$. For ventilation flow rates below 75,000 $\mathrm{m}^{3} \mathrm{~h}^{-1}$, only the small fans are activated.

\subsubsection{Monitoring system description}

The indoor air temperature $\left(\theta_{\text {air_i }}\right)$ and the indoor air relative humidity $\left(R H_{\mathrm{i}}\right)$ were monitored using four sensors embedded in portable data loggers that were set with an acquisition time step of 30 minutes. The outdoor weather conditions of $\theta_{\text {air_o }}$ and relative humidity $\left(R H_{\mathrm{o}}\right)$ were monitored using a weather station that was set with an acquisition time step of 10 minutes. The daily value of $\Delta p_{\mathrm{st}}$ was obtained by the logged data in the farm automatic climate control system that manages the window openings to maintain a constant $\Delta p_{\text {st }}$ daily. The total horizontal solar irradiance ( $\left.I_{\text {tot_hor }}\right)$ was obtained with a 30-minute time step through a third-party weather station. The beam and diffuse components of the solar radiation were obtained using the model of Reindl, Beckman, and Duffie [327].

The percentage of activation time of the nine large fans $\left(\omega_{1}\right)$ and the seven small ones $\left(\omega_{\mathrm{s}}\right)$, were monitored with a time step of $90 \mathrm{~s}$ with the procedure described by Calvet et al. [155]. The measurement of gas concentration regarded $\mathrm{NH}_{3}$ and $\mathrm{CO}_{2}$. A photoacoustic multi gas monitor equipped with a gas multiplexer was adopted in this work. This instrument enabled sequential measurements in eight different points in a 2-hour time step since 15 minutes are needed to complete each measurement. Four sampling points were placed next to the fans at $1.2 \mathrm{~m}$ of height to determine the exhaust concentrations of the gas $x\left(C_{\mathrm{e}_{-} \mathrm{x}}\right)$, and two were placed at the air inlet openings for the characterization of gas concentration of the outside air $\left(C_{\mathrm{o}_{-} \mathrm{x}}\right)$. The remaining two measurement points were placed in the center of the 
broiler house at $1.2 \mathrm{~m}$ of height to obtain further data on the distribution of gas concentrations $\left(C_{\mathrm{c}_{-} \mathrm{x}}\right)$ within the enclosure. The locations of the sensors inside the analyzed broiler house are shown in Figure 7.1, while the summary of the measured parameters is presented in Table 5.4.

Every week, 50 broilers ( $0.02 \%$ of the flock) were weighed for monitoring the trend of their live weight $\left(w_{\mathrm{b}}\right)$ during the experiment.

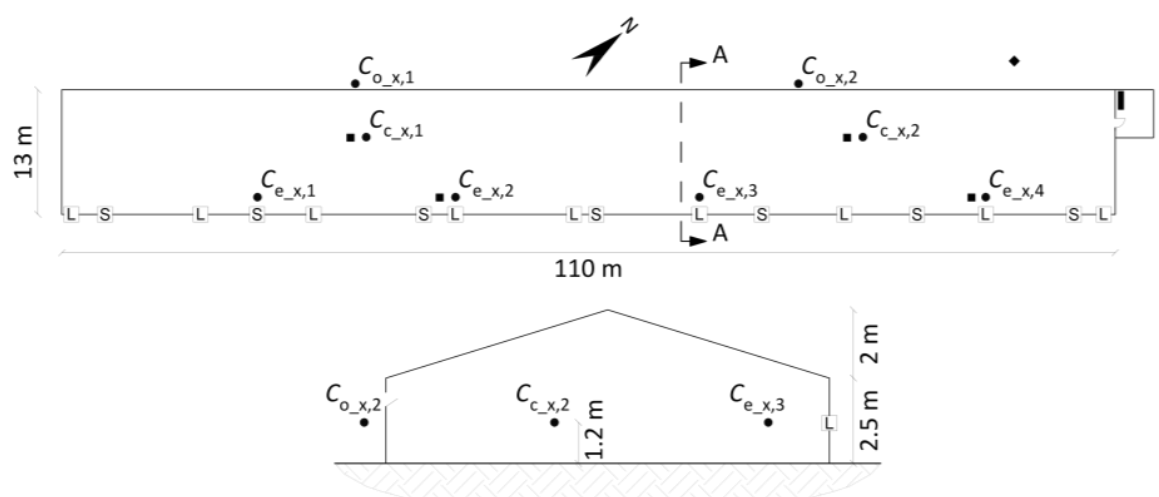

Section A-A

\section{Legend}

L. Large fan - Outdoor air temperature and relative humidity sensor

s Small fan

- Indoor air temperature and relative humidity sensor

- Gas concentration sensor

I Automatic climate control system

Figure 7.1 - Position of the sensors inside the monitored broiler house. Plan and cross section view -not at the same scale- show the main geometrical dimensions of the analyzed house.

Table 7.2 - Detail of the monitored parameters.

\begin{tabular}{cccc}
\hline Monitored parameter & Symbol & $\begin{array}{c}\text { Unit of } \\
\text { measurement }\end{array}$ & $\begin{array}{c}\text { Acquisition time } \\
\text { step }\end{array}$ \\
\hline Activation time of large fans & $\omega_{1}$ & $\%$ & 90 seconds \\
Activation time of small fans & $\omega_{\mathrm{s}}$ & $\%$ & 90 seconds \\
Outdoor air temperature & $\theta_{\text {air_o }}$ & ${ }^{\circ} \mathrm{C}$ & 10 minutes \\
Outdoor relative humidity & $R H_{\mathrm{o}}$ & $\%$ & 10 minutes \\
Indoor air temperature & $\theta_{\text {air_i }}$ & ${ }^{\circ} \mathrm{C}$ & 30 minutes \\
Indoor relative humidity & $R H_{\mathrm{i}}$ & $\%$ & 30 minutes \\
Total horizontal solar irradiance & $I_{\text {tot_hor }}$ & $\mathrm{W} \mathrm{m}^{-2}$ & 30 minutes \\
Exhaust gas concentration & $C_{\mathrm{e}_{-} \mathrm{x}}$ & $\mathrm{ppm}$ & 2 hours \\
Outdoor gas concentration & $C_{\mathrm{o}_{-} \mathrm{x}}$ & $\mathrm{ppm}$ & 2 hours \\
Gas concentration (center) & $C_{\mathrm{c}_{-} \mathrm{x}}$ & $\mathrm{ppm}$ & 2 hours \\
Static pressure difference & $\Delta p_{\mathrm{st}}$ & $\mathrm{Pa}$ & 1 day \\
Broiler live weight & $w_{\mathrm{b}}$ & $\mathrm{kg}$ & 1 week \\
\hline
\end{tabular}

\subsubsection{Calculation process}

\section{Estimation of the increased ventilation flow rate to fulfil the gas concentration requirements}

The calculation process adopted in this work with the performed calculation steps are presented in Figure 7.2. In all the calculations, the monitored gas emissions are considered constant in the hourly time step. 


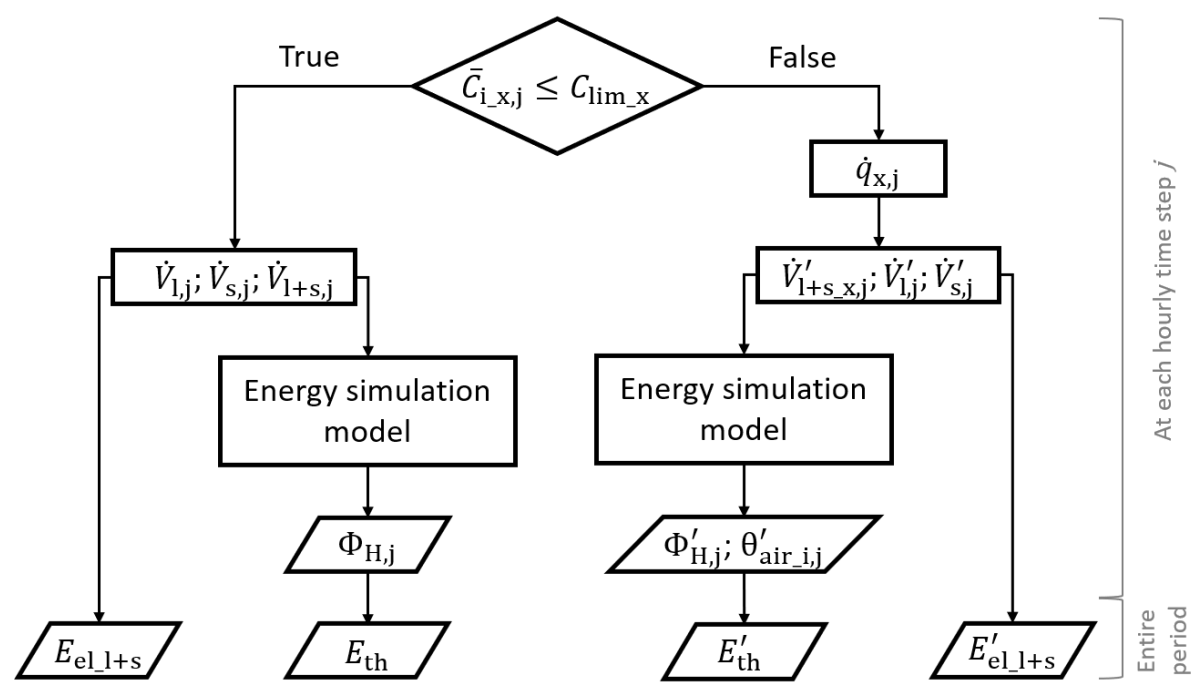

Figure 7.2 - Flow chart of the calculation process.

At each hourly time step $j$, the indoor gas concentrations should be maintained below the established thresholds. This condition is expressed using the following inequation that must be fulfilled for both $\mathrm{NH}_{3}$ and $\mathrm{CO}_{2}$

$$
\bar{C}_{\mathrm{i}_{-} \mathrm{x}, \mathrm{j}} \leq C_{\lim _{-} \mathrm{x}}
$$

where $\bar{C}_{\mathrm{i}_{\mathrm{X}} \mathrm{j}, \mathrm{j}}$ is the average mass concentration of the analyzed gas $x$ (subscript $x$ ) inside the building (subscript $i$ ) at time step $j$. The value of $\bar{C}_{\mathrm{i}_{\mathrm{x}} \mathrm{x}, \mathrm{j}}$ is the arithmetic mean between the average value of the two measured $C_{\mathrm{c}_{-} \mathrm{x}, \mathrm{j}}$, and the average value of the four measured $C_{\mathrm{e}_{-} \mathrm{x}, \mathrm{j}}$. The term $C_{\lim _{-} \mathrm{x}}$ is the mass concentration limit (subscript lim) of gas $x$.

If the constraint of Eq. (100) is respected, the actual ventilation flow rate of large $\left(\dot{V}_{\mathrm{l}, \mathrm{j}}\right)$ and small $\left(\dot{V}_{\mathrm{s}, \mathrm{j}}\right)$ fans is calculated on the basis of the real monitored data $\left(\omega_{\mathrm{l}}, \omega_{\mathrm{s}}\right.$ and $\left.\Delta p_{\mathrm{st}}\right)$, according to the method described in Calvet et al. [155]. The total actual ventilation flow rate $\left(\dot{V}_{\mathrm{l}+\mathrm{s}, \mathrm{j}}\right)$ is the sum of $\dot{V}_{\mathrm{l}, \mathrm{j}}$ and $\dot{V}_{\mathrm{s}, \mathrm{j}}$. The obtained values of $\dot{V}_{\mathrm{l}, \mathrm{j}}, \dot{V}_{\mathrm{s}, \mathrm{j}}$ and $\dot{V}_{\mathrm{l}+\mathrm{s}, \mathrm{j}}$ are used to calculate the fan electrical energy consumption $\left(E_{\text {el_l+s }}\right)$ through the $S F P$, while the supplemental heating load $\left(\phi_{\mathrm{H}, \mathrm{j}}\right)$ and the thermal energy consumption for supplemental heating $\left(E_{\mathrm{th}}\right)$ are calculated through the energy simulation model.

If the constraint of Eq. (100) is not respected, the theoretical increased ventilation flow rate $\left(\dot{V}_{\mathrm{l}_{+\mathrm{S} \_\mathrm{x}, \mathrm{j}}^{\prime}}^{\prime}\right)$ needed to guarantee $C_{\lim _{-} \mathrm{x}}$ is then calculated. At each time step $j, \dot{V}_{\mathrm{l}_{+} \mathrm{x}, \mathrm{j}}^{\prime}$ depends on the gas emission rate from internal sources $\left(\dot{q}_{\mathrm{x}, \mathrm{j}}\right)$, such as the reared broilers and the bedding material. At each time step $j, \dot{q}_{\mathrm{x}, \mathrm{j}}$ reads

$$
\dot{q}_{\mathrm{x}, \mathrm{j}}=\left(\bar{C}_{\mathrm{i}_{\mathrm{B}} \mathrm{x}, \mathrm{j}}-{\overline{C_{\mathrm{o}} \mathrm{x}, \mathrm{j}}}\right) \cdot \frac{m_{\mathrm{x}}}{V_{\mathrm{mol} \_\mathrm{x}}} \cdot \dot{V}_{\mathrm{l}+\mathrm{s}, \mathrm{j}} \quad\left[\frac{\mathrm{mg} \mathrm{x}}{\mathrm{h}}\right]
$$

where $\bar{C}_{\mathrm{O} \_\mathrm{x}, \mathrm{j}}(\mathrm{ppm})$ is the is the average outdoor (subscript $o$ ) concentration of gas $x$ at hourly time step $j$, obtained as the arithmetic mean between the two 
monitored values of $C_{\mathrm{o}_{\mathrm{x}} \mathrm{j}, \mathrm{j}}$. The term $m_{\mathrm{x}}$ is the molecular mass of gas $x$ that is equal to $1.7031 \cdot 10^{-2} \mathrm{~kg} \mathrm{~mol}^{-1}$ for $\mathrm{NH}_{3}$ and $4.40 \cdot 10^{-2} \mathrm{~kg} \mathrm{~mol}^{-1}$ for $\mathrm{CO}_{2}$. The term $V_{\text {mol_x }}$ is the molar volume of gas $x$, that in this work is considered constant and equal to $2.445 \cdot 10^{-2} \mathrm{~m}^{3} \mathrm{~mol}^{-1}$ for both $\mathrm{NH}_{3}$ and $\mathrm{CO}_{2}$. The term $\dot{V}_{\mathrm{l}+\mathrm{s}, \mathrm{j}}$ is the actual ventilation flow rate, calculated using the real monitored data calculated, as previously stated. In Eq. (101), some simplifications are assumed, since $\dot{q}_{\mathrm{x}, \mathrm{j}}$ is considered constant and not influenced by the variation of the indoor environmental conditions in the considered time step $j$.

Once estimated $\dot{q}_{\mathrm{x}, \mathrm{j}}, \dot{V}_{\mathrm{l}+\mathrm{s}_{-} \mathrm{x}, \mathrm{j}}^{\prime}$ is calculated through the following gas mass balance in steady-state conditions

$$
\dot{V}_{1+s_{-} \mathrm{x}, \mathrm{j}}^{\prime}=\frac{\dot{q}_{\mathrm{x}, \mathrm{j}}}{C_{\lim _{-} \mathrm{x}}-\bar{C}_{\mathrm{o}_{-} \mathrm{x}, \mathrm{j}}} \cdot \frac{V_{\mathrm{mol} \_\mathrm{x}}}{m_{\mathrm{x}}} \quad\left[\frac{\mathrm{m}^{3}}{\mathrm{~h}}\right]
$$

Eqs. (101) and (102) are applied at each time step of the analyzed period for which the constraint of Eq. (100) is not respected. Considering $\mathrm{NH}_{3}$ and $\mathrm{CO}_{2}$ in Eqs. (101) and (102), $\dot{V}_{1+\mathrm{s}_{-} \mathrm{NH}_{3}, \mathrm{j}}^{\prime}$ and $\dot{V}_{\mathrm{l}+\mathrm{s}_{-} \mathrm{CO}_{2}, \mathrm{j}}$ are obtained, respectively. At the time step $j$, the total theoretical ventilation flow rate $\left(\dot{V}_{l+s, j}^{\prime}\right)$ is calculated as

$$
\dot{V}_{1+\mathrm{s}, \mathrm{j}}^{\prime}=\max \left\{\dot{V}_{1+\mathrm{s}_{-} \mathrm{NH}_{3}, \mathrm{j}}^{\prime} \dot{V}_{1+\mathrm{s}_{-} \mathrm{CO}_{2}, \mathrm{j}}^{\prime}\right\} \quad\left[\frac{\mathrm{m}^{3}}{\mathrm{~h}}\right]
$$

The obtained $\dot{V}_{1+s, j}^{\prime}$ is split into the flow rate provided by large $\left(\dot{V}_{1, j}^{\prime}\right)$ and small fans $\left(\dot{V}_{\mathrm{s}, \mathrm{j}}^{\prime}\right)$ according to the control logic of the automatic climate control system of the broiler house since below $75,000 \mathrm{~m}^{3} \mathrm{~h}^{-1}$ only small fans are activated. The obtained values of $\dot{V}_{1+s, j}^{\prime}, \dot{V}_{1, j}^{\prime}$ and $\dot{V}_{\mathrm{s}, \mathrm{j}}^{\prime}$ are used to calculate the fan electrical energy consumption $\left(E_{\mathrm{el} \_l+\mathrm{s}}^{\prime}\right)$, the theoretical heating load $\left(\phi_{\mathrm{H}, \mathrm{j}}^{\prime}\right)$, the simulated indoor air temperature $\left(\theta_{\text {air } \_ \text {i }}^{\prime}\right)$ and the thermal energy consumption for heating $\left(E_{\text {th }}^{\prime}\right)$, as described in the following section.

\section{Estimation of the electrical and thermal energy consumption}

The estimation of the electrical energy consumption due to ventilation was carried out by characterizing each fan model with the SFP curve, according to the previously presented Eq. (28). The empirical coefficients adopted for simulating the considered fans were obtained by a regression from the technical datasheets of both the considered fan models and are reported in Appendix A (Table A.13) of this thesis.

The electrical energy consumption due to the actual ventilation $\left(E_{\text {el_l+s }}\right)$ of the analyzed period can be calculated according to Eq. (70), that for this specific analysis can be written as 


$$
E_{\mathrm{el} \_l+s}=\left[\sum_{\mathrm{j}=1}^{967}\left(\frac{\dot{V}_{\mathrm{l}, \mathrm{j}}}{S F P_{\mathrm{l}}}+\frac{\dot{V}_{\mathrm{s}, \mathrm{j}}}{S F P_{\mathrm{S}}}\right)\right] \cdot 10^{-3} \quad\left[\mathrm{kWh} \mathrm{el}_{\mathrm{el}}\right]
$$

where $\dot{V}_{\mathrm{l}, \mathrm{j}}$ and $\dot{V}_{\mathrm{s}, \mathrm{j}}$ are the actual ventilation flow rates provided the large and small fans at the time step $j, S F P_{1}$ and $S F P_{\mathrm{s}}$ are the $S F P$ of large and small fans respectively, and 967 is the number of hours of the analyzed period.

In a similar way, the electrical energy consumption due to the increased ventilation $\left(E_{\mathrm{el} \_l+\mathrm{s}}^{\prime}\right)$ is calculated as

$$
E_{\text {el_l+s }}^{\prime}=\left[\sum_{\mathrm{j}=1}^{967}\left(\frac{\dot{V}_{1, \mathrm{j}}^{\prime}}{S F P_{1}}+\frac{\dot{V}_{\mathrm{s}, \mathrm{j}}^{\prime}}{S F P_{\mathrm{S}}}\right)\right] \cdot 10^{-3} \quad\left[\mathrm{kWh} \mathrm{he}_{\mathrm{el}}\right]
$$

The thermal energy consumption considering the actual ventilation $\left(E_{\mathrm{th}}\right)$ and the thermal energy consumption considering the theoretical ventilation needed to maintain $C_{\text {lim }_{-} \mathrm{NH}_{3}}$ and $C_{\text {lim }_{-} \mathrm{CO}_{2}}\left(E_{\mathrm{th}}^{\prime}\right)$ during the 967 hours of the monitoring period are estimated using the energy simulation model for broiler houses presented in section 5.4 .

\subsection{Results and discussion}

\subsubsection{Analysis of the monitored data}

In Figure 7.3a, the hourly values of $\theta_{\text {air_i }}$ and $\theta_{\text {air_o }}$ during the monitored period are shown. The pattern of $\theta_{\text {air_i }}$ strictly followed the settings of the automatic control system of the farm and it can be considered similar to those obtained in other regions with different outdoor climate conditions [328]. At the beginning of the monitored period, (December $22^{\text {nd }}$, the $8^{\text {th }}$ day of the production cycle) $\theta_{\text {air_i }}$ had an average daily value of around $27^{\circ} \mathrm{C}$. During the production cycle, $\theta_{\text {air_i }}$ gradually decreased reaching an average daily value of around $18^{\circ} \mathrm{C}$ at the end of the production cycle (January $31^{\text {st }}$ ). This decreasing trend had an exception on January $19^{\text {th }}$, when $\theta_{\text {air_i }}$ was considerably higher than in the previous days. This $\theta_{\text {air_i }}$ peak was caused by $\theta_{\text {air_o }}$ that reached the highest value $\left(26^{\circ} \mathrm{C}\right)$ of the entire monitored period on that day. Before January $19^{\text {th }}$, the trend of $\theta_{\text {air_o }}$ was quite constant daily, and the average value of the period from December $22^{\text {nd }}$ to January $18^{\text {th }}$ was around $10^{\circ} \mathrm{C}$. After the peak of January $19^{\text {th }}, \theta_{\text {air_o }}$ remained higher than in the previous days with an average daily value of around $14.5^{\circ} \mathrm{C}$ (January $19^{\text {th }}-21^{\text {st }}$ ). From January $22^{\text {nd }}$ to the end of the monitored period, $\theta_{\text {air_o }}$ decreased to an average value of $7.6^{\circ} \mathrm{C}$. 

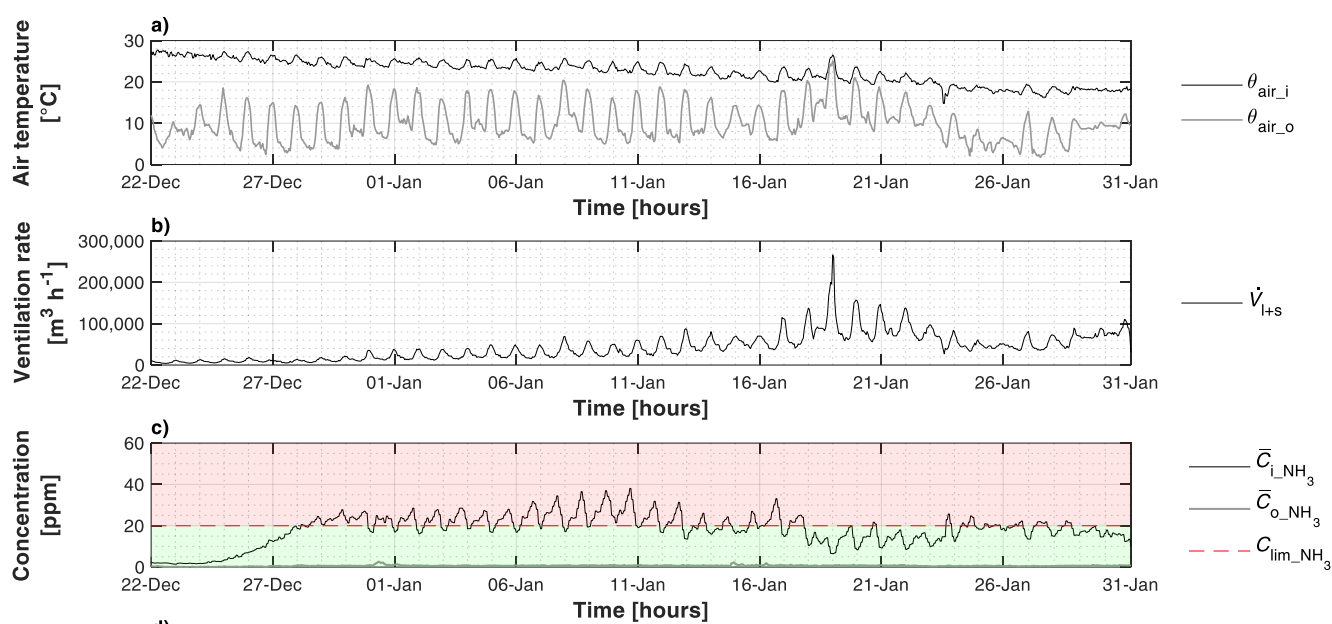

要

Figure 7.3 - a) monitored indoor $\left(\theta_{\text {air_i }}\right)$ and outdoor $\left(\theta_{\text {air_o }}\right)$ air temperatures; b) actual total ventilation flow rate $\left.\dot{V}_{\mathrm{l}+\mathrm{s}} ; \mathrm{c}\right)$ monitored indoor $\left(\bar{C}_{\mathrm{i}_{-} \mathrm{NH}_{3}}\right)$ and outdoor $\left(\bar{C}_{\mathrm{O}_{-} \mathrm{NH}_{3}}\right) \mathrm{NH}_{3}$ concentrations and indoor concentration limit $\left(C_{\mathrm{lim}_{-} \mathrm{NH}_{3}}\right)$; d) monitored indoor $\left(\bar{C}_{\mathrm{i}_{-} \mathrm{CO}_{2}}\right)$ and outdoor $\left(\bar{C}_{\mathrm{O}_{-} \mathrm{CO}_{2}}\right) \mathrm{CO}_{2}$ concentrations and indoor concentration limit $\left(C_{\lim _{-} \mathrm{CO}_{2}}\right)$.

The trend of the total actual ventilation flow rate $\dot{V}_{\mathrm{l}+\mathrm{s}}$ during the monitored period is presented in Figure 7.3b. From the beginning of the monitored period to January $18^{\text {th }}, \dot{V}_{\text {l+s }}$ gradually increased. On January $18^{\text {th }}$, a considerable increase in $\dot{V}_{\text {l+s }}$ can be noticed and a peak of about $266,000 \mathrm{~m}^{3} \mathrm{~h}^{-1}$-the maximum monitored value of $\dot{V}_{\mathrm{l}+\mathrm{s}^{-}}$occurred on January $19^{\text {th }}$, corresponding to the sudden increase of $\theta_{\text {air_o }}$. From January $22^{\text {nd }}$ to the end of the production cycle, $\dot{V}_{1+s}$ falls off due to the decrease of $\theta_{\text {air_o }}$ during the last days and due to the reduction of the number of broilers since $15 \%$ of them was harvested on January $24^{\text {th }}$. The actual ventilation flow rate can be expressed in air changes per hour (ach). During the monitored period, the minimum ventilation flow rate was around 1 ach, the maximum one was higher than 50 ach while the average one was around 9 ach.

As stated before, intensive broiler farms usually are designed, equipped, and operated to maintain the adequate $\theta_{\text {air_i }}$ to ensure an optimum animal development. By contrast, farm installations are not usually designed and operated to maintain established $\mathrm{NH}_{3}$ and $\mathrm{CO}_{2}$ concentrations. Consequently, concentration thresholds are normally exceeded in winter periods when ventilation rates are low, as evidenced by Groot Koerkamp et al. [88] and by the monitored emission trends highlighted in Figure 7.3c and d.

In Figure 7.3c, the monitored $\mathrm{NH}_{3}$ mass concentration is presented. During the analyzed period, $\bar{C}_{\mathrm{O}_{-} \mathrm{NH}_{3}}$ remained quite constant with an average value lower than $1 \mathrm{ppm}$ over the entire period. The average value of $\bar{C}_{\mathrm{i}_{-} \mathrm{NH}_{3}}$ was $18.3 \mathrm{ppm}$, but it varied considerably being the minimum value $1.4 \mathrm{ppm}$ and the maximum one $38.1 \mathrm{ppm}$. As visible in Figure 7.3c, $\bar{C}_{\mathrm{i}-\mathrm{NH}_{3}}$ exceeded the threshold mainly in the 
central part of the monitored period. Although this tendency is described in literature [322], the evolution of $\mathrm{NH}_{3}$ concentration is, to some extent, hard to predict, being influenced by litter management, environmental conditions, ventilation rates and broiler health status [329]. In Figure 7.3c, it stands out that during the first days, $\bar{C}_{\text {i_NH }}$ was considerably below the $\bar{C}_{\text {lim_N }} \mathrm{NH}_{3}$. Later, it sudden increased since the chicks were growing and because the excreta quantity in the bedding material increased over time, affecting the $\mathrm{NH}_{3}$ emissions. From December $28^{\text {th }}$ to January $18^{\text {th }}, \bar{C}_{\mathrm{i}_{-} \mathrm{NH}_{3}}$ remained higher than $C_{\text {lim_N }} \mathrm{NH}_{3}$ for most of the time. After January $18^{\text {th }}$ to the end of the production cycle, the increased $\dot{V}_{\mathrm{l}+\mathrm{s}}$ due to the high values of $\theta_{\text {air_o }}$ improved the indoor climate conditions in terms of gas concentration. In this period, $\bar{C}_{\mathrm{i}_{-} \mathrm{NH}_{3}}$ decreased below $C_{\mathrm{lim} \_\mathrm{NH}_{3}}$ for most of the time. The reduction of the animal stocking density inside the house of January $24^{\text {th }}$ may have partially affected this decrease.

Despite $\mathrm{CO}_{2}$ production from broilers and manure increases as broilers grow [330], $\mathrm{CO}_{2}$ concentrations inside the house followed a decreasing trend in the analyzed period due to the diluting effect of increasing ventilation rates. During the first days of the monitored period, $\bar{C}_{\mathrm{i}_{-} \mathrm{CO}_{2}}$ had higher values than in the remaining days and was considerably higher than $C_{\lim _{-} \mathrm{CO}_{2}}$, as shown in Figure 7.3d. This difference was due to the need to maintain $\theta_{\text {set_H }}$ during the first days of the production cycle. Combining the high temperature needs of broiler chicks during their first days of life with their low sensible thermal emission, supplemental heating had to be provided to maintain $\theta_{\text {set_H }}$. The supplemental heating was provided by propane air heaters that emitted the exhaust fumes directly inside the enclosure, increasing $\theta_{\text {air_i }}$ and $\bar{C}_{\mathrm{i}_{-} \mathrm{CO}_{2}}$. During these days (December $22^{\text {nd }}-$ January $6^{\text {th }}$ ), $\dot{V}_{\mathrm{l}+\mathrm{s}}$ was at minimum values (below $50,000 \mathrm{~m}^{3} \mathrm{~h}^{-1}$ ) and the $\mathrm{CO}_{2}$ in the house could not be diluted through ventilation. When $\theta_{\text {set_H }}$ was maintained without supplemental heating, $\bar{C}_{\mathrm{i}_{-} \mathrm{CO}_{2}}$ decreased considerably and after January $6^{\text {th }}$ remained stably below $C_{\text {lim_CO }}$. During the monitored period, the average value of $\bar{C}_{\mathrm{i}_{-} \mathrm{CO}_{2}}$ was 2,517 ppm, with $819 \mathrm{ppm}$ as minimum and 5,765 ppm as maximum values. The average $\bar{C}_{\mathrm{i}_{-} \mathrm{CO}_{2}}$ value was around $480 \mathrm{ppm}$ and it was almost constant. The outdoor concentration $\bar{C}_{\mathrm{O}_{-} \mathrm{CO}_{2}}$ had a mean value of $484 \mathrm{ppm}$ during the monitoring period, with the minimum value of $430 \mathrm{ppm}$ and the maximum one of $763 \mathrm{ppm}$.

The absolute and cumulative frequencies of $\bar{C}_{\mathrm{i}_{-} \mathrm{NH}_{3}}$ and $\bar{C}_{\mathrm{i}_{-} \mathrm{CO}_{2}}$ are presented in Figure 7.4, respectively. Comparing the trends of the two cumulative frequencies, the control of $\bar{C}_{\mathrm{i}_{-} \mathrm{NH}_{3}}$ appears more problematic than the control of $\bar{C}_{\mathrm{i}_{-} \mathrm{CO}_{2}}$. Analyzing separately the $\mathrm{NH}_{3}$ and $\mathrm{CO}_{2}$ concentrations, it stands out that $43 \%$ of the $\bar{C}_{\mathrm{i}_{\mathrm{N} H}}$ values are above $20 \mathrm{ppm}$, while around $30 \%$ of the $\bar{C}_{\mathrm{i}_{1} \mathrm{CO}_{2}}$ values result above 3,000 ppm. Considering the analyzed gas concentration together, $\bar{C}_{\mathrm{i}_{-} \mathrm{NH}_{3}}$ and $\bar{C}_{\mathrm{i}_{-} \mathrm{CO}_{2}}$ are below their thresholds only for $40 \%$ of the monitored time. It means that 
the gas concentration limits were not respected in the monitored broiler house for $60 \%$ of time.
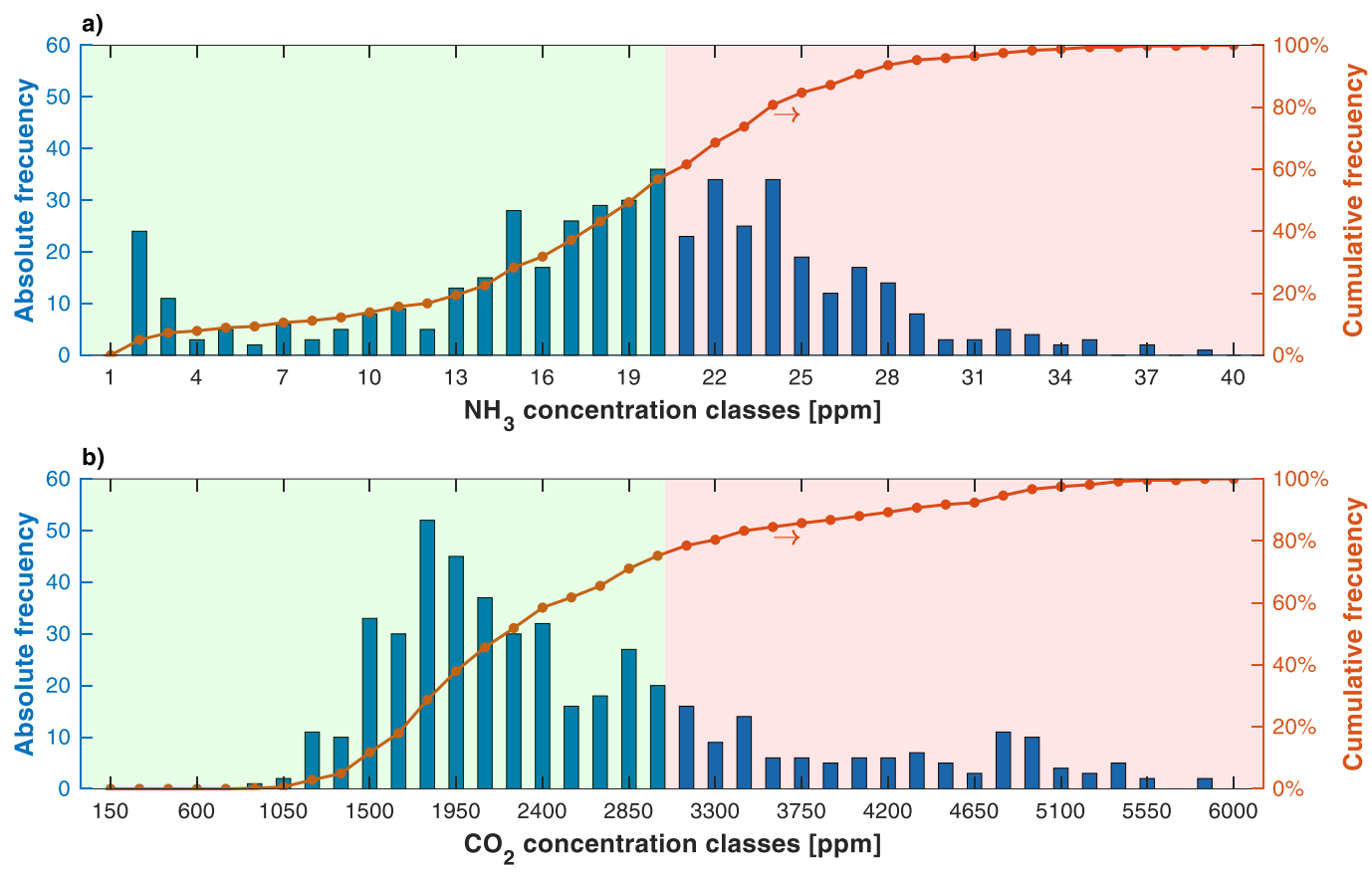

Figure 7.4 - Absolute and cumulative frequencies of: a) monitored indoor average $\mathrm{NH}_{3}$ concentration $\left(\bar{C}_{\mathrm{i}_{-} \mathrm{NH}_{3}}\right)$; b) monitored indoor average $\mathrm{CO}_{2}$ concentration $\left(\bar{C}_{\mathrm{i}_{-} \mathrm{CO}_{2}}\right)$. The arrows indicate the reference axis.

The negative effects of a stressor on the animal's welfare are dependent on both its severity and its duration [331,332]. Although acute exposure to lethal concentrations of gases may occur in livestock buildings, the effects of chronic exposure are more insidious [28]. A long exposure of around 42 days to $\mathrm{NH}_{3}$ at $20 \mathrm{ppm}$, for example, may cause pulmonary congestion, oedema, and hemorrhage [319,333]. Broilers exposed to 25 and $50 \mathrm{ppm}$ of $\mathrm{NH}_{3}$ concentration for 35 days increased the respiratory rate, the hemoglobin and hematocrit, which could indicate an increase in the metabolic activity to meet energy demands under stressful situations [109]. For this reason, it is important to consider both the concentration values and the exposure time. Table 7.3 shows the number of events -defined as the periods of time in which the gas concentration limit is continuously exceeded-and their duration, that is defined as the time in which the gas concentration is continuously above the established limit. The number of events in which $C_{\lim \_\mathrm{NH}_{3}}$ was exceeded in the monitored period was 30. About half of these events (14) lasted less than 8 hours with maximum $\bar{C}_{\mathrm{i}_{-} \mathrm{NH}_{3}}$ values lower than $27 \mathrm{ppm}$, while 11 events lasted more than 18 hours reaching concentration values considerably higher than $C_{\text {lim_NH }}$ (e.g. 36.5 and $38.1 \mathrm{ppm}$ ). Such high concentrations may have a deleterious effect on growth [108,317,319], may cause alterations in blood physiological parameters [109] and aversion to atmospheres [316,334].

The number of events in which $\bar{C}_{\mathrm{i}_{-} \mathrm{CO}_{2}}$ exceeded $C_{\text {lim_- } \mathrm{CO}_{2}}$ was 12 . In 5 of them, the duration was higher than 18 hours with concentrations considerably higher than 
the limit, being up to 5,796 ppm as maximum value. These high concentrations can be considered tolerated by broilers if intermittent [335], otherwise they represent a risk for their health.

According to literature, it seems easy for most of the farms to maintain $\mathrm{CO}_{2}$ levels below the limits that can cause damages to the broilers [110]. The results reported in Figure 7.4 and Table 7.3 confirm what stated in literature since in the analyzed case study the control of $\mathrm{CO}_{2}$ concentration was easier than the one of $\mathrm{NH}_{3}$.

Table 7.3 - Number of events and duration in which the indoor average $\mathrm{NH}_{3}\left(\bar{C}_{\mathrm{i}_{-} \mathrm{NH}_{3}}\right)$ and $\mathrm{CO}_{2}$ $\left(\bar{C}_{\mathrm{i}_{-} \mathrm{CO}_{2}}\right)$ concentrations exceeded the established thresholds.

\begin{tabular}{|c|c|c|c|c|}
\hline \multirow[b]{2}{*}{$\begin{array}{c}\text { Duration } \\
{[\mathrm{h}]}\end{array}$} & \multicolumn{2}{|c|}{$\mathbf{N H}_{3}$} & \multicolumn{2}{|c|}{$\mathrm{CO}_{2}$} \\
\hline & $\begin{array}{c}\text { Number of } \\
\text { events }\end{array}$ & $\begin{array}{c}\text { Maximum } \\
\bar{C}_{\mathrm{i} \_\mathrm{NH}_{3}} \\
{[\mathrm{ppm}]}\end{array}$ & $\begin{array}{c}\text { Number of } \\
\text { events }\end{array}$ & $\begin{array}{c}\text { Maximum } \\
\bar{C}_{\mathrm{i}_{1} \mathrm{Co}_{2}} \\
{[\mathrm{ppm}]}\end{array}$ \\
\hline From 2 to 4 & 7 & 22.3 & 2 & 3,121 \\
\hline From 6 to 8 & 7 & 27.0 & 1 & 3,101 \\
\hline From 10 to 12 & 1 & 22.0 & 1 & 3,178 \\
\hline From 14 to 16 & 4 & 33.1 & 3 & 3,508 \\
\hline From 18 to 20 & 9 & 36.5 & 2 & 4,113 \\
\hline From 22 to 24 & 0 & - & 2 & 4,744 \\
\hline More than 24 & 2 & 38.1 & 1 & 5,796 \\
\hline Total & 30 & - & 12 & - \\
\hline
\end{tabular}

\subsubsection{Evaluation of the theoretical ventilation increase}

As described in the previous sections, the thresholds of $\mathrm{NH}_{3}$ and $\mathrm{CO}_{2}$ were exceeded repeatedly during the monitored period with different time durations. In the case study, the adopted strategy to reduce those concentrations is to increase the ventilation rate. In other words, gas concentrations were used as additional control parameters of ventilation, in addition to $\theta_{\text {air_i }}$ that is the most commonly used. The required ventilation was modelled assuming a constant emission rate of $\mathrm{NH}_{3}$ and $\mathrm{CO}_{2}$. Although other options are available, the increased ventilation strategy may be the most readily convenient for a farmer. A critical assumption of the approach in this study is that gas emissions do not differ for different ventilation rates. Despite it is known that $\mathrm{NH}_{3}$ emissions are affected by airflow rates and patterns [336], the effect of changing ventilation rate on gas emissions is unclear in research. On the one hand, Knížatová et al. [322] suggested that higher ventilation is the reason of increased emissions in summer. However, higher ventilation rates at certain $\theta_{\text {air_i }}$ and $\mathrm{RH}_{\mathrm{i}}$ also contribute to litter drying, thus reducing the emission of $\mathrm{NH}_{3}$ [329]. There is no evidence of variations in $\mathrm{CO}_{2}$ emissions due to changes in ventilation rates, and therefore the hypothesis of a constant emission of this gas seems adequate. Furthermore, the variation in percentage between $\dot{V}_{1+s}$ and $\dot{V}_{1+s}^{\prime}$ is generally small, being lower than $60 \%$ in $90 \%$ of the considered time steps. In the primary axis of Figure 7.5 , the relative variation -in percentage- between $\dot{V}_{1+\mathrm{s}}^{\prime}$ and 
$\dot{V}_{l+s}$ is shown. The graph shows that, during the first days, the difference in percentage is higher than in the following ones, reaching its maximum value (116\%). After the first days, the difference decreases, and a further increase can be noticed in the half of the monitored period. To better understand the trend of the increased ventilation flow rate, the absolute variation between $\dot{V}_{1+s}^{\prime}$ and $\dot{V}_{1+s}\left(\Delta \dot{V}_{1+s}^{\prime}\right)$ is analyzed. This trend is reported in the secondary axis of Figure 7.5 and is expressed in $\mathrm{m}^{3} \mathrm{~h}^{-1}$. The graph shows that $\Delta \dot{V}_{1+\mathrm{s}}^{\prime}$ is higher from January $7^{\text {th }}$ to $18^{\text {th }}$ when peaks that exceed $25,000 \mathrm{~m}^{3} \mathrm{~h}^{-1}$ are present. These considerable values of $\Delta \dot{V}_{1+\mathrm{s}}^{\prime}$ depend on the increase of $\bar{C}_{\mathrm{i}_{-} \mathrm{NH}_{3}}$ that characterizes those days, as reported in Figure $7.3 \mathrm{c}$. From January $19^{\text {th }}$ to the end of the cycle, $\Delta \dot{V}_{1+s}^{\prime}$ is not needed because higher values of $\dot{V}_{\text {l+s }}$ were monitored due to the increase of $\theta_{\text {air_o }}$. The only exception is from January $24^{\text {th }}$ to $30^{\text {th }}$ when the decrease of $\theta_{\text {air_o }}$ entails a reduction of $\dot{V}_{\mathrm{l}+\mathrm{s}}$ that is not enough to maintain $\bar{C}_{\mathrm{i}_{-} \mathrm{NH}_{3}}$ below the established limit. From the beginning of the monitored period to January $6^{\text {th }}, \Delta \dot{V}_{1+s}^{\prime}$ values rarely exceed $10,000 \mathrm{~m}^{3} \mathrm{~h}^{-1}$. These increases in ventilation are needed to dilute the high $\mathrm{CO}_{2}$ concentration of those day that are caused by the low values of $\dot{V}_{1+s}$ and the activation of the propane air heaters that emit exhaust fumes directly inside the house.

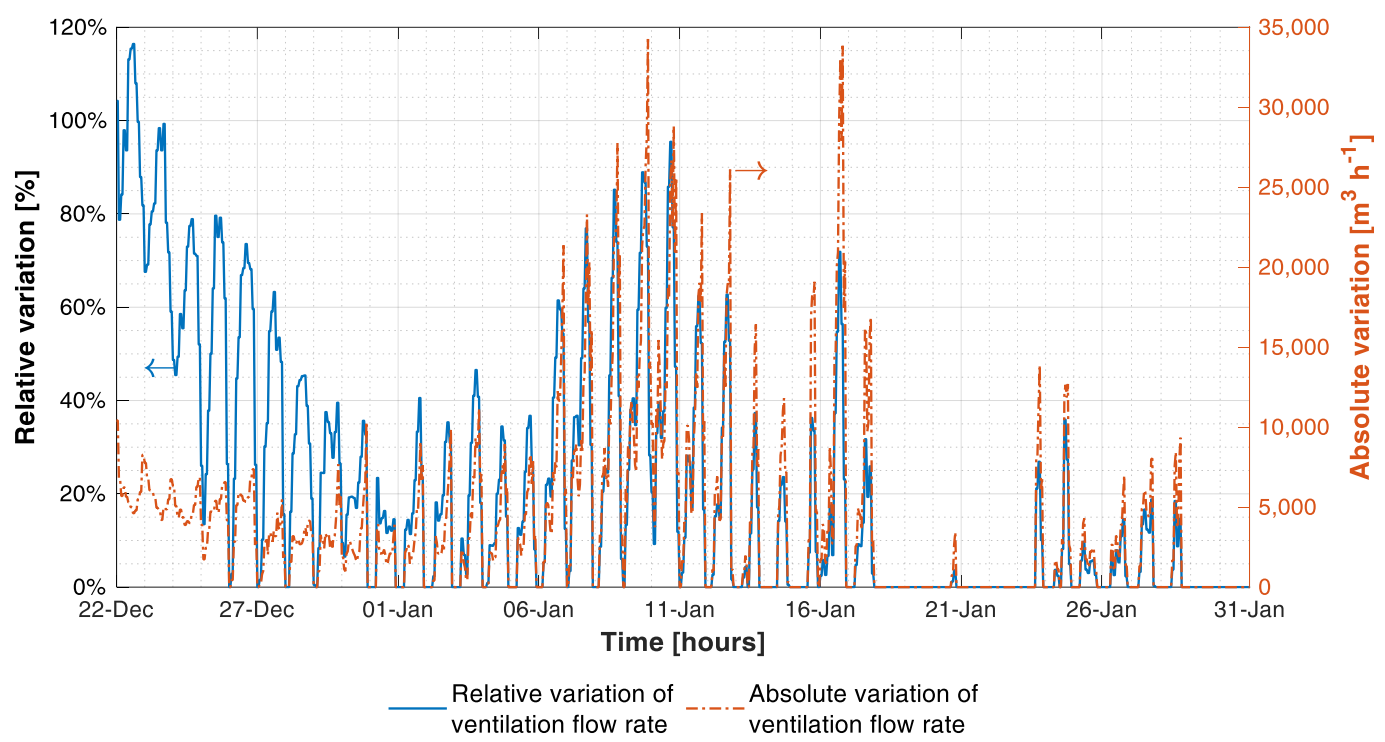

Figure 7.5 - Relative and absolute ventilation variation $\left(\Delta \dot{V}_{1+s}^{\prime}\right)$ between increased $\left(\dot{V}_{1+s}^{\prime}\right)$ and actual $\left(\dot{V}_{\mathrm{l}+\mathrm{s}}\right)$ ventilation flow rates (arrows indicate the reference axis).

In this analysis, the increased ventilation flow rate was calculated considering each gas emission $\dot{q}_{\mathrm{x}}$ constant and not influenced by the variation of the indoor environmental conditions. A future improvement of the present work may involve the evaluation of the theoretical increase of the ventilation flow rate considering a not constant gas emission. Different parameters that influence $\mathrm{NH}_{3}$ and $\mathrm{CO}_{2}$ emissions, such as the litter conditions, could be considered.

In the present work, the extra ventilation flow rate was calculated considering that the supplemental heating system does not emit exhaust fumes inside the house. 
In this way, $\mathrm{CO}_{2}$ concentration is not further increased when extra supplemental heat is needed to maintain $\theta_{\text {set_H. }}$. Anyway, it was verified that if the supplemental heat is provided by the same propane heaters present inside the analyzed broiler house, the emitted exhaust fumes would increase the $\mathrm{CO}_{2}$ concentration by less than $3 \%$ on average. This is because the $\mathrm{CO}_{2}$ emissions from broilers are considerably higher than the one from the propane air heaters.

\subsubsection{Evaluation of the energy consumption}

The analyses show that during the monitored period around $41,900,000 \mathrm{~m}^{3}$ of fresh air were provided by the fans to the broiler house. To maintain the required gas concentration during all the monitored period, around 45,800,000 $\mathrm{m}^{3}$ of fresh air are theoretically needed, an increase by $9.3 \%$. This increase in ventilation flow rate makes it possible to respect the established gas concentration thresholds. At same time, the increased ventilation boosts the consumption of electrical energy for

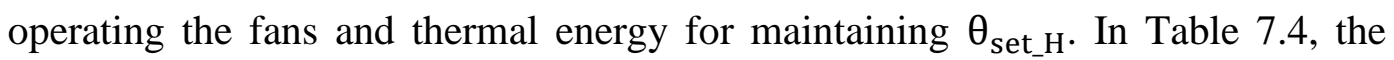
thermal and electrical energy consumption considering $\dot{V}_{\mathrm{l}+\mathrm{s}}$ and $\dot{V}_{\mathrm{l+s}}^{\prime}$ are presented and compared. From the table it stands out that considering the increased ventilation, the electrical energy consumption rises from $1,946 \mathrm{kWh}_{\mathrm{el}}\left(E_{\mathrm{el} \_\mathrm{l}+\mathrm{s}}\right)$ to $2,137 \mathrm{kWh}_{\mathrm{el}}\left(E_{\mathrm{el} \_\mathrm{l}+\mathrm{s}}^{\prime}\right)$, an increase by $9.8 \%$. Focusing on the share of the electrical energy consumption of large and small fans, the table shows that, on the one hand, the electrical energy consumption of the small fans increases by $11.5 \%$, rising from $1,689 \mathrm{kWh}_{\mathrm{el}}\left(E_{\mathrm{el} \_\mathrm{s}}\right)$ to $1,883 \mathrm{kWh}_{\mathrm{el}}\left(E_{\mathrm{el} \_\mathrm{s}}^{\prime}\right)$. On the other hand, the electrical energy consumption due to the operation of large fans slightly decreases by $1.2 \%$, from $257 \mathrm{kWh}_{\mathrm{el}}\left(E_{\text {el_ll }}\right)$ to $254 \mathrm{kWh}_{\mathrm{el}}\left(E_{\text {el_l}}^{\prime}\right)$. This slight decrease depends on the control logic that is set in the climate control system for activating the fans. Most of the estimated values of $\dot{V}_{1+s}^{\prime}$, in fact, are below the threshold of activation of the large fans $\left(75,000 \mathrm{~m}^{3} \mathrm{~h}^{-1}\right)$ and the increased ventilation flow rate is provided almost only by the small fans and their energy consumption increases. Little differences between the real control logic of the fans and the modelled one may exist, and they may slightly affect the results.

The increase of ventilation air flow rate also entails an increase in the thermal energy consumption for supplemental heating, as reported in Table 7.4. During the monitored period, the energy simulation model estimates $E_{\text {th }}$ to be around $31,816 \mathrm{kWh}_{\mathrm{th}}$, while, considering $\dot{V}_{\mathrm{l}+\mathrm{s}}^{\prime}, E_{\mathrm{th}}^{\prime}$ becomes $36,190 \mathrm{kWh}_{\mathrm{th}}$, an increase by $13.7 \%$. 
Table 7.4 - Comparison between the electrical $\left(E_{\mathrm{el}}\right)$ and thermal energy consumption $\left(E_{\mathrm{th}}\right)$ considering the actual ventilation flow rate $\left(\dot{V}_{\mathrm{l}+\mathrm{s}}\right)$ and the electrical $\left(E_{\mathrm{el}}^{\prime}\right)$ and thermal energy consumption $\left(E_{\text {th }}^{\prime}\right)$ considering the increased ventilation flow rate $\left(\dot{V}_{1+\mathrm{s}}^{\prime}\right)$.

\begin{tabular}{|c|c|c|}
\hline $\begin{array}{c}\text { Energy consumption } \\
\text { considering } \dot{V}_{l+s}\end{array}$ & $\begin{array}{c}\text { Energy consumption } \\
\text { considering } \dot{V}_{l+s}^{\prime} \\
\end{array}$ & $\begin{array}{c}\text { Difference } \\
\text { (percentage) }\end{array}$ \\
\hline${ }^{1} E_{\text {el_l }}$ & $E_{\text {el_l }}^{\prime}$ & \\
\hline $257 \mathrm{kWh}_{\mathrm{el}}$ & $254 \mathrm{kWh}_{\mathrm{el}}$ & $-1.2 \%$ \\
\hline${ }^{2} E_{\text {el_s }}$ & $E_{\text {el_s }}^{\prime}$ & \\
\hline $1,689 \mathrm{kWh}_{\mathrm{el}}$ & $1,883 \mathrm{kWh}_{\mathrm{el}}$ & $+11.5 \%$ \\
\hline$E_{\text {el_ll+s }}$ & $E_{\text {el_l+s }}^{\prime}$ & \\
\hline $1,946 \mathrm{kWh}_{\mathrm{el}}$ & $2,137 \mathrm{kWh}_{\mathrm{el}}$ & $+9.8 \%$ \\
\hline$E_{\text {th }}$ & $E_{\mathrm{th}}^{\prime}$ & \\
\hline $31,816 \mathrm{kWh}_{\mathrm{th}}$ & $36,190 \mathrm{kWh}_{\mathrm{th}}$ & $+13.7 \%$ \\
\hline
\end{tabular}

The increase of thermal energy consumption is focused especially on the central part of the analyzed period, as shown in Figure 7.6 where the heating load needed considering $\dot{V}_{\mathrm{l}+\mathrm{s}}\left(\phi_{\mathrm{H}}\right)$ and the theoretical heating load considering $\dot{V}_{\mathrm{l+s}}^{\prime}\left(\phi_{\mathrm{H}}^{\prime}\right)$ are shown on the primary axis. The monitored value of $\theta_{\text {air_i }}$, the values of $\theta_{\text {set_H }}, \theta_{\text {set_C }}$ and the simulated indoor air temperature $\left(\theta_{\text {air_i }}^{\prime}\right)$ are displayed on the secondary axis of the same graph. The analysis of the heating loads shows that $\phi_{\mathrm{H}}$ does not reach $170 \mathrm{~kW}$, that is the maximum heating capacity of the two propane air heaters of the broiler house. The average value of $\phi_{\mathrm{H}}$ was estimated to be around $33 \mathrm{~kW}$, with a maximum value of around $94 \mathrm{~kW}$. The average value of $\phi_{\mathrm{H}}^{\prime}$ is not far from the one of $\phi_{\mathrm{H}}$, being around $37 \mathrm{~kW}$, but the charts shows that $\phi_{\mathrm{H}}^{\prime}$ trend is characterized by some peaks that are not present in $\Phi_{\mathrm{H}}$ trend, especially from January $7^{\text {th }}$ to $18^{\text {th }}$, when the highest values of $\Delta \dot{V}_{1+\mathrm{s}}^{\prime}$ were estimated. The $\phi_{\mathrm{H}}^{\prime}$ peaks exceed the threshold of $170 \mathrm{~kW}$, the maximum heat capacity of the two air heaters, reaching a value around $227 \mathrm{~kW}$. It means that, adopting $\dot{V}_{1+s}^{\prime}$ as ventilation strategy, the propane gas heaters would not be able to maintain the established $\theta_{\text {set_H }}$ during few hours of the monitored period. This aspect represents a further issue in increasing the ventilation flow rate to control gas concentration beyond the increase in energy consumption. This is since it may happen that, in an existing broiler house, the existing climate control system -air heaters and fans- would not be sized and designed to provide the needed ventilation flow rate and/or the adequate heating load when $\mathrm{NH}_{3}$ and $\mathrm{CO}_{2}$ concentrations should be controlled. 


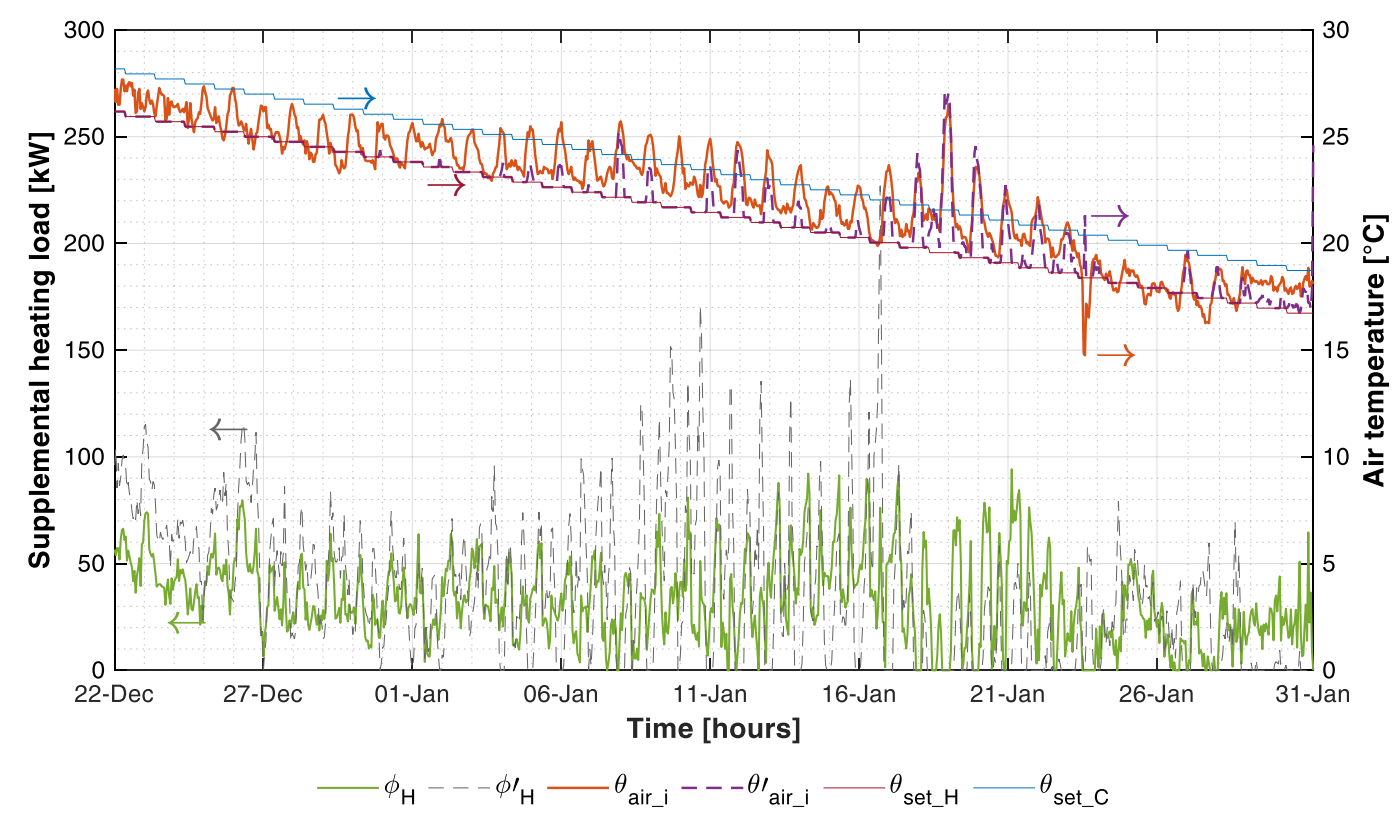

Figure 7.6 - Trend of indoor air temperature $\left(\theta_{\text {air }_{i} i}\right)$, indoor air temperature considering increased ventilation $\left(\theta_{\text {air_i }}^{\prime}\right)$, heating $\left(\theta_{\text {set_H }}\right)$ and cooling $\left(\theta_{\text {set_C }}\right)$ set point temperatures. On the secondary $y$-axis, heating load $\left(\phi_{\mathrm{H}}\right)$ and theoretical heating load $\left(\phi_{\mathrm{H}}^{\prime}\right)$ are shown (arrows indicate the reference axis).

Analyzing the trends of indoor air temperatures of Figure 7.6, the graph highlights that $\theta_{\text {air_i }}$ and $\theta_{\text {air_i }}^{\prime}$ trends are quite similar between them, even though $\theta_{\text {air_i }}$ tends to fluctuate between $\theta_{\text {set_H }}$ and $\theta_{\text {set_C }}$ more than $\theta_{\text {air_i }}^{\prime}$. Both $\theta_{\text {air_i }}$ and $\theta_{\text {air_i }}^{\prime}$ increase considerably over $\theta_{\text {set_c }}$ on January $19^{\text {th }}$ when the peak of $\theta_{\text {air_o }}$ was monitored. On January $24^{\text {th }}$, the trends of $\theta_{\text {air_i }}$ and $\theta_{\text {air_i }}^{\prime}$ differ relevantly. This difference is due to the broiler harvesting operations of that day that increase outdoor air infiltration due to door opening, with a consequent decrease of $\theta_{\text {air_i }}$. This ventilation flow rate increase is not considered by the energy simulation model that, consequently, underestimates $\theta_{\text {air_i }}^{\prime}$.

As stated before, the production of the analyzed cycle was 23,212 broilers with a final live weight of $62,534 \mathrm{~kg}$. Considering a carcass yield of $73 \%$, a total meat production of roughly $45,650 \mathrm{~kg}$ is estimated. Expressing $E_{\text {el_l+s }}$ and $E_{\text {th }}$ per unit of final product ( $\mathrm{kg}_{\text {meat }}$ ), the specific energy consumption is estimated to be $43 \mathrm{Wh}_{\mathrm{el}} \mathrm{kg}_{\text {meat }}^{-1}$ and $697 \mathrm{Wh}_{\mathrm{th}} \mathrm{kg}_{\text {meat }}^{-1}$, respectively. These values are comparable to the average ones found in another previous work in literature [337] that estimated a specific energy consumption to produce a $\mathrm{kg}$ of broiler meat between 20 and $45 \mathrm{Wh}_{\mathrm{el}}$ for ventilation and between 380 and $760 \mathrm{Wh}_{\mathrm{th}}$ for heating. Considering the increase in ventilation, the previously mentioned values would increase up to $47 \mathrm{Wh}_{\mathrm{el}}$ and $793 \mathrm{Wh}_{\mathrm{th}}$, but further analysis should be carried out for investigating how the improvement in the $I A Q$ conditions may increase the meat production, entailing a consequent reduction of the specific energy consumption values.

In Figure 7.7, the total primary energy consumption -the concept was previously presented in Chapter 6- and the share due to heating and ventilation are shown considering the actual and the increased ventilation flow rates. To convert 
the electrical and thermal energy into primary energy, the following total conversion factors -renewable plus non-renewable energy- of Spain were used [338]:

- $f_{\mathrm{p}_{-} \text {tot }}=2.403\left[\mathrm{kWh}_{\mathrm{p}} \mathrm{kWh}_{\mathrm{el}}^{-1}\right]$ for the electrical energy from the grid;

- $f_{\mathrm{p}_{-} \text {tot }}=1.195\left[\mathrm{kWh}_{\mathrm{p}} \mathrm{kWh}_{\mathrm{th}}^{-1}\right]$ for the natural gas.

The chart shows that the primary energy consumption considering the actual ventilation flow rate is estimated to be about $42,696 \mathrm{kWh}_{\mathrm{p}}$ with $12 \%\left(4,676 \mathrm{kWh}_{\mathrm{p}}\right)$ due to ventilation and the remaining $88 \%\left(38,020 \mathrm{kWh}_{\mathrm{p}}\right)$ due to heating. Increasing the ventilation flow rate, the primary energy consumption reaches $48,383 \mathrm{kWh}_{\mathrm{p}}$ with similar shares of energy for ventilation $5,135 \mathrm{kWh}_{\mathrm{p}}(9 \%)$ and heating $43,248 \mathrm{kWh}_{\mathrm{p}}(91 \%)$. The increase of the ventilation flow rate entails an increase by $13 \%$ in terms of total primary energy.

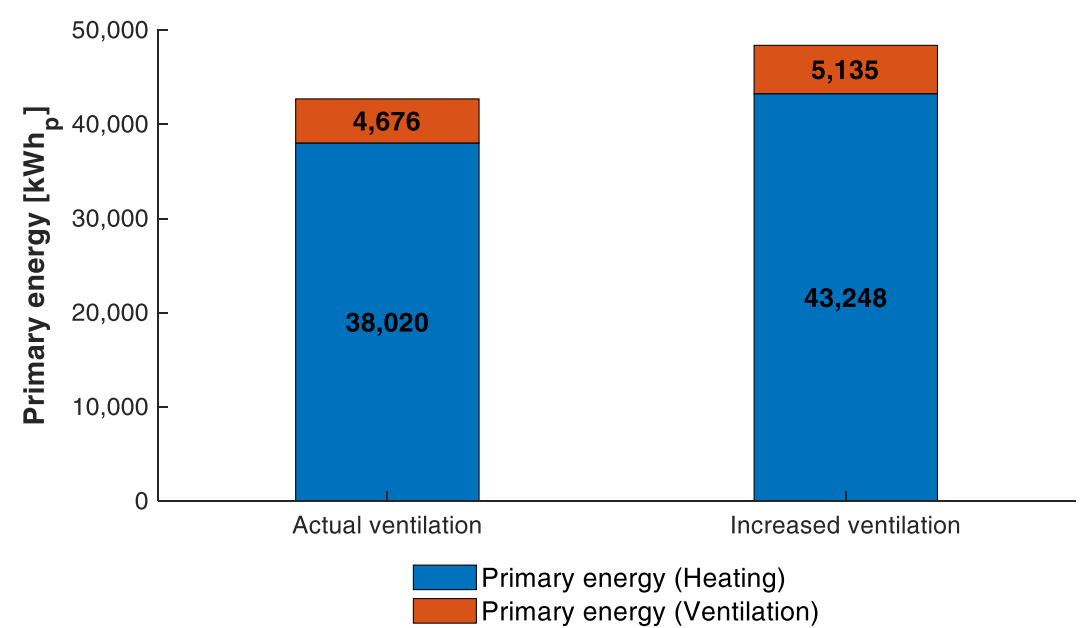

Figure 7.7 - Comparison between the total primary energy consumption and the shares due to heating and ventilation considering the actual and the increased ventilation flow rates.

A last consideration concerns the financial implications of increasing the ventilation flow rate to maintain the gas concentrations below the established thresholds. Assuming a cost -excluding taxes- for the electrical energy in Spain equal to $0.14 € \mathrm{kWh}_{\mathrm{el}}^{-1}$ [339] and $0.08 € \mathrm{kWh}_{\mathrm{th}}^{-1}$ for the thermal energy from propane [340], the total cost for climate control considering the actual ventilation flow rate is estimated to be $2,818 €$, meaning around $0.117 €$ per harvested broiler. Increasing the ventilation flow rate, the production cost due to the energy for climate control will increase up to $3,194 €(0.133 €$ per broiler), an increase by $14 \%$.

\subsection{Final considerations}

In this chapter, the variation of the energy consumption due to the increase of ventilation for maintaining $\mathrm{NH}_{3}$ and $\mathrm{CO}_{2}$ concentrations below established thresholds -20 and 3,000 ppm, respectively- were evaluated. A winter growing cycle of broilers in a Mediterranean broiler farm was used as a case study. In the monitored case study, $\mathrm{NH}_{3}$ and $\mathrm{CO}_{2}$ concentrations were both below the established 
thresholds at the same time during $40 \%$ of time. The control of $\mathrm{CO}_{2}$ concentration represented a major issue during the first part of the analyzed period, while the control of $\mathrm{NH}_{3}$ concentration was relevant during the central part of the production cycle. To maintain the desired gas concentrations, the ventilation flow rate needed to be increased by around $9 \%$. This resulted in electrical energy consumption increasing by around $10 \%$ (from 1,946 to $2,137 \mathrm{kWh}_{\mathrm{el}}$ ), while the thermal energy increased roughly by $14 \%$ (from $31,816 \mathrm{kWh}_{\text {th }}$ to $36,190 \mathrm{kWh}_{\mathrm{th}}$ ). The additional energy cost to maintain the gas concentration below the thresholds was estimated to be $376 €(+14 \%)$.

The methodology presented here can be used for other situations, such as different farm designs and climate conditions, but specific technical limitations of existing farms to provide higher ventilation rates should be considered, such as the limited capacity of fans and heaters. This work may be improved implementing in the adopted simulation model the short-and long-term effects of changing ventilation on $\mathrm{NH}_{3}$ and $\mathrm{CO}_{2}$ emissions.

\subsection{Chapter nomenclature}

\begin{tabular}{|c|c|}
\hline$a_{\text {perf }}-c_{\text {perf }}$ & Regression coefficients for $S F P$ calculation (large fans) \\
\hline$b_{\mathrm{s}_{-} 2}-b_{\mathrm{s}_{-} 0}$ & Regression coefficients for $S F P$ calculation (small fans) \\
\hline$C_{\mathrm{c}_{-} \mathrm{x}}$ & Mass concentration of gas $x$ in the center of the house [ppm] \\
\hline$C_{\mathrm{e} \_\mathrm{x}}$ & Exhaust mass concentration of gas $x$ [ppm] \\
\hline $\bar{C}_{\mathrm{i} \_\mathrm{x}}$ & Indoor average mass concentration of gas $x[\mathrm{ppm}]$ \\
\hline $\bar{C}_{\mathrm{i}_{-} \mathrm{CO}_{2}}$ & Indoor average mass concentration of $\mathrm{CO}_{2}[\mathrm{ppm}]$ \\
\hline $\bar{C}_{\mathrm{i}_{-} \mathrm{NH}_{3}}$ & Indoor average mass concentration of $\mathrm{NH}_{3}[\mathrm{ppm}]$ \\
\hline$C_{\lim _{-} \mathrm{x}}$ & Mass concentration limit of gas $x[\mathrm{ppm}]$ \\
\hline$C_{\lim _{-} \mathrm{CO}_{2}}$ & Mass concentration limit of $\mathrm{CO}_{2}[\mathrm{ppm}]$ \\
\hline$C_{\text {lim_NH }} \mathrm{NH}_{3}$ & Mass concentration limit of $\mathrm{NH}_{3}[\mathrm{ppm}]$ \\
\hline$C_{\mathrm{o} \_\mathrm{x}}$ & Outdoor mass concentration of gas $x$ [ppm] \\
\hline $\bar{C}_{\mathrm{o}_{\mathrm{x}} \mathrm{x}}$ & Outdoor average mass concentration of gas $x$ [ppm] \\
\hline $\bar{C}_{\mathrm{O}_{-} \mathrm{CO}_{2}}$ & Outdoor average mass concentration of $\mathrm{CO}_{2}[\mathrm{ppm}]$ \\
\hline $\bar{C}_{\mathrm{O}_{-} \mathrm{NH}_{3}}$ & Outdoor average mass concentration of $\mathrm{NH}_{3}[\mathrm{ppm}]$ \\
\hline$E_{\text {el_l }}$ & Actual electrical energy consumption of large fans $[\mathrm{kWh}$ el $]$ \\
\hline$E_{\text {el_l }}^{\prime}$ & Electrical energy consumption of large fans (increased ventilation) $\left[\mathrm{kWh}_{\mathrm{el}}\right]$ \\
\hline$E_{\text {el_l+s }}$ & Actual electrical energy consumption of all fans $\left[\mathrm{kWh} \mathrm{h}_{\mathrm{el}}\right]$ \\
\hline$E_{\text {el_l}+\mathrm{s}}^{\prime}$ & Electrical energy consumption of all fans (increased ventilation) $\left[\mathrm{kWh}_{\mathrm{el}}\right]$ \\
\hline$E_{\mathrm{el} \_\mathrm{s}}$ & Actual electrical energy consumption of small fans $\left[\mathrm{kWh}_{\mathrm{el}}\right]$ \\
\hline$E_{\mathrm{el} \_\mathrm{s}}^{\prime}$ & Electrical energy consumption of large fans (increased ventilation) $\left[\mathrm{kWh}_{\mathrm{el}}\right]$ \\
\hline$E_{\text {th }}$ & Thermal energy consumption for heating $\left[\mathrm{kWh}_{\mathrm{th}}\right]$ \\
\hline$E_{\text {th }}^{\prime}$ & Thermal energy consumption for heating (increased ventilation) $\left[\mathrm{kWh}_{\mathrm{th}}\right]$ \\
\hline$f_{\mathrm{p}_{\mathrm{t}} \text { tot }}$ & Total primary energy conversion factor $\left[\mathrm{kWh}_{\mathrm{p}} \mathrm{kWh}^{-1}\right]$ \\
\hline$I_{\text {tot_hor }}$ & Total solar radiation on horizontal plane $\left[\mathrm{W} \mathrm{m}^{-2}\right]$ \\
\hline$I A Q$ & Indoor Air Quality \\
\hline$j$ & Considered time step \\
\hline$m_{\mathrm{x}}$ & Molecular mass of gas $x\left[\mathrm{~kg} \mathrm{~mol}^{-1}\right]$ \\
\hline$\dot{q}_{\mathrm{x}}$ & Emission rate of gas $x$ from internal sources $\left[\mathrm{mg}_{\mathrm{x}} \mathrm{h}^{-1}\right]$ \\
\hline
\end{tabular}


$R H_{\mathrm{i}} \quad$ Indoor air relative humidity [\%]

$R H_{\mathrm{o}} \quad$ Outdoor air relative humidity [\%]

SFP Specific Fan Performance $\left[\mathrm{m}^{3} \mathrm{Wh}^{-1}\right]$

$S F P_{1} \quad$ Specific Fan Performance of large fans $\left[\mathrm{m}^{3} \mathrm{Wh}^{-1}\right]$

$S F P_{\mathrm{s}} \quad$ Specific Fan Performance of small fans $\left[\mathrm{m}^{3} \mathrm{Wh}^{-1}\right]$

$U$-value $\quad$ Stationary thermal transmittance $\left[\mathrm{W} \mathrm{m}^{-2} \mathrm{~K}^{-1}\right]$

$\dot{V}_{1}$

$\dot{V}_{1}^{\prime}$

$\dot{V}_{\mathrm{l}+\mathrm{s}}$

$\dot{V}_{1+s}^{\prime}$

$\dot{V}_{1+S_{-} \mathrm{x}}^{\prime}$

$\dot{V}_{1+s_{-} \mathrm{CO}_{2}}^{\prime}$

$\dot{V}_{1+\mathrm{s}_{-} \mathrm{NH}_{3}}^{\prime}$

$V_{\text {mol_x }}$

$\dot{V}_{\mathrm{s}}$

Actual ventilation flow rate of large fans $\left[\mathrm{m}^{3} \mathrm{~h}^{-1}\right]$

Increased ventilation flow rate of large fans $\left[\mathrm{m}^{3} \mathrm{~h}^{-1}\right]$

Total actual ventilation flow rate of fans $\left[\mathrm{m}^{3} \mathrm{~h}^{-1}\right]$

Total increased ventilation flow rate of fans $\left[\mathrm{m}^{3} \mathrm{~h}^{-1}\right]$

Total increased ventilation flow rate to control gas $x$ concentration $\left[\mathrm{m}^{3} \mathrm{~h}^{-1}\right]$

Total increased ventilation flow rate to control $\mathrm{CO}_{2}$ concentration $\left[\mathrm{m}^{3} \mathrm{~h}^{-1}\right]$

Total increased ventilation flow rate to control $\mathrm{NH}_{3}$ concentration $\left[\mathrm{m}^{3} \mathrm{~h}^{-1}\right]$

$\dot{V}_{\mathrm{s}}^{\prime}$

$w_{\mathrm{b}}$

Molar volume of gas $x\left[\mathrm{~m}^{3} \mathrm{~mol}^{-1}\right]$

Actual ventilation flow rate of small fans $\left[\mathrm{m}^{3} \mathrm{~h}^{-1}\right]$

Increased ventilation flow rate of small fans $\left[\mathrm{m}^{3} \mathrm{~h}^{-1}\right]$

$\Delta p_{\mathrm{st}}$

$\Delta \dot{V}_{1+\mathrm{s}}^{\prime}$

$\eta_{\mathrm{H}}$

$\theta_{\text {air_i }}$

$\theta_{\text {air_i }}^{\prime}$

$\theta_{\text {air_o }}$

Broiler mass (live weight) $[\mathrm{kg}]$

Static pressure difference between inside and outside [Pa]

Variation between actual and increased ventilation flow rate $\left[\mathrm{m}^{3} \mathrm{~h}^{-1}\right]$

Conversion efficiency of the supplemental heating system [-]

Indoor air temperature $\left[{ }^{\circ} \mathrm{C}\right]$

Indoor air temperature (increased ventilation) $\left[{ }^{\circ} \mathrm{C}\right]$

Outdoor air temperature $\left[{ }^{\circ} \mathrm{C}\right]$

$\theta_{\text {set_C }}$

Air set point temperature for cooling $\left[{ }^{\circ} \mathrm{C}\right]$

$\theta_{\text {set_H }}$

$\kappa_{\mathrm{i}}$

Air set point temperature for heating $\left[{ }^{\circ} \mathrm{C}\right]$

$\kappa_{\mathrm{i}}$

Internal areal heat capacity $\left[\mathrm{kJ} \mathrm{m}^{-2} \mathrm{~K}^{-1}\right]$

Heat load $\left[\mathrm{kW}_{\mathrm{th}}\right]$

Heat load (increased ventilation) $\left[\mathrm{kW}_{\text {th }}\right]$

$\phi_{H}^{\prime}$

Percentage of activation time of large fans [\%]

$\omega_{1}$

Percentage of activation time of small fans [\%] 
Chapter 8 Conclusions 



\subsection{Final remarks}

In the previous chapters, the overall objective and the three specific objectives of this thesis declared in Chapter 1 were achieved. The tangled network of relations between climate control, energy and other relevant topics of agricultural productions -e.g. productivity, gaseous emissions and health- was investigated by analyzing previous works present in scientific literature (Chapter 2). This analysis was complemented by analyzing real datasets ad-hoc acquired through monitoring campaigns carried out in a greenhouse and two pig houses (Chapter 3). To further analyze the nexus between indoor climate and energy consumption, two energy simulation frameworks were developed for climate-controlled agricultural buildings. The first energy simulation framework regarded mechanically controlled greenhouses and it was validated against real monitored data (Chapter 4). The second simulation framework was focused on mechanically ventilated livestock houses and it was then customized and validated for the energy simulation of broiler houses and growing-finishing pig houses (Chapter 5). The developed frameworks can estimate the thermal and electrical energy consumption for climate control and the lumped values of indoor air temperature and relative humidity. Finally, the potentialities of the developed energy frameworks were shown for what it concerns the evaluation of new approaches for the sustainability and for analyzing specific energy-related problems of climate-controlled agricultural buildings. The validated broiler house model, in fact, was used to investigate the role of envelope and the importance of its design in livestock houses, by evaluating the delivered and primary energy consumptions (Chapter 6). The same model was also adopted to evaluate how an improved ventilation strategy for maintaining established $\mathrm{NH}_{3}$ and $\mathrm{CO}_{2}$ concentration limits -20 and 3,000 ppm, respectively- affects the thermal and electrical energy consumption of a broiler house in Mediterranean area (Chapter 7).

Several conclusions can be derived from the various activities performed in the framework of this thesis and most of them were reported at the end of each chapter. Nevertheless, it seems worth highlighting some general conclusions.

The main contribution of this thesis is to increase the knowledge about climate control in greenhouses and livestock houses, with the focus on the nexus between climate control and energy consumption. This represents a novelty since few works in scientific literature are focused on this specific topic. This nexus was analyzed adopting different approaches based on a literature analysis (Chapter 2), experimental activities (Chapter 3) and numerical simulations (Chapters 4 and 5). All the adopted approaches provide useful information, especially the numerical one. The potentialities of the energy simulation frameworks, in fact, are several as demonstrated in the last part of this thesis. For this reason, the developed energy simulation frameworks are valuable outputs of this investigation, being useful tools for stakeholders and for future research in this field.

The impact of this investigation could be at both global and local levels. At global level, the generated knowledge may represent the basis for developing new 
normative frameworks and incentive schemes aimed at improving the energy performance of climate-controlled agricultural buildings through a top-down process. For this purpose, minimum requirements regarding, for example, energy performance, system efficiency and share of renewable energy production should be fixed. To be effective, the proposed normative framework and incentive scheme should be fine-tuned on the peculiarities of climate-controlled agricultural buildings that were previously presented in this work. The impact of this work at local level may consist in the adoption of the developed energy frameworks by stakeholders, namely farmers, engineers, and manufacturers. The developed energy simulation frameworks, in fact, could represent powerful decision support tools for evaluating the effectiveness of energy-efficient solutions, such as the adoption of new technologies and new strategies.

\subsection{Future works}

This thesis enhances the development of further investigations on the analyzed topics. Future works may aim at further improving the developed energy simulation frameworks. Currently, they can be used to create digital mockups of the analyzed building. Stakeholders, hence, can test the effectiveness of different solutions and technologies, mainly in the design stage. Further improvements may convert the developed frameworks into predictive models that can be implemented as an algorithm directly in the climate control systems of greenhouses and livestock houses. This implementation would make it possible to create digital twins of the analyzed climate-controlled agricultural buildings that can simulate in real time different scenarios, also considering the real-time monitored data, weather forecast and price of energy. In this way, climate control systems can be considerably improved and they will be able to further minimize the energy consumption while guaranteeing the adequate indoor climate conditions, with positive effects on animal welfare and productivity. More ambitious works may consider the energy simulation frameworks developed in this thesis as the starting point to create holistic models of climate-controlled agricultural buildings. These models may estimate with a good reliability all the dynamics of greenhouses and livestock houses, such as the decrease of productivity due to not adequate indoor climate conditions, potential risks for workers' safety and feed and water consumption. For the development of these holistic models, all the mutual relations that were highlighted in Chapter 2 should be considered and modelled. A critical point for the development of similar holistic models would be the modelling of gaseous emissions from livestock houses since it is a tricky challenge, as shown by the literature review of Chapter 2.

\subsection{Future perspectives}

At the end of this thesis a question arises: what are the next steps to reach the sustainability of climate-controlled agricultural buildings? 
Giving an answer, of course, is complex, but some perspective may be provided.

A first step to be done could be a gradual conversion of climate-controlled agricultural buildings from simply energy consumers to energy prosumers. It means that these productive systems will both use and produce energy. In this context, the role of renewable energy technologies and their implementation in micro-smart grids will be fundamental. For this reason, it is of a foremost importance that research will focus on how to improve the exploitation of renewable energy sources in climate-controlled agricultural buildings. This transition from energy consumer to energy prosumer could culminate in a new concept of farm that could be called the Zero Energy Farms. In these farms, on a yearly or shorter time basis, the total amount of energy used by these productive systems will be equal to the amount of energy produced on site using renewable energy sources. It means that farms could sell energy to other nearby energy users, creating a new paradigm that could be a driver for the development of rural areas.

In this transition toward sustainability, energy will not be the only focus since the use of all the resources needed in climate-controlled agricultural buildings -e.g. water, feed and soil- should be optimized, as well as the waste should be minimized. In this sense, an important role could be played by space explorations and by the investigations related to them. Some research projects, in fact, have been focusing on the development of Lunar and Martian greenhouse prototypes that are designed with the objective of being used in contexts in which resource are scarce and most of the waste should be reused. The technology and knowledge generated in the context of these specific applications may be transferred to be applied on climatecontrolled agricultural buildings on Earth to achieve the minimum environmental impact. 



\section{References}

[1] United Nations. World Population Prospects 2019: Highlights. 2019.

[2] Cervantes-Godoy D, Dewbre, Amegnaglo CJ, Soglo YY, Akpa AF, Bickel M, et al. The future of food and agriculture - trends and challenges. vol. 4. Rome (Italy): FAO; 2017.

[3] United Nations - Department of Economic and Social Affairs - Population Division. World Urbanization Prospects: The 2018 Revision (ST/ESA/SER.A/420). New York (USA): United Nations; 2019.

[4] Maia ASC, Culhari E de A, Fonsêca V de FC, Milan HFM, Gebremedhin KG. Photovoltaic panels as shading resources for livestock. J Clean Prod 2020;258:120551. https://doi.org/https://doi.org/10.1016/j.jclepro.2020.120551.

[5] Alexandratos N, Bruinsma J. World agriculture towards 2030/2050: the 2012 revision. ESA Working paper No. 12-03. Rome (Italy): FAO; 2012.

[6] FAO. Global agriculture towards 2050. 2009.

[7] Katsoulas N, Kittas C. Impact of Greenhouse Microclimate on Plant Growth and Development with Special Reference to the Solanaceae. Eur J Plant Sci Biotechnol 2008;2:31-44.

[8] Jat R, Singh VP, Kumar V. Greenhouse cultivation of fruit crops with special reference to India: An overview. J Appl Nat Sci 2020;12:252-60. https://doi.org/https://doi.org/10.31018/jans.v12i2.2276.

[9] Iddio E, Wang L, Thomas Y, McMorrow G, Denzer A. Energy efficient operation and modeling for greenhouses: A literature review. Renew Sustain Energy Rev 2020;117:109480. https://doi.org/10.1016/j.rser.2019.109480.

[10] Albright LD, Reines RG, Anderson SE, Chandra P, Price DR. Experimental results of solar heating a brace institute style greenhouse. Proc. third Annu. Conf. Sol. energy Heat. greenhouses, 1978.

[11] McCartney L, Lefsrud MG. Protected Agriculture in Extreme Environments: A Review of Controlled Environment Agriculture in Tropical, Arid, Polar, and Urban Locations. Appl Eng Agric 2018;34:455-73. https://doi.org/https://doi.org/10.13031/aea.12590.

[12] Taki M, Ajabshirchi Y, Ranjbar SF, Rohani A, Matloobi M. Modeling and experimental validation of heat transfer and energy consumption in an innovative greenhouse structure. Inf Process Agric 2016;3:157-74. https://doi.org/10.1016/j.inpa.2016.06.002.

[13] Vadiee A, Martin V. Energy management strategies for commercial greenhouses. Appl Energy 2014;114:880-8. https://doi.org/10.1016/j.apenergy.2013.08.089.

[14] Khoshnevisan B, Shariati HM, Rafiee S, Mousazadeh H. Comparison of energy consumption and GHG emissions of open field and greenhouse strawberry production. Renew Sustain Energy Rev 2014;29:316-24. https://doi.org/10.1016/j.rser.2013.08.098.

[15] De Villiers DS, Wien HC, Reid JE, Albright LD. Energy use and yields in tomato production: Field, high tunnel and greenhouse compared for the northern tier of the USA (Upstate New York). Acta Hortic. 893, 2011, p. 373-80. https://doi.org/10.17660/ActaHortic.2011.893.34.

[16] IEA. World energy balances - 2019 edition - Database documentation. 2019.

[17] Kittas C, Katsoulas N, Bartzanas T, Bakker S. Greenhouse climate control and energy use. In: Baudoin W, Nono-Womdim R, Lutaladio N, Hodder A, Castilla N, Leonardi C, et al., editors. Good Agric. Pract. Greenh. Veg. Crop., Rome: FAO; 2013.

[18] The Carbon Trust. CT009 Agriculture and Horticulture - Sector Overview. London (UK): 2012.

[19] Runkle E, Both AJ. Greenhouse Energy Conservation Strategies. Extention Bull 2011:1-16. https://doi.org/10.7282/T3K64KWN.

[20] Xu J, Li Y, Wang RZ, Liu W, Zhou P. Experimental performance of evaporative cooling pad systems in greenhouses in humid subtropical climates. Appl Energy 2015;138:291-301. https://doi.org/10.1016/j.apenergy.2014.10.061.

[21] Firfiris VK, Fragos VP, Kotsopoulos TA, Nikita-Martzopoulou C. Energy and environmental analysis of an innovative greenhouse structure towards frost prevention and heating needs conservation. Sustain Energy Technol Assessments 2020;40:100750. https://doi.org/10.1016/j.seta.2020.100750.

[22] Mottet A, de Haan C, Falcucci A, Tempio G, Opio C, Gerber P. Livestock: On our plates or 
eating at our table? A new analysis of the feed/food debate. Glob Food Sec 2017. https://doi.org/10.1016/j.gfs.2017.01.001.

[23] FAO. Dietary protein quality evaluation in human nutrition. Report of an FAQ Expert Consultation. FAO Food Nutr Pap 2013.

[24] Elmadfa I, Meyer AL. Animal Proteins as Important Contributors to a Healthy Human Diet. Annu Rev Anim Biosci 2017. https://doi.org/10.1146/annurev-animal-022516-022943.

[25] Firfiris VK, Martzopoulou AG, Kotsopoulos TA. Passive cooling systems in livestock buildings towards energy saving: A critical review. Energy Build 2019;202. https://doi.org/10.1016/j.enbuild.2019.109368.

[26] FAO. Energy-smart food for people and climate - Issue Paper. Rome: 2011.

[27] ASHRAE. 2011 ASHRAE Handbook: HVAC Applications. Atlanta, GA: ASHRAE; 2011.

[28] Wathes CM, Charles DR. Livestock housing. Wallingford (UK): CAB International; 1994.

[29] Clark JA. Environmental aspects of housing for animal production. 1st Editio. ButterworthHeinemann; 1981. https://doi.org/10.1016/C2013-0-04140-0.

[30] Daramola JO, Abioja MO, Onagbesan OM. Heat Stress Impact on Livestock Production BT - Environmental Stress and Amelioration in Livestock Production. In: Sejian V, Naqvi SMK, Ezeji T, Lakritz J, Lal R, editors., Berlin, Heidelberg: Springer Berlin Heidelberg; 2012, p. 53-73. https://doi.org/10.1007/978-3-642-29205-7_3.

[31] Rötter R, Van De Geijn SC. Climate change effects on plant growth, crop yield and livestock. Clim Change 1999;43:651-81. https://doi.org/10.1023/A:1005541132734.

[32] Strpić K, Barbaresi A, Tinti F, Bovo M, Benni S, Torreggiani D, et al. Application of ground heat exchangers in cow barns to enhance milk cooling and water heating and storage. Energy Build 2020;224:110213. https://doi.org/10.1016/j.enbuild.2020.110213.

[33] Roland-holst D, Zilberman D. How Vulnerable is California Agriculture to Higher Energy Prices? Agric Resour Econ Updat 2006;9:1-4.

[34] Thornton PK. Livestock production: recent trends, future prospects. Philos Trans R Soc B Biol Sci 2010;365:2853-67. https://doi.org/10.1098/rstb.2010.0134.

[35] Pervanchon F, Bockstaller C, Girardin P. Assessment of energy use in arable farming systems by means of an agro-ecological indicator: The energy indicator. Agric Syst 2002;72:149-72. https://doi.org/10.1016/S0308-521X(01)00073-7.

[36] Ecim-Djuric O, Topisirovic G. Energy efficiency optimization of combined ventilation systems in livestock buildings. Energy Build 2010;42:1165-71. https://doi.org/10.1016/j.enbuild.2009.10.035.

[37] Tognoni F, Pardossi A, Serra G. Strategies to match greenhouses to crop production. Acta Hortic., International Society for Horticultural Science (ISHS), Leuven, Belgium; 1999, p. 451-62. https://doi.org/10.17660/ActaHortic.1999.481.52.

[38] Gruda N. Impact of Environmental Factors on Product Quality of Greenhouse Vegetables for Fresh Consumption. CRC Crit Rev Plant Sci 2005;24:227-47. https://doi.org/10.1080/07352680591008628.

[39] Bakker JC. Physiological disorders in cucumber under high humidity conditions and low ventilation rates in greenhouses. Acta Hortic., International Society for Horticultural Science (ISHS), Leuven, Belgium; 1985, p. 257-64. https://doi.org/10.17660/ActaHortic.1985.156.31.

[40] Mortensen LM. Review: CO2 enrichment in greenhouses. Crop responses. Sci Hortic (Amsterdam) 1987;33:1-25. https://doi.org/https://doi.org/10.1016/0304-4238(87)90028-8.

[41] Hicklenton PR. CO2 enrichment in the greenhouse. Principles and practice. Portland (OR), USA: Timber Press; 1988.

[42] Marcelis LFM. Fruit growth and biomass allocation to the fruits in cucumber. 1. Effect of fruit load and temperature. Sci Hortic (Amsterdam) 1993;54:107-21. https://doi.org/https://doi.org/10.1016/0304-4238(93)90059-Y.

[43] Rylski I, Aloni B, Karni L, Zaidman Z. Flowering, fruit set, fruit development and fruit quality under different environmental conditions in tomato and pepper crops. Acta Hortic., International Society for Horticultural Science (ISHS), Leuven, Belgium; 1994, p. 45-56. https://doi.org/10.17660/ActaHortic.1994.366.3.

[44] de Koning ANM. Quantifying the responses to temperature of different plant processes involved in growth and development of glasshouse tomato. Acta Hortic., International Society for Horticultural Science (ISHS), Leuven, Belgium; 1996, p. 99-104. https://doi.org/10.17660/ActaHortic.1996.406.9.

[45] ALONI B, PRESSMAN E, KARNI L. The Effect of Fruit Load, Defoliation and Night 
Temperature on the Morphology of Pepper Flowers and on Fruit Shape. Ann Bot 1999;83:529-34. https://doi.org/10.1006/anbo.1999.0852.

[46] Baytorun AN, Topçu S, Abak K, Dasgan Y. Growth and Production of Tomatoes in Greenhouses at DifferentTemperature Levels. Gartenbauwissenschaft 1999;64:33-39.

[47] Ventura Y, Mendlinger S. Effects of suboptimal low temperature on yield, fruit appearance and quality in muskmelon (Cucumis melo L.) cultivars. J Hortic Sci Biotechnol 1999;74:602-7. https://doi.org/10.1080/14620316.1999.11511160.

[48] Dorais M, Papadopoulos AP, Gosselin A. Greenhouse Tomato Fruit Quality. In: Janick J, editor. Hortic. Rev. (Am. Soc. Hortic. Sci)., Oxford, UK: John Wiley \& Sons, Inc.; 2000, p. 239-319.

[49] Zipelevish E, Grinberge A, Amar S, Gilbo Y, Kafkafi U. Eggplant dry matter composition fruit yield and quality as affected by phosphate and total salinity caused by potassium fertilizers in the irrigation solution. J Plant Nutr 2000;23:431-42. https://doi.org/10.1080/01904160009382030.

[50] Kang H-M, Park K-W, Saltveit ME. Elevated growing temperatures during the day improve the postharvest chilling tolerance of greenhouse-grown cucumber (Cucumis sativus) fruit. Postharvest Biol Technol 2002;24:49-57. https://doi.org/https://doi.org/10.1016/S09255214(01)00129-6.

[51] Blasco X, Martínez M, Herrero JM, Ramos C, Sanchis J. Model-based predictive control of greenhouse climate for reducing energy and water consumption. Comput Electron Agric 2007;55:49-70. https://doi.org/10.1016/j.compag.2006.12.001.

[52] Sabeh NC, Giacomelli GA, Kubota C. Water Use by Greenhouse Evaporative Cooling Systems in a Semi-Arid Climate. Proc. ASAE Annu. Meet. Am. Soc. Agric. Biol. Eng., Minneapolis (MN), USA: 2007, p. 074013. https://doi.org/10.13031/2013.23054.

[53] Hasani Balyani H, Sohani A, Sayyaadi H, Karami R. Acquiring the best cooling strategy based on thermal comfort and $3 \mathrm{E}$ analyses for small scale residential buildings at diverse climatic conditions. Int J Refrig 2015;57:112-37. https://doi.org/https://doi.org/10.1016/j.ijrefrig.2015.04.008.

[54] O’Connor N, Mehta K. Modes of Greenhouse Water Savings. Procedia Eng 2016;159:259_ 66. https://doi.org/https://doi.org/10.1016/j.proeng.2016.08.172.

[55] Omar MN, Taha AT, Samak AA, Keshek MH, Gomaa EM, Elsisi SF. Simulation and validation model of cooling greenhouse by solar energy $(\mathrm{P} \mathrm{V})$ integrated with painting its cover and its effect on the cucumber production. Renew Energy 2021;172:1154-73. https://doi.org/https://doi.org/10.1016/j.renene.2021.03.092.

[56] Tsafaras I, Campen JB, Stanghellini C, de Zwart HF, Voogt W, Scheffers K, et al. Intelligent greenhouse design decreases water use for evaporative cooling in arid regions. Agric Water Manag 2021;250:106807. https://doi.org/https://doi.org/10.1016/j.agwat.2021.106807.

[57] Cecchini M, Colantoni A, Massantini R, Monarca D. Estimation of the risks of thermal stress due to the microclimate for manual fruit and vegetable harvesters in central Italy. J Agric Saf Health 2010;16:141-59. https://doi.org/10.13031/2013.32040.

[58] Callejon-Ferre AJ, Manzano-Agugliaro F, Diaz-Perez M, Carreno-Sanchez J. Improving the climate safety of workers in Almería-type greenhouses in Spain by predicting the periods when they are most likely to suffer thermal stress. Appl Ergon 2011;42:391-6. https://doi.org/https://doi.org/10.1016/j.apergo.2010.08.014.

[59] Marucci A, Pagniello B, Monarca D, Cecchini M, Colantoni A, Biondi P. Heat stress suffered by workers employed in vegetable grafting in greenhouses. J Food, Agric Environ 2012;10:1117-21.

[60] Canakci M, Akinci I. Energy use pattern analyses of greenhouse vegetable production. Energy 2006;31:1243-56. https://doi.org/https://doi.org/10.1016/j.energy.2005.05.021.

[61] Sethi VP, Sharma SK. Greenhouse heating and cooling using aquifer water. Energy 2007;32:1414-21. https://doi.org/https://doi.org/10.1016/j.energy.2006.10.022.

[62] Najjar A, Hasan A. Modeling of greenhouse with PCM energy storage. Energy Convers Manag 2008;49:3338-42. https://doi.org/https://doi.org/10.1016/j.enconman.2008.04.015.

[63] Djevic M, Dimitrijevic A. Energy consumption for different greenhouse constructions. Energy 2009. https://doi.org/10.1016/j.energy.2009.03.008.

[64] Qian T, Dieleman JA, Elings A, De Gelder A, Marcelis LFM, Van Kooten O. Comparison of climate and production in closed, semi-closed and open greenhouses. Acta Hortic., International Society for Horticultural Science (ISHS), Leuven, Belgium; 2011, p. 807-14. https://doi.org/10.17660/ActaHortic.2011.893.88. 
[65] Hemming S, Balendonck J, Dieleman JA, de Gelder A, Kempkes FLK, Swinkels GLAM, et al. Innovations in greenhouse systems - energy conservation by system design, sensors and decision support systems. Acta Hortic., International Society for Horticultural Science (ISHS), Leuven, Belgium; 2017, p. 1-16. https://doi.org/10.17660/ActaHortic.2017.1170.1.

[66] Ntinas GK, Neumair M, Tsadilas CD, Meyer J. Carbon footprint and cumulative energy demand of greenhouse and open-field tomato cultivation systems under Southern and Central European climatic conditions. J Clean Prod 2017;142:3617-26. https://doi.org/https://doi.org/10.1016/j.jclepro.2016.10.106.

[67] Shen Y, Wei R, Xu L. Energy Consumption Prediction of a Greenhouse and Optimization of Daily Average Temperature. Energies 2018;11. https://doi.org/10.3390/en11010065.

[68] Yano A, Cossu M. Energy sustainable greenhouse crop cultivation using photovoltaic technologies. Renew Sustain Energy Rev 2019;109:116-37. https://doi.org/10.1016/j.rser.2019.04.026.

[69] Ben Amara H, Bouadila S, Fatnassi H, Arici M, Allah Guizani A. Climate assessment of greenhouse equipped with south-oriented PV roofs: An experimental and computational fluid dynamics study. Sustain Energy Technol Assessments 2021;45:101100. https://doi.org/https://doi.org/10.1016/j.seta.2021.101100.

[70] Bot GPA. The solar greenhouse- technology for low energy consumption. Acta Hortic., International Society for Horticultural Science (ISHS), Leuven, Belgium; 2004, p. 29-33. https://doi.org/10.17660/ActaHortic.2004.633.2.

[71] Fanger PO. Thermal comfort. Analysis and applications in environmental engineering. Copenhagen (Denmark): Danish Technical Press; 1970.

[72] Yaglou CP, Minard D. Control of heat casualties at military training centers. AMA Arch Ind Health 1957;16:302-16.

[73] Barbaresi A, Maioli V, Bovo M, Tinti F, Torreggiani D, Tassinari P. Application of basket geothermal heat exchangers for sustainable greenhouse cultivation. Renew Sustain Energy Rev 2020;129:109928. https://doi.org/https://doi.org/10.1016/j.rser.2020.109928.

[74] Barre HJ, Sammet LL, Nelson GL. Environmental and Functional Engineering of Agricultural Buildings. New York: Van Nostrand Reinhold Company; 1988. https://doi.org/10.1007/978-1-4684-1443-1.

[75] European Union. Council Directive 99/74/EC of 19 July 1999 laying down minimum standards for the protection of laying hens. Off J Eur Communities 1999.

[76] European Union. Council Directive 2007/43/EC of 28 June 2007: Laying down minimum rules for the protection of chickens kept for meat production. 2007.

[77] European Commission. Council Directive 2008/120/EC of 18th December 2008: Laying down minimum standards for the protection of pigs. 2008.

[78] Newburgh LH, Johnston MNW, Newburgh JD. Some fundamental principles of metabolism. MW Edwards; 1948.

[79] Hutchinson JCD. Progress in the physiology of farm animals. London (UK): Butterworths Scientific Publications; 1954.

[80] Hughes BO. Behaviour as index of welfare. 5th Eur. Poult. Conf., Malta: 1976.

[81] Broom DM. Indicators of poor welfare. $\mathrm{Br}$ Vet $\mathrm{J}$ 1986;142:524-6. https://doi.org/10.1016/0007-1935(86)90109-0.

[82] Farm Animal Welfare Council. Second report on priorities for research and development in farm animal welfare. Tolworth, UK: 1993.

[83] Fregley MJ. Adaptations: some general characteristics. In: Fregley MJ, Blatteis CM, editors. Environ. Physiol., Oxford (UK): Oxford University Press; 1996, p. 3-15.

[84] Fregley MJ, Blatteis CM. Handbook of physiology. Oxford: Oxford University Press; 1996.

[85] Blokhuis H, Miele M, Veissier I, Jones B. Improving farm animal welfare - Science and society working together: The welfare quality approach. 2013. https://doi.org/10.3920/978 90-8686-770-7.

[86] Carr LE, Wheaton FW, Douglass LW. Empirical models to determine ammonia concentrations from broiler chicken litter. Trans Am Soc Agric Eng 1990;33:1337-42. https://doi.org/10.13031/2013.31325.

[87] Aarnink AJA, Van Den Berg AJ, Keen A, Hoeksma P, Verstegen MWA. Effect of slatted floor area on ammonia emission and on the excretory and lying behaviour of growing pigs. J Agric Eng Res 1996;64:299-310. https://doi.org/10.1006/jaer.1996.0071.

[88] Groot Koerkamp PWG, Metz JHM, Uenk GH, Phillips VR, Holden MR, Sneath RW, et al. Concentrations and emissions of ammonia in livestock buildings in Northern Europe. $\mathrm{J}$ 
Agric Eng Res 1998;70:79-95. https://doi.org/10.1006/jaer.1998.0275.

[89] Huynh TTT, Aarnink AJA, Gerrits WJJ, Heetkamp MJH, Canh TT, Spoolder HAM, et al. Thermal behaviour of growing pigs in response to high temperature and humidity. Appl Anim Behav Sci 2005;91:1-16. https://doi.org/10.1016/j.applanim.2004.10.020.

[90] Blanes-Vidal V, Hansen MN, Pedersen S, Rom HB. Emissions of ammonia, methane and nitrous oxide from pig houses and slurry: Effects of rooting material, animal activity and ventilation flow. Agric Ecosyst Environ 2008;124:237-44. https://doi.org/10.1016/j.agee.2007.10.002.

[91] Groot Koerkamp PWG, Groenestein CM. Ammonia and odour emission from a broiler house with a litter drying ventilation system. Proc. AgEng 2008, 2008.

[92] Knížatová M, Mihina Š, Brouček J, Karandušovská I, Mačuhová J. The influence of litter age, litter temperature and ventilation rate on ammonia emissions from a broiler rearing facility. Czech J Anim Sci 2010;55:337-45. https://doi.org/10.17221/176/2009-cjas.

[93] Banhazi TM. Seasonal, Diurnal and Spatial Variations of Environmental Variables in Australian Livestock Buildings. Aust J Multi-Disciplinary Eng 2013;10:60-9. https://doi.org/10.7158/14488388.2013.11464865.

[94] Winkel A, Cambra-López M, Groot Koerkamp PWG, Ogink NWM, Aarnink AJA. Abatement of particulate matter emission from experimental broiler housings using an optimized oil spraying method. Trans ASABE 2014;57:1853-64. https://doi.org/10.13031/trans.57.10870.

[95] Thorne PS. Industrial livestock production facilities: Airborne emissions. Encycl. Environ. Heal., Elsevier; 2019, p. 652-60. https://doi.org/10.1016/B978-0-12-409548-9.11862-7.

[96] Rodriguez MR, Losada E, Besteiro R, Arango T, Velo R, Ortega JA, et al. Evolution of NH3 Concentrations in Weaner Pig Buildings Based on Setpoint Temperature. Agron 2020;10. https://doi.org/10.3390/agronomy10010107.

[97] Grieve D. Heat stress in commercial layers and breeders. Tech Bull Hy-Line Int 2003;19:13.

[98] St-Pierre NR, Cobanov B, Schnitkey G. Economic Losses from Heat Stress by US Livestock Industries. J Dairy Sci 2003;86:E52-77. https://doi.org/10.3168/jds.s0022-0302(03)740405 .

[99] Lu Q, Wen J, Zhang H. Effect of chronic heat exposure on fat deposition and meat quality in two genetic types of chicken. Poult Sci 2007;86:1059-64. https://doi.org/10.1093/ps/86.6.1059.

[100] Kilic I, Simsek E. The effects of heat stress on egg production and quality of laying hens. J Anim Vet Adv 2013;12:42-7. https://doi.org/10.36478/javaa.2013.42.47.

[101] Barrett NW, Rowland K, Schmidt CJ, Lamont SJ, Rothschild MF, Ashwell CM, et al. Effects of acute and chronic heat stress on the performance, egg quality, body temperature, and blood gas parameters of laying hens. Poult Sci 2019;98:6684-92. https://doi.org/https://doi.org/10.3382/ps/pez541.

[102] Settar P, Yalçin S, Türkmut L, Özkan S, Cahanar A. Season by genotype interaction related to broiler growth rate and heat tolerance. Poult Sci 1999;78:1353-8. https://doi.org/10.1093/ps/78.10.1353.

[103] Liu M, Lu Y, Gao P, Xie X, Li D, Yu D, et al. Effect of curcumin on laying performance, egg quality, endocrine hormones, and immune activity in heat-stressed hens. Poult Sci 2020;99:2196-202. https://doi.org/10.1016/j.psj.2019.12.001.

[104] Moreno I, Ladero L, Cava R. Effect of the Iberian pig rearing system on blood plasma antioxidant status and oxidative stress biomarkers. Livest Sci 2020;235:104006. https://doi.org/https://doi.org/10.1016/j.livsci.2020.104006.

[105] Kristensen HH, Wathes CM. Ammonia and poultry welfare: a review. Worlds Poult Sci J 2000;56:235-45. https://doi.org/10.1079/wps20000018.

[106] McGovern RH, Feddes JJR, Zuidhof MJ, Hanson JA, Robinson FE. Growth performance, heart characteristics and the incidence of ascites in broilers in response to carbon dioxide and oxygen concentrations. Can Biosyst Eng / Le Genie Des Biosyst Au Canada 2001;43:41-6. https://doi.org/10.7939/R3319SG48.

[107] Donham KJ, Cumro D, Reynolds S. Synergistic effects of dust and ammonia on the occupational health effects of poultry production workers. J Agromedicine 2002;8:57-76. https://doi.org/10.1300/J096v08n02_09.

[108] Beker A, Vanhooser SL, Swartzlander JH, Teeter RG. Atmospheric ammonia concentration effects on broiler growth and performance. J Appl Poult Res 2004;13:5-9. 
https://doi.org/10.1093/japr/13.1.5.

[109] Olanrewaju HA, Miller WW, Maslin WR, Thaxton JP, Dozier WA, Purswell J, et al. Interactive effects of ammonia and light intensity on ocular, fear and leg health in broiler chickens. Int J Poult Sci 2007;6:762-9.

[110] Olanrewaju HA, Dozier WA, Purswell JL, Branton SL, Miles DM, Lott BD, et al. Growth performance and physiological variables for broiler chickens subjected to short-term elevated carbon dioxide concentrations. Int J Poult Sci 2008;7:738-42. https://doi.org/10.3923/ijps.2008.738.742.

[111] Smit LAM, Heederik D, Doekes G, Blom C, Van Zweden I, Wouters IM. Exposureresponse analysis of allergy and respiratory symptoms in endotoxin-exposed adults. Eur Respir J 2008;31:1241-8. https://doi.org/10.1183/09031936.00090607.

[112] European Commission. Protecting health and safety of workers in agriculture, livestock farming, horticulture and forestry Protecting Social Europe. Luxembourg (Luxembourg): European Commission - Directorate-General for Employment, Social Affairs and Inclusion Unit B.3; 2012. https://doi.org/10.2767/53801.

[113] Aland A, Banhazi T. Livestock housing: Modern management to ensure optimal health and welfare of farm animals. 2013. https://doi.org/10.3920/978-90-8686-771-4.

[114] Ngajilo D. Respiratory health effects in poultry workers. Curr Allergy Clin Immunol 2014;27:116-24.

[115] FAO. Drivers, dynamics, and epidemiology of antimicrobial resistance in animal production. 2016. https://doi.org/10.3109/03009734.2014.905664.

[116] O'Neill J. Tackling Drug-Resistant Infections Globally: Final Report and Recommendations 2016:1-80.

[117] Yi B, Chen L, Sa R, Zhong R, Xing H, Zhang H. Transcriptome Profile Analysis of Breast Muscle Tissues from High or Low Levels of Atmospheric Ammonia Exposed Broilers (Gallus gallus). PLoS One 2016;11:e0162631. https://doi.org/https://doi.org/10.1371/journal.pone.0162631.

[118] Hristov AN, Degaetano AT, Rotz CA, Hoberg E, Skinner RH, Felix T, et al. Climate change effects on livestock in the Northeast US and strategies for adaptation. Clim Change 2018;146:33-45. https://doi.org/10.1007/s10584-017-2023-z.

[119] Laurent JW. Alternatives to common preventive uses of antibiotics for cattle, swine, and chickens. New York (USA): 2018.

[120] Ranjan A, Sinha R, Devi I, Rahim A, Tiwari S. Effect of Heat Stress on Poultry Production and their Managemental Approaches. Int J Curr Microbiol Appl Sci 2019;8:1548-55. https://doi.org/10.20546/ijcmas.2019.802.181.

[121] Yasmeen R, Ali Z, Tyrrel S, Nasir ZA. Assessment of Respiratory Problems in Workers Associated with Intensive Poultry Facilities in Pakistan. Saf Health Work 2020;11:118-24. https://doi.org/https://doi.org/10.1016/j.shaw.2019.12.011.

[122] Thornton PK, Herrero M. The Inter-linkages between Rapid Growth in Livestock Production, Climate Change, and the Impacts on Water Resources, Land Use , and Deforestation. Washington (DC): 2010.

[123] El Mogharbel O, Ghali K, Ghaddar N, Abiad MG. Simulation of a localized heating system for broiler brooding to improve energy performance. Int J Energy Res 2014;38:125-38. https://doi.org/10.1002/er.3023.

[124] Fabrizio E, Airoldi G, Chiabrando R. Study of the environmental control of sow farrowing rooms by means of dynamic simulation. Lect Notes Electr Eng 2014;263:3-11. https://doi.org/10.1007/978-3-642-39578-9_1.

[125] Zhou Y, Bidarmaghz A, Narsilio G, Aye L. Heating and Cooling Loads of a Poultry Shed in Central Coast, NSW, Australia. Proc. World Sustain. Built Environ. Conf. 2017 Hong Kong, Hong Kong: 2017.

[126] Xie Q, Ni JQ, Bao J, Su Z. A thermal environmental model for indoor air temperature prediction and energy consumption in pig building. Build Environ 2019;161:106238. https://doi.org/10.1016/j.buildenv.2019.106238.

[127] Lee SY, Lee IB, Kim RW, Yeo UH, Kim JG, Kwon KS. Dynamic energy modelling for analysis of the thermal and hygroscopic environment in a mechanically ventilated duck house. Biosyst Eng 2020;200:431-49. https://doi.org/10.1016/j.biosystemseng.2020.10.015.

[128] Lindley JA, Whitaker JH. Agricultural buildings and structures. St. Joseph: American Society of Agricultural Engineers; 1996. 
[129] Panagakis P, Blanes-Vidal V, Barbosa JC, Banhazi T, da Cruz VF, Berckmans D, et al. Glossary of Terms on Animal Housing: Interconnecting Engineering, Physical and Physiological Definitions. Aarhus: University of Aarhus; 2009.

[130] Ni J. Mechanistic models of ammonia release from liquid manure: A review. J Agric Eng Res 1999;72:1-17. https://doi.org/10.1006/jaer.1998.0342.

[131] European Centre for Disease Prevention and Control. Towards One Health preparedness. Stockholm (Sweden): 2018.

[132] World Health Organization. One Health n.d. https://www.who.int/news-room/q-adetail/one-health (accessed July 13, 2020).

[133] Rojas-Downing MM, Nejadhashemi AP, Harrigan T, Woznicki SA. Climate change and livestock: Impacts, adaptation, and mitigation. Clim Risk Manag 2017;16:145-63. https://doi.org/10.1016/j.crm.2017.02.001.

[134] Costantino A, Fabrizio E, Biglia A, Cornale P, Battaglini L. Energy Use for Climate Control of Animal Houses: The State of the Art in Europe. Energy Procedia, vol. 101, 2016, p. 18491. https://doi.org/10.1016/j.egypro.2016.11.024.

[135] OECD. Improving Energy Efficiency in the Agro-food Chain. Paris (France): OECD Publishing; 2017. https://doi.org/https://doi.org/10.1787/9789264278530-en.

[136] FAO. Livestock solutions for climate change. Fao 2017. https://doi.org/10.1109/CAMAP.2005.1574227.

[137] Gerber PJ, Steinfeld H, Henderson B, Mottet A, Opio C, Dijkman J, et al. Tackling climate change through livestock - A global assessment of emissions and mitigation opportunities. Rome (Italy): Food and Agriculture Organization of the United Nations (FAO); 2013.

[138] Battisti DS, Naylor RL. Historical warnings of future food insecurity with unprecedented seasonal heat. Science (80- ) 2009;323:240-4. https://doi.org/10.1126/science.1164363.

[139] Renaudeau D, Collin A, Yahav S, De Basilio V, Gourdine JL, Collier RJ. Adaptation to hot climate and strategies to alleviate heat stress in livestock production. Animal 2012;6:70728. https://doi.org/10.1017/S1751731111002448.

[140] Steinfeld H, Wassenaar T, Jutzi S. Livestock production systems in developing countries: Status, drivers, trends. Rev Sci Tech Int Off Epizoot 2006;25:505-16. https://doi.org/10.20506/rst.25.2.1677.

[141] Brundtland G. Report of the World Commision on Environement and Development: Our Common Future. Oxford Pap 1987. https://doi.org/10.2307/2621529.

[142] Taki M, Rohani A, Rahmati-Joneidabad M. Solar thermal simulation and applications in greenhouse. Inf Process Agric 2018;5:83-113. https://doi.org/10.1016/j.inpa.2017.10.003.

[143] Mobtaker HG, Ajabshirchi Y, Ranjbar SF, Matloobi M. Simulation of thermal performance of solar greenhouse in north-west of Iran: An experimental validation. Renew Energy 2019;135:88-97.

[144] Joudi KA, Farhan AA. A dynamic model and an experimental study for the internal air and soil temperatures in an innovative greenhouse. Energy Convers Manag 2015;91:76-82. https://doi.org/10.1016/j.enconman.2014.11.052.

[145] Zhang G, Ding X, Li T, Pu W, Lou W, Hou J. Dynamic energy balance model of a glass greenhouse: An experimental validation and solar energy analysis. Energy 2020;198:117281. https://doi.org/10.1016/j.energy.2020.117281.

[146] Hamilton J, Negnevitsky M, Wang X. Thermal analysis of a single-storey livestock barn. Adv Mech Eng 2016;8:1-9. https://doi.org/10.1177/1687814016643456.

[147] García-Ruiz RA, López-Martínez J, Blanco-Claraco JL, Pérez-Alonso J, Callejón-Ferre ÁJ. On air temperature distribution and ISO 7726-defined heterogeneity inside a typical greenhouse in Almería. Comput Electron Agric 2018;151:264-75. https://doi.org/10.1016/J.COMPAG.2018.06.001.

[148] ISO. ISO 7726: 1998 - Ergonomics of the thermal environment - Instruments for measuring physical quantities. 1998.

[149] López-Martínez J, Blanco-Claraco JL, Pérez-Alonso J, Callejón-Ferre ÁJ. Distributed network for measuring climatic parameters in heterogeneous environments: Application in a greenhouse. Comput Electron Agric 2018;145:105-21. https://doi.org/https://doi.org/10.1016/j.compag.2017.12.028.

[150] EN ISO. EN ISO 7730:2006 - Ergonomics of the thermal environment - Analytical determination and interpretation of thermal comfort using calculation of the PMV and PPD indices and local thermal comfort criteria. 2006.

[151] ISO. EN ISO 27243:1996 - Hot environments. Estimation of the heat stress on the working 
man, based on the WBGT index (wet bulb globe temperature). 1996.

[152] Bazgaou A, Fatnassi H, Bouharroud R, Ezzaeri K, Gourdo L, Wifaya A, et al. Effect of active solar heating system on microclimate, development, yield and fruit quality in greenhouse tomato production. Renew Energy 2021;165:237-50. https://doi.org/https://doi.org/10.1016/j.renene.2020.11.007.

[153] Coomans M, Allaerts K, Wittemans L, Pinxteren D. Monitoring and energetic performance of two similar semi-closed greenhouse ventilation systems. Energy Convers Manag 2013;76:128-36. https://doi.org/https://doi.org/10.1016/j.enconman.2013.07.028.

[154] Calvet S, Cambra-López M, Estellés F, Torres AG. Characterization of gas emissions from a Mediterranean broiler farm. Poult Sci 2011;90:534-42. https://doi.org/10.3382/ps.201001037.

[155] Calvet S, Cambra-López M, Blanes-Vidal V, Estellés F, Torres AG. Ventilation rates in mechanically-ventilated commercial poultry buildings in Southern Europe: Measurement system development and uncertainty analysis. Biosyst Eng 2010;106:423-32. https://doi.org/https://doi.org/10.1016/j.biosystemseng.2010.05.006.

[156] Baker JR, Jones RK. Screening as part of insect and disease management in the greenhouse. North Carolina Flower Grow Bull 1989;34:1-9.

[157] Costantino A, Comba L, Sicardi G, Bariani M, Fabrizio E. Thermal environment inside mechanically ventilated greenhouses: Results from a long-term monitoring campaign. In: Coppola A, Di Renzo GC, Altieri G, D’Antonio P, editors. Innov. Biosyst. Eng. Sustain. Agric. For. Food Prod. MID-TERM AIIA 2019. Lecture No, Springer; 2020, p. 223-30. https://doi.org/10.1007/978-3-030-39299-4_25.

[158] Zhou N, Yu Y, Yi J, Liu R. A study on thermal calculation method for a plastic greenhouse with solar energy storage and heating. Sol Energy 2017;142:39-48. https://doi.org/10.1016/j.solener.2016.12.016.

[159] Esmay ME, Dixon JE. Environmental control for agricultural buildings. Westport: The AVI Publishing company, Inc; 1986.

[160] Gompertz B. On the nature of the function expressive of the law of human mortality, and on a new mode of determining the value of life contingencies. Philos Trans R Soc London 1825.

[161] Coyne JM, Berry DP, Mäntysaari EA, Juga J, McHugh N. Comparison of fixed effects and mixed model growth functions in modelling and predicting live weight in pigs. Livest Sci 2015;177:8-14. https://doi.org/10.1016/j.livsci.2015.03.031.

[162] Sabbioni A, Beretti V, Manini R, Cervi C, Superchi P. Application of different growth models to "Nero di Parma" pigs. Ital J Anim Sci 2009;8:537-9. https://doi.org/10.4081/ijas.2009.s2.537.

[163] Rossi P, Gastaldi A, Ferrari P. Shelters, equipment and systems for pig rearing (Ricoveri, attrezzature e impianti per l'allevamento dei suini, in Italian). Verona, Italy: Edizioni l'Informatore Agrario; 2004.

[164] Harper AF. Virginia 4-H Youth Market Hog Project Guide. 2003.

[165] Panagakis P, Axaopoulos P. Comparing fogging strategies for pig rearing using simulations to determine apparent heat-stress indices. Biosyst Eng 2008;99:112-8. https://doi.org/10.1016/J.BIOSYSTEMSENG.2007.10.007.

[166] Xin H, Harmon JD. Livestock Industry Facilities and Environment: Heat Stress Indices for Livestock. Agric Enviromental Ext Publ 1998;163. https://doi.org/10.1007/BF02978744.

[167] Yang SH, Rhee JY. Utilization and performance evaluation of a surplus air heat pump system for greenhouse cooling and heating. Appl Energy 2013;105:244-51. https://doi.org/10.1016/j.apenergy.2012.12.038.

[168] Bibbiani C, Fantozzi F, Gargari C, Campiotti CA, Schettini E, Vox G. Wood Biomass as Sustainable Energy for Greenhouses Heating in Italy. Agric Agric Sci Procedia 2016;8:63745. https://doi.org/10.1016/j.aaspro.2016.02.086.

[169] Sethi VP, Sumathy K, Lee C, Pal DS. Thermal modeling aspects of solar greenhouse microclimate control: A review on heating technologies. Sol Energy 2013;96:56-82. https://doi.org/10.1016/j.solener.2013.06.034.

[170] EN. Greenhouses - Design and construction - Part 1: Commercial production greenhouses. 2019.

[171] Ward R, Mortada A, Choudhary R. Simulation of Thermal Performance and Retrofit of a Historic Greenhouse. In: Mahdavi A, Martens B, editors. Proc. from 2nd Cent. Eur. Symp. Build. Phys., 2013, p. 245-52.

[172] Ahamed MS, Guo H, Tanino K. Modeling heating demands in a Chinese-style solar 
greenhouse using the transient building energy simulation model TRNSYS. J Build Eng 2020;29:101114. https://doi.org/10.1016/j.jobe.2019.101114.

[173] CERES - Greenhouse solutions. An Introduction To Vapor Pressure Deficit 2018. https://ceresgs.com/an-introduction-to-vapor-pressure-deficit/ (accessed October 20, 2020).

[174] Comba L, Biglia A, Ricauda Aimonino D, Tortia C, Mania E, Guidoni S, et al. Leaf Area Index evaluation in vineyards using 3D point clouds from UAV imagery. Precis Agric 2020;21:881-96. https://doi.org/10.1007/s11119-019-09699-x.

[175] Hellickson MAMA, Walker JNJN. Ventilation of agricultural structures. St. Joseph: ASAE; 1983.

[176] Chen J, Xu F, Ding B, Wu N, Shen Z, Zhang L. Performance analysis of radiation and electricity yield in a photovoltaic panel integrated greenhouse using the radiation and thermal models. Comput Electron Agric 2019;164:104904. https://doi.org/10.1016/j.compag.2019.104904.

[177] Lando I, Serale G, Fabrizio E. Dynamic thermal modelling of a large plastic multi-span greenhouse: Calibrated simulation and energy retrofit. ASABE 2018 Annu. Int. Meet., 2018. https://doi.org/10.13031/aim.201800553.

[178] Campbell CD, Sage RF, Kocacinar F, Way DA. Estimation of the whole-plant CO2 compensation point of tobaco (Nicotiana tabacum L.). Glob Chang Biol 2005;11:1956-67. https://doi.org/10.1111/j.1365-2486.2005.01045.x.

[179] Nederhoff E. Carbon Dioxide Enrichment - Fuels \& Figures. Pract Hydroponics Greenhouses 2004;May/June:50-9.

[180] Singh MC, Singh JPP, Singh KGG. Development of a microclimate model for prediction of temperatures inside a naturally ventilated greenhouse under cucumber crop in soilless media. Comput Electron Agric 2018;154:227-38.

[181] Golzar F, Heeren N, Hellweg S, Roshandel R. A novel integrated framework to evaluate greenhouse energy demand and crop yield production. Renew Sustain Energy Rev 2018;96:487-501. https://doi.org/10.1016/j.rser.2018.06.046.

[182] Van Beveren PJM, Bontsema J, Van Straten G, Van Henten EJ. Minimal heating and cooling in a modern rose greenhouse. Appl Energy 2015;137:97-109. https://doi.org/10.1016/j.apenergy.2014.09.083.

[183] van Beveren PJM, Bontsema J, van Straten G, van Henten EJ. Optimal control of greenhouse climate using minimal energy and grower defined bounds. Appl Energy 2015;159:509-19. https://doi.org/10.1016/j.apenergy.2015.09.012.

[184] Lin D, Zhang L, Xia X. Hierarchical model predictive control of Venlo-type greenhouse climate for improving energy efficiency and reducing operating cost. J Clean Prod 2020;264:121513. https://doi.org/10.1016/j.jclepro.2020.121513.

[185] Chen J, Yang J, Zhao J, Xu F, Shen Z, Zhang L. Energy demand forecasting of the greenhouses using nonlinear models based on model optimized prediction method. Neurocomputing 2016;174:1087-100. https://doi.org/10.1016/j.neucom.2015.09.105.

[186] Altes-Buch Q, Quoilin S, Lemort V. Greenhouses: A Modelica Library for the Simulation of Greenhouse Climate and Energy Systems. Proc. 13th Int. Model. Conf. Regensburg, Ger. March 4-6, 2019, 2019. https://doi.org/10.3384/ecp19157533.

[187] Reyes-Rosas A, Molina-Aiz FD, Valera DL, López A, Khamkure S. Development of a single energy balance model for prediction of temperatures inside a naturally ventilated greenhouse with polypropylene soil mulch. Comput Electron Agric 2017;142:9-28. https://doi.org/10.1016/j.compag.2017.08.020.

[188] Brown J, Ward R, Choudhary R, Slater R. Algorithmic and declarative modeling of a greenhouse. Proc. 5th Int. Build. Phys. Conf., 2012, p. 577-84.

[189] Jans-Singh MK, Ward R, Choudhary R. Co-simulation of a Rooftop Greenhouse and a School Building in London, UK. Proc. Build. Simul. 2019 16th Conf. IBPSA, 2020. https://doi.org/10.26868/25222708.2019.210355.

[190] Gholami M, Barbaresi A, Tassinari P, Bovo M, Torreggiani D. A Comparison of Energy and Thermal Performance of Rooftop Greenhouses and Green Roofs in Mediterranean Climate: A Hygrothermal Assessment in WUFI. Energies 2020;13:2030. https://doi.org/10.3390/en13082030.

[191] del Sagrado J, Sánchez JA, Rodríguez F, Berenguel M. Bayesian networks for greenhouse temperature control. J Appl Log 2016;17:25-35. https://doi.org/10.1016/j.jal.2015.09.006.

[192] Taki M, Abdanan Mehdizadeh S, Rohani A, Rahnama M, Rahmati-Joneidabad M. Applied machine learning in greenhouse simulation; new application and analysis. Inf Process Agric 
2018;5:253-68. https://doi.org/10.1016/j.inpa.2018.01.003.

[193] Jolliet O, Danloy L, Gay JB, Munday GL, Reist A. HORTICERN: an improved static model for predicting the energy consumption of a greenhouse. Agric For Meteorol 1991;55:26594. https://doi.org/10.1016/0168-1923(91)90066-Y.

[194] Singh RD, Tiwari GN. Energy conservation in the greenhouse system: A steady state analysis. Energy 2010;35:2367-73. https://doi.org/10.1016/j.energy.2010.02.003.

[195] Campiotti C, Latini A, Scoccianti M, Viola C. L'ottenimento dei Certificati Bianchi. La scheda 40 E: I sistemi serra (in Italian). 2014.

[196] Ahamed MS, Guo H, Tanino K. A quasi-steady state model for predicting the heating requirements of conventional greenhouses in cold regions. Inf Process Agric 2018;5:33-46. https://doi.org/10.1016/j.inpa.2017.12.003.

[197] Chen C, Yu N, Yang F, Mahkamov K, Han F, Li Y, et al. Theoretical and experimental study on selection of physical dimensions of passive solar greenhouses for enhanced energy performance. Sol Energy 2019;191:46-56. https://doi.org/10.1016/j.solener.2019.07.089.

[198] Rasheed A, Na WH, Lee JW, Kim HT, Lee HW. Optimization of greenhouse thermal screens for maximized energy conservation. Energies 2019;12:3592. https://doi.org/10.3390/en12193592.

[199] Bambara J, Athienitis AK. Energy and Economic Analysis for Greenhouse Envelope Design. Trans ASABE 2018;61:1795-810 https://doi.org/https://doi.org/10.13031/trans.13025.

[200] Costantino A, Fabrizio E, Ghiggini A, Bariani M. Climate control in broiler houses: A thermal model for the calculation of the energy use and indoor environmental conditions. Energy Build 2018;169:110-26. https://doi.org/10.1016/j.enbuild.2018.03.056.

[201] Duffie JA, Beckman WA. Solar Engineering of Thermal Processes: Fourth Edition. 2013. https://doi.org/10.1002/9781118671603.

[202] Adeyemi O, Grove I, Peets S, Domun Y, Norton T. Dynamic modelling of lettuce transpiration for water status monitoring. Comput Electron Agric 2018;155:50-7. https://doi.org/10.1016/j.compag.2018.10.008.

[203] Stanghellini C. Transpiration of greenhouse crops an aid to climate management. Agric Eng 1987.

[204] Penman HL. Natural evaporation from open water, bare soil and grass. Proc R Soc 1948;193. https://doi.org/https://doi.org/10.1098/rspa.1948.0037.

[205] Monteith JL. Photosynthesis and transpiration of crops. Exp Agric 1966;2:1-14. https://doi.org/https://doi.org/10.1017/s0014479700003938.

[206] Li L, Chen S, Yang C, Meng F, Sigrimis N. Prediction of plant transpiration from environmental parameters and relative leaf area index using the random forest regression algorithm. J Clean Prod 2020;261:121136. https://doi.org/10.1016/j.jclepro.2020.121136.

[207] Boulard T, Wang S. Greenhouse crop transpiration simulation from external climate conditions. Agric For Meteorol 2000;100:25-34. https://doi.org/10.1016/S01681923(99)00082-9.

[208] Villarreal-Guerrero F, Kacira M, Fitz-Rodríguez E, Kubota C, Giacomelli GA, Linker R, et al. Comparison of three evapotranspiration models for a greenhouse cooling strategy with natural ventilation and variable high pressure fogging. Sci Hortic (Amsterdam) 2012. https://doi.org/10.1016/j.scienta.2011.10.016.

[209] Jolliet O. HORTITRANS, a model for predicting and optimizing humidity and transpiration in greenhouses. J Agric Eng Res 1994;57:23-37. https://doi.org/10.1006/jaer.1994.1003.

[210] Marquardt DW. An Algorithm for Least-Squares Estimation of Nonlinear Parameters. J Soc Ind Appl Math 1963;11:431-41. https://doi.org/10.1137/0111030.

[211] European Committee for Standardisation, EN ISO. EN ISO 13790: Energy performance of buildings-Calculation of energy use for space heating and cooling. 2008.

[212] Roujol S, Fleury E, Marchio D, Millet JR, Stabat P, Paris M De, et al. Testing the energy simulation building model of consoclim using bestest method and experimental data. Conférence IBPSA World, Eindhoven, 2003, p. 1131-8.

[213] Marchio D, Millet JR, Morisot O. Simple modelling for energy consumption estimation in air conditionned buildings. Proc. Clima 2000, Brussel, Belgium: 1997.

[214] ASHRAE. 2012 ASHRAE Handbook: HVAC Systems and Equipment. Atlanta, GA: ASHRAE; 2012.

[215] Munters. CELdek® 7060-15 Evaporative Cooling Pad 2009:2. https://www.munters.com/globalassets/inriver/resources/products/coolers-- 
humidifiers/agh_prodsheet_celdek.pdf (accessed October 20, 2020).

[216] Munters. CELdek $\circledR^{2}$ 7090-15 Evaporative Cooling Pad 2011:2. https://www.munters.com/globalassets/inriver/resources/products/coolers-humidifiers/1782-celdek-7090_15_gb.pdf (accessed October 20, 2020).

[217] Guzmán-Cruz R, Castañeda-Miranda R, García-Escalante JJ, López-Cruz IL, Lara-Herrera A, de la Rosa JI. Calibration of a greenhouse climate model using evolutionary algorithms. Biosyst Eng 2009;104:135-42. https://doi.org/10.1016/j.biosystemseng.2009.06.006.

[218] Tap F. Economics-based optimal control of greenhouse tomato crop production. S.n., 2000.

[219] ASAE. Heating, Ventilating, and Cooling Greenhouses - ANSI/ASAE EP406.4 JAN03. 2003. https://doi.org/10.1016/B978-185617513-5.50030-5.

[220] Fabrizio E, Monetti V. Methodologies and advancements in the calibration of building energy models. Energies 2015;8:2548-74. https://doi.org/10.3390/en8042548.

[221] Monetti V, Davin E, Fabrizio E, André P, Filippi M. Calibration of building energy simulation models based on optimization: A case study. Energy Procedia, vol. 78, Elsevier Ltd; 2015, p. 2971-6. https://doi.org/10.1016/j.egypro.2015.11.693.

[222] Comba L, Belforte G, Gay P. Modelling techniques for the control of thermal exchanges in mixed continuous-discontinuous flow food plants. J Food Eng 2011;106:177-87. https://doi.org/10.1016/j.jfoodeng.2011.04.015.

[223] Diago MP, Correa C, Millán B, Barreiro P, Valero C, Tardaguila J. Grapevine yield and leaf area estimation using supervised classification methodology on RGB images taken under field conditions. Sensors (Switzerland) 2012;12:16988-7006. https://doi.org/10.3390/s121216988.

[224] Arnó J, Escolà A, Vallès JM, Llorens J, Sanz R, Masip J, et al. Leaf area index estimation in vineyards using a ground-based LiDAR scanner. Precis Agric 2013;14:290-306. https://doi.org/10.1007/s11119-012-9295-0.

[225] ANSI/ASHRAE. ASHRAE Guideline 14-2002 Measurement of Energy and Demand Savings. Ashrae 2002.

[226] IPMVP New Construction Subcommittee. International Performance Measurement \& Verification Protocol: Concepts and Option for Determining Energy Savings in New Construction, Volume III. Washington, DC, USA: 2003.

[227] Federal Energy Management Program. Federal Energy Management Program, M\&V Guidelines: Measurement and Verification for Federal Energy Projects Version 3.0. 2008.

[228] OECD/FAO. OECD-FAO Agricultural Outlook 2019-2028. 2019. https://doi.org/10.1787/agr_outlook-2019-en.

[229] Albright L. Environmental Control for Animals and Plants. St. Joseph: ASAE; 1990.

[230] Carvalho VF, Yanagi T, Xin H, Gates RS, Damasceno F, Moraes SRP. Mathematical Model for Thermal Environment and Broiler Chickens Performance Prediction in Acclimatized Housings. Proc. from Livest. Environ. VIII Conf., Iguassu Falls: 2008, p. 729-36.

[231] Midwest Plan Service. Structures and Environment Handbook (11th Edition, revised 1987). Ames: Midwest Plan Service; 1983.

[232] Axaopoulos P, Panagakis P, Axaopoulos I. Effect of wall orientation on the optimum insulation thickness of a growing-finishing piggery building. Energy Build 2014;84:40311. https://doi.org/10.1016/j.enbuild.2014.07.091.

[233] Daskalov PI, Arvanitis KG, Pasgianos GD, Sigrimis NA. Non-linear Adaptive Temperature and Humidity Control in Animal Buildings. Biosyst Eng 2006;93:1-24. https://doi.org/10.1016/J.BIOSYSTEMSENG.2005.09.006.

[234] Daskalov PI. Prediction of temperature and humidity in a naturally ventilated pig building. J Agric Eng Res 1997. https://doi.org/10.1006/jaer.1997.0211.

[235] Jackson P, Guy J, Edwards SA, Sturm B, Bull S. Application of dynamic thermal engineering principles to improve the efficiency of resource use in UK pork production chains. Energy Build 2017;139:53-62. https://doi.org/10.1016/j.enbuild.2016.12.090.

[236] Jackson P, Guy JH, Sturm B, Bull S, Edwards SA. An innovative concept building design incorporating passive technology to improve resource efficiency and welfare of finishing pigs. Biosyst Eng 2018;174:190-203. https://doi.org/10.1016/j.biosystemseng.2018.07.008.

[237] Liberati P, Zappavigna P. A computer model for optimisation of the internal climate in animal housing design. Proc. from Livest. Environ. VII Symp., Beijing: 2005.

[238] Seo IH, Lee IB, Moon OK, Kim HT, Hwang HS, Hong SW, et al. Improvement of the ventilation system of a naturally ventilated broiler house in the cold season using computational simulations. Biosyst Eng 2009;104:106-17. 
https://doi.org/10.1016/j.biosystemseng.2009.05.007.

[239] Bjerg B, Rong L, Zhang G. Computational prediction of the effective temperature in the lying area of pig pens. Comput Electron Agric 2018;149:71-9. https://doi.org/10.1016/j.compag.2017.09.016.

[240] Blanes-Vidal V, Guijarro E, Balasch S, Torres AG. Application of computational fluid dynamics to the prediction of airflow in a mechanically ventilated commercial poultry building. $\quad$ Biosyst Eng 2008;100:105-16. https://doi.org/10.1016/j.biosystemseng.2008.02.004.

[241] Bustamante E, Calvet S, Estellés F, Torres AG, Hospitaler A. Measurement and numerical simulation of single-sided mechanical ventilation in broiler houses. Biosyst Eng 2017;160:55-68. https://doi.org/10.1016/j.biosystemseng.2017.05.009.

[242] Fidaros D, Baxevanou C, Bartzanas T, Kittas C. Numerical study of mechanically ventilated broiler house equipped with evaporative pads. Comput Electron Agric 2018;149:101-9. https://doi.org/10.1016/j.compag.2017.10.016.

[243] Guerra-Galdo EHEH, Calvet Sanz S, Estellés Barber F, Amparo López-Jiménez P. INTERNATIONAL JOURNAL OF ENERGY AND ENVIRONMENT CFD model for ventilation assessment in poultry houses with different distribution of windows. vol. 6 . Online; 2015.

[244] Kwon K seok, Lee I bok, Zhang GQ, Ha T. Computational fluid dynamics analysis of the thermal distribution of animal occupied zones using the jet-drop-distance concept in a mechanically ventilated broiler house. Biosyst Eng 2015;136:51-68. https://doi.org/10.1016/j.biosystemseng.2015.05.008.

[245] Mostafa E, Lee IB, Song SH, Kwon KS, Seo IH, Hong SW, et al. Computational fluid dynamics simulation of air temperature distribution inside broiler building fitted with duct ventilation system. Biosyst Eng 2012;112:293-303. https://doi.org/10.1016/j.biosystemseng.2012.05.001.

[246] Qin C, Wang X, Zhang G, Yi Q, He Y, Wang K. Effects of the slatted floor layout on flow pattern in a manure pit and ammonia emission from pit-A CFD study. Comput Electron Agric 2020;177:105677. https://doi.org/10.1016/j.compag.2020.105677.

[247] Rojano F, Bournet PE, Hassouna M, Robin P, Kacira M, Choi CY. Modelling heat and mass transfer of a broiler house using computational fluid dynamics. Biosyst Eng 2015;136:2538. https://doi.org/10.1016/j.biosystemseng.2015.05.004.

[248] Rong L. Effect of partial pit exhaust ventilation system on ammonia removal ratio and mass transfer coefficients from different emission sources in pig houses. Energy Built Environ 2020;1:343-50. https://doi.org/10.1016/j.enbenv.2020.04.006.

[249] Rong L, Aarnink AJA. Development of ammonia mass transfer coefficient models for the atmosphere above two types of the slatted floors in a pig house using computational fluid dynamics. $\quad$ Biosyst Eng 2019;183:13-25. https://doi.org/10.1016/j.biosystemseng.2019.04.011.

[250] Seo I hwan, Lee I bok, Moon O kyeong, Hong S woon, Hwang H seob, Bitog JP, et al. Modelling of internal environmental conditions in a full-scale commercial pig house containing animals. Biosyst Eng 2012;111:91-106. https://doi.org/10.1016/j.biosystemseng.2011.10.012.

[251] Tabase RK, Millet S, Brusselman E, Ampe B, De Cuyper C, Sonck B, et al. Effect of ventilation control settings on ammonia and odour emissions from a pig rearing building. Biosyst Eng 2020;192:215-31. https://doi.org/https://doi.org/10.1016/j.biosystemseng.2020.01.022.

[252] Zhu S, Liu P, Yang N, He J, Ye Z. Optimization of local ventilation system for gaseous pollutants removal in broiler house using CFD simulation. ASABE - 9th Int. Livest. Environ. Symp. 2012, ILES 2012, 2012. https://doi.org/10.13031/2013.41553.

[253] Pedersen S\&, Sällvik K. 4th Report of Working Group on Climatization of Animal Houses - Heat and moisture production at animal and house levels. Horsens: 2002.

[254] Bjerg B, Cascone G, Lee IB, Bartzanas T, Norton T, Hong SW, et al. Modelling of ammonia emissions from naturally ventilated livestock buildings. Part 3: CFD modelling. Biosyst Eng 2013. https://doi.org/10.1016/j.biosystemseng.2013.06.012.

[255] Dekock J, Vranken E, Gallmann E, Hartung E, Berckmans D. Optimisation and validation of the intermittent measurement method to determine ammonia emissions from livestock buildings. Biosyst Eng 2009;104:396-403. https://doi.org/https://doi.org/10.1016/j.biosystemseng.2009.07.003. 
[256] Hendriks J, A. A, Saevels P, Leribaux C, Vranken E, Vinkier C, et al. Development of a Simplified Procedure for Determination of Odor and Ammonia Emissions of Agricultural Buildings on Behalf of Environmental Legislation in Flanders. 2001.

[257] Robinson TP, Thornton PK, Franceschini G, Kruska RL, Chiozza F, Notenbaert A, et al. Global Livestock Production Systems. Rome: Food and Agriculture Organization of the United Nations (FAO) and International Livestock Research Institute (ILRI); 2011. https://doi.org/10.1103/PhysRevA.86.010102.

[258] FAO. World Livestock 2011 - Livestock in food security. Rome: FAO; 2011.

[259] CIGR. CIGR Handbook of Agricultural Engineering Volume II. St. Joseph: American Society of Agricultural Engineers; 1999.

[260] Cambra-López M, Aarnink AJA, Zhao Y, Calvet S, Torres AG. Airborne particulate matter from livestock production systems: A review of an air pollution problem. Environ Pollut 2010;158:1-17. https://doi.org/https://doi.org/10.1016/j.envpol.2009.07.011.

[261] Harner JP, John S. Water consumption of an evaporative cooling system in the midwest. Kansas Agric Exp Stn Res Reports 2009;0. https://doi.org/10.4148/2378-5977.3118.

[262] Lohmann Meat. Broiler Stock Performance Objectives. Huntsville, Alabama (US): 2007.

[263] Cobb. Broiler Management Guide. Siloam Springs, Arkansas (USA): 2008.

[264] European Committee for Standardisation. EN ISO 13786: Thermal performance of building components -- Dynamic thermal characteristics -- Calculation methods. 2018.

[265] FAO. The state of food and agriculture. Rome: Food and Agriculture Organization of the United Nations; 2009. https://doi.org/10.18356/6e4ebb75-en.

[266] Losinger WC. Feed-conversion ratio of finisher pigs in the USA. Prev Vet Med 1998;36:287-305. https://doi.org/10.1016/S0167-5877(98)00094-4.

[267] Gołaszewski J, de Visser C, Brodziński Z, Myhan R, Olba-Zięty E, Stolarski MJ, et al. State of the Art on Energy Efficiency in Agriculture (agrEE)- Country data on energy consumption in different agroproduction sectors in the European countries. (Project Deliverable 2.1). 2012.

[268] De Corato U, Cancellara FA. L'efficienza energetica nel comparto zootecnico (in Italian). Bari: 2014.

[269] Costantino A, Fabrizio E. Building Design for Energy Efficient Livestock Housing. In: Holden NM, Wolfe ML, Ogejo JA, Cummins EJ, editors. Introd. to Biosyst. Eng., Blacksburg, Virginia: ASABE, VT 2020. https://doi.org/10.21061/IntroBiosystemsEngineering/Livestock_Housing_Energy.

[270] PIC, PIC North America. Wean to finish manual. 2014 editi. Hendersonville, Tennessee: PIC North America; 2014.

[271] L.B. White Company. Wean-to-Finish. Heating protocol. Onalaska, Wisconsin: L.B. White Company; 2013.

[272] Howden SM, Crimp SJ, Stokes CJ. Climate change and Australian livestock systems: impacts, research and policy issues. Aust J Exp Agric 2008;48:780. https://doi.org/10.1071/ea08033.

[273] Wellock IJ, Emmans GC, Kyriazakis I. Describing and predicting potential growth in the pig. Anim Sci 2004;78:379-88. https://doi.org/10.1017/s1357729800058781.

[274] Teshome EJ, F. Haghighat F. Zonal Models for Indoor Air Flow - A Critical Review. Int J Vent 2004;3:119-29. https://doi.org/10.1080/14733315.2004.11683908.

[275] European Commission. Pig Market Situation. Pigmeat C Comm 22 April 20212021. https://ec.europa.eu/info/sites/default/files/food-farming-fisheries/farming/documents/pigmarket-situation_en.pdf (accessed May 17, 2021).

[276] Fernandez MD, Losada E, Ortega JA, Arango T, Ginzo-Villamayor MJ, Besteiro R, et al. Energy, Production and Environmental Characteristics of a Conventional Weaned Piglet Farm in North West Spain. Agron 2020;10. https://doi.org/10.3390/agronomy10060902.

[277] Eurostat. Natural gas price statistics 2020. https://ec.europa.eu/eurostat/statisticsexplained/index.php?title=Natural_gas_price_statistics (accessed February 16, 2021).

[278] Eurostat. Electricity price statistics 2020. https://ec.europa.eu/eurostat/statisticsexplained/index.php/Electricity_price_statistics (accessed February 17, 2021).

[279] Corrado V, Ballarini I, Dirutigliano D, Paduos S. Cost-optimal analysis of Italian office buildings through the application of a quasi-steady state model validated by detailed dynamic simulation. 14th Int. Conf. IBPSA - Build. Simul. 2015, BS 2015, Conf. Proc., 2015, p. 2043-50.

[280] Ballarini I, Corrado V. A new thermal analysis by numerical simulation to investigate the 
energy performance of buildings. Build Simul 2011:2225-32.

[281] Roma R, Corrado S, De Boni A, Forleo MB, Fantin V, Moretti M, et al. Life Cycle Assessment in the Livestock and Derived Edible Products Sector. Life Cycle Assess. Agrifood Sect., Springer International Publishing; 2015, p. 251-332. https://doi.org/10.1007/978-3-319-11940-3_5.

[282] Costantini M, Lovarelli D, Orsi L, Ganzaroli A, Ferrante V, Febo P, et al. Investigating on the environmental sustainability of organic animal products? The case of organic eggs. J Clean Prod 2020:123046. https://doi.org/https://doi.org/10.1016/j.jclepro.2020.123046.

[283] Heidari MD, Omid M, Akram A. Energy efficiency and econometric analysis of broiler $\begin{array}{lll}\text { production } & \text { farms. } & \text { 2011;36:6536-41. }\end{array}$ https://doi.org/https://doi.org/10.1016/j.energy.2011.09.011.

[284] Odum HT. Environmental Accounting: Emergy and Environmental Decision Making. New York (USA): Wiley,; 1995.

[285] Castellini C, Bastianoni S, Granai C, Bosco AD, Brunetti M. Sustainability of poultry production using the emergy approach: Comparison of conventional and organic rearing $\begin{array}{llll}\text { systems. } & \text { Agric } & \text { Ecosyst } & \text { Environ }\end{array}$ https://doi.org/https://doi.org/10.1016/j.agee.2005.11.014.

[286] Allegretti G, Talamini E, Schmidt V, Bogorni PC, Ortega E. Insect as feed: An emergy assessment of insect meal as a sustainable protein source for the Brazilian poultry industry. J Clean Prod 2018;171:403-12. https://doi.org/https://doi.org/10.1016/j.jclepro.2017.09.244.

[287] Izar-Tenorio J, Jaramillo P, Griffin WM, Small M. Impacts of projected climate change scenarios on heating and cooling demand for industrial broiler chicken farming in the $\begin{array}{lllll}\text { Eastern } & \text { U.S. } & \text { J } & \text { Clean }\end{array}$ https://doi.org/https://doi.org/10.1016/j.jclepro.2020.120306.

[288] Manolakos D, Panagakis P, Bartzanas T, Bouzianas K. Use of heat pumps in HVAC systems for precise environment control in broiler houses: System's modeling and calculation of the basic design parameters. Comput Electron Agric 2019;163. https://doi.org/10.1016/j.compag.2019.104876.

[289] Choi HC, Salim HM, Akter N, Na JC, Kang HK, Kim MJ, et al. Effect of heating system using a geothermal heat pump on the production performance and housing environment of broiler chickens. Poult Sci 2012;91:275-81. https://doi.org/10.3382/ps.2011-01666.

[290] Gad S, El-Shazly MA, Wasfy KI, Awny A. Utilization of solar energy and climate control systems for enhancing poultry houses productivity. Renew Energy 2020;154:278-89. https://doi.org/https://doi.org/10.1016/j.renene.2020.02.088.

[291] Coulombe F, Rousse DR, Paradis P-L. CFD simulations to improve air distribution inside cold climate broiler houses involving heat exchangers. Biosyst Eng 2020;198:105-18. https://doi.org/https://doi.org/10.1016/j.biosystemseng.2020.07.015.

[292] Pimentel D, Hurd LE, Bellotti AC, Forster MJ, Oka IN, Sholes OD, et al. Food production and the energy crisis. Science (80- ) 1973. https://doi.org/10.1126/science.182.4111.443.

[293] Vigne M, Vayssières J, Lecomte P, Peyraud J-L. Evaluating the ability of current energy use assessment methods to study contrasting livestock production systems. J Environ Manage 2012;112:199-212. https://doi.org/https://doi.org/10.1016/j.jenvman.2012.07.017.

[294] ISO. ISO 52000-1:2017 Energy performance of buildings - Overarching EPB assessment - Part 1: General framework and procedures. ISO 2017.

[295] European Commission. EPBD - Energy performance of buildings and Directive (EU) 2018/844. Off J Eur Union 2018.

[296] Bilardo M, Ferrara M, Fabrizio E. Performance assessment and optimization of a solar cooling system to satisfy renewable energy ratio (RER) requirements in multi-family buildings. Renew Energy 2020;155:990-1008. https://doi.org/https://doi.org/10.1016/j.renene.2020.03.044.

[297] Krstić-Furundžić A, Vujošević M, Petrovski A. Energy and environmental performance of the office building facade scenarios. Energy 2019;183:437-47. https://doi.org/https://doi.org/10.1016/j.energy.2019.05.231.

[298] Dunkelberg H, Wagner J, Hannen C, Schlüter BA, Phan L, Hesselbach J, et al. Optimization of the energy supply in the plastics industry to reduce the primary energy demand. J Clean Prod 2018;192:790-800. https://doi.org/https://doi.org/10.1016/j.jclepro.2018.04.254.

[299] Baxevanou C, Fidaros D, Bartzanas T, Kittas C. Energy Consumption and Energy Saving Measures in Poultry. Environ Eng 2017;5:29-36. 
https://doi.org/10.13189/eee.2017.050201.

[300] ISO. Building components and building elements - Thermal resistance and thermal transmittance- Calculation methods (ISO 6946:2017). 2017.

[301] ASHRAE. ASHRAE Handbook - Fundamentals (SI Edition). Atlanta: 2017.

[302] Ahn HK, Sauer TJ, Richard TL, Glanville TD. Determination of thermal properties of composting bulking materials. Bioresour Technol 2009;100:3974-81. https://doi.org/10.1016/j.biortech.2008.11.056.

[303] Van Horne PLM. Competitiveness of the EU poultry meat sector, base year 2017: international comparison of production costs. 2018. https://doi.org/10.18174/404949.

[304] CEN. EN 15459:2007 - Energy performance of buildings - Economic evaluation procedure for energy systems in buildings. 2007.

[305] Hermelink AH, de Jager D. Evaluating our future - The crucial role of discount rates in European Commission energy system modelling. 2015.

[306] Eurostat. Price level indices for construction and its components, 20192019. https://ec.europa.eu/eurostat/statistics-

explained/index.php?title=File:Price_level_indices_for_construction_and_its_components, _2019,_(EU-27\%3D100)_update_December.png (accessed February 14, 2021).

[307] Hörndahl T. Energy Use in Farm Buildings - A study of 16 farms with different enterprises Revised and translated second edition. Alnarp: 2008.

[308] Technical Institute of Poultry. Summary of propane and electricity consumption in poultry farming (Synthèse des consommations de propane et d'électricité en aviculture, in French). 2010.

[309] Rossi P, Gastaldo A, Riva G, de Carolis C. Re Sole Projet - Guidelines for the energy saving and solar energy production in livestock facilities (Progetto Re Sole - Linee guida per il risparmio energetico e per la produzione di energia da fonte solare negli allevamenti zootecnici, in Italian). Reggio Emilia: 2013.

[310] Polish Ministry of Economy. National Energy Efficiency Action Plan for Poland 2014. Warsaw: 2014.

[311] French Ministry of Territorial Equality and Housing. Thermal regulation 2012: an energy leap for new buildings (Réglementation thermique 2012: un saut énergétique pour les bâtiments neufs, French). 2011.

[312] E. Molenbroek, E. Stricker TB. Primary energy factors for electricity in buildings - Toward a flexible electricity supply. Utrecht: 2011.

[313] German Association of Energy and Water Industries (BDEW). Primary energy factors - the relationship between primary energy and final energy in the energy evaluation (Primärenergiefaktoren - Der Zusammenhang von Primärenergie und Endenergie in der energetischen Bewertung, in German). Berlin: 2015.

[314] Spanish Ministry of Industry Energy and Tourism. CO2 emission factors and primary energy factors of different energy sources used in the Spanish building sector (Factores de emisión de $\mathrm{CO} 2$ y coeficientes de paso a energía primaria de diferentes fuentes de energía final consumidas en el sector de edifici. 2016. https://doi.org/10.1017/CBO9781107415324.004.

[315] Italian Ministry of Economic Development. Interministerial Decree of 26 June 2015 Application of the methodologies for calculating energy performance and defining the prescriptions and minimum requirements for buildings (Decreto interministeriale 26 giugno 2015 - Applicazione delle metodologie . Italy: 2015.

[316] Kristensen HH, Burgess LR, Demmers TGH, Wathes CM. The preferences of laying hens for different concentrations of atmospheric ammonia. Appl Anim Behav Sci 2000;63:30718. https://doi.org/10.1016/S0168-1591(00)00110-6.

[317] Valentine H. A Study of the Effect of Different Ventilation Rates on the Ammonia Concentrations in the Atmosphere of Broiler Houses. Br Poult Sci 1964;5:149-59. https://doi.org/10.1080/00071666408415526.

[318] Gustin P, Urbain B, Prouvost JF, Ansay M. Effects of Atmospheric Ammonia on Pulmonary Hemodynamics and Vascular Permeability in Pigs: Interaction with Endotoxins. Toxicol Appl Pharmacol 1994;125:17-26. https://doi.org/https://doi.org/10.1006/taap.1994.1044.

[319] Quarles CL, Kling HF. Evaluation of Ammonia and Infectious Bronchitis Vaccination Stress on Broiler Performance and Carcass Quality1. Poult Sci 1974;53:1592-6. https://doi.org/https://doi.org/10.3382/ps.0531592.

[320] Gerritzen M, Lambooij B, Reimert H, Stegeman A, Spruijt B. A note on behaviour of poultry 
exposed to increasing carbon dioxide concentrations. Appl Anim Behav Sci 2007;108:17985. https://doi.org/10.1016/j.applanim.2006.11.014.

[321] Verspecht A, Vanhonacker F, Verbeke W, Zoons J, Van Huylenbroeck G. Economic impact of decreasing stocking densities in broiler production in Belgium. Poult Sci 2011;90:184451. https://doi.org/https://doi.org/10.3382/ps.2010-01277.

[322] Knížatová M, Mihina Š, Broucek, J., Karandušovská I, Sauter GJ, Macuhová J. Effect of the age and season of fattening period on carbon dioxide emissions from broiler housing. Czech J Anim Sci 2010;55:436-44.

[323] Zhang Y, Barber EM. An Evaluation of Heating and Ventilation Control Strategies for Livestock Buildings. J Agric Eng Res 1995;60:217-25. https://doi.org/https://doi.org/10.1006/jaer.1995.1016.

[324] Oviedo-Rondón EO. Energy savings in poultry farms (Ahorro energético en granjas avícolas , in Spanish). Proc. XLII Symp. científico Avic., Zaragoza (Spain): 2010.

[325] ASHRAE. Standard 90.1-2016. Energy Standard for Buildings Except Low-Rise Residential Buildings. Am Soc Heating, Refrig Air-Conditioning Eng Inc 2016. https://doi.org/http://dx.doi.org/10.1108/17506200710779521.

[326] European Committee for Standardisation. EN ISO 15927-6: Hygrothermal performance of buildings - Calculation and presentation of climatic data. 2007.

[327] Reindl DT, Beckman WA, Duffie JA. Diffuse fraction correlations. Sol Energy 1990;45:17. https://doi.org/https://doi.org/10.1016/0038-092X(90)90060-P.

[328] Jones TA, Donnelly CA, Stamp Dawkins M. Environmental and management factors affecting the welfare of chickens on commercial farms in the United Kingdom and Denmark stocked at five densities. Poult Sci 2005;84:1155-65. https://doi.org/https://doi.org/10.1093/ps/84.8.1155.

[329] WEAVER WD, MEIJERHOF R. The Effect of Different Levels of Relative Humidity and Air Movement on Litter Conditions, Ammonia Levels, Growth, and Carcass Quality for Broiler Chickens. Poult $\quad$ Sci $1991 ; 70: 746-55$. https://doi.org/https://doi.org/10.3382/ps.0700746.

[330] Calvet S, Estelles F, Cambra-Lopez M, Torres AG, van den Weghe HFA. The influence of broiler activity, growth rate, and litter on carbon dioxide balances for the determination of ventilation flow rates in broiler production. Poult Sci 2011. https://doi.org/10.3382/ps.201101580 .

[331] Gerritzen MA, Lambooij E, Hillebrand SJ, Lankhaar JA, Pieterse C. Behavioral Responses of Broilers to Different Gaseous Atmospheres. Poult Sci 2000;79:928-33. https://doi.org/https://doi.org/10.1093/ps/79.6.928.

[332] Ritz CW, Fairchild BD, Lacy MP. Implications of Ammonia Production and Emissions from Commercial Poultry Facilities: A Review. J Appl Poult Res 2004;13:684-92. https://doi.org/https://doi.org/10.1093/japr/13.4.684.

[333] Anderson DP, Beard CW, Hanson RP. The Adverse Effects of Ammonia on Chickens Including Resistance to Infection with Newcastle Disease Virus. Avian Dis 1964;8:369-79. https://doi.org/10.2307/1587967.

[334] M. Wathes C, B. Jones J, H. Kristensen H, K. M. Jones E, J. F. Webster A. Aversion of pigs and domestic fowl to atmospheric ammonia. Trans ASAE 2002;45:1605. https://doi.org/https://doi.org/10.13031/2013.11067.

[335] Verstegen MWA, Tamminga S, Greers R. The effect of gaseous pollutants on animals. In: Dewi IA, Axford RFE, Fayez I, Marai M, Omed H, editors. Pollut. Livest. Prod. Syst., CAB International; 1994, p. 71-9.

[336] Morsing S, Strøm JS, Zhang G, Kai P. Scale model experiments to determine the effects of internal airflow and floor design on gaseous emissions from animal houses. Biosyst Eng 2008;99:99-104. https://doi.org/https://doi.org/10.1016/j.biosystemseng.2007.09.028.

[337] Costantino A, Fabrizio E, Biglia A, Cornale P, Battaglini L. Energy Use for Climate Control of Animal Houses: The State of the Art in Europe. Energy Procedia 2016;101:184-91. https://doi.org/10.1016/j.egypro.2016.11.024.

[338] Resolución conjunta de los Ministerios de Industria Energía y Turismo y Ministerio de Fomento. $\mathrm{CO} 2$ emission factors and coefficients of conversion to primary energy of different sources of final energy consumed in the building sector in Spain (Factores de emisión de $\mathrm{CO} 2$ y coeficientes de paso a energía primaria de diferentes fuentes de energía fina. 2014.

[339] EUROSTAT. Electricity prices for household consumers 2019. 
http://appsso.eurostat.ec.europa.eu/nui/show.do?dataset=nrg_pc_204\&lang=en (accessed May 22, 2019).

[340] IDAE (Instituto para la Diversificación y ahorro de la Energía). Energy prices report: fuels (Informe de precios energéticos: combustibles y carburantes). 2019. 



\section{Appendix A Tables of regression coefficients}





\section{A.1. Regression coefficients for Chapter 4}

Table A.1 - Regression coefficients of Eqs. (17) and (18).

\begin{tabular}{ccc}
\hline Coefficient & Value & Unit of measurement \\
\hline$z_{1}$ & 0.154 & - \\
$z_{2}$ & 1.10 & - \\
$z_{3}$ & 1.13 & - \\
$z_{4}$ & 1.65 & $\mathrm{~W} \mathrm{~m}^{-2} \mathrm{~K}^{-1}$ \\
$z_{5}$ & 0.56 & - \\
$z_{6}$ & 13.0 & $\mathrm{~W} \mathrm{~m}^{-2}$ \\
\hline
\end{tabular}

Table A.2 - Performance parameters of the fan model installed in the monitored greenhouse for the $S F P$ calculation through Eq. (29) (data from manufacturer).

\begin{tabular}{ccc}
\hline Coefficient & Value & Unit of measurement \\
\hline$d_{\text {perf }}$ & $6.418 \cdot 10^{-4}$ & $\mathrm{~W}^{-1}$ \\
$e_{\text {perf }}$ & $-3.382 \cdot 10^{-8}$ & $\mathrm{~h} \mathrm{~m}^{-3} \mathrm{~W}^{-1}$ \\
$f_{\text {perf }}$ & -2.579 & $\mathrm{~m}^{3} \mathrm{~h}^{-1} \mathrm{~W}^{-1} \mathrm{~Pa}^{-1}$ \\
$g_{\text {perf }}$ & $1.028 \cdot 10^{-2}$ & $\mathrm{~m}^{3} \mathrm{~h}^{-1} \mathrm{~W}^{-1} \mathrm{~Pa}^{-2}$ \\
$h_{\text {perf }}$ & $2.973 \cdot 10^{-2}$ & $\mathrm{~W}^{-1} \mathrm{~Pa}^{-1}$ \\
$i_{\text {perf }}$ & 96.188 & $\mathrm{~m}^{3} \mathrm{Wh}^{-1}$ \\
\hline
\end{tabular}

\section{A.2. Regression coefficients for Chapter 5}

Table A.3 - Regression coefficients for the calculation of the broiler live weight as a function of the broiler age (Eq. (50)).

\begin{tabular}{ccc}
\hline Coefficient & Value & Unit of measurement \\
\hline$k_{\mathrm{wb} \_3}$ & $-2.1164 \cdot 10^{-5}$ & $\mathrm{~kg} \mathrm{day}^{-1}$ \\
$k_{\mathrm{wb} \_2}$ & $+2.5608 \cdot 10^{-3}$ & $\mathrm{~kg} \mathrm{day}^{-2}$ \\
$k_{\mathrm{wb} \_1}$ & $-5.3002 \cdot 10^{-3}$ & $\mathrm{~kg} \mathrm{day}^{-3}$ \\
$k_{\mathrm{wb} \_0}$ & $+7.0839 \cdot 10^{-2}$ & $\mathrm{~kg}$ \\
\hline
\end{tabular}

Table A.4 - Regression coefficients for the calculation of the optimal indoor air set point temperature as a function of the broiler age (Eq. (51)).

\begin{tabular}{ccc}
\hline Coefficient & Value & Unit of measurement \\
\hline$k_{\theta \mathrm{b}_{\_} 6}$ & $+2.0950 \cdot 10^{-9}$ & ${ }^{\circ} \mathrm{C} \mathrm{day}{ }^{-6}$ \\
$k_{\theta \mathrm{b}_{\_} 5}$ & $-4.7774 \cdot 10^{-7}$ & ${ }^{\circ} \mathrm{C} \mathrm{day}^{-5}$ \\
$k_{\theta \mathrm{b}_{\_} 4}$ & $+4.0737 \cdot 10^{-5}$ & ${ }^{\circ} \mathrm{C} \mathrm{day}^{-4}$ \\
$k_{\theta \mathrm{b}_{\_} 3}$ & $-1.5447 \cdot 10^{-3}$ & ${ }^{\circ} \mathrm{C} \mathrm{day}^{-3}$ \\
$k_{\theta \mathrm{b} \_2}$ & $+2.6264 \cdot 10^{-2}$ & ${ }^{\circ} \mathrm{C} \mathrm{day}^{-2}$ \\
$k_{\theta \mathrm{b}_{\_} 1}$ & $-5.2732 \cdot 10^{-1}$ & ${ }^{\circ} \mathrm{C} \mathrm{day}^{-1}$ \\
$k_{\theta \mathrm{b}_{\_} 0}$ & 32.5259 & ${ }^{\circ} \mathrm{C}$ \\
\hline
\end{tabular}


Table A.5 - Regression coefficients for the calculation of the dead band as a function of the broiler age (Eq. (52)).

\begin{tabular}{ccc}
\hline Coefficient & Value & Unit of measurement \\
\hline$k_{\Delta_{-} 6}$ & $-2.3230 \cdot 10^{-8}$ & ${ }^{\circ} \mathrm{C} \mathrm{day}^{-6}$ \\
$k_{\Delta_{-} 5}$ & $+3.0335 \cdot 10^{-6}$ & ${ }^{\circ} \mathrm{C} \mathrm{day}^{-5}$ \\
$k_{\Delta_{-} 4}$ & $-1.5345 \cdot 10^{-4}$ & ${ }^{\circ} \mathrm{C} \mathrm{day}^{-4}$ \\
$k_{\Delta_{-} 3}$ & $+3.5256 \cdot 10^{-3}$ & ${ }^{\circ} \mathrm{C} \mathrm{day}^{-3}$ \\
$k_{\Delta_{-} 2}$ & $-3.2925 \cdot 10^{-2}$ & ${ }^{\circ} \mathrm{C} \mathrm{day}^{-2}$ \\
$k_{\Delta_{-} 1}$ & $+1.0326 \cdot 10^{-1}$ & ${ }^{\circ} \mathrm{C} \mathrm{day}^{-1}$ \\
$k_{\Delta_{-} 0}$ & +0.9494 & ${ }^{\circ} \mathrm{C}$ \\
\hline
\end{tabular}

Table A.6 - Regression coefficients for the calculation of sensible fraction of the broiler heat emission as a function of the optimal set point temperature (Eq. (56)).

\begin{tabular}{ccc}
\hline Coefficient & Value & Unit of measurement \\
\hline$k_{\mathrm{R} \_6}$ & $+1.1570 \cdot 10^{-9}$ & ${ }^{\circ} \mathrm{C}^{-6}$ \\
$k_{\mathrm{R} \_5}$ & $+1.1814 \cdot 10^{-7}$ & ${ }^{\circ} \mathrm{C}^{-5}$ \\
$k_{\mathrm{R} \_4}$ & $-5.1467 \cdot 10^{-6}$ & ${ }^{\circ} \mathrm{C}^{-4}$ \\
$k_{\mathrm{R} \_3}$ & $+9.7688 \cdot 10^{-5}$ & ${ }^{\circ} \mathrm{C}^{-3}$ \\
$k_{\mathrm{R} \_2}$ & $-4.8856 \cdot 10^{-4}$ & ${ }^{\circ} \mathrm{C}^{-2}$ \\
$k_{\mathrm{R} \_1}$ & $-7.2767 \cdot 10^{-3}$ & ${ }^{\circ} \mathrm{C}^{-1}$ \\
$k_{\mathrm{R} \_0}$ & $+6.3921 \cdot 10^{-1}$ & - \\
\hline
\end{tabular}

Table A.7 - Regression coefficients for the calculation of the base ventilation flow rate emission as a function of the broiler age and weight (Eq. (60)).

\begin{tabular}{ccc}
\hline Coefficient & Value & Unit of measurement \\
\hline$k_{\mathrm{Vb} \_4}$ & $+3.6000 \cdot 10^{-7}$ & $\mathrm{~m}^{3} \mathrm{~h}^{-1} \mathrm{~kg}^{-1}$ day $^{-4}$ \\
$k_{\mathrm{Vb} \_3}$ & $-6.6070 \cdot 10^{-5}$ & $\mathrm{~m}^{3} \mathrm{~h}^{-1} \mathrm{~kg}^{-1}$ day $^{-3}$ \\
$k_{\mathrm{Vb} \_2}$ & $+4.6223 \cdot 10^{-3}$ & $\mathrm{~m}^{3} \mathrm{~h}^{-1} \mathrm{~kg}^{-1} \mathrm{day}^{-2}$ \\
$k_{\mathrm{Vb} \_1}$ & $-1.5193 \cdot 10^{-1}$ & $\mathrm{~m}^{3} \mathrm{~h}^{-1} \mathrm{~kg}^{-1} \mathrm{day}^{-1}$ \\
$k_{\mathrm{Vb} \_}$ & +2.4666 & - \\
\hline
\end{tabular}

Table A.8 - Regression coefficients for the calculation of the static pressure difference as a function of the air velocity (Eq. (69)).

\begin{tabular}{ccc}
\hline Coefficient & Value & Unit of measurement \\
\hline$k_{\Delta \mathrm{p} \_2}$ & $+2.5714 \cdot 10^{-2}$ & $\mathrm{~Pa} \mathrm{~s}^{2} \mathrm{~m}^{-3}$ \\
$k_{\Delta \mathrm{p} \_1}$ & $+3.1429 \cdot 10^{-3}$ & $\mathrm{~Pa} \mathrm{~s} \mathrm{~m}^{-2}$ \\
$k_{\Delta \mathrm{p} \_0}$ & $+6.0000 \cdot 10^{-3}$ & $\mathrm{~Pa} \mathrm{~m}^{-1}$ \\
\hline
\end{tabular}


Table A.9 - Regression coefficients for characterizing the fans installed in the considered broiler house through Eqs. (27) and (28).

\begin{tabular}{ccc}
\hline Coefficient & Value & Unit of measurement \\
\hline$a_{\text {flow }}$ & -0.8644 & $\mathrm{~m}^{3} \mathrm{~Pa}^{-2} \mathrm{~h}^{-1}$ \\
$b_{\text {flow }}$ & -135.04 & $\mathrm{~m}^{3} \mathrm{~Pa}^{-1} \mathrm{~h}^{-1}$ \\
$c_{\text {flow }}$ & $+42,088.5$ & $\mathrm{~m}^{3} \mathrm{~h}^{-1}$ \\
$a_{\text {perf }}$ & -0.0007 & $\mathrm{~m}^{3} \mathrm{~Pa}^{-2} \mathrm{Wh}^{-1}$ \\
$b_{\text {perf }}$ & -0.2116 & $\mathrm{~m}^{3} \mathrm{~Pa}^{-1} \mathrm{Wh}^{-1}$ \\
$c_{\text {perf }}$ & +34.481 & $\mathrm{~m}^{3} \mathrm{Wh}^{-1}$ \\
\hline
\end{tabular}

Table A.10 - Regression coefficients for the calculation of the optimal indoor air set point temperature as a function of the pig live weight (Eq. (81)).

\begin{tabular}{ccc}
\hline Coefficient & Value & Unit of measurement \\
\hline$k_{\theta \mathrm{p} \_3}$ & $-6.4342 \cdot 10^{-5}$ & ${ }^{\circ} \mathrm{C} \mathrm{kg}^{-3}$ \\
$k_{\theta \mathrm{p} \_2}$ & $+1.1213 \cdot 10^{-2}$ & ${ }^{\circ} \mathrm{C} \mathrm{kg}^{-2}$ \\
$k_{\theta \mathrm{p} \_1}$ & $-6.9958 \cdot 10^{-1}$ & ${ }^{\circ} \mathrm{C} \mathrm{kg}^{-1}$ \\
$k_{\theta \mathrm{p} \_0}$ & +32.5557 & ${ }^{\circ} \mathrm{C}$ \\
\hline
\end{tabular}

Table A.11 - Regression coefficients for the calculation of the base ventilation air flow rate as a function of the pig live weight (Eq. (83)).

\begin{tabular}{ccc}
\hline Coefficient & Value & Unit of measurement \\
\hline$k_{\mathrm{Vp} \_}$ & $+2.6038 \cdot 10^{-9}$ & $\mathrm{~m}^{3} \mathrm{~h}^{-1} \mathrm{~kg}^{-6}$ \\
$k_{\mathrm{Vp} \_5}$ & $-4.8760 \cdot 10^{-7}$ & $\mathrm{~m}^{3} \mathrm{~h}^{-1} \mathrm{~kg}^{-5}$ \\
$k_{\mathrm{Vp} \_}$ & $+3.6548 \cdot 10^{-5}$ & $\mathrm{~m}^{3} \mathrm{~h}^{-1} \mathrm{~kg}^{-4}$ \\
$k_{\mathrm{Vp} \_3}$ & $-1.4028 \cdot 10^{-3}$ & $\mathrm{~m}^{3} \mathrm{~h}^{-1} \mathrm{~kg}^{-3}$ \\
$k_{\mathrm{Vp} \_2}$ & $+2.9219 \cdot 10^{-2}$ & $\mathrm{~m}^{3} \mathrm{~h}^{-1} \mathrm{~kg}^{-2}$ \\
$k_{\mathrm{Vp} \_1}$ & $-3.1898 \cdot 10^{-1}$ & $\mathrm{~m}^{3} \mathrm{~h}^{-1} \mathrm{~kg}^{-1}$ \\
$k_{\mathrm{Vp} \_0}$ & +1.6905 & $\mathrm{~m}^{3} \mathrm{~h}^{-1}$ \\
\hline
\end{tabular}

Table A.12 - Regression coefficients for characterizing the fans installed in pig house A through Eqs. (27) and (28).

\begin{tabular}{ccc}
\hline Coefficient & Value & Unit of measurement \\
\hline$a_{\text {flow }}$ & $-5.8796 \cdot 10^{-2}$ & $\mathrm{~m}^{3} \mathrm{~Pa}^{-2} \mathrm{~h}^{-1}$ \\
$b_{\text {flow }}$ & -25.7989 & $\mathrm{~m}^{3} \mathrm{~Pa}^{-1} \mathrm{~h}^{-1}$ \\
$c_{\text {flow }}$ & $+6,496.24$ & $\mathrm{~m}^{3} \mathrm{~h}^{-1}$ \\
$a_{\text {perf }}$ & $-1.7888 \cdot 10^{-3}$ & $\mathrm{~m}^{3} \mathrm{~Pa}^{-2} \mathrm{Wh}^{-1}$ \\
$b_{\text {perf }}$ & $-6.3776 \cdot 10^{-2}$ & $\mathrm{~m}^{3} \mathrm{~Pa}^{-1} \mathrm{Wh}^{-1}$ \\
$c_{\text {perf }}$ & +11.14 & $\mathrm{~m}^{3} \mathrm{Wh}^{-1}$ \\
\hline
\end{tabular}




\section{A.3. Regression coefficients for Chapter 7}

Table A.13 - Regression coefficients for the $S F P$ of both the fan models.

\begin{tabular}{cccc}
\hline Fan model & Coefficient & Value & Unit of measurement \\
\hline \multirow{4}{*}{ Large fans } & $a_{\text {perf }}$ & $-5.0000 \cdot 10^{-8}$ & $\mathrm{~m}^{3} \mathrm{Wh}^{-1} \mathrm{~Pa}^{-2}$ \\
& $b_{\text {perf }}$ & $+2.0250 \cdot 10^{-4}$ & $\mathrm{~m}^{3} \mathrm{Wh}^{-1} \mathrm{~Pa}^{-1}$ \\
& $c_{\text {perf }}$ & +0.0316 & {$[-]$} \\
\hline \multirow{3}{*}{ Small fans } & $a_{\text {perf }}$ & 0 & $\mathrm{~m}^{3} \mathrm{Wh}^{-1} \mathrm{~Pa}^{-2}$ \\
& $b_{\text {perf }}$ & $+3.7110 \cdot 10^{-5}$ & $\mathrm{~m}^{3} \mathrm{Wh}^{-1} \mathrm{~Pa}^{-1}$ \\
& $c_{\text {perf }}$ & +0.0486 & {$[-]$} \\
\hline
\end{tabular}


Appendix B

Set of equations for the application of the simple hourly method 



\section{B.1. Overview on the simple hourly method}

The energy models for greenhouses (Chapter 4) and livestock houses (Chapter $5)$ that were developed in the framework of this thesis are based on customizations of the simple hourly $(\mathrm{SH})$ method from ISO 13790:2008 standard [211]. This method is adopted to solve the dynamic thermal balance with the final aim of estimating the indoor air temperature and the required theoretical heating and cooling loads needed to maintain the required set point temperatures. In this Appendix, the main equations that were adopted for implementing this calculation method in the energy simulation models are provided. Please note that the full set of equations can be found in paragraph C.3 of Annex C of ISO 13790 standard [211].

As previously presented in this thesis (section 4.3.3), the $S H$ method consists in the thermal-electrical analogy between the analyzed building and an equivalent 5R1C electrical network. In Figure B.1, the equivalent electrical network is presented with a general schematization suitable for any type of building. The figure shows that the electrical network is composed by five electrical resistances that, in the thermal-electrical analogy, represent the heat transfer coefficients $\left(H_{\mathrm{ve}}, H_{\mathrm{tr} \text { fen }}\right.$, $H_{\text {tr_em }}, H_{\text {tr_is }}$ and $H_{\text {tr_ms }}$ ). In addition, there are five nodes that represent as many the lumped temperatures $\left(\theta_{\text {air_sup }}, \theta_{\text {air_o }}, \theta_{\text {air_i }}, \theta_{\mathrm{s}}\right.$ and $\left.\theta_{\mathrm{m}}\right)$ and four current sources that represent as many heat flows $\left(\phi_{\mathrm{H} / \mathrm{C}_{-} \text {nd }}, \phi_{\mathrm{ia}}, \phi_{\mathrm{st}}\right.$ and $\left.\phi_{\mathrm{m}}\right)$.

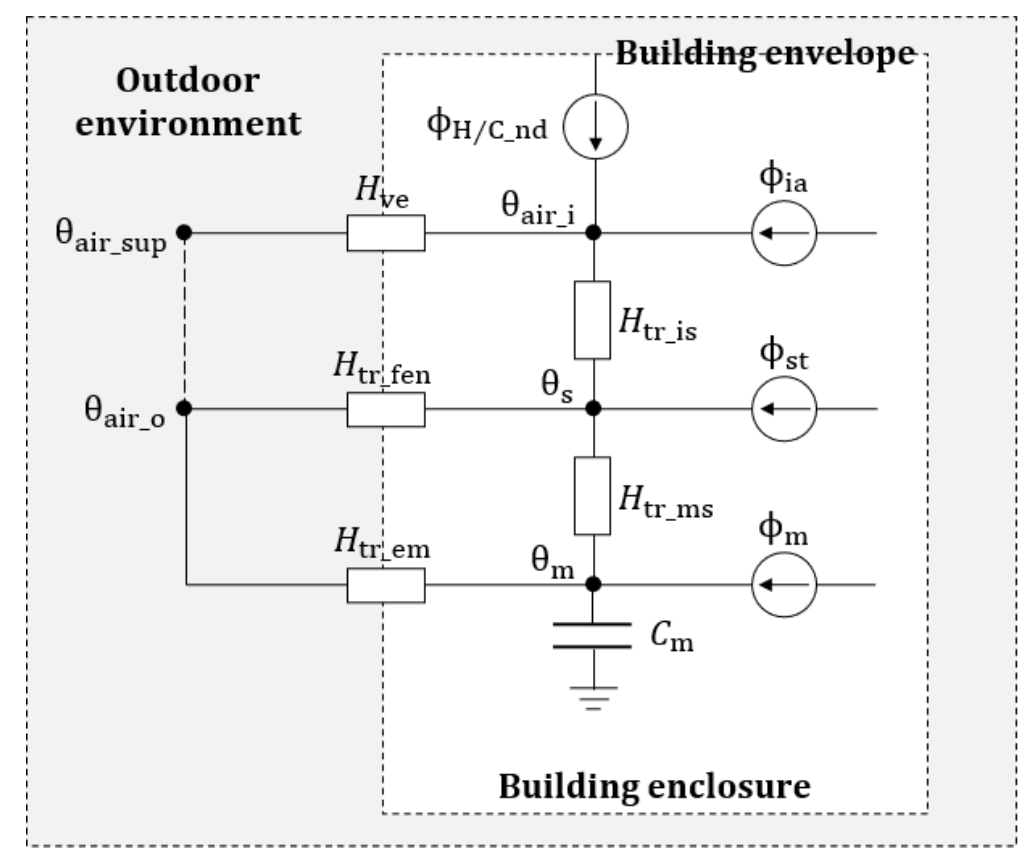

Figure B.1 - General schematization of the equivalent 5R1C electrical network at the basis of the simple hourly method of ISO 13790.

The last element included in the equivalent electrical network is a capacitor which, in the thermal-electrical analogy, represents the lumped fabric heat capacity of the building $\left(C_{\mathrm{m}}\right)$. A more detailed description of this schematization can be 
found in section 4.3.3 and the equations for calculating each term presented in Figure B.1 are provided in the following sections.

\section{B.1.1. Setting the thermal balance}

The $S H$ method makes it possible to simulate the thermal behavior of a building during a period with a time discretization of one hour. It means that the thermal balance should be set and solved at each hourly simulation time step, updating the thermal balance terms considering the variations of the boundary conditions that took place in the considered simulation time step. The terms that are needed to set the thermal balance are the heat flows and the heat transfer coefficients, which calculation procedure is presented below.

\section{Calculation of heat flows}

As visible in Figure B.1, the $S H$ method considers four different heat flows, namely $\phi_{\mathrm{ia}}, \phi_{\mathrm{st}}, \phi_{\mathrm{m}}$ and $\phi_{\mathrm{H} / \mathrm{C}_{-} \text {nd }}$. The last term $\left(\phi_{\mathrm{H} / \mathrm{C}_{-} n d}\right)$ is one of the two outputs of the calculation, with indoor air temperature $\left(\theta_{\text {air_i }}\right)$, hence it is obtained once solved the thermal balance. By contrast, the terms $\phi_{\mathrm{ia}}, \phi_{\mathrm{st}}$ and $\phi_{\mathrm{m}}$ are needed to set the thermal balance, hence they should be calculated starting from the input data and the boundary conditions.

The heat flows $\phi_{\mathrm{ia}}, \phi_{\mathrm{m}}$ and $\phi_{\mathrm{st}}$ are all function of the solar heat load $\left(\phi_{\mathrm{sol}}\right)$ and internal sensible heat load ( $\left.\phi_{\text {int }}\right)$. It means that each one of them should be calculated at each considered time step, since $\phi_{\text {sol }}$ and $\phi_{\text {int }}$ are, in turn, time dependent.

The heat flow $\phi_{\text {ia }}$ is a convective heat flow that is directly applied to $\theta_{\text {air_i }}$ node, as visible in the schematization of Figure B.1, and it reads

$$
\phi_{\text {ia }}=0.5 \cdot \phi_{\text {int }} \quad[\mathrm{W}]
$$

where $\phi_{\text {int }}$ is the internal sensible heat load proper of greenhouses (Eq. (20)), broiler houses (Eq. (57)) or growing-finishing pig houses (Eq. (78)).

By contrast, $\phi_{\mathrm{m}}$ is a radiative heat flow that is directly applied to $\theta_{\mathrm{m}}$ node and reads

$$
\phi_{\mathrm{m}}=\frac{A_{\mathrm{m}}}{A_{\mathrm{tot}}}\left(0.5 \cdot \phi_{\text {int }}+\phi_{\mathrm{sol}}\right) \quad[\mathrm{W}]
$$

where $A_{\text {tot }}$ is the total area of all the surfaces that face on the building thermal zone $\left(\mathrm{m}^{2}\right)$, such as walls, floor, and ceiling. The term $A_{\mathrm{m}}$ is the effective mass area and reads

$$
A_{\mathrm{m}}=\frac{C_{\mathrm{m}}^{2}}{\sum_{k}^{n_{\mathrm{comp}}}\left(A_{\mathrm{k}} \cdot \kappa_{\mathrm{i}, \mathrm{k}}^{2}\right)} \quad\left[\mathrm{m}^{2}\right]
$$

where $C_{\mathrm{m}}$ is the lumped fabric heat capacity of the building $\left(\mathrm{J} \mathrm{K}^{-1}\right), A_{\mathrm{k}}$ is the area of the $k$-th building component facing on the thermal zone $\left(\mathrm{m}^{2}\right), \kappa_{\mathrm{i}, \mathrm{k}}$ is the 
internal areal heat capacity of the $k$-th building component $\left(\mathrm{J} \mathrm{m}^{-2} \mathrm{~K}^{-1}\right)$ and $n_{\text {comp }}$ is the number of building components considered in the calculation. The term $\phi_{\text {sol }}$ in Eq. (B.1) represents the solar heat load that enters in the considered building. The calculation of this term for greenhouses was presented in section 4.3.3 through Eq. (14) to consider, for example, the presence of shading screens. The calculation of $\phi_{\text {sol }}$ in livestock houses was performed in compliance with ISO 13790 standard [211]. The total $\phi_{\text {sol }}$ is calculated as

$$
\phi_{\text {sol }}=\phi_{\text {sol_op }}+\phi_{\text {sol_gl }} \quad[\mathrm{W}]
$$

where $\phi_{\text {sol_op }}$ and $\phi_{\text {sol_gl }}$ are the solar heat load through the opaque and glazed building element, respectively, of the livestock house envelope. The term $\phi_{\text {sol_op }}$ is calculated as

$$
\phi_{\text {sol_op }}=\sum_{k=1}^{n_{\text {comp }}}\left(F_{\text {sh,k }} \cdot \alpha_{\text {sol, } \mathrm{k}} \cdot R_{\text {se }, \mathrm{k}} \cdot U_{\mathrm{k}} \cdot A_{\mathrm{k}} \cdot I_{\text {sol, } \mathrm{k}}\right) \quad[\mathrm{W}]
$$

where, referring to the $k$-th element of the opaque envelope, $F_{\mathrm{sh}, \mathrm{k}}$ is its dimensionless shading factor, $\alpha_{\mathrm{sol}, \mathrm{k}}$ is its dimensionless absorption coefficient for solar radiation, $R_{\mathrm{se}, \mathrm{k}}$ is its external surface heat resistance $\left(\mathrm{m}^{2} \mathrm{~K}^{-1} \mathrm{~W}^{-1}\right), U_{\mathrm{k}}$ is the thermal transmittance $\left(\mathrm{W} \mathrm{m}^{-2} \mathrm{~K}^{-1}\right), A_{\mathrm{k}}$ is the area of the opaque envelope component $\left(\mathrm{m}^{2}\right)$ and $I_{\mathrm{sol}, \mathrm{k}}$ is the total solar irradiance on the considered element ( $\mathrm{W} \mathrm{m}^{-2}$ ). The term $n_{\text {comp }}$ is the number of the considered elements of the opaque envelope.

Similarly, $\phi_{\text {sol_gl }}$ is calculated as

$$
\phi_{\text {sol_gl }}=\sum_{k=1}^{n_{\text {comp }}}\left(F_{\mathrm{sh}, \mathrm{k}} \cdot g_{\mathrm{gl}, \mathrm{k}} \cdot\left(1-F_{\mathrm{fr}}\right) \cdot A_{\mathrm{k}} \cdot I_{\mathrm{sol}, \mathrm{k}}\right) \quad[\mathrm{W}]
$$

where $g_{\mathrm{gl}, \mathrm{k}}$ is the total dimensionless solar energy transmittance of the $k$-th glazed element of the envelope and $F_{\mathrm{fr}, \mathrm{k}}$ is the dimensionless frame area fraction of the $k$-th glazed element of the envelope. The term $n_{\text {comp }}$ is the number of the considered elements of the glazed envelope.

The heat flow $\phi_{\mathrm{st}}$ is a radiative heat flow directly applied to $\theta_{\mathrm{s}}$ node and it is calculated as

$$
\phi_{\mathrm{st}}=\left(1-\frac{A_{\mathrm{m}}}{A_{\mathrm{tot}}}-\frac{H_{\mathrm{tr} f \mathrm{fen}}}{9.1 \cdot A_{\mathrm{tot}}}\right) \cdot\left(0.5 \cdot \phi_{\mathrm{int}}+\phi_{\mathrm{sol}}\right) \quad[\mathrm{W}]
$$

where $H_{\text {tr }}$ fen is the heat transfer coefficient due to heat conduction across the glazed surfaces $\left(\mathrm{W} \mathrm{K}^{-1}\right)$ which formulation will be provided in the following section. 


\section{Calculation of heat transfer coefficients}

As visible from the schematization of Figure B.1, the $S H$ method considers five heat transfer coefficient, which main equation for their calculation are here presented.

The term $H_{\text {tr_ is }}$ represents the natural convection between the glazed surface and the indoor air and it reads

$$
H_{\text {tr_is }}=h_{\text {is }} \cdot A_{\text {tot }} \quad\left[\frac{\mathrm{W}}{\mathrm{K}}\right]
$$

where $h_{\text {is }}$ is the heat transfer coefficient between the $\theta_{\text {air_i }}$ and $\theta_{\mathrm{s}}$ nodes which value is constant and equal to $3.45 \mathrm{~W} \mathrm{~m}^{-2} \mathrm{~K}^{-1}$.

The term $H_{\text {tr_ms }}$ represents the heat transfer between the building thermal mass and the building surface and it reads

$$
H_{\mathrm{tr} \_\mathrm{ms}}=h_{\mathrm{ms}} \cdot A_{\mathrm{m}} \quad\left[\frac{\mathrm{W}}{\mathrm{K}}\right]
$$

where $h_{\mathrm{m} s}$ is the heat transfer coefficient between the $\theta_{\mathrm{m}}$ and $\theta_{\mathrm{s}}$ nodes which value is constant and equal to $9.1 \mathrm{~W} \mathrm{~m}^{-2} \mathrm{~K}^{-1}$.

The term $H_{\text {tr_em }}$ is introduced to consider the heat conduction occurring from the external environment to the building thermal mass and it reads

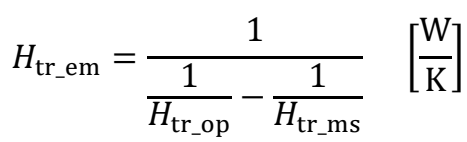

where $H_{\text {tr_op }}$ is the heat transfer coefficient through the opaques elements of the envelope that reads

$$
\begin{gathered}
H_{\text {tr_op }}=\sum_{k}^{n_{\mathrm{comp}}}\left(b_{\mathrm{tr}, \mathrm{k}} \cdot A_{\mathrm{k}} \cdot U_{\mathrm{k}}\right)+\sum_{m}^{n_{\mathrm{comp}}}\left(b_{\mathrm{tr}, \mathrm{m}} \cdot l_{\mathrm{m}} \cdot \Psi_{\mathrm{m}}\right)+ \\
\sum_{q}^{n_{\mathrm{comp}}}\left(b_{\mathrm{tr}, \mathrm{q}} \cdot \chi_{\mathrm{q}}\right) \quad\left[\frac{\mathrm{w}}{\mathrm{K}}\right]
\end{gathered}
$$

where $b_{\mathrm{tr}, \mathrm{k}}$ is a dimensionless adjustment factor of temperature to be used if the air temperature at the other side of the building element is not $\theta_{\text {air_o }}$. Values of $b_{\text {tr }}$ can be found in ISO 13790 [211]. The terms $A_{\mathrm{k}}$ and $U_{\mathrm{k}}$ are the area $\left(\mathrm{m}^{2}\right)$ and the thermal transmittance $\left(\mathrm{W} \mathrm{m}^{-2} \mathrm{~K}^{-1}\right)$ of the $k$-th building element of the opaque envelope. The term $l_{\mathrm{m}}$ is the length $(\mathrm{m})$ of the $m$-th linear thermal bridge and $\Psi_{\mathrm{m}}$ is its linear thermal transmittance $\left(\mathrm{W} \mathrm{m}^{-1} \mathrm{~K}^{-1}\right)$. The term $\chi_{\mathrm{q}}$ is the point thermal transmittance of the $q$-th thermal bridge $\left(\mathrm{W} \mathrm{K}^{-1}\right)$. Please note that in the present work thermal bridges were not considered due to their minor relevance.

The previously presented heat transfer coefficients $\left(H_{\mathrm{tr}_{-} \mathrm{fen}}, H_{\mathrm{tr}-\mathrm{em}}, H_{\mathrm{tr}}\right.$ is and $H_{\text {tr_ms }}$ ) are not time dependent since they are function of constant input values, such as surface area of building components or their thermal transmittance. By contrast, $H_{\mathrm{ve}}$ represents the heat transfer coefficient due to ventilation and it is function of 
the ventilation flow rate that is present in the building at the considered time step. Thus, $H_{\mathrm{ve}}$ should be calculated at each simulation time step as

$$
H_{\mathrm{ve}}=\rho_{\mathrm{air}} \cdot c_{\mathrm{air}} \cdot \dot{V} \quad\left[\frac{\mathrm{W}}{\mathrm{K}}\right]
$$

where $\rho_{\text {air }}$ and $c_{\text {air }}$ are the volumetric mass density and the specific heat capacity of ventilation air, respectively. The value of the product $\rho_{\text {air }} \cdot c_{\text {air }}$ is considered constant and equal to $1,200 \mathrm{~J} \mathrm{~m}^{3} \mathrm{~K}^{-1}$, in compliance with ISO 13790 [211]. The term $\dot{V}$ is the ventilation air flow rate $\left(\mathrm{m}^{3} \mathrm{~s}^{-1}\right)$.

To simplify the calculations for the thermal balance solution, the previously presented heat transfer coefficients are grouped into $H_{\mathrm{tr}_{-} 1}, H_{\mathrm{tr}_{-} 2}$, and $H_{\mathrm{tr} \_3}$, as reported in paragraph C.3 of Annex C of ISO 13790 standard [211]. The term $H_{\text {tr_1 }}$ reads

$$
H_{\mathrm{tr}_{-1}}=\frac{1}{\frac{1}{H_{\mathrm{ve}}}-\frac{1}{H_{\mathrm{tr} \_ \text {is }}}} \quad\left[\frac{\mathrm{W}}{\mathrm{K}}\right]
$$

The heat transfer coefficient $H_{\mathrm{tr} \_} 2$ reads

$$
H_{\mathrm{tr} \_}=H_{\mathrm{tr} \_1}+H_{\mathrm{tr} \_ \text {fen }} \quad\left[\frac{\mathrm{W}}{\mathrm{K}}\right]
$$

where $H_{\text {tr_fen }}$ is the heat transfer by transmission through the glazed surface of the building envelope $\left(\mathrm{W} \mathrm{K}^{-1}\right)$ calculated with a formulation similar to the one of Eq. (B.11), but considering only the glazed surface of the envelope.

Finally, $H_{\text {tr_3 }}$ reads

$$
H_{\mathrm{tr}_{-} 1}=\frac{1}{\frac{1}{H_{\mathrm{tr} \_} 2}-\frac{1}{H_{\mathrm{tr} \_\mathrm{ms}}}} \quad\left[\frac{\mathrm{W}}{\mathrm{K}}\right]
$$

Please note that $H_{\mathrm{tr} \_}, H_{\mathrm{tr} \_2}$, and $H_{\mathrm{tr} \_3}$ are all direct or indirect function of $H_{\mathrm{ve}}$, so their calculations should be updated at each simulation time step.

\section{B.1.2. Solving the thermal balance}

Once calculated the needed heat flows and the needed heat transfer coefficients, the thermal balance can be solved at each considered simulation time step. The solution of the thermal balance through the $S H$ method provides the hourly value the theoretical heating or cooling load $\left(\phi_{\mathrm{H} / \mathrm{C}_{n} \mathrm{nd}}\right)$ that is needed to maintain the heating $\left(\theta_{\text {set_H }}\right)$ or cooling $\left(\theta_{\text {set_C }}\right)$ set point temperature inside the building. The term $\phi_{\mathrm{H} / \mathrm{C}_{-} \text {nd }}$ is considered "theoretical" since to obtain the real heating or cooling heat flow, the efficiency of the heating or ventilation system should be considered, as shown for example in sections 4.3.3 and 5.4.3. If no $\phi_{\mathrm{H} / \mathrm{C}_{-} n d}$ is needed at the considered time step, the model provides the value of the indoor air temperature 
$\left(\theta_{\text {air_i }}\right)$ that, hence, is in free-floating conditions. For this purpose, the equivalent electrical network is solved with an hourly time discretization according to a Cranck-Nicolson time scheme. Once calculated the heat transfer coefficients and the heat loads, the following equations (Eqs. (B.16(B.20)) are applied twice for each simulation time step, imposing the following two values of $\phi_{\mathrm{H} / \mathrm{C}_{-} n d}$ :

- $\phi_{\mathrm{H} / \mathrm{C}_{-} \mathrm{nd}}=0 \mathrm{~W} \mathrm{~m}^{-2}$;

- $\phi_{\mathrm{H} / \mathrm{C} \_n d}=10 \mathrm{~W} \mathrm{~m}^{-2}$.

First, the average building mass temperature over the hour $\left(\theta_{m}\right)$ is calculated at each time step. To do so, the instantaneous values of $\theta_{\mathrm{m}}$ at the end of the considered time step $\left(\theta_{\mathrm{m}_{-} \tau}\right)$ is calculated as

$$
\theta_{\mathrm{m}_{-} \tau}=\frac{\theta_{\mathrm{m}_{-} \tau-1} \cdot\left[\frac{C_{\mathrm{m}}}{3600}-0.5 \cdot\left(H_{\mathrm{tr}_{-} 3}+H_{\text {tr_em }}\right)\right]+\phi_{\mathrm{m}_{-} \text {tot }}}{\frac{C_{\mathrm{m}}}{3600}+0.5 \cdot\left(H_{\mathrm{tr}_{-} 3}+H_{\mathrm{tr} \_\mathrm{em}}\right)} \quad\left[{ }^{\circ} \mathrm{C}\right]
$$

where $\theta_{m_{-} \tau-1}$ is $\theta_{m_{-} \tau}$ that was calculated at the previous simulation time step, and $C_{\mathrm{m}}$ is total building fabric heat capacity $\left(\mathrm{J} \mathrm{K}^{-1}\right)$. The term $\phi_{\mathrm{m}_{-} \text {tot }}$ represents the whole heat flow occurring at the considered time-step and reads

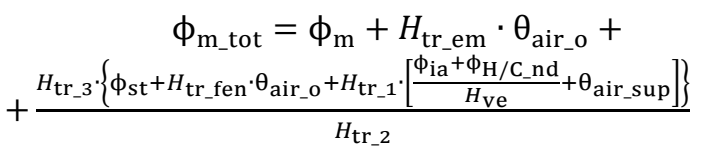

Once known the instantaneous values of the building mass temperature at the end of the considered time step $\left(\theta_{\mathrm{m}_{-} \tau}\right)$, the average building mass temperature over the hour $\left(\theta_{\mathrm{m}}\right)$ is then calculated as

$$
\theta_{\mathrm{m}}=\frac{\theta_{\mathrm{m}_{-} \tau}+\theta_{\mathrm{m}_{\_} \tau-1}}{2} \quad\left[{ }^{\circ} \mathrm{C}\right]
$$

At each simulation time step, the surface temperature $\left(\theta_{\mathrm{s}}\right)$ is calculated as

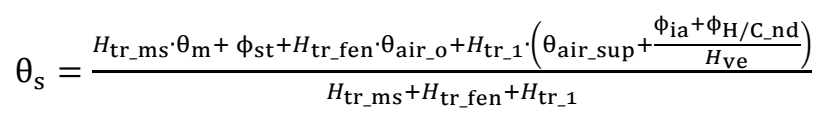

where $\theta_{\text {air_sup }}$ is the supply air temperature $\left({ }^{\circ} \mathrm{C}\right)$. In the previous equation, $\theta_{\text {air_o }}$ is used instead of $\theta_{\text {air_sup }}$ when evaporative pads are not activated or not present.

Finally, $\theta_{\text {air_i }}$ is calculated as

$$
\theta_{\text {air_i }_{-}}=\frac{H_{\mathrm{tr} \_ \text {is }} \cdot \theta_{\mathrm{s}}+H_{\mathrm{ve}} \cdot \theta_{\text {air_sup }}+\phi_{\mathrm{ia}}+\phi_{\mathrm{H} / \mathrm{C}_{\_} \mathrm{nd}}}{H_{\mathrm{tr} \_ \text {is }}+H_{\mathrm{ve}}} \quad\left[{ }^{\circ} \mathrm{C}\right]
$$

The value of $\theta_{\text {air_i }}$ calculated imposing $\phi_{\mathrm{H} / \mathrm{C} \_n d}$ equal to $0 \mathrm{~W} \mathrm{~m}^{-2}$ is named $\theta_{\text {air_i }(0)}$, while when it is calculated imposing $\phi_{\mathrm{H} / \mathrm{C}_{-} \text {nd }}$ equal to $10 \mathrm{~W} \mathrm{~m}^{-2}$ is named $\theta_{\text {air_i(10) }}$. At this stage of calculation, two different situations can occur: 
1. if $\theta_{\text {air_i(0) }}$ stays within $\theta_{\text {set_H }}$ and $\theta_{\text {set_c }}$, the analyzed building does not require neither supplemental heating nor cooling $\left(\phi_{\mathrm{H} / \mathrm{C}_{-} n d}=0 \mathrm{~W} \mathrm{~m}^{-2}\right)$ and $\theta_{\text {air_i }}$ is in free-floating conditions;

2. if $\theta_{\text {air_i }(0)}$ falls out of the range $\left(\theta_{\text {set_H }}-\theta_{\text {set_C }}\right), \phi_{H / C_{-} n d}$ is calculated as

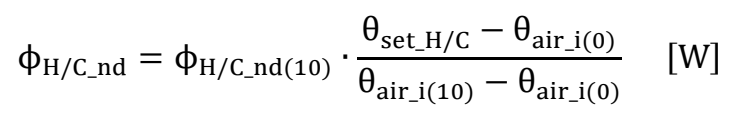

where $\phi_{\mathrm{H} / \mathrm{C}_{-} \mathrm{nd}(10)}$ is the heating or cooling load calculated considering $10 \mathrm{~W} \mathrm{~m}^{-2}$.

Once obtained $\theta_{\text {air_i }}$ and $\phi_{\mathrm{H} / \mathrm{C}_{-} n d}$, the calculation step ends and the following one starts. The value of $\theta_{m_{-} \tau}$ calculated in the time step that has just ended (Eq.(B.16)) will become $\theta_{\mathrm{m}_{-} \tau-1}$ of the new time step.

\section{B.2. Chapter nomenclature}

A

$A_{\mathrm{m}}$

$A_{\text {tot }}$

$b_{\mathrm{tr}}$

$C_{\mathrm{m}}$

$c_{\text {air }}$

$F_{\text {fr }}$

$F_{\mathrm{sh}}$

$H_{\text {tr_-1 }}$

$H_{\text {tr_ } 2}$

$H_{\text {tr_-3 }}$

$H_{\text {tr }- \text { em }}$

$H_{\text {tr }}$ fen

$H_{\text {tr_is }}$

$H_{\text {tr }}$ ms

$H_{\text {tr_op }}$

$H_{\mathrm{ve}}$

$h_{\text {is }}$

$h_{\mathrm{ms}}$

$I_{\text {sol }}$

$k$

l

$m$

$n_{\text {comp }}$

$q$

$R_{\mathrm{se}}$

$U$

$\dot{V}$

$\alpha_{\text {sol }}$

$\theta_{\text {air_i }}$

$\theta_{\text {air_i }(0)}$
Area of building component $\left[\mathrm{m}^{2}\right]$

Effective mass area $\left[\mathrm{m}^{2}\right]$

Total area of surfaces facing on the building thermal zone $\left[\mathrm{m}^{2}\right]$

Temperature adjustment factor $[-]$

Total building fabric heat capacity [ $\mathrm{J} \mathrm{K}^{-1}$ ]

Specific heat capacity of air $\left[\mathrm{J} \mathrm{kg}^{-1} \mathrm{~K}^{-1}\right]$

Frame area fraction of the glazed envelope element [-]

Shading factor $[-]$

Heat transfer coefficient [ $\mathrm{W} \mathrm{K}^{-1}$ ]

Heat transfer coefficient [W K ${ }^{-1}$ ]

Heat transfer coefficient [ $\mathrm{W} \mathrm{K}^{-1}$ ]

Heat transfer coefficient [ $\mathrm{W} \mathrm{K}^{-1}$ ]

Heat transfer coefficient [ $\mathrm{W} \mathrm{K}^{-1}$ ]

Heat transfer coefficient [W K ${ }^{-1}$ ]

Heat transfer coefficient [ $\mathrm{W} \mathrm{K}^{-1}$ ]

Heat transfer coefficient $\left[\mathrm{W} \mathrm{K}^{-1}\right.$ ]

Heat transfer coefficient due to ventilation [ $\mathrm{W} \mathrm{K}^{-1}$ ]

Heat transfer coefficient $\left[\mathrm{W} \mathrm{m}^{-2} \mathrm{~K}^{-1}\right]$

Heat transfer coefficient $\left[\mathrm{W} \mathrm{m}^{-2} \mathrm{~K}^{-1}\right.$ ]

Total solar irradiance on the considered element $\left[\mathrm{W} \mathrm{m}^{-2}\right]$

$k$-th considered building component

Length of the linear thermal bridge $[\mathrm{m}]$

$m$-th considered linear thermal bridge

Number of considered building components

$q$-th considered point thermal bridge

External surface heat resistance $\left[\mathrm{m}^{2} \mathrm{~K}^{-1} \mathrm{~W}^{-1}\right]$

Stationary thermal transmittance $\left[\mathrm{W} \mathrm{m}^{-2} \mathrm{~K}^{-1}\right]$

Ventilation air flow rate $\left[\mathrm{m}^{3} \mathrm{~s}^{-1}\right]$

Absorption coefficient for solar radiation of opaque envelope component [-]

Indoor air temperature $\left[{ }^{\circ} \mathrm{C}\right]$

Indoor air temperature $\left(0 \mathrm{~W} \mathrm{~m}^{-2}\right.$ of heat load $)\left[^{\circ} \mathrm{C}\right]$ 


$\begin{array}{ll}\theta_{\text {air_i(10) }} & \text { Indoor air temperature }\left(10 \mathrm{~W} \mathrm{~m}^{-2} \text { of heat load }\right)\left[{ }^{\circ} \mathrm{C}\right] \\ \theta_{\text {air_o }} & \text { Outdoor air temperature }\left[{ }^{\circ} \mathrm{C}\right] \\ \theta_{\text {air_sup }} & \text { Supply air temperature }\left[{ }^{\circ} \mathrm{C}\right] \\ \theta_{\mathrm{m}} & \text { Building mass temperature }\left[{ }^{\circ} \mathrm{C}\right] \\ \theta_{\mathrm{m}_{\_} \tau} & \text { Building mass temperature at time instant } \tau\left[{ }^{\circ} \mathrm{C}\right] \\ \theta_{\mathrm{m} \_\tau-1} & \text { Building mass temperature at time instant } \tau-1\left[{ }^{\circ} \mathrm{C}\right] \\ \theta_{\mathrm{s}} & \text { Building surface temperature }\left[{ }^{\circ} \mathrm{C}\right] \\ \theta_{\text {set_C }} & \text { Cooling set point temperature }\left[{ }^{\circ} \mathrm{C}\right] \\ \theta_{\text {set_H }} & \text { Heating set point temperature }\left[{ }^{\circ} \mathrm{C}\right] \\ \kappa_{\mathrm{i}} & \text { Internal areal heat capacity of the building component }\left[\mathrm{J} \mathrm{m}{ }^{-2} \mathrm{~K}^{-1}\right] \\ \rho_{\text {air }} & \text { Volumetric mass density of air }\left[\mathrm{kg} \mathrm{m}{ }^{-3}\right] \\ \phi_{\mathrm{H} / \mathrm{C} \_n d} & \text { Theoretical supplemental heat load for heating or cooling }[\mathrm{W}] \\ \phi_{\mathrm{H} / \mathrm{C} \_n d(10)} & \text { Theoretical heating or cooling load of } 10 \mathrm{~W} \mathrm{~m}^{-2}[\mathrm{~W}] \\ \phi_{\text {ia }} & \text { Convective heat flow }[\mathrm{W}] \\ \phi_{\text {int }} & \text { Sensible heat flow from internal sources }[\mathrm{W}] \\ \phi_{\mathrm{m}} & \text { Radiative heat flow [W] } \\ \phi_{\mathrm{m} \_ \text {tot }} & \text { Heat flow [W] } \\ \phi_{\text {sol }} & \text { Heat flow from solar source }[\mathrm{W}] \\ \phi_{\text {sol_gl }} & \text { Heat flow from solar source through glazed envelope }[\mathrm{W}] \\ \phi_{\text {sol_op }} & \text { Heat flow from solar source through opaque envelope }[\mathrm{W}] \\ \phi_{\text {st }} & \text { Radiative heat flow [W] } \\ \chi & \text { Stationary point thermal transmittance }\left[\mathrm{W} \mathrm{K}^{-1}\right] \\ \Psi & \text { Stationary linear thermal transmittance }\left[\mathrm{W} \mathrm{m}^{-1} \mathrm{~K}^{-1}\right]\end{array}$




\section{Publication list}

The main publications of the candidate that are relevant for this thesis are grouped referring to the previous chapters.

\section{Chapter 2:}

Climate control in agricultural buildings: a tangled network of relations

- A. Costantino, E. Fabrizio, S. Calvet, "The role of climate control in monogastric animal farming: the effects of indoor climate on animal welfare, air emissions, productivity, health, and energy use", Applied Science, accepted manuscript.

- A. Costantino, S. Calvet, E. Fabrizio, "The use of renewable energy sources as a driver to reduce the carbon footprint of livestock sector", in: T. Bartzanas and S. Calvet (Eds.), in: Technology for environmentally friendly livestock production, Springer 2021, Under review.

- A. Costantino, E. Fabrizio, "Building Design for Energy Efficient Livestock Housing", in: N.M. Holden, M.L. Wolfe, J.A. Ogejo, E.J. Cummins (Eds.), Introd. to Biosyst. Eng., ASABE, VT Publishing, Blacksburg, Virginia, 2020.

https://doi.org/10.21061/IntroBiosystemsEngineering/Livestock_Housing_Energy.

- A. Costantino, E. Fabrizio, A. Biglia, P. Cornale, L. Battaglini, "Energy Use for Climate Control of Animal Houses: The State of the Art in Europe", Energy Procedia. 2016, 101: 184-191.

https://doi.org/10.1016/j.egypro.2016.11.024.

\section{Chapter 3}

\section{The nexus between climate control and energy: results from case studies}

- A. Costantino, L. Comba, G. Sicardi, M. Bariani, E. Fabrizio, "Thermal environment inside mechanically ventilated greenhouses: Results from a long-term monitoring campaign", in: A. Coppola, G.C. Di Renzo, G. Altieri, P. D'Antonio (Eds.), Innov. Biosyst. Eng. Sustain. Agric. For. Food Prod. MID-TERM AIIA 2019, Lecture No, Springer, 2020: pp. 223-230. https://doi.org/10.1007/978-3-030-39299-4_25.

- M. Bilardo, L. Comba, P. Cornale, A. Costantino, E. Fabrizio, "Relation between energy use and indoor thermal environment in animal husbandry: A case study", in: S. Tanabe, H. Zhang, J. Kurnitski, M.C. Gameiro da Silva, I. Nastase, P. Wargocki, G. Cao, L. Mazzarela, C. Inard (Eds.), E3S Web Conf., 2019: p. 01042. https://doi.org/10.1051/e3sconf/201911101042.

- A. Costantino, L. Comba, A. Rolfo, P. Cornale, L. Battaglini, E. Fabrizio, "Analysis of the Indoor Climate and Energy Use in two Animal Houses for Fattening Pigs", European Conference on Agricultural and Biosystems engineering (AgEng Conference) 2018, July 8th - 12th 2018, Wageningen, the Netherlands. 


\section{Chapter 4}

\section{A new modelling framework for fully mechanically controlled greenhouses}

- $\quad$ A. Costantino, L. Comba, G. Sicardi, M. Bariani, E. Fabrizio, "Energy performance and climate control in mechanically ventilated greenhouses: A dynamic modelling-based assessment and investigation", Appl. Energy 2021, 288: 116583. https://doi.org/https://doi.org/10.1016/j.apenergy.2021.116583.

\section{Chapter 5:}

\section{A new modelling framework for fully mechanically controlled livestock houses}

- $\quad$ A. Costantino, L. Comba, P. Cornale, E. Fabrizio, "Energy impact of climate control in pig farming: a new dynamic model and experimental validation", under submission.

- A. Costantino, E. Fabrizio, "Energy savings in livestock houses through the use of variable speed fans", in: Proceedings of RoomVent 2020, $15^{\text {th }}$ February $-15^{\text {th }}$ March 2021: pp. 182185.

- A. Costantino, E. Fabrizio, "Energy modelling of livestock houses: the results from the EPAnHaus project”, in: V. Corrado, E. Fabrizio, A. Gasparella, F. Patuzzi (Eds.), Proc. Build. Simul. 2019 16th Conf. IBPSA, 2020: pp. 4251-4258.

- A. Costantino, E. Fabrizio, A. Ghiggini, M. Bariani, "Climate control in broiler houses: A thermal model for the calculation of the energy use and indoor environmental conditions", Energy Build. 2018, 169: 110-126.

https://doi.org/10.1016/j.enbuild.2018.03.056.

- E. Fabrizio, A. Costantino, L. Comba, “A calculation model for the energy performance assessment of fattening pig houses", in: International Conference On Building Energy \& Environment (COBEE), Melbourne February $5^{\text {th }}-9^{\text {th }} 2018$.

- A. Costantino, I. Ballarini, E. Fabrizio, "Comparison between simplified and detailed methods for the calculation of heating and cooling energy needs of livestock housing: A case study", in: Build. Simul. Appl., 2017: pp. 193-200.

- E. Fabrizio, A. Costantino, A. Ghiggini, M. Bariani, "Environmental control in poultry buildings: a tool for the estimation of energy consumption”, La Termotecnica, July - August 2016, 57-61.

\section{Chapter 6}

\section{The role of envelope in livestock houses:}

- A. Costantino, S. Calvet, E. Fabrizio, "Identification of energy-efficient solutions for broiler house envelopes through a primary energy approach”, J. Clean. Prod., 2021, 312: 127639 https://doi.org/https://doi.org/10.1016/j.jclepro.2021.127639. 


\section{Chapter 7}

The role of ventilation in livestock houses: $I A Q$ improvements and energy consumption

- A. Costantino, E. Fabrizio, A. Villagrá, F. Estellés, S. Calvet, "The reduction of gas concentrations in broiler houses through ventilation: Assessment of the thermal and electrical energy consumption", Biosyst. Eng. 2020, 199: 135-148.

https://doi.org/10.1016/j.biosystemseng.2020.01.002.

\section{Other publications of the author:}

- I. Ballarini, A. Costantino, E. Fabrizio, V. Corrado, "A Methodology to Investigate the Deviations between Simple and Detailed Dynamic Methods for the Building Energy Performance Assessment", Energies 2020, 13(23): 6217.

https://doi.org/10.3390/en13236217.

- I. Ballarini, A. Costantino, E. Fabrizio, V. Corrado, "The Dynamic Model of EN ISO 520161 for the Energy Assessment of Buildings Compared to Simplified and Detailed Simulation Methods", in: V. Corrado, E. Fabrizio, A. Gasparella, F. Patuzzi (Eds.), Proc. Build. Simul. $201916^{\text {th }}$ Conf. IBPSA, 2020: pp. 3847-3854.

- E. Fabrizio, A. Costantino, L. Comba, P. Cornale, L.M. Battaglini, "Energy consumption certification of animal housing: results from the EPAnHaus project", 2017 American Society of Agricultural and Biological Engineers (ASABE) Annual International Meeting, July $16^{\text {th }}$ $-19^{\text {th }} 2017$, Spokane, Washington, USA.

http://dx.doi.org/ 10.13031/aim.201701480.

- A. Costantino, E. Fabrizio, L. Comba, P. Cornale, "A model for the assessment of the energy performance of fattening pig houses", 11th Italian Society of Agricultural Engineering (AIIA) Conference, July $5^{\text {th }}-8^{\text {th }} 2017$, Bari, Italy.

- E. Fabrizio, V. Branciforti, A. Costantino, M. Filippi, S. Barbero, G. Tecco, P. Mollo, A. Molino, "Monitoring and managing of a micro-smart grid for renewable sources exploitation in an agro-industrial site", Sustain. Cities Soc. 2017, 28: 88-100.

http://dx.doi.org/10.1016/j.scs.2016.08.026.

- I. Ballarini, A. Costantino, D. Dirutigliano, E. Fabrizio, S. Paduos, V. Corrado, "On the costoptimal design: comparison of quasi-steady-state and dynamic simplified methods of calculation of H/C energy needs", $3^{\text {rd }}$ IBPSA-Italy Conference, February $8^{\text {th }}-10^{\text {th }} 2017$, Bozen-Bolzano, Italy.

- E. Sirombo, A. Costantino, M. Filippi, V.M. López Toledo, "Life cycle energy consumption and environmental impact: assessment of a detached house in Almansa (Spain)", $3^{\text {rd }}$ Energy for Sustainability International (EFS) Conference, February $8^{\text {th }}-10^{\text {th }} 2017$, Funchal, Portugal.

- A. Costantino, E. Fabrizio, A. Biglia, P. Cornale, L. Battaglini, "Benchmarks of energy performance for the indoor climate control of livestock houses", $4^{\text {th }}$ CIGR International Conference of Agricultural Engineering (CIGR AgEng) 2016, June $26^{\text {th }}-29^{\text {th }} 2016$, Aarhus, Denmark. 
- E. Sirombo, A. Costantino, M. Filippi, V.M. López Toledo, "An integrated approach to the energy and environmental evaluation of buildings: the case study of a detached house in Spain" (in Italian), $16^{\text {th }}$ CIRIAF National Congress, April $7^{\text {th }}-9^{\text {th }} 2016$, Assisi, Italy. 

